\title{
Model Commissioning
}

\section{Plan and Guide Specifications}

Sponsored by

US Department of Energy

Seattle Regional Support Office

800 5th Ave. Suite 3950

Seattle, WA 98104

RECEIVED

MAR 251997

Prepared by:

OSTI

Portland Energy Conservation, Inc. (PECI)

. 921 SW Washington, Suite 312

Portland, OR 97205

503-248-4636, F $2 x$ 503-295-0820

Version 2.02

March 1997

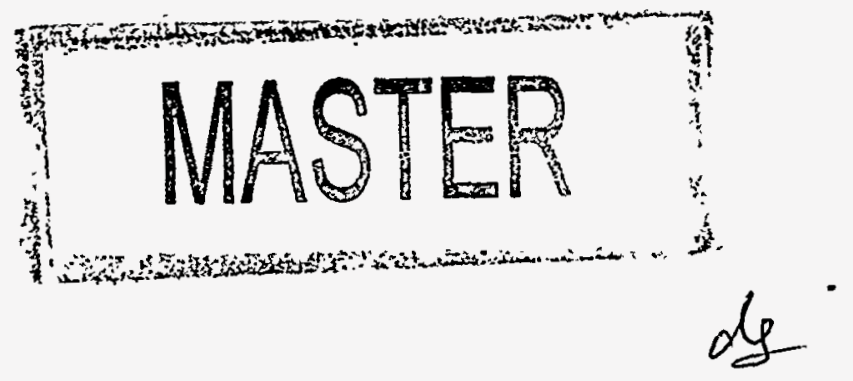

BTTIBUTION OF THIS DOCUMENT IS UNLMITLD 


\section{Acknowledgments}

This project was funded through the USDOE contracts DE-AP51-96R020748 and DE-AP51-95R020661. Appreciation is extended to Arun Jhaveri of USDOE, Seattle Regional Support Office for his vision for the project and to Anne Sprunt-Crawley, USDOE FEMP (Federal Energy Management Program)

headquarters, for her ongoing support. This project was the synthesis of our own experience and the ideas and experience of a number of commissioning experts, whose contributing documents are listed in the Overview. I acknowledge the insightful review and comments of Version 1 by Mike Kaplan of Kaplan Engineering and Phoebe Caner of the University of Washington. The invaluable contributions, review and support of my colleague, Tudi Haasl, are also deeply appreciated. 


\section{Table of Contents}

Part l: Commissioning Requirements-Design Phase Part I

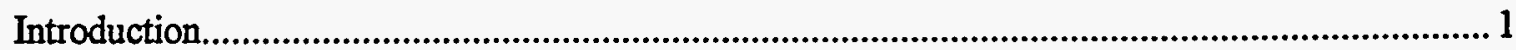





Appendix 1: Solicitation for Commissioning Agents................................................. Appendix 1

Part II: Model Commissioning Plan—Design Phase Part II

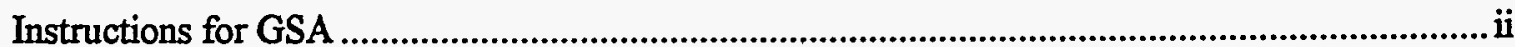

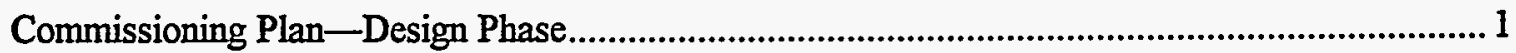

Appendix 1: Design Documentation Format ........................................................... Appendix 1

Appendix 2: Fire and Emergency Power Response Matrix......................................... Appendix 2

Appendix 3: Commissioning for Indoor Air Quality Checklist ..................................... Appendix 3

Part III: Commissioning Guide Specifications Part III

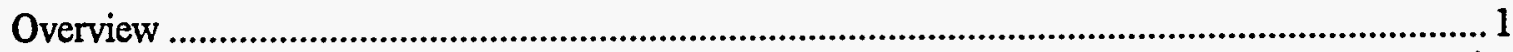

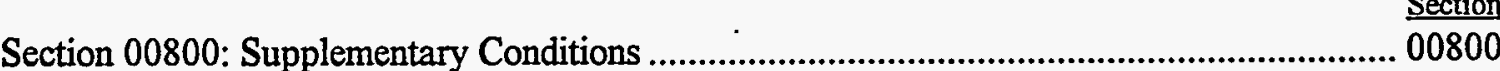

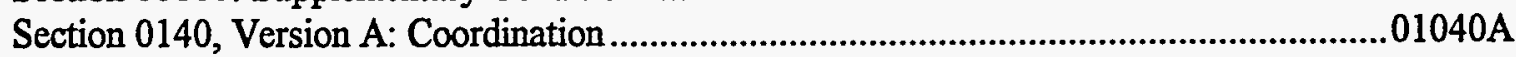

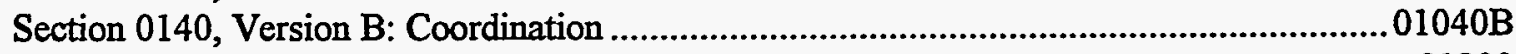

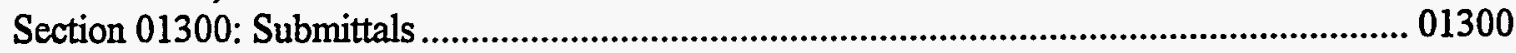



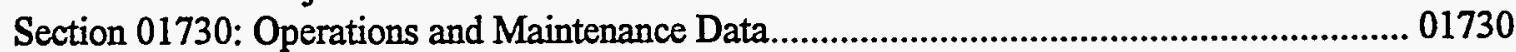

Section 15010: Mechanical-General Provisions ......................................................... 15010



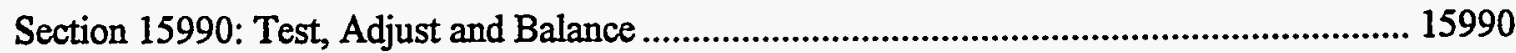

Section 15995: Mechanical Systems Commissioning........................................................ 15995

Section 15997: Mechanical Testing Requirements.......................................................... 15997

Section 15998: Prefunctional Checklists-Mechanical \& Electrical...................................... 15998

Section 15999: Sample Functional Test Procedures-Mechanical ....................................... 15999

Section 16010: Electrical—General Provisions .............................................................. 16010

Section 16995: Electrical Systems Commissioning ........................................................ 16995



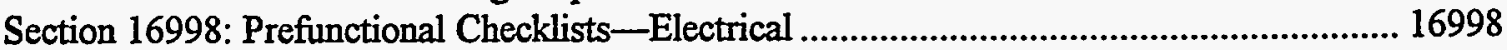

Section 16999: Sample Functional Test Procedures......................................................... 16999

Section 17100: Commissioning Requirements ............................................................. 17100

Part IV: Model Commissioning Plan-Construction Phase Part IV

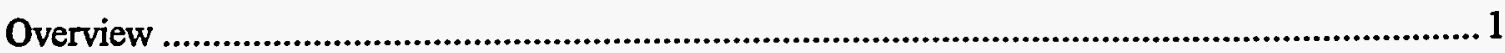

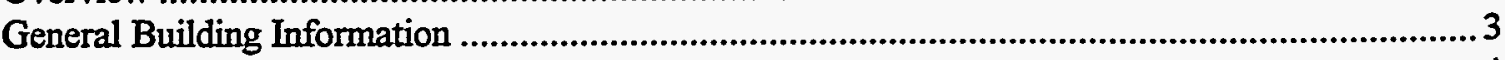

Construction/Commissioning Team Data .............................................................................. 4

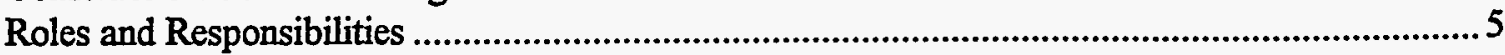

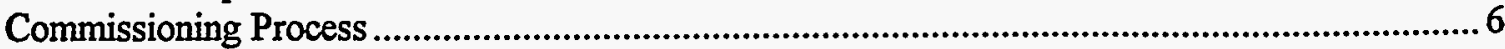

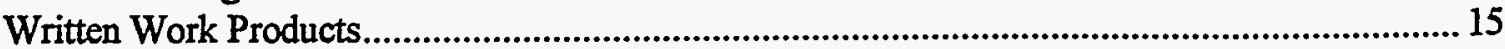

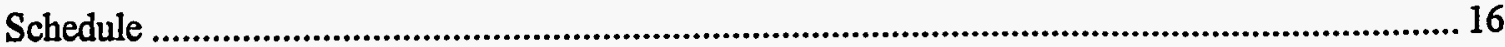

Appendix 1: Construction Phase Application Forms................................................. Appendix 1

Appendix 2: Document and Test Development Flow Charts, Submittal Maps ............... Appendix 2

Commissioning Model Plan and Guide Specifications - Large Buildings ii

PECI/USDOE, ALL_OVR.VU4, 3/20/97 


\title{
Model Commissioning Plan and Guide Specifications
}

\author{
Overview
}

Commissioning. Commissioning $(\mathrm{Cx})$ is a systematic process of ensuring that building systems perform interactively according to the design intent and the owner's operational needs. This is achieved beginning in the design phase by documenting the design intent and continuing through construction, acceptance, and the warranty period with actual verification of performance, operation and maintenance (O\&M) documentation verification and the training of operating personnel.

\section{Objectives}

The objectives of the Model Commissioning Plan and Guide Specifications are to:

During design:

1. Ensure that the design team applies commissioning concepts to the design, e.g., clear and complete design intent documentation is developed and commissioning-focused design reviews are conducted.

2. Ensure that the design team prepares commissioning specifications and a commissioning plan for inclusion in the bid construction documents.

Meeting these objectives during design prepares the way so that the:

- Contractors can accurately bid the commissioning work.

- Contractors can understand how to efficiently execute the commissioning process.

- There is a systematic, efficient and enforceable method to accomplish the commissioning objectives.

- The commissioning objectives are met. At the building level these objectives include:

- Ensure that applicable equipment and systems are installed properly and receive adequate operational checkout by installing contractors.

- Verify and document proper performance of equipment and systems.

- Ensure that O\&M documentation left on site is complete.

- Ensure that the Owner's operating personnel are adequately trained.

\section{General Overview}

The Model Commissioning Plan and Guide Specification is not intended to be a workbook or a manual on commissioning. Little background information on commissioning approaches, narrative of the commissioning process, costs and benefits of commissioning, etc. is included. This information is readily available in a number of other publications. The model plan and guide specifications were developed to provide those who are ready to incorporate commissioning, boilerplate-type language, content, format and forms for specifying and executing the commissioning process, so that they do not have to start from "scratch." 
The Model Commissioning Plan and Guide Specifications generally follow the guidelines described in the ASHRAE document, The HVAC Commissioning Process referenced at the end of this overview. A number of other documents were used, as referenced, along with the authors' own commissioning experience. The Model Commissioning Plan and Guide Specifications were developed to be as generic as possible - though they were tailored to fit the management structure of General Services Administration (GSA), Region 10 - for conventional design / spec / bid construction. Refer to the introduction to Part III Commissioning Guide Specifications for additional details on management structure assumptions.

The term "model" in model commissioning plan means that the commissioning plan is intended to be broadly representative of what a commissioning plan should actually look like. The commissioning plans have been developed to be somewhat generic and yet be structured so as to be easily adaptable to specific projects.

The term "guide" in guide specifications means that the commissioning specifications represent recommended language intended to be broadly applicable. The architect and design engineer, along with the commissioning agent, adapt this guide specification to incorporate commissioning into their projects.

The model plan and guide specifications were developed for larger, more complex projects and systems. A more streamlined commissioning approach may be appropriate for buildings less than 70,000 sf with simple equipment (packaged equipment and controls, no building automation system, etc.).

\section{Document Organization}

The Model Commissioning Plan and Guide Specifications are comprised of the following four separate documents designated as "parts."

Part I. Commissioning Requirements-Design Phase

Part II. Model Commissioning Plan-Design Phase

Part III. Commissioning Guide Specifications

Part IV. Model Commissioning Plan-Construction Phase

A brief description of each part follows:

\section{Part I. Commissioning Requirements-Design Phase}

The Commissioning Requirements-Design Phase are requirements relating to commissioning which the design team is required to carry out during the development of the contract documents. The requirements include a listing of the responsibilities for each member of the design team. In addition, for perspective it lists the responsibilities of all players during the construction phase. This document is intended to be included in the request for proposal (RFP) for architectural/engineering (A/E) services and for prospective commissioning agents, after having the appropriate check boxes and blanks filled in by the Owner. The list of requirements provide little detail, as they point to the fully explained procedures in the Model Commissioning Plan-Design Phase. In the Appendix to Part I, a sample RFP for a commissioning agent is provided. (Part I length: Requirements and appendices 31 pgs)

\section{Part II. Model Commissioning Plan-Design Phase}

The Model Commissioning Plan-Design Phase guides the commissioning activities during the design phase. It provides details of responsibilities called out in Part I, Commissioning Requirements-Design Phase for the architect, design engineers, commissioning agent, construction and project managers. The plan describes the duties of the $\mathrm{A} / \mathrm{E}$ team and commissioning agent in developing the site-specific 
commissioning specifications and for developing the first two drafts of the Commissioning PlanConstruction Phase. (Part II length: Plan and appendices 85 pgs)

\section{Part III. Commissioning Guide Specifications}

The commissioning guide specifications contain recommended language that describes both the requirements and the process to incorporate commissioning into the construction specifications. All divisions and sections that relate to commissioning include language to ensure that the contractors are clearly informed regarding their commissioning responsibilities. Adequate explanation of the commissioning process is also provided. In addition, prefunctional checklists and sample functional tests are included for the many common types of equipment and systems. (Part III length: Specifications 132 pgs, prefunctional checklists $\sim 100 \mathrm{pgs}$, functional tests $\sim 126 \mathrm{pgs}$ )

\section{Part IV. Commissioning Plan-Construction Phase}

The Commissioning Plan-Construction Phase is developed in draft form for the specific project during the design phase. During the design phase, the plan provides direction for the development of the site-specific commissioning specifications by the design team. During the construction phase, the plan provides direction for the commissioning tasks during construction. The plan focuses on providing support to the specifications and provides forms for application of the commissioning process. (Plan $16 \mathrm{pgs}$, forms $40 \mathrm{pgs}$ )

\section{Limitations}

The Model Commissioning Plan and Guide Specifications do not cover specific commissioning testing requirements, checklists, or sample functional tests for the following. However, the process described herein, particularly in Section 17100, can apply to any equipment.

- Plumbing fixtures and equipment (other than heating and cooling water piping)

- Architectural features, finishes and hardware

- Interstitial cavity differential pressure gradients and moisture control

- Laboratory fume hoods and clean rooms

- Medical gas systems

- Measurable equipment sound and vibration control

- Electrical system components, sometimes covered by municipal inspections (grounding, transformers, switchboards, etc.)

\section{Document Use}

All documents have been provided on electronic disk for adapting, as explained in a later section. All four parts of the Model Commissioning Plan and Guide Specifications are intended to be used together during the design phase. If formal commissioning is not going to be incorporated during design, some of the commissioning concepts and tasks from Parts I and II could still be assigned to the design team. At minimum, the development of commissioning specifications for construction sections should be completed during design (Part II, Commissioning Plan-Design Phase, Task 6).

The recommended procedure for using the Model Commissioning Plan and Guide Specifications starts in or before the design phase, as follows: 
Step 1. Before beginning design, the owner uses the commissioning agent solicitation documents in Appendix 1 of Part I, Commissioning Requirements-Design Phase to obtain the services of a commissioning agent. If this commissioning agent is engaged before design, the commissioning agent contract may need to be structured in two parts: one for the design phase and one drawn up later for the construction phase, once more is known about what systems will be in the building. Also, the owner may choose to have the construction phase commissioning agent hired under or be part of a construction management contractor, who may not be known during design.

Step 2. The commissioning agent and the owner fill out an initial draft of the Commissioning PlanDesign Phase (in Part II).* Full directions are provided at the beginning of the plan for filling this out.

Step 3. The commissioning agent and the owner edit and adapt the Commissioning Requirements-Design Phase (in Part I) to be appropriate for the specific project.*

*If the commissioning agent is not formally engaged yet, the owner may complete this step on their own or may use the temporary consulting services of a commissioning agent or qualified engineer.

Step 4. The adapted Commissioning Requirements-Design Phase (Part I) and the filled-in Commissioning Plan-Design Phase (Part II), along with the as-is Guide Specifications (Part III) and asis Commissioning Plan-Construction Phase (Part IV) are provided to the design firms in the solicitation for their services. Due to the size of these documents, it may be appropriate to distribute the documents after short listing is completed.

Step 5. In the design contract, the owner explicitly includes Parts I and II (Commissioning Requirements-Design Phase and Commissioning Plan-Design Phase) and refers to Part III and Part IV (Guide Specifications and Commissioning Plan-Construction Phase), as reference material.

Step 6. The owner engages a commissioning agent per Step 1, if not already completed.

Step 7. The selected design firm uses Parts I, II, III and IV during design as they follow the Commissioning Plan-Design Phase (Part II). The design team develops clear design documentation, incorporate commissioning specifications into the main building specifications using the guide specifications (Part III), and create two drafts of the Commissioning Plan-Construction Phase, specific to this project. The owner participates in this process according to the design-phase plan.

Step 8. The owner includes the second draft of the Commissioning Plan-Construction Phase (Part IV) along with the construction specifications that include commissioning specifications in the construction bid documents.

Step 9. The owner makes sure all contract language referring to testing, completion milestones, etc. are consistent with the commissioning specifications in the bid documents.

Step 10. The owner engages a commissioning agent per Step 1, if not already completed.

Step 11. The commissioning process is executed per the bid commissioning specifications and commissioning plan.

The following graphic illustrates the above process. 


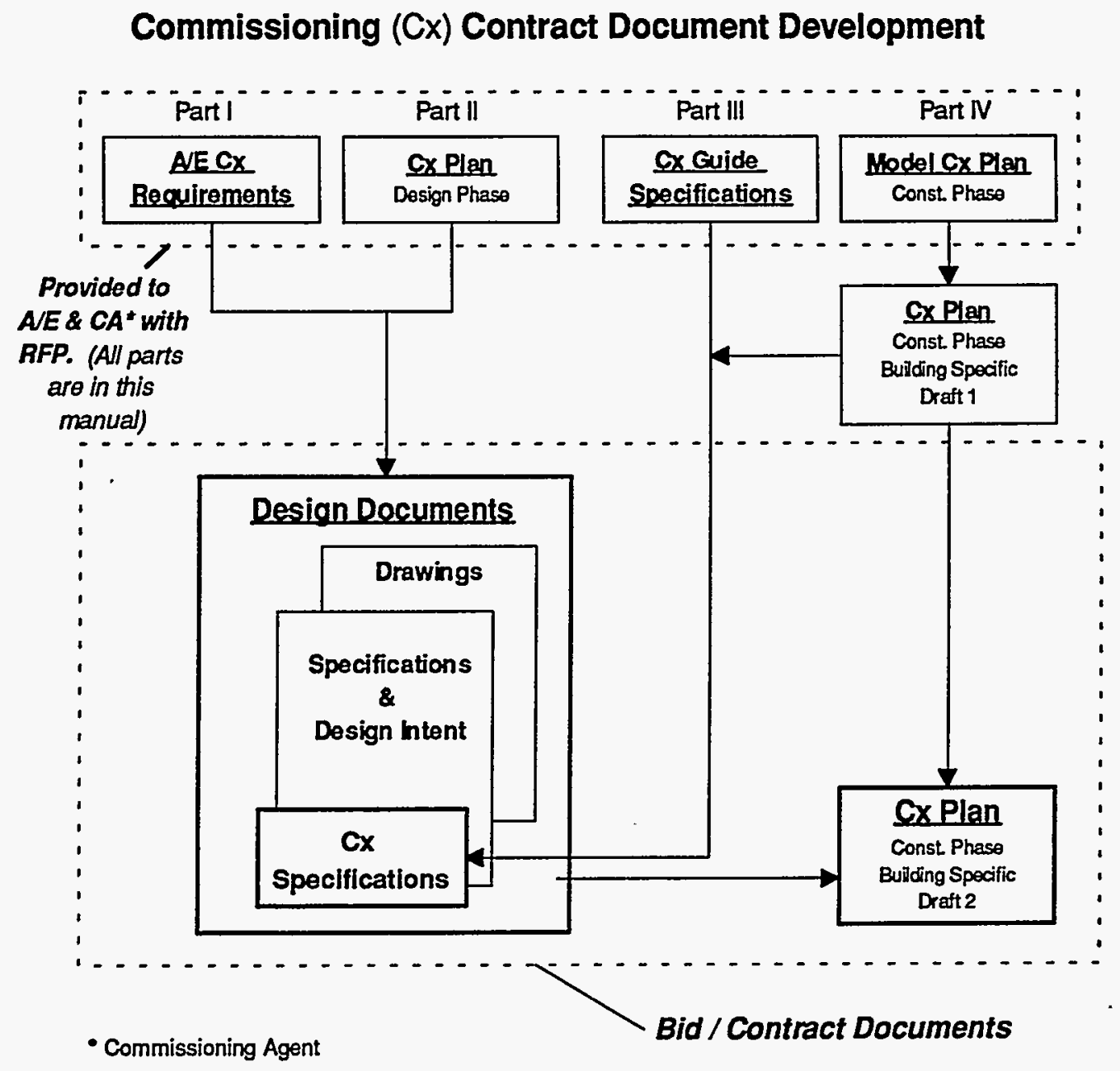

\section{Copyright}

This work is in the public domain and may be copied and distributed at will. However, once files have been edited they should have the reference to PECI and USDOE removed from the footers. When appropriate, referencing the source of the documents would be appreciated.

\section{Electronic Format}

All parts of the Model Commissioning Plan and Guide Specifications have been included on diskette for modification, adaptation and use, as necessary. The commissioning plans are provided as one document each. The appendices of each plan are included as separate documents. Each of the forms in the Appendix of the construction phase commissioning plan is included as a separate document file, as is each individual section of the specifications. The file format is Word 6.0 for Windows 3.1 with a few forms in Excel 5.0 for Windows. Filenames are included in the footer for reference in all hard copies. For ease of access, all electronic files have been archived into two master files that will automatically create and extract the files into seven directories, as described in the readme.txt file. 


\section{Order of Electronic Files}

The following list of files corresponds to the order of the documents in the hardcopy of the Model Commissioning Plan and Guide Specifications. Preceding the file listing for each section is the subdirectory where the files are contained, after being expanded.

Directory: IDESIREQR.PT1 (The underscore in the file name extension is a place holder for the version number.)

Model Commissioning Plan and Guide Specifications Overview ALL_OVR.VU_

Part I: Commissioning Requirements-Design Phase DES_REQR.V Appendix 1: Solicitation for Commissioning Agent Services CA_RFP.O Exhibit 4: Commissioning Firm Experience (2 files) CA_INFOR.FRM CA_EXPER.XLS

\section{Directory: IDESIPLAN.PT2}

Part II: Model Commissioning Plan-Design Phase. DESIPLAN.V

Appendix 1: Design Documentation Format-Instructions .INSTRUCT.D

Design Documentation Format D_INTENT.V

Appendix 2: Fire \& Emergency Power Response Matrix RESPONSM.TRX Appendix 3: Commissioning for Indoor Air Quality Checklist DPLANAP3.0

Directory: IGIDESPEC.PT3

Part III: Commissioning Guide Specifications Overview

Section 00800: Supplementary Conditions SPEC_OVR.V

Section 01040, Version A: Coordination $.00800 . \mathrm{V}$

Section 01040, Version B: Coordination $01040 \mathrm{~A} . \mathrm{V}$

Section 01300: Submittals 01040B.V

Section 01700: Project Close-Out $01300 . \mathrm{V}$

Section 01730: Operations and Maintenance Data $01700 . \mathrm{V}$

Section 15010: Mechanical-General Provisions $01730 . V$

Section 15950: Automatic Controls $15010 . \mathrm{V}$

Section 15990: Test, Adjust and Balance $15950 . V$

Section 15995: Mechanical Systems Commissioning 15990.V

Section 15997: Mechanical Testing Requirements 15995.V

Section 15998: Prefunctional Checklists-Mechanical \& Electrical $15997 . \mathrm{V}$ 15998.V

Directory: IPREFUNCT.PT3 ("PC" in the file name extension refers to Prefunctional Checklist. The underscore is a placeholder for the current version \#.)

Air handler unit AHU.PC_

Air-cooled Condenser and Compressor AIRCNDSR.PC

Boiler BOILER.PC

Condenser Water Piping CDWPIPE.PC_

Chiller CHILLER.PC

Sample chiller system startup documentation plan CHILRDOC.PC_

Chilled Water Piping CHWPIPE.PC_

Computer Room AC Unit. COMPUTAC.PC

Controls System (BAS) CONTROLS.PC

Cooling Tower COOLTWR.PC

Exhaust Fan. EXH FAN.PC

Fan Coil Unit FANCOILU.PC

Heating Water Piping HWPIPE.PC 
Packaged Rooftop Unit PKGUNIT.PC

Pump (water)... PUMP.PC

Start-up Documentation Plan Template

STARTPLN.CO6

TAB TABPLAN.PC_

Terminal Unit TU_PC05.XLS

Variable Frequency Drive VFD.PC_

Directory: IGIDESPEC.PT3

Section 15999: Sample Functional Test Procedures-Mechanical $15999 . V$

Directory: IFUNCTEST.PT3 ("FT" in the file name extension refers to Functional Test. The underscore is the version \#.)

Air Compressor (for smoke dampers) AIRCOMPR.FT

Air Handler Unit (cooling unit only) AHU_COOL.FT_

Air-Side Economizer ECONTEST.FT_

Cabinet Unit Heater . CABUNHTR.FT_

Chilled Water Sequence of Operations CHILRSEQ.EXA

Chiller Functional Test. CHILLER.FT

Fan Coil (heating) HTFNCOIL.FT_

Fin Tube Radiator FINTUBE.FT

Packaged Rooftop DX Air Conditioning Unit PKG_RTU.FT_

Packaged Boiler Control Sequences (not included in hard copy) BOILRSEQ.00

Packaged Boiler Functional Test BOILERHW.FT_

Multiple Boiler System Functional Test (not included in hard copy)

Service Water Heater (Gas) BOILERSYS.FT_

Small Service Hot Water Circulating Pumps SRVC_WH.FT_

Split Air Conditioning Unit SMLCPUMP.FT_

Terminal Unit-HW Reheat Single Duct SPLIT_AC.FT_

Terminal Unit-Dual Duct TU_REHET.FT_

Terminal Unit--Dual Duct Fan (Series) TU_DDVAV.FT_

Terminal Unit--Cooling Only VAV Single Duct TU_DDFAN.FT_

Unit Heater. TU_CLG.FT_

Variable Speed Drive (fan application) UNIT_HTR.FT_

Variable Speed Drive (pump application) VFDFAN.FT_ VFDPUMP.FT_

Directory: IGIDESPEC.PT3

Section 16010: Electrical-General Provisions ........................................................16010.V

Section 16995: Electrical Systems Commissioning ......................................................16995.V_

Section 16997: Electrical Testing Requirements ........................................................16997.V

Section 16998: Prefunctional Checklists-Electrical ......................................................16998.V

Section 16999: Sample Functional Test Procedures......................................................16999.V_

Directory: IFUNCTEST.PT3

Emergency Power System and UPS E-POWER.FT_

Emergency Power System and UPS (larger UPS test; not included in hard copy) ... E-POWBIG.FT_

Exterior Lighting Controls EXTLIGHT.FT_

Lighting Sweep Controls SWEEP.FT

Directory: IGIDESPEC.PT3

Section 17100: Commissioning Requirements $17100 . \mathrm{V}$ 


\section{Directory: ICONSPLAN.PT4}

Part IV: Model Commissioning Plan-Construction Phase

CONSPLAN.V

Directory: ICONFORMS.PT4 (The file name extension refers to the Form ID number)

Appendix 1: Construction Phase Application Forms (25 files)

C-1: Commissioning Issues Log. ISSULOG.C01

C-2: Request for Documentation and Record of Submissions DOCREQC2.XLS

C-3a: Commissioning Test or Review Approval APROVAL2.C3A

C-3b: Commissioning Prefunctional Check Submittal / Approval PCSUBMIT.C3B

C-3c: Commissioning Transmittal TRANSMIT.C3C

C-3d: Commissioning Request for Information INFOREQ.C3D

C-3e: Commissioning Memorandum MEMORAND.C3E

C-3f: Commissioning Submittal for Sequences and Test Forms SUBFTFRM.CBF

C-4: Commissioning Progress Report PROGREPT.CO4

Training: Project Training and Orientation Procedures TRAINPRO.CED

C-5a: Overall Staff Training and Orientation Plan. .TRAINPLN.C5A

C-5b: Training and Orientation Agenda TRAINAGE.C5B

C-5c: Staff Training and Orientation Record TRAINREC.C5C

C-6: Commissioning Corrective Action Report. CORECTON.CO6

C-7: Commissioning Progress Record. RECORDC7.XLS

C-8: Plan and Documentation Requirements for Startup and Initial Checkout .... STARTPLN.C08

C-9: Detailed Commissioning Schedule (blank) TIMEBLC9.XLS

C-10: Detailed Commissioning Schedule (filled in) TIMEFC10.XLS

C-11: Commissioning Functional Testing Plan Overview FTOVRVU.C11

C-12: Phasing of Commissioning Testing PHASES.C12

C-13: Owner-Contracted Tests OWNRTEST.C13

C-14: Facility Staff Participation in Commissioning STAFPART.C14

C-15: Functional Testing Scope Outline (example). SCOPEFIL.C15

C-16: Commissioning Formal Written Work Products. PRODUCTS.C16

C-17: Commissioning Record Notebook Format BOOK_C17.XLS

Appendix 2: Document and Test Development Flow Charts, Submittal Maps PT4_APP2.V03

\section{Sources}

The primary sources used for the development of these commissioning plans and specifications were (listed by date):

1. Heinz, John A., Rick Casault and Phoebe Caner, The Building Commissioning Handbook, The Association of Higher Education Facilities Officers (APPA), 1996.

2. Building Commissioning Guide, Enviro-Management \& Research, Inc., 1996.

3. The HVAC Commissioning Process, ASHRAE Guideline 1-1989R, final draft 1996.

4. Electrical Engineering Building Commissioning Specifications, Notkin Engineering/ University of Washington, 1995.

5. Caner, Phoebe, Commissioning the Building Automation System of the Physics/Astronomy Building: A Case Study, University of Washington, 1995.

6. Systems Commissioning Procedures, US Army Corp of Engineers, 1995.

7. Chamberlin, G. A. and D. M. Schwenk, Standard HVAC Control Systems Commissioning and Quality Verification User Guide. USACERL, FEAP-UG-FE-94/20, September 1994. 
8. GSA Portland, Oregon Federal Courthouse Specifications, general commissioning section and controls testing sections, 1994.

9. Dunn, Wayne A., C-2000 Quality Guideline, Commissioning Specifications, Canadian Department of Energy Mines and Resources, 1994.

10. Contractor Quality Control and Commissioning Program, Montgomery County, Maryland, 1993.

11. General Commissioning Guide Specifications, University of Washington Facility Management Office, September 1993.

12. Kao, James Y., U.S. Department of Commerce, HVAC Functional Inspection and Testing Guide, March 1992

13. Building Commissioning Guidelines, PECI/Bonneville Power Administration, 1992.

14. Misc. specifications, guidelines and tests developed by PECI, 1990-1996. 


\title{
Part I
}

\section{Commissioning Requirements --Design Phase--}

\author{
For Inclusion in the RFP for A/E Services
}

\author{
Sponsored by \\ US Department of Energy \\ Seattle Regional Support Office \\ 800 5th Ave. Suite 3950 \\ Seattle, WA 98104
}

\author{
Prepared by: \\ Portland Energy Conservation, Inc. (PECI) \\ 921 SW Washington, Suite 312 \\ Portland, OR 97205 \\ 503-248-4636, Fax 503-295-0820
}

Version 2.02

March 1997 


\section{Part 1}

\section{Commissioning Requirements --Design Phase--}

\section{Summary}

The Commissioning Requirements-Design Phase are specifications relating to commissioning which the design team is required to carry out during the development of the contract documents. The requirements include a listing of the responsibilities for each member of the design team. In addition, for perspective the requirements list the responsibilities of all players during the construction phase. These requirements are intended to be included in the RFP for A/E services and for prospective commissioning agents, after GSA fills in the appropriate check boxes and blanks. The requirements include little detail, rather they point to the fully explained procedures in the Model Commissioning Plan-Design Phase.

In the Appendix to Part I, a sample request for proposal (RFP) for a commissioning agent is provided which will assist in engaging the services of a qualified commissioning agent for the project. This RFP was developed as a stand-alone document and is redundant of much of the material in the main part of this section.

The information in this section should be adapted for inclusion in any AIA or other standard documents used for acquiring design and consulting services. Special instructions to the specification or contract writer have been enclosed in boxes.

\section{Table of Contents}

\section{Introduction}

\subsection{General}

1.1 Party Definitions

1.2 Participation

2.0 Responsibilities

2.1 All Parties

2.2 Architect (of the AVE team)

2.3 HVAC Mechanical and Electrical Designers/Engineers (of the A/E team) 3

2.4 Commissioning Agent

2.5 Contractor and Subcontractors

2.6 Construction Manager (Owner's Rep, GSA)

2.7 Project Manager (of GSA) 


\section{Request for Proposal of A/E Services}

\section{--Design Team Commissioning Requirements--}

\section{Introduction}

The General Services Administration (GSA), Region 10 is committed to the concept of commissioning all new buildings and major renovations. Commissioning is the process of achieving, verifying and documenting the performance of building systems in accordance with the design intent and the client's functional and operational needs. Commissioning starts in the design phase and extends through the construction process and into the warranty period. In brief, the commissioning process entails developing clear and complete design and operational intent documentation, verifying and documenting proper equipment and system performance, ensuring that appropriate $0 \& M$ documentation is left with the building operating staff and ensuring that the building operators are sufficiently trained. Building commissioning is a team effort and requires cooperation by all parties to succeed efficiently.

\subsection{General}

\subsection{Party Definitions}

Commissioning Agent (CA) - an independent agent, not otherwise associated with the A/E team members or the Contractor, though he/she may be hired as a subcontractor to them. The CA or the architect may coordinate the commissioning during design. The CA coordinates the commissioning during construction. The CA reports directly to the GSA Project Manager during design.

Commissioning Coordinator - the party assigned to coordinate the commissioning activities during the design phase. This may be the CA or the architect.

Project Manager (PM) - the contracting and managing authority for GSA over the design and/or construction of the project.

Construction Manager (CM) - GSA's on-site representative or agent. The Contractor reports to the CM.

Contractor (GC) - the general contractor for the project.

Architect / Engineer (A/E) - the prime consultant (architect) and sub-consultants who comprise the design team dealing with mechanical and electrical systems, generally the HVAC mechanical designer/engineer and the electrical designer/engineer.

\subsection{Participation}

For the Design Phase, a commissioning agent will be hired by:

GSA directly

the CM

the A/E

the GC 


\subsection{Responsibilities}

By responding to this RFP, the A/E team acknowledges their willingness to participate in the commissioning process. The commissioning process is fully defined in the following reference documents developed by Region 10, USDOE included with this RFP: Commissioning Guide Specifications, Model Commissioning Plan-Design Phase, Model Commissioning PlanConstruction Phase. The GSA Building Commissioning Guide is also a valuable general reference guideline. For use, modification or customizing, an electronic copy of the Guide Specifications, as well as the other two USDOE documents, will be provided to the parties awarded the design contract.

To provide an overall perspective of the commissioning process, a summary of the commissioning responsibilities of all parties is provided below for all design and construction phases. This includes the responsibilities and tasks of the CM, PM and GC, which are not a part of the scope of this RFP. The CA responsibilities during construction and warranty are not included in the scope of this RFP. If the CA is checked below, the CA services during Design Development and Construction Documents phase are included in the scope of this RFP.

In summary, only the tasks of the following checked parties are part of the scope of $\mathrm{A} / \mathrm{E}$ commissioning services for this RFP.

Architect (Programming through Warranty)

HVAC mechanical designer (Programming through Warranty)

Electrical designer (Programming through Warranty)

Commissioning agent (during Design Development and Construction Documents Phases)

\subsection{All Parties}

\section{All Phases}

1. Follow the Commissioning Plan-Design Phase included with this RFP.

\subsection{Architect (of the A/E team)}

\section{Programming and Conceptual Development Phases}

1. Document the tenant and GSA building criteria, needs, etc. for this building in a programming report.

2. If assigned as the design phase commissioning coordinator, make any changes necessary to the original Commissioning Plan-Design Phase provided by GSA.

\section{Design Development}

1. Coordinate the commissioning work, ___ Commissioning agent coordinates the commissioning work.

2. Document the design intent for general building design and function as specified in the Commissioning Plan included with this RFP.

\section{Construction Documents Phase}

1. Coordinate the commissioning work, Commissioning agent coordinates the commissioning work.

2. Coordinate the development of the design intent by all design team members. 
3. Document the design intent, design narrative and design parameters as specified in the Commissioning Plan included with this RFP and include this documentation in the specifications sections shown in the Commissioning Plan-Design Phase.

4. Adapt the Division 1, Sections 00800, 01040, 01300, 01700, and 01730 from Guide Commissioning Specifications into Division 1 for this project. Developing performance verification requirements to be executed by others shall not be construed to relieve the architect and design engineers of any responsibility assigned under the contractual agreement.

\section{Construction and Acceptance Phase}

1. Manage the CA contract, manages the CA contract.

2. Perform normal submittal review, construction observation, as-built drawing preparation, O\&M manual preparation, etc., as contracted.

3. Provide any design narrative documentation requested by the $\mathrm{CA}$.

4. Coordinate resolution of system deficiencies identified during commissioning, according to the contract documents.

5. Prepare and submit final as-built design intent documentation for inclusion in the O\&M manuals. Review and approve the O\&M manuals.

\section{Warranty Period}

1. Coordinate resolution of design non-conformance and design deficiencies identified during warranty-period commissioning.

\subsection{HVAC Mechanical and Electrical Designers/Engineers (of the A/E team)}

\section{Programming and Conceptual Development Phase}

$$
\text { -None- }
$$

\section{Design Development Phase}

1. Document design intent and general operating parameters according to the Commissioning Plan included with this RFP.

\section{Construction Documents Phase}

1. Complete the documentation of the design intent and operating parameters according to the Commissioning Plan included with this RFP and include this documentation in the specifications sections shown in the Commissioning Plan-Design Phase.

2. Adapt the Division 15 (HVAC mechanical designer) and Division 16 (electrical designer) Guide Commissioning Specifications into Division 15 and 16 for this project.

\section{Construction and Acceptance Phase}

1. Perform normal submittal review, construction observation, as-built drawing preparation, etc., as contracted. One site observation should be completed just prior to system start-up.

2. The designers shall provide the $\mathrm{CA}$ with additional detailed equipment and system information, as requested. The designers shall assist (along with the contractors) in clarifying the operation and control of commissioned equipment in areas where the specifications, control drawings or equipment documentation are not sufficient for writing detailed testing procedures. 
3. Participate in the resolution of Division 15,16 and 17 system deficiencies identified during commissioning, according to the contract documents.

4. Prepare and submit the Division 15 and 16 final as-built design intent and design and operating parameters documentation for inclusion in the O\&M manuals. Review and approve the O\&M manuals.

5. Provide a presentation at the first training session for the Owner's personnel.

\section{Warranty Period}

1. Participate in the resolution of respective Division 15 and 16 non-compliance and design deficiencies identified during commissioning during warranty-period commissioning.

\subsection{Commissioning Agent}

The CA is not responsible for design concept, design criteria, compliance with codes, design or general construction scheduling, cost estimating, or construction management. The CA may assist with problem-solving or resolving non-conformance or deficiencies, but ultimately these responsibilities reside with the general contractor and the $A / E$. The primary role of the $C A$ is to develop and coordinate the execution of a testing plan, observe and document performance-that is determine whether systems are functioning in accordance with the documented design intent and in accordance with the Contract Documents. The Contractors will provide all tools or the use of tools to start, check-out and functionally test equipment and systems, except for specified testing with portable data-loggers, which shall be supplied and installed by the CA.

\section{Programming and Conceptual Development Phase}

-None-

\section{Design Development Phase}

1. If assigned as the design phase commissioning coordinator, make any changes necessary to the original Commissioning Plan-Design Phase provided by GSA.

2. Coordinate the commissioning work,_Architect coordinates the commissioning work.

3. Perform, Do not perform a design review at the end of Design Development.

4. Assist design team members in developing their portions of the design intent.

\section{Construction Documents Phase}

1. Coordinate the commissioning work,___ Architect coordinates the commissioning work.

2. Perform a review of the drawings and specifications when $50 \%$ and $95 \%$ complete.

3. Assist, review and approve the development of the design intent and operating parameters documentation by all design team members.

4. Develop a draft project-specific commissioning plan for the construction phase, using the Commissioning Plan-Construction Phase model document.

5. Coordinate the development of the construction commissioning specifications.

6. Assist, review and approve the development of the construction commissioning specifications by all design team members.

7. Assist the $\mathrm{A} / \mathrm{E}$ in adapting the special commissioning Division 17 Guide Commissioning Specifications into Division for this project.

\section{Construction and Acceptance Phase}

According to the Contract Documents: 
1. Coordinate and direct the commissioning activities in a logical, sequential and efficient manner using consistent protocols and forms, centralized documentation, clear and regular communications and consultations with all necessary parties, frequently updated timelines and schedules and technical expertise.

2. Coordinate the commissioning work and, with the $\mathrm{GC}$ and $\mathrm{CM}$, ensure that commissioning activities are being scheduled into the master schedule.

3. Revise, as necessary, the Draft 2, Commissioning Plan-Construction Phase.

4. Plan and conduct a commissioning scoping meeting.

5. Request and review additional information required to perform commissioning tasks, including O\&M materials, contractor start-up and checkout procedures.

6. Before startup, gather and review the current control sequences and interlocks and work with contractors and design engineers until sufficient clarity has been obtained, in writing, to be able to write detailed testing procedures.

7. Review and approve normal Contractor submittals applicable to systems being commissioned for compliance with commissioning needs, concurrent with the $\mathrm{A} / \mathrm{E}$ reviews.

8. Write and distribute prefunctional tests and checklists.

9. Develop an enhanced start-up and initial systems checkout plan with Subcontractors.

10. Perform site visits, as necessary, to observe component and system installations. Attend selected planning and job-site meetings to obtain information on construction progress. Review construction meeting minutes for revisions/substitutions relating to the commissioning process. Assist in resolving any discrepancies.

11. Witness all or part of the HVAC piping test and flushing procedure, sufficient to be confident that proper procedures were followed. Document this testing and include documentation in O\&M manuals. Notify owner's project manager of any deficiencies in results or procedures.

12. Witness all or part of any ductwork testing and cleaning procedures, sufficient to be confident that proper procedures were followed. Document this testing and include documentation in O\&M manuals. Notify owner's project manager of any deficiencies in results or procedures.

13. Approve prefunctional tests and checklist completion by reviewing prefunctional checklist reports or by direct site observation.

14. Approve systems startup by reviewing start-up reports and by selected site observation.

15. Review testing, adjusting, and balancing (TAB) execution plan.

16. Oversee sufficient functional testing of the control system and approve it for use by TAB, before TAB is executed.

17. Approve air and water systems balancing by spot testing and by reviewing completed reports and by selected site observation.

18. With necessary assistance and review from installing contractors, write the functional performance test procedures for equipment and systems. This may include energy management control system trending, stand-alone data-logger monitoring or manual functional testing. Submit to CM for review, and approval if required.

19. Analyze any functional performance trend logs and monitoring data to verify performance.

20. Coordinate, witness and approve manual functional performance tests performed by installing contractors. Coordinate retesting as necessary until satisfactory performance is achieved.

21. Maintain a master deficiency and resolution log and a separate testing record. Provide to the $\mathrm{CM}$ written progress reports and test results with recommended actions. 
22. Witness performance testing of smoke control systems by others and all other owner contracted tests or tests by manufacturer's personnel over which the CA may not have direct control. Document this testing and include in Commissioning Record in documentation in O\&M manuals.

23. Review equipment warranties to ensure that the Owner's responsibilities are clearly defined.

24. Oversee and approve the training of the Owner's operating personnel.

25. Compile and maintain a commissioning record and building systems book(s).

26. Review and approve the preparation of the O\&M manuals.

27. Provide a final commissioning report.

\section{Warranty Period}

1. Supervise any seasonal or deferred testing and deficiency corrections required by the specifications.

2. Return to the site at 10 months into the 12 month warranty period and review with facility staff the current building operation and the condition of outstanding issues related to the original and seasonal commissioning. Also interview facility staff and identify problems or concerns they have with operating the building as originally intended. Make suggestions for improvements and for recording these changes in the O\&M manuals. Identify areas that may come under warranty or under the original construction contract. Assist facility staff in developing reports and documents and requests for services to remedy outstanding problems.

3. Optional: Assist in the development of a preventative maintenance plan, a detailed operating plan or an energy and resource management plan or as-built documentation.

\subsection{Contractor and Subcontractors}

No part of these specifications are to be construed to relieve the Contractor of their responsibilities under the building contract.

\section{Programming through Construction Documents Phases}

$$
\text { -None- }
$$

\section{Construction and Acceptance Phase}

1. The GC shall ensure that all Subcontractors (Subs) execute their commissioning responsibilities according to the contract documents in a timely fashion.

2. A representative of the subcontractor for each applicable trade shall attend a commissioning scoping meeting.

3. Subs shall provide normal cut sheets and shop drawing submittals and O\&M manuals, with one copy for each piece of commissioned equipment going to the CA. Subs shall provide the $\mathrm{CA}$ with additional detailed equipment and system information, as requested. Subs shall assist (along with the design engineers) in clarifying the operation and control of commissioned equipment in areas where the specifications, control drawings or equipment documentation are not sufficient for writing detailed testing procedures.

4. Subs shall provide limited assistance to the $\mathrm{CA}$ in preparation of the specific functional performance test procedures. Subs shall review test procedures to ensure feasibility, safety and equipment protection. 
5. Subs shall execute their normal system prestart-up checkout procedures without a decrease in rigor. In addition, they will complete prefunctional performance checklists and tests provided to them by the CA.

6. Subs shall perform and clearly document their normal start-up and system check-out procedures without a decrease in rigor. Subs shall provide a start-up report and a copy of the manufacturer's recommended start-up procedures to the CA. Subs shall address all $\mathrm{A} / \mathrm{E}$ punch list items to date and TAB shall be completed with discrepancies and problems remedied before functional testing. Subs shall perform standard start-up testing and system operational checkouts with normal rigor. Commissioning performance verification is intended to verify proper performance, not replace the startup testing and system debugging responsibilities of the Subs.

7. Subs shall execute functional performance testing, witnessed by the CA.

8. Correct deficiencies (differences between specified and observed performance) as interpreted by the $\mathrm{CA}, \mathrm{CM}$ and $\mathrm{A} / \mathrm{E}$.

9. Prepare O\&M manuals according to the contract documents.

10. Prepare red-line as-built drawings for all drawings and final as-builts for contractorgenerated coordination drawings.

11. Provide training of the Owner's operating personnel.

12. Coordinate with equipment manufacturers to determine specific requirements to maintain the validity of the warranty.

13. Furnish a copy of all construction documents, addenda, change orders and approved submittals and shop drawings to the $\mathrm{CA}$.

14. General contractor shall coordinate the training of owner personnel.

\section{Warranty Period}

1. Subs shall execute seasonal and other deferred functional performance testing, witnessed by the $\mathrm{CA}$, according to the specifications.

2. Correct deficiencies and make necessary adjustments to O\&M manuals and as-built drawings for applicable issues identified in any seasonal testing.

\subsection{Construction Manager (Owner's Rep, GSA)}

\section{Programming through Design Development Phases}

-None-

\section{Construction Documents Phase}

1. Perform a general review of the drawings and specifications. Perform a constructibility review and/or perform a value engineering analysis according to their contract.

\section{Construction and Acceptance Phase}

1. Facilitate the coordination of the commissioning work by the $C A$, and with the $G C$ and CA ensure that commissioning activities are being scheduled into the master schedule.

2. Review and approve the final Commissioning Plan-Construction Phase.

3. Attend a commissioning scoping meeting.

4. Perform the normal review of Contractor submittals.

5. Review and approve the functional performance test procedures submitted by the CA, prior to testing.

6. Review periodic commissioning progress and deficiency reports.

7. Coordinate the resolution of non-compliance and design deficiencies identified in all phases of commissioning. 
8. Assist the Contractor in coordinating the training of owner personnel.

9. Sign-off on individual commissioning tests completed and passing. Recommend completion of the commissioning process to the Project Manager.

Note: If the CA is hired by the CM or directly by GSA, the CM tasks listed above for the commissioning process become the responsibility of the $\mathrm{CA}$, as the need for oversight of the CA is essentially eliminated, except for the coordination of deficiency resolution.

\section{Warranty Period}

1. Assist the CA as necessary in the seasonal testing and deficiency corrections required by the specifications.

\subsection{Project Manager (of GSA)}

\section{Programming through Design Development Phases}

- 1. Manage the A/E contract.

2. Work with the client in determining their functional needs.

3. Perform the normal reviews of the $A / E$ work.

4. Approve the final Commissioning Plan-Design Phase.

\section{Construction Documents Phase}

1. Manage the $\mathrm{A} / \mathrm{E}$ contract.

2. As normal, represent GSA and the client in drawing and specification reviews.

3. Review and approve the design intent documentation.

4. Review and approve the commissioning specifications.

5. As normal, review the value engineering analysis and approve any changes to be incorporated.

\section{Construction and Acceptance Phase}

1. Manage the contract of the $\mathrm{A} / \mathrm{E}$ and of the $\mathrm{GC}$.

2. Arrange for facility operating and maintenance personnel to attend various field commissioning activities and field training sessions according to the Commissioning Plan-Construction Phase.

3. Provide final approval for the completion of the commissioning work.

\section{Warranty Period}

1. Ensure that any seasonal testing and any deficiency issues are addressed. 
Part 1. Commissioning Requirements-Design Phase Appendix 1. Solicitation for Commissioning Agent Services

\section{Part I}

\section{APPENDIX 1}

\section{Solicitation for Commissioning Agent Services}


Part I. Commissioning Requirements-Design Phase

Appendix 1. Solicitation for Commissioning Agent Services

\section{Solicitation for Commissioning Agent Services}

\section{BACKGROUND}

(Owner) is seeking the services of a qualified

commissioning agent/firm for a new commercial construction project. The project is a gross sf, story, Class [type] building in [city \& state]

to be comprised of with a project budget of $\$$ million. The facility is expected medical laboratory. $\%$ office space, $\%$ retail, parking garage, and $\%$

The project has gone through the programming phase, with a programming report available for review. The balance of design is expected to be completed by and construction started by , with a final occupancy date of

If the project is already designed, onclude detalled descriptions of the systems in the building that will be commissioned.

The management structure is traditional "design and spec" with full design documents and specifications to be developed by an architectural firm. The construction documents will be let out to bid and a general contractor will be hired to complete the construction. The design team will have limited construction oversight. The Owner's primary construction representative onsite will be provided by the separately contracted services of a construction management firm. The commissioning agent will report to the construction manager.

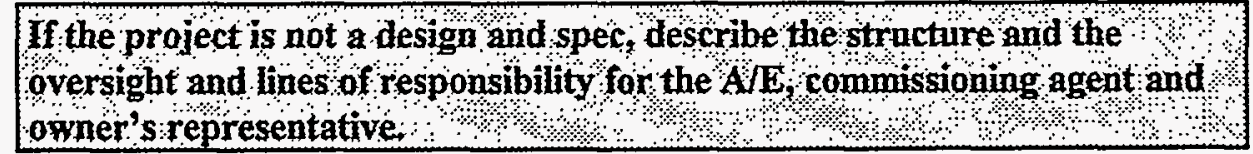

If you are providing the CA with more detailed design phase
commissioning requirements, a design phase model plan, sample
commissioning construction specifications and a model constraction phase,
commissioning plan for reference, you can delete out the redumdant areas of
this RFP.

\section{SCOPE OF WORK}

The Owner is committed to commissioning this facility to ensure that all systems are complete and functioning properly upon occupancy and that facility staff have adequate system documentation and training. Commissioning consists of systematically documenting that specified components and systems have been installed and started up properly, and then functionally tested to verify and document proper operation through all modes and conditions. In 
Part I. Commissioning Requirements-Design Phase

addition, owner-personnel training will be verified and final project operations and maintenance (O\&M) documents will be reviewed for completeness.

The following is a summary of the commissioning process which the Owner intends to have implemented on this project. The proposer is free to suggest changes and improvements to this process. However, for this proposal the following process will be assumed.

\section{Commissioning Process During Design}

A summary of the commissioning process during design is:

1. A design phase commissioning plan is developed by the commissioning agent (CA).

2. The design team members perform their normal functions in addition to the commissioning related tasks of documenting the design intent.

3. The CA performs a focused review of design development.

4. The CA develops the draft commissioning plan for the construction phase.

5. The CA develops commissioning specifications for the construction documents, with review by the design team, for inclusion in their construction specifications.

6. The design team develops in-depth design documentation, including design intent, basis of design and full sequences of operation for inclusion in the construction documents.

7. The CA performs a design review at $50 \%$ and $95 \%$ completion of the drawings and specifications.

8. The CA updates the original draft of the commissioning plan for the construction phase.

\section{Commissioning Process During Construction and Warranty}

A summary of the commissioning process that the Owner will follow during construction is:

1. A commissioning plan is developed by the commissioning agent.

2. A scoping meeting is conducted by the $\mathrm{CA}$ where the commissioning process is reviewed with the commissioning team members.

3. Additional meetings will be required throughout construction, scheduled by the $C A$ with necessary parties attending, to plan, scope, coordinate, and schedule future activities and resolve problems.

4. Equipment documentation is submitted to the CA during normal submittals, including detailed start-up procedures.

5. The CA works with the Subcontractors (Subs) in developing start-up plans and start-up documentation formats, including providing to the Subs prefunctional checklists to be completed during the startup process.

6. In general, the checkout and performance verification proceeds from simple to complex; from component level to equipment to systems and intersystem levels with prefunctional checklists being completed before functional testing.

7. The Subs, under their own direction, execute and document the prefunctional checklists and perform startup and initial checkout. The CA documents that the checklists and startup were completed according to the approved plans. This may include the CA witnessing startup of selected equipment.

8. The CA develops specific equipment and system functional performance test procedures. The Subs review the procedures.

9. The procedures are executed by the Subs, under the direction of, and documented by the CA.

10. Items of non-compliance are corrected at the Subs' expense and the system retested.

11. The CA reviews the O\&M documentation for completeness.

Model Commissioning Plan and Guide Specifications

PECINSDOE CA_RFP.015, 03/2097

Part I, A-3 
Part I. Commissioning Requirements-Design Phase

Appendix 1. Solicitation for Commissioning Agent Services

12. Commissioning is completed before Substantial Completion.

13. The CA reviews, pre-approves and coordinates the training provided by the Subs and verifies that it was completed.

14. Deferred and seasonal testing and performance evaluation is conducted, as specified or required.

\section{Commissioning Agent Responsibilities}

The proposer is free to suggest changes and improvements to following task list. However, for this proposal the following tasks will be assumed.

The commissioning agent/firm (CA) will have the following responsibilities:

The CA is not responsible for design concept, design criteria, compliance with codes, design or general construction scheduling, cost estimating, or construction management. The CA may assist with problem-solving or resolving non-conformance or deficiencies, but ultimately that responsibility resides with the general contractor and the $A / E$. The primary role of the $C A$ is to develop and coordinate the execution of a testing plan, observe and document performance-that is determine whether systems are functioning in accordance with the documented design intent and in accordance with the Contract Documents. The Contractors will provide all tools or the use of tools to start, check-out and functionally test equipment and systems, except for specified testing with portable data-loggers, which shall be supplied and installed by the CA.

\section{Programming and Conceptual Development Phase}

-None-

\section{Schematic Design and Design Development Phase}

1. Coordinate the commissioning work during design

2. Develop a design-phase commissioning plan, using the draft or "boilerplate" version provided by the Owner or other approved models.

3. Perform a focused design review at the end of Design Development, as described in Exhibit 1.

4. Assist design team members in developing their portions of the design intent. Approve their submissions.

\section{Construction Documents Phase}

1. Coordinate the commissioning work during this phase.

2. Perform a focused review of the drawings and specifications when $50 \%$ and $95 \%$ complete, as described in Exhibit 2.

3. Assist, review and approve the development of the design intent and operating parameters documentation by all design team members.

4. Develop a draft project-specific commissioning plan for the construction phase, using the "boilerplate" version provided by the owner or other approved models.

5. Develop full commissioning specifications for all commissioned equipment listed below using one or more of the following documents as a guide for content, rigor and format: 1) Model Commissioning Plan and Guide Specifications, USDOE/FEMP; Portland Energy Conservation, Inc. (PECI). Available in electronic and hard copy form from National Technical Information Service (NTIS) at 1-800-553-6847 and on the internet through PECI, 
Part I. Commissioning Requirements-Design Phase

Appendix 1. Solicitation for Commissioning Agent Services

http://www.teleport.com/ peci. 2) Facility Design Information Manual, Engineering

Services, University of Washington. Available over the internet at

http://weber.u.washington.edu/ fsesweb, under Vol. 2 Division 17 Commissioning. 3) The

HVAC Commissioning Process, ASHRAE Guideline 1-1989R. Available from ASHRAE at 404-636-8400.

The commissioning specification will include a detailed description of the responsibilities of all parties included in the commissioning process; details of the commissioning process; reporting and documentation requirements, including formats; deficiency resolution; prefunctional checklist and startup requirements; the functional testing process; specific functional test requirements, including testing conditions and acceptance criteria for each piece of equipment being commissioned.

6. Have the commissioning specifications approved by the $\mathrm{A} / \mathrm{E}$ team and included in the $\mathrm{A} / \mathrm{E}$ construction specifications.

\section{Construction and Acceptance Phase}

1. Coordinate and direct the commissioning activities in a logical, sequential and efficient manner using consistent protocols and forms, centralized documentation, clear and regular communications and consultations with all necessary parties, frequently updated timelines and schedules and technical expertise.

2. Coordinate the commissioning work and, with the general contractor (GC) and construction manager (CM), ensure that commissioning activities are being scheduled into the master schedule.

3. Revise, as necessary, the current draft of the construction phase commissioning plan developed during design.

4. Plan and conduct a commissioning scoping meeting.

5. Request and review additional information required to perform commissioning tasks, including O\&M materials, contractor start-up and checkout procedures.

6. Before startup, gather and review the current control sequences and interlocks and work with contractors and design engineers until sufficient clarity has been obtained, in writing, to be able to write detailed testing procedures.

7. Review and approve normal Contractor submittals applicable to systems being commissioned for compliance with commissioning needs, concurrent with the A/E reviews.

8. Write and distribute prefunctional tests and checklists.

9. Develop an enhanced start-up and initial systems checkout plan with Subs.

10. Perform site visits, as necessary, to observe component and system installations. Attend selected planning and job-site meetings to obtain information on construction progress.

Review construction meeting minutes for revisions/substitutions relating to the commissioning process. Assist in resolving any discrepancies.

11. Witness all or part of the HVAC piping test and flushing procedure, sufficient to be confident that proper procedures were followed. Document this testing and include documentation in O\&M manuals. Notify owner's project manager of any deficiencies in results or procedures.

12. Witness all or part of any ductwork testing and cleaning procedures, sufficient to be confident that proper procedures were followed. Document this testing and include documentation in O\&M manuals. Notify owner's project manager of any deficiencies in results or procedures.

13. Approve prefunctional tests and checklist completion by reviewing prefunctional checklist reports or by direct site observation.

14. Approve systems startup by reviewing start-up reports and by selected site observation.

Model Commissioning Plan and Guide Specifications

Part I, A-5

PECINSDOE CA_RFP.015, 03/20197 
Part I. Commissioning Requirements-Design Phase

Appendix 1. Solicitation for Commissioning Agent Services

15. Review testing, adjusting and balancing (TAB) execution plan.

16. Oversee sufficient functional testing of the control system and approve it to be used for $\mathrm{TAB}$, before $\mathrm{TAB}$ is executed.

17. Approve air and water systems balancing by spot testing and by reviewing completed reports and by selected site observation.

18. With necessary assistance and review from installing contractors, write the functional performance test procedures for equipment and systems. This may include energy management control system trending, stand-alone data-logger monitoring or manual functional testing. Submit to CM for review, and approval if required.

19. Analyze any functional performance trend logs and monitoring data to verify performance.

20. Coordinate, witness and approve manual functional performance tests performed by installing contractors. Coordinate retesting as necessary until satisfactory performance is achieved.

21. Maintain a master deficiency and resolution log and a separate testing record. Provide to the $\mathrm{CM}$ written progress reports and test results with recommended actions.

22. Witness performance testing of smoke control systems by others and all other owner contracted tests or tests by manufacturer's personnel over which the CA may not have direct control. Document and include in Commissioning Record in O\&M manuals.

23. Review equipment warranties to ensure that the Owner's responsibilities are clearly defined.

24. Oversee and approve the training of the Owner's operating personnel.

25. Compile and maintain a commissioning record and building systems book(s).

26. Review and approve the preparation of the O\&M manuals.

27. Provide a final commissioning report.

Select the warranty period services desired below:

\section{Warranty Period}

1. Coordinate and supervise required seasonal or deferred testing and deficiency corrections and provide the final testing documentation for the commissioning record and $0 \& \mathrm{M}$ manuals.

2. Return to the site at 10 months into the 12 month warranty period and review with facility staff the current building operation and the condition of outstanding issues related to the original and seasonal commissioning. Also interview facility staff and identify problems or concerns they have with operating the building as originally intended. Make suggestions for improvements and for recording these changes in the O\&M manuals. Identify areas that may come under warranty or under the original construction contract. Assist facility staff in developing reports and documents and requests for services to remedy outstanding problems.

3. Assist in the development of a preventative maintenance plan, a detailed operating plan or an energy and resource management plan.

\section{Assumptions}

It is assumed that the $\mathrm{A} / \mathrm{E}$ will provide adequate written design intent, basis of design and full sequences of operation for all equipment and systems for the O\&M manuals and for the commissioning agent to use in writing functional tests. It is also assumed that the contractors will execute the functional testing of equipment, coordinated and documented by the commissioning agent, using forms provided by the commissioning agent. 
Part I. Commissioning Requirements-Design Phase

Appendix 1. Solicitation for Commissioning Agent Services

\section{Systems To Be Commissioned}

The following systems, including all components and controls, will be commissioned:

Delete and add systems as desired.

1. Central building automation systems, including linkages to remote monitoring and control sites (this excludes any security-related control systems or interlocks).

2. All equipment of the heating, ventilating and air conditioning systems.

3. Medical laboratory clean room hoods and pressurization

4. Refrigeration systems

5. Life safety systems (fire alarm, egress pressurization, fire protection)

6. Domestic and process water pumping systems

7. Emergency power and uninterruptible power supply (UPS) systems

8. Lighting control systems

9. Communication and paging systems

The following outlines the level of effort expected for each commissioned system:

The CA shall review the design documentation (design intent, basis of design and sequences of operation) for completeness. The CA shall develop prefunctional checklists for the installing contractors to include in their startup and initial checkout. The CA shall develop detailed written test procedures for guiding and documenting performance during functional testing.

The functional testing shall include operating the system and components through each of the written sequences of operation and other significant modes and sequences, including startup, shutdown, unoccupied mode, manual mode, staging, miscellaneous alarms, power failure, security alarm when impacted and interlocks with other systems or equipment. Sensors and actuators shall be calibrated during prefunctional checklisting by the installing contractors and spot checked by the commissioning agent during functional testing.

Tests on respective HVAC equipment shall be executed during both the heating and cooling season. However, some overwriting of control values to simulate conditions may be allowed, if used judiciously. The central plant shall have its efficiency bench-marked for later use by operations staff. Functional testing shall be done using conventional manual methods, control system trend logs or stand-alone dataloggers, to provide a high level of confidence in proper system function, as deemed appropriate by the commissioning agent and the Owner.

\section{DESIRED OUALIFICATIONS}

It is desired that the person designated as the site commissioning agent satisfy as many of the following requirements as possible:

1. Have acted as the principal commissioning agent for at least three projects over 100,000 sf.

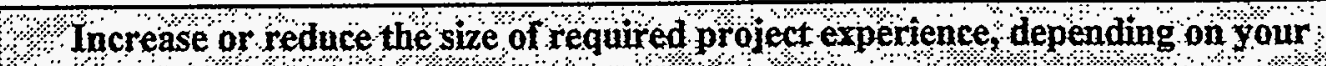
pproject, 
Part l. Commissioning Requirements-Design Phase

Appendix 1. Solicitation for Commissioning Agent Services

2. Have extensive experience in the operation and troubleshooting of HVAC systems, energy management control systems and lighting controls systems. Extensive field experience is required. A minimum of five full years in this type of work is required.

3. Knowledgeable in building operation and maintenance and O\&M training.

4. Knowledgeable in test and balance of both air and water systems.

5. Experienced in energy-efficient equipment design and control strategy optimization.

6. Direct experience in monitoring and analyzing system operation using energy management control system trending and stand-alone datalogging equipment.

7. Excellent verbal and writing communication skills. Highly organized and able to work with both management and trade contractors.

8. Experienced in writing commissioning specifications.

9. A bachelors degree in Mechanical Engineering is strongly preferred and P.E. certification is desired, however, other technical training and past commissioning and field experience will be considered.

10. The majority of the required expertise for this project must be part of the skill and experience set of the prime firm making the proposal. A member of that firm will be the designated Commissioning Agent. The Commissioning Agent must be fully qualified to commission most of the above listed systems. If the Commissioning Agent or prime firm does not have sufficient skills to commission a specific system, the prime firm shall subcontract with a qualified party to do so. That party's qualifications shall be included and clearly clesignated in the response to this RFP.

11. The Commissioning Agent will be an independent contractor and not an employee or subcontractor of the General Contractor or any other subcontractor on this project, including the $\mathrm{A} / \mathrm{E}$.

If the project is large $(200,000$ sf or so), include the following language and other language as appropriate, Specify project sizes, etc

It is desired that the prime commissioning firm have a designated project manager with the following qualifications. This person may also be the designated primary site commissioning agent.

1. Experienced in the design process of large projects $>$ sf.

2. Experienced in working with the construction management and process protocols of large buildings and projects.

3. Experienced in managing multi-year projects.

\section{INSTRUCTIONS TO PROPOSERS}

A proposer must propose to execute all phases of the commissioning in a single proposal. However, the proposer will provide separate prices for the design and construction/warranty phases shall be provided.

The proposal shall be limited to 15 single-sided pages, including graphics. A letter of introduction, section dividers, detailed resumes and the sample work products of item five below are not included in this limit.

The proposal must be signed by an officer of your firm with the authority to commit the firm. 
1. Fill out the attached Commissioning Firm Experience form, including the Project Experience Listing form (Exhibits 4 and 5).

2. List the key individual who will be the commissioning agent for this contract and describe his or her relevant qualifications and experience. This information is required in addition to any detailed resumes the proposer submits. The contract will require that this individual be committed to the project for its duration.

3. List the relevant experience of project management, supporting staff and subconsuitants, including detailed resumes, with the fraction of expected hours for each. Project management, supporting staff and subconsultants shall provide less than __ of the total . time on the project.

\section{The above fraction should range from 20 to: $50 \%$. Larger, more camplex} projects and projects with a variety of primany system types will have fractions in the upper range.

4. Provide project and professional references and experience for three to five commissioning projects for which the proposer was the principal commissioning agent in the last three years. Include a description of the project, including square footage and systems commissioned. Identify when the proposer came into the project. Describe the involvement of each individual on the proposer's team in the projects for the following areas: systems and components commissioned, specification writing, design review, commissioning plan development, functional testing procedures and forms, coordinating and overseeing functional testing, actually performing the functional testing (hands-on), troubleshooting involvement, project management, O\&M manual reviews and O\&M training. Provide this data on the attached Commissioning Project Experience Listing form. For each project, attach a sheet that includes the name and telephone number of the owner's project manager, construction manager, facility administrator of the building, the mechanical designer, the controls contractor site project manager, the mechanical contractor and electrical contractor.

5. Describe any experience of the proposer's team in the following areas. List the each party's involvement.

a) traditional test and balance;

b) commissioning laboratories;

c) O\&M experience;

d) energy-efficient equipment design and control strategy optimization;

e) life cycle costing; and

f) experience in environmental sustainable design.

g) project and construction management

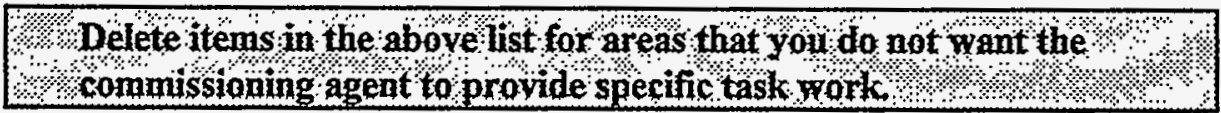

6. Describe your proposed approach to managing the project expertly and efficiently, including your team participation. Describe what approach you will take to integrate the commissioning into the normal design and construction process in order to minimize potential time delays. Describe what you will do to foster teamwork and cooperation from contractors and designers and what you will do to minimize adversarial relationships. Describe how you intend to determine the appropriate level of commissioning effort for the various systems and equipment. Describe how your work will facilitate the use of your product as a prototype 
Part I. Commissioning Requirements-Design Phase

Appendix 1. Solicitation for Commissioning Agent Services

which may be subsequently used by the Owner in future projects, including access to the electronic versions of all documents and forms.

7. As an attachment, provide the following work products that members of the proposer's team wrote. List the team member who actually wrote the document and the projects on which they were used. Work from the designated commissioning agent is highly preferred.

a) commissioning plan;

b) commissioning specifications; and

c) an actual functional test procedure form that was executed.

8. Provide both an estimated total fee to accomplish the work and an hourly rate for each team member if the project is set up on a time-and-materials basis. The Owner will negotiate with the selected proposer and may contract on a fixed fee or time and materials basis.

\section{SELECTION CRITERIA}

\section{Scale the weights below as desired}

The submitted proposals will be reviewed and ranked according to the following (items from the above numbered list):

1. \& 2. Key individual experience

3. Staff and subconsultant experience

4. Similar project experience

5. Team experience in related skill areas

6. Management approach

7. Work examples

8. Fee proposal
20 points

10 points

15 points

15 points

20 points

10 points

10 points

100 points

Reference checks will not be scored individually, but may be used to supplement all categories. The Owner reserves the right to eliminate or change the weight of extremely high or extremely . low fee proposals.

\section{SUBMISSION AND SELECTION}

Consultants will submit Owner's office at [address ( ) copies of the written proposal, to be received in the time ] by [date and ]. Late proposals will not be accepted.

Review and selection process

Requirement of personal interview for finalists. 
Part I. Commissioning Requirements-Design Phase

Appendix 1. Solicitation for Commissioning Agent Services

\section{PROTESTS}

Wording as required.

\section{LIMITATIONS AND PROVISIONS}

Wording on right to reject, to seek clarifications, to negotiate a final contract. Cost of proposal preparation not reimbursable. Primary contact for questions. Other necessary legal language, etc.

Date due, where to submit, number of copies, etc.

\section{MINIMUM REOUIREMENTS FOR CONTRACT EXECUTION}

\section{General Conditions.}

Misc. as required.

\section{Insurance}

The commissioning firm shall obtain, at the firm's expense, and keep in effect during the term of the project, with the following limits liability insurance covering

\section{Change in Personnel}

If the commissioning firm's personnel or subconsultants change for this project, the Owner must review and approve the replacement personnel, in advance. The replacement personnel shall have, at minimum, equivalent qualifications as the original personnel.

List other legal requirements as required 
Part I. Commissioning Requirements-Design Phase

\section{Exhibit 1}

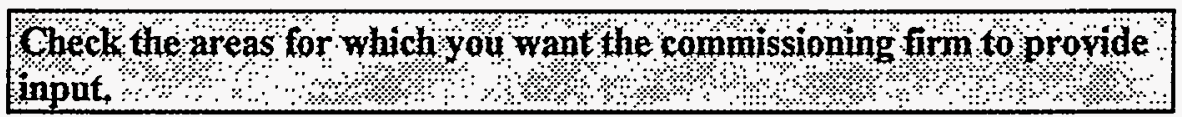

\section{FOCUSED DESIGN DEVELOPMENT REVIEW ELEMENTS}

The following checked areas will be reviewed by the commissioning agent.

\begin{tabular}{|c|l|}
\hline \multicolumn{1}{|c|}{ Design Area } & \multicolumn{1}{|c|}{ Review Description } \\
\hline Commissioning facilitation & $\begin{array}{l}\text { Input regarding making the building easier to commission } \\
\text { (see Exhibit 3) }\end{array}$ \\
\hline Energy Efficiency & $\begin{array}{l}\text { General efficiency of building shell, building layout, HVAC } \\
\text { system types, lighting system type, etc. }\end{array}$ \\
\hline Operations and Maintenance (O\&M). & $\begin{array}{l}\text { How building O\&M can be made easier (accessibility and } \\
\text { system control, etc.) }\end{array}$ \\
\hline Indoor Environmental Quality (IEQ) & $\begin{array}{l}\text { How thermal, visual, acoustical comfort or air quality can } \\
\text { be improved }\end{array}$ \\
\hline Functionality for Tenants & $\begin{array}{l}\text { How the design can be changed to improve functionality } \\
\text { for the occupants }\end{array}$ \\
\hline Environmental Sustainability & $\begin{array}{l}\text { How the building materials and systems and landscaping } \\
\text { can create less of an impact on the environment }\end{array}$ \\
\hline Life Cycle Costs & $\begin{array}{l}\text { Life cycle assessment of options relative to energy } \\
\text { efficiency, O\&M, IEQ or functionality }\end{array}$ \\
\hline
\end{tabular}


Part I. Commissioning Requirements-Design Phase

Appendix 1. Solicitation for Commissioning Agent Services

\section{Exhibit 2}

Check the areas for which you want the commissioning firm to pronide input.

\section{FOCUSED 50\% AND 95\% DESIGN REVIEW ELEMENTS}

The commissioning agent will perform a review at $50 \%$ and $95 \%$ design construction documents completion comprised of the following checked areas:

\begin{tabular}{|c|c|}
\hline Design Area & Review Description \\
\hline Commissioning facilitation & $\begin{array}{l}\text { Input regarding making the building easier to commission } \\
\text { (see Exhibit 3). }\end{array}$ \\
\hline _Component energy efficiency & $\begin{array}{l}\text { Review for adequacy of the efficiency of bldg. shell components, } \\
\text { HVAC systems and lighting systems. }\end{array}$ \\
\hline Control system \& control strategies & $\begin{array}{l}\text { Review _HVAC, _lighting, fire control, } \\
\text { emergency power, security control system, strategies and } \\
\text { sequences of operation for adequacy and efficiency. }\end{array}$ \\
\hline Operations and maintenance & $\begin{array}{l}\text { Review for effects of specified systems and layout toward } \\
\text { facilitating O\&M (equipment accessibility, system control, } \\
\text { etc.). }\end{array}$ \\
\hline Indoor environmental quality & $\begin{array}{l}\text { Review to ensure that systems relating to } \\
\text { visual, _thermal, } \\
\text { distribution are in accourdance with the design intent. }\end{array}$ \\
\hline Environmental sustainability & $\begin{array}{l}\text { Review to ensure that the building materials, } \\
\text { landscaping, w use of water resources, waste } \\
\text { management are in accordance with the design intent. }\end{array}$ \\
\hline Functionality for occupants & $\begin{array}{l}\text { Review to ensure that the design meets the functionality needs of } \\
\text { the occupants. }\end{array}$ \\
\hline Life cycle costs & $\begin{array}{l}\text { Perform a qualitative, _quantitative life cycle } \\
\text { assessment of the primary competing systems relative to } \\
\text { energy efficiency, O\&M, IIEQ, functionality. }\end{array}$ \\
\hline O\&M documentation & $\begin{array}{l}\text { Verify that building O\&M plan and documentation requirements } \\
\text { specified are adequate }\end{array}$ \\
\hline _Training & $\begin{array}{l}\text { Verify that operator training requirements specified are } \\
\text { adequate. }\end{array}$ \\
\hline Commissioning specifications & $\begin{array}{l}\text { Verify that bid documents adequately specify building } \\
\text { commissioning and that there are adequate monitoring and } \\
\text { control points specified to facilitate commissioning and O\&M } \\
\text { (trending capabilities, test ports, control points, gages and } \\
\text { thermometers). }\end{array}$ \\
\hline
\end{tabular}


Part I. Commissioning Requirements-Design Phase

Appendix 1. Solicitation for Commissioning Agent Services

\section{Exhibit 3}

\section{COMMISSIONING FACILITATION REVIEW}

One of the primary tasks for the commissioning agent is reviewing the design documents to facilitate commissioning during construction. The construction-phase commissioning process can be made easier and more effective if certain features are included in the design. The added upfront costs for most of these features can be justified because they reduce the cost of commissioning, allow for a better commissioning job and reduce the O\&M costs for the building. Below is a list of some of these features. Not all are addressed in detail in the design development review. However, they should be brought to the attention of the $A / E$ at this time, so that they can be incorporated during the construction documents phase. The review is not expected to be limited to only those issues listed below.

- Clear and rigorous design documentation, including detailed and complete sequences of operation.

- An HVAC fire and emergency power response matrix that lists all equipment and components (air handlers, dampers, valves, etc.) with their status and action during a fire alarm and under emergency power.

- Access for reading gages, entering doors and panels, observing and replacing filters, coils, etc.

- Required isolation valves, dampers, interlocks, piping, etc. to allow for manual overrides, simulating failures, seasons and other testing conditions.

- Sufficient monitoring points in the building automation system (BAS), even beyond that necessary to control the systems, to facilitate performance verification and O\&M.

- Adequate trending and reporting features in the BAS.

- Pressure and temperature $(\mathrm{P} / \mathrm{T})$ plugs close to controlling sensors for verifying their calibration.

- Pressure gages, thermometers and flow meters in strategic areas to facilitate verifying system performance and ongoing $O \& M$.

- Pressure and temperature $(\mathrm{P} / \mathrm{T})$ plugs at less critical areas or on smaller equipment where gages and thermometers would be over-kill.

- Specification of the location and criteria for the VAV duct static pressure sensor and chilled water differential pressure sensor.

- Adequate balancing valves, flow metering and control stations and control system functions to facilitate and verify reliable test and balance.

- Uniform inlet connection requirements to VAV terminal boxes.

- Clear and complete commissioning specifications for the construction phase.

- Complete O\&M documentation requirements in the specifications.

- Complete training requirements in the specifications.

- Review entire document and building information management plan from design through construction and turnover to ensure adequacy and compliance with the owner's program. 
Part I. Commissioning Requirements-Design Phase

Appendix 1. Solicitation for Commissioning Agent Services

Exhibit 4

COMMISSIONING FIRM EXPERIENCE

\begin{tabular}{lllll}
\hline Company Name & & Contact Person & Title \\
\hline Address & & City & State/Prov & Zjp/Postal Code \\
\hline Telephone & & & & E-Mail
\end{tabular}

\section{Description of Business}

\section{Commissioning Activities}

Percentage of overall business devoted to commissioning services

How long has the firm offered commissioning services

Average number of commissioning projects performed each year:

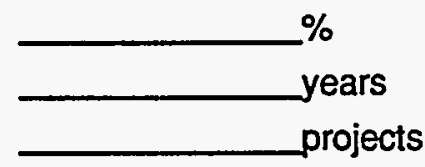

Systems (technologies) for which firm has provided commissioning services (check all that apply)
口. Pkg or split HVAC
$\square$ Daylighting
ㅁ Electrical, general
口 Commercial refrigeration
Q Chiller system
- Electrical, emerg. power
口 Telecommunications
B Boiler system
口 Envelope
口 Thermal Energy Storage
口 Energy Mgmt. System
口 Fire/Life Safety
a Variable Freq.Drives
口 Lighting Controls
ㅁ Plumbing
ㄴ Labs \& Clean Rooms

Number of registered professional engineers on staff who have directed commissioning projects:

The firm has provided commissioning services in the following: (check all that apply)

\begin{tabular}{|c|c|c|c|}
\hline Bullding Sector & $\begin{array}{l}\text { New Construction } \\
\text { Major Renovation }\end{array}$ & $\begin{array}{l}\text { Existing Bullding } \\
\text { (Building Tune-up) }\end{array}$ & $\begin{array}{c}\text { Equipment } \\
\text { Replacement }\end{array}$ \\
\hline Office & $\square$ & $\square$ & $\square$ \\
\hline Retail & $\square$ & $\square$ & $\square$ \\
\hline Grocery & $\square$ & $\square$ & $\square$ \\
\hline Hospitals & $\square$ & $\square$ & $\square$ \\
\hline Laboratories & $\square$ & $\square$ & $\square$ \\
\hline Schools & $\square$ & $\square$ & $\square$ \\
\hline Universities & $\square$ & $\square$ & $\square$ \\
\hline Federal, state, local gov't & $\square$ & $\square$ & $\square$ \\
\hline Industrial / Manufacturing & $\square$ & $\square$ & $\square$ \\
\hline $\begin{array}{l}\text { Special purpose-prisons, } \\
\text { museums, libraries, etc. }\end{array}$ & $\square$ & $\square$ & $\square$ \\
\hline
\end{tabular}









\title{
Part II
}

\section{Model Commissioning Plan --Design Phase--}

\author{
Sponsored by \\ US Department of Energy \\ Seattle Regional Support Office \\ 800 5th Ave. Suite 3950 \\ Seattle, WA 98104 \\ Prepared by: \\ Portland Energy Conservation, Inc. (PECI) \\ 921 SW Washington, Suite 312 \\ Portland, OR 97205 \\ 503-248-4636, Fax 503-295-0820
}

Version 2.02

March 1997 


\section{Part II}

\section{Model Commissioning Plan --Design Phase--}

\section{Summary}

The Model Commissioning Plan-Design Phase guides the commissioning activities during the design phase. It provides details of responsibilities called out in Part I, Commissioning Requirements-Design Phase for the architect, design engineers, commissioning agent, construction and project managers. The plan describes the duties of the $\mathrm{A} / \mathrm{E}$ team and commissioning agent in developing the site-specific commissioning specifications and for developing the first two drafts of the Commissioning PlanConstruction Phase.

\section{Table of Contents}

Instructions for GSA: Using the Model Commissioning Plan-Design Phase ii

Using the Plan with the RFP

Instructions for Filling Out the Model Plan ii

Commissioning Plan—Design Phase $\quad 1$

1. Overview of Commissioning During Design 1

2. Building Information 1

3. Design Project Team Data 3

4. Responsibilities 4

Tasks $\quad 4$

Scope $\quad 4$

Reporting $\quad 4$

5. Commissioning Scope of Work 5

5.1 Task 1. Coordination of Commissioning During Design 6

5.2 Task 2. Design Phase Commissioning Plan 6

5.3 Task 3. Design Development Review 7

5.4 Task 4. Design Intent and Basis of Design Documentation 8

5.5 Task 5. Draft Commissioning Plan for Construction 12

5.6 Task 6. Commissioning Specification Development 13

5.7 Task 7. General Review of Drawings and Specifications 14

5.8 Commissioning Facilitation $\quad 15$

6. General Schedule 16

Appendix 1. Design Documentation Format (Instructions and Forms) A1-i

Appendix 2. Fire and Emergency Power Response Matrix A2-I

Appendix 3. Commissioning for Indoor Quality Checklist-Design Phase A3-1 


\section{Instructions for the Owner Filling Out the Model Commissioning Plan-Design Phase}

\section{Using the Plan with the RFP}

The Model Commissioning Plan-Design Phase should be used for obtaining design proposals which will include commissioning and to guide the commissioning work throughout the design process. The Design Phase Commissioning Plan is referred to as the Model plan when it is not yet filled out. Refer to the Overview of the entire Model Commissioning Plan and Guide Specifications for further instructions about using the plan during the design process.

\section{Instructions for Filling Out the Model Plan}

With the following directions, the owner's staff can confidently fill out the Model Plan and RFP Requirements. The awarded commissioning agent or architect will later revise the plan as necessary. The Model Plan is intended as a true "boilerplate" for most projects and can be filled out by hand without any attachments. For projects with unusual contracting arrangements, editing the Model Plan may be necessary, and is provided on electronic media.

First fill out Section 2, Building Information, to provide the expected magnitude of the project in gross terms. Section 3 will not be filled out until the design contract is awarded.

Next, skip to Section 5, Commissioning Scope of Work. Here, the first decision to be made is to decide which systems will be commissioned. At a minimum, the HVAC, HVAC control system and lighting controls should be commissioned. Consulting with other project managers, your own experience and budget considerations will help you decide on the others.

Next, under Task 1 of Section 5, Overall Coordination, decide whether the architect or the commissioning agent will coordinate the commissioning during design. The commissioning agent is generally a good choice to start with, but in some design teams the architect may be the better party, especially where the architect is more than just casually interested in commissioning, or where, with the commissioning agent as the coordinator, not enough support will be given to the commissioning agent from the other members of the team. Your decision can always be changed after the award of the contract.

Generally the formal commissioning should start at the beginning of the Design Development Phase. For smaller, less complex projects, the commissioning effort could wait until the beginning of the Construction Documents Phase.

Next, under Task 3 of Section 5, Design Development Review, decide how much, if any, the commissioning agent will review the design at the end of Design Development. This is highly recommended. The number of design areas the commissioning agent reviews is dependent on the commissioning agent's skills and the emphasis and interest by the owner and the tenants in particular areas. At a minimum, the commissioning agent should review the energy-efficiency, operations and maintenance and the indoor environmental quality issues. Desired areas for review should be checked in Table 5-1.

Under Task 4 of Section 5, Develop Design Documentation, decide for which systems the designers will provide documented detailed design intent and operational parameters. Generally, all of the listed areas are highly recommended. Also under Task 4, who will coordinate the development of the design intent documentation - the commissioning agent or the architect- must be determined. Either party should work well. The desired areas for documentation should be checked. 
Task 5 of Section 5, Develop Construction Phase Commissioning Plan, requires no input, unless there are areas in the as-is Model Commissioning Plan-Construction Phase (Part IV) that the owner does not want to include. If so, the exclusions should be footnoted under this task.

Task 6 of Section 5, Develop Commissioning Specifications, requires no input at this time, unless there are large significant areas of the Guide Specifications (Part III) that the owner wants changed or clarified now, rather than during the normal adaptation process. If so, these exclusions or clarifications should be given under Task 6. It is noted that the Guide Specifications are not intended to be totally applicable to the project at hand and that the job of the design team is to adapt them. Thus, most or all of the changes needed will be made during the design process with guidance and approval of the owner.

Task 7 of Section 5, Conduct a Final Design Review, requires similar input as Task 3, using Table 5-3.

The Commissioning Schedule in Section 6 is fairly universal and will generally require no input. The only change that might be needed is if the commissioning starts later than the beginning of Design Development.

Finally, go to Table 4-1 in Section 4. This is a one-page view of the commissioning roles and responsibilities of the design team. In Table 4-1, there are two areas requiring input: 1) Who the overall commissioning coordinator during design will be, and 2) Who the lead on Task 4 will be. Check the appropriate party for these tasks and verify the other checks. 


\section{Commissioning Plan-Design Phase}

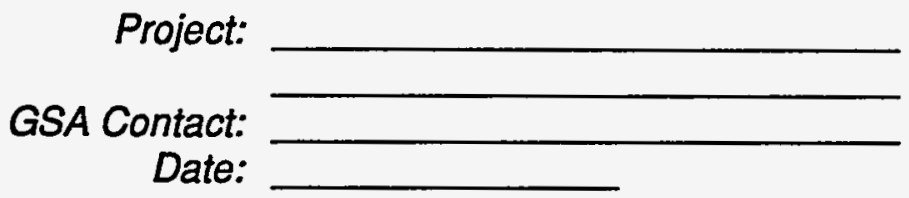

\section{Overview of Commissioning During Design}

Commissioning $(\mathrm{Cx})$ is a systematic process of ensuring that all building systems perform interactively according to the design intent and the owner's operational needs. This is achieved by beginning at the design phase with documented design and operating intent and continuing through construction and acceptance with actual verification of performance.

Commissioning during design is intended to achieve the following specific objectives:

- Provide commissioning focused design review.

- Ensure that the design and operational intent are clearly documented.

- Ensure that commissioning for the construction phase is adequately reflected in the bid documents.

The commissioning process during design is illustrated in Figure 1-1.

For reference, a brief description of the GSA design phases follows. Refer to the Part I, Commissioning Requirements-Design Phase for a listing of party definitions.

Programming-Design team and GSA Project Manager meet with representatives of the occupying agency or client and determine the square footage and occupancy requirements of the building.

Conceptual Design Phase-Architect develops block diagrams, building sizing, rough space planning and sketches of exterior types. Multiple choices are provided. Mechanical and electrical designers generally have no input in this phase.

Design Development Phase-Additional detail is applied to the block diagrams and layouts. Interior and exterior features and finishes and general HVAC system types are determined and a rough floor plan is approved. Value engineering, if any, is completed.

Construction Documents Phase-Drawings are completed. Specifications are completed, generally using the GSA Master Spec. Bid documents are prepared.

\section{Building Information}

Project Name:

Location:

Building Type (office, court, etc.):

Square Footage:

Expected number of stories:

Agency: Tenants:

Design Period: Const. Period: 
Figure 1-1. Commissioning During Design

\section{GSA Comentional Activities Commissioning Activities}

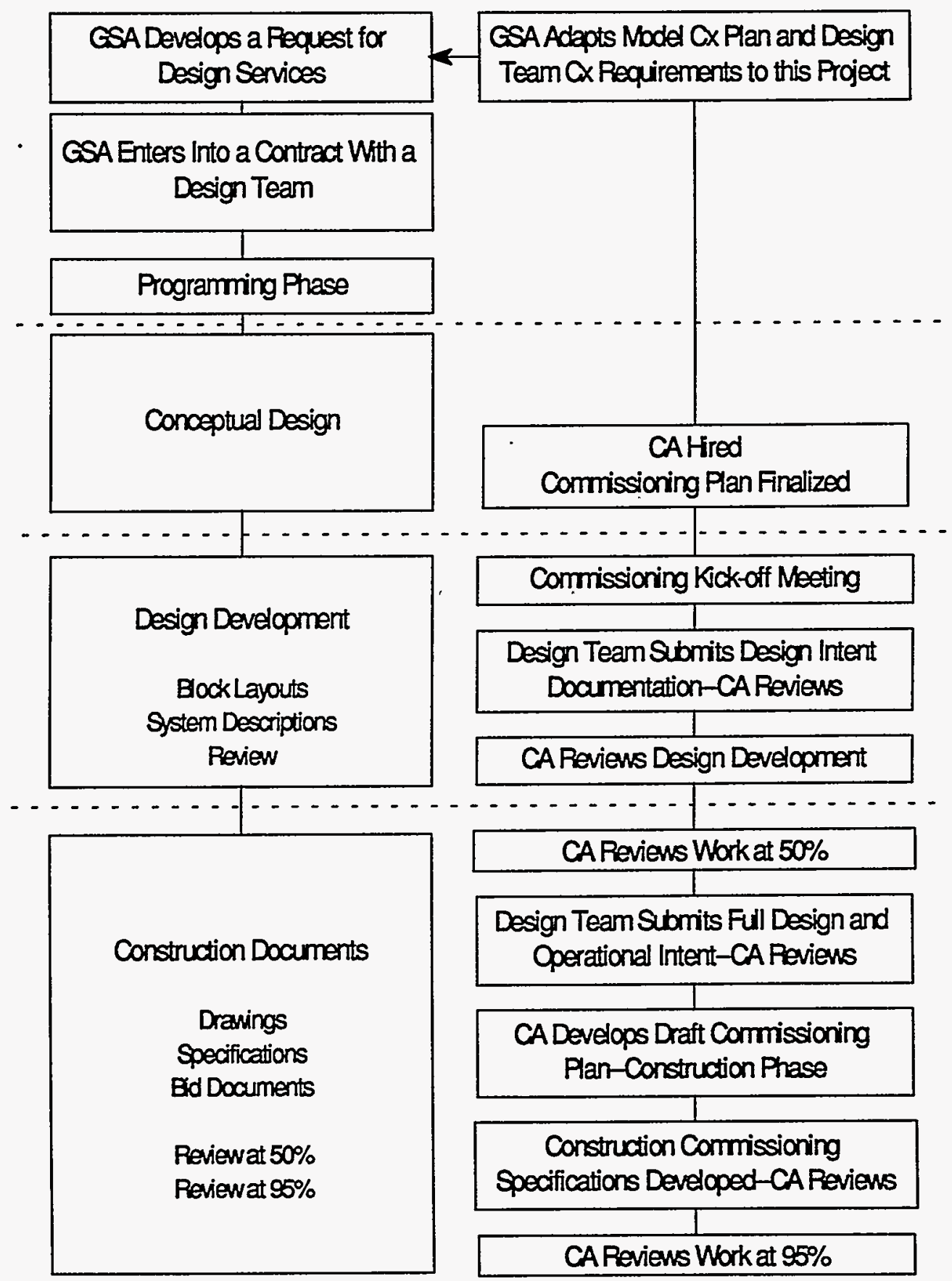




\section{Design Project Team Data}

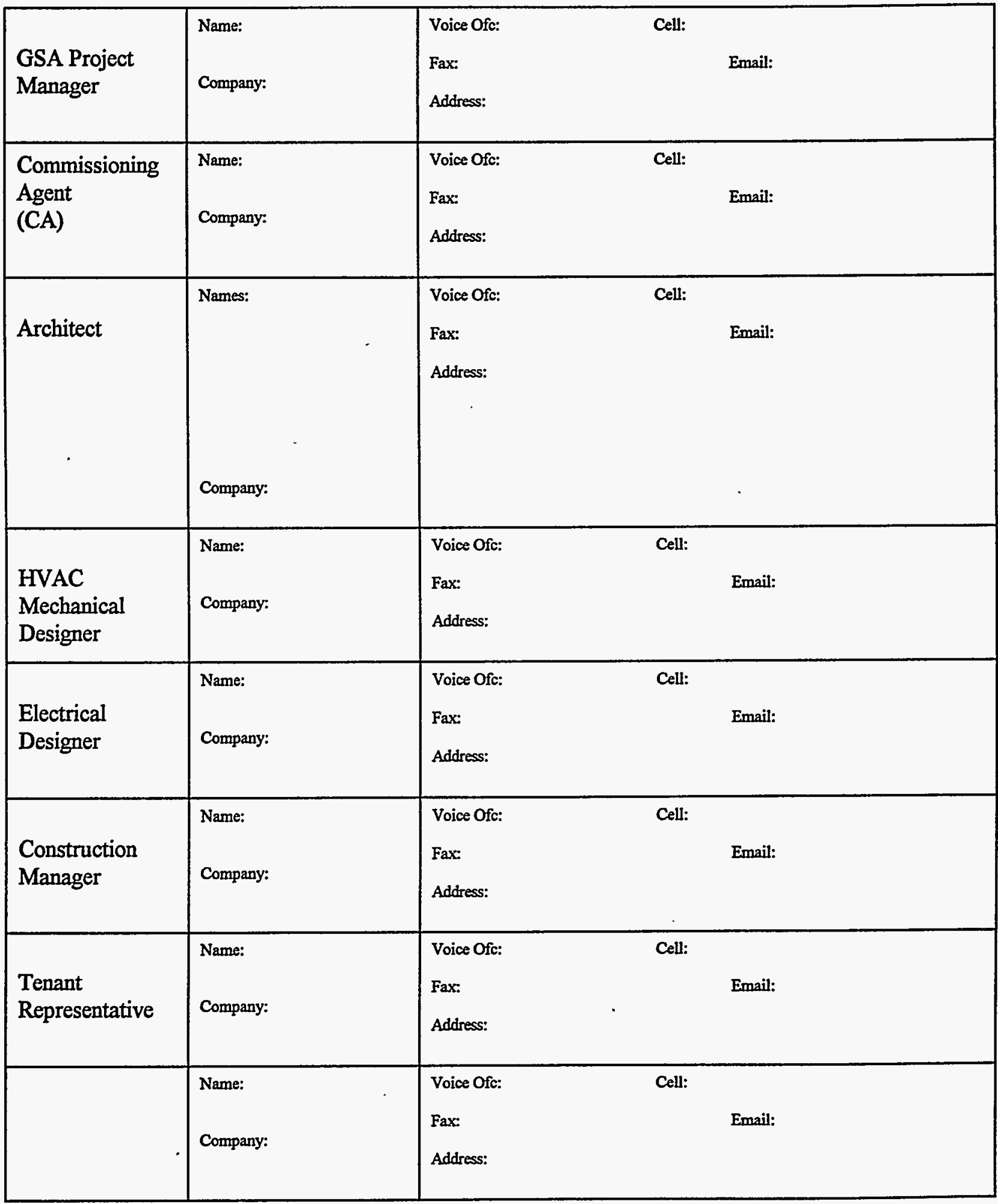




\section{Responsibilities}

\section{Tasks}

A list of the responsibilities and tasks for each party of the design team are presented in Table 4-1. The member assigned as the lead for a given task is shown. The lead will coordinate the completion of the task. Under each task listing are subtasks with an " $\mathrm{X}$ " marked by the participating team members. The tenant representative(s) are considered members of the design team and will contribute in their normal fashion. They have no new role in the commissioning effort and so are not listed in the table.

\section{Scope}

Section 5 provides additional detail regarding scope of the tasks.

\section{Reporting}

Members completing subtasks report to the lead for that task, per Table 4-1. The task lead reports to the Coordinator lead (the lead in Task 1). 
Table 4-1. Commissioning Roles and Responsibilities During Design

\begin{tabular}{|c|c|c|c|c|c|c|}
\hline \multirow[b]{2}{*}{$\begin{array}{l}\text { Design Phase } \\
\text { Commissioning Responsibilities and Tasks }\end{array}$} & \multicolumn{6}{|c|}{ Parties Involved } \\
\hline & \multirow[t]{2}{*}{ 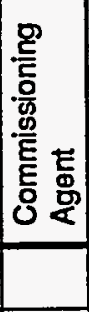 } & \multirow{2}{*}{ 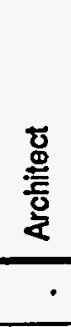 } & \multirow[t]{2}{*}{ 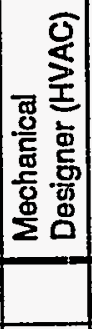 } & \multirow[t]{2}{*}{ 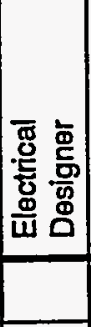 } & \multirow[t]{2}{*}{ 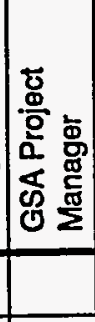 } & \multirow[t]{2}{*}{ 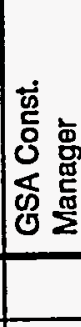 } \\
\hline 1 Overall coordinatlon of the $C \times$ work during Design & & & & & & \\
\hline a. Plan and schedule meetings & $x$ & $\mathrm{x}$ & & & $\underline{x}$ & \\
\hline b. Soe that all tasks are carried out & $x$ & $x$ & & & $\mathrm{x}$ & \\
\hline \multicolumn{7}{|l|}{ c. } \\
\hline 2 Finalize the Cx plan for Design Phase & $\underline{x}$ & & & & & \\
\hline a. Edit the original Cx Plan as necessary & $x$ & & & & & \\
\hline b. Review and comment on Cx plan & & $\underline{x}$ & & & $x$ & \\
\hline \multicolumn{7}{|l|}{ c. } \\
\hline 3 Perform design development review [1] & $\mathbf{X}$ & & . & & & \\
\hline $\begin{array}{l}\text { a. After completion of Design Development, review design concepts of the } \\
\text { areas checked in Table 5-1. }\end{array}$ & $\mathbf{x}$ & - & - & - & - & \\
\hline \multicolumn{7}{|l|}{ b. } \\
\hline 4 Develop design \& operating intent documentation & & & & & & \\
\hline a. Provide design intent format and assistance & $\underline{x}$ & & & & & \\
\hline b. Write design intent for systems checked under Task 4 in Section 5. & & $\underline{x}$ & $x$ & $\underline{x}$ & $x$ & \\
\hline c. Reviow and approve design intent for clarity and completeness & $x$ & & & & $\mathbf{x}$ & \\
\hline \multicolumn{7}{|l|}{ d. } \\
\hline 5 Develop draft Cx plan for Construction Phase & $\mathbf{x}$ & & & & & \\
\hline 2. Adapt and edit the Model Cx Plan--Const. Phase, Draft 1 and 2 & $x$ & & & & & \\
\hline b. Review Cxplan & & & & & $x$ & $\mathrm{x}$ \\
\hline \multicolumn{7}{|l|}{ c. } \\
\hline 6 Develop Cx specifications for construction & $\underline{\mathbf{x}}$ & & & & & \\
\hline a. Assist in, review \& approve all sections & $x$ & & & & & $\underline{x}$ \\
\hline b. Adap! Cx guide specs \& include in Division 1 & $x$ & $x$ & & & & \\
\hline c. Adapt $C x$ guide specs \& include in Division 15 (HVAC) & & & $x$ & & & \\
\hline d. Adapt Cx guide specs \& include in Division 16 (electrical) & & & & $x$ & & $i$ \\
\hline e. Adapt Cx quide specs in special Cx Division & $x$ & & & & & \\
\hline \multicolumn{7}{|l|}{ f. Adapt $\mathrm{Cx}$ guide spoas $\&$ include in Division } \\
\hline \multicolumn{7}{|l|}{ g. } \\
\hline 7 Review final drawings and specifications [1] & $\mathbf{x}$ & & & & & \\
\hline $\begin{array}{l}\text { a. Review full drawings \& specifications at } \sim 50 \% \& \sim 95 \% \text { complete to } \\
\text { ensure that the design intent is met (see Table 5-3). }\end{array}$ & $x$ & - & - & - & - & - \\
\hline & & & & & & \\
\hline
\end{tabular}

[1] This does not preclude the normal reviews by all parties, denoted by a dash -, but is intended to show the added review by the commissioning agent.

\section{Commissioning Scope of Work}

The following checked systems will be commissioned in this project:

HVAC system (virtually all equipment)

HVAC system (primary equipment only). 
HVAC energy management control system

Indoor air quality (moderate level of effort)

Indoor air quality (rigorous level of effort)

Automatic Lighting controls

Electrical system power quality, grounding, etc.

Emergency power system

Communications system, e.g.,

Security system

Fire/smoke alarm and control system

Plumbing systems

Telecommunications and data systems

The following tasks comprise the commissioning work during design:

1. Coordinate the commissioning activities

2. Finalize design phase commissioning plan

3. Perform a review of Design Development

4. Develop design intent documentation

5. Develop the draft commissioning plan for the construction phase

6. Develop commissioning specifications for the construction bid documents

7. Perform a final review of the drawings and specifications

A listing of these tasks with the parties involved with them is included in Table 4-1. Each of the tasks in Table 4-1 will be executed unless specifically noted otherwise.

\subsection{Task 1. Coordination of Commissioning During Design}

The _commissioning agent, ___ architect will be the coordinator of the commissioning activities during design, per the designations in Table 4-1. The beginning of this task consists of holding a kick-off meeting with the design team at the beginning of _Conceptual Design Phase, Design Development Phase, _Construction Documents Phase. This meeting is held after the Cx Plan has been finalized (Task 2). The meeting includes reviewing the process and outlining each party's responsibilities.

The coordinator will ensure that commissioning issues are part of design team meeting agendas and will ensure that the Leads for each task understand their responsibilities and execute them. The coordinator makes any necessary changes to the design phase Commissioning Plan provided by GSA to the A/E team during the proposal process (Task 2). The coordinator reports to the architect and to the GSA Project Manager.

\subsection{Task 2. Design Phase Commissioning Plan}

The commissioning coordinator for the design phase (Task 1) makes any necessary clarifications and changes to the original design phase Commissioning Plan provided by the Owner at the RFP stage and submits it to the architect and GSA Project Manager for approval. This final plan guides the commissioning work during design. Necessary adjustments to the design team's fees relative to Commissioning Plan changes are negotiated. All design team members receive a copy of the plan from the coordinator. 


\subsection{Task 3. Design Development Review}

At the end of Design Development, the commissioning agent _reviews, __does not review the design along with the other design team members. If the commissioning agent does not perform this review, the rest of this section does not apply, otherwise:

The commissioning agent compares the design with the interests and needs of GSA as identified in the programming report of the Programming and Conceptual Design Phases. The commissioning agent also compares the proposed design against the GSA design guide (PBSPQ100.1, Facilities Standards for the Public Buildings Service) for the design areas checked below. The commissioning agent also identifies any improvements that can be made in areas checked below. Though the commissioning agent may review the areas checked below, they are not responsible for design concept, design criteria or compliance with codes.

Table 5-1. Commissioning Agent Design Development Review

\begin{tabular}{|c|l|}
\hline \multicolumn{1}{|c|}{ Design Area } & \multicolumn{1}{c|}{ Review Description } \\
\hline Commissioning facilitation & $\begin{array}{l}\text { Input regarding making the building easier to } \\
\text { commission (see Commissioning Facilitation under } \\
\text { Section 5.7) }\end{array}$ \\
\hline Energy Efficiency & $\begin{array}{l}\text { General efficiency of building shell, building layout, } \\
\text { HVAC system types, lighting system type, etc. }\end{array}$ \\
\hline Operation and Maintenance (O\&M). & $\begin{array}{l}\text { How building O\&M can be made easier } \\
\text { (accessibility and system control, etc.) }\end{array}$ \\
\hline Indoor Environmental Quality (IEQ) & $\begin{array}{l}\text { How thermal, visual, acoustical comfort or air } \\
\text { quality can be improved }\end{array}$ \\
\hline Functionality for Tenants & $\begin{array}{l}\text { How the design can be changed to improve } \\
\text { functionality for the occupants }\end{array}$ \\
\hline Environmental Sustainability & $\begin{array}{l}\text { How the building materials and systems and } \\
\text { landscaping can create less of an impact on the } \\
\text { environment }\end{array}$ \\
\hline Life Cycle Costs & $\begin{array}{l}\text { Life cycle assessment of options relative to energy } \\
\text { efficiency, O\&M, IEQ or functionality }\end{array}$ \\
\hline
\end{tabular}

${ }^{l}$ To perform this review, the commissioning agent, in consultation with the owner to establish scope, shall use the checklists provided in Appendix 3. Indoor air quality (IAQ) commissioning does not ensure that indoor air quality will be adequate or without deficiency at building turnover or during occupancy, unless the owner has specifically specified that actual air quality testing is performed. Commissioning indoor air quality entails performing tasks that minimize the potential for IAQ problems, but it does not eliminate their possibility.

This review is documented in writing and submitted to the design phase commissioning coordinator and forwarded to the architect and GSA Project Manager. The architect distributes the comments to the design team members. The team members respond to the architect who provides a written response to the commissioning agent and to the GSA Project Manager describing the team's response and any changes or considerations made in the design. 


\subsection{Task 4. Design Intent and Basis of Design Documentation}

Specifically identifying and developing the design intent and basis of design provides each party involved, at each respective stage, an understanding of the building systems. This allows team members to perform their respective responsibilities regarding the design, construction or operation of the building.

The design documentation differs from traditional specifications in that it provides a more narrative description of the system or issue and "frames" the issue or building component with clear and useful background information. However, design documentation often includes parts of specifications. In general, specifications detail what is to be done on a component level, while design documentation explains why something is done and, in general terms, how design and operating objectives will be accomplished. Sections of the design documentation can look like specifications, especially where tasks depart from conventional practice, e.g., energy-efficient design and construction.

Design documentation includes the salient information from the programming report, the conceptual design phase and from the design and construction process necessary to guide the design, verify compliance during construction and aid building operations. Design documentation consists of two dynamic components: design intent and the basis of design.

\section{Design Intent}

The design intent is a dynamic document that provides the explanation of the ideas, concepts and criteria that are considered to be very important to the owner. It is initially the outcome of the programming and conceptual design phases. The design intent narrative should cover the following, for each system, major component, facility and area:

- General system description

- Objectives and functional use of the system, equipment or facility

- General quality of materials and construction

- Occupancy requirements

- Indoor environmental quality, IEQ (space temperature, relative humidity, indoor air quality, noise level, illumination level, etc.)

- Performance criteria (general efficiency, energy and tolerances of the IEQ objectives, etc.)

- Budget considerations and limitations

- Restrictions and limitations of system or facility

Many of the above topics may not be necessary for smaller components, such as VAV terminal units.

\section{Basis of Design}

The basis of design is the documentation of the primary thought processes and assumptions behind design decisions that were made to meet the design intent. The basis of design describes the systems, components, conditions and methods chosen to meet the intent. Some reiterating of the design intent may be included. The following should be included in the basis of design for major equipment:

- Specific description of systems, components and methods for achieving the design intent objectives. (For example, for a rooftop air conditioning unit include: why this system was chosen above others, details of size, efficiencies, areas served, capacity control details, compressors, coils, dampers, setpoints, filters, economizers, minimum ventilation control, 
control type, noise and vibration criteria, tie-in to other systems, sequences of operation under all modes of operation, control strategies, etc.)

- Equipment maintainability

- Fire, life, safety: criteria, general strategy narrative and detailed sequences

- Emergency power control and function

- Energy performance

- Ventilation strategies and methods

- Complete sequences of operation, including setpoints and control parameters

- Schedules

- Applicable codes and standards

- Primary load and design assumptions

- Diversity used in sizing

- Occupant density and function

- Indoor conditions (space temperature, relative humidity, lighting power density, ventilation and infiltration rates, etc.)

- Outdoor conditions

- Glazing fraction, U-value and shading coefficient

Information of secondary importance to the commissioning and operation of the building should be documented by the design team, but is not included in the design documentation described here or included in the O\&M manuals (e.g., wall R-values, mass, etc.)

The detail of both the design intent and basis of design increase as the design process progresses, as described in Table 5-2. In the beginning, the design documentation required is primarily a narrative of the building system descriptions, the purpose of the systems, how the systems will meet those objectives and why this system or method was chosen above others. As the design process progresses, the design documentation includes the basis of design, a specific description of the system and components, its function, how it relates to other systems, sequences of operation, and operating control parameters.

Each contributing designer clearly documents in writing the intent behind the chosen design and the operating parameters of the system. The design intent required here is not a substitute for what may be required in the specifications or contract for other systems.

Table 5-2. Progression of Design Documentation

\begin{tabular}{|c|l|l|}
\hline Stage & \multicolumn{1}{|c|}{ Issues Addressed } & \multicolumn{1}{|c|}{$\begin{array}{c}\text { Responsible } \\
\text { Parties }\end{array}$} \\
\hline Programming & $\begin{array}{l}\text { The owner's and tenant's needs are identified in detail. } \\
\text { The applicable parts of the programming report become } \\
\text { the initial design intent. }\end{array}$ & $\begin{array}{l}\text { Owner } \\
\text { Architect }\end{array}$ \\
\hline $\begin{array}{l}\text { Conceptual } \\
\text { Design and } \\
\text { Design Dev. }\end{array}$ & $\begin{array}{l}\text { Design intent clarified. Basis of design begun: overall } \\
\text { system descriptions, objectives of systems, general } \\
\text { methods of achieving objectives, etc. }\end{array}$ & $\begin{array}{l}\text { Owner } \\
\text { Architect }\end{array}$ \\
\hline
\end{tabular}




\begin{tabular}{|l|l|l|}
\hline $\begin{array}{l}\text { Construction } \\
\text { Documents and } \\
\text { Specification } \\
\text { Development }\end{array}$ & $\begin{array}{l}\text { Same as Conceptual Design and Design Dev. above, but } \\
\text { in more detail, including complete basis of design: } \\
\text { complete system \& component description, specific } \\
\text { methods of achieving system objectives, design \& load } \\
\text { assumptions, applicable codes and standards, complete } \\
\text { sequences of operation and control strategies }\end{array}$ & $\begin{array}{l}\text { Architect } \\
\text { Design Engineers }\end{array}$ \\
\hline $\begin{array}{l}\text { As-Built } \\
\text { Documentation }\end{array}$ & $\begin{array}{l}\text { Same as Construction Documents and Specification } \\
\text { Development, plus: } \\
\text { Adjusted sequences with final control parameters }\end{array}$ & $\begin{array}{l}\text { Design Engineers } \\
\text { Installing } \\
\text { Contractors } \\
\text { Building Operator } \\
\text { Architect }\end{array}$ \\
\hline
\end{tabular}

The initial design intent from the programming phase is developed by the architect with review by the design team and commissioning agent. The architect, or other assigned party, acts as the design documentation task lead and coordinates the creation of the full design documentation by the design team. Each member of the team provides the written basis of design and detailed sequences of operation for the areas of design that are their responsibility. They submit the documentation in parts to the task lead at the pre-determined phases of design. The architect, task lead and commissioning agent review, comment on and approve the submissions. Design intent documentation for other components and systems such as structural, interior design, furnishings, plumbing, etc. may be required, but are not a part of the commissioning work unless listed and checked herein. The full sequences of operation from the basis of design shall be included in the bid specifications.

\section{Design Documentation Submitted:}

\section{By the Architect}

general building design and function interior lighting building shell efficiency

environmental sustainable construction landscaping / irrigation

\section{By the HVAC Mechanical Designer/Engineer}

HVAC systems (air and water) automatic controls fire/smoke protection systems thermal comfort air quality acoustical quality

By the Electrical Designer/Engineer interior lighting automatic lighting controls (exterior and interior) security system 
communications system

fire and smoke alarm system

power quality

emergency power

\section{Documentation Format and Detail}

The format and rigor of the design intent documentation will be similar to the example documentation format found in the Design Documentation Format Form in Appendix 1 of this plan. The design team follows the example format and level of detail for, at a minimum, the systems checked above. The general outline of the full documentation is:

- A design narrative describing the system in general

- The objectives of each system and its functional use

- The full sequence of operations under all modes and conditions

- The setpoints and operating parameters

- Performance criteria and applicable codes and standards

\section{Reporting and Review}

Each team member submits his or her design documentation to the architect at the end of the phase listed in the example design documentation format in Appendix 1 (Design Development Phase, Construction Documents for Specification Development). The architect provides a copy of the design intent to the GSA Project Manager and to the commissioning agent. Documentation listed to be completed in the As-Built stage is not provided during design. The commissioning agent reviews the documentation and provides written comments, through the architect, to each designer. Each designer makes necessary changes according to the commissioning agent request and resubmits the documentation to the commissioning agent, through the architect.

At the end of Design, the architect compiles and submits the full design intent documentation to the commissioning agent and to the GSA Project Manager. Team members include their full sequences of operation in their bid document specifications. A draft copy of the full design intent and basis of design are provided to the commissioning agent at the beginning of construction. A final as-built copy is prepared and is included in the O\&M manuals at the end of construction.

\section{Sequences of Operation}

Detailed written sequences of operation shall be developed with the following components clearly and completely described for each piece of dynamic equipment:

- An overview narrative of the system (1 or 2 paragraphs) generally describing its purpose, components and function

- All interactions and interlocks with other systems

- Detailed delineation of control between any packaged controls and the building automation system, listing what points the BAS monitors only and what BAS points are control points and are adjustable

- Written sequences of control for packaged controlled equipment. (Equipment manufacturers' stock sequences may be included, but will generally require additional narrative.)

- Startup sequences 
- Warm-up mode sequences

- Normal operating mode sequences

- Unoccupied mode sequences

- Shutdown sequences

- Capacity control sequences and equipment staging

- Temperature and pressure control: setbacks, setups, resets, etc.

- Detailed sequences for all control strategies, e.g., economizer control, optimum start/stop, staging, optimization, demand limiting, etc.

- Effects of power or equipment failure with all standby component functions

- Sequences for all alarms and emergency shut downs

- Seasonal operational differences and recommendations

- Initial and recommended values for all adjustable settings, setpoints and parameters that are typically set or adjusted by operating staff; and any other control settings or fixed values, delays, etc. that will be useful during testing and operating the equipment

- Schedules, if known

- All sequences shall be written in small statements, each with a number for reference. For a given system, numbers will not repeat for different sequence sections, unless the sections are numbered.

Fire and Emergency Power Response Matrix

An HVAC fire and emergency power response matrix that lists all equipment and components (air handlers, damipers, valves, etc.) with their status and action during a fire alarm and under emergency power shall be developed. An example of a fire and power response matrix and flow chart are found in Appendix 2.

\subsection{Task 5. Draft Commissioning Plan for Construction}

When the drawings, traditional specifications (non-commissioning) and design intent documentation are partially complete, prior to developing commissioning specifications, the commissioning agent uses the Model Commissioning Plan-Construction Phase (Part IV of the Model Commissioning Plan and Guide Specifications) to develop the draft construction phase commissioning plan for this project. The plan contains a list of the systems and specific equipment and components to be commissioned and the general modes to be tested with the probable testing method. In addition, sections of standard language regarding process, responsibilities, O\&M documentation, training and scheduling are included.

The parts in the construction phase commissioning plan with blanks that need to be filled in prior to construction bidding are noted to the right of the section heading with "[Bid Docs]." Other fillin blanks are not filled in until after construction begins.

When completed, this draft (Draft 1) of the construction phase plan, provides the general scope for the construction commissioning specification development (Task 7). Then, after all drawings and specifications are complete, the commissioning agent updates the construction-phase Commissioning Plan (which becomes Draft 2). Draft 2 of the commissioning plan is included as part of the construction bid documents.

The GSA project manager and construction manager review both drafts of the plan and the commissioning agent makes recommended changes. 


\subsection{Task 6. Commissioning Specification Development}

Commissioning specifications for inclusion in the construction bid documents are developed by members of the design team as part of the commissioning process during design.

\section{Purpose}

The specifications provide detail so that those bidding on the project can clearly understand how the commissioning process works and specifically what role they have in the process. They provide the requirements and process for properly executing the commissioning work.

\section{Specification Content}

The commissioning specifications shall provide the bidders a clear description of the extent of the verification testing required, including what components and systems will be tested and the documentation, reporting and scheduling requirements. Details of the extent of testing and who is responsible for writing tests, executing tests, witnessing and signing-off on tests shall be included. The relationship between and requirements for start-up, prefunctional checklists, manual functional performance tests, control system trend logs and stand-alone data logging shall also be given. Example tests shall also be provided. The specifications shall also detail the operator training and the $0 \& \mathrm{M}$ documentation and any $O \& \mathrm{M}$ plan requirements. Any specific program of tasks focusing on indoor air quality should be included in the specifications.

\section{Guide Specifications}

Each designer uses the Guide Commissioning Specifications, adapts them for this project and includes them in specifications. Draft 1 of the Commisioning Plan-Construction Phase as explained in Task 5 is used to guide the commissioning specification development. This plan was developed earlier in the design process.

\section{Coordination, Reporting and Review}

The responsibilities for developing the individual sections of the commissioning specifications are listed in Table 4-1. The Specification Overview section in Part III, Commissioning Guide Specifications, of the Model Commissioning Plan and Guide Specifications provides a listing of what needs to be addressed in each specification section. The commissioning agent coordinates the commissioning specification effort and provides assistance as needed to all team members. Each team member submits the full specification of any division that includes references to commissioning, in _electronic format, _hard copy format to the commissioning agent for review at least two weeks prior to the printing of final specifications. Each page contains the filename and date of the document. A list is provided of any areas where the commissioning specifications deviate significantly from the guide specifications and the rationale for the deviation. Each team member also provides an electronic copy, hard copy to the architect and to the GSA Project Manager.

The commissioning agent reviews the specifications and provides written comments to each designer who edits the specifications according to the commissioning agent request and resubmits edited sections to the commissioning agent. The printed edited sections show the filename and date automatically printed on each page. The commissioning agent notifies each designer in writing of the approval of his or her commissioning specification. The commissioning agent provides to the architect in writing, the filenames and dates of the approved specification sections of each designer, which must preceed printing of the final specifications. Though the 
commissioning agent coordinates and reviews the commissioning specifications, the ultimate responsibility for their content and preparation lies with the $\mathrm{A} / \mathrm{E}$.

\subsection{Task 7. General Review of Drawings and Specifications}

The commissioning agent, along with the traditional design team members, reviews the full set of Construction Documents and specifications when approximately $50 \%$ and $95 \%$ complete. Parts of this review dealing with commissioning specifications will have been completed in Task 6Commissioning Specification Development. The architect provides the necessary documents to the commissioning agent.

The commissioning agent compares the design with the interests and needs of GSA as identified in the programming report of the Programming and Conceptual Design Phases. The commissioning agent also compares the proposed design against the GSA design guide (PBSPQ100.1, Facilities Standards for the Public Buildings Service) for the design areas checked in Table 5-3. The commissioning agent also identifies any improvements that can be made in areas that do comply with, or are not specifically mentioned in the design guide in areas checked in Table 5-3. The rigor of the review listed for the commissioning agent in Table 5-3 provides general guidance.

Though the commissioning agent may review the areas checked below, they are not responsible for design concept, design criteria or compliance with codes. The commissioning agent does not verify the designers' calculations or proof schematics or layouts in detail. The constructibility review is performed by another party. The commissioning agent will use his or her expertise to provide input into the areas checked in Table 5-3. For example, the commissioning agent does not verify appropriate pipe or duct sizing, but may provide comments on unusually tight or restrictive duct layouts and bends or a poor location of a static pressure sensor.

For the non-commissioning specifications and all the drawings, the commissioning agent provides written comment to the architect within days from receiving the documents. The commissioning specification review is detailed in Task 6. The commissioning agent also provides a copy of the comments to the GSA Project Manager. The architect provides a written response to the commissioning agent and GSA Project Manager as to how the comments will be reflected in the final bid documents.

Table 5-3. Commissioning Agent Drawing and Specification Review (50\% \& 95\%), Task 7

\begin{tabular}{|c|c|c|}
\hline Design Area & Review Description & Rigor \\
\hline _ Commissioning & $\begin{array}{l}\text { Input regarding making the building easier to commission } \\
\text { (see Commissioning Facilitation under Section 5.7) }\end{array}$ & $\begin{array}{l}\text { moderate } \\
\text { rigorous }\end{array}$ \\
\hline $\begin{array}{l}\text { Component energy } \\
\text { efficiency }\end{array}$ & $\begin{array}{l}\text { Review for adequacy of the efficiency of bldg. shell components, } \\
\text { HVAC systems and lighting systems. }\end{array}$ & $\begin{array}{c}\text { moderate } \\
\text { rigorous }\end{array}$ \\
\hline $\begin{array}{l}\text { Control system \& } \\
\text { control strategies }\end{array}$ & $\begin{array}{l}\text { Review } \text { HVAC, lighting, fire control, _ security } \\
\text { control system, strategies and sequences of operation for } \\
\text { adequacy and efficiency. }\end{array}$ & $\begin{array}{l}\text { moderate } \\
\text { _rigorous }\end{array}$ \\
\hline $\begin{array}{l}\text { Operation and } \\
\text { maintenance }\end{array}$ & $\begin{array}{l}\text { Review for effects of specified systems and layout toward } \\
\text { facilitating O\&M (equipment accessibility, system control, } \\
\text { etc.). }\end{array}$ & $\begin{array}{l}\text { moderate } \\
\text { _rigorous }\end{array}$ \\
\hline
\end{tabular}




\begin{tabular}{|c|c|c|}
\hline Design Area & Review Description & Rigor \\
\hline $\begin{array}{l}\text { Indoor environmental } \\
\text { quality }^{1}\end{array}$ & $\begin{array}{l}\text { Review to ensure that systems relating to } \ldots \text { thermal, } \\
\text { visual, acoustical, _air quality comfort, air } \\
\text { distribution are in accordance with the design intent. }\end{array}$ & $\begin{array}{l}\text { moderate } \\
\text { _rigorous }\end{array}$ \\
\hline $\begin{array}{l}\text { Environmental } \\
\text { sustainability }\end{array}$ & $\begin{array}{l}\text { Review to ensure that the building materials, } \\
\text { landscaping, wase of water resources, waste } \\
\text { management are in accordance with the design intent. }\end{array}$ & $\begin{array}{l}\text { moderate } \\
\text {-rigorous }\end{array}$ \\
\hline $\begin{array}{l}\text { Functionality for } \\
\text { tenants }\end{array}$ & $\begin{array}{l}\text { Review to ensure that the design meets the functionality needs of } \\
\text { the tenants. }\end{array}$ & $\begin{array}{l}\text { moderate } \\
\text {-rigorous } \\
\end{array}$ \\
\hline _Life cycle costs & $\begin{array}{l}\text { Perform a _qualitative, quantitative lifecycle assessment } \\
\text { of the primary competing systems relative to energy } \\
\text { efficiency, _O\&M, IEQ, functionality. }\end{array}$ & $\begin{array}{l}\text {-moderate } \\
\text {-rigorous }\end{array}$ \\
\hline O\&M documentation & $\begin{array}{l}\text { Verify that building O\&M plan and documentation requirements } \\
\text { specified are adequate }\end{array}$ & $\begin{array}{l}\text { moderate } \\
\text { _rigorous }\end{array}$ \\
\hline _Training & $\begin{array}{l}\text { Verify that operator training requirements specified are } \\
\text { adequate. }\end{array}$ & $\begin{array}{l}\text { moderate } \\
\text { _rigorous }\end{array}$ \\
\hline $\begin{array}{l}\text { Commissioning } \\
\text { specifications }\end{array}$ & $\begin{array}{l}\text { Verify that bid documents adequately specify building } \\
\text { commissioning and that there are adequate monitoring and } \\
\text { control points specified to facilitate commissioning and O\&M } \\
\text { (trending capabilities, test ports, control points, gages and } \\
\text { thermometers). }\end{array}$ & _moderate \\
\hline $\begin{array}{l}\text { Review of engineering } \\
\text { assumptions }\end{array}$ & $\begin{array}{l}\text { Review the engineering assumptions relating to equipment } \\
\text { sizing, energy efficiency decisions and HVAC cost-benefit } \\
\text { calculations }\end{array}$ & $\begin{array}{l}\text { moderate } \\
\text { _rigorous }\end{array}$ \\
\hline
\end{tabular}

${ }^{1}$ To perform this review, the commissioning agent, in consultation with the owner to establish scope, shall use the checklists provided in Appendix 3. See the disclaiming note at the bottom of Table 5-1.

\subsection{Commissioning Facilitation}

One of the primary tasks for the commissioning agent is reviewing the design documents to facilitate commissioning during construction. Many of the features that facilitate commissioning will also enhance ease of building operation. All items from the list below shall be considered for incorporation into the project. Some of the items in the list will be appropriate for the Design Development review, while the majority will apply to the $50 \%$ and $95 \%$ Construction Documents phase reviews. The commissioning agent will make recommendations to the design team as to which items are needed. The design team will respond in writing regarding their disposition on incorporating each item.

1. Clear and rigorous design documentation, including detailed and complete sequences of operation.

2. An HVAC fire and emergency power response matrix that lists all equipment and components (air handlers, dampers, valves, etc.) with their status and action during a fire alarm and under emergency power. See Appendix 2.

3. Access for reading gages, entering doors and panels, observing and replacing filters, coils, etc. 
4. Required isolation valves, dampers, interlocks, piping, etc. to allow for manual overrides, simulating failures, seasons and other testing conditions.

5. Sufficient monitoring points in the building automation system (BAS), even beyond that necessary to control the systems, to facilitate performance verification and O\&M.

6. Adequate trending and reporting features in the BAS.

7. Pressure and temperature $(\mathrm{P} / \mathrm{T})$ plugs close to controlling sensors for verifying their calibration.

8. Pressure gages, thermometers and flow meters in strategic areas for verifying system performance and ongoing O\&M.

9. Pressure and temperature $(\mathrm{P} / \mathrm{T})$ plugs at less critical areas or on smaller equipment where gages and thermometers would be over-kill.

10. Specification of the location and criteria for the VAV duct static pressure sensor and chilled water differential pressure sensor.

11. Adequate balancing valves, flow metering and control stations and control system functions to facilitate and verify reliable test and balance.

12. Uniform inlet connection requirements to VAV terminal boxes.

13. Clear and complete commissioning specifications for the construction phase.

14. Complete O\&M documentation requirements in the specifications.

15. Complete training requirements in the specifications.

16. Review entire document and building information management plan from design through construction and turnover to ensure adequacy and compliance with the owner's program.

\section{General Schedule}

The commissioning activities are integrated into the typical design process without any real increase in the timetable of deliverables. Table 6-1 illustrates the location of the commissioning activities during design.

Table 6-1. Commissioning Schedule-Design Phase

\begin{tabular}{|l|l|l|l|c|}
\hline \multicolumn{1}{|c|}{ Tasks } & Programming & $\begin{array}{c}\text { Conceptual } \\
\text { Development }\end{array}$ & $\begin{array}{c}\text { Construction } \\
\text { Design } \\
\text { Development }\end{array}$ & $\begin{array}{c}\text { Documents \& } \\
\text { Specifications }\end{array}$ \\
\hline 1. Coordination & & & & \\
\hline 2. Design Phase Cx Plan & & & & \\
\hline \multicolumn{1}{|c|}{ a. Kick-off Meeting } & & & & \\
\hline 3. Design Dev. Review & & & & \\
\hline 4. Design Intent Doc. & & & & \\
\hline 5. Construction Cx Plan & & & & \\
\hline 6. Cx Specifications & & & & \\
\hline $\begin{array}{l}\text { 7. Drawing \& Spec } \\
\text { Reviews }\end{array}$ & & & & \\
\hline
\end{tabular}


Part Il. Commissioning Plan-Design Phase Appendix 1. Design Documentation Instructions

\section{Part II}

\section{APPENDIX 1}

\section{Design Documentation Format}




\section{Instructions for Documenting Design Intent and Basis of Design of Energy- and Comfort-Related Systems}

\section{Objective}

This appendix presents a format for the building designers to use in documenting the design intent and fundamental operation of the building systems they have designed. Refer to Section 3 for a narrative on the need of a written design intent and clear sequences of operation and Section 5 for an example. The design-intent documentation requested here is primarily a narrative description of the building systems, what the objectives of the systems are, and how the systems will meet those objectives. This written documentation is intended for use by the designers, the commissioning agent, the installing contractors, and the building operators. This document does not constitute the required documentation and operations manual for these systems, but is a part of the O\&M manuals.

The design intent provides the explanation of the ideas, concepts and criteria that are considered to be very important to the owner, resulting from the programming and conceptual design phases. The basis of design is the documentation of the primary thought processes and assumptions behind design decisions that were made to meet the design intent. The format below merges the salient parts of the design intent and basis of design.

Following these instructions is a form that is used for structuring the format and content of the design documentation.

This design intent document format contains examples for the following issues, equipment, and systems.

1. General building design and function

- Overview

- Sustainable construction and environmental compatibility

- Indoor environmental quality-thermal, air distribution, acoustics, air quality, visual quality

- Landscaping

2. HVAC systems-general

- Overview

- Design conditions and load assumptions

3. Chiller system (chillers, cooling towers, pumps)

4. Boiler and heating water system

5. Roof top packaged system, including all components

6. VAV terminal units (cooling only)

7. VAV terminal units (reheat)

8. Heat recovery unit

9. Computer room $\mathrm{AC}$ unit

10. Daylighting controls

11. Lighting sweep control

12. Building automation system 
Part II. Commissioning Plan-Design Phase

13. Split air conditioner or heat pump

14. Emergency power system

The design documentation for components or systems not listed above should follow the general form and content of this document and should describe the system, its purpose, why it was chosen above others, how it functions, and how it relates to other components and the parameters for its operation and control, including detailed sequences of operation. For additional details, refer to ASHRAE Guidelines 1-1989R The HVAC Commissioning Process, ASHRAE, 1996.

The design intent document may be filled out by hand for applicable systems, with attachments when necessary, or by preparing an entirely new document using the electronic version as a template.

\section{Design Documentation for This Building}

Adequate documentation of the design intent and basis of design of the energy- and comfortrelated systems in a building is rarely found in bid documents. It is vital, however, that design intent and sequences of operation be documented adequately. That documentation serves as the goal that testing and verification seek to achieve. In addition, the design-intent document provides valuable information over the life of the building to the different parties involved in operating, maintaining, and troubleshooting the building systems.

Following are the primary areas related to energy use and comfort for which the design intent should be defined. Under each area or building system is an outline of pertinent questions concerning what should be included in the design-intent documentation and where additional clarification is needed. Sequences of operation for all outlined dynamic systems and components should be documented. Attaching equipment manufacturers' sequences is acceptable, but these sequences will generally require additional narrative. Sample sequences are found in Section 5 .

To the right of the heading for each section, the party responsible for providing the design intent is indicated, as is the phase of the design construction process during which design intent should be established. For example:

\subsection{System Description Mech Engr Design Dev}

The above sample heading indicates that the mechanical engineer or designer is responsible for developing the design narrative that follows the heading and that it should be completed during the design development stage. The responsible parties and design phases are sometimes abbreviated as in the table below. The phases of the design construction process are as follows.

Programming Design team and GSA Project Manager meet with representatives of the occupuying agency or client and determine the floor area and occupancy requirements of the building.

Conceptual Design Architect develops block diagrams, building sizing, rough space planning and sketches of exterior types. Multiple choices are provided. Mechanical and electrical designers generally have no input in this phase.

Design Development Additional detail is applied to the block diagrams and layouts. Interior and exterior features and finishes and general HVAC system types are determined and a rough floor plan is approved. 
Part II. Commissioning Plan-Design Phase

Appendix 1. Design Documentation Instructions

Construction Complete architectural drawings are completed. Specifications are completed, Documents generally using the GSA Master Spec. Bid documents are prepared.

\begin{tabular}{lll}
\hline Hem & Abbreviation & Refers To \\
\hline Responsible Party & Arch & Architect \\
\cline { 2 - 3 } & Mech Engr & Mechanical Engineer \\
\cline { 2 - 3 } & Elec Engr & Electrical Engineer \\
\cline { 2 - 3 } & Ltg Des & Lighting Designer \\
\cline { 2 - 3 } & Ctrls Cont & Controls Contractor \\
\hline Design Phase & Program & Programming Phase \\
\cline { 2 - 3 } & Concept Des & Conceptual or Schematic Design Phase \\
\cline { 2 - 3 } & Design Dev & Design Development Phase \\
\cline { 2 - 3 } & Const Doc & Construction Documents Phase \\
\cline { 2 - 3 } & Spec Dev & Specification Development (late Const. Documents Phase) \\
\hline
\end{tabular}

\section{The Need for Written Design Documentation}

Developing a statement of design intent and basis of design (design documentation) enables the parties involved with the building to better understand the building systems and better meet their responsibilities in designing, constructing, and operating the building.

The objective of specifically identifying and developing the design intent and basis of design is to provide the parties involved with the building, at each respective stage, an understanding of the building systems so as to better perform their respective responsibilities regarding the design, construction or operation of the building.

The design documentation differs from traditional specifications in that it gives a more narrative description of the system or issue and "frames" the issue or building component with background information useful and understandable to all parties. However, design documentation often includes specifications. In general, specifications tell what is to be done on a component level, where design documentation tells why something is done and, in general, how design and operating objectives will be accomplished. Sections of the design documentation can look like specifications, especially where conventional practice is departed from, e.g., energy-efficient design and construction.

Design documentation is needed from the architect so that the design engineers can design systems and write specifications. Design documentation is needed from the design engineers and architect so that the building contractors and technicians can properly construct the building. Final design documentation is needed from the building contractors and all of the above parties so that the building operator and maintenance contractors can properly maintain the original intent of the systems' operations over time.

The design documentation evolves from more general descriptors during the conceptual design, to more specific descriptors during actual design, to in-depth and specific descriptors during the specifying stage. The design documentation is completed by fine tuning and adding further detail and specificity for some components during the as-built documentation stage. Though design documentation for some components cannot be completed until the end of building fine-tuning, it is not warranted to allow design documentation to be general or incomplete prior to construction. 
Design documentation should be as firm and complete as possible as early as possible. The following table outlines these concepts including the parties responsible for defining the design documentation.

\begin{tabular}{|l|l|l|}
\hline \multicolumn{1}{|c|}{ Stage } & \multicolumn{1}{|c|}{ Issues Addressed } & \multicolumn{1}{c|}{$\begin{array}{c}\text { Responsible } \\
\text { Parties }\end{array}$} \\
\hline Programming & $\begin{array}{l}\text { The owner's and tenant's needs are identified in detail. } \\
\text { The applicable parts of the programming report become } \\
\text { the initial design intent. }\end{array}$ & $\begin{array}{l}\text { Owner } \\
\text { Architect }\end{array}$ \\
\hline $\begin{array}{l}\text { Conceptual } \\
\text { Design and } \\
\text { Design Dev. }\end{array}$ & $\begin{array}{l}\text { Design intent clarified. Basis of design begun: overall } \\
\text { system descriptions, objectives of systems, general } \\
\text { methods of achieving objectives, etc. }\end{array}$ & $\begin{array}{l}\text { Owner } \\
\text { Architect }\end{array}$ \\
\hline $\begin{array}{l}\text { Construction } \\
\text { Documents and } \\
\text { Specification } \\
\text { Development }\end{array}$ & $\begin{array}{l}\text { Same as above, but in more detail, including complete } \\
\text { basis of design: complete system \& component } \\
\text { description, specific methods of achieving system } \\
\text { objectives, design \& load assumptions, applicable codes } \\
\text { and standards, complete sequences of operation and } \\
\text { control strategies }\end{array}$ & $\begin{array}{l}\text { Architect } \\
\text { Design Engineers }\end{array}$ \\
\hline $\begin{array}{l}\text { As-Built } \\
\text { Documentation }\end{array}$ & $\begin{array}{l}\text { Same as above, plus: } \\
\text { Adjusted sequences with final control parameters }\end{array}$ & $\begin{array}{l}\text { Design Engineers } \\
\text { Installing } \\
\text { Contractors } \\
\text { Building Operator } \\
\text { Architect }\end{array}$ \\
\hline
\end{tabular}

\section{Sequences of Operation}

Detailed written sequences of operation shall be developed with the following components clearly and completely described for each piece of dynamic equipment:

- An overview of the system (1 or 2 paragraphs) generally describing its purpose, components and function

- All interactions and interlocks with other systems

- Detailed delineation of control between any packaged controls and the building automation system, listing what points the BAS monitors only and what BAS points are control points and are adjustable

- Written sequences of control for packaged controlled equipment. (Equipment manufacturers' stock sequences may be included, but will generally require additional narrative.)

- Startup sequences

- Warmup mode sequences

- Normal operating mode sequences

- Unoccupied mode sequences

- Shutdown sequences

- Capacity control sequences and equipment staging

- Temperature and pressure control: setbacks, setups, resets, etc.

- Detailed sequences for all control strategies, e.g., economizer control, optimum start/stop, staging, optimization, demand limiting, etc. 
Part II. Commissioning Plan-Design Phase

Appendix 1. Design Documentation Instructions

- Effects of power or equipment failure with all standby component functions

- Sequences for all alarms and emergency shut downs

- Seasonal operational differences and recommendations

- Initial and recommended values for all adjustable settings, setpoints and parameters that are typically set or adjusted by operating staff; and any other control settings or fixed values, delays, etc. that will be useful to know during testing and operating the equipment

- Planned schedules, if known

- All sequences shall be written in small statements, each with a numerical number for reference. For a given system, numbers will not repeat for different sequence sections, unless the sections are numbered.

\section{Example Design Narrative and Sequences of Operation}

Part of the design documentation involves providing a brief overview of the system in narrative form. This is very appropriate at the beginning of the sequences of operation. The following is an example for a simple packaged boiler system with some interface with the building automation system (BAS). Additional examples are found in the Guide Specifications.

\section{Packaged Boiler Control Sequence-Example}

\section{System Overview}

The boiler water system serves the space heating needs of the entire building. Heating is achieved through reheat coils in every terminal box. There are two atmospherically vented packaged boilers which work lead / lag: one boiler when outside air temperatures are less than $65 \mathrm{~F}$ and both boilers at temperatures below 45F (adjustable). The boilers work to maintain a constant temperature output (currently 170F), and delivery to a 3-way mixing valve which mixes return water to maintain a hot water loop temperature setpoint. Each boiler has two burners and two stages of fire per burner. There are three levels of capacity: 1) both beds low fire, 2) one bed high and one low, 3) both beds high fire.

The water is delivered by two constant speed pumps, one for each boiler. Upon failure of the lead pump or boiler, the lag will start. Most coils have 2-way valves. There are a few that have 3-way valves to allow constant speed on the pumps. Each boiler has a small blend pump that circulates water through the boiler whenever the boiler is enabled.

The boiler has packaged controls that regulate the temperature of water it is supplying to the 3way valve, prior to mixing. Those sequences are listed in Part I, below. The building automation system (BAS) enables the boiler, controls the temperature of the supply loop through a 3-way mixing valve and performs boiler lead/lag control and hot water temperature reset. Those sequences are listed in Part II, below.

\section{Seasonal Settings}

It is expected that the boilers will be shut off during summer. During the swing seasons, if the boiler will be enabled, the firing rate control should be set as low as possible. According to Proctor Sales who supplied the boiler, condensation can occur and be a potential problem if the Firing Rate Control setting is below 160F. If the control is ever raised above 170F during winter, it should be lowered back to $160 \mathrm{~F}$ during spring and fall, to minimize energy use. The loop 
temperature (via the BAS) should be kept as low as possible and is automatically changed via a reset strategy.

\section{Part I. Packaged Boiler Controls}

Once the boiler is enabled, it tries to maintain the temperature of the output, prior to the mixing valve, at the boiler Operating Control Setpoint, in the following manner.

1. When the heating water system is enabled, via the outside air temperature setpoint (initially $65 \mathrm{~F}$ ) in the BAS, the lead boiler comes on with both burners at the high firing rate.

2. Once the water temperature climbs to the low limit setpoint of the Firing Rate Control (initially at 150F), one burner bed drops to low fire (less gas pressure). The low limit setpoint is the main dog on the low limit dial.

3. If the temperature continues to climb to the high limit setpoint of the firing rate control (initially at 160F), the other burner bed drops to low fire.

4. If the temperature continues to rise to the Operating Control setpoint (initially set at 170F), the boiler cycles OFF.

5. Upon cooling, when the temperature lowers to the Operating Control Setpoint minus the differential of $10 \mathrm{~F}$, the boiler starts at low fire on both beds.

6. If the temperature continues to drop to the high limit of the Firing Rate Control setting minus a fixed $10 \mathrm{~F}$ differential, one burner bed goes to high fire.

7. If the temperature continues to drop to the lower setting (via the differential dog) of the Low Firing Rate Control setpoint, the other burner goes to high fire.

Setting recommendations: 1) Set the Operating Control Setpoint. 2) Set the High Limit of the Firing Rate Control 10F to $15 \mathrm{~F}$ lower than the Operating Control Setpoint. 3) Set the main dog of the Low Limit of the Firing Rate Control 10 to 15F lower than the High Limit (of the Firing Rate Control), 4) Set the differential dog of the Low Limit of the Firing Rate Control to 5 to $15 \mathrm{~F}$ below the Low Limit. 5) Set the High Limit Safety to 30F above the Operating Control Setpoint.

\section{Boiler Safeties}

8. Loss of power will shut burners OFF.

9. Low water level sensed via the water low limit control will shut burners OFF (manual reset required).

10. If the operating control fails or the sensor is bad, and the water temperature goes to $200 \mathrm{~F}$, the safety high limit shuts the burner off. Manual reset is required.

11. In all of the above three cases, the BAS will be sent an alarm.

12. If the electronic ignition tries to light the pilot and a flame is not sensed, the main gas valve will not open.

13. Sensors. The high limit safety, the Operating Control and the Firing Rate Control all have their own sensors. 


\section{Part II. Building Automation System Controlled Boiler Sequences}

14. When the outside air temperature (OSAT) is less than the OSAT setpoint, initially at $65 \mathrm{~F}$ (adjustable), the lead boiler and its integral blend pump and its associated heating water pump will start. Whenever a boiler is enabled, its associated hot water pump shall run and the lag boiler will be isolated by a automatic valve. Boilers are not scheduled by time.

15. The lag boiler isolation valve will open and the lag boiler and associated pumps will start when the OSAT is less than 45F (adjustable).

16. Via pump status monitoring, after the boiler system has been enabled and the lead pump ON status has not been established within 30 seconds, the lead pump shall stop, the lag pump shall be started and an alarm generated.

17. Via boiler status monitoring, after the boiler system has been enabled and the lead boiler $O N$ status has not been established within 30 seconds, the lead boiler shall stop, lead boiler isolation valve close, lag boiler isolation valve open and the lag boiler shall be started and an alarm generated.

18. During unoccupied periods, during night low limit operation, the boiler will cycle $\mathrm{ON}$ and OFF with the air handlers to maintain the night low limit setpoint.

\section{Hot Water Mixing Valve Control}

19. The 3-way mixing valve in the hot water supply is modulated to mix return water with boiler-supplied hot water to maintain a hot water supply temperature (HWST) based on the OSAT, according to the following proportional reset schedule:

\begin{tabular}{ll} 
OSAT & HWST \\
\hline $23 \mathrm{~F}$ & $180 \mathrm{~F}$ \\
$70 \mathrm{~F}$ & $140 \mathrm{~F}$
\end{tabular}




\section{Design Intent and Basis of Design of Energy- and Comfort-Related Systems}

Project:

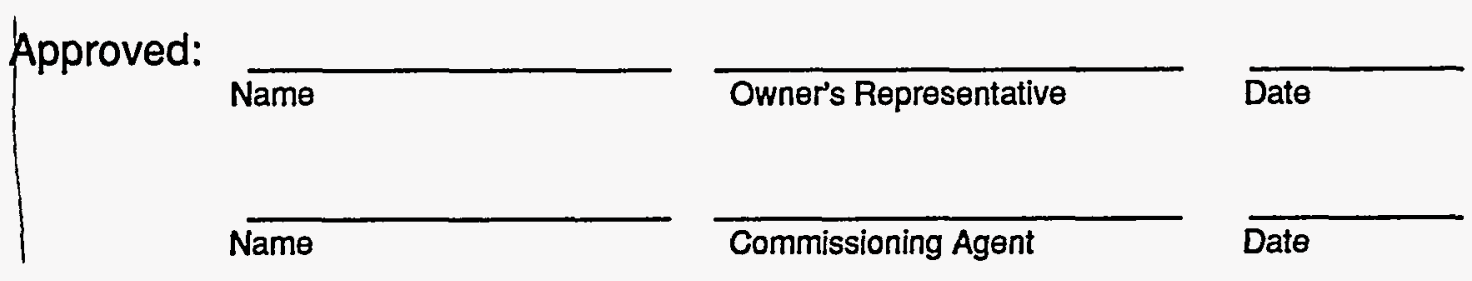

\section{Overview}

Following are the primary areas related to energy use and comfort for which the design intent and basis of design should be defined. The design intent provides the explanation of the ideas, concepts and criteria that are considered to be very important to the owner, coming out of the programming and conceptual design phases. The basis of design is the documentation of the primary thought processes and assumptions behind design decisions that were made to meet the design intent. The format below merges the salient parts of the design intent and basis of design. The design intent evolves from more general descriptors during the conceptual design, to more specific descriptors during actual design, to in-depth and specific descriptors during the specifying stage, which are finalized during the as-built phase.

Under each area or building system is an outline of pertinent questions and data needed. Sequences of operation for all outlined dynamic systems and components should be clearly documented. Attaching equipment manufacturers' sequences may acceptable, but will generally require additional narrative.

To the right of the heading for each section, the party responsible for providing the design intent is indicated, as is the phase of the design construction process during which design documentation should be established. Refer to the Instructions section, just previous in this Appendix for full instructions.

The following abbreviations are used: 


\begin{tabular}{lll}
\hline Hem & Abbreviation & Refers To \\
\hline Responsible Party & Arch & Architect \\
\cline { 2 - 3 } & Mech Engr & Mechanical Engineer \\
\cline { 2 - 3 } & Elec Engr & Electrical Engineer \\
\cline { 2 - 3 } & Ltg Des & Lighting Designer \\
\cline { 2 - 3 } & Ctrls Cont & Controls Contractor \\
\hline Design Phase & Program & Programming Phase \\
\cline { 2 - 3 } & Concept Des & Conceptual or Schematic Design Phase \\
\cline { 2 - 3 } & Design Dev & Design Development Phase \\
\cline { 2 - 3 } & Const Doc & Construction Documents Phase \\
\cline { 2 - 3 } & Spec Dev & Specification Development (late Const. Documents \\
& Phase) \\
\hline
\end{tabular}

\section{Contents}

The following systems and issues are included in this document in this order:

1. General building design and function

- Overview

- Sustainable construction and environmental compatibility

- Indoor environmental quality-thermal, air distribution, acoustics, air quality, visual quality

- Landscaping

2. HVAC systems-General

- Overview

- Design conditions and load assumptions

3. Chiller system (chillers, cooling towers, pumps)

4. Boiler and heating water system

5. Roof top packaged System, including all components

6. VAV terminal units (cooling only)

7. VAV terminal units (reheat)

8. Heat recovery unit

9. Computer room $\mathrm{AC}$ unit

10. Daylighting controls

11. Lighting sweep control

12. Building automation system

13. Split air conditioner or heat pump

14. Emergency power system 
Part II. Commissioning Plan-Design Phase Appendix 1. Design Documentation Form

Heading Format Used at the Beginning of Each Section:

$X . X \quad$ Issue to be Documented

Responsible Party

When To Do It

\section{General Building Design, Function, and Landscaping}

\subsection{General Building Design and Function}

Architect

Design Dev

What are the general design objectives regarding energy efficiency?

Comfort and indoor environmental quality?

Sustainability and environmental compatibility?

Other:

\section{Sequences}

Architect

Spec Dev

What are the main control sequences for the watering systems that ensure water conservation?

Maintenance

Architect

Spec Dev

Are there any special instructions as to the care of the landscape elements that will enhance or degrade their energy and comfort benefits? (refer to O\&M manual sections, if applicable) 


\subsection{Sustainable Construction and Environmental Compatibility}

Design Intent

Architect

Concept Des

What are the objectives regarding sustainability and environmental compatibility?

Basis of Design-General Description and Function

Architect

Design Dev

How will the building/grounds systems meet the design intent?

\subsection{Indoor Environmental Quality}

\section{Design Intent}

Mech Engr

Concept Des

What are the general objectives for indoor environmental quality?

Thermal Comfort-General Description and Function

Mech Engr

Design Dev

Record the occupant activity and design temperatures for the various spaces in Table 1.

\section{Air Distribution}

Mech Engr

Const Doc

What issues were considered in choosing diffusers?

Is the return air (RA) ducted of open-plenum? Why?

Are the RA grills in every room? Why? 
What special considerations are being given to spaces with high solar load regarding cooling, large glazed areas, cold-air convective drafts, etc.? What solutions were used?

\section{Acoustics}

Mech Engr

Const Doc

What is the design NC (noise criteria) sound level? Provide this information in Table 1. Are there any special acoustical considerations for any areas (areas close to the AHU, private areas, open office areas, etc.)? How will this criteria be met? (flexible duct, duct lining, fan type, lead wraps, diffuser type, TU damper type, etc.)

Noise class (NC) 35-40 for closed offices and $41-43$ for open offices, recommended by ASHRAE)

\section{Air Quality}

Mech Engr

Const Doc

For the general building and individual spaces, what is the desired outside air fraction or cfm per person and the number of persons per square foot? (Provide this information in Table 1). Is the outside air (OSA) controlled by $\mathrm{CO}_{2}$ monitors? Explain.

Can occupants adjust ventilation? How and what limits apply to what areas?

Are there any special indoor pollutant source concentrations? How are they handled? List areas served by exhaust fans, the fan size, air changes per hour and operational control.

How will the fresh air rate be maintained at low supply air volumes of the VAV system? Are perimeter zones treated differently than interior zones (reheat box damper settings, etc.)?

Where are the outside air intakes located? Are they near any potential sources of pollutants? 
Part II. Commissioning Plan-Design Phase Appendix 1. Design Documentation Form

Are full-drain condensate pans used in the air handler units? $\square$ Yes / $\square$ No

What other special IAQ issues were considered?

Visual Quality

Arch, Ltg Des,

Design Dev

What are the design footcandle levels for the various spaces? (Provide this information in Table 1). Why? Is additional task lighting assumed?

Do any spaces have special glare requirements? $\square$ Yes / $\square$ No

How will they be met? (special light fixtures and lenses, fixture layout, special CRT screens, etc.)

How will glare be controlled in daylit areas?

What are the parameters and sequences of operation for the daylighting controls and dimming lights? How will occupants interact with the system (overrides, education, etc.)?

\subsection{Landscaping}

Architect

Design Dev

\section{Design Intent}

Describe the objectives and the elements of the specific landscape design that contribute to energy efficiency, water conservation, and comfort?

Number of sheets attached to this section: 


\subsection{Interior Conditions Basis of Design Mech Engr Const Doc}

\section{Table 1}

Reception, records, conference room, closed offices, open offices, exercise room, lunch room, inventory, stock, etc.

\begin{tabular}{|c|c|c|c|c|c|c|c|c|c|c|}
\hline Space & $\begin{array}{l}\text { Use I } \\
\text { Activity }\end{array}$ & $\begin{array}{c}\text { Occupant } \\
\text { Type }\end{array}$ & $\begin{array}{c}\text { Num } \\
\text { of } \\
\text { Occs }\end{array}$ & $\begin{array}{c}\text { Operating } \\
\text { Hours per } \\
\text { Day }\end{array}$ & $\begin{array}{c}\text { Design } \\
\text { Cooling } \\
\text { DB }\end{array}$ & $\begin{array}{c}\text { Design } \\
\text { Cooling } \\
\text { WB or } \\
\text { RH }\end{array}$ & $\begin{array}{c}\text { Design } \\
\text { Heating } \\
\text { DB } \\
\text { OSAT }\end{array}$ & $\begin{array}{c}\text { OSA } \\
\text { CFM } 1 \\
\text { Person } \\
\text { or } \mathrm{CO}_{2}\end{array}$ & $\begin{array}{l}\text { Design } \\
\text { Noise } \\
\text { Level } \\
\text { (NC) }\end{array}$ & $\begin{array}{l}\text { Design } \\
\text { Light } \\
\text { Level } \\
\text { (FC) }\end{array}$ \\
\hline & & & & & & & & & & \\
\hline & & & & & & & & & & \\
\hline & & & & & & & & & & \\
\hline & & & & & & & & & & \\
\hline & & & & & & & & & & \\
\hline & & & & & & & & & & \\
\hline & & & & & & & & & & \\
\hline & & & & & & & & & & \\
\hline & & & & & & & & & & \\
\hline & & & & & & & & & & \\
\hline & & & & & & & & & & \\
\hline & & & & & & & & & & \\
\hline & & & & & & & & & & \\
\hline & & & & & & & & & & \\
\hline & & & & & & & & & & \\
\hline & & & & & & & & & & \\
\hline
\end{tabular}


Part II. Model Commissioning Plan-Design Phase

Appendix 1. Design Documentation Form

\section{HVAC Systems and Design Parameters}

\subsection{General}

Mech Engr

Design Dev

General description of the main HVAC systems and areas served.

System

Areas Served

Why were the above particular systems chosen?

Describe the level of priority given to energy conservations for the system.

2.2 Specific System Descriptions

\begin{tabular}{|l|l|l|}
\hline System & $\begin{array}{c}\text { Heating / } \\
\text { Cooling / } \\
\text { Both }\end{array}$ & \\
\hline & & \\
\hline & & \\
\hline & & \\
\hline & & \\
\hline & & \\
\hline & & \\
\hline & & \\
\hline & & \\
\hline
\end{tabular}

Mech Engr

Areas Served

Model Commissioning Plan and Guide Specifications 
What is the rationale for the way the HVAC and lighting were zoned?

\subsection{Load Calculations}

What outdoor design conditions were assumed for load calculations?

Summer: DB WB

Winter: DB

What indoor design conditions were assumed for load calculations?

Summer: DB $\mathrm{RH}$

Winter: DB $\mathrm{RH}$

Internal load assumptions: Lighting: W/sf. Misc: W/sf. Other:

People/100 sf: Btu/hr/person: sensible , latent

Ventilation: cfm/person. Basis (code, etc.):

Infiltration: cf,/sf wall area, or $\square$ air changes per hour.

Glazing:

\begin{tabular}{|c|c|c|c|}
\hline Orientation & \% of Wall Area & Overall U & SC \\
\hline N & & & \\
\hline S & & & \\
\hline E & & & \\
\hline W & & & \\
\hline
\end{tabular}

What overall safety factor was used and how much diversity was assumed for the heating, cooling plant and fan size?

For redundant equipment, what redundancy criteria were used?

Number of sheets attached to this section: 


\section{Chiller System (Chillers, Cooling Towers, Pumps, Piping)}

\subsection{Design Intent}

Mech Engr

Design Dev

What is this chiller system used for? $\square$ Supplies chilled water to air handler units to cool building space. $\square$ Computer room AC units. $\square$ Process chilled water

DHeat recovery for:

Other:

What areas of the building do the chillers serve?

List the areas that the chillers do not serve?

What types of air conditioning equipment serve the areas not served by the chillers?

What vibration and noise considerations are given to the location of the chillers?

What energy efficiency objectives are there for the chiller system? $\square$ Highly efficient, $\square$ Moderately efficient, $\square$ Standard efficiency

What level of automatic control features are desired for this chiller system relative to automatic staging, optimization, central building automation system monitoring and control capabilities, etc.? $\square$ Highly automated, $\square$ Moderately automated, $\square$ Minimally automated

What type of refrigerant will be used and why?

\subsection{Basis of Design-Components Description and Methods for Meeting Design Intent}

\section{Chillers}

Mech Engr

Const Doc

Briefly describe the chiller system. 
Centrifugal $\square$ Screw $\square$ Chiller

$\square$ Hermetically sealed

$\square$ Heat recovery

$\square$ Refrigerant type:

$\square$ Air cooled $\square \overline{\text { Water cooled }}$

$\square$ Evaporative cooled

$\square$ Capacity control type:

$\square$ Prerotation vanes

$\square$ Other: $\square$ Reciprocating chiller

$\square$ Heat recovery

$\square$ Refrigerant type:

$\square$ Air cooled $\square$ Water cooled

$\square$ Evaporative cooled

$\square$ Stages of unloading:

$\square$ Other:

How many chillers of each size are there? (size and number of each size):

Is there a standby / redundant chiller during design conditions?

What method was used for determining the design cooling load?

Attach load calculations and assumptions, if not given in a previous section. (Diversity, safety factor, outdoor $\mathrm{DB}, \mathrm{WB}$, indoor $\mathrm{DB}$, lighting W/sf, plug loads W/sf, people/100 sf, ventilation $\mathrm{cfm} /$ person, infiltration rate, glazing \% of wall, overall $\mathrm{U}$; $\mathrm{SC}$ ).

Describe any provisions in the chiller system for accomodating future building or load expansion.

What evidence can be provided to show the chillers are not oversized?

Why were they chosen to be different or equal size?

Was variable compressor speed seriously considered? If not, why not?

Was heat recovery for the chiller analyzed? Why or why not?

What were the results of the analysis?

What vibration and noise considerations are given to the model and features of the chosen chillers?

What is the rated efficiency of each chiller at full load and the APLV, in $\mathrm{kW} /$ ton?

What rationale was used to select these efficiencies with the sizes? Were more efficient models analyzed? 
Attach engineering or energy simulation and economic calculations for the selections.

Are the chillers intended to be staged back and forth, depending on load, to minimize energy use?

Will staging occur manually or automatically?

What special control strategies will be employed with the chiller system?

What controls will be in place to allow the lowest economical entering condenser water temperature to be realized? What other options were considered besides this strategy?

Fully describe the interface that the building automation system has with the chiller system:

What control will the building automation system (BAS) have over the chiller system?

BAS enables/disables the chiller, $\square$ assigns the lead chiller, $\square$ assigns the lead primary chilled water pump, $\square$ assigns the lead secondary chilled water pump, $\square$ assigns the lead condenser pump, $\square$ assigns the lead cooling tower

The BAS monitors the following: $\square$ LCHWT, $\square$ RCHWT, $\square$ ECDWT, $\square$ LCDWT, $\square$ CDW flow, $\square$ CHW primary flow, $\square$ Secondary CHW flow, $\square$ Cooling tower bypass valve, $\square$ Chiller alarms that report to BAS (list):

Other

The BAS can change the following: $\square$ LCHWT setpoint, $\square$ Reset parameters, $\square$ ECDWT setpoint, $\square$ Cooling tower fan staging parameters, $\square$ Chilled water pumping pressure setpoints, $\square$ Pressure reset parameters, $\square$ Demand limits, $\square$ Other 
Describe the cooling tower (cross flow, counterflow, etc.)

What are the sizes of the cooling towers?

What is the approach temperature rating of the cooling tower?

Why was a lower approach not chosen?

Attach energy and economic analyses.

Were oversized cooling towers analyzed to improve chiller efficiency?

Why or why not?

Attach analysis.

How many motors are there per tower fan? Describe.

Are the motors premium efficiency?

How is the fan speed controlled?

How do the sizes of the chillers affect the sizes of the cooling towers selected? Are they paired?

Can two cooling towers serve one chiller?

How are the cooling towers staged?

Will condenser water flows be monitored?

Will the cooling tower be used in winter?
If not, explain why.

Why?

\section{Air or Evaporative Cooled Condenser}

Mech Engr

Const Doc

$\square$ Air cooled $\square$ Evaporative cooled

Why was an air-cooled condenser chosen over a cooling tower?

Why was an air-cooled condenser chosen over an evaporative condenser?

Describe main features of the condensers and the chillers they serve. 
Were more efficient models analyzed? (attach analysis)

. Describe the staging features

\section{Chilled and Condenser Water Pumps}

What pressure drop range was the piping system designed to:

$\square$ Very low pressure drop, $\square$ Moderately low pressure drop, $\square$ Standard pressure drop. Was an analysis performed for using a lower pressure drop to reduce pump size and energy use? Attach analysis.

Describe the pumps chosen. Primary:

Secondary:

\section{Condenser pumps}

Are they equipped with premium energy-efficient motors?

Why or why not?

Were the pumps not over specified? What was the over-sizing rationale for the pumps?

$\square$ Potential system expansion, $\square$ Safety factor, $\square$ End of curve safety, $\square$ All of above. Are these issues all likely to occur together? Was the end of curve safety really necessary? Could a software control loop safety achieve the same thing, allowing for a smaller pump?

Describe any standby or redundant pumps and their operation.

Will the control sequences allow for automatic changeover to the lag or standby pump upon pump failure and similarly for cooling tower fan failure or will manual valving be required? Upon failure, does the lag pump or tower start or does the chiller go down and lag chiller start. Explain fully for each:

Primary chilled water pumps: 
Secondary chilled water pumps:

Condenser water pumps:

Cooling tower fans:

How is the secondary chilled water capacity controlled? $\square$ Variable speed drives (VFD) on pumps, $\square$ Bypass valve. If by bypass valve, explain the rationale for not using variable speed drives and attach the economic analysis.

For VFD's, how will the pump speed be controlled? $\square$ Constant water pressure setpoint, $\square$ Reset water pressure setpoint. If the pressure is not reset, why not?

For a VFD on pressure reset, how low of speed will the pump be allowed to go? Is this is as low as possible? Explain.

Will chilled water flows be monitored? $\square$ Primary flow, $\square$ Secondary flow. If not, explain.

\section{Chiller System Sequence of Operations and Operating Parameters}

\section{Mech Engr}

Const Doc

Attach a full and comprehensive sequence of operations, including but not limited to the following conditions and systems, including all interactions:

\section{Chiller, Cooling Tower and Pumps}

- List parameter conditions that initiate start-up.

- Provide a detailed narrative of the full sequence and status and action of EACH component during EACH stage of start-up: low load, medium load, high load, staging to next chiller, up to full load on all chillers, and then back down again to OFF condition. List all setpoints, delays, parameters, conditions, etc., that are required to pass through each stage. The components for which status will be given at each stage are: chiller stage and load, primary, secondary and condenser pump status, speed and flow, cooling tower stage, cooling tower bypass valve, cooling tower fans and speed, pipe pressures and setpoint resets.

Describe the sequences for the following:

- Chiller optimization staging.

- Temperature lockouts.

- Status and sequence at power outage and fire alarm.

- Effects of manual shutoff or failure of chiller, primary pump and secondary pump, condenser pump, cooling tower fan, vibration alarm. 
- List all alarms.

- Include full sequences and setpoints for capacity and pressure control of the secondary chilled water system.

- Include full sequences and setpoints for condenser water temperature control and cooling tower fan control parameters.

- Cooling tower sump heater sequences, parameters and setpoints.

- List the full sequence of operation for all energy conserving strategies, including their setpoints and parameters.

- Weekend operation.

- Normal occupied and unoccupied modes.

Equipment manufacturers' sequences and control drawings may be included, but will generally require additional narrative. Flow charts may be used if sufficiently detailed. Narrative and flow chart examples are found in Section 4 of the instructions.

For the chiller, cooling tower and pumps, the sequences are expected to be about five singlespaced, typewritten pages.

Number of sheets attached to this section: 


\section{Boilers and Heating Water System}

\subsection{Design Intent}

Mech Engr

Design Dev

Hot Water. What is this boiler system used for? $\square$ Supplies hot water to air handler units to heat building space, preheat incoming cold air. $\square$ Supplies hot water to perimeter, core VAV reheat terminal units.

Steam. What is this boiler system used for? $\square$ Supplies steam to air handler units to __ heat building space, _ preheat incoming cold air. $\square$ Supplies hot water to __ perimeter, _ core VAV reheat terminal units.

Other:

What areas of the building do the boilers serve?

List the areas that the boilers do not serve?

What types of heating equipment serve the areas not served by the boilers?

What vibration and noise considerations are given to the location of the boilers?

What energy efficiency objectives are there for the boiler system? $\square$ Highly efficient, $\square$ Moderately efficient, $\square$ Standard efficiency

What level of automatic control features are desired for this boiler system relative to automatic staging, optimization, central building automation system monitoring and control capabilities, etc.? $\square$ Highly automated, $\square$ Moderately automated, $\square$ Minimally automated

What type of fuel will be used and why? $\square$ Natural gas, $\square$ Fuel oil, $\square$ Other

4.2 Basis of Design-Components Description and Methods for Meeting Design Intent

Boilers Mech Engr Const Doc

The boiler is a $\square$ Condensing, $\square$ Forced draft, $\square$ Atmospheric burner, $\square$ Packaged, $\square$ Other:

Briefly describe the boiler system.

How many boilers of each size and type are there? (list number and size):

Is there a standby / redundant boiler during design conditions? 
What method was used for determining the design heating load?

Attach load calculations and assumptions, if not given in a previous section. (Diversity, safety factor, outdoor $\mathrm{DB}, \mathrm{WB}$, indoor DB, lighting W/sf, plug loads W/sf, people/100 sf, ventilation $\mathrm{cfm} /$ person, infiltration rate, glazing \% of wall, overall $\mathrm{U} ; \mathrm{SC}$ ).

Describe any provisions in the boiler system for accomodating future building or load expansion.

What evidence can be provided to show that the boilers are not oversized?

Why were they chosen to be different or equal size?

What vibration and noise considerations are given to the model and features of the chosen boilers?

How many total stages of capacity does each boiler have? (burner beds and stages of fire)

What is the rated efficiency of each boiler?

What rationale was used to select these efficiencies with the sizes? Were more efficient models analyzed?

Attach engineering or energy simulation and economic calculations for the selections.

Are the boilers intended to be staged back and forth, depending on load, to minimize energy use?

Will this be done manually or automatically?

What special control strategies will be employed with the boiler system?

Fully describe the interface that the building automation system has with the boiler system: 
What control will the building automation system (BAS) have over the boiler system?

BAS enables/disables the boiler, $\square$ assigns the lead boiler, $\square$ assigns the lead primary boiler pump, $\square$ assigns the lead secondary boiler water pump.

The BAS monitors the following: $\square$ boiler alarm status, $\square$ pump status, $\square$ internal water temperature, $\square$ steam pressure, $\square$ HW primary flow, $\square$ secondary HW flow, $\square$ three-way mixing valve, $\square$ boiler alarms that report to BAS (list):

Other

The BAS can change the following: $\square$ LHWT setpoint, $\square$ Reset parameters, $\square$ Boiler water pumping pressure setpoints, $\square$ Pressure reset parameters, $\square$ Demand limits, $\square$ Other

Will the boilers have low water cutout controls?

\subsection{Heating Water Pumps}

What pressure drop range was the piping system designed to:

$\square$ Very low pressure drop, $\square$ Moderately low pressure drop, $\square$ Standard pressure drop. Was an analysis performed for using a lower pressure drop to reduce pump size and energy use? Attach analysis.

Describe the pumps chosen. Primary:

Secondary:

Are they equipped with premium energy-efficient motors?

Why or why not?

Were the pumps not over specified? What was the over-sizing rationale for the pumps? $\square$ Potential system expansion, $\square$ Safety factor, $\square$ End of curve safety, $\square$ All of above. Are these issues all likely to occur together? Was the end of curve safety really necessary? Could a software control loop safety achieve the same thing, allowing for a smaller pump?

Describe any standby or redundant pumps and their operation. 
Will the control sequences allow for automatic changeover to the lag or standby pump upon pump failure or will manual valving be required? Explain fully.

Primary heating water pumps:

Secondary heating water pumps:

How is the secondary heating water capacity controlled? $\square$ Variable speed drives (VFD) on pumps, $\square$ Bypass valve(s). If by bypass valves, explain the rationale for not using variable speed drives and attach the economic analysis.

For VFD's, how will the pump speed be controlled? $\square$ Constant water pressure setpoint, $\square$ Reset water pressure setpoint. If the pressure is not reset, why not?

For a VFD on pressure reset, how low of speed will the pump be allowed to go? Is this is as low as possible? Explain.

Will heating water flows be monitored? $\square$ Primary flow, $\square$ Secondary flow. If not, explain.

How is supply water temperature controlled? $\square$ 3-way mixing valve, $\square$ Other

\subsection{Boiler System Sequence of Operations and Operating Parameters Mech Engr

Attach a full and comprehensive sequence of operations, including but not limited to the following conditions and systems, including all interactions:

- List parameter conditions that initiate start-up.

- Provide a detailed narrative of the full sequence and status and action of EACH component during EACH stage of start-up: low load, medium load, high load, staging to next boiler, up to full load on all boilers, and then back down again to OFF condition. List all setpoints, delays, parameters, lockouts, conditions, etc., that are required to pass through each stage. The components for which status will be given at each stage are: boiler stage and load, primary, secondary pump status, speed and flow, pipe pressures and setpoint resets.

Describe the sequences for the following:

- Boiler optimization staging.

- Temperature lockouts.

- Status and sequence at power outage and fire alarm.

- Effects of manual shutoff or failure of boiler, primary pump and secondary pump.

- List all alarms. 


\section{Part II. Model Commissioning Plan-Design Phase}

Appendix 1. Design Documentation Form

- Include full sequences and setpoints for capacity and pressure control of the secondary heating water system.

- List the full sequence of operation for all energy conserving strategies, including their setpoints and parameters.

- Weekend operation.

- Normal occupied and unoccupied modes.

- Warm-up mode

Equipment manufacturers' sequences and control drawings may be included, but will generally require additional narrative. Flow charts may be used if sufficiently detailed. Narrative and flow chart examples are found in Section 4 of the instructions.

For the boiler and pumps, the sequences are expected to be about single spaced, typewritten pages.

Number of sheets attached to this section: 
Part Il. Model Commissioning Plan-Design Phase Appendix 1. Design Documentation Form

\section{Roof Top Packaged System(s) (RTU)}

\subsection{Design Intent}

Mech Engr

Design Dev

What is this system or component used for?

Systems Description

Mech Engr

Const Doc

Briefly describe the system:

$\square$ Heat pump
$\square$ Gas pack
$\square$ AC only
$\square$ Resistance coil
$\square$ Hot water
$\square$ VAV

List equipment and areas served:
$\square$ Steam
Q Constant volume
$\square$ Dual duct
$\square$ Multizone
$\square$ Other
$\square$ Other

5.2 Basis of Design-Components Description and Methods for Meeting the Design Intent Mech Engr

Const Doc

Give size, quantity, and other specific information and the areas served, and how it will meet the objectives.

\section{Plant}

Number of units of this type:

EER (cooling): Tons cooling each unit:

Accumulated capacity for all units of this type: Total tons cooling:

MBtu heating: Heat Pump COP: Gas efficiency:

Areas served:

\section{Supply Fans and Capacity Control}

Total CFM for packaged systems of this type:

$\square$ Inlet vanes $\square$ VFD $\square$ Vane axial $\square$ Outlet damper $\square$ Other:

Motor efficiency: ___ Std. effic., ___ Premium effic.

\section{Return Fans / Exhaust Fans / Relief Dampers}

Describe return fans, exhaust fans, or relief dampers, if any, and their function. 
Describe how building static pressure is controlled (setpoints, etc.).

\section{VFD control:}

Which fans does each VFD control? $\square$ Supply $\square$ Return/Exhaust

Location of duct static-pressure sensor (distance from fan and proximity from branch takeoffs up and down stream):

Duct static pressure: $\square$ Fixed setpoint / $\square$ Reset or variable

Expected duct static pressure setpoint (or average if reset):

Total pressure across fan at design flow: [discharge pressure - suction pressure (negative)]

Minimum fan capacity (lower frequency limit setting in VFD, $\%$ of max.)

Are VFD settings $\square$ monitored or $\square$ controlled by the BAS system? (check one)

Method used for sizing ducts equal friction static regain

Note: Equal friction gives smaller ducts and higher pressure requirements. If equal friction was used, was a calculation made to make sure the increased pressure and subsequent increase in energy use by the fan is more than offset by the savings in duct materials?

\section{Compressor(s)}

Number of compressors per RTU: Low ambient compressor package?

Number of condenser fans per RTU:

Compressor capacity control; general description:

\section{Cooling coil}

Provide general description and any special features (high efficiency, face velocity, low pressure drop, etc.). Was a low pressure drop coil analyzed? What were the results?

\section{Dampers}

Describe the dampers and their function. 


\section{Smoke and Fire Dampers}

Describe the smoke and fire damper system (location and operation).

\section{Setpoint Temperatures}

Supply air (SA):

SA reset (see strategy sequence):

Mixed air:

\section{Filters}

Provide general description and any special features (low pressure drop, etc.). Were low pressure drop filters analyzed? What were the results?

\section{Heating System}

Describe type, fuel, perimeter reheat, areas served, etc.

\section{Economizer and OSA Dampers}

$\square$ Enthalpy $\square$ Dry Bulb $\square$ Integrated $\square$ Economizer is first stage of cooling

Number of damper positions: or $\square$ infinite.

Dampers closed during warm-up? $\square$ Yes / $\square$ No

If dry-bulb type: OSA changeover temperature:

Other special features of the RTU:

How will the fresh air rate be maintained at low supply air volumes of the VAV system? Are perimeter zones treated differently than interior zones (reheat box damper settings, etc.)? 
Part II. Model Commissioning Plan-Design Phase

Appendix 1. Design Documentation Form

\section{Integration of Control and Monitoring Points With the BAS}

\begin{tabular}{|c|c|c|c|c|c|}
\hline $\begin{array}{l}\text { Point or } \\
\text { Feature }\end{array}$ & $\begin{array}{c}\text { BAS } \\
\text { Monitors }\end{array}$ & $\begin{array}{c}\text { BAS Can } \\
\text { Change } \\
\text { SetPts }\end{array}$ & $\begin{array}{l}\text { Point or } \\
\text { Feature }\end{array}$ & $\begin{array}{c}\text { BAS } \\
\text { Monitors }\end{array}$ & $\begin{array}{c}\text { BAS Can } \\
\text { Change } \\
\text { SetPts }\end{array}$ \\
\hline Mixed air temp. & & & Compressor stage & & NA \\
\hline RA temp. & & NA & Bldg. static pressure & & \\
\hline SA temp & & & Temp. lockouts & & \\
\hline SA reset parameters & & & $\mathrm{CO}_{2}$ for OSA control & & \\
\hline RA enthalpy & & NA & Htg. coil position & & NA \\
\hline DA static pressure & & & Optimum start & NA & \\
\hline Duct static pressure & & & Night purge & NA & \\
\hline Supply fan statuc & & NA & Demand limit & NA & \\
\hline Ret./Exh. fan status & & NA & Alarms (list): & & \\
\hline Supply fan speed & & NA & -Dirty filter & & \\
\hline Ret/Exh. fan speed & & NA & -Compressor fail & & \\
\hline Supply fan cfm & & NA & -Fan loss of air & & \\
\hline Ret/Exh. fan cfm & & NA & -High DA pressure & & \\
\hline Inlet vane position & & NA & -Fire/smoke & & \\
\hline Filter Diff. pressure & & & -Emerg. shutdown & & $\mathrm{NA}$ \\
\hline $\begin{array}{l}\text { Occup. schedule } \\
\text { override }\end{array}$ & & & $\begin{array}{l}\text { OSA compensation for } \\
\text { VAV }\end{array}$ & & \\
\hline Night low limits & & & OSA economizer & & \\
\hline
\end{tabular}

Describe other equipment tied to the ON/OFF status of the RTU (exhaust fans, etc.)

\subsection{RTU Sequence of Operations and Operating Parameters}

Mech Engr

Spec Dev

Provide a full and comprehensive sequence of operations, including but not limited to the following conditions and systems, including all interactions: 
Part II. Model Commissioning Plan-Design Phase

Appendix 1. Design Documentation Form

Systems

- supply fans

- exhaust fans

- return air and exhaust dampers

- supply air capacity control

- economizer and OSA dampers

- building static pressure control

- coil valve operation

- $\mathrm{CO}_{2}$ sensor OSA control

- smoke dampers

\section{Conditions or Modes}

- start-up

- shut-down

- normal occupied \& unoccupied periods

- warm-up

- temperature lockouts

- compressor and condenser staging

- override sequences

- winter/summer changeover

- weekend operation

- normal operation heating

- normal operation cooling

- through deadband ranges

- alarms: fire, smoke, shutdown, equip. failure, temp. and pressure limits, etc.

- all energy conserving strategies (optimum start/stop, resets, etc.)

- fire alarm

Include the position or status at which each component resides at start-up, what occurs at fire alarm, provide all setpoints and control parameters, including all time delays. In the sequences, describe what controls what. That is, what components must be $O N$ or at certain conditions in order for others to operate. Equipment manufacturers' sequences and control drawings may be included, but will generally require additional narrative. Flow charts may be used if sufficiently detailed. Narrative and flow chart examples are found in Section 4 of the instructions.

For this RTU system, these sequences are expected to be about single spaced, typewritten pages.

Number of sheets attached to this section: 
6 VAV Terminal Units-Air Conditioning Only (TU_AC)

6.1 System Description

Mech Engr

Design Dev

Briefly describe the TU:

Number of TU_ACs:

Type of area served:

TU type: $\square$ pressure independent $/ \square$ pressure dependent

Minimum air damper position: $\%$ open.

Are these fan powered? . $\square$ Parallel, 口Series. Why?

TU measures air flow via total and static pressure sensors. $\mathrm{Y} / \mathrm{N}$

$\square$ Cross, $\square$ Linear flow station? Other flow method:

Describe TU controller type:

Damper actuator type: $\square$ Electric, $\square$ Pneumatic.

What noise considerations were used when specifying the TU's?

Integration of Control and Monitoring Points With the BAS

\begin{tabular}{lllllllll}
$\begin{array}{c}\text { Point or } \\
\text { Feature }\end{array}$ & $\begin{array}{c}\text { BAS } \\
\text { Monitors }\end{array}$ & $\begin{array}{c}\text { BAS Can } \\
\text { Change } \\
\text { SetPts }\end{array}$ & & $\begin{array}{c}\text { Point or } \\
\text { Feature }\end{array}$ & $\begin{array}{c}\text { BAS } \\
\text { Monitors }\end{array}$ & $\begin{array}{c}\text { BAS Can } \\
\text { Change } \\
\text { SetPts }\end{array}$ \\
\hline $\begin{array}{l}\text { TU air flow } \\
\text { TU air flow min. }\end{array}$ & - & - & & TU air flow max. & - & - \\
\hline
\end{tabular}

\subsection{TU_AC Sequence of Operations and Operating Parameters}

\section{Mech Engr Spec Dev}

Provide a full and comprehensive sequence of operations (including all sequences, deadband, alarm actions, etc.) on a separate sheet(s) and attach to this section of the form.

Number of sheets attached to this section: 


\section{VAV Terminal Units-Reheat (TU_RH)}

\subsection{System Description}

Briefly describe the TU:

Number of TU_RHs: Type of area served:

TU type: $\square$ pressure independent / $\square$ pressure dependent

Are these fan powered?

Why?

What provisions will be made to minimize reheat?

What provisions will be made to minimize system simultaneous heating and cooling?

TU measures air flow via total and static pressure sensors. $\mathrm{Y} / \mathrm{N}$

$\square$ Cross, $\square$ Linear flow station? Other flow method:

Minimum air damper position: $\%$ open.

When the damper is at minimum in heating and space setpoint is not being maintained, will dampers open? Why?

Describe TU controller type:

Damper actuator type: $\square$ Electric, $\square$ Pneumatic.

Heating coil type: $\square$ hot water, $\square$ electric resistence and stages

Describe heating coil valve: $\square$ Two position, $\square$ Modulating.

Heating valve actuator type: $\square$ Electric, $\square$ Pneumatic.

Do some units have 3-way valves? Why?

Automatic flow control valve? Describe:

What noise considerations were used when specifying the TU's?

\section{Integration of Control and Monitoring Points With the BAS}

\begin{tabular}{llllllll}
$\begin{array}{c}\text { Point or } \\
\text { Feature }\end{array}$ & $\begin{array}{c}\text { BAS } \\
\text { Monitors }\end{array}$ & $\begin{array}{c}\text { BAS Can } \\
\text { Change } \\
\text { SetPts }\end{array}$ & & $\begin{array}{l}\text { Point or } \\
\text { Feature }\end{array}$ & $\begin{array}{c}\text { BAS } \\
\text { Monitors }\end{array}$ & $\begin{array}{c}\text { BAS Can } \\
\text { Change } \\
\text { SetPts }\end{array}$ \\
\hline TU air flow & - & - & & & TU air flow max. \\
TU air flow min. & - & - & & Valve position & -1 & - \\
\hline
\end{tabular}


Part II. Model Commissioning Plan-Design Phase Appendix 1. Design Documentation Form

\subsection{TU_RH Sequence of Operations and Operating Parameters}

Mech Engr

Spec Dev

Provide a full and comprehensive sequence of operations (including heat lockout parameters, heating valve sequences, deadbands, alarm actions, etc.) on a separate sheet(s) and attach to this section of the form.

Number of sheets attached to this section: 
Part II. Model Commissioning Plan-Design Phase Appendix 1. Design Documentation Form

8 Heat Recovery Unit (HRU)

\subsection{Design Intent}

Mech Engr

Design Dev

Describe the purpose of the HRU:

\subsection{System Description}

Mech Engr

Design Dev

Briefly describe the system:

On which air handlers does this system operate?

Integration of Control and Monitoring Points With the BAS

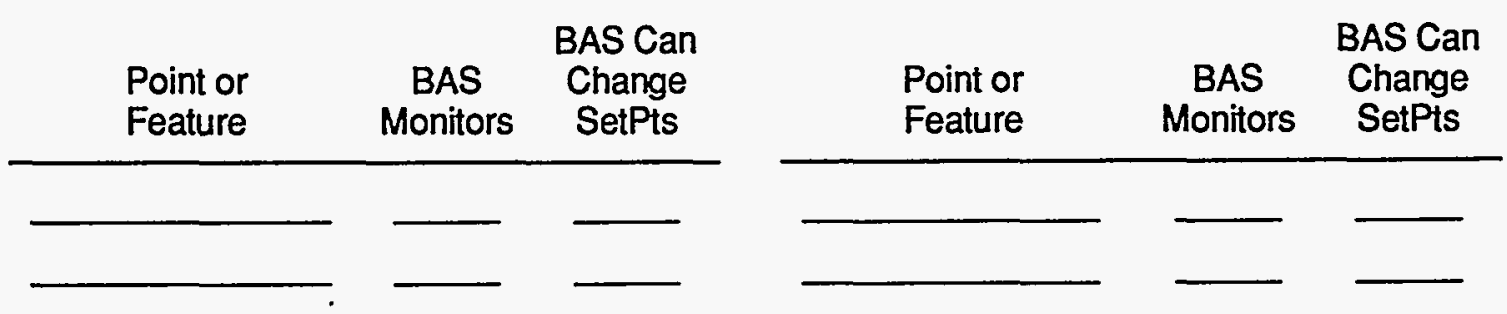

\subsection{HRU Sequence of Operations and Operating Parameters}

\section{Mech Engr}

Spec Der

Provide a full and comprehensive sequence of operations (including seasonal variations) on a separate sheet(s) and attach to this section of the form.

Number of sheets attached to this section: 
Part II. Model Commissioning Plan-Design Phase Appendix 1. Design Documentation Form

\section{Computer Room Conditioning Unit (ACU)}

\subsection{Design Intent}

Mech Engr

Design Dev

What is this system or component used for?

General Description

Mech Engr

Design Dev

Briefly describe the system or component.

9.2 Basis of Design-Component Description and Methods for Meeting the Design Intent Mech Engr Design Dev

Areas served:

Number of ACUs: Sizes (tons) EER:

Location of ACU:

$\square$ Ducted system or $\square$ discharge only?

How is heat rejected? $\square$ Cooling tower / $\square$ DX air-cooled condenser / $\square$ Other

Location of condenser:

Humidifier description:

Reheat description:

How is the ACU controlled?

$\square$ Stand-alone controllers with thermostats in zones

$\square$ Same, but enabled/disabled by central building automation system

$\square$ "fully" controlled by BAS

Does supply air enter this space from the main HVAC system? $\square$ Yes / $\square$ No

If Yes, when?

How is fresh air brought into and controlled in the space?

\section{Integration of Control and Monitoring Points With the BAS}

\begin{tabular}{lllllll}
$\begin{array}{c}\text { Point or } \\
\text { Feature }\end{array}$ & $\begin{array}{c}\text { BAS } \\
\text { Monitors }\end{array}$ & $\begin{array}{c}\text { BAS Can } \\
\text { Change } \\
\text { SetPts }\end{array}$ & $\begin{array}{l}\text { Point or } \\
\text { Feature }\end{array}$ & $\begin{array}{c}\text { BAS } \\
\text { Monitors }\end{array}$ & $\begin{array}{c}\text { BAS Can } \\
\text { Change } \\
\text { SetPts }\end{array}$ \\
\hline & - & - & - & -
\end{tabular}


Part 1l. Model Commissioning Plan-Design Phase

Appendix 1. Design Documentation Form

\subsection{ACU Sequence of Operations and Operating Parameters}

\section{Mech Engr \\ Spec Dev}

Provide a full and comprehensive sequence of operations (including setpoints, unoccupied, occupied, fire alarm periods, etc.) on a separate sheet(s) and attach to this section of the form.

Number of sheets attached to this section: 


\section{Daylighting Controls}

\subsection{Design Intent}

Elec Engr

Design Dev

Briefly describe the system:

What is the primary reason for using daylighting?

energy savings / $\square$ view/aesthetics

What budget limitations were there?

$\square$ visual light quality

\subsection{Basis of Design}

Elec Engr

Design Dev

System type: $\square$ continuous dimming / $\square$ stepped dimming in steps

Describe related architectural features such as light shelves, sloped ceilings, skylights, special interior finishes, etc.

How low are the lights allowed to dim? $\%$.

The system is controlled by: $\square$ main BAS / $\square$ stand alone controllers

What is the light level setpoint(s) at the work plane:

Area

Desion Foot

Candles

How deep into the building do the lights dim? ft.

Are the dimming rates the same across this distance? $\square$ Yes / $\square$ No

Explain:

What areas of the building have dimming control?

How many zones and controllers (light sensors) are there?

Model Commissioning Plan and Guide Specifications

PECIUSDOE D_INTENT.VO7, 03/20/97 
How do occupants override the dimming?

Who has access for adjusting light levels?

Where are these adjustments made?

Where are the sensors located?

\subsection{Sequence of Operations and Operating Parameters}

Elec Engr

Spec Dev

Provide a full and comprehensive sequence of operations (including setpoints and occupied and unoccupied conditions, etc.) on a separate sheet(s) and attach to this section of the form.

Number of sheets attached to this section: 


\section{Lighting Sweep Control}

\subsection{System Description}

Elec Engr, Ctrls Cont, Design Dev

Briefly describe the system:

\subsection{Operating Parameters}

Elec Engr, Ctrls Cont, Spec Dev

The system is controlled by: $\square$ Main BAS / $\square$ Stand-alone controller

How many zones will there be?

What is the floor area of the largest zone?

How many sweeps will there be?

At what times?

Weekdays:

Saturday:

Sunday:

Describe the type of switching system that occupants will use to turn the lights back on in their zone.

What is the maximum override duration? hours

Who will be able to globally override the sweeps or change the schedule?

How will the sweeps work with housekeeping schedules?

Number of sheets attached to this section: 


\section{Building Automation System (BAS)}

\subsection{Design Intent}

Mech Engr, Ctris Cont Design Dev

Briefly describe the system:

Why was this system chosen over others considered?

Describe any budget limitations:

How important was energy conservation in the decision of BAS type?

\subsection{Basis of Design-Component Description and Methods for Meeting the Design Intent Mech Engr, Ctrls Cont, Const Doc}

Central systèm is: $\square$ DDC, $\square$ pneumatic

Valve actuators: $\square$ electric, $\square$ pneumatic. AHU damper actuators: $\square$ electric, $\square$ pneumatic VAV terminal box damper actuators: $\square$ electric, $\square$ pneumatic

Fire / smoke damper actuators: $\square$ electric, $\square$ pneumatic

User interface: $\square$ graphical display of components

Limitations of the modules or features specified, compared to the higest model line system:

Check the systems that the BAS will control (vs local equipment. packaged controllers). Refer to the individual system section for a complete description of the points and their control by the BAS 
Part Il. Model Commissioning Plan—Design Phase

Appendix 1. Design Documentation Form

Rooftop packaged unit

$\begin{array}{cccc}\text { Virtually } & \text { Partial } & \text { Enable/Disable } & \text { Monitor } \\ \text { Full Control } & \text { Control } & \text { Only } & \text { Only }\end{array}$

Air handler unit

Economizer functions

$\square$

$\square$

口

$\cdot$

Boiler plant

Heating water pumping system

Chiller plant

Chilled water pumping system

Cooling tower

Condenser water pumping

Terminal unit settings

Heat recovery unit

Daylighting setpoints

Lighting sweep control

Exterior lighting

Computer room HVAC unit

Fan coil unit and condenser

Unit heaters

Smoke and fire control

Emergency power system

UPS power system

Service water heating pump

Location of user interface:

Type of user interface:

$\square$ Permanent on-site computer terminal

$\square$ Plug-in portable computer

Remote terminal of

$\square$ Keypad only

Describe parties who will be able to change schedules only:

Describe parties who will have full access to system: 
Check the energy conserving control strategies that will be operational in this building through the BAS.
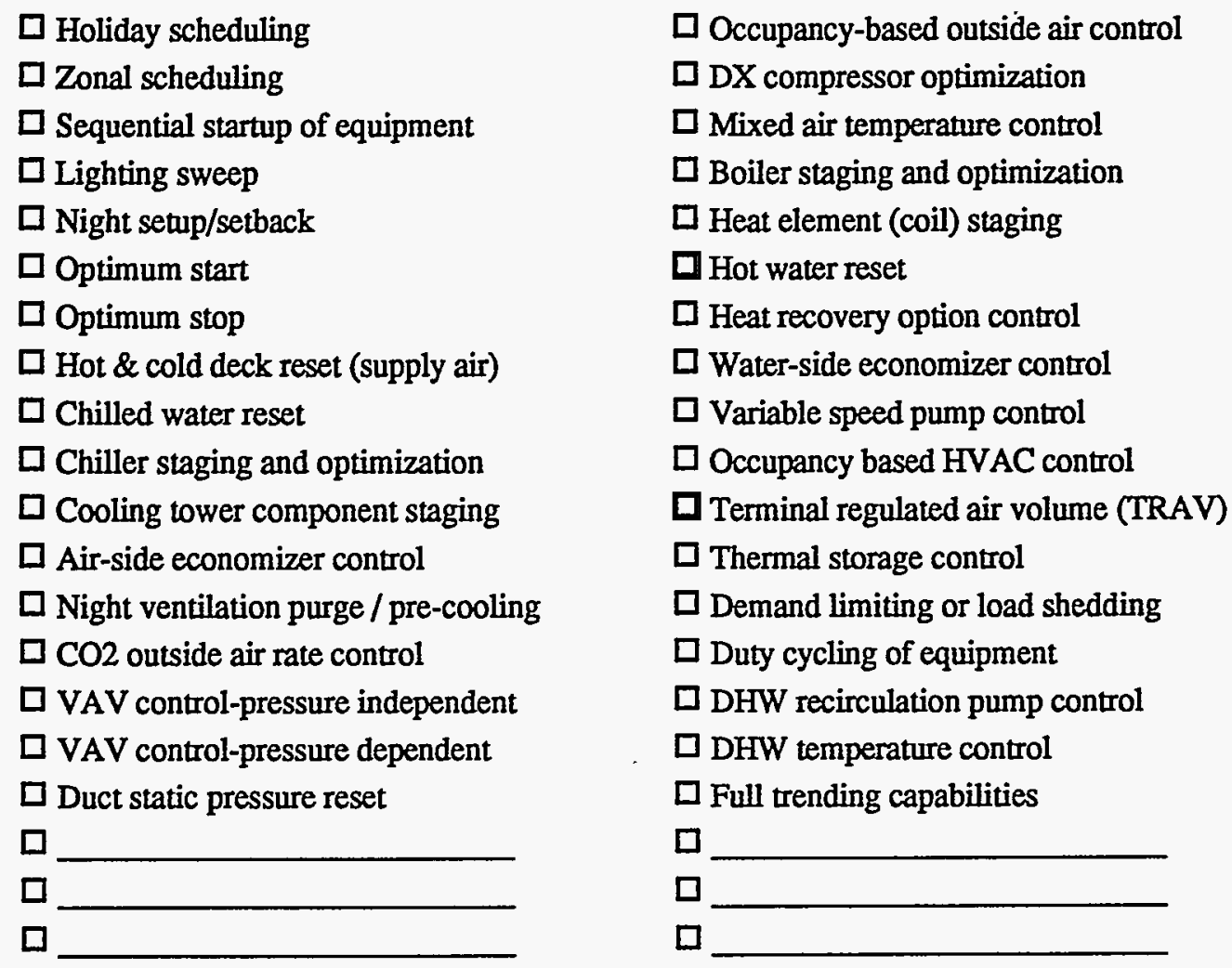

List all special monitoring points installed for diagnostic, performance verification and trouble shooting purposes, which are not needed to execute the control sequences and strategies?

\subsection{BAS Sequence of Operations and Operating Parameters}

Mech Engr

Spec Dev

Provide a full and comprehensive sequence of operations, including setpoints, deadbands, etc. List full control sequences for all control strategies. Refer to sequences already provided in other component sections, if applicable. List on a separate sheet(s) and attach to this section of the form.

Include the position or status at which each component resides at start-up, provide all setpoints and control parameters, including all time delays. In the sequences, describe what controls what. That is, what components must be ON or at certain conditions in order for others to operate. Equipment manufacturers' sequences and control drawings may be included, but will generally require additional narrative. Flow charts may be used if sufficiently detailed. Narrative and flow chart examples are found in Section 4 of the instructions. 
Note: Complete BAS description, points list with all details, program listing, etc. are not part of the design intent, but will be required as part of the O\&M documentation.

\subsection{Points List}

\section{Mech Engr, Ctrls Cont Spec Dev}

For this design intent, list all points in a table that includes at least the information shown in the following example table.

\begin{tabular}{|c|c|c|c|c|c|c|c|}
\hline $\begin{array}{c}\text { Controlled } \\
\text { System }\end{array}$ & $\begin{array}{c}\text { Point } \\
\text { Abbr. }\end{array}$ & $\begin{array}{c}\text { Point } \\
\text { Description }\end{array}$ & $\begin{array}{c}\text { Display } \\
\text { Units }\end{array}$ & $\begin{array}{c}\text { Control or } \\
\text { Setpoint } \\
\text { Y/N }\end{array}$ & $\begin{array}{c}\text { Monitoring } \\
\text { Point } \\
\text { Y/N }\end{array}$ & $\begin{array}{c}\text { Intermediate } \\
\text { Point } \\
\text { Y/N }\end{array}$ & $\begin{array}{c}\text { Calculated } \\
\text { Point } \\
\text { Y/N }\end{array}$ \\
\hline & & & & & & & \\
\hline & & & & & & & \\
\hline & & & & & & & \\
\hline
\end{tabular}

\section{Key:}

Point Description: DB temp, airflow, etc.

Control or Setpoint: Point that controls equipment and can have its setpoint changed (OSA, SAT, etc.)

Intermediate Point: Point whose value is used to make a calculation which then controls equipment (space temperatures that are averaged to a virtual point to control reset).

Monitoring Point: Point that does not control or contribute to the control of equipment, but is used for operation, maintenance, or performance verification.

Calculated Point: "Virtual" point generated from calculations of other point values.

\section{Number of sheets attached to this section:}




\section{Split __ Air Conditioning; __ Heat Pump System}

\subsection{Design Intent \\ Mech Engr \\ Design Dev}

What is this system or component used for?

Systems Description

Mech Engr

Const Doc

Briefly describe the system:

$\square$ DX AC only
$\square$ Heat Pump and AC
$\square$ Resistance coil
$\square$ Hot water coil
$\square$ Gas furnace
$\square$ VAV
$\square$ Constant volume
$\square$ Dual duct
$\square$ Multizone
$\square$ Other
$\square$ Other

List equipment and areas served:

\subsection{Basis of Design-Component Description and Methods for Meeting the Design Intent Mech Eng Const DoC}

Give size, quantity, and other specific information and the areas served, and how it will meet the objectives.

\section{Plant}

Number of units of this type:

EER (cooling): Tons cooling each:

Accumulated capacity for all units of this type: Total tons cooling:

MBtu heating: Heat Pump COP: Gas efficiency:

Areas served:

\section{Compressor(s) and Condenser(s)}

Number of compressors per condenser unit: Low ambient compressor package?

Number of condenser fans condenser unit:

Compressor capacity control; general description: 


\section{Evaporator / Cooling Coil}

Provide general description and any special features (high efficiency, face velocity, low pressure drop, etc.). Was a low pressure drop coil analyzed? What were the results?

\section{Supply Fans and Capacity Control}

Total CFM for inside fan coil or air handler of this type:

$\square$ Constant volume $\square$ Inlet vanes $\square$ VFD $\square$ Vane axial $\square$ Outlet damper $\square$ Other:

$\square$ Evaporator fan cycles $\mathrm{ON}$ and OFF with compressor. Motor efficiency: ___ Std. effic., Premium effic.

\section{Dampers}

Describe any dampers and their function.

\section{Smoke and Fire Dampers}

Describe the smoke and fire damper system (location and operation).

\section{Setpoint Temperatures}

Supply air (SA):

SA reset (see strategy sequence):

\section{Filters}

Provide general description and any special features (low pressure drop, etc.). Were low pressure drop filters analyzed? What were the results?

\section{Heating System}

Describe type, fuel, perimeter reheat, areas served, etc.

\section{Economizer and OSA Dampers}

$\square$ No OSA via this unit $\square$ Enthalpy $\square$ Dry Bulb $\square$ Integrated

Economizer is first stage of cooling 
Number of damper positions: or $\square$ infinite.

Dampers closed during warm-up? $\square$ Yes / $\square$ No

If dry-bulb type: OSA changeover temperature:

Other special features of the split system:

How will the fresh air rate be maintained at low supply air volumes of the VAV system? Are perimeter zones treated differently than interior zones (reheat box damper settings, etc.)?

How is the split system controlled?

Stand-alone controllers with thermostats in zones. Number of zones:

$\square$ Above, but enabled/disabled by central building automation system (BAS)

$\square$ Integrated into BAS as below:

Integration of Control and Monitoring Points With the BAS



Describe other equipment tied to the ON/OFF status of the split system unit (exhaust fans, etc.) 
Part II. Model Commissioning Plan-Design Phase Appendix 1. Design Documentation Form

\subsection{Split System Sequence of Operations and Operating Parameters}

\section{Mech Engr Spec Dev}

Provide a full and comprehensive sequence of operations, including but not limited to the following conditions and systems, including all interactions:

Systems

- supply fans

- supply air capacity control

- economizer and OSA dampers

- building static pressure control

- coil valve operation

- $\mathrm{CO}_{2}$ sensor OSA control

- smoke dampers

\section{Conditions or Modes}

- start-up

- shut-down

- normal occupied \& unoccupied periods

- warm-up

- temperature lockouts

- compressor and condenser staging

- override sequences

- winter/summer changeover

- weekend operation

- normal operation heating

- normal operation cooling

- through deadband ranges

- alarms: fire, smoke, shutdown, equip. failure, temp. and pressure limits, etc.

- all energy conserving strategies (optimum start/stop, resets, etc.)

- fire alarm

Include the position or status at which each component resides at start-up,what occurs at fire alarm, provide all setpoints and control parameters, including all time delays. In the sequences, describe what controls what. That is, what components must be ON or at certain conditions in order for others to operate. Equipment manufacturers' sequences and control drawings may be included, but will generally require additional narrative. Flow charts may be used if sufficiently detailed. Narrative and flow chart examples are found in Sections 4 of the instructions.

For this system, these sequences are expected to be about single spaced, typewritten pages.

Number of sheets attached to this section: 
Part II. Model Commissioning Plan—Design Phase

Appendix 1. Design Documentation Form

\section{Emergency Power System}

\subsection{Design Intent}

Elec Engr

Design Dev

Briefly describe the system:

What is the purpose of the emergency power and any UPS for each load other than the fire, life, safety loads?

\subsection{Basis of Design-Component Description and Methods for Meeting the Design Intent Elec Engr Spec Dev}

\section{Generator}

Is the generator sized to be able to handle additional loads?

How many?

What is the maximum time it should take the generator to be providing power from the time street power is lost (seconds)?

Is there an automatic generator exercizer?

For how long should the generator be able to provide power without refueling?

Describe any special frequency and voltage regulation output requirements for the generator.

\section{Power Quality}

Elec Engr

Spec Dev

Describe any special power quality concerns or considerations (sensitive equipment, etc.).

\section{UPS}

How many UPS systems are there? List all, including integral batteries in equipment.

What kind of UPS bypass will be used on the stand-alone UPS?

\section{Emergency Power and UPS Schedule}

Elec Engr

Spec Dev

In the following table, list each load on emergency power and/or on a UPS. List the UPS discharge time. List all the loads first that are only on emergency power. 
Part Il. Model Commissioning Plan-Design Phase Appendix 1. Design Documentation Form

\begin{tabular}{|c|c|c|c|c|}
\hline \multirow[b]{2}{*}{ Equipment / Loads } & \multirow[b]{2}{*}{$\begin{array}{c}\text { On Emerg. } \\
\text { Power } \\
(\mathrm{Y} / \mathrm{N}) \\
\end{array}$} & \multicolumn{3}{|c|}{ UPS } \\
\hline & & $\begin{array}{l}\text { On UPS } \\
\text { (give } \\
\text { UPS ID) }\end{array}$ & $\begin{array}{l}\text { Stand Alone } \\
\text { UPS (SA) or } \\
\text { Integral (I) }\end{array}$ & $\begin{array}{l}\text { Full Load } \\
\text { Discharge } \\
\text { Time (min.) }\end{array}$ \\
\hline & & & & \\
\hline & & & & \\
\hline & & & & \\
\hline & & & & \\
\hline & & & & \\
\hline & & & & \\
\hline & & & & \\
\hline & & & & \\
\hline & & & & \\
\hline & & & & \\
\hline & & & & \\
\hline & & & & \\
\hline & & & & \\
\hline & & & & \\
\hline & & & & \\
\hline & & & & \\
\hline & & & & \\
\hline & & & & \\
\hline & & & & \\
\hline & & & & \\
\hline & & & & \\
\hline & & & & \\
\hline & & & & \\
\hline
\end{tabular}

Number of sheets attached to this section: 
Part Il. Model Commissioning Plan-Design Phase Appendix 1. Design Documentation Form

15 OTHER SYSTEMS FOR WHICH TO DEVELOP SAMPLE FORMATS

Fire Alarm and Protection

Systems

Service Water Heating

\begin{tabular}{ll}
\hline Air Handler Units & Capacity control \\
& Supply fan \\
& Return/exhaust fan and dampers \\
& Heating and cooling coil valves \\
& Economizer and OSA and retum air dampers \\
& Mixed air control \\
\hline
\end{tabular}

Exhaust Fans

Model Commissioning Plan and Guide Specifications

Part II, 15-1

PECIUSDOE D_INTENT.VO7, 03/20,97

OTHER 
Part II. Commissioning Plan-Design Phase

Appendix 2. Fire and Emergency Power Response

\section{Part II}

\section{APPENDIX 2}

Fire and Emergency Power Response Matrix

Model Commissioning Plan and Guide Specifications

PECI/USDOE RESPONSM.TRX, 03/20/97 
Part II. Commissioning Plan-Design Phase Appendix 2. Fire and Emergency Power Response

--SAMPLE--

Fire and Emergency Power Response Matrix

\begin{tabular}{|c|c|c|c|c|c|c|}
\hline \multirow[b]{2}{*}{ Component } & \multicolumn{3}{|c|}{ Response to Fire / Smoke Alarm } & \multicolumn{3}{|c|}{ Response to a Street Power Outage } \\
\hline & $\begin{array}{l}\text { Alarm Type-1: } \\
\text { Any Fire Alarm in Bldg } \\
\text { (unless noted) }\end{array}$ & $\begin{array}{l}\text { Alarm } \\
\text { Typo-2: }\end{array}$ & $\begin{array}{l}\text { Controls } \\
\text { to Use \& } \\
\text { Reset, } \\
\text { (Manual, } \\
\text { BAS, etc.) }\end{array}$ & Response & $\begin{array}{l}\text { Control } \\
\text { s to Use } \\
\text { (Manual, } \\
\text { BAS, өtc.) }\end{array}$ & $\begin{array}{c}\text { Manual } \\
\text { Reset } \\
\text { Reg'd? }\end{array}$ \\
\hline \multicolumn{7}{|c|}{ Rooftop units-1,2,3;4: } \\
\hline Start / Stop & Shutdown & & $\begin{array}{l}\text { Off--no } \\
\text { control. } \\
\text { Reset } \\
\text { varies: }\end{array}$ & Shutdown & none & $\begin{array}{l}\text { No, but } \\
\text { smoke } \\
\text { dprs } \\
\text { must be } \\
\text { open }\end{array}$ \\
\hline Dampers & $\begin{array}{l}\text { Go to normal: } \\
\text { OA is closed } \\
\text { RA is open } \\
\text { EA is closed }\end{array}$ & & na & Go to Normal & none & No \\
\hline $\begin{array}{l}\text { Terminal } \\
\text { Units }\end{array}$ & $\begin{array}{l}\text { Dampers: } 100 \% \text { open } \\
\text { Valves: no change }\end{array}$ & & na & $\begin{array}{l}\text { Dampers: stop where } \\
\text { they are } \\
\text { Valves: open }\end{array}$ & none & No \\
\hline $\begin{array}{l}\text { Split FCU-2; } \\
\text { ACU-1 }\end{array}$ & none & & $\begin{array}{l}\text { Normal } \\
\text { (manual) }\end{array}$ & $\begin{array}{l}\text { None (go on } \\
\text { emergency power) }\end{array}$ & $\begin{array}{l}\text { Normal } \\
\text { (manual) }\end{array}$ & na \\
\hline BAS & Receive and $\log$ an alarm & & Normal & $\begin{array}{l}\text { None (goes on own } \\
\text { battery backup) }\end{array}$ & Off & na \\
\hline $\begin{array}{l}\text { Exh. Fans } \\
\text { EF-1a,b, 2, } 3\end{array}$ & Off with RTU's & & $\begin{array}{l}\text { Override } \\
\text { in BAS }\end{array}$ & Off & none & No \\
\hline $\begin{array}{l}\text { Exh. Fans } \\
\text { EF-1c; } 4\end{array}$ & none & & Normal & Off & none & $\begin{array}{l}\text { Manual } \\
\text { Timers }\end{array}$ \\
\hline Boiler & none & & Normal & Off & none & No \\
\hline Boiler pumps & none & & Normal & Off & none & No \\
\hline CUH's & none & & Normal & Off & none & No \\
\hline Elevators & $\begin{array}{l}\text { Any general alarm: go to } \\
\text { 1st floor. SD in eley } \\
\text { shaft or equip. room: go to } \\
\text { 2nd flor. SD in front of } \\
\text { eley on lst floor; go to } \\
\text { 2nd floor. Heat det. in } \\
\text { shaft or equip. rm. shunt } \\
\text { trip elev. off. }\end{array}$ & & Manual & $\begin{array}{l}\text { Lights ON; car stops } \\
\text { where it is }\end{array}$ & none & No \\
\hline $\begin{array}{l}\text { Med-Gas } \\
\text { Vac. compr }\end{array}$ & none & & Normal & Off & none & No \\
\hline $\begin{array}{l}\text { Med-Gas } \\
\text { Gas compr }\end{array}$ & none & & Normal & $\begin{array}{l}\text { Off, but medgas } \\
\text { alarm on emerg. gen }\end{array}$ & none & No \\
\hline
\end{tabular}


Part II. Commissioning Plan-Design Phase

Appendix 2. Fire and Emergency Power Response

\begin{tabular}{|c|c|c|c|c|c|}
\hline $\begin{array}{l}\text { Normal } \\
\text { Lighting Sys. }\end{array}$ & none & Normal & Off & none & No \\
\hline $\begin{array}{l}\text { Emerg. } \\
\text { Lighting Sys. }\end{array}$ & none & Normal & $\begin{array}{l}\text { None: goes on } \\
\text { emerg. power }\end{array}$ & BAS & nao \\
\hline $\begin{array}{l}\text { Data } \\
\text { Management }\end{array}$ & none & Normal & $\begin{array}{l}\text { None: goes on } \\
\text { emerg. power+UPS }\end{array}$ & Normal & na \\
\hline $\begin{array}{l}\text { Paging } \\
\text { System }\end{array}$ & none & Normal & Off & none & No \\
\hline $\begin{array}{l}\text { Security } \\
\text { System }\end{array}$ & $\begin{array}{l}\text { Operates per normal, } \\
\text { sending alarms }\end{array}$ & Normal & $\begin{array}{l}\text { None: goes on } \\
\text { emerg. power + on } \\
\text { battery backup }\end{array}$ & Normal & na \\
\hline $\begin{array}{l}\text { Fire/Smoke } \\
\text { Dampers }\end{array}$ & All close & $\begin{array}{l}\text { auto-reset } \\
\text { if fusible } \\
\text { link } \\
\text { didn't } \\
\text { release }\end{array}$ & $\begin{array}{l}\text { None: slowly leak } \\
\text { down and close }\end{array}$ & Normal & na \\
\hline Fire Doors & $\begin{array}{l}\text { All close, except OH doors } \\
\text { at pharmacy, unless } 1 \text { of } 3 \\
\text { adjacent clg. SD alarms }\end{array}$ & $\begin{array}{l}\text { manually } \\
\text { reset }\end{array}$ & $\begin{array}{l}\text { None: goes on } \\
\text { emerg. power + on } \\
\text { battery backup }\end{array}$ & na & na \\
\hline $\begin{array}{l}\text { Emerg. Gen. } \\
\text { \& UPS }\end{array}$ & none & na & $\begin{array}{l}\text { Goes on-line \& } \\
\text { alarms to Security }\end{array}$ & Normal & na \\
\hline $\begin{array}{l}\text { Emerg. Pwr. } \\
\text { Circuits }\end{array}$ & none & na & $\begin{array}{l}\text { None: go on emerg. } \\
\text { power }\end{array}$ & Normal & na \\
\hline $\begin{array}{l}\text { Fire Alarm } \\
\text { System } \\
\text { Functions }\end{array}$ & normal operation & $\overline{\mathrm{na}}$ & $\begin{array}{l}\text { None: goes on } \\
\text { emerg. power + on } \\
\text { battery backup }\end{array}$ & Normal & na \\
\hline $\begin{array}{l}\text { Communica- } \\
\text { tions to BAS }\end{array}$ & $\begin{array}{c}\text { alarm sent to BAS from } \\
\text { FAP }\end{array}$ & na & None & na & na \\
\hline \multicolumn{6}{|c|}{ Communication to Outside } \\
\hline Owner's Site & $\begin{array}{l}\text { gets fire and trouble } \\
\text { message via Sec. Co. }\end{array}$ & na & $\begin{array}{l}\text { gets message via } \\
\text { Security Co. }\end{array}$ & na & na \\
\hline Owner's Secur & $\begin{array}{l}\text { gets fire and trouble } \\
\text { message via in-bldg } \\
\text { Security Co's dialer }\end{array}$ & $\overline{\mathrm{na}}$ & $\begin{array}{l}\text { gets message via } \\
\text { in-bldg Security } \\
\text { Co. dialer, due to } \\
\text { UPS starting }\end{array}$ & na & na \\
\hline Fire Dept. & fire alarm via Sec. Co & na & none & na & na \\
\hline
\end{tabular}

'Any Fire Alarm: (pull station, space or duct smoke detector, heat detector or sprinkler flow). This does not include trouble alarms or release of fusible links in fire dampers, or heat detection and smoke detector in elevator shaft or equipment rooms. A smoke detector trip in the elevator shaft or equipment room causes elevator to go to 2 nd floor.

${ }^{2}$ A duct detector trip will cause a general alarm and will shut down all RTU's. Only RTU associated with tripped detector requires manual reset at the RTU panel. On a normal general alarm, all RTU's are automatically reset upon resetting the fire alarm panel. 
Part II. Commissioning Plan-Design Phase

Appendix 2. Fire and Emergency Power Response

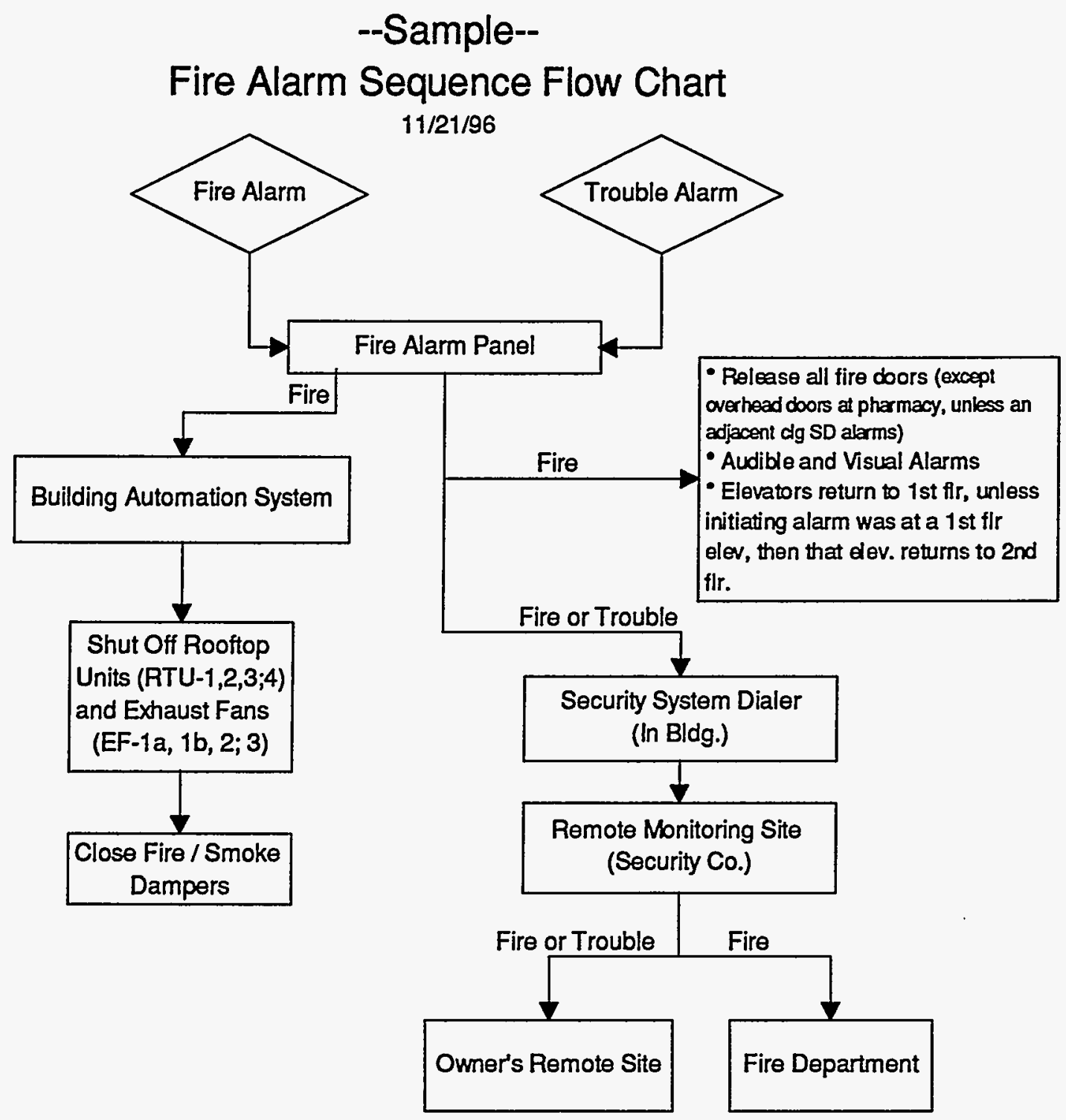

Fire Alarm includes any initiating event (pull station, space or duct smoke detector, heat dector or sprinkler flow). It does not include fire damper fusible link release of a fire damper. Heat detector in elevator equip. room or shaft has 30 sec.delay to allow recall to floors, then power to elevator is shunt-tripped off. Trouble Alarm includes any of the troubles listed in Appendix M of the FAP O\&M. 
Part II. Model Commissioning Plan-Design Phase

Appendix 3

\section{Part II}

\section{APPENDIX 3}

\section{Commissioning For Indoor Air Quality Checklist -Design Phase-}




\section{Commissioning For Indoor Air Quality Checklist}

\section{-Design Phase-}

\section{Program Phase}

Document the results from each of the following tasks:

1. Determine indoor air quality requirements in accordance with the initial design intent of the owner's needs. Codes, standards: ASHRAE Standard 62-1989, Ventilation for Acceptable Air Quality and Standard 55-1992 Thermal Environmental Conditions for Human Occupancy.

2. Identify the sources of outdoor pollutants in the vicinity of the building site: general ambient air quality, exhaust systems, nearby cooling towers, smoke stacks, and existing or proposed parking garages, etc.

3. Review expected occupant activity, density and locations where special attention is needed: kitchens and break rooms, smoking lounges, photocopy and print rooms, janitorial rooms, labs, material storage rooms, and conference rooms, etc. Review the need for exhaust systems or increased supply air capacity for each area, etc.

\section{Design Development and Construction Documents Phase}

Document the results from each of the following tasks:

1. Ensure that the indoor air quality objectives established in the programming phase are included in the design and are well documented in the design intent.

2. Establish the outdoor air intake requirements for each area of the building.

3. Establish procedures for verifying and documenting ventilation rates in each area.

4. Establish air flow rates for needed exhaust systems, including spot pollutant source removal.

5. Determine how adequate ventilation rates will be maintained during all occupied modes of operations, particularly during VAV terminal box turn-down.

6. Review air intakes and exhausts for short-circuiting.

7. Review exterior pollution sources such as garages, loading docks, and cooling towers.

8. Review the impact of the office partitions configurations with respect to ventilation effectiveness.

9. Review choice of filtration type and design, materials, and location.

10. Review HVAC material specifications and application regarding potential for airflow erosion, corrosion and microbial contamination (HVAC insulation materials, etc.).

11. Review air supply system components to ensure control and minimization of the presence of free water and to minimize microbial contamination (condensate trays, humidifiers, water baffles, mist eliminators and cooling towers). 
12. Verify the suitability of access doors and inspection ports to all chambers and components of air handling system plenums. Verify that proper cleaning of both sides of coils, condensate pans and/or humidifier reservoirs can be accomplished through the doors.

13. Optional: Examine manufacturer's safety data sheets (MSDS) for products specified in contract documents that may be suspected contributors to indoor pollutants (carpets, flooring, fabrics, adhesives, wall coverings, partitions, and ceilings; insulating and fire-proofing materials; sealants on walls and floors; use of preservatives, paints, varnishes, and other finish materials).

14. Obtain manufacturer's data on curing, drying and airing procedures to minimize emission rates.

15. Verify that the specifications specify proper methods and conditions for operating the HVAC system prior to full control and occupancy, to minimize dirt and unwanted moisture entering the duct work, coils, building cavities and any occupied portions of the building.

\section{Note:}

Indoor air quality (IAQ) commissioning does not ensure that indoor air quality will be adequate or without deficiency at building turnover or during occupancy, unless the owner has specifically specified that actual air quality testing be performed. Commissioning for indoor air quality entails performing tasks that minimize the potential for IAQ problems, but it does not eliminate their possibility.

The primary source for this checklist was Annex C in ASHRAE Guideline 1-1989R The HVAC Commissioning Process, Public Review Draft, 1996. 


\title{
Part III
}

\section{Commissioning Guide --Specifications--}

\author{
Sponsored by \\ US Department of Energy \\ Seattle Regional Support Office \\ 800 5th Ave. Suite 3950 \\ Seattle, WA 98104
}

\author{
Prepared by: \\ Portland Energy Conservation, Inc. (PECI) \\ 921 SW Washington, Suite 312 \\ Portland, OR 97205 \\ 503-248-4636, Fax 503-295-0820
}

Version 2.02

March 1997 


\section{Commissioning Guide Specifications}

\section{Overview}

\section{General Overview}

These commissioning guide specifications contain recommended language that describes both the requirements and the process to incorporate commissioning into larger construction or renovation projects. Significant process language is required because commissioning is new to many construction professionals. The specifications generally follow the ASHRAE document, The HVAC Commissioning Process, ASHRAE Guideline 1-1989R, final draft 1996, though significant additional detail, clarification and interpretation has been made.

The guide specifications are intended to be modified by the architect and design engineers (A/E) in consultation with the design phase commissioning agent, the project manager and the facility engineer, if known. The $\mathrm{A} / \mathrm{E}$ shall modify other specification sections as necessary to reflect commissioning requirements applicable to the current project.

Abbreviations are used in the Specifications and are defined in Section 01040 and 17100, Part 1.

\section{Management Scenarios}

The specifications were developed for the construction management protocols of GSA, Region 10, which include:

1. The construction manager (CM) is a subcontractor to the owner (GSA) and represents the owner in the day-to-day activities and job coordination for the entire construction project.

2. GSA's staff project manager (PM) manages the CM.

3. The A/E's role during construction consists of the basic services of submittal review and periodic site observation. The $\mathrm{A} / \mathrm{E}$ team is not significantly involved in performance verification or quality control. Therefore, its role in commissioning is limited to dealing with design and other problems identified during commissioning, attending selected commissioning team meetings, reviewing clarifications to the control sequences by the commissioning agent, reviewing selected functional test procedures, providing as-built design intent for the O\&M manuals, and presenting at the first owner personnel training.

Other notable management and process information:

1. The specifications are applicable to a variety of commissioning agent (CA) hiring scenarios: CA hired by the CM, directly by GSA, by the general contractor (GC) or by the $\mathrm{A} / \mathrm{E}$.

2. The $\mathrm{CA}$ is the person directly coordinating and directing all commissioning activities on a day-to-day basis.

3. If the $\mathrm{CA}$ is hired by the $\mathrm{GC}$ or $\mathrm{A} / \mathrm{E}$, the $\mathrm{CM}$ will verify that the $\mathrm{CA}$ is properly executing the commissioning as per specification. In this case the $\mathrm{CA}$ reports directly to the $\mathrm{CM}$. 
4. If the CA is hired by the CM or directly by GSA, the verification of the CA's commissioning work in (3) is eliminated.

5. The subcontractors (under the GC) direct, execute and document their own startup and initial checkout, incorporating the CA's prefunctional checklists and the CA's review comments of their start-up procedures.

6. The CA develops the functional testing procedures and the subcontractors execute them under the direction, observation and approval of the $\mathrm{CA}$. The $\mathrm{CA}$ documents the functional testing.

Specification Section 17100 provides some graphic illustrations of various management scenarios. Appropriate name substitutions can be made for the various parties involved, allowing the specifications to be applicable to other agencies or groups.

Test Engineer Scenario. There are guide specifications in the industry that use this scenario. These specifications do not. The following is a short explanation to prevent confusion. In the test engineer scenario, the contractor hires a test engineer who writes and executes the commissioning tests, etc. A person designated as the "commissioing agent" is hired by or is on the owner's staff. This commissioning agent is the line supervisor for the test engineer and acts as the owner's representative for commissioning issues. For comparison, the test engineer in the test engineer scenario, performs virtually all the tasks that the commissioning agent does under the Model Commissioning Plan and Guide Specifications. The commissioning agent in the test engineer scenario is analogous to the construction manager in the Model Plan and Specs. However, in the test engineer scenario, the commissioning agent must have considerably more commissioning experience than does the construction manager in the Model Plan and Specs scenario.

\section{Scope}

This draft of the commissioning specifications covers HVAC and automatic control systems for larger buildings. Future versions will cover electrical and other mechanical systems. However, Section 17100 describes the common requirements and processes that are applicable to all commissioned systems, not just HVAC and controls. The A/E can add systems to be commissioned without making any modifications to Section 17100, except for adding references to added systems. In general, these specifications assume that clear and complete design intent documentation was developed during the design phase. However, some language is included to handle cases when it is not.

\section{Specification Sections and Responsibilities}

The following describes the approach that was used to incorporate commissioning into the standard specification format.

1. The intent was to minimize redundancy and repetition whenever possible, and yet still have as many requirements for a given trade, in the trade's normal specification division and section. Specific commissioning requirements for a given trade are all listed in one place. However, the commissioning procedures to execute the requirements, many of which are common to all trades, are necessarily found in other sections. Cross references are used extensively to provide access to all procedures and requirements. 
2. In all divisions with requirements that relate to commissioning, there are references to the specific commissioning requirements in other divisions.

a. In Division 1, Section 00800, Suplementary Conditions, there is language providing a penalty for not completing commissioning on time.

b. In Section 01040, Coordination, there is an introduction to commissioning, the commissioning agent and a reference to Division 17.

c. Section 01300 Submittals, Section 01700 Project Close-out and Section 01730 O\&M Data also contain references to Division 17.

d. The trade sections of 15010 Mechanical General, Section 16010 Electrical General contain references to Division 17 and to the special commissioning sections within their respective divisions (15995; 16995).

3. The commissioning process details, the commissioning requirements that apply to all parties, and the specific responsibilities of the commissioning agent and non-trades, (construction and project manager) are included in a special Division 17, Commissioning.

4. A special commissioning section of Division 15, Section 15995 is used to specify common and specific commissioning requirements of all Division 15 contractors. In addition, the specific, unique responsibilities of Division 15 contractors are included in appropriate sections of Division 15 and 16 (e.g., 15950 controls, 15990 TAB).

5. Specific functional testing requirements are found in the Sections 15997 and 16997 , Mechanical and Electrical Testing Requirements.

6. Specific prefunctional checklists are found in Sections 15998 and 16998.

7. Sample functional test procedures are found in Sections 15999 and 16999.

The following lists the sections included in the commissioning $(\mathrm{Cx})$ guide specifications. Refer to Figure 1 for a graphical layout of the specification sections. A detailed table of contents is provided at the beginning of the major sections $(15995,17100)$.

00800 Supplementary Conditions Provides for a penalty if commissioning is not completed by the Functional Completion milestone.

* If the commissioning agent is hired by the owner or construction manager, 01040a applies:

01040a Coordination Introduces commissioning and refers to Division 17.

* If the commissioning agent is hired by the general contractor, $01040 \mathrm{~b}$ applies:

01040b Coordination

01300 Submittals

01700 Project Close-out

01730 O\&M Data
Introduces commissioning, refers to Division 17 and requires that the $\mathrm{GC}$ hire a qualified $\mathrm{CA}$.

Alerts all parties that additional detail in submittals may be required and directs to Division 17.

Defines Substantial Completion and Functional Completion milestones, relative to commissioning.

Alerts all parties that O\&M documentation may be more detailed and directs to Division 17. 
15010 Mechanical General

15950 Automatic Controls

$15990 \mathrm{TAB}$

15995 Mechanical Cx

15997 Mechanical Testing

Requirements

15998 Mechanical Prefunctional Checklists

15999 Mechanical Functional Tests-Examples

16010 Electrical General

16995 Electrical Cx

16997 Electrical Testing Requirements

16998 Electrical

16999 Electrical Functional Tests-Examples

17100 Commissioning
Alerts the mechanical contractor of $\mathrm{Cx}$ responsibilities in 15995.

Lists special requirements and alerts the controls contractor of the special requirements of the control contractor and control system in 15995.

Alerts the TAB of $\mathrm{Cx}$ responsibilities in 15995.

Describes the $\mathrm{Cx}$ responsibilities of the mechanical, controls and TAB contractors and the prefunctional testing and start-up responsibilities of each. Points to 15997 for functional testing requirements.

Describes the specific functional testing requirements Division 15 equipment in the project.

Provides the prefunctional checklists for use on this project, including items for Div. 15 and Div. 16.

Provides example functional test procedures and formats for mechanical equipment.

Alerts the electrical contractor of $\mathrm{Cx}$ responsibilities in 16995.

Describes the $\mathrm{Cx}$ responsibilities of the electrical contractor.

Describes the specific functional testing requirements for Division 16 equipment in the project.

Points to Section 15998 prefunctional checklists.

Provides example functional test procedures and formats for electrical equipment.

Describes the commissioning process, responsibilities common to all parties, responsibilities of the $\mathrm{A} / \mathrm{E}, \mathrm{CA}$, $\mathrm{CM}, \mathrm{PM}, \mathrm{GC}$ and Suppliers, focusing on the $\mathrm{CA}$. The unique mechanical contractor, controls contractor, $\mathrm{TAB}$ and electrical contractor responsibilities are included in Div. 15 and 16.

\section{Electronic Format}

All sections have been included as separate files on diskette in Word 6.0 for Windows 3.1 with the following file name format. The version number refers to the specific file or section version, not the entire Guide Specification version.

[ Section \#. Version \# ] For example: file 15995.V02 is Section 15995 Version 2.

A complete listing of files is found in the overview of the entire document prior to Part I (file: all_ovr.v10). 
Figure 1.

\section{Specification Structure}

\section{Division 1}

\begin{tabular}{|c:c:c:c:c|}
\hline $\begin{array}{c}00800 \\
\text { Suppl. } \\
\text { Conditions }\end{array}$ & 01040 & 01300 & 01700 & 01730 \\
\hline
\end{tabular}

Division 17

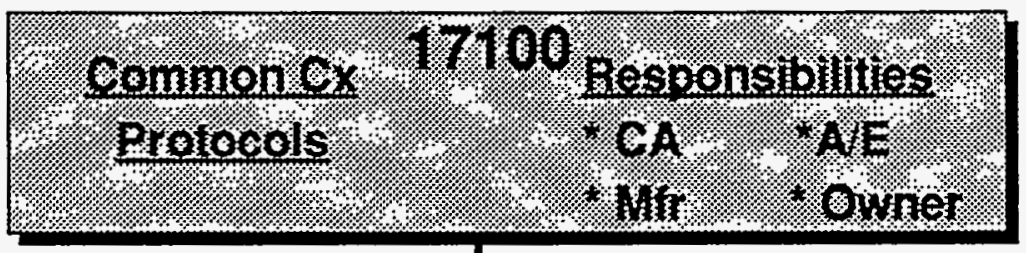

Division 15

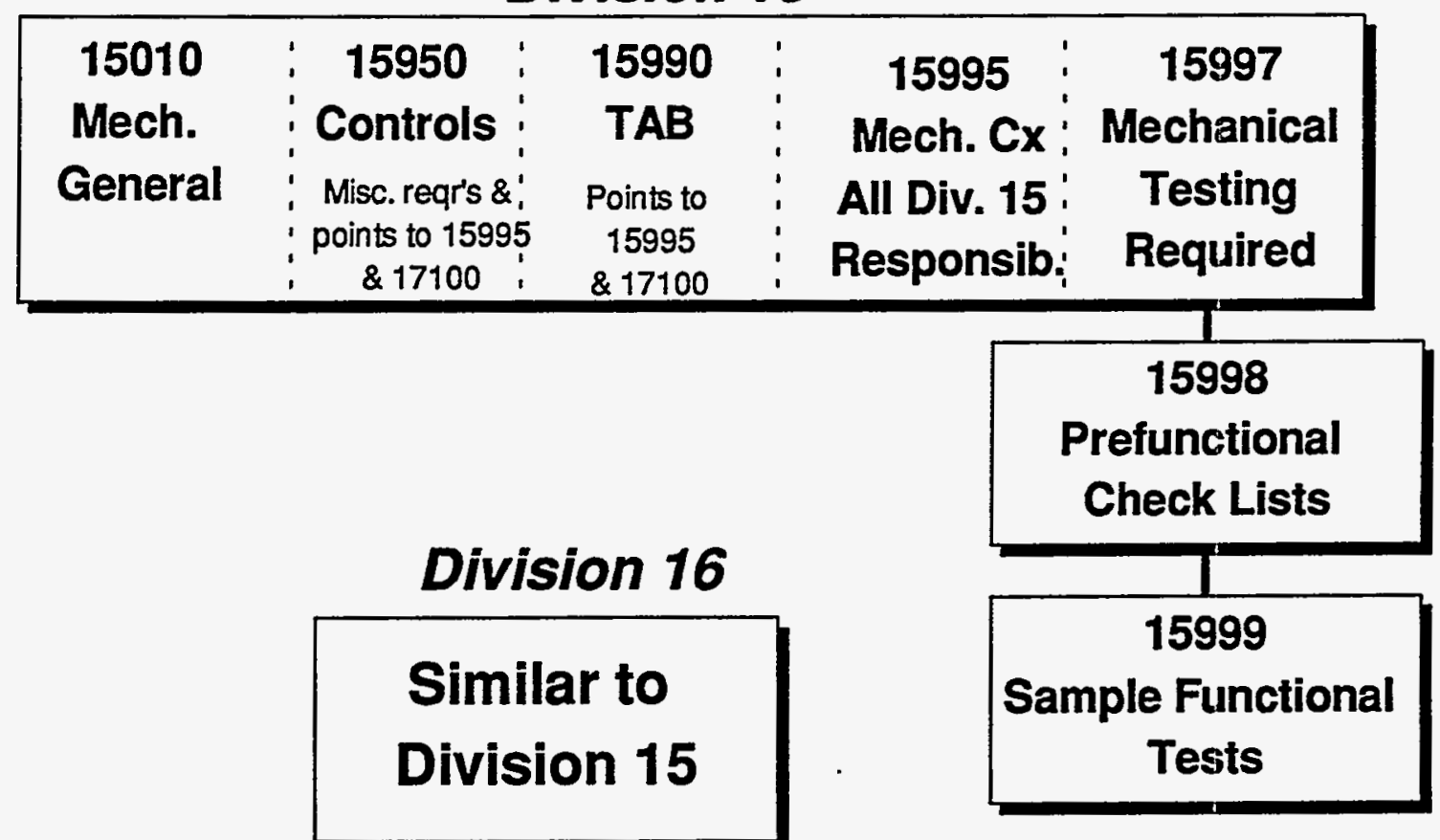




\section{COMMISSIONING GUIDE SPECIFICATIONS}

Spec writer:

\section{SECTION 00800 SUPPLEMENTARY CONDITIONS}

The following guide specifications are intended to be reviewed, modified and inserted into the noted specification section to meet the specific commissioning needs and requirements for the current project. Any modifications to these specifications shall only be made after consultation with the Owner's representative and with approval of the engineer of record. Where there are check boxes or fill-in blanks, fill in as appropriate and delete all but the cholce(s) that apply. Delete all direction boxes.

Frequently it is difficult enforce the requirement that the Contractor finish all their commissioning tasks prior to Substantial Completion. If this is not a practical stipulation, it then may be difficult to ever get the Contractor to finish all their commissioning responsibilities. Therefore:

To ensure that the commissioning is completed in a timely manner, and as an incentive for the

Contractor to complete the commissioning work, add a new milestone and apply liquidated damages to it. The milestone is called "Functional Completion," and is defined in Section 01700. Functional Completion is a specific time period (days), after Substantial Completion, when all remaining $T A B$ and commissioning responsibilities of the Contractor, (except for seasonal or approved deferred testing and controls training), must be completed or the stipulated liquidated damages will begin accruing.

Add language to this or other appropriate Section and that applies liquidated damages for not meeting the Functional Completion milestone.

\section{For example:}

There will be a $\$$ exceeded. per day penalty for every day that the Functional Completion milestone is

The inclusion of commissioning in the definition for Substantial Completion and the new term Functional Completion should also be included in the General Conditions of the construction contract.

\section{END OF GUIDE SPECIFICATION}




\section{COMMISSIONING GUIDE SPECIFICATIONS}

\section{SECTION 01040 \\ COORDINATION \\ COMMISSIONING AGENT AND GENERAL REQUIREMENTS}

Spec writer:

The following guide specifications are intended to be reviewed, modified and inserted into the noted specification section to meet the specific commissioning needs and requirements for the current project. Any modifications to these specifications shall only be made after consultation with the Owner's representative and with approval of the engineer of record. Where there are check boxes or fill-in blanks, fill in as appropriate and delete all but the cholce(s) that apply. Delete all direction boxes.

\section{THIS VERSION (A) OF THIS SECTION APPLIES WHEN THE COMMISSIONING AGENT IS} HIRED BY GSA'S CONSTRUCTION MANAGER OR DIRECTLY BY GSA

(The Commissioning Agent is the party personally directing the day-to-day commissioning activities)

Alert the Contractor that this project will be commissioned and that the Contractor will be responsible to carry out the execution of the commissioning process under the direction and approval of the Commissioning Agent.

Include the following section under PART 1 - GENERAL:

PART 1 - GENERAL

1.1. COMMISSIONING

A. This project will have selected building systems commissioned. The equipment and systems to be commissioned are specified in Section 17100, Part 1.4. The commissioning process, which the Contractor is responsible to execute, is defined in Division 17. The commissioning process will be directed by a Commissioning Agent whose services will be provided by GSA. 
B. Abbreviations. The following are common abbreviations used in the Specifications and in the Commissioning Plan. Definitions are found in Section 17100, Part 1.6.

A/E- Architect and design engineers

CA- Commissioning agent

CC- Controls contractor

CM- Construction Manager (GSA's representative)

Cx- Commissioning

Cx Plan- Commissioning Plan document

EC- Electrical contractor
FT- Functional performance test

GC- General contractor (prime)

MC- Mechanical contractor

PC- Prefunctional checklist

PM- Project manager (GSA, the Owner)

Subs- Subcontractors to General

TAB- Test and balance contractor

List the Commissioning Agent under the following section:

A. Commissioning Agent: GSA will provide the services of a qualified Commissioning Agent. The responsibilities of the Commissioning Agent are defined in Division 17. The Commissioning Agent directs and approves the commissioning work.

If the Test and Balancing Contractor (TAB) will be hired by someone other than the Owner, have the TAB qualifications submitted and approved by the Owner and refer to the requirement here, per the language below. Otherwise include wording that the Owner will provide the services of a qualified TAB contractor, similar to that for the Commissioning Agent above.

B. Test and Balance Contractor (TAB) Qualifications. The Contractor will provide the services of a qualified test and balance contractor, approved by the Owner, as specified in Section 15990.

C. Controls Contractor and Lead Technician Qualifications. The Control contractor and the lead technician shall be approved by the Owner as specified in Section 15950.

Though not directly applicable to this section, an important reminder is made here:

The Spec Writer should review any quality assurance sections, particularly 01400 , and make sure that any stock language about costs of testing being the Owner's responsibility are correctly reflected consistent with the commissioning specifications. 


\section{COMMISSIONING GUIDE SPECIFICATIONS}

\section{SECTION 01040 \\ COORDINATION \\ COMMISSIONING AGENT AND GENERAL REQUIREMENTS}

\section{Spec writer:}

The following guide specifications are intended to be reviewed, modified and inserted into the noted specification section to meet the specific commissioning needs and requirements for the current project. Any modifications to these specifications shall only be made after consultation with the Owner's representative and with approval of the engineer of record. Where there are check boxes or fill-in blanks, fill in as appropriate and delete all but the choice(s) that apply. Delete all direction boxes.

\section{THIS VERSION (B) OF THIS SECTION APPLIES WHEN THE COMMISSIONING AGENT IS HIRED BY THE GENERAL CONTRACTOR}

(The Commissioning Agent is the party personally directing the day-to-day commissioning activities)

Alert the Contractor that this project will be commissioned and that the Contractor will be responsible to carry out the execution of the commissioning process under the approval of the Owner's Construction Manager.

Include the following section under PART 1 - GENERAL:

PART 1 - GENERAL

\section{COMMISSIONING}

A. This project will have selected building systems commissioned. The equipment and systems to be commissioned are specified in Section 17100, Part 1.4. The commissioning process, which the Contractor is responsible to execute, is defined in Division 17. The commissioning process will be directed by a Commissioning Agent whose services will be provided by the Contractor. The commissioning will be approved by GSA's Construction Manager. 
B. Abbreviations. The following are common abbreviations used in the Specifications and in the Commissioning Plan. Definitions are found in Section 17100, Part 1.6.

A/E- Architect and design engineers

CA- Commissioning agent

CC- Controls contractor

CM- Construction Manager (GSA's Representative)

Cx- Commissioning

Cx Plan- Commissioning Plan document

EC- Electrical contractor
FT- Functional performance test

GC- General contractor (prime)

MC- Mechanical contractor

PC- Prefunctional checklist

PM- Project manager (GSA, the Owner)

Subs- Subcontractors to General

TAB- Test and balance contractor

Alert the Contractor that they will be responsible to provide the services of a qualified Commissioning Agent as follows:

\section{$1.2 \quad$ ADMINISTRATIVE / SUPERVISORY PERSONNEL}

A. Commissioning Agent: The Contractor will provide the services of a qualified Commissioning Agent. The responsibilities of the Commissioning Agent are defined in Division 17. The Commissioning Agent will report directly to the Owner's Construction Manager.

1. Commissioning Agent Qualifications: The Commissioning Agent will satisfy the following requirements:

The A/E should modify the requirements as appropriate for the complexity of the systems to be commissioned in this building.

List other systems that are being commissioned. If they are highly specialized (fume hoods, clean room, security, communications, etc.) state that two parties may be hired, with one acting as lead, to fulfill the expertise required.

a. Have extensive experience in the operation and troubleshooting of HVAC systems, energy management control systems and lighting controls systems. Extensive field experience is required. A minimum of ___ full years in this type of work is required.

b. Knowledgeable in test and balance of both air and water systems.

c. Direct experience in monitoring and analyzing system operation using energy management control system trending or stand-alone datalogging equipment.

d. Excellent verbal and written communication skills, highly organized and able to work with both management and trade contractors.

e. A bachelors degree in Mechanical Engineering is highly preferred and P.E. certification is desired, however, other technical training and past commissioning and field experience will be considered. 


\section{SECTION 01040 Version B - 3 COORDINATION \\ COMMISSIONING AGENT-GENERAL REQUIREMENTS}

f. The Commissioning Agent requirements cannot be fulfilled by the combined expertise of a company, but must be part of the skill and experience set of the one individual who will be the designated Commissioning Agent, unless specifically noted above.

g. The Commissioning Agent will be an independent contractor and not an employee of the General Contractor or any other subcontractor on this project, including the A/E.

h. The Commissioning Agent shall have been the prime commissioning agent for commissioning at least ___ facilities of ___ sf and similar complexity in system type in the last 5 years.

i. The Commissioning Agent will provide a detailed description of at least three commissioning projects completed recently with their personal involvement, the names and telephone numbers of the Owner's project manager and the general contractor's site superintendent.

Spec Writer: To make this section more rigorous, consider using all or parts of the commissioning agent RFP solicitation found in Part I, Appendix 1 of the Model Commissioning Plan and Guide Specifications.

2. The Contractor will submit, with the construction bid proposal, the CA's resume and qualifications to the CM, the GSA Project Manager and the A/E for approval. The Owner reserves the right to require the Contractor to submit another party for the position, in the event the first party submitted is considered unqualified for the project. Final approval will reside with the Project Manager.

Extend the duties of the $\mathrm{CM}$ to cover their $\mathrm{Cx}$ responsibilities under Administrative Personnel.

B. Construction Manager (CM): In general, the construction management services contractor is hired by GSA to assist the government in the overall management of the project including supervising and on-site managing authority over a project's construction. The General Contractor reports to the CM. A qualified member of the CM team acts for GSA and reviews and approves the work of the Commissioning Agent and commissioning team and witnesses selected tests, as well as performing tasks specified in Division 17. This member of the $\mathrm{CM}$ shall have significant mechanical engineering training and expertise and have extensive field experience in troubleshooting, inspecting HVAC systems, controls and lighting systems and

If the Test and Balancing Contractor (TAB) will be hired by someone other than the Owner, have the TAB qualifications submitted and approved by the Owner and refer to the requirement here, per the language below.

C. Test and Balance Contractor (TAB) Qualifications. The Contractor will provide the services of a qualified test and balance contractor, approved by the Owner, as specified in Section 15990. 


\section{SECTION 01040 Version B - 4 COORDINATION COMMISSIONING AGENT-GENERAL REQUIREMENTS}

D. Controls Contractor and Lead Technician Qualifications. The Control contractor and the lead technician shall be approved by the Owner as specified in Section 15950.

Though not directly applicable to this section, an important reminder is made here:

The Spec Writer should review any quality assurance sections, particularly 01400 , and make sure that any stock language about costs of testing being the Owner's responsibility are correctly reflected consistent with the commissioning specifications.

\section{END OF GUIDE SPECIFICATION SECTION}




\section{COMMISSIONING GUIDE SPECIFICATIONS}

\section{SECTION 01300 SUBMITTALS}

\section{Spec writer:}

The following guide spectications are intended to be reviewed, modified and inserted into the noted specification section to meet the specific commissioning needs and requirements for the current project. Any modifications to these specifications shall only be made after consultation with the Owner's representative and with approval of the engineer of record. Where there are check boxes or fill-in blanks, fill in as appropriate and delete all but the choice(s) that apply. Delete all direction boxes.

Inform the Contractor that additional information is required to be submitted to the Commissioning Agent beyond normal submittals and that the Commissioning Agent will be reviewing and approving the submittals.

The following wording is to be added to the normal Submittal specification text:

\subsection{SUBMITTAL REQUIREMENTS FOR COMMISSIONING}

A. Normal Submittals.

1. The Commissioning Agent will receive a copy of the normal submittals for equipment to be commissioned.

2. The Commissioning Agent will review and approve normal Contractor submittals applicable to systems being commissioned for compliance with commissioning needs, concurrent with the $\mathrm{A} / \mathrm{E}$ reviews.

B $\quad$ Data for Commissioning.

1. The Contractor will receive a written request from the Commissioning Agent requesting specific information needed about each piece of commissioned equipment or system.

2. Typically this will include detailed manufacturer installation and start-up, operating, troubleshooting and maintenance procedures, full details of any owner-contracted tests, fan and pump curves, full factory testing reports, if any, and full warranty information, including all responsibilities of the Owner to keep the warranty in force clearly identified. In addition, the installation and checkout materials that are actually shipped inside the equipment and the actual field checkout sheet forms to be used by the factory or field technicians shall be submitted to the Commissioning Agent.

3. The Commissioning Agent may request further documentation necessary for the commissioning process.

4. This data request may be made prior to normal submittals. 
5. Much of this information is contained in the regular O\&M manual submittals normally submitted in the project. Typically, this information is required prior to the regular formal O\&M manual submittals.

C. Contractor's responsibility for deviations in submittals from requirements of the Contract Documents is not relieved by the Commissioning Agent's review.

\section{END OF GUIDE SPECIFICATION SECTION}




\section{COMMISSIONING GUIDE SPECIFICATIONS}

Spec writer:

\section{SECTION 01700 PROJECT CLOSE-OUT}

The following guide specifications are intended to be reviewed, modified and inserted into the noted specification section to meet the specific commissioning needs and requirements for the current project. Any modifications to these speciflcations shall only be made after consultation with the Owner's representative and with approval of the engineer of record. Where there are check boxes or fill-in blanks, fill in as appropriate and delete all but the cholce(s) that apply. Delete all direction boxes.

Frequently it is difficult to enforce the requirement that the Contractor finish all their commissioning tasks prior to Substantial Completion. If this is not a practical stipulation, it then may be difficult to ever get the Contractor to finish all their commissioning responsibilities. Therefore:

To ensure that the commissioning is completed in a timely manner, and as an incentive for the

Contractor to complete the commissioning work, add a new milestone and apply liquidated damages to it (Section 00800). The milestone in this section called "Functional Completion." Functional Completion is a specific time period (days), after Substantial Completion, when all remaining $T A B$ and commissioning responsibilities of the Contractor, (except for seasonal or approved deferred testing and controls training), must be completed or the stipulated liquidated damages will begin accruing.

Inform the Contractor that all Commissioning in Div. 17 must be
completed, except for functional testing and controls training before Substantial Completion.

Under the prerequisites to Substantial Completion section, include the following:

\section{PREREQUISITES TO SUBSTANTIAL COMPLETION}

The commissioning of Division 17 must be complete, except for functional testing and controls training, prior to Substantial Completion, unless approved in writing by the Owner's Project Manager.

The definition for Substantial Completion should also be added to the appropriate section of the General Conditions of the construction contract. 
Inform the Contractor that all Commissioning in Div. 17 must be completed before Functional Completion, except for seasonal or approved deferred testing and controls training.

Under the prerequisites to Functional Completion section, include the following:

\section{PREREQUISITES TO FUNCTIONAL COMPLETION}

A. All TAB work and the commissioning of Division 17 must be complete prior to Functional Completion, unless approved in writing by the Owner's Project Manager. Exceptions to this are the planned control system training performed after occupancy and any required seasonal or approved deferred testing.

1. The Owner's Project Manager will determine the date of Functional Completion after reviewing the Commissioning Agent's recommendation for Functional Completion.

The definition for Functional Completion should also be added to the appropriate section of the General Conditions of the construction contract.

END OF GUIDE SPECIFICATION 


\section{COMMISSIONING GUIDE SPECIFICATIONS}

\section{SECTION 01730 \\ OPERATIONS AND MAINTENANCE DATA}

Spec writer:

The following guide specifications are intended to be reviewed, modified and inserted into the noted specification section to meet the specific commissioning needs and requirements for the current project. Any modifications to these specifications shall only be made after consultation with the Owner's representative and with approval of the engineer of record. Where there are check boxes or fill-in blanks, fill in as appropriate and delete all but the choice(s) that apply. Delete all direction boxes.

In an appropriate Section, alert Division 1 that they will be responsible for additional O\&M documentation according to Section 17100.

A. The commissioning process requires detailed O\&M documentation. Division 1 is alerted to the O\&M documentation requirements identified in this section, in Section 17100 and other referenced sections.

B. The commissioning agent's contribution to the O\&M manuals is found in Section 17100 .

Following are minimum requirements for O\&M manuals. This wording or other wording requiring equal or greater detail should be included and merged with the other O\&M manual requirements in Division 1. Using the ASHRAE guideline: Preparation of O\&M Documentation for Building Systems, 1993 is highly recommended.

This is not intended to be the full text for the specification section on O\&M manual preparation. Additional parts dealing with submittal and review of the manuals and sections on materials and finishes manuals, etc. must still be covered.

Wording about reviews should take into account the review by the commissioning agent as described in Section 17100.

C. The _ GC, _ A/E shall compile O\&M manuals for every piece of equipment and building operating or electrical system with the following format.

1. Quantity:

2. Format: $8 \overline{1 / 2 " \times 11^{\prime \prime}}$ loose leaf binders. Each binder shall be clearly labeled on the spine. Use as many as required. Do not overload binders. There shall be dividers with permanently marked tabs of card stock separating each section and sub section. Tab labels shall not be handwritten.

3. There shall be a title page and table of contents in the front of each binder for each binder's contents. In each binder, there shall be a main tab for each specification section. Behind the 
section number tab there shall be the equipment ID tag sub-tab for each piece of major equipment (or group, if small or numerous). These sub-tabs shall be similar to the specification number tabs but of a different color. Behind each equipment name tab shall be the following sections, in the given order, divided by a double weight colored sheet labeled with the title of the section.

a. Contractor. The first page behind the equipment tab shall contain the name, address and telephone number of the manufacturer and installing contractor and the 24-hour number for emergency service for all equipment in this section, identified by equipment.

b. Submittal and Product Data. This section shall include all approved submittal data, cut sheets and appropriate shop drawings. If submittal was not required for approval, descriptive product data shall be included.

c. Operation and Maintenance Instructions. These shall be the written manufacturer's data with the model and features of this installation clearly marked and edited to omit reference to products or data not applicable to this installation. This section shall include data on the following:

1. Installation, startup and break-in instructions

2. All starting, normal shutdown, emergency shutdown, manual operation, seasonal changeover and normal operating procedures and data, including any special limitations.

3. $O \& M$ and installation instructions that were shipped with the unit.

4. Preventative maintenance and service procedures and schedules.

5. Troubleshooting procedures.

6. A parts list, edited to omit reference to items which do not apply to this installation.

7. A list of any special tools required to service or maintain the equipment.

8. Performance data, ratings and curves.

9. Warranty, which clearly lists conditions to be maintained to keep warranty in effect and conditions that would affect the validity of the warranty.

10. Any service contracts issued.

d. Supplemental Data. Prepare written text and/or special drawings to provide necessary information, where manufacturer's standard printed data is not available and information is necessary for a proper understanding and operation and maintenance of equipment or systems, or where it is necessary to provide additional information to supplement data included in the manual or project documents.

e. Control Drawings. Include the control drawings for the piece of equipment and its components, including the sequence of operation. This section will be provided by the controls contractor. The drawings will be repeated in the control contractor's O\&M submittals.

The above are considered a minimum standard. Items $\mathrm{f}-\mathrm{i}$ should also be considered.

f. Specifications. This section is comprised of the component or system specification section copied and inserted complete with all addenda. 
g. System Description. This section shall include the individual equipment portion of the overall system Design Documentation Narrative, if available. It will contain simplified professionally drawn single line system diagrams on $81 / 2 \times 11$ or $11 \times 17$ sheets, if the system's control drawing is not adequate.

h. Preventive Maintenance Instructions. This section shall include condensed typewritten excerpts from the manufacturer's written instructions for weekly, monthly, quarterly, annual, etc. maintenance. This summary shall be prepared by the HVAC mechanical contractor with help from the equipment supplier. It shall be prepared for all items listed under condensed operating instructions (below), plus package, window or through the wall $\mathrm{AC}$ units and electric unitary heating equipment.

\section{Below is an Option for $(\mathrm{h}$.}

h. Preventive Maintenance Instructions. This section shall include a list of the location by $O \& M$ document name and page number of the any preventative maintenance instructions applicable to this piece of equipment.

Spec writer:

The following requirement of condensed operating instructions is rarely implemented. Don't include it, unless you really want it, as the commissioning agent will not let it slip by and not be done, if it is specified. If condensed instructions are used, they should be inserted just after the Contractors' listing.

i. Condensed Operating Instructions, This section shall include condensed instructions for start-up, shut-down, emergency operation, safety precautions, unusual features and troubleshooting suggestions. Where control is clearly covered in controls description, it is not to be duplicated here.

In addition, a copy of these instructions shall be clearly laminated and secured adjacent to the equipment where it can be easily read by operating personnel. These instructions shall be provided for boilers, furnaces, chillers, pumps, heat rejection equipment, large air handling units (greater than 10 tons), heat pump systems, control system, air compressors and dryers.

4. Controls and Test and Balance (TAB) O\&M Manuals. The controls contractor and TAB contractor have special O\&M manual preparation requirements in Section 15995 that shall be merged with those of this section.

5. Architect and Design Engineers' Contributions. The architect and design engineers have special contributions to the O\&M manuals as described in Section 17100.

6. Commissioning Record and Testing Data. There will be a separate manual dedicated to documenting the commissioning process which will include all certifications and testing data and some repeating of O\&M data. Description of this manual is found in Section 17100 and shall be prepared by the commissioning agent.

\section{END OF GUIDE SPECIFICATION SECTION}




\section{COMMISSIONING GUIDE SPECIFICATIONS}

\section{SECTION 15010 \\ MECHANICAL-GENERAL PROVISIONS}

Spec writer:

The following guide specifications are intended to be reviewed, modified and inserted into the noted specification section to meet the specific commissioning needs and requirements for the current project. Any modifications to these specifications shall only be made after consultation with the Owner's representative and with approval of the engineer of record. Where there are check boxes or fill-in blanks, fill in as appropriate and delete all but the choice(s) that apply. Delete all direction boxes.

In an appropriate section, alert Division 15 that they will be responsible for commissioning according to Section 15995, 17100 and other referenced sections.

A. Division 15 will be responsible to carry out the commissioning requirements specified in Section 15995,17100 and other sections referenced in 17100 .

END OF GUIDE SPECIFICATION SECTION 


\section{COMMISSIONING GUIDE SPECIFICATIONS}

\section{SECTION 15950 AUTOMATIC CONTROLS}

\section{Spec writer:}

The following guide specifications are intended to be reviewed, modified and inserted into the noted specification section to meet the specific commissioning needs and requirements for the current project. Any modifications to these speciflcations shall only be made after consultation with the Owner's representative and with approval of the engineer of record. Where there are check boxes or fill-in blanks, fill in as appropriate and delete all but the choice(s) that apply. Delete all direction boxes.

In Part 1 - GENERAL, include the following text about quality assurance and commissioning and qualification of the controls manufacturer and lead installing technician.

\subsection{COMMISSIONING AND QUALITY ASSURANCE}

A. Quality Assurance. Quality assurance for automatic controls systems shall be accomplished through the commissioning process consisting of submittal review of system engineering work, documented prefunctional testing and initial checkout, documented functional performance testing, operator training and $0 \& M$ documentation. In addition there will be a qualification procedure for the manufacturer and lead installation technician.

B. Related Sections. The general commissioning process procedures and requirements are given in Section 17100 with responsibilities unique to Division 15 included in Section 15995, including O\&M manual documentation and training requirements. The common process requirements for initial system checkout are found in Section 17100. Specific functional testing requirements are identified in Section 15997. Specific prefunctional checklists are found in Section 15998 and sample functional test procedure formats are found in Section 15999.

\subsection{QUALIFICATION OF MANUFACTURER AND LEAD INSTALLING TECHNICIAN}

A. Manufacturer and Vendor. Within 14 days after notice to proceed, the controls contractor shall submit to the GC, CM and PM a certified statement, signed by an officer of the manufacturer and vendor which includes the following: name and address of company; name, address and telephone number of the local representative; a general sales bulletin covering the full line of products manufactured; a certification that the products proposed for this contract have been in continuous and successful use for at least 1 year, not including beta testing, and general information covering the functions and characteristics of the systems proposed. In addition, provide a list of four projects which the vendor has installed that are similar in size and complexity to this contract, with the name and telephone number of the contracting officer and facility administrator, size of project, location and brief description and date of completion. 


\section{SECTION $15950-2$ \\ AUTOMATIC CONTROLS}

B. Lead Installation Technician (LIT). The automatic controls will be installed under the direct and continuous supervision of a lead technician authorized by the manufacturer. Within 14 days after notice to proceed, the controls contractor shall submit the following regarding the LIT: name; address; telephone number; list of two projects of similar size and complexity to this contract which were directly supervised by the LIT; and for each project the project name, location, description, cost, name and telephone number of the contracting officer and current facility administrator and date of completion. A replacement to the LIT must be approved in writing by the Owner.

C. Acceptance. A review of the qualifications and action upon the acceptance of the manufacturer and the LIT will be completed by the Owner. If the manufacturer, the proposed product line or the qualifications of the LIT are not in accordance with the Contract Documents or, in the opinion of the Owner, will not result in a satisfactory completed product, alternatives must be submitted for approval.

Under PART 2 - PRODUCTS, provide requirements for trend logging capabilities of the system which will aid in the commissioning process and the operation and maintenance of the building.

\subsection{TREND LOGGING CAPABILITIES}

A. The control system installed shall be capable of, and set up to readily trend data with the following minimum features.

1. At least six columns of data can be viewed on the screen at once and can be graphed using a graphing program integral to the control system, with at least six parameters graphed against time on the same graph. The columnar format shall have time down the left column with columns of data to the right (one column for each parameter).

2. Without any special or difficult conversions, this data shall be able to be storable as an ASCII delimited file in the same columnar format for use in graphing with normal commercial spreadsheet software.

3. The trend log data is automatically downloaded at appropriate intervals onto the hard drive when space in the central computer or field cabinets becomes full, so that no data is lost. This is done without the user having to calculate the size of the trends and download frequency.

4. Any limitations in the trending as to speed of sampling vs number of sampled points in a given trend, and the effect on actual sampling rate and simultaneousness of the sampling across parameters shall be clearly explained in writing. Programming and trending setup examples of all representative situations shall be provided.

5. The trends shall be capable of being set up to start sampling all trended points in a given trend or group of trends at the same exact time.

6. Specifications for standard trends shall be able to be set up by the user and be saved by a name and initiated by only recalling the name. The control contractor shall assist the operators in setting up at least six standard trends during training.

7. Ideal, but not required, shall be the capability to graph with the control system software, one or more points against another, rather than just against time.

8. Trending features shall be capable of easily monitoring the parameter value both on a time basis and on a change-of-state basis. 
9. A key for the names and definitions of all point abbreviations (both physical and virtual) shall be provided.

Under PART 2 - PRODUCTS, require that if there is a significant difference in update time the controls contractor provide a temporary second programming and testing terminal through the entire TAB and commissioning process for text format (no graphics) to speed up the point readout updating time.

\subsection{TEMPORARY PROGRAMMING AND TESTING TERMINAL}

A. If the permanent terminal and display is graphical for viewing values and setpoints, and the update time for the graphical display is considered by the CA to be too slow, the controls contractor shall provide and set up, during the entire functional testing process, a second input and output terminal with a text based format (in addition to the graphics-capable permanent terminal), which will significantly speed up the point readout update time. Both terminals will be simultaneously active.

Require that the system be capable of making global commands, which simplifies the TAB and commissioning processes and operation of the building.

\subsection{GLOBAL COMMAND CAPABILITY}

A. The system shall be capable of executing from the central control terminal, temporary or permanent global commands, such as a change in space temperature setpoint.

Under PART 2 - PRODUCTS, provide requirements for including additional control points for commissioning and better operation of the system over time.

The AVE and the design phase CA should review this list and determine which points should be included in this project (including any not listed). TAB and commissioning costs will be lower when appropriate additional points are included, and the troubleshooting process for the building operators will be improved. It is not assumed that all those points listed are needed. The value of any given point is dependent on the equipment and system, the expertise of the operating staff to make use of the points, the size of the equipment, etc. Those marked with an asterisk $\left(^{*}\right)$ are considered generally more valuable by the author.

\subsection{COMMISSIONING AND MONITORING POINTS}

A. All control points of the central building automation system, required to automatically control the equipment specified in the Contract Documents and to execute all specified control sequences, shall be installed and be able to be monitored. To simplify TAB and commissioning of the systems and to provide better control during occupancy, the following points shall be provided as monitored points in the control system, even if they are part of equipment integral controls, or are not required 
in any control sequence or intermediate calculation. Some points may be measured values or output signals, while others may be calculated or virtual points. Many points listed below may already be required to control the equipment.

\section{Chiller System}

*Primary CHW supply flow (gpm)

*Primary pump status

*Percentage of load on chiller

KW of chiller

$\mathrm{KW} /$ ton (instantaneous value)

*Secondary CHW supply flow (gpm)

*Secondary pump status

System load (calculation from temperature difference and $\mathrm{gpm}$ )

*Secondary pump rpm or $\mathrm{Hz}$

*Return CHW temperature

*Supply CHW temperature

*Alarm

Cooling Tower

*Tower status (lead, lag, etc.)

*Fan step status, current or speed

Damper status

Spray pump status

*Leaving water temperature

*Entering water temperature

*Bypass valve position

*Condenser pump status

Condenser pump current

Sump level

*Alarm (low water, fan vibration)

Boiler System

Primary HW supply flow (gpm), if no secondary

*Primary pump status

*Lead/lag status of boiler

Firing rate status (high/low)

*Primary HW return temperature

*Primary HW supply temperature

Secondary HW supply flow (gpm)

Secondary HW return temperature

System load (calculation from temperature difference and gpm)

*Secondary pump rpm or $\mathrm{Hz}$

*Boiler in alarm

*3 way mixing valve position

Air Handler Units (AHUs) of 100 tons capacity or greater

Supply Fan

*Discharge static pressure 
*Flow at discharge (cfm)

*Supply fan rpm or $\mathrm{Hz}$ if on VFD, else vane or vane-axial blade position or current

*Mixed air temperature (unless a tight packaged unit where a good mixed air reading is difficult)

* Cooling coil leaving air temperature

*Heating coil leaving air temperature

* Supply air temperature

*Return air temperature

* Outside air temperature

*Mixed air damper position

*Return air damper position

*Exhaust or relief damper position, optional

*Outside air dampers position (min. damper and economizing damper)

Leaving RH

Inside RH

Outside RH

*Cooling coil valve position

*Heating coil valve position

Coil CHW supply temperature

*Coil CHW return temperature

Coil HW supply temperature

*Coil HW return temperature

*Duct static pressure

Return Fan/Relief Fan (associated with AHUs of 100 tons capacity or greater)

Flow near inlet

*Return fan rpm or $\mathrm{Hz}$, if on VFD or current

*Relief damper and return damper position, optional

Flow of minimum outside air (OSA), if varies with VAV boxes

$\mathrm{CO}_{2}$ sensor for OSA control

*Building static, if control point

Air Terminal Units

*Flow (primary)

*Percentage of design flow cooling

*Percentage of design flow heating

*Reheat fan status

Supply air temperature to zone

*Zone space temperature

*Reheat valve position

The Spec Writer should specify all additional monitoring points desired for all systems in the project.

Air Handler Units (AHUs) of less than 100 tons capacity

Packaged Rooftop Units (RTUs) greater than or equal to 100 tons capacity 
Packaged Rooftop Units (RTUs) less than 100 tons capacity

Computer Room AC Units

Spot AC Units (greater than 1.5 ton)

Spot Unit Heaters (greater than 1.5 ton)

Elevator Shaft Fans

Stairwell Fans

Restroom Central Exhaust Fans

Garage Exhaust Fans

Emergency Generator

Domestic Hot Water Systems

(boiler, HW heaters, leaving temp, recirc pumps)

Domestic Water Booster Pump

Sewage Ejector

Fire Alarm Interface

Lighting and Controls

\subsection{TEST PORTS}

A. The controls contractor shall provide test ports for handheld instrument readings near all piping system sensors in the primary system (not at the zone level).

\subsection{GAGES}

A. The controls contractor shall provide gages in the following locations, even if included as a sensor and monitored point in the control system:

1. Pressure gages on both sides of all pumps greater than $1 \mathrm{hp}$.

2. Mercury thermometers in the return and supply of all primary thermal plant equipment (chillers, cooling towers, boilers, converters, etc.).

In PART 3 - EXECUTION (or in Part 1), include a reference to the submittal requirements related to commissioning in other sections and to the submission of qualification data.

\subsection{SUBMITTALS}

A. The controls contractor shall submit the manufacturer and lead installation technician data according to Part 1 of this section. Upon acceptance, proceed with shop drawings and other submittal data.

B. The controls contractor shall follow the other submittal requirements in Section 15995, 01300 and 17100.

\section{END OF GUIDE SPECIFICATION SECTION}




\section{COMMISSIONING GUIDE SPECIFICATIONS}

\section{SECTION 15990 TEST, ADJUST AND BALANCE}

\section{Spec writer.}

The following guide specifications are intended to be reviewed, modified and inserted into the noted specification .. section to meet the specific commissioning needs and requirements for the current project. Any modifications to these specifications shall only be made after consultation with the Owner's representative and with approval of the engineer of record. Where there are check boxes or fill-in blanks, fill in as appropriate and delete all but the choice(s) that apply. Delete all direction boxes.

In an appropriate section, alert TAB that they will be responsible for commissioning according to Section 15995, 17100 and other sections referenced in 17100.

A. TAB will be responsible to carry out the commissioning requirements specified in Section 15995 , 17100 and other sections referenced in 17100 .

If the Test and Balancing Contractor (TAB) will be hired by someone other than the Owner, have the TAB qualifications submitted and approved by the Owner.

\section{1._ QUALIFICATIONS OF TAB CONTRACTOR AND LEAD TECHNICIAN}

A. The Contractor will provide the services of a qualified test and balance contractor. The qualifications of the TAB contracting firm shall be submitted, along with the specific qualifications of the lead site technician who will remain on site during all TAB work, within days of notice to proceed. Recent projects shall be listed and described for both the company and the lead technician. Names and telephone numbers of the project contractors and facility managers will be provided.

D. The Owner must approve in writing the qualifications of both the company and the lead technician.

The AVE should modify the TAB requirements to be appropriate for the complexity of the systems to be installed in this building.

\section{END OF GUIDE SPECIFICATION SECTION}




\section{COMMISSIONING GUIDE SPECIFICATIONS}

\section{SECTION 15995 MECHANICAL SYSTEMS COMMISSIONING}

\section{Spec writer:}

The following guide specifications are intended to be reviewed, modified and inserted into the noted specification section to meet the speciflc commissioning needs and requirements for the current project. Any modifications to these specifications shall only be made after consultation with the Owner's representative and with approval of the engineer of record. Where there are check boxes or fill-in blanks, fill in as appropriate and delete all but the choices that apply. Delete all direction boxes.

TABLE OF CONTENTS (with selected subheadings)

1.1 Description

1.2 Responsibilities

A. All Division 15 Contractors (Mechanical, Controls and TAB)

B. Mechanical Contractor

C. Controls Contractor

1. Sequences of Operations Submittal

2. Controls Drawings Submittal

3. As-builds

4. Required Assistance to TAB

5. Required Assistance to the CA

6. Written Agenda

7. Checkout Certification

8. Additional Control Points

D. TAB Contractor

E. Mechanical Designer

1.3 Related Work

2.1 Test Equipment

3.1 Submittals

3.2 Startup

3.3 TAB

3.4 Functional Performance Tests

3.5 Testing Documentation, Non-Conformance and Approvals

3.6 Operation and Maintenance Manuals

D. Special Control System O\&M Manual Requirements

3.7 Training of Owner Personnel

C. Mechanical Contractor

D. Controls Contractor

E. TAB Contractor

3.8 Deferred Testing

3.9 Written Work Products 
PART 1 - GENERAL

\subsection{DESCRIPTION}

A. The purpose of this section is to specify Division 15 responsibilities in the commissioning process.

B. The systems to be commissioned are listed in Section 17100.1.7.

C. Commissioning requires the participation of Division 15 to ensure that all systems are operating in a manner consistent with the Contract Documents. The general commissioning requirements and coordination are detailed in Division 17. Division 15 shall be familiar with all parts of Division 17 and the commissioning plan issued by the CA and shall execute all commissioning responsibilities assigned to them in the Contract Documents.

\subsection{RESPONSIBILITIES}

A. Mechanical, Controls and TAB Contractors. The commissioning responsibilities applicable to each of the mechanical, controls and TAB contractors of Division 15 are as follows (all references apply to commissioned equipment only):

\section{Construction and Acceptance Phases}

1. Include and itemize the cost of commissioning in the contract price.

2. In each purchase order or subcontract written, include requirements for submittal data, commissioning documentation, O\&M data and training.

3. Attend a commissioning scoping meeting and other meetings necessary to facilitate the $\mathrm{Cx}$ process.

4. Contractors shall provide the CA with normal cut sheets and shop drawing submittals of commissioned equipment.

5. Provide additional requested documentation, prior to normal O\&M manual submittals, to the CA for development of start-up and functional testing procedures.

a. Typically this will include detailed manufacturer installation and start-up, operating, troubleshooting and maintenance procedures, full details of any owner-contracted tests, fan and pump curves, full factory testing reports, if any, and full warranty information, including all responsibilities of the Owner to keep the warranty in force clearly identified. In addition, the installation, start-up and checkout materials that are actually shipped inside the equipment and the actual field checkout sheet forms to be used by the factory or field technicians shall be submitted to the Commissioning Agent.

b. The Commissioning Agent may request further documentation necessary for the commissioning process.

c. This data request may be made prior to normal submittals.

The above information about special commissioning submittals is repeated in Section 01300. Maintain consistency.

6. Provide a copy of the O\&M manuals and submittals of commissioned equipment, through normal channels, to the CA for review and approval. 
7. Contractors shall assist (along with the design engineers) in clarifying the operation and control of commissioned equipment in areas where the specifications, control drawings or equipment documentation is not sufficient for writing detailed testing procedures.

8. Provide limited assistance to the $\mathrm{CA}$ in preparing the specific functional performance test procedures as specified in Section 15997. Subs shall review test procedures to ensure feasibility, safety and equipment protection and provide necessary written alarm limits to be used during the tests.

9. Develop a full start-up and initial checkout plan using manufacturer's start-up procedures and the prefunctional checklists from the CA for all commissioned equipment. Submit to CA for review and approval prior to startup. Refer to Section 17100 for further details on start-up plan preparation.

10. During the startup and initial checkout process, execute the mechanical-related portions of the prefunctional checklists for all commissioned equipment.

11. Perform and clearly document all completed startup and system operational checkout procedures, providing a copy to the $C A$.

12. Address current $\mathrm{A} / \mathrm{E}$ punch list items before functional testing. Air and water TAB shall be completed with discrepancies and problems remedied before functional testing of the respective air- or water-related systems.

13. Provide skilled technicians to execute starting of equipment and to execute the functional performance tests. Ensure that they are available and present during the agreed upon schedules and for sufficient duration to complete the necessary tests, adjustments and problemsolving.

14. Perform functional performance testing under the direction of the $\mathrm{CA}$ for specified equipment in Section 15997 and 17100. Assist the CA in interpreting the monitoring data, as necessary.

15. Correct deficiencies (differences between specified and observed performance) as interpreted by the $\mathrm{CA}, \mathrm{CM}$ and $\mathrm{A} / \mathrm{E}$ and retest the equipment.

16. Prepare O\&M manuals according to the Contract Documents, including clarifying and updating the original sequences of operation to as-built conditions.

17. Prepare red-line as-built drawings for all drawings and final as-builds for contractor-generated coordination drawings.

18. Provide training of the Owner's operating personnel as specified.

19. Coordinate with equipment manufacturers to determine specific requirements to maintain the validity of the warranty. 


\section{SECTION $15995-4$ \\ MECHANICAL SYSTEMS COMMISSIONING}

\section{Warranty Period}

1. Execute seasonal or deferred functional performance testing, witnessed by the $\mathrm{CA}$, according to the specifications.

2. Correct deficiencies and make necessary adjustments to $O \& M$ manuals and as-built drawings for applicable issues identified in any seasonal testing.

B. Mechanical Contractor. The responsibilities of the HVAC mechanical contractor, during construction and acceptance phases in addition to those listed in (A) are:

1. Provide startup for all HVAC equipment, except for the building automation control system.

2. Assist and cooperate with the TAB contractor and CA by:
a. Putting all HVAC equipment and systems into operation and continuing the operation during each working day of TAB and commissioning, as required.
b. Including cost of sheaves and belts that may be required by TAB.
c. Providing test holes in ducts and plenums where directed by TAB to allow air measurements and air balancing. Providing an approved plug.
d. Providing temperature and pressure taps according to the Construction Documents for $\mathrm{TAB}$ and commissioning testing.

3. Install a $\mathrm{P} / \mathrm{T}$ plug at each water sensor which is an input point to the control system.

4. List and clearly identify on the as-built drawings the locations of all air-flow stations.

5. Prepare a preliminary schedule for Division 15 pipe and duct system testing, flushing and cleaning, equipment start-up and TAB start and completion for use by the $\mathrm{CA}$. Update the schedule as appropriate.

6. Notify the CM or CA depending on protocol, when pipe and duct system testing, flushing, cleaning, startup of each piece of equipment and TAB will occur. Be responsible to notify the $\mathrm{CM}$ or $\mathrm{CA}$, ahead of time, when commissioning activities not yet performed or not yet scheduled will delay construction. Be proactive in seeing that commissioning processes are executed and that the $\mathrm{CA}$ has the scheduling information needed to efficiently execute the commissioning process.

C. Controls Contractor. The commissioning responsibilities of the controls contractor, during construction and acceptance phases in addition to those listed in (A) are:

1. Sequences of Operation Submittals. The Controls Contractor's submittals of control drawings shall include complete detailed sequences of operation for each piece of equipment, regardless of the completeness and clarity of the sequences in the specifications. They shall include:
a. An overview narrative of the system (1 or 2 paragraphs) generally describing its purpose, components and function.
b. All interactions and interlocks with other systems.
c. Detailed delineation of control between any packaged controls and the building automation system, listing what points the BAS monitors only and what BAS points are control points and are adjustable.
d. Written sequences of control for packaged controlled equipment. (Equipment manufacturers' stock sequences may be included, but will generally require additional narrative).
e. Start-up sequences.
f. Warm-up mode sequences.
g. Normal operating mode sequences. 
h. Unoccupied mode sequences.

i. Shutdown sequences.

j. Capacity control sequences and equipment staging.

k. Temperature and pressure control: setbacks, setups, resets, etc.

1. Detailed sequences for all control strategies, e.g., economizer control, optimum start/stop, staging, optimization, demand limiting, etc.

m. Effects of power or equipment failure with all standby component functions.

n. Sequences for all alarms and emergency shut downs.

o. Seasonal operational differences and recommendations.

p. Initial and recommended values for all adjustable settings, setpoints and parameters that are typically set or adjusted by operating staff; and any other control settings or fixed values, delays, etc. that will be useful during testing and operating the equipment.

q. Schedules, if known.

r. All sequences shall be written in small statements, each with a number for reference. For a given system, numbers will not repeat for different sequence sections, unless the sections are numbered.

2. Control Drawings Submittal

a. The control drawings shall have a key to all abbreviations.

b. The control drawings shall contain graphic schematic depictions of the systems and each component.

c. The schematics will include the system and component layout of any equipment that the control system monitors, enables or controls, even if the equipment is primarily controlled by packaged or integral controls.

d. Provide a full points list with at least the following included for each point:

1) Controlled system

2) Point abbreviation

3) Point description

4) Display unit

5) Control point or setpoint (Yes / No)

6) Monitoring point (Yes / No)

7) Intermediate point (Yes / No)

8) Calculated point (Yes / No)

Key:

Point Description: DB temp, airflow, etc.

Control or Setpoint: Point that controls equipment and can have its setpoint changed (OSA, SAT, etc.)

Intermediate Point: Point whose value is used to make a calculation which then controls equipment (space temperatures that are averaged to a virtual point to control reset).

Monitoring Point: Point that does not control or contribute to the control of equipment, but is used for operation, maintenance, or performance verification. Calculated Point: "Virtual" point generated from calculations of other point values.

The Controls Contractor shall keep the CA informed of all changes to this list during programming and setup.

3. An updated as-built version of the control drawings and sequences of operation shall be included in the final controls O\&M manual submittal. 
4. Assist and cooperate with the TAB contractor in the following manner:

a. Meet with the $\mathrm{TAB}$ contractor prior to beginning $\mathrm{TAB}$ and review the $\mathrm{TAB}$ plan to determine the capabilities of the control system toward completing TAB. Provide the $T A B$ any needed unique instruments for setting terminal unit boxes and instruct $T A B$ in their use (handheld control system interface for use around the building during $T A B$, etc.).

b. For a given area, have all required prefunctional checklists, calibrations, startup and selected functional tests of the system completed and approved by the CA prior to TAB.

c. Provide a qualified technician to operate the controls to assist the TAB contractor in performing $T A B$, or provide sufficient training for $T A B$ to operate the system without assistance.

5. Assist and cooperate with the $\mathrm{CA}$ in the following manner:

a. Execute the functional testing of the controls system as specified for the controls contractor in Section 15997 and 16997.

b. Assist in the functional testing of all equipment specified in Section 15997 and 16997.

c. Execute all control system trend logs specified in Section 15997 and 16997.

6. The controls contractor shall prepare a written plan indicating in a step-by-step manner, the procedures that will be followed to test, checkout and adjust the control system prior to functional performance testing, according to the process in Section 17100. At minimum, the plan shall include for each type of equipment controlled by the automatic controls:

a. System name.

b. List of devices.

c. Step-by-step procedures for testing each controller after installation, including:

1) Process of verifying proper hardware and wiring installation.

2) Process of downloading programs to local controllers and verifying that they are addressed correctly.

3) Process of performing operational checks of each controlled component.

4) Plan and process for calibrating valve and damper actuators and all sensors.

5) A description of the expected field adjustments for transmitters, controllers and control actuators should control responses fall outside of expected values.

d. A copy of the log and field checkout sheets that will document the process. This log must include a place for initial and final read values during calibration of each point and clearly indicate when a sensor or controller has "passed" and is operating within the contract parameters.

e. A description of the instrumentation required for testing.

f. Indicate what tests on what systems should be completed prior to TAB using the control system for $\mathrm{TAB}$ work. Coordinate with the $\mathrm{CA}$ and $\mathrm{TAB}$ contractor for this determination.

7. Provide a signed and dated certification to the $\mathrm{CA}$ and $\mathrm{CM}$ upon completion of the checkout of each controlled device, equipment and system prior to functional testing for each piece of equipment or system, that all system programming is complete as to all respects of the Contract Documents, except functional testing requirements.

8. Beyond the control points necessary to execute all documented control sequences, provide monitoring, control and virtual points as specified in Section 15950. 


\section{SECTION $15995-7$}

MECHANICAL SYSTEMS COMMISSIONING

9. List and clearly identify on the as-built duct and piping drawings the locations of all static and differential pressure sensors (air, water and building pressure).

D. TAB Contractor. The duties of the TAB contractor, in addition to those listed in (A) are:

1. Six weeks prior to starting $T A B$, submit to the $C M$ the qualifications of the site technician for the project, including the name of the contractors and facility managers of recent projects the technician on which was lead. The Owner will approve the site technician's qualifications for this project.

2. Submit the outline of the $T A B$ plan and approach for each system and component to the $C A$, $\mathrm{CM}$ and the controls contractor six weeks prior to starting the TAB. This plan will be developed after the TAB has some familiarity with the control system.

3. The submitted plan will include:

a. Certification that the TAB contractor has reviewed the construction documents and the systems with the design engineers and contractors to sufficiently understand the design intent for each system.

b. An explanation of the intended use of the building control system. The controls contractor will comment on feasibility of the plan.

c. All field checkout sheets and logs to be used that list each piece of equipment to be tested, adjusted and balanced with the data cells to be gathered for each.

d. Discussion of what notations and markings will be made on the duct and piping drawings during the process.

e. Final test report forms to be used.

f. Detailed step-by-step procedures for TAB work for each system and issue: terminal flow calibration (for each terminal type), diffuser proportioning, branch / submain proportioning, total flow calculations, rechecking, diversity issues, expected problems and solutions, etc. Criteria for using air flow straighteners or relocating flow stations and sensors will be discussed. Provide the analogous explanations for the water side.

g. List of all air flow, water flow, sound level, system capacity and efficiency measurements to be performed and a description of specific test procedures, parameters, formulas to be used.

h. Details of how total flow will be determined (Air: sum of terminal flows via BAS calibrated readings or via hood readings of all terminals, supply (SA) and return air (RA) pitot traverse, SA or RA flow stations. Water: pump curves, circuit setter, flow station, ultrasonic, etc.).

i. The identification and types of measurement instruments to be used and their most recent calibration date.

j. Specific procedures that will ensure that both air and water side are operating at the lowest possible pressures and provide methods to verify this.

k. Confirmation that $\mathrm{TAB}$ understands the outside air ventilation criteria under all conditions.

1. Details of whether and how minimum outside air cfm will be verified and set, and for what level (total building, zone, etc.).

m. Details of how building static and exhaust fan / relief damper capacity will be checked.

n. Proposed selection points for sound measurements and sound measurement methods.

o. Details of methods for making any specified coil or other system plant capacity measurements.

p. Details of any TAB work to be done in phases (by floor, etc.), or of areas to be built out later. 
q. Details regarding specified deferred or seasonal TAB work.

r. Details of any specified false loading of systems to complete TAB work.

s. Details of all exhaust fan balancing and capacity verifications, including any required room pressure differentials.

t. Details of any required interstitial cavity differential pressure measurements and calculations.

u. Plan for hand-written field technician logs of discrepancies, deficient or uncompleted work by others, contract interpretation requests and lists of completed tests (scope and frequency).

v. Plan for formal progress reports (scope and frequency).

w. Plan for formal deficiency reports (scope, frequency and distribution).

4. A running log of events and issues shall be kept by the TAB field technicians. Submit handwritten reports of discrepancies, deficient or uncompleted work by others, contract interpretation requests and lists of completed tests to the $\mathrm{CA}$ and $\mathrm{CM}$ at least twice a week.

5. Communicate in writing to the controls contractor all setpoint and parameter changes made or problems and discrepancies identified during TAB which affect the control system setup and operation.

6. Provide a draft TAB report within two weeks of completion. A copy will be provided to the CA. The report will contain a full explanation of the methodology, assumptions and the results in a clear format with designations of all uncommon abbreviations and column headings. The report should follow the latest and most rigorous reporting recommendations by AABC, NEBB or ASHRAE Standard 111.

7. Provide the $\mathrm{CA}$ with any requested data, gathered, but not shown on the draft reports.

8. Provide a final TAB report for the $\mathrm{CA}$ with details, as in the draft.

9. Conduct functional performance tests and checks on the original $T A B$ as specified for $T A B$ in Section 15997.

E. Mechanical Designer. Refer to Section 17100 for the responsibilities of the mechanical designer.

\subsection{RELATED WORK}

A. Refer to Section 17100 , Part 1.5 for a listing of all sections where commissioning requirements are found.

B. Refer to Section 17100 Part 1.4 for systems to be commissioned and section 17100 Part 1.6 and 15997 for functional testing requirements. 
PART 2 - PRODUCTS

\subsection{TEST EQUIPMENT}

A. Division 15 shall provide all test equipment necessary to fulfill the testing requirements of this Division.

B. Refer to Section 17100 Part 2.1 for additional Division 15 requirements.

\section{PART 3 - EXECUTION}

\subsection{SUBMITTALS}

A. Division 15 shall provide submittal documentation relative to commissioning as required in this Section Part 1, Section 01300 and Section 17100.

\subsection{STARTUP}

A. The HVAC mechanical and controls contractors shall follow the start-up and initial checkout procedures listed in the Responsibilities list in this section and in 17100. Division 15 has start-up responsibility and is required to complete systems and sub-systems so they are fully functional, meeting the design objectives of the Contract Documents. The commissioning procedures and functional testing do not relieve or lessen this responsibility or shift that responsibility partially to the commissioning agent or Owner.

B. Functional testing is intended to begin upon completion of a system. Functional testing may proceed prior to the completion of systems or sub-systems at the discretion of the CA and CM. Beginning system testing before full completion, does not relieve the Contractor from fully completing the system, including all prefunctional checklists as soon as possible.

\subsection{TAB}

A. Refer to the TAB responsibilities in Part 1.2 above.

\subsection{FUNCTIONAL PERFORMANCE TESTS}
A. Refer to Section 17100 Part 1.4 for a list of systems to be commissioned and to Part 3.6 for a description of the process and to Section 15997 for specific details on the required functional performance tests.

\subsection{TESTING DOCUMENTATION, NON-CONFORMANCE AND APPROVALS}

A. Refer to Section 17100 Part 3.4 for specific details on non-conformance issues relating to prefunctional checklists and tests.

B. Refer to Section 17100 Part 3.7 for issues relating to functional performance tests. 


\subsection{OPERATION AND MAINTENANCE (O\&M) MANUALS}

The following O\&M documentation requirements assume that the general contractor is compiling the O\&M manuals, with all Subs compiling their own sections, including some submissions for the AVE and CA.

These requirements may need to be merged and edited to follow the protocols and scope of the current agency or project. However, the comprehensiveness and accessibility described herein shall be maintained.

A. The following O\&M manual requirements do not replace O\&M manual documentation requirements elsewhere in these specifications.

B. Division 15 shall compile and prepare documentation for all equipment and systems covered in Division 15 and deliver this documentation to the $\mathrm{GC}$ for inclusion in the O\&M manuals, according to this section and Section 01730, prior to the training of owner personnel.

C. The CA shall receive a copy of the O\&M manuals for review.

D. Special Control System O\&M Manual Requirements. In addition to documentation that may be specified elsewhere, the controls contractor shall compile and organize at minimum the following data on the control system in labeled 3-ring binders with indexed tabs.

1. Three copies of the controls training manuals in a separate manual from the O\&M manuals.

2. Operation and Maintenance Manuals containing:

a. Specific instructions on how to perform and apply all functions, features, modes, etc. mentioned in the controls training sections of this specification and other features of this system. These instructions shall be step-by-step. Indexes and clear tables of contents shall be included. The detailed technical manual for programming and customizing control loops and algorithms shall be included.

b. Full as-built set of control drawings (refer to Submittal section above for details).

c. Full as-built sequence of operations for each piece of equipment.

d. Full points list. In addition to the updated points list required in the original submittals (Part 1 of this section), a listing of all rooms shall be provided with the following information for each room:
1) Floor.
2) Room number
3) Room name
.4) Air handler unit ID
5) Reference drawing number
6) Air terminal unit tag ID
7) Heating and/or cooling valve tag $\mathrm{ID}$
8) Minimum cfm
9) Maximum cfm

e. Full print out of all schedules and set points after testing and acceptance of the system. 
f. Full as-built print out of software program.

g. Electronic copy on disk of the entire program for this facility.

h. Marking of all system sensors and thermostats on the as-built floor plan and mechanical drawings with their control system designations.

i. Maintenance instructions, including sensor calibration requirements and methods by sensor type, etc.

j. Control equipment component submittals, parts lists, etc.

k. Warranty requirements.

1. Copies of all checkout tests and calibrations performed by the Contractor (not commissioning tests).

3. The manual shall be organized and subdivided with permanently labeled tabs for each of the following data in the given order:
a. Sequences of operation
b. Control drawings
c. Points lists
d. Controller / module data
e. Thermostats and timers
f. Sensors and DP switches
g. Valves and valve actuators
h. Dampers and damper actuators
i. Program setups (software program printouts)

4. Field checkout sheets and trend logs should be provided to the CA for inclusion in the Commissioning Record Book.

E. Special TAB Documentation Requirements. The TAB will compile and submit the following with other documentation that may be specified elsewhere in the Specifications.

1. Final report containing an explanation of the methodology, assumptions, test conditions and the results in a clear format with designations of all uncommon abbreviations and column headings.

2. The TAB shall mark on the drawings where all traverse and other critical measurements were taken and cross reference the location in the TAB report.

F. Review and Approvals. Review of the commissioning related sections of the O\&M manuals shall be made by the A/E and by the CA. Refer to Section 17100, Part 3.8 for details.

\subsection{TRAINING OF OWNER PERSONNEL}

A. The GC shall be responsible for training coordination and scheduling and ultimately to ensure that training is completed. Refer to Section 17100 for additional details.

B. The CA shall be responsible for overseeing and approving the content and adequacy of the training of Owner personnel for commissioned equipment. Refer to Section 17100 for additional details.

C. Mechanical Contractor. The mechanical contractor shall have the following training responsibilities: 
1. Provide the $\mathrm{CA}$ with a training plan two weeks before the planned training according to the outline described in Section 17100, Part 3.9.

2. Provide designated Owner personnel with comprehensive orientation and training in the understanding of the systems and the operation and maintenance of each piece of HVAC equipment including, but not limited to, pumps, boilers, furnaces, chillers, heat rejection equipment, air conditioning units, air handling units, fans, terminal units, controls and water treatment systems, etc.

3. Training shall normally start with classroom sessions followed by hands-on training on each piece of equipment, which shall illustrate the various modes of operation, including startup, shutdown, fire/smoke alarm, power failure, etc.

4. During any demonstration, should the system fail to perform in accordance with the requirements of the O\&M manual or sequence of operations, the system will be repaired or adjusted as necessary and the demonstration repeated.

5. The appropriate trade or manufacturer's representative shall provide the instructions on each major piece of equipment. This person may be the start-up technician for the piece of equipment, the installing contractor or manufacturer's representative. Practical building operating expertise as well as in-depth knowledge of all modes of operation of the specific piece of equipment are required. More than one party may be required to execute the training.

6. The controls contractor shall attend sessions other than the controls training, as requested, to discuss the interaction of the controls system as it relates to the equipment being discussed.

7. The training sessions shall follow the outline in the Table of Contents of the operation and maintenance manual and illustrate whenever possible the use of the O\&M manuals for reference.

8. Training shall include:

a. Use of the printed installation, operation and maintenance instruction material included in the O\&M manuals.

b. A review of the written O\&M instructions emphasizing safe and proper operating requirements, preventative maintenance, special tools needed and spare parts inventory suggestions. The training shall include start-up, operation in all modes possible, shutdown, seasonal changeover and any emergency procedures.

c. Discussion of relevant health and safety issues and concerns.

d. Discussion of warranties and guarantees.

e. Common troubleshooting problems and solutions.

f. Explanatory information included in the O\&M manuals and the location of all plans and manuals in the facility.

g. Discussion of any peculiarities of equipment installation or operation.

h. The format and training agenda in The HVAC Commissioning Process, ASHRAE Guideline 1-1989R, 1996 is recommended.

i. Classroom sessions shall include the use of overhead projections, slides, video/audiotaped material as might be appropriate.

9. Hands-on training shall include start-up, operation in all modes possible, including manual, shut-down and any emergency procedures and preventative maintenance for all pieces of equipment.

10. The mechanical contractor shall fully explain and demonstrate the operation, function and overrides of any local packaged controls, not controlled by the central control system. 
11. Training shall occur after functional testing is complete, unless approved otherwise by the Project Manager.

12. Duration of Training. The mechanical contractor shall provide training on each piece of equipment according to the following schedule.

\begin{tabular}{|c|c|}
\hline Hours & System \\
\hline & Cooling Towers \\
\hline & Boilers and System \\
\hline & Piping Systems \\
\hline & Chemical Treatment \\
\hline & Air Compressors and dryers \\
\hline & Air Handler Units \\
\hline & Variable Speed Drives \\
\hline & Supplementary Supply Fans \\
\hline & Return Fan/Relief Fan \\
\hline & Air Terminal Units \\
\hline & Air Handler Units \\
\hline & Packaged Rooftop Units \\
\hline & Packaged Rooftop Units \\
\hline & Computer Room AC Units \\
\hline & Split System AC or Heat Pumps \\
\hline & Spot AC Units \\
\hline & Spot Unit Heaters \\
\hline & Elevator Shaft Fans \\
\hline & Stairwell Fans \\
\hline & Specialty Exhaust Fans \\
\hline & Restroom Central Exhaust Fans \\
\hline & Garage Exhaust Fans \\
\hline & Emergency Generator \\
\hline & Service Hot Water Heaters \\
\hline & Domestic Water Booster Pump \\
\hline & Sewage Ejector \\
\hline & Fire Protection System \\
\hline & Fire Sprinklers \\
\hline & Irrigation \\
\hline & Fountain pumping \\
\hline
\end{tabular}

The Spec Writer should list and specify training for all equipment not listed here. 
D. Controls Contractor. The controls contractor shall have the following training responsibilities:

1. Provide the $\mathrm{CA}$ with a training plan four weeks before the planned training according to the outline described in Section 17100, Part 3.9.

2. The controls contractor shall provide designated Owner personnel training on the control system in this facility. The intent is to clearly and completely instruct the Owner on all the capabilities of the control system.

3. Training manuals. The standard operating manual for the system and any special training manuals will be provided for each trainee, with three extra copies left for the O\&M manuals. In addition, copies of the system technical manual will be demonstrated during training and three copies submitted with the O\&M manuals. Manuals shall include detailed description of the subject matter for each session. The manuals will cover all control sequences and have a definitions section that fully describes all relevant words used in the manuals and in all software displays. Manuals will be approved by the CA. Copies of audiovisuals shall be delivered to the Owner.

4. The trainings will be tailored to the needs and skill-level of the trainees.

5. The trainers will be knowledgeable on the system and its use in buildings. For the on-site sessions, the most qualified trainer(s) will be used. The Owner shall approve the instructor prior to scheduling the training.

6. During any demonstration, should the system fail to perform in accordance with the requirements of the 0\&M manual or sequence of operations, the system will be repaired or adjusted as necessary and the demonstration repeated.

7. The controls contractor shall attend sessions other than the controls training, as requested, to discuss the interaction of the controls system as it relates to the equipment being discussed.

8. There shall be three training sessions:

a. Training I. Control System. The first training shall consist of ___ hours of actual training. This training may be held on-site or in the supplier's facility. If held off-site, the training may occur prior to final completion of the system installation. Upon completion, each student, using appropriate documentation, should be able to perform elementary operations and describe general hardware architecture and functionality of the system.

b. Training II. Building Systems. The second session shall be held on-site for a period of hours of actual hands-on training after the completion of system commissioning.

The session shall include instruction on:

1) Specific hardware configuration of installed systems in this building and specific instruction for operating the installed system, including HVAC systems, lighting controls and any interface with security and communication systems.

2) Security levels, alarms, system start-up, shut-down, power outage and restart routines, changing setpoints and alarms and other typical changed parameters, overrides, freeze protection, manual operation of equipment, optional control strategies that can be considered, energy savings strategies and set points that if changed will adversely affect energy consumption, energy accounting, procedures for obtaining vendor assistance, etc.

3) All trending and monitoring features (values, change of state, totalization, etc.), including setting up, executing, downloading, viewing both tabular and graphically and printing trends. Trainees will actually set-up trends in the presence of the trainer.

4) Every screen shall be completely discussed, allowing time for questions. 
5) Use of keypad or plug-in laptop computer at the zone level.

6) Use of remote access to the system via phone lines or networks.

7) Setting up and changing an air terminal unit controller.

c. Training III. The third training will be conducted on-site six months after occupancy and consist of __ hours of training. The session will be structured to address specific topics that trainees need to discuss and to answer questions concerning operation of the system.

E. TAB The TAB contractor shall have the following training responsibilities:

1. TAB shall meet for hours with facility staff after completion of $\mathrm{TAB}$ and instruct them on the following:
a) Go over the final $\mathrm{TAB}$ report, explaining the layout and meanings of each data type.
b) Discuss any outstanding deficient items in control, ducting or design that may affect the proper delivery of air or water.
c) Identify and discuss any terminal units, duct runs, diffusers, coils, fans and pumps that are close to or are not meeting their design capacity.
d) Discuss any temporary settings and steps to finalize them for any areas that are not finished.
e) Other salient information that may be useful for facility operations, relative to TAB.

\subsection{DEFERRED TESTING}

A. Refer to Section 17100, Part 3.10 for requirements of deferred testing.

\subsection{WRITTEN WORK PRODUCTS}

A. Written work products of Contractors will consist of the start-up and initial checkout plan described in Section 17100 and the filled out start-up, initial checkout and prefunctional checklists.

\section{END OF GUIDE SPECIFICATION SECTION}




\section{COMMISSIONING GUIDE SPECIFICATIONS}

\section{SECTION 15997 MECHANICAL TESTING REQUIREMENTS}

\section{Spec writer:}

The following guide specifications are intended to be reviewed and modified to meet the specific commissioning needs and requirements for the current project and systems. Any modifications to these specifications shall only be made after consultation with the Owner's representative and with approval of the engineer of record. Where there are check boxes or fill-in blanks, fill in as appropriate and delete all but the choice(s) that apply. Delete all direction boxes.

Spec Writer: A/E and design phase CA should:

1. Review the functional test requirements and add or change requirements, as necessary, for the current project. Pay particular attention to smaller equipment (small AHU, RTUs etc.) which will not warrant the same rigor as larger units portrayed here currently. Delete requirements for equipment not existing in the current project.

2. Make sure that every piece of mechanical equipment or system has a unique test requirement or is listed as a component of a system with testing requirements given. Use the format of this section for new test requirements.

3. Include intersystem test requirements where significant interactions or interlocks exist between systems.

4. Consider the adequacy of the Guide Specification Acceptance Criteria and add detail where necessary.

PART 1 - GENERAL

\subsection{INCLUDED SYSTEMS AND EQUIPMENT}

A. The following is a list of the equipment and system test requirements included in this section:

1. Cooling tower

2. Chiller system

3. Air handler system

4. Terminal unit

5. Packaged DX air conditioning or heat pump

6. Boiler system

7. Exhaust fans

8. Service hot water system

9. Building automation system

10. Test and balance (TAB) work

11. Indoor air quality (IAQ)

\subsection{DESCRIPTION}


A. This section specifies the functional testing requirements for Division 15 systems and equipment. From these requirements, the Commissioning Agent (CA) shall develop step-by-step procedures to be executed by the Subs. The general functional testing process, requirements and test method definitions are described in Section 17100. The test requirements for each piece of equipment or system contain the following:

1. The contractors responsible to execute the tests, under the direction of the CA.

2. A list of the integral components being tested.

3. Prefunctional checklists associated with the components.

4. Functions and modes to be tested.

5. Required conditions of the test for each mode.

6. Special procedures.

7. Required methods of testing.

8. Required monitoring.

9. Acceptance criteria.

10. Sampling strategies allowed.

\subsection{PREREQUISITES}

The following applicable generic prerequisite checklist items are required to be listed on each written functional test form and be completed and checked off by CA prior to functional testing.

All related equipment has been started up and start-up reports and prefunctional checklists submitted and approved ready for functional testing:

All control system functions for this and all interlocking systems are programmed and operable per contract documents, including final setpoints and schedules with debugging, loop tuning and sensor calibrations completed.

Controls Contractor Signature or Verbal

Date

Piping system flushing complete and required report approved.

Water treatment system complete and operational.

_ Vibration control report approved (if required).

- Test and balance (TAB) complete and approved for the hydronic system.

- All A/E punchlist items for this equipment corrected.

- These functional test procedures reviewed and approved by installing contractor.

- Safeties and operating ranges reviewed by the CA.

- Test requirements and sequences of operation attached.

- Schedules and setpoints attached.

False loading equipment, system and procedures ready.

- Crankcase heaters have been on long enough for immediate startup.

- Sufficient clearance around equipment for servicing.

— Record of all values for pre-test setpoints changed to accomodate testing has been made and a check box provided to verify return to original values (control parameters, limits, delays, lockouts, schedules, etc.).

_Other miscellaneous checks of the prefunctinal checklist and start-up reports completed successfully.

\subsection{MONITORING}

a. Monitoring is a method of testing as a stand-alone method or to augment manual testing.

b. All points listed in the required monitoring section of the test requirements which are control system monitored points shall be trended by the controls contractor. Other points shall be monitored by the 
CA using dataloggers. At the option of the $\mathrm{CA}$, some control system monitoring may be replaced with datalogger monitoring. At the CA's request, the controls contractor shall trend up to $20 \%$ more points than listed herein at no extra charge.

c. Hard copies of monitored data must be in columnar format with time down the left column and at least 5 columns of point values on the same page.

d. Graphical output is desirable, and will be required for all output, if the system can produce it.

\section{PART 2 - PRODUCTS}

- NOT APPLICABLE -

\section{PART 3 - EXECUTION}


1. COOLING TOWER

The cooling tower can be tested integrally with the chiller testing.

A. Parties Responsible to Execute Functional Test

1. Controls contractor: operate the controls

2. HVAC mechanical contractor or vendor: assist in testing sequences

B. Integral Components or Related Equipment Being Tested

1. Condenser water pump

2. Cooling tower and components

3. Condenser water piping system

4. Fan VFD

Prefunctional Checklist ID

PC-

$\mathrm{PC}$ -

PC-

PC-

C. Prerequisites The applicable prerequisite checklist items listed in the beginning of Section 15997 shall be listed on each functional test form and checked off prior to functional testing.

D. Functions / Modes Required To Be Tested. Test Methods and Seasonal Test Requirements The following testing requirements are an addition to and do not replace any testing requirements elsewhere in this Division.

\begin{tabular}{|c|c|c|}
\hline Function / Mode & $\begin{array}{l}\text { Test Method } \\
\text { Manual, } \\
\text { Monitoring, } \\
\text { Either or } \\
\text { Both }\end{array}$ & $\frac{\frac{\text { Required }}{\text { Seasonal }}}{\text { Test }^{1}}$ \\
\hline $\begin{array}{l}\text { General } \\
\text { 1. Test each sequence in the sequence of operations, and other significant } \\
\text { modes and sequences not mentioned; including startup, shutdown, } \\
\text { unnoccupied \& manual modes and power failure. Test functionality of } \\
\text { this piece of equipment or system in all control strategies or interlocks } \\
\text { with which it is associated. }\end{array}$ & Manual & \\
\hline \multicolumn{3}{|l|}{ In addition to, or as part of (1) above, the following modes or tests are required: } \\
\hline 2. Cooling season modes of operation. & Both & Cooling \\
\hline 3. Heating season modes of operation. & Both & Heating \\
\hline $\begin{array}{l}\text { 4. Lead/lag staging of towers, including testing each tower as lead tower. } \\
\text { Staging of fans, spray pumps, condenser pumps, CDWT reset, time } \\
\text { delays. }\end{array}$ & Both, except ${ }^{2}$ & \\
\hline $\begin{array}{l}\text { 5. Bypass valve operation and ability of } \mathrm{CT} \text { to maintain entering } \mathrm{CDW} \\
\text { temperature. }\end{array}$ & Either & \\
\hline 6. Sump heater and freeze protection operation. & Either & Heating \\
\hline 7. All alarms: vibration, fan failure, high water, low water. & Manual & \\
\hline 8. Verify approach temperature with manuf. specs, optional. & Either & \\
\hline $\begin{array}{l}\text { 9. VFD operation: modulation to low limit, controlling PID, proportional } \\
\text { band of speed vs control parameter, verification of program settings, } \\
\text { alarms. }\end{array}$ & Both & \\
\hline 10. Capacity test, optional. & Manual & Clg. Des. \\
\hline 11. Sensor and actuator calibration checks: See Chiller requirements. & Manual & \\
\hline 12. Verify schedules and setpoints to be reasonable and appropriate. & & \\
\hline
\end{tabular}


${ }^{2}$ Monitoring testing each tower as lead tower is not necessary.

E. Special Procedures or Conditions (other equipment to test with, etc.; reference to function ID)

1. Tests to be made with chiller in automatic mode.

2. False load chiller, if necessary.

F. Required Monitoring

1. All points listed below which are control system monitored points shall be trended by the controls contractor. Other points shall be monitored by the $\mathrm{CA}$ using dataloggers. Refer to the Monitoring section at the beginning of Section 15997 for additional monitoring details.

\begin{tabular}{|c|c|c|c|c|c|}
\hline Point & $\begin{array}{l}\text { Time } \\
\text { Step } \\
\text { (min.) } \\
\end{array}$ & $\begin{array}{c}\text { Minimum } \\
\text { Time Period } \\
\text { of Trend }\end{array}$ & $\begin{array}{l}\text { Hard } \\
\text { Copy? } \\
(\mathrm{Y} / \mathrm{N}) \\
\end{array}$ & $\begin{array}{l}\text { ASCII } \\
\text { File? } \\
(\mathrm{Y} / \mathrm{N}) \\
\end{array}$ & $\begin{array}{l}\text { Function } \\
\text { Being Tested }\end{array}$ \\
\hline \multicolumn{6}{|l|}{ For each CT: } \\
\hline CDEWT & 5 & Wed. - Sat & $Y$ & $\mathrm{Y}$ & $1,2,4,9$ \\
\hline CDLWT & 5 & Wed. - Sat & $Y$ & $Y$ & $1,2,4,8,9$ \\
\hline OSAT-DB & 5 & Wed. - Sat & $\mathrm{Y}$ & $\mathrm{Y}$ & $1,2,4,8,9$ \\
\hline OSAT-WB (optional) & 5 & Wed. - Sat & $\bar{Y}$ & $\bar{Y}$ & 8 \\
\hline $\begin{array}{l}\text { Fan motor speed, stage or } \\
\text { current }\end{array}$ & 5 & Wed. - Sat & $\mathrm{Y}$ & $Y$ & 4,9 \\
\hline $\begin{array}{l}\text { CDW pump status or } \\
\text { current }\end{array}$ & 5 & Wed. - Sat & $\bar{Y}$ & $\bar{Y}$ & $1,2,4,9$ \\
\hline $\begin{array}{l}\text { Each chiller status or } \\
\text { current }\end{array}$ & 5 & Wed. - Sat & $\bar{Y}$ & $\bar{Y}$ & $1,2,4,9$ \\
\hline & & & & & \\
\hline
\end{tabular}

Remarks:

G. Acceptance Criteria (referenced by function or mode $\mathrm{DD}$ )

1-12. For the conditions, sequences and modes tested, the cooling tower(s), integral components and related equipment respond to varying loads and changing conditions and parameters appropriately as expected, as specified and according to acceptable operating practice.

5. Cooling tower should be able to maintain the current specified setpoint for entering condenser water to within $+/-2 \mathrm{~F}$, when outside conditions do not restrict this thermodynamically.

H. Sampling Strategy for Identical Units ( $x x \%$ Sampling - yy\% Failure Rule is defined in Section 17100, Part 3.6)

1. No sampling, test all. 


\section{SECTION 15997 - 6 \\ MECHANICAL TESTING REQUIREMENTS}

\section{CHILLER}

The cooling tower can be tested integrally with the chiller testing. The cooling tower test requirements are listed elsewhere.

A. Parties Responsible to Execute Functional Test

1. Controls contractor: operate the controls

2. HVAC mechanical contractor or vendor: assist in testing sequences

C. Prerequisites The applicable prerequisite checklist items listed in the beginning of Section 15997 shall be listed on each functional test form and checked off prior to functional testing.

C. Integral Components or Related Equipment Being Tested

1. Chiller

2. Primary CHW supply pumps

3. Chilled water piping system

4. Secondary CHW supply pumps

5. VFD on secondary pumps

Prefunctional Checklist ID

PC-

$\mathrm{PC}$ -

PC-

PC-

PC-

D. Functions / Modes Required To Be Tested, Test Methods and Seasonal Test Requirements

The following testing requirements are an addition to and do not replace any testing requirements elsewhere in this Division.

\begin{tabular}{|c|c|c|}
\hline Function / Mode & $\begin{array}{l}\text { Test Method } \\
\text { Manual, } \\
\text { Monitoring, } \\
\text { Either or } \\
\text { Both }\end{array}$ & $\frac{\text { Required }}{\text { Seasonal }}$ \\
\hline $\begin{array}{l}\text { General } \\
\text { 1. Test each sequence in the sequence of operations, and other significant } \\
\text { modes and sequences not mentioned; including startup, shutdown, } \\
\text { unnoccupied \& manual modes and power failure. Test functionality of } \\
\text { this piece of equipment or system in all control strategies or interlocks } \\
\text { with which it is associated. A full cycle from no load to full load and } \\
\text { then to no load and compressors off shall be demonstrated. }\end{array}$ & Manual & \\
\hline \multicolumn{3}{|l|}{ In addition to, or as part of (1) above, the following modes or tests are required: } \\
\hline $\begin{array}{l}\text { 2. Primary Side. Lead/lag staging of chillers, optimization, capacity } \\
\text { modulation (loading and unloading), heat reclaim, and primary CHW } \\
\text { supply pumps, all relating to maintaining CDW and CHW temperatures. }\end{array}$ & Both & Cooling \\
\hline $\begin{array}{l}\text { 3. Secondary Side. Secondary CWH supply pump staging, bypass valve } \\
\text { operation, if no VFD and CHWT reset. VFD operation: modulation to } \\
\text { minimum, control system PID, proportional band of speed vs controlling } \\
\text { parameter, alarms, verification of program settings, etc. }\end{array}$ & Both & Cooling \\
\hline 4. All alarms: high and low pressure, low oil, etc. & Manual & \\
\hline $\begin{array}{l}\text { 5. Test each possible lead chiller as lead chiller, and each pump as lead } \\
\text { pump, including standby pumps. }\end{array}$ & Manual & \\
\hline 6. $\mathrm{kW} /$ ton and APLV efficiency test, optional & Manual & Cooling \\
\hline 7. Capacity test, optional & Manual & $\begin{array}{l}\text { Cooling } \\
\text { Design }\end{array}$ \\
\hline
\end{tabular}




\begin{tabular}{|l|c|c|}
\hline \multicolumn{1}{|c|}{ Function / Mode } & $\begin{array}{c}\frac{\text { Test Method }}{\text { Manual, }} \\
\text { Monitoring, } \\
\text { Either or } \\
\text { Both }\end{array}$ & $\begin{array}{c}\frac{\text { Required }}{\text { Seasonal }} \\
\text { Test }\end{array}$ \\
\hline 8. & $\begin{array}{l}\text { Sensor and actuator calibration checks on: ECDWT, CHWST, pressure } \\
\text { sensor controlling pump speed, 3-way valve, and other random checks } \\
\text { (EMS readout against handheld calibrated instrument must be within } \\
\text { 0.5०F for temps, or within a tolerance equal to 10\% of the pressure } \\
\text { setpoint, with a test gage) }\end{array}$ & Manual \\
\hline 9. Verify schedules and setpoints to be reasonable and appropriate & & \\
\hline
\end{tabular}

${ }^{1}$ Cooling season, Heating season or Both. "Design" means within $5^{\circ} \mathrm{F}$ of season design (ASHRAE 2 $1 / 2 \%$ ), or $95 \%$ of loading design. A blank cell denotes no special seasonal test is required and that test can be executed during any season, if condition simulation is appropriate.

E. Special Procedures (other equipment with which to test, etc.; reference to function ID)

1. Test with cooling tower in automatic mode.

2. False load chiller, if necessary.

F. Required Monitoring

1. All points listed below which are control system monitored points shall be trended by the controls contractor. Other points shall be monitored by the $\mathrm{CA}$ using dataloggers. Refer to the Monitoring section at the beginning of Section 15997 for additional monitoring details.

\begin{tabular}{|c|c|c|c|c|c|}
\hline Point & $\begin{array}{l}\text { Time } \\
\text { Step } \\
\text { (min.) }\end{array}$ & $\begin{array}{l}\text { Minimum } \\
\text { Time Period } \\
\text { of Trend }\end{array}$ & $\begin{array}{l}\text { Hard } \\
\text { Copy? } \\
\text { (Y/N) }\end{array}$ & $\begin{array}{l}\text { ASCII } \\
\text { File? } \\
\text { (Y/N) }\end{array}$ & $\begin{array}{c}\text { Function } \\
\text { Being Tested } \\
\end{array}$ \\
\hline \multicolumn{6}{|l|}{ For each chiller and pump: } \\
\hline Chiller current & 5 & 5 days incl. weekend & $Y$ & $Y$ & $1-3$ \\
\hline ECDWT & 5 & 5 days incl. weekend & $Y$ & $\mathrm{Y}$ & $1-3$ \\
\hline LCDWT & 5 & 5 days incl. weekend & $\bar{Y}$ & $Y$ & $1-3$ \\
\hline $\begin{array}{l}\text { CDW pump current or } \\
\text { status }\end{array}$ & 5 & 5 days incl. weekend & $\mathrm{Y}$ & $\mathrm{Y}$ & $1-3$ \\
\hline CHWST & 5 & 5 days incl. weekend & $\mathbf{Y}$ & $Y$ & 1,3 \\
\hline CHWRT & 5 & 5 days incl. weekend & $\bar{Y}$ & $\mathrm{Y}$ & 1,3 \\
\hline OSAT-DB & 5 & 5 days incl. weekend & $\bar{Y}$ & $\bar{Y}$ & $1-3$ \\
\hline $\begin{array}{l}\text { CHWS primary pump } \\
\text { current or status }\end{array}$ & 5 & 5 days incl. weekend & $\bar{Y}$ & $\mathrm{Y}$ & 1,2 \\
\hline $\begin{array}{l}\text { CHWS secondary pump } \\
\text { speed, if variable }\end{array}$ & 5 & 5 days incl. weekend & $\bar{Y}$ & $\bar{Y}$ & 1,3 \\
\hline $\begin{array}{l}\text { CHWS secondary pump } \\
\text { flow rate }\end{array}$ & 5 & 5 days incl. weekend & $\bar{Y}$ & $\bar{Y}$ & 1,3 \\
\hline $\begin{array}{l}\text { CHWS secondary pump } \\
\text { speed controlling parameter } \\
\text { value }\end{array}$ & 5 & 5 days incl. weekend & $\bar{Y}$ & $\bar{Y}$ & 1,3 \\
\hline
\end{tabular}

Remarks:

G. Acceptance Criteria (referenced by function or mode ID) 
1-9. For the conditions, sequences and modes tested, the chillers, integral components and related equipment respond to varying loads and changing conditions and parameters appropriately as expected, as specified and according to acceptable operating practice.

2. Chiller shall maintain the chilled water supply setpoint to within $+/-1.0 \mathrm{~F}$ of setpoint deadband without excessive hunting.

9. Pumping system and controls shall maintain the current desired pressure setpoint to within an amount equal to $10 \%$ of the setpoint value either side of the deadband without excessive hunting.

H. Sampling Strategy for Identical Units ( $x x \%$ Sampling - yy\% Failure Rule is defined in Section 17100, Part 3.6)

1. No sampling, test all.

END OF REQUIREMENTS FOR CHILLER TEST 


\section{AIR HANDLER UNITS (AHU)}

A. Parties Responsible to Execute Functional Test

1. Controls contractor: operate the controls to activate the equipment.

B. Integral Components or Related Equipment Being Tested

1. AHU and components (fans, coils, valves, ducts, VFD)

2. Heat recovery coil, humidifier or evaporative cooling sections
Prefunctional Checklist ID
PC-
PC-

C. Prerequisites The applicable prerequisite checklist items listed in the beginning of Section 15997 shall be listed on each functional test form and checked off prior to functional testing.

D. Functions / Modes Required To Be Tested, Test Methods and Seasonal Test Requirements The following testing requirements are an addition to and do not replace any testing requirements elsewhere in this Division.

\begin{tabular}{|c|c|c|}
\hline Function / Mode & $\begin{array}{l}\text { Test Method } \\
\text { Manual, } \\
\text { Monitoring, } \\
\text { Either or } \\
\text { Both }^{3}\end{array}$ & $\frac{\text { Required }}{\frac{\text { Seasonal }}{\text { Test }^{1}}}$ \\
\hline $\begin{array}{l}\text { General } \\
\text { 1. Test each sequence in the sequence of operations, and other significant } \\
\text { modes and sequences not mentioned; including startup, shutdown, } \\
\text { unnoccupied \& manual modes and power failure. Test functionality of } \\
\text { this piece of equipment or system in all control strategies or interlocks } \\
\text { with which it is associated. }\end{array}$ & Manual & \\
\hline \multicolumn{3}{|l|}{ In addition to, or as part of (1) above, the following modes or tests are required: } \\
\hline 2. Mixed \& supply air, \& reset temperature control functions. & Both & \\
\hline 3. Economizer functions. & Both & Cooling \\
\hline 4. SF, RF and exhaust fan interlocks. & Either & \\
\hline 5. No CCV flow when there is HCV flow. & Both & \\
\hline 6. CCV \& HCV modulation \& positive shutoff (no leak-thru). & Manual & \\
\hline 7. Duct static pressure (SP) control. & Both & \\
\hline 8. Return or exhaust fan tracking and building SP. & Monitoring & \\
\hline $\begin{array}{l}\text { 9. VFD (or inlet vanes) operation on SF and RF: modulation to minimum, } \\
\text { control system PID, proportional band of speed vs controlling parameter, } \\
\text { constancy of static pressure, verification of program settings, alarms, etc. }\end{array}$ & Both & 2 \\
\hline $\begin{array}{l}\text { 10. Damper interlocks and correct modulation in all modes, including smoke } \\
\text { and fire dampers. }\end{array}$ & Manual & \\
\hline 11. Temperature difference across HC \& CC per specifications. & Manual & \\
\hline $\begin{array}{l}\text { 12. Verification of minimum OSA control through varying VAV box } \\
\text { positions. }\end{array}$ & Either & 2 \\
\hline 13. Heating and cooling coils freeze protection. & Manual & 2 \\
\hline 14. Branch duct control damper control. & Manual & \\
\hline 15. Night low limit, morning warmup cycle. & Either & \\
\hline 16. Heat recovery operation. & Monitoring & \\
\hline 17. Verify $\mathrm{TAB}$ reported $\mathrm{SF}$ cfm with control system reading. & Manual & 2 \\
\hline 18. All alarms (low limits, high static, etc.). & Manual & \\
\hline 19. Heating and cooling coil capacity test, optional. & Manual & Design \\
\hline
\end{tabular}




\begin{tabular}{|c|c|c|c|}
\hline & Function / Mode & $\begin{array}{l}\text { Test Method } \\
\text { Manual, } \\
\text { Monitoring, } \\
\text { Either or } \\
\text { Both }^{3}\end{array}$ & $\frac{\text { Required }}{\frac{\text { Seasonal }}{\text { Test }^{1}}}$ \\
\hline 20. & $\begin{array}{l}\text { Sensor and actuator calibration checks: on duct static pressure sensor on } \\
\text { SAT, MAT, OSAT, OSA \& RA damper and valve positions, SF cfm } \\
\text { reading with TAB, and other random checks (EMS readout against } \\
\text { hand-held calibrated instrument or observation must be within specified } \\
\text { tolerances) }\end{array}$ & Manual & \\
\hline 21. & Verify schedules and setpoints to be reasonable and appropriate & & \\
\hline
\end{tabular}

${ }^{1}$ Cooling season, Heating season or Both. "Design" means within $5^{\circ}$ of season design (ASHRAE $21 / 2 \%$ ), or $95 \%$ of loading design. A blank cell denotes no special seasonal test is required and that test can be executed during any season, if condition simulation is appropriate.

${ }^{2}$ Seasonal test not required if seasonal conditions can be adequately simulated.

${ }^{3}$ Refer to Special Procedures

E. Special Procedures (other equipment to test with, etc.; reference to function ID)

1. Reduced Testing for Smaller Units. For standard application AHU's less than 15 tons, the following modifications to the testing requirements apply: 1) either Manual or Monitoring will satisfy the verification requirement--where Both is listed, choose one. 2) Testing Modes 6,8, 11,13 and 16 is not required.

F. Required Monitoring

1. All points listed below which are control system monitored points shall be trended by the controls contractor. Other points shall be monitored by the CA using dataloggers. Refer to the Monitoring section at the beginning of Section 15997 for additional monitoring details.

\begin{tabular}{|c|c|c|c|c|c|}
\hline Point & $\begin{array}{c}\text { Time } \\
\text { Step } \\
\text { (min.) }\end{array}$ & $\begin{array}{l}\text { Minimum } \\
\text { Time Period } \\
\text { of Trend }\end{array}$ & $\begin{array}{l}\text { Hard } \\
\text { Copy? } \\
(\mathrm{Y} / \mathrm{N}) \\
\end{array}$ & $\begin{array}{l}\text { ASCII } \\
\text { File? } \\
(\mathrm{Y} / \mathrm{N}) \\
\end{array}$ & $\begin{array}{c}\text { Function } \\
\text { Being Tested }\end{array}$ \\
\hline \multicolumn{6}{|l|}{ For each AHU being tested: } \\
\hline RAT & 5 & 5 days incl. weekend & $\mathbf{Y}$ & $\bar{Y}$ & $1-3,5$ \\
\hline SAT & 5 & 5 days incl. weekend & $\bar{Y}$ & $\bar{Y}$ & $1-3,5$ \\
\hline CC LAT (optional) & 5 & 5 days incl. weekend & $\bar{Y}$ & $\mathrm{Y}$ & $1-3,5$ \\
\hline HC LAT (optional) & 5 & 5 days incl. weekend & $\bar{Y}$ & $\mathrm{Y}$ & $1-3,5$ \\
\hline MAT & 5 & 5 days incl. weekend & $\bar{Y}$ & $\bar{Y}$ & 1,3 \\
\hline $\begin{array}{l}\text { Indoor WB or enthalpy, if } \\
\text { enthalpy economizer }\end{array}$ & 5 & 5 days incl. weekend & $\bar{Y}$ & $\bar{Y}$ & 1,3 \\
\hline $\begin{array}{l}\text { SF speed, if variable, else } \\
\text { status }\end{array}$ & 5 & 5 days incl. weekend & $\bar{Y}$ & $\bar{Y}$ & $1,5-9$ \\
\hline $\begin{array}{l}\text { RF.speed, if variable, else } \\
\text { status }\end{array}$ & 5 & 5 days incl. weekend & $\bar{Y}$ & $\bar{Y}$ & $1,5-9$ \\
\hline Duct SP & 5 & 5 days incl. weekend & $\mathrm{Y}$ & $\bar{Y}$ & $1,7,9$ \\
\hline Building SP differential & 5 & 5 days incl. weekend & $\bar{Y}$ & $\bar{Y}$ & 8 \\
\hline OSAT & 5 & 5 days incl. weekend & $\mathrm{Y}$ & $\mathrm{Y}$ & All \\
\hline $\begin{array}{l}\text { OSA-WB or enthalpy, if } \\
\text { enthalpy economizer }\end{array}$ & 5 & 5 days incl. weekend & $\mathbf{Y}$ & $\mathbf{Y}$ & 1,3 \\
\hline $\begin{array}{l}\text { Indoor dry-bulb _zones } \\
\text { (expected to be most } \\
\text { problematic) }\end{array}$ & 5 & 5 days incl. weekend & $\mathbf{Y}$ & $\mathbf{Y}$ & All \\
\hline & & & & & \\
\hline
\end{tabular}


Remarks:

CCV position (optional)

HCV position (optional)

$\mathrm{SF} \mathrm{cfm}$ not required if not monitored

$\mathrm{RF}$ cfm not required if not monitored

G. Acceptance Criteria (referenced by function or mode ID)

1-21. For the conditions, sequences and modes tested, the AHU, integral components and related equipment respond to varying loads and changing conditions and parameters appropriately as expected, as specified and according to acceptable operating practice.

2. AHU shall be able to maintain the SA temperature within $1.0 \mathrm{~F}$ either side of the deadband of the current setpoint without excessive hunting.

7. AHU and controls shall control the duct static pressure so that it does not drift more than an amount equal to $10 \%$ of the setpoint value either side of the deadband without excessive hunting.

H. Sampling Strategy for Identical Units ( $x x \%$ Sampling - yy\% Failure Rule is defined in Section 17100, Part 3.6)

1. All identical AHU's over 15 tons shall not have any sampling-test all units. However, $25 \%$ of the units may have monitoring be the verification method for modes listed with Monitoring or Both as testing methods, with no less than three units being fully tested per the above requirements.

2. All identical AHU's equal to or less than 15 tons shall be tested as required above according to the $50 \%$ Sampling--20\% Failure Rule. The other $50 \%$ shall be monitored for the modes listed above as needing monitoring.

\section{END OF REQUIREMENTS FOR AHU TEST}


4. TERMINAL UNITS (TU) (all types)

A. Parties Responsible to Execute Functional Test

1. Controls contractor: operate the controls to activate the equipment.

B. Integral Components or Related Equipment Being Tested

1. Terminal unit

Prefunctional Checklist ID

PC-

C. Prerequisites The applicable prerequisite checklist items listed in the beginning of Section 15997 shall be listed on each functional test form and checked off prior to functional testing.

D. Functions / Modes Required To Be Tested. Test Methods and Seasonal Test Requirements The following testing requirements are in addition to and do not replace any testing requirements elsewhere in this Division.

\begin{tabular}{|c|c|c|}
\hline Function / Mode & $\begin{array}{l}\frac{\text { Test Method }}{\text { Manual, }} \\
\text { Monitoring, } \\
\text { Either or } \\
\text { Both }^{3}\end{array}$ & $\begin{array}{l}\text { Required } \\
\frac{\text { Seasonal }}{\text { Test }^{1}}\end{array}$ \\
\hline $\begin{array}{l}\text { General } \\
\text { 1. Test each sequence in the sequence of operations, and other significant } \\
\text { modes and sequences not mentioned; including startup, warmup, } \\
\text { shutdown, unnoccupied \& manual modes and power failure and } \\
\text { restoration. Test functionality of this piece of equipment or system in all } \\
\text { control strategies or interlocks that it is associated with, including all } \\
\text { damper, valve and fan functions. }\end{array}$ & Manual & \\
\hline \multicolumn{3}{|l|}{ In addition to, or as part of (1) above, the following modes or tests are required: } \\
\hline $\begin{array}{l}\text { 2. Sensor activator calibration checks on: SAT, MAT, zone air temperature } \\
\text { damper position and other random checks (EMS readout against visual } \\
\text { or hand-held calibrated instrument must be within } 0.5^{\circ} \mathrm{F} \text { for temps. or } \\
\text { within a tolerance equal to } 10 \% \text { of static pressure setpoint, with an } \\
\text { inclined manometer) }\end{array}$ & Manual & \\
\hline $\begin{array}{l}\text { 3. Device and actuator calibration and stroke checks for heating coil valve } \\
\text { and non-DDC dampers }\end{array}$ & Manual & \\
\hline 4. For the TU's tested, check the prefunctional checklist items. & Observation & \\
\hline $\begin{array}{l}\text { 5erify control parameters and setpoints to be reasonable and appropriate } \\
\text { by reviewing the full program of } 5 \% \text { of all the TU's with each other for } \\
\text { consistency. Verify the max. and min. cfm setpoints of all tested TU's } \\
\text { against the control drawing and TAB values. Verify other TU } \\
\text { programming parameters such as K-factors, deadbands, setpoints, stroke } \\
\text { times, etc. }\end{array}$ & Observation & \\
\hline 6. Verify no CCV flow when there is HCV flow & Either & \\
\hline 7. Verify no hunting or significant overshoot by damper or valves. & Either & \\
\hline 8. Verify by measurement, CCV \& HCV positive shutoff (no leak-thru) & Manual & \\
\hline $\begin{array}{l}\text { 9. Verification of minimum OSA control through varying VAV box } \\
\text { positions, if applicable }\end{array}$ & Either & $\overline{2}$ \\
\hline 10. All alarms (fan status, low limits, high static, etc.) & Manual & \\
\hline 11. Verify that $\mathrm{TU}$ is maintaining space setpoint temperatures & Monitoring & $\begin{array}{l}\text { Both } \\
\text { Design }\end{array}$ \\
\hline 12. Verify airflows and pressures (this random test is part of the TAF & - & \\
\hline
\end{tabular}


${ }^{1}$ Cooling season, Heating season or Both. "Design" means within $5^{\circ} \mathrm{F}$ of season design (ASHRAE 2 $1 / 2 \%$ ), or $95 \%$ of loading design. A blank cell denotes no special seasonal test is required and that test can be executed during any season, if condition simulation is appropriate.

${ }^{2}$ Seasonal test not required if seasonal conditions can be adequately simulated.

${ }^{3}$ Refer to Special Procedures

E. Special Procedures (other equipment to test with, etc.; reference to function ID)

None

F. Required Monitoring

1. All points listed below which are control system monitored points shall be trended by the controls contractor. Monitoring is required on $1 / 2$ of the tested TU's. Other points shall be monitored by the CA using dataloggers. Refer to the Monitoring section at the beginning of Section 15997 for additional monitoring details.

\begin{tabular}{|c|c|c|c|c|c|}
\hline & Time & Minimum & Hard & ASCII & \\
& $\begin{array}{c}\text { Step } \\
\text { (min.) }\end{array}$ & $\begin{array}{c}\text { Time Period } \\
\text { of Trend }\end{array}$ & $\begin{array}{c}\text { Copy? } \\
\text { (Y/N) }\end{array}$ & $\begin{array}{c}\text { File? } \\
\text { (Y/N) }\end{array}$ & $\begin{array}{c}\text { Function } \\
\text { Being Tested }\end{array}$ \\
\hline
\end{tabular}

For each zone thermostat and space sensor and other critical areas, monitor:

\begin{tabular}{|l|c|c|c|c|c|}
\hline Space temperature & 10 & $\begin{array}{c}3 \text { weekdays, } \\
\text { summer design }\end{array}$ & $\mathrm{Y}$ & $\mathrm{Y}$ & 11 \\
\hline Space temperature & 10 & $\begin{array}{c}3 \text { weekdays, } \\
\text { winter design }\end{array}$ & $\mathrm{Y}$ & $\mathrm{Y}$ & 11 \\
\hline Space temperature & 2 & 8 hours, occupied & $\mathrm{Y}$ & $\mathrm{Y}$ & 7 \\
\hline Heating coil valve & 2 & 8 hours, occupied & $\mathrm{Y}$ & $\mathrm{Y}$ & 7 \\
\hline Damper position or cfm & 2 & 8 hours, occupied & $\mathrm{Y}$ & $\mathrm{Y}$ & 7 \\
\hline
\end{tabular}

Remarks:

G. Acceptance Criteria (referenced by function or mode ID)

1-11. For the conditions, sequences and modes tested, the TU, integral components and related equipment respond to varying loads and changing conditions and parameters appropriately as expected, as specified and according to acceptable operating practice.

10. Space temperature during occupied modes shall remain within $1^{\circ} \mathrm{F}$ of the ends of the deadband without excessive hunting of either the damper or coil valve.

H. Sampling Strategy for Identical Units ( $\mathrm{xx} \%$ Sampling - yy\% Failure Rule is defined in Section 17100, Part 3.6). Units of the same type and function, but different in size, are considered identical for sampling purposes.

1. Random sample according to the $10 \%$ Sampling - $10 \%$ Failure Rule. This applies to the testing subsections. That is, if calibration is off on more than $10 \%$ of the tested TU's, then another sample shall have calibrations checked, but not all other tests need to be done on the second sample.

\section{END OF REQUIREMENTS FOR TERMINAL UNIT TEST}




\section{PACKAGED DX AIR CONDITIONING OR HEAT PUMP UNITS}

A. Parties Responsible to Execute Functional Test

1. Controls contractor: operate the controls to activate the equipment.

B. Integral Components or Related Equipment Being Tested

1. Unit (fans, coils, condenser, compressors, ducts, VFD)

2. Heat recovery coil , humidifier or direct / indirect evaporative cooling sections

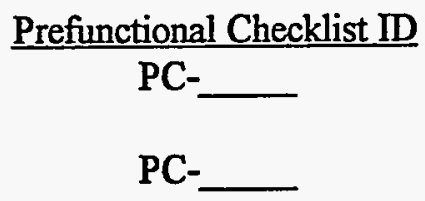

C. Prerequisites The applicable prerequisite checklist items listed in the beginning of Section 15997 shall be listed on each functional test form and checked off prior to functional testing.

D. Functions / Modes Required To Be Tested, Test Methods and Seasonal Test Requirements The following testing requirements are in addition to and do not replace any testing requirements elsewhere in this Division.

\begin{tabular}{|c|c|c|}
\hline Function / Mode & $\begin{array}{l}\text { Test Method } \\
\text { Manual, } \\
\text { Monitoring, } \\
\text { Either or } \\
\text { Both }^{3}\end{array}$ & $\frac{\text { Required }}{\text { Seasonal }}$ \\
\hline $\begin{array}{l}\text { General } \\
\text { 1. Test each sequence in the sequence of operations, and other significant } \\
\text { modes and sequences not mentioned; including startup, shutdown, } \\
\text { unnoccupied \& manual modes and power failure. Test functionality of } \\
\text { this piece of equipment or system in all control strategies or interlocks } \\
\text { that it is associated with. }\end{array}$ & Manual & \\
\hline \multicolumn{3}{|l|}{ In addition to, or as part of (1) above, the following modes or tests are required: } \\
\hline 2. Mixed and supply air, and reset temp. control functions & Both & \\
\hline 3. Economizer functions & Both & Cooling \\
\hline 4. SF, RF and exhaust fan interlocks & Either & \\
\hline 5. Compressor unloading \& condenser fan staging for head pressure control & Both & \\
\hline 6. Demand limiting control (if applicable) & Monitoring & Cooling \\
\hline 7. Duct static pressure (SP) control & Both & \\
\hline 8. Return or exhaust fan tracking and building SP & Monitoring & \\
\hline $\begin{array}{l}\text { 9. VFD (or inlet vanes) operation on SF and RF: modulation to minimum, } \\
\text { control system PID, proportional band of speed vs controlling parameter, } \\
\text { constancy of static pressure, verification of program settings, alarms, etc }\end{array}$ & Both & 2 \\
\hline $\begin{array}{l}\text { 10. Damper interlocks and correct modulation in all modes, including fire } \\
\text { and smoke dampers }\end{array}$ & Manual & \\
\hline 11. Temperature difference across heating and cooling coils, if spec'd & Manual & \\
\hline $\begin{array}{l}\text { 12. Verification of minimum OSA quantity and control through varying } \\
\text { VAV box positions }\end{array}$ & Either & 2 \\
\hline 13. Branch duct control damper control & Manual & \\
\hline 14. Night low and high limit, morning warmup cycle, & Either & \\
\hline 15. Heat recovery operation & Monitoring & \\
\hline 16. Verify $\mathrm{TAB}$ reported $\mathrm{SF}$ cfm with control system reading & Manual & 2 \\
\hline 17. All alarms (low limits, high static, freezestat, etc.) & Manual & \\
\hline 18. Unit heating and cooling capacity tests, optional & Manual & Design \\
\hline 19. Heating and cooling EER or COP efficiency tests, optional & & Design \\
\hline 20. Change over function from heating to cooling and defrost (heatpumps) & Manual & \\
\hline
\end{tabular}


SECTION 15997 - 15

MECHANICAL TESTING REQUIREMENTS

\begin{tabular}{|c|c|c|c|}
\hline & Function / Mode & $\begin{array}{l}\text { Test Method } \\
\text { Manual, } \\
\text { Monitoring, } \\
\text { Either or } \\
\text { Both }^{3}\end{array}$ & $\frac{\frac{\text { Required }}{\text { Seasonal }}}{\text { Test }^{1}}$ \\
\hline & $\begin{array}{l}\text { Sensor and actuator calibration checks on: duct static pressure sensor on } \\
\text { units }>10 \text { tons, SAT, MAT, OSAT, economizer and RA dampers and } \\
\text { other random checks (EMS readout against hand-held calibrated } \\
\text { instrument must be within } 0.5^{\circ} \mathrm{F} \text { for temps. or within a tolerance equal to } \\
10 \% \text { of static pressure setpoint, with an inclined manometer) }\end{array}$ & Manual & \\
\hline & $\begin{array}{l}\text { Verify control strategies, schedules and setpoints to be reasonable and } \\
\text { appropriate }\end{array}$ & & \\
\hline
\end{tabular}

${ }^{1}$ Cooling season, Heating season or Both. "Design" means within $5^{\circ}$ of season design (ASHRAE $21 / 2 \%$ ), or $95 \%$ of loading design. A blank cell denotes no special seasonal test is required and that test can be executed during any season, if condition simulation is appropriate.

${ }^{2}$ Seasonal test not required if seasonal conditions can be adequately simulated.

${ }^{3}$ Refer to Special Procedures

E. Special Procedures (other equipment to test with, etc.; reference to function ID)

1. Reduced Testing for Smaller Units. For standard application AHU's less than 15 tons, the following modifications to the testing requirements apply: 1) either Manual or Monitoring will satisfy the verification requirement--where Both is listed, choose one. 2) Testing Modes 6, 8, 11,13 and 16 is not required.

F. Required Monitoring

1. All points listed below which are control system monitored points shall be trended by the controls contractor. Other points shall be monitored by the CA using dataloggers. Refer to the Monitoring section at the beginning of Section 15997 for additional monitoring details.

\begin{tabular}{|l|c|c|c|c|c|}
\hline \multicolumn{1}{|c|}{ Point } & $\begin{array}{c}\text { Time } \\
\text { Step } \\
\text { (min.) }\end{array}$ & $\begin{array}{c}\text { Minimum } \\
\text { Time Period } \\
\text { of Trend }\end{array}$ & $\begin{array}{c}\text { Hard } \\
\text { Copy? } \\
\text { (Y/N) }\end{array}$ & $\begin{array}{c}\text { ASCII } \\
\text { File? } \\
\text { (Y/N) }\end{array}$ & $\begin{array}{c}\text { Function } \\
\text { Being Tested }\end{array}$ \\
\hline For each Unit being tested: \\
\hline RAT & 5 & 5 days incl. weekend & Y & Y & $1-3,5,19$ \\
\hline SAT & 5 & 5 days incl. weekend & Y & Y & $1-3,5$ \\
\hline CC LAT & 5 & 5 days incl. weekend & Y & Y & $1-3,5$ \\
\hline HC LAT & 5 & 5 days incl. weekend & Y & Y & $1-3,5$ \\
\hline MAT & 5 & 5 days incl. weekend & Y & Y & $1,3,19$ \\
\hline Indoor WB or enthalpy & 5 & 5 days incl. weekend & Y & Y & 1,3 \\
\hline SF speed & 5 & 5 days incl. weekend & Y & Y & $1,5-9$ \\
\hline RF speed & 5 & 5 days incl. weekend & Y & Y & $1,5-9$ \\
\hline Duct SP & 5 & 5 days incl. weekend & Y & Y & $1,7,9$ \\
\hline Building SP differential & 5 & 5 days incl. weekend & Y & Y & 8 \\
\hline OSAT & 5 & 5 days incl. weekend & Y & Y & All \\
\hline OSAT-WB or enthalpy & 5 & 5 days incl. weekend & Y & Y & 1,3 \\
\hline Indoor dry-bulb zones & 5 & 5 days incl. weekend & Y & Y & All \\
\hline Compressor amps or stage & 5 & 5 days incl. weekend & Y & Y & 5 \\
\hline $\begin{array}{l}\text { Condenser fan amps or } \\
\text { stage }\end{array}$ & 5 & 5 days incl. weekend & Y & Y & 5 \\
\hline
\end{tabular}

Remarks: 
G. Acceptance Criteria (referenced by function or mode ID)

1-22. For the conditions, sequences and modes tested, the system, integral components and related equipment respond to varying loads and changing conditions and parameters appropriately as expected, as specified and according to acceptable operating practice.

2. RTU shall be able to maintain the SA temperature within $1.0 \mathrm{~F}$ either side of the deadband of the current setpoint without excessive hunting.

7. RTU and controls shall control the duct static pressure so that it does not drift more than an amount equal to $10 \%$ of the setpoint value either side of the deadband without excessive hunting.

H. Sampling Strategy for Identical Units ( $x x \%$ Sampling - yy\% Failure Rule is defined in Section 17100, Part 3.6)

1. All identical AHU's over 30 tons shall not have any sampling-test all units. However, $25 \%$ of the units may have monitoring be the verification method for modes listed with Monitoring or Both as testing methods, with no less than three units being fully tested per the above requirements.

2. All identical AHU's equal to or less than 30 tons shall be tested as required above according to the $50 \%$ Sampling- $-20 \%$ Failure Rule. The other $50 \%$ shall be monitored for the modes listed above as needing monitoring.

END OF REQUIREMENTS FOR PACKAGED UNIT TEST 


\section{BOILER SYSTEM (Heating Water)}

A. Parties Responsible to Execute Functional Test

1. Controls contractor: operate the controls

2. HVAC mechanical contractor or vendor: assist in testing sequences

B. Integral Components or Related Equipment Being Tested

1. Boiler

2. Primary HW supply pumps

3. Heating water piping system

4. Secondary HW supply pumps

5. VFD on secondary pumps
Prefunctional Checklist ID

PC-

PC-

$\mathrm{PC}-$

PC-

$\mathrm{PC}$ -

C. Prerequisites The applicable prerequisite checklist items listed in the beginning of Section 15997 shall be listed on each functional test form and checked off prior to functional testing.

D. Functions / Modes Required To Be Tested. Test Methods and Seasonal Test Requirements

The following testing requirements are in addition to and do not replace any testing requirements elsewhere in this Division.

\begin{tabular}{|c|c|c|}
\hline Function / Mode & $\begin{array}{l}\text { Test Method } \\
\text { Manual, } \\
\text { Monitoring, } \\
\text { Either or } \\
\text { Both }\end{array}$ & $\begin{array}{l}\frac{\text { Required }}{\text { Seasonal }} \\
\text { Test }^{1}\end{array}$ \\
\hline $\begin{array}{l}\text { General } \\
\text { 1. Test each sequence in the sequence of operations, and other significant } \\
\text { modes and sequences not mentioned; including startup, shutdown, } \\
\text { unnoccupied \& manual modes and power failure. Test functionality of } \\
\text { this piece of equipment or system in all control strategies or interlocks } \\
\text { that it is associated with. }\end{array}$ & Manual & \\
\hline \multicolumn{3}{|l|}{ In addition to, or as part of (1) above, the following modes or tests are required: } \\
\hline $\begin{array}{l}\text { 2. Primary Side. Lead/lag staging of boilers, optimization, capacity } \\
\text { modulation, and primary HW supply pumps. }\end{array}$ & Both & Heating \\
\hline $\begin{array}{l}\text { 3. Secondary Side. Secondary WH supply pump staging, bypass valve } \\
\text { operation, if no VFD and HWT reset. VFD operation: modulation to } \\
\text { minimum, control system PID, proportional band of speed vs controlling } \\
\text { parameter, verification of program settings, }{ }_{2} \text { alarms, etc. }\end{array}$ & Both & Heating \\
\hline $\begin{array}{l}\text { 4. Check all alarms and safeties (high and low pressure and temperature, } \\
\text { etc.), PRV and flow switch functions }\end{array}$ & Manual & \\
\hline $\begin{array}{l}\text { 5. Test each possible lead boiler as lead boiler, and each pump as lead } \\
\text { pump. Test pump lockouts. }\end{array}$ & Manual & \\
\hline 6. Flue gas analysis verification, optional & Manual & \\
\hline 7. Efficiency and capacity tests, optional & Manual & Heating \\
\hline $\begin{array}{l}\text { 8. Verify boiler inlet/outlet pressures with startup report and } \\
\text { manufacturer's recommendations }\end{array}$ & Manual & \\
\hline $\begin{array}{l}\text { 9. Sensor and actuator calibration checks on: HWST, HWRT, pressure } \\
\text { sensor controlling pump speed, mixing valve and other random checks } \\
\text { (EMS readout against hand-held calibrated instrument must be within } \\
0.5^{\circ} \mathrm{F} \text { for temps. or within a tolerance equal to } 10 \% \text { of the pressure } \\
\text { setpoint, with a test gage) }\end{array}$ & Manual & \\
\hline 10. Constancy of differential pressure (pump control parameter) & Monitoring & Heating \\
\hline
\end{tabular}


11. Verify schedules and setpoints to be reasonable and appropriate

${ }^{1}$ Cooling season, Heating season or Both. "Design" means within $5^{\circ}$ of season design (ASHRAE $21 / 2 \%$ ), or $95 \%$ of loading design. A blank cell denotes no special seasonal test is required and that test can be executed during any season, if condition simulation is appropriate.

E. Special Procedures (other equipment to test with, etc.; reference to function ID)

1. False load boiler, if necessary.

F. Required Monitoring

1. All points listed below which are control system monitored points shall be trended by the controls contractor. Other points shall be monitored by the CA using dataloggers. Refer to the Monitoring section at the beginning of Section 15997 for additional monitoring details.

\begin{tabular}{|c|c|c|c|c|c|}
\hline Point & $\begin{array}{c}\text { Time } \\
\text { Step } \\
\text { (min.) }\end{array}$ & $\begin{array}{c}\text { Minimum } \\
\text { Time Period } \\
\text { of Trend }\end{array}$ & $\begin{array}{l}\text { Hard } \\
\text { Copy? } \\
(Y / N)\end{array}$ & $\begin{array}{l}\text { ASCII } \\
\text { File? } \\
(Y / N) \\
\end{array}$ & $\begin{array}{c}\text { Function } \\
\text { Being Tested } \\
\end{array}$ \\
\hline \multicolumn{6}{|l|}{ For each boiler and pump: } \\
\hline Boiler current or status & 5 & 5 days incl. weekend & $\mathrm{Y}$ & $Y$ & $1-3$ \\
\hline HWST & 5 & 5 days incl. weekend & $\mathbf{Y}$ & $Y$ & 1,3 \\
\hline HWRT & 5 & 5 days incl. weekend & $Y$ & 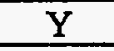 & 1,3 \\
\hline OSAT-DB & 5 & 5 days incl. weekend & $\mathbf{Y}$ & $Y$ & $1-3$ \\
\hline $\begin{array}{l}\text { HWS primary pump current } \\
\text { or status }\end{array}$ & 5 & 5 days incl. weekend & $\bar{Y}$ & $\mathrm{Y}$ & 1,2 \\
\hline $\begin{array}{l}\text { HWS secondary pump } \\
\text { speed, if variable }\end{array}$ & 5 & 5 days incl. weekend & $Y$ & $\mathrm{Y}$ & 1,3 \\
\hline $\begin{array}{l}\text { HWS secondary pump flow } \\
\text { rate, if in EMS }\end{array}$ & 5 & 5 days incl. weekend & $\bar{Y}$ & $\bar{Y}$ & 1,3 \\
\hline $\begin{array}{l}\text { HWS secondary pump speed } \\
\text { controlling parameter value }\end{array}$ & 5 & 5 days incl. weekend & $\bar{Y}$ & $\bar{Y}$ & $1,3,10$ \\
\hline
\end{tabular}

Remarks:

G. Acceptance Criteria (referenced by function or mode ID)

1-11. For the conditions, sequences and modes tested, the boilers, integral components and related equipment respond to varying loads and changing conditions and parameters appropriately as expected, as specified and according to acceptable operating practice.

2. Boiler shall maintain the supply water setpoint to within $+/-1.0 \mathrm{~F}$ of setpoint deadband without excessive hunting.

9.-10. Pumping system and controls shall maintain the current desired pressure setpoint to within an amount equal to $10 \%$ of the setpoint value either side of the deadband without excessive hunting.

H. Sampling Strategy for Identical Units ( $x x \%$ Sampling - yy\% Failure Rule is defined in Section 17100, Part 3.6)

1. No sampling, test all. 


\section{EXHAUST FANS}

The testing requirements apply to the following fans (check all that apply): _central restroom, _mechanical room, _stairwell pressurization, _elevator pressurization, __kitchen hood, garage

A. Parties Responsible to Execute Functional Test

1. Controls contractor: operate the controls to activate the equipment.

B. Integral Components or Related Equipment Being Tested

1. Exhaust fans

Prefunctional Checklist ID

$P C$ -

C. Prerequisites The applicable prerequisite checklist items listed in the beginning of Section 15997 shall be listed on each functional test form and checked off prior to functional testing.

D. Functions / Modes Required To Be Tested, Test Methods and Seasonal Test Requirements The following testing requirements are in addition to and do not replace any testing requirements elsewhere in this Division.

\begin{tabular}{|c|c|c|}
\hline Function / Mode & $\begin{array}{l}\text { Test Method } \\
\text { Manual, } \\
\text { Monitoring, } \\
\text { Either or } \\
\text { Both }^{1}\end{array}$ & $\frac{\frac{\text { Required }}{\text { Seasonal }}}{\underline{\text { Test }}}$ \\
\hline $\begin{array}{l}\text { General } \\
\text { 1. Test each sequence in the sequence of operations, and other significant } \\
\text { modes and sequences not mentioned; including startup, shutdown, } \\
\text { unnoccupied \& manual modes and power failure. Test functionality of } \\
\text { this piece of equipment or system in all control strategies or interlocks } \\
\text { that it is associated with. }\end{array}$ & Manual & \\
\hline \multicolumn{3}{|l|}{ In addition to, or as part of (1) above, the following modes or tests are required: } \\
\hline 2. Verify schedules and setpoints to be reasonable and appropriate & & \\
\hline 3. Function at fire alarm (off, depressurization, etc.) & Manual & \\
\hline 4. Interlocks to building pressurization control & Manual & \\
\hline 5. Speed controls & Either & \\
\hline $\begin{array}{l}\text { 6. Check TAB report record of sound power level tests and space pressures } \\
\text { and compare to specifications }\end{array}$ & Review & \\
\hline $\begin{array}{l}\text { 7. Sensor calibration checks on any controlling temperature or pressure } \\
\text { sensor }\end{array}$ & Manual & \\
\hline
\end{tabular}

${ }^{1}$ Refer to Special Procedures

E. Special Procedures (other equipment to test with, etc.; reference to function ID) None 


\section{F. Required Monitoring}

1. All points listed below which are control system monitored points shall be trended by the controls contractor. Other points shall be monitored by the CA using dataloggers. Refer to the Monitoring section at the beginning of Section 15997 for additional monitoring details.

\begin{tabular}{|l|c|c|c|c|c|}
\hline \multicolumn{1}{|c|}{} & $\begin{array}{c}\text { Time } \\
\text { Step } \\
\text { Point }\end{array}$ & $\begin{array}{c}\text { Minimum } \\
\text { Time Period } \\
\text { of Trend }\end{array}$ & $\begin{array}{c}\text { Hard } \\
\text { Copy? } \\
\text { (Y/N) }\end{array}$ & $\begin{array}{c}\text { ASCII } \\
\text { File? } \\
\text { (Y/N) }\end{array}$ & $\begin{array}{c}\text { Function } \\
\text { Being Tested }\end{array}$ \\
\hline For each fan: & & & & & \\
\hline Do be determined & & & & & \\
\hline
\end{tabular}

Remarks:

G. Acceptance Criteria (referenced by function or mode ID)

1-6. For the conditions, sequences and modes tested, the fans, integral components and related equipment respond to changing conditions and parameters appropriately as expected, as specified and according to acceptable operating practice.

H. Sampling Strategy for Identical Units ( $x x \%$ Sampling - yy\% Failure Rule is defined in Section 17100, Part 3.6)

1. All identical fans shall have the $20 \%$ Sampling - $10 \%$ Failure Rule apply.

END OF REQUIREMENTS FOR EXHAUST FAN TEST 


\section{SERVICE HOT WATER SYSTEM}

A. Parties Responsible to Execute Functional Test

1. Controls contractor: operate the controls to activate the equipment.

B. Integral Components or Related Equipment Being Tested

1. Hot water heaters (heaters, mixing valves)

2. Recirculating pumps

Prefunctional Checklist ID

PC-

PC-

C. Prerequisites The applicable prerequisite checklist items listed in the beginning of Section 15997 shall be listed on each functional test form and checked off prior to functional testing.

D. Functions / Modes Required To Be Tested, Test Methods and Seasonal Test Requirements The following testing requirements are in addition to and do not replace any testing requirements elsewhere in this Division.

\begin{tabular}{|c|c|c|}
\hline Function / Mode & $\begin{array}{l}\text { Test Method } \\
\text { Manual, } \\
\text { Monitoring, } \\
\text { Either or } \\
\text { Both }\end{array}$ & $\frac{\frac{\text { Required }}{\text { Seasonal }}}{\underline{\text { Test }}}$ \\
\hline $\begin{array}{l}\text { General } \\
\text { 1. Test each sequence in the sequence of operations, and other significant } \\
\text { modes and sequences not mentioned; including startup, shutdown, } \\
\text { unnoccupied \& manual modes and power failure. Test functionality of } \\
\text { this piece of equipment or system in all control strategies or interlocks } \\
\text { that it is associated with. }\end{array}$ & Manual & \\
\hline \multicolumn{3}{|l|}{ In addition to, or as part of (1) above, the following modes or tests are required: } \\
\hline 2. Verify schedules and setpoints to be reasonable and appropriate & & \\
\hline 3. Unoccupied pump operation & Either & \\
\hline 4. Mixing valve operation and temperature control & Either & \\
\hline 5. Sensor calibration checks on hot water temperature & Manual & \\
\hline
\end{tabular}

E. Special Procedures (other equipment to test with, etc.; reference to function $\mathrm{D}$ )

None

F. Required Monitoring

None

G. Acceptance Criteria (referenced by function or mode ID)

1-6. For the conditions, sequences and modes tested, the fan's integral components and related equipment respond to changing conditions and parameters appropriately as expected, as specified and according to acceptable operating practice.

H. Sampling Strategy for Identical Units ( $x x \%$ Sampling - yy\% Failure Rule is defined in Section 17100, Part 3.6)

1. All identical fans shall have the $20 \%$ Sampling $-10 \%$ Failure Rule apply.

END OF REQUIREMENTS FOR SERVICE HOT WATER SYSTEM TEST 


\section{BUILDING AUTOMATION SYSTEM (BAS)}

Spec writer:

If all BAS controlled systems or equipment are not going to be functionally tested and trended, additional monitoring, trending and point-to-point checkout will be required above what is outlined below. In fact, the BAS cannot really be functionally tested without functionally testing all the equipment it controls.

A. Parties Responsible to Execute Functional Test

1. Controls contractor: operate the controls to activate the equipment.

B. Integral Components or Related Equipment Being Tested

1. Building Automation System

2. All prefunctional checklists of controlled equipment

Prefunctional Checklist ID

PC-

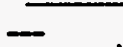

D. Prerequisites The applicable prerequisite checklist items listed in the beginning of Section 15997 shall be listed on each functional test form and checked off prior to functional testing.

E. A significant part of the BAS functional testing requirements is the successful completion of the functional tests of equipment the BAS controls or interlocks with. Uncompleted equipment functional tests or outstanding deficiencies in those tests lend the required BAS functional testing incomplete.

F. Integral or stand-alone controls are functionally tested with the equipment they are attached to, including any interlocks with other equipment or systems and thus are not covered under the BAS testing requirements, except for any integrated functions or interlocks listed below.

G. In addition to the controlled equipment testing, the following tests are required for the BAS, where features have been specified. The following testing requirements are in addition to and do not replace any testing requirements elsewhere in the specifications.

\begin{tabular}{|c|c|}
\hline Function / Mode & $\begin{array}{c}\text { Test Method } \\
\text { Manual (demonstration), } \\
\text { Monitoring, Either or } \\
\text { Both }\end{array}$ \\
\hline \multicolumn{2}{|l|}{ MISC. FUNCTIONS } \\
\hline $\begin{array}{l}\text { 1. All specified functions and features are set up, debugged and fully } \\
\text { operable }\end{array}$ & $\begin{array}{l}\text { Verbal discussion of } \\
\text { features }\end{array}$ \\
\hline 2. Power failure and battery backup and power-up restart functions & Demonstration \\
\hline 3. Specified trending and graphing features demonstration & See equipment trends \\
\hline 4. Global commands features & Demonstration \\
\hline 5. Security and access codes & Demonstration \\
\hline 6. Occupant over-rides (manual, telephone, key, keypad, etc.) & Demonstration \\
\hline 7. O\&M schedules and alarms & Demonstration \\
\hline 8. Scheduling features fully functional and setup, including holidays & $\begin{array}{l}\text { Observation in terminal } \\
\text { screens or printouts }\end{array}$ \\
\hline $\begin{array}{l}\text { 9. Date and time setting in central computer and verify field panels read the } \\
\text { same time }\end{array}$ & Demonstration \\
\hline
\end{tabular}




\begin{tabular}{|c|c|}
\hline Function / Mode & $\begin{array}{c}\text { Test Method } \\
\text { Manual (demonstration), } \\
\text { Monitoring, Either or } \\
\text { Both }\end{array}$ \\
\hline 10. Included features not specified to be setup are installed (list) & Demonstration \\
\hline 11. Occupancy sensors and controls & Demonstration \\
\hline $\begin{array}{l}\text { 12. Demonstrate functionality of field panels using local operator keypads and } \\
\text { local ports (plug-ins) using portable computer/keypad }\end{array}$ & $\begin{array}{l}\text { Demonstration of } 100 \% \text { of } \\
\text { panels and } 10 \% \text { of ports }\end{array}$ \\
\hline 13. All graphic screens and value readouts completed & Demonstration \\
\hline 14. Setpoint changing features and functions & $\begin{array}{c}\text { Done during equipment } \\
\text { testing }\end{array}$ \\
\hline 15. Communications to remote sites & Demonstration \\
\hline 16. Sensor calibrations & $\begin{array}{l}\text { Sampled during } \\
\text { equipment tests }\end{array}$ \\
\hline 17. "After hours" use tracking and billing & \\
\hline $\begin{array}{l}\text { 18. Final as-builts or redlines (per spec) control drawings, final points list, } \\
\text { program code, setpoints, schedules, warranties, etc. per specs, submitted } \\
\text { for O\&Ms. }\end{array}$ & Observation \\
\hline $\begin{array}{l}\text { 19. Verify that points that are monitored only, having no control function, are } \\
\text { checked for proper reporting to BAS. }\end{array}$ & Observation \\
\hline \multicolumn{2}{|l|}{ INTEGRATED TESTS } \\
\hline 20. Fire alarm interlocks and response & Demonstration \\
\hline 21. Duty cycling (if specified) & Monitoring \\
\hline 22. Demand limiting (including over-ride of limiting) & Monitoring \\
\hline 23. Sequential staging ON of equipment & Either \\
\hline 24. Optimum start-stop functions & Monitoring \\
\hline $\begin{array}{l}\text { 25. All control strategies and sequences not tested during controlled } \\
\text { equipment testing }\end{array}$ & Either \\
\hline 26. Other integrated tests specified in the contract documents & \\
\hline 27. Security system interlocks & Demonstration \\
\hline 28. Fire protection and suppression & - \\
\hline
\end{tabular}

H. Special Procedures (other equipment to test with, etc.; reference to function ID)

None

I. Additional Required Monitoring

1. Besides the trending and monitoring required with the functional testing of equipemint, all points listed below which are control system monitored points shall be trended by the controls contractor. Other points shall be monitored by the CA using dataloggers. Refer to the Monitoring section at the beginning of Section 15997 for additional monitoring details.

\begin{tabular}{|l|c|c|c|c|c|}
\hline \multicolumn{1}{|c|}{ Point } & $\begin{array}{c}\text { Time } \\
\text { Step } \\
\text { (min.) }\end{array}$ & $\begin{array}{c}\text { Minimum } \\
\text { Time Period } \\
\text { of Trend }\end{array}$ & $\begin{array}{c}\text { Hard } \\
\text { Copy? } \\
\text { (Y/N) }\end{array}$ & $\begin{array}{c}\text { ASCII } \\
\text { File? } \\
\text { Y/N) }\end{array}$ & $\begin{array}{c}\text { Function } \\
\text { Being Tested }\end{array}$ \\
\hline $\begin{array}{l}\text { Misc. equipment current or } \\
\text { status for duty cycling and } \\
\text { demand limiting }\end{array}$ & 5 & 5 days incl. weekend & $\mathrm{Y}$ & $\mathrm{Y}$ & $21-22$ \\
\hline $\begin{array}{l}\text { Equipment or building } \mathrm{kW} \\
\text { or current for demand } \\
\text { limiting }\end{array}$ & 5 & 5 days incl. weekend & $\mathrm{Y}$ & $\mathrm{Y}$ & $21-22$ \\
\hline Optimum start/stop equip. & 5 & 5 days incl. weekend & $\mathrm{Y}$ & $\mathrm{Y}$ & 24 \\
\hline
\end{tabular}


Remarks:

I. Acceptance Criteria (referenced by function or mode ID)

All For the conditions, sequences and modes tested, the BAS, integral components and related equipment respond to changing conditions and parameters appropriately as expected, as specified and according to acceptable operating practice.

J. Sampling Strategy for Identical Units ( $x x \%$ Sampling - yy\% Failure Rule is defined in Section 17100, Part 3.6)

1. Sampling of field panels and local ports for procedures 9 and 12 above, with a $10 \%$ Failure Rule.

\section{END OF REQUIREMENTS FOR BAS TEST}




\section{TEST AND BALANCE WORK (TAB)}

A. Parties Responsible to Execute Functional Test

1. TAB contractor: perform checks using test instruments.

2. Controls contractor: operate the controls to activate the equipment.

B. Integral Components or Related Equipment Being Tested

1. TAB water-side

2. $\mathrm{TAB}$ air-side

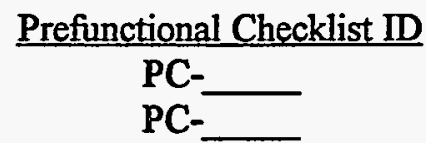

C. Prerequisites The applicable prerequisite checklist items listed in the beginning of Section 15997 shall be listed on each functional test form and checked off prior to functional testing.

D. Purpose. The purpose of this test is to spot check the TAB work to verify that it was done in accordance with the contract documents and acceptable practice and that the TAB report is accurate.

E. The following tests and checks will be conducted. The following testing requirements are in addition to and do not replace any testing requirements elsewhere in this Division.

\begin{tabular}{|c|c|c|}
\hline Test or Check & Test Method & $\begin{array}{c}\text { Required } \\
\text { Seasonal Test }^{3}\end{array}$ \\
\hline $\begin{array}{l}\text { 1. A random sample of up to } \\
\text { for verification (air velocity, air or water flow rate, pressure differential, } \\
\text { electrical or sound measurement, etc.). The original TAB contractor will } \\
\text { execute the checks, witnessed by the commissioning authority. The TAB } \\
\text { contractor will use the same test instruments as used in the original TAB } \\
\text { work. } \\
\text { A failure } 1 \text { of more than } 10 \% \text { of the selected items of a given system }{ }^{2} \text { shall } \\
\text { result in the failure of acceptance of the final TAB report and the TAB } \\
\text { contractor shall be responsible to rebalance the system, provide a new } \\
\text { total system TAB reports and repeat random verifications of the new TAB } \\
\text { report. } \\
\text { The random testing will include the verification of minimum outdoor air } \\
\text { intake flows at minimum, maximum and intermediate total airflow rates } \\
\text { for } \% \text { of the air handlers. Other selected data to be verified will be } \\
\text { made known upon day of testing. }\end{array}$ & Demonstration & $\begin{array}{l}\text { Cooling } \\
\text { Design }\end{array}$ \\
\hline $\begin{array}{l}\text { 2. Verify that settings of all valves, splitters, dampers and other adjustment } \\
\text { devices have been permanently marked by the Contractor, after } \\
\text { completion and acceptance of functional testing. }\end{array}$ & Demonstration & \\
\hline $\begin{array}{l}\text { 3. Verification that the air system is being controlled to the lowest possible } \\
\text { static pressure while still meeting design loads, less diversity. This shall } \\
\text { include a review of TAB methods, control setpoints established by TAB } \\
\text { and a physical verification of at least one leg from fan to diffuser having } \\
\text { all balancing dampers wide open. }\end{array}$ & Demonstration & \\
\hline $\begin{array}{l}\text { 4. Verification that the water system is being controlled to the lowest } \\
\text { possible pressure while still meeting design loads, less diversity. This } \\
\text { shall include a review of } T A B \text { methods, control setpoints established by } \\
\text { TAB and a physical verification of at least one leg from the pump to the } \\
\text { coil having all balancing valves wide open. }\end{array}$ & Demonstration & \\
\hline
\end{tabular}


${ }^{1}$ Failure of an item is defined as follows:

For air flow: a deviation of more than $10 \%$ of instrument reading

For temperatures: a deviation of more than $1^{\circ} \mathrm{F}$

For air and water pressures: a deviation of more than $10 \%$ of full scale of test instrument reading

For sound pressures: a deviation of more than 3 decibels. (Variations in background noise must be considered)

2Examples of a "system" are: the air distribution system served by one air handler or the hydronic chilled water supply system served by a chiller or the condenser water system. Systems can be defined smaller if inaccuracies in $\mathrm{TAB}$ work within the smaller defined system will have little or no impact on connected systems.

${ }^{3}$ Cooling season, Heating season or Both. "Design" means within $5 \circ$ of season design (ASHRAE $21 / 2 \%$ ), or $95 \%$ of loading design. A blank cell denotes no special seasonal test is required and that test can be executed during any season, if condition simulation is appropriate.

F. Special Procedures (other equipment to test with, etc.; reference to function ID)

None

G. Required Monitoring

None

I. Acceptance Criteria (referenced by function or mode ID)

Provided in footnote to test table above.

J. Sampling Strategy for Identical Units

Described in test table above.

END OF REQUIREMENTS FOR TAB TEST 


\section{INDOOR AIR QUALITY CHECK (IAQ)}

IAQ checking activities are not technically "functional testing." However, they are included here for consistency. Indoor air quality (IAQ) commissioning does not ensure that indoor air quality will be adequate or without deficiency at building turnover or during occupancy, unless the owner has specifically specified that actual air quality testing be performed. Commissioning for indoor air quality entails performing tasks that minimize the potential for IAQ problems, but it does not eliminate their possibility. The primary source for this checklist was Annex C in ASHRAE Guideline 1-1989R The HVAC Commissioning Process, Public Review Draft, 1996.

\section{Spec Writer:}

The IAQ checks here should be carefully reviewed for completeness and applicability to the current project and the Owner's documented program regarding IAQ. In particular, specifying any actual "testing" can have significant cost and liability ramifications.

A. Parties Responsible to Perform IAQ Checks

1. Commissioning agent: performs and oversees checks, inspections and reviews.

2. $\mathrm{TAB}$ contractor: performs checks using test instruments for tasks under Part $\mathrm{C}$

C. Prerequisites CA will perform each check and review as soon as the materials or work is such that IAQ related determinations can be made.

D. Purpose. The purpose of the IAQ check is to minimize the potential for IAQ problems in the facility during occupancy. The CA is not responsible for any IAQ issues during construction, nor for IAQ issues in the occupied part of the facility, if construction is being performed in other parts of the facility.

E. The following tasks will be conducted and documented:

Spec Writer: Edit and enhance this list as appropriate. Performing all tasks on this list is currently rarely done by commissioning agents.

More specificity will also be needed on many of the tasks before the TAB and CA can bid this work.

\section{Submittal Reviews}

Compare specified data with submitted data sheets for the following:

a. Filtration and filter type.

b. Materials that had specifications for emissions rates as part of the contract documents.

c. HVAC materials that have a potential for airflow erosion, corrosion and microbial contamination (HVAC insulation materials, etc.).

d. Manufacturer's safety data sheets (MSDS) for products specified in the contract documents that may be suspected contributors to indoor pollutants (carpets, flooring, fabrics, adhesives, wall coverings, partitions, and ceilings; insulating and fire-proofing materials; sealants on walls and floors; use of preservatives, paints, varnishes, and other finish materials). 


\section{Static Inspections and Checks}

a. Review the code compliance calculations for accuracy.

b. Verify that the outdoor air intakes are sized and located according the plans and specifications.

c. Verify that no outside conditions exist that could compromise the quality of the air entering the outdoor intakes.

d. Inspect air intakes and exhausts for short-circuiting.

e. Document any required ductwork cleaning.

f. Prior to building turnover, verify that final filters are installed and coils, inside of units and ductwork is clean.

g. Inspect air supply system components to ensure control and minimization of the presence of free and standing water and to minimize microbial contamination (condensate trays, traps, humidifiers, water baffles, mist eliminators and cooling towers).

h. Verify proper access for cleaning of both sides of coils, condensate pans and/or humidifier reservoirs in all HVAC equipment.

i. Meet with contractors and review any specified manufacturer's recommended curing, drying and airing procedures (for minimizing emission rates). Document the compliance of the contractors.

j. When the building is partially occupied during construction, meet with the Contractor and issue a plan in writing for operation of the HVAC system. The plan will describe how the system can be operated at as close to normal operating conditions as possible, to minimize dust and dirt from contaminating the ductwork and coils and polluting the occupied areas, and to prevent damaging moisture migration.

k. Review TAB reports for consistency with the specifications.

1. After completion of $\mathrm{TAB}$, review with the $\mathrm{TAB}$ contractor, any areas they may consider as being potentially problematic regarding maintaining adequate minimum outdoor air, proper exhaust or room pressure differential.

\section{Air Flow and Pressurization Checks}

a. Verify that the specified minimum ventilation rates are maintained during all occupied modes of operation, particularly during VAV terminal box turn-down.

b. Spot-check TAB supply air flow readings in critical areas.

c. Spot-check the TAB measurements and setup of the exhaust systems for each area. When purging is specified in the contract documents, develop a plan for, and see that the Contractor purges the building prior to occupancy.

d. Verify that the total building pressurization criteria is met through varying HVAC loads and economizing conditions.

e. Verify that room pressure differentials are as specified between critical areas (clean rooms, biohazards, film developing rooms, chemical storage areas, etc.).

f. Verify that the design engineer's specification for interstitial and area pressurization differentials has been met.

Spec Writer: The following procedures require considerably more detail than is given here to specify a requirement. The verification concepts are mentioned for reference only. 


\title{
4. Verification
}

a. Verify that the specified ventilation effectiveness throughout the various areas of the building is being met by: smoke tube testing for airflow patterns, flow hood readings, air contaminant monitoring, other

b. Perform IAQ testing using the following methods (surface cultures for microbial contamination, airborne culture testing, $\mathrm{CO}_{2}$ monitoring, VOC monitoring, $\mathrm{CO}$ monitoring, etc.).

I. Acceptance Criteria

Unless noted in the requirements, the commissioning agent in concert with the CM will make determinations and interpretations for when IAQ issues are considered to be in compliance with the contract documents.

\author{
END OF IAQ REQUIREMENTS
}

\section{END OF THIS GUIDE SPECIFICATION SECTION}




\title{
COMMISSIONING GUIDE SPECIFICATIONS
}

\author{
SECTION 15998 \\ PREFUNCTIONAL CHECKLISTS
}

MECHANICAL and ELECTRICAL

Specwriter:

The following guide specifications are intended to be reviewed, modified and inserted into the noted specification section to meet the specific commissioning needs and requirements for the current project. Any modifications to these speciffcations shall only be made after consultation with the Owner's representative and with approval of the engineer of record. Where there are check boxes or fill-in blanks, fill in as appropriate and delete all but the choice(s) that apply. Delete all direction boxes.

\section{SECTION 15998}

\section{PREFUNCTIONAL CHECKLISTS}

\section{MECHANICAL and ELECTRICAL}

\section{A. GENERAL}

This section contains representative Prefunctional Checklists in a form format (PC).

The PC procedures displayed in a form format here are intended to provide the $\mathrm{CA}$ with an example of a format and an indication of the rigor of the required prefunctional checklists and documentation for various equipment types. Though they were not developed specifically for this project, they are generally applicable.

The checklists contain items for both Division 15 and 16 contractors to perform. On each checklist, a column is provided that should be filled out by the Contractor assigning responsibility for that line item to a trade. Those executing the checklists are only responsible to perform items that apply to the specific application at hand. These checklists do not take the place of the manufacturer's recommended checkout and start-up procedures or report. Some checklist procedures may be redundant of some checkout procedures that will be documented on typical factory field checkout sheets. Double documenting is required in those cases.

Refer to Section 17100 for additional requirements regarding prefunctional checklists, startup and initial checkout. Items that do not apply should be noted along with the reasons on the form. If this form is not used for documenting; one of similar rigor and clarity shall be used. Contractors assigned responsibility for sections of the checklist shall be responsible to see that checklist items by their subcontractors are completed and checked off. "Contr." column or abbreviations in brackets to the right of an item refer to the contractor responsible to verify completion of this item. $\mathrm{A} / \mathrm{E}=$ architect/engineer, $\mathrm{All}=$ all contractors, $\mathrm{CA}=$ commissioning agent, $\mathrm{CC}=$ controls contractor, $\mathrm{EC}=$ electrical contractor, $\mathrm{GC}=$ general contractor, $\mathrm{MC}=$ mechanical contractor, $\mathrm{SC}=$ sheet metal contractor, $\mathrm{TAB}=$ test and balance contractor. 


\section{B. PREFUNCTIONAL CHECKLISTS}

This guide specification section continues with prefunctional checklists for the following equipment. The checklists are provided in electronic file format (Word 6.0 for Windows 3.1). The file name is at the bottom of

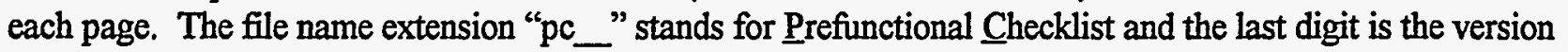
number. Any MS Excel spreadsheet files are noted with their usual .xls extension.

\section{COMPONENT}

ELECTRONIC FILE NAME

Mechanical Equipment (checklists have both mechanical and electrical parts)

Air handler unit

Air cooled condenser and compressor

Boiler

Condenser water piping

Chiller

Chiller system sample startup

Chilled water piping

$$
\text { documentation plan }
$$

Computer room AC unit

Controls system (BAS)

Cooling tower

Exhaust fan

Fan coil unit

Heating water piping

Packaged roof top unit

Pump (water)

Startup documentation plan template

TAB

Terminal unit

Variable frequency drive

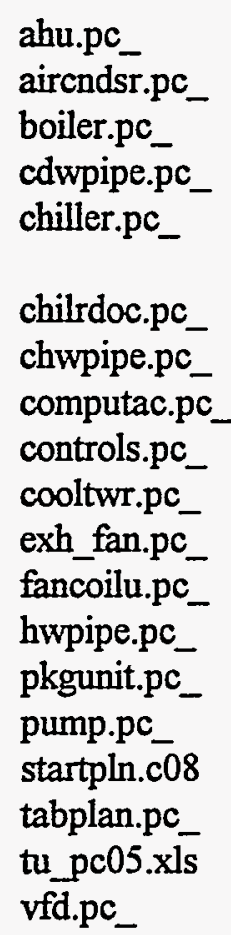

\section{SUGGESTED NUMBERING KEY FOR COMMISSIONING PROCEDURES}

The checklists, functional tests, documentation and training use the following identification numbering:

At the beginning of the identification number is a text abbreviation for the following:

Document or Event Abbreviations
DOC = Documentation
$\mathrm{PC} \quad=$ Prefunctional Checklist
SP = Startup Plan
SR = Startup Report
FT = Functional Test
$\mathrm{R} \quad=$ Review
$\mathrm{TR}=$ Training Record 
Prefunctional Checklist Numbering Key

FT-0102.3: The first four digits uniquely identify the piece of equipment to the component level. The first 2 digits are the System Type, the second 2 digits are an arbitrary component number (not necessarily the same as the specified ID number). The number after the decimal is the test number. For example, FT-0102.3 = Functional Test 3 of system Type 1, component number 2 (e.g., 0102.3 = Chiller \#2, FT \#3, because chillers are system Type 1). Other components under chillers are: additional chillers, pumps, valves, piping; VFDs. The component number of 00 means "general" or "all" components, as with the entire system. All tests, procedures, trainings and records should have the same first 4 digits for any given equipment component.

Another example is TUs. If there were only 1 TU type, then tests would be numbered FT$0500.1,0500.2$, etc. If there were 2 types of TUs: FT-0501.1, 0501.2, etc and 0502.1, 0502.2 , etc.

An example of the number system follows:

0100 Chilled Water System

0101 Chiller 1

0200 Boiler System

0201 Boiler 1

0102 Chiller 2

.0202 Boiler 2

0103 Cooling tower 1

0203 Pump HWP-1

0104 Cooling tower 2

0204 Pump HWP-2

0105 Pump CHWP-1

$0205 \mathrm{HW}$ piping

0106 Pump CHWP-2

0206 Sensor calibration

0107 CHW piping

etc.

$0108 \mathrm{CDW}$ piping

0109 Sensor calibration

\section{Numbers for Primary System Types and Components}

Components are in parentheses.

01 Chilled water system (chillers, cooling towers, pumps, condensers, piping, valves)

02 Hot water system (boilers, hot water pumps, valves, piping)

03 Air handler units (SF, RF, coils, valves, VFD, ducts, dampers)

04 Packaged, AC or HP units (SF, RF, coils, valves, VFD, ducts, dampers, compressors, condensers)

05 Terminal units

06 Computer room AC units

07 Unit heaters or AC spot coolers

08 Heat exchangers

09 Service water system

10 Test and balance (TAB)

11 Building automation system (controls)

12 Lighting controls

13 Specialty fans

14 Fume hoods

END OF SECTION 


\section{Prefunctional Checklist}

Project

PC-03 AIR HANDLER UNIT, AHU \#'S

Components included: ___ supply fans, valves, VFD, dampers

return and exhaust fans, coils,

Associated Checklists: CHW, HW Piping,

\section{Submittal / Approvals}

Submittal. The above equipment and systems integral to them are complete and ready for functional testing. The checklist items are complete and have been checked off only by parties having direct knowledge of the event, as marked below, respective to each responsible contractor. This prefunctional checklist is submitted for approval, subject to an attached list of outstanding items yet to be completed. A Statement of Correction will be submitted upon completion of any outstanding areas. None of the outstanding items preclude safe and reliable functional tests being performed. List attached.

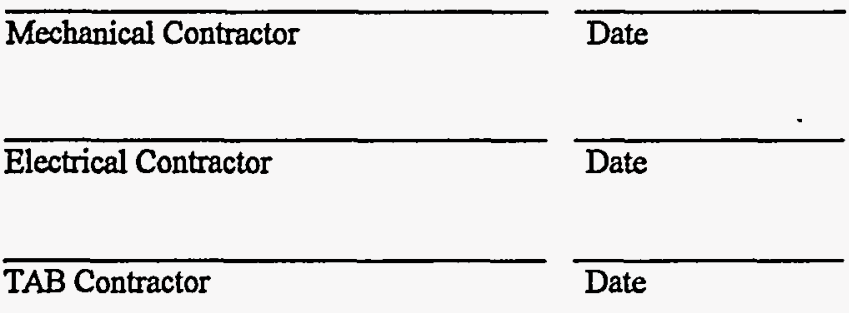

$\begin{array}{ll}\overline{\text { Controls Contractor }} & \text { Date } \\ \overline{\text { Sheet Metal Contractor }} & \text { Date } \\ \overline{\text { General Contractor }} & \text { Date }\end{array}$

Prefunctional checklist items are to be completed as part of startup \& initial checkout, preparatory to functional testing.

- This checklist does not take the place of the manufacturer's recommended checkout and startup procedures or report.

- Items that do not apply shall be noted with the reasons on this form (N/A = not applicable, $B O=$ by others).

- If this form is not used for documenting, one of similar rigor shall be used.

- Contractors assigned responsibility for sections of the checklist shall be responsible to see that checklist items by their subcontractors are completed and checked off.

- "Contr." column or abbreviations in brackets to the right of an item refer to the contractor responsible to verify completion of this item. $\mathrm{A} / \mathrm{E}=$ architect/engineer, $\mathrm{All}=$ all contractors, $\mathrm{CA}=$ commissioning agent, $\mathrm{CC}=$ controls contractor, $\mathrm{EC}=$ electrical contractor, $\mathrm{GC}=$ general contractor, $\mathrm{MC}=$ mechanical contractor, $\mathrm{SC}=$ sheet metal contractor, $\mathrm{TAB}=$ test and balance contractor, $=$

Approvals. This filled-out checklist has been reviewed. Its completion is approved with the exceptions noted below.

\section{Notes:}




\section{Requested documentation submitted}

Check if Okay. Enter comment or note number if deficient.

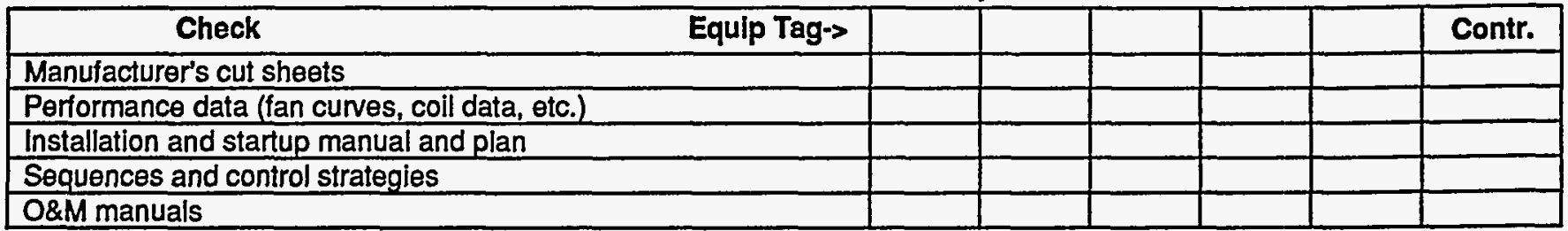

- Documentation complete as per contract documents for given trade.......__ YES _ NO

3. Model verification

$[$ Contr $=$ ]

$1=$ as specified, $2=$ as submitted, $3=$ as installed. Check if Okay. Enter note number if deficient.

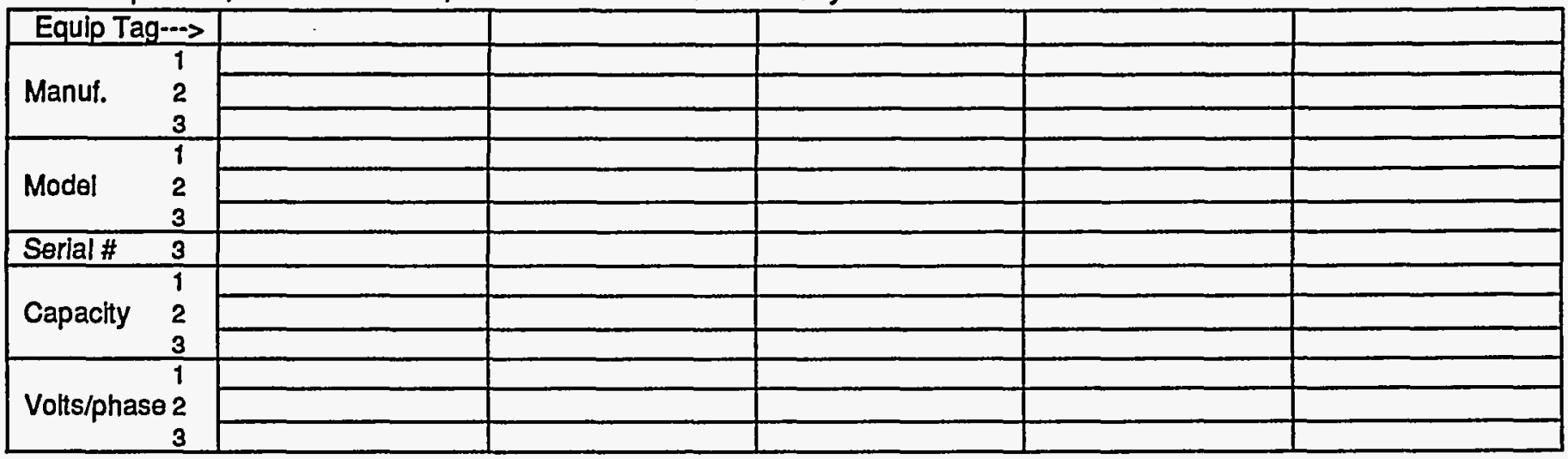

- The equipment installed matches the specifications for given trade.........__ YES __ NO

\section{Installation Checks}

Check if Okay. Enter comment or note number if deficient.

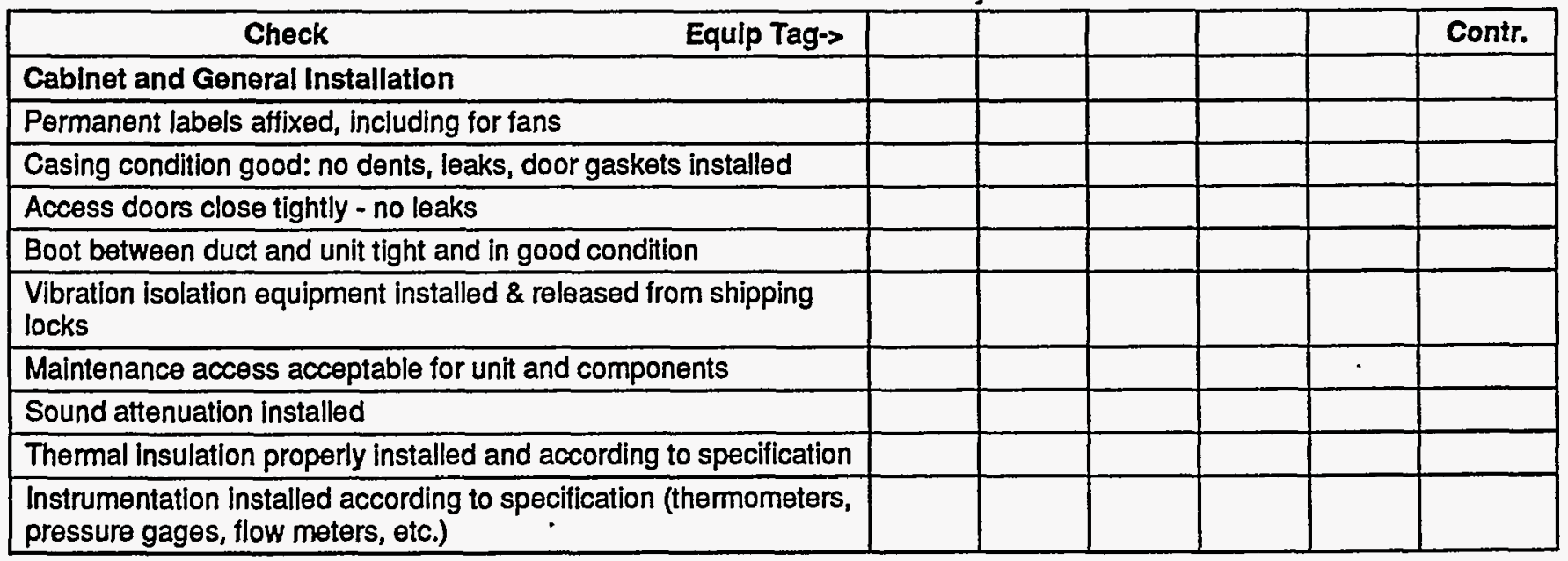

\section{Notes:}


Check if Okay. Enter comment or note number if deficient.

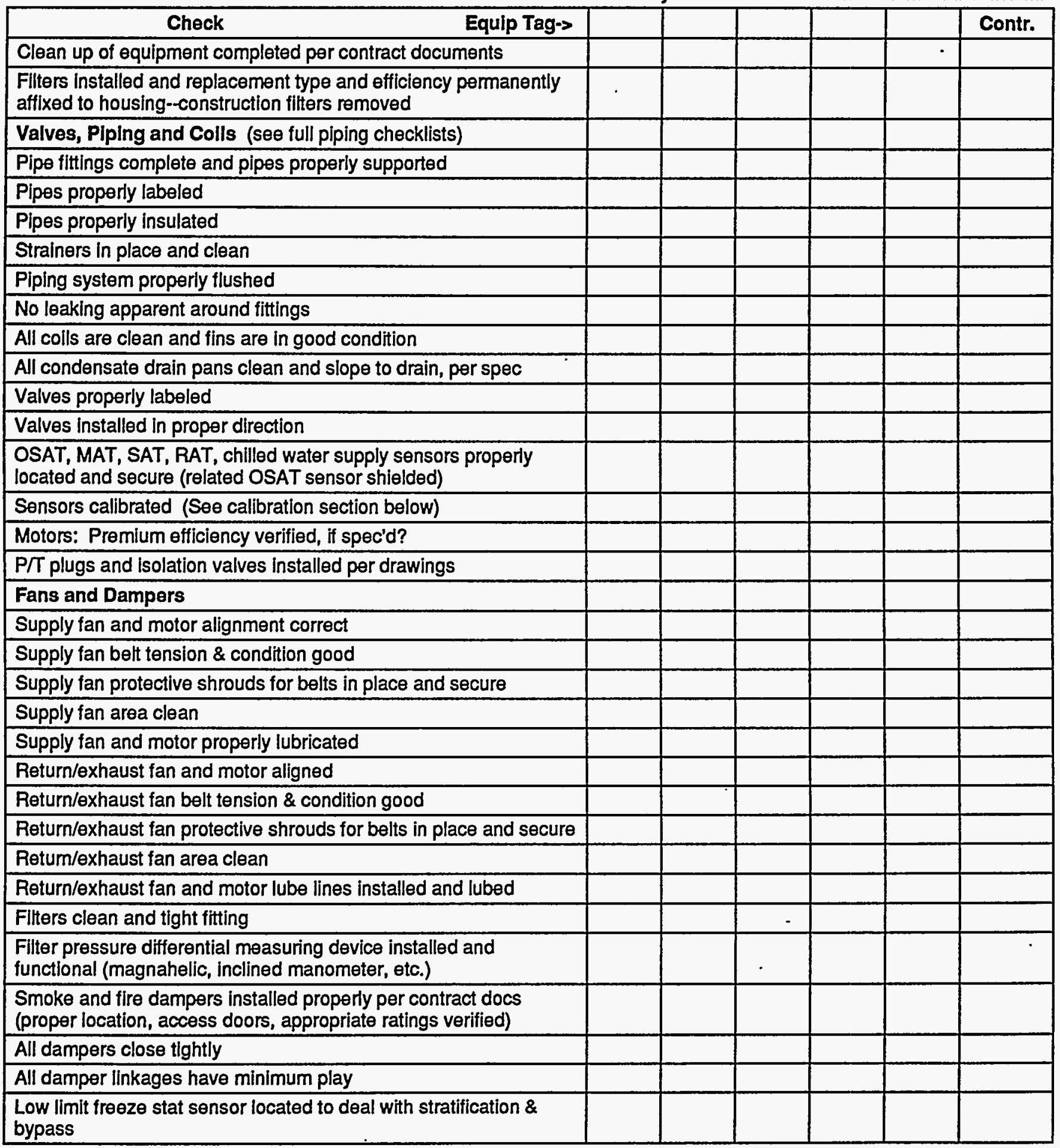

\section{Notes:}


Check if Okay. Enter comment or note number if deficient.

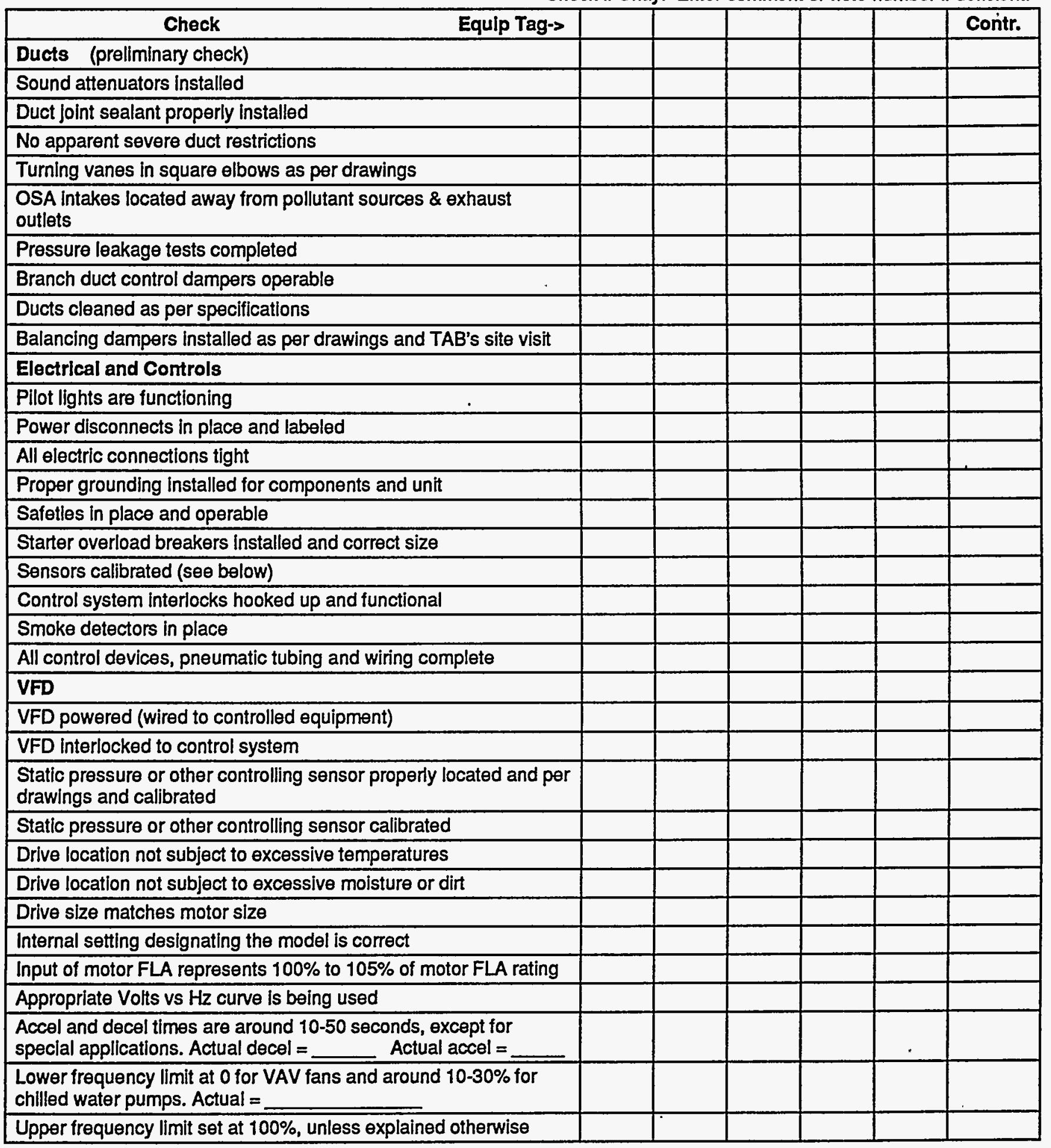

\section{Notes:}


Check if Okay. Enter comment or note number if deficient.

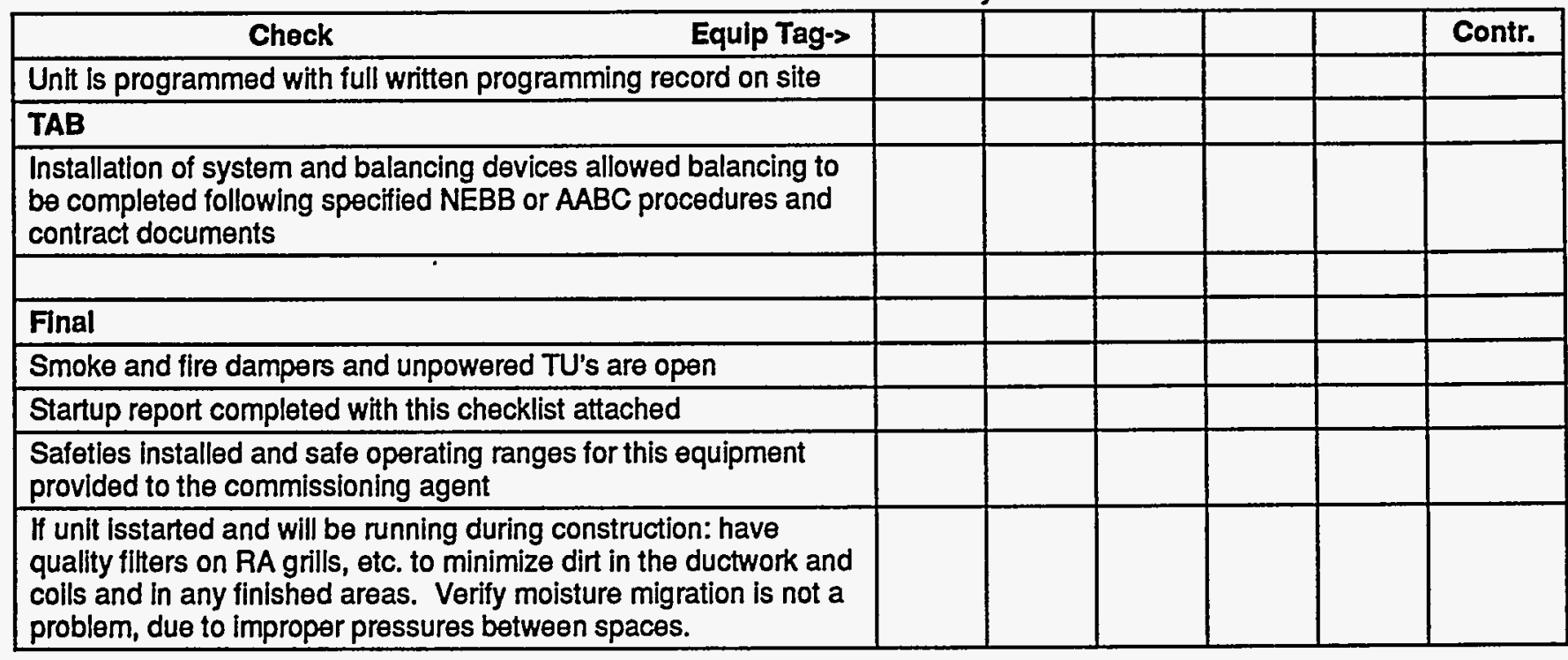

- The checklist items of Part 4 are all successfully completed for given trade.

YES

5. Operational Checks (These augment mfr's list. This is not the functional performance testing.)

Check if Okay. Enter comment or note number if deficient.

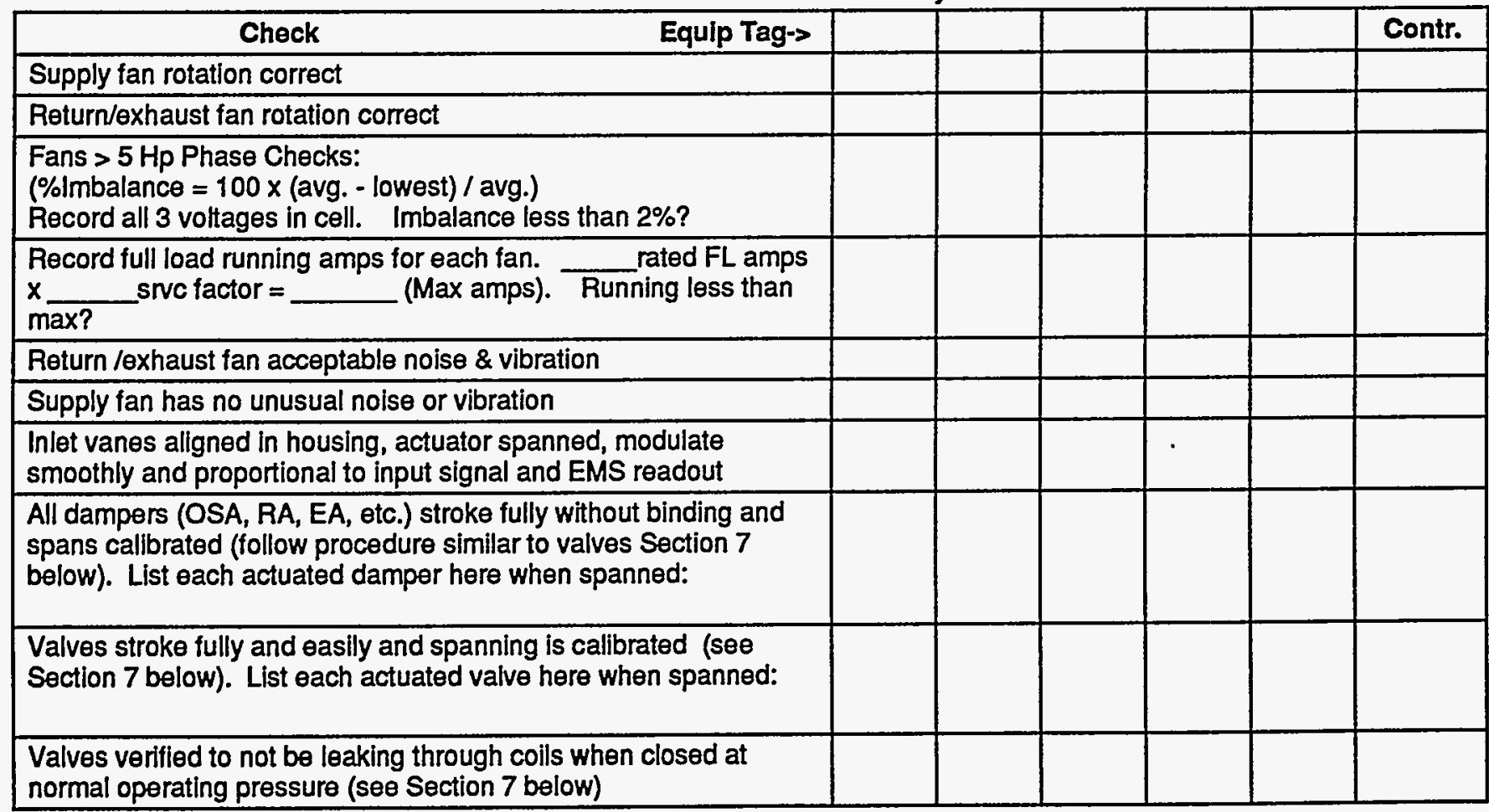

Notes: 
Check if Okay. Enter comment or note number if deficient.

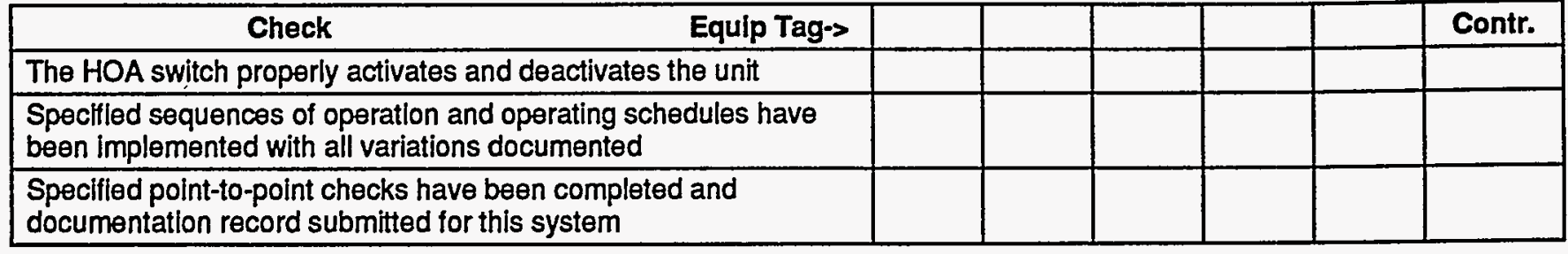

- The checklist items of Part 5 are all successfully completed for given trade.__ YES _ NO

\section{Sensor Calibration}

All field-installed temperature, relative humidity, $\mathrm{CO}, \mathrm{CO}_{2}$ and pressure sensors and gages on this piece of equipment shall be calibrated using the methods described below. All test instruments shall have had a certified calibration within the last 12 months: $\mathrm{Y} / \mathrm{N}$ Sensors installed in the unit at the factory with calibration certification provided need not be field calibrated. All actuators should also be calibrated, per the above checklist.

\begin{tabular}{|c|c|c|c|c|c|}
\hline $\begin{array}{c}\text { Sensor \& } \\
\text { Locatlon }\end{array}$ & $\begin{array}{c}\text { Loc- } \\
\text { ation } \\
\text { OK }\end{array}$ & $\begin{array}{c}\text { 1st } \\
\text { Gage } \\
\text { Value }\end{array}$ & $\begin{array}{c}\text { Instr. } \\
\text { Meas'd } \\
\text { Value }\end{array}$ & $\begin{array}{c}\text { Final } \\
\text { Gage } \\
\text { of BAS } \\
\text { Value }\end{array}$ \\
\hline \hline & - & & & & \\
\hline & & & & & \\
\hline
\end{tabular}

The Contractor's own sensor check-out sheets may be used in lieu of the above, if the same recording fields are included and the procedures below are followed.

- All sensors are calibrated within required tolerances. YES NO

\section{Misc. Procedures (Referenced above)}

\subsection{Sensor Calibration Methods}

All Sensors. Verify that all sensor locations are appropriate and away from causes of erratic operation. Verify that sensors with shielded cable, are grounded only at one end. For sensor pairs that are used to determine a temperature or pressure difference, make sure they are reading within $0.2^{\circ} \mathrm{F}$ of each other for temperature and within a tolerance equal to $2 \%$ of the reading, of each other, for pressure. Tolerances for critical applications may be tighter.

A. Sensors Without Transmitters--Standard Application. Make a reading with a calibrated test instrument within 6 inches of the site sensor. Verify that the sensor reading (via the permanent thermostat, gage or building automation system (BAS)) is within the tolerances in the table below of the instrument-measured value. If not, install offset in BAS, calibrate or replace sensor.

B. Sensors With Transmitters--Standard Application. Disconnect sensor. Connect a signal generator in place of sensor. Connect ammeter in series between transmitter and BAS control panel. Using manufacturer's resistance-temperature data, simulate minimum desired temperature. Adjust transmitter potentiometer zero until $4 \mathrm{~mA}$ is read by the ammeter. Repeat for the maximum temperature matching $20 \mathrm{~mA}$ to the potentiometer span or maximum and verify at the BAS. Record all values and recalibrate controller as necessary to conform with specified control ramps, reset schedules, proportional relationship, reset relationship and P/I reaction. Reconnect sensor. Make a reading with a calibrated test instrument within 6 inches of the site sensor. Verify that the sensor reading (via the permanent thermostat, gage or

\section{Notes:}


bullding automation system (BAS)) is within the tolerances in the table below of the instrument-measured value. If not, replace sensor and repeat. For pressure sensors, perform a similar process with a suitable signal generator.

C. Critlcal Applications. For critical applications (process, manufacturing, etc.) more rigorous calibration techniques may be required for selected sensors. Describe any such methods used on an attached sheet.

\begin{tabular}{|c|c|c|c|}
\hline Nollo & $\stackrel{\text { Required }}{\text { Tolerance }(+t-)}$ & Sensor & Tolerance ( $+/-)$ \\
\hline $\begin{array}{l}\text { ooling coll, chilled and condenser } \\
\text { later temps }\end{array}$ & $0.3 \mathrm{~F}$ & Flow rates, water & $4 \%$ of design \\
\hline $\begin{array}{l}\text { AHU wet bulb or dew point } \\
\text { Hot water coll and boiler water temp }\end{array}$ & $\begin{array}{l}1.0 \mathrm{~F} \\
1.0 \mathrm{~F}\end{array}$ & $\begin{array}{l}\text { Combustion flue temps } \\
\text { Oxygen or } \mathrm{CO}_{2} \text { monitor }\end{array}$ & $\begin{array}{l}5.0 F \\
0.1 \% \text { pts }\end{array}$ \\
\hline ce air, coil air temps & $0.5 \mathrm{~F}$ & CO monitor & $0.01 \%$ pts \\
\hline tthour, ve & $1 \%$ of & Natural gas and oil flow rate & $1 \%$ of design \\
\hline $\begin{array}{l}\text { Pressures, air, water and gas } \\
\text { Flow rates, air }\end{array}$ & $\begin{array}{l}3 \% \text { of design } \\
10 \% \text { of design }\end{array}$ & $\begin{array}{l}\text { Steam flow rate } \\
\text { Barometric pressure }\end{array}$ & $\begin{array}{l}3 \% \text { of design } \\
0.1 \text { in. of } \mathrm{Hg}\end{array}$ \\
\hline
\end{tabular}

\subsection{Coil Valve Leak Check}

A. Method 1--Water Temperature With 2-Way Valve. Calibrate water temperature sensors on each side of coil to be within $0.5^{\circ} \mathrm{F}$ of each other. Turn off air handler fans and close OSA dampers. Make sure appropriate coil dampers are open. Normally closed valves will close. Override normally open valves to the closed position. After 10 minutes observe water delta $T$ across coil. If it is greater than $2^{\circ} \mathrm{F}$, leakage is probably occuring. Reset valve stroke to close tighter. Repeat test until compliance.

B. Method 2--Air Temperature With 2 or 3-Way Valve. Calibrate air temperature sensors on each side of coil to be within $0.5^{\circ} \mathrm{F}$ of each other. Change mixed or discharge air setpoint, override values or bleed or squeeze bulb pneumatic controller to cause the valve to close. Air handler fans should be on. After 5 minutes observe air delta T across coil. If it is greater than $1^{\circ} \mathrm{F}$, leakage is probably occuring. Reset valve stroke to close tighter. Repeat test until compliance.

C. Method 3 Coil Drain Down (not for 3-way valves). Put systems in normal mode. If cooling coil valve, remove all call for cooling or if heating coil valve put system in full cooling. Close isolation valve on supply side of coil, open air bleed cap, open drain-down cock and drain water from coil. Water should stop draining, else there may be a leak through the control valve. Return all to normal when done.

\subsection{Valve Stroke Setup and Check}

For all valve and actuator positions checked, verify the actual position against the BAS readout.

Set pumps to normal operating mode. Command valve closed, verify that valve is closed and adjust output zero signal as required. Command valve open, verify position is full open and adjust output signal as required. Command valve to a few intermediate positions. If actual valve position doesn't reasonably correspond, replace actuator or add pilot positioner (for pneumatics). For heating coil valves (NO): Set heating setpoint $20^{\circ} \mathrm{F}$ above room temperature. Observe valve open. Remove control air or power from the valve and verify that the valve stem and actuator position do not change. Restore to normal. Set heating setpoint to $20^{\circ} \mathrm{F}$ below room temperature. Observe the valve close. For pneumatics, by override in the EMS, increase pressure to valve by 3 psi (do not exceed actuator pressure rating) and verify valve stem and actuator position does not change. Restore to normal.

For cooling coll valves (NC): Set cooling setpoint $20^{\circ} \mathrm{F}$ above room temperature. Observe the valve close. Remove control air or power from the valve and verify that the valve stem and actuator position do not change. Restore to normal. Set cooling setpoint to $20^{\circ} \mathrm{F}$ below room temperature. Observe valve open. For pneumatics, by override in the EMS, increase pressure to valve by 3 psi (do not exceed actuator pressure rating) and verify valve stem and actuator position does not change. Restore to normal.

\section{- END OF CHECKLIST-}

Notes: 


\section{Prefunctional Checklist}

Project

\section{PC-04 AIR COOLED CONDENSER and COMPRESSOR (For AC or Split Heat Pump) ID\#'s}

Components included: FCU-

Associated Checklists:

\section{Submittal / Approvals}

Submittal. The above equipment and systems integral to them are complete and ready for functional testing. The checklist items are complete and have been checked off only by parties having direct knowledge of the event, as marked below, respective to each responsible contractor. This prefunctional checklist is submitted for approval, subject to an attached list of outstanding items yet to be completed. A Statement of Correction will be submitted upon completion of any outstanding areas. None of the outstanding items preclude safe and reliable functional tests being performed. List attached.

Mechanical Contractor

Electrical Contractor

TAB Contractor

\section{Date}

Date

Date
Controls Contractor

Sheet Metal Contractor

General Contractor
Date

Date

Prefunctional checklist items are to be completed as part of startup \& initial checkout, preparatory to functional testing.

- This checklist does not take the place of the manufacturer's recommended checkout and startup procedures or report.

- Items that do not apply shall be noted with the reasons on this form (N/A = not applicable, BO = by others).

- If this form is not used for documenting, one of similar rigor shall be used.

- Contractors assigned responsibility for sections of the checklist shall be responsible to see that checklist items by their subcontractors are completed and checked off.

- "Contr." column or abbreviations in brackets to the right of an item refer to the contractor responsible to verify completion of this item. $\mathrm{A} / \mathrm{E}=$ architect/engineer, $\mathrm{All}=$ all contractors, $\mathrm{CA}=$ commissioning agent $\mathrm{CC}=$ controls contractor, $\mathrm{EC}=$ electrical contractor, $\mathrm{GC}=$ general contractor, $\mathrm{MC}=$ mechanical contractor, $\mathrm{SC}=$ sheet metal contractor, $\mathrm{TAB}=$ test and balance contractor, $=$

Approvals. This filled-out checklist has been reviewed. Its completion is approved with the exceptions noted below.

Notes: 


\section{Requested documentation submitted}

Check if Okay. Enter comment or note number if deficient.

\begin{tabular}{|l|l|l|l|l|l|l|}
\hline \multicolumn{1}{|c|}{ Check } & & & & & Contr. \\
\hline Manufacturer's cut sheets & & & & & & \\
\hline Performance data (fan curves, coll data, etc.) & & & & & & \\
\hline Installation and startup manual and plan & & & & & & \\
\hline Sequences and control strategies & & & & & & \\
\hline O\&M manuals & & & & & & \\
\hline
\end{tabular}

- Documentation complete as per contract documents for given trade.......__ YES _ NO

\section{Model verification}

[C̣ontr $=$

$1=$ as specified, $2=$ as submitted, $3=$ as installed. Check if Okay. Enter note number if deficient.

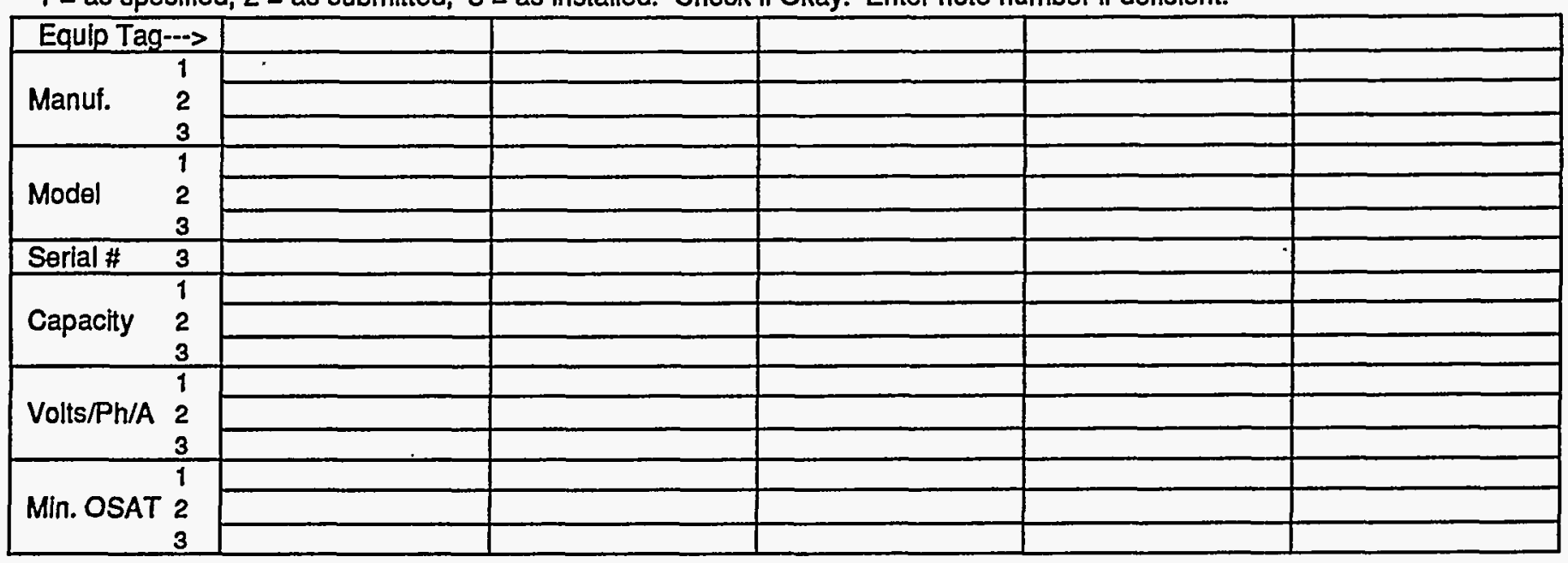

- The equipment installed matches the specifications for given trade........._ YES _ NO

\section{Installation Checks}

Check if Okay. Enter comment or note number if deficient.

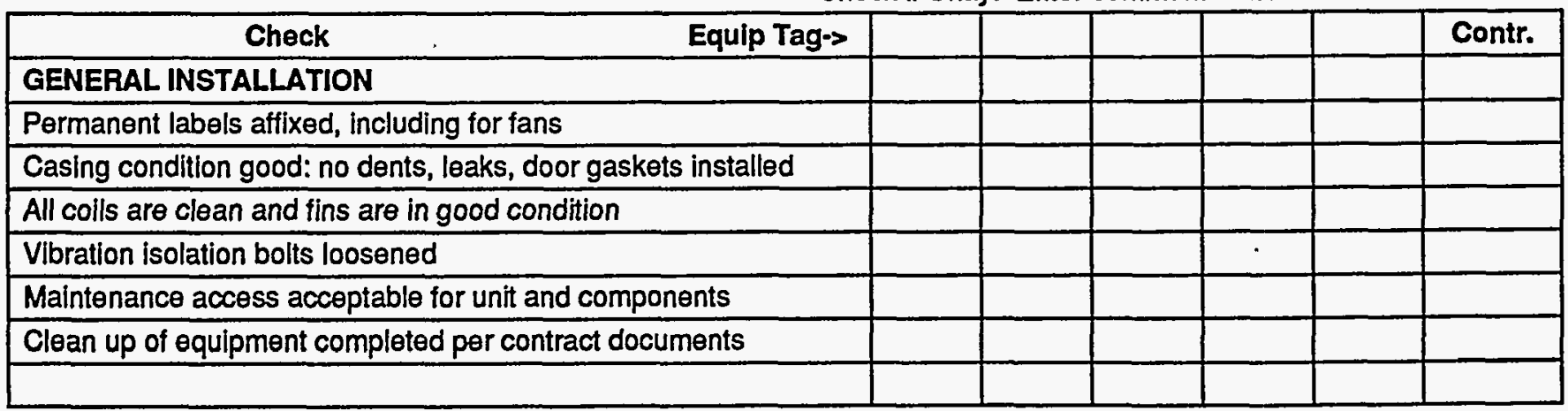

Notes: 
Check if Okay. Enter comment or note number if deficient.

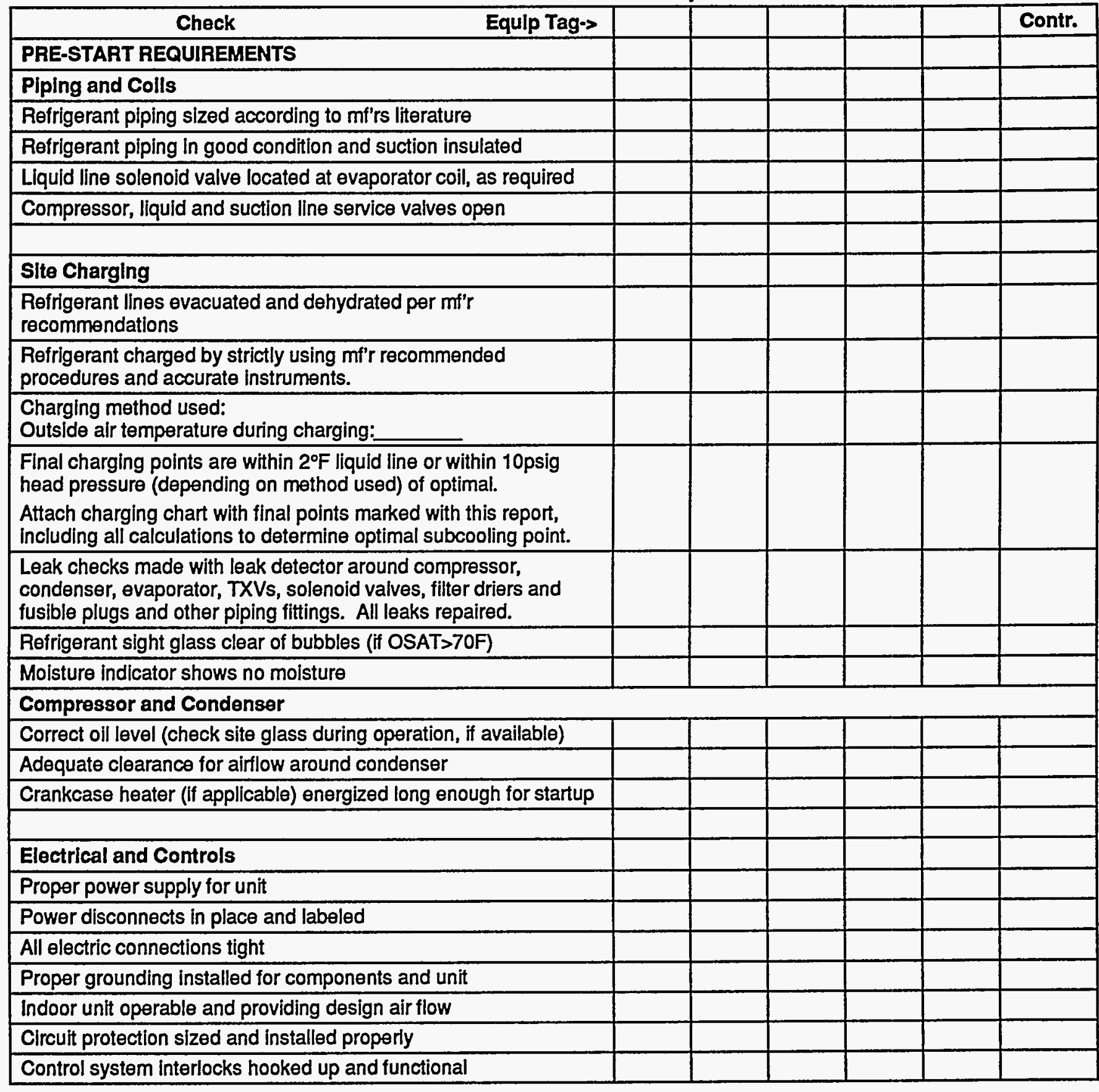

- The checklist items of Part 4 are all successfully completed for given trade.

\section{Notes:}


5. Operational Checks (These augment mfr's list. This is not the functional performance testing.)

Check if Okay. Enter comment or note number if deficient.

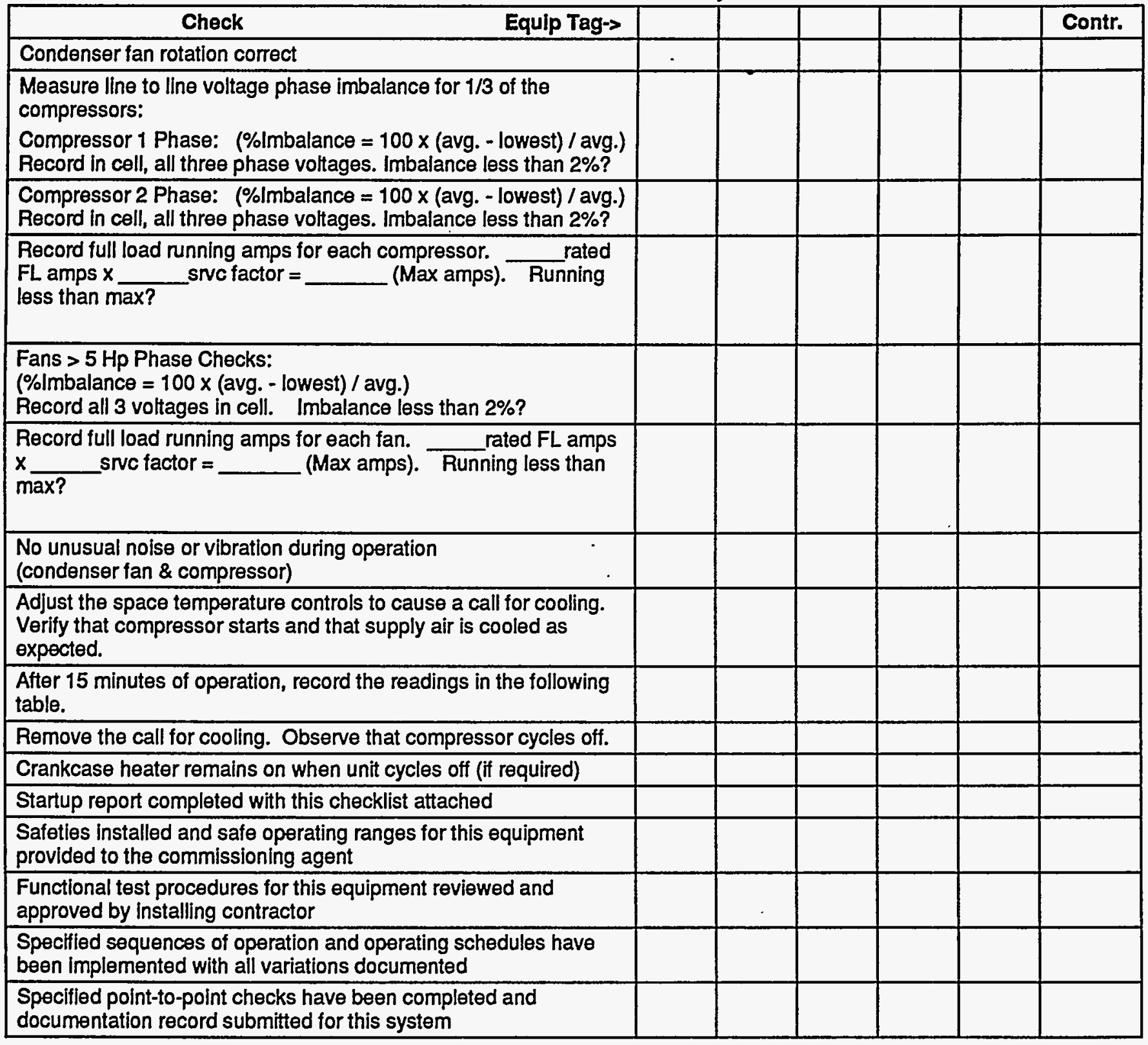

- The checklist items of Part 5 are all successfully completed for given trade.

Notes: 


\section{Operational Record}

\begin{tabular}{|c|c|c|}
\hline Indoor fan speed & Discharge pressure & Evap entering air WB \\
\hline Condenser fan speed & Discharge line temp & Evap leaving air DB \\
\hline Oil pressure (optional) & Entering cond. air temp. & Evap leaving air WB \\
\hline Suction pressure & Leaving cond. air temp. & Compressor amps \\
\hline Suction line temp. & Evap. entering air DB & (L1 / L2 / L3) \\
\hline
\end{tabular}

\section{Sensor Calibration}

All field-installed temperature, relative humidity, $\mathrm{CO}, \mathrm{CO}_{2}$ and pressure sensors and gages on this piece of equipment shall be calibrated using the methods described below. All test instruments shall have had a certified calibration within the last 12 months: $\mathrm{Y} / \mathrm{N}$ _. Sensors installed in the unit at the factory with calibration certification provided need not be field calibrated. All actuators should also be calibrated, per the above checklist.

\begin{tabular}{|l|l|c|c|c|c|}
\hline $\begin{array}{c}\text { Sensor \& } \\
\text { Location }\end{array}$ & $\begin{array}{c}\text { Loc- } \\
\text { ation } \\
\text { OK }\end{array}$ & $\begin{array}{c}\text { 1st } \\
\text { Gage } \\
\text { or BAS } \\
\text { Value }\end{array}$ & $\begin{array}{c}\text { Instr. } \\
\text { Meas'd } \\
\text { Value }\end{array}$ & $\begin{array}{c}\text { Final } \\
\text { Gage } \\
\text { or BAS } \\
\text { Value }\end{array}$ & $\begin{array}{c}\text { Pass } \\
\text { YNN? }\end{array}$ \\
\hline \hline & & & & & \\
\hline & & & & & \\
\hline & & & & & \\
\hline
\end{tabular}

\begin{tabular}{|l|c|c|c|c|c|}
\hline $\begin{array}{c}\text { Sensor \& } \\
\text { Location }\end{array}$ & $\begin{array}{c}\text { Loc- } \\
\text { ation } \\
\text { OK }\end{array}$ & $\begin{array}{c}\text { 1st } \\
\text { Gage } \\
\text { or BAS } \\
\text { Value }\end{array}$ & $\begin{array}{c}\text { Instr. } \\
\text { Meas'd } \\
\text { Value }\end{array}$ & $\begin{array}{c}\text { Final } \\
\text { Gage } \\
\text { or BAS } \\
\text { Value }\end{array}$ & $\begin{array}{c}\text { Pass } \\
\text { YN? }\end{array}$ \\
\hline & & & & & \\
\hline & & & & & \\
\hline & & & & & \\
\hline
\end{tabular}

The Contractor's own sensor check-out sheets may be used in lieu of the above, if the same recording fields are included and the procedures below are followed.

- All sensors and actuators are calibrated within required tolerances. YES NO

\section{Misc. Procedures (as referenced above)}

\subsection{Sensor Callbration Methods}

All Sensors. Verify that all sensor locations are appropriate and away from causes of erratic operation. Verify that sensors with shlelded cable, are grounded only at one end. For sensor pairs that are used to determine a temperature or pressure difference, make sure they are reading within $0.2^{\circ} \mathrm{F}$ of each other for temperature and within a tolerance equal to $2 \%$ of the reading, of each other, for pressure. Tolerances for critical applications may be tighter.

A. Sensors Without Transmitters--Standard Application. Make a reading with a calibrated test instrument within 6 inches of the site sensor. Verify that the sensor reading (via the permanent thermostat, gage or building automation system (BAS)) is within the tolerances in the table below of the instrument-measured value. If not, install offset in BAS, calibrate or replace sensor.

B. Sensors With Transmitters--Standard Application. Disconnect sensor. Connect a signal generator in place of sensor. Connect ammeter in series between transmitter and BAS control panel. Using manufacturer's resistance-temperature data, simulate minimum desired temperature. Adjust transmitter potentiometer zero until $4 \mathrm{~mA}$ is read by the ammeter. Repeat for the maximum temperature matching $20 \mathrm{~mA}$ to the potentiometer span or maximum and verify at the BAS. Record all values and recalibrate controller as necessary to conform with specified control ramps, reset schedules, proportional relationship, reset relationship and P/I reaction. Reconnect sensor. Make a reading with a calibrated test

\section{Notes:}


Instrument within 6 inches of the site sensor. Verify that the sensor reading (via the permanent thermostat, gage or building automation system (BAS)) is within the tolerances in the table below of the instrument-measured value. If not, replace sensor and repeat. For pressure sensors, perform a similar process with a suitable signal generator.

C. Critical Applications. For critical applications (process, manufacturing, etc.) more rigorous calibration techniques may be required for selected sensors. Describe any such methods used on an attached sheet.

\begin{tabular}{|c|c|c|c|}
\hline Sensor & Tolerance ( $+l-)$ & Sensor & Tolequnce ( $+/-)$ \\
\hline $\begin{array}{l}\text { Cooling coil, chilled and condenser } \\
\text { vater temps }\end{array}$ & $0.3 F$ & Flow rates, water & $4 \%$ of design \\
\hline $\begin{array}{l}\text { AHU wet bulb or dew point } \\
\text { Hot water coil and boiler water temp } \\
\text { Outside air, space air, coll air temps } \\
\text { Watthour, voltage \& amperage } \\
\text { Pressures, air, water and gas } \\
\text { Flow rates, air }\end{array}$ & $\begin{array}{l}1.0 \mathrm{~F} \\
1.0 \mathrm{~F} \\
0.5 \mathrm{~F} \\
1 \% \text { of design } \\
3 \% \text { of design } \\
10 \% \text { of design }\end{array}$ & $\begin{array}{l}\text { Combustion flue temps } \\
\text { Oxygen or } \mathrm{CO}_{2} \text { monitor } \\
\mathrm{CO} \text { monitor } \\
\text { Natural gas and oil flow rate } \\
\text { Steam flow rate } \\
\text { Barometric pressure }\end{array}$ & $\begin{array}{l}5.0 \mathrm{~F} \\
0.1 \% \text { pts } \\
0.01 \% \text { pts } \\
1 \% \text { of design } \\
3 \% \text { of design } \\
0.1 \text { in. of } \mathrm{Hg}\end{array}$ \\
\hline
\end{tabular}

\subsection{Coll Valve Leak Check}

A. Method 1--Water Temperature With 2-Way Valve. Calibrate water temperature sensors on each side of coil to be within $0.5^{\circ} \mathrm{F}$ of each other. Turn off air handler fans and close OSA dampers. Make sure appropriate coil dampers are open. Normally closed valves will close. Override normally open valves to the closed position. After 10 minutes observe water delta $T$ across coil. If it is greater than $2^{\circ} \mathrm{F}$, leakage is probably occuring. Reset valve stroke to close tighter. Repeat test until compliance.

B. Method 2--Air Temperature With 2 or 3-Way Valve. Calibrate air temperature sensors on each side of coil to be within $0.5^{\circ} \mathrm{F}$ of each other. Change mixed or discharge air setpoint, override values or bleed or squeeze bulb pneumatic controller to cause the valve to close. Air handler fans should be on. After 5 minutes observe air delta T across coil. If it is greater than $1^{\circ} \mathrm{F}$, leakage is probably occuring. Reset valve stroke to close tighter. Repeat test until compliance.

\section{- END OF CHECKLIST-}

\section{Notes:}




\title{
Prefunctional Checklist
}

\author{
Project \\ PC-02_ BOILER \#'S \\ Associated checklists: Boiler, Heating Water Piping, HW Pumps
}

\section{Submittal / Approvals}

Submittal. The above equipment and systems integral to them are complete and ready for functional testing. The checklist items are complete and have been checked off only by parties having direct knowledge of the event, as marked below, respective to each responsible contractor. This prefunctional checklist is submitted for approval, subject to an attached list of outstanding items yet to be completed. A Statement of Correction will be submitted upon completion of any outstanding areas. None of the outstanding items preclude safe and reliable functional tests being performed. List attached.

Mechanical Contractor

Electrical Contractor

TAB Contractor

\section{Date}

Date

Date
Controls Contractor

Sheet Metal Contractor

General Contractor
Date

Date

Date

Prefunctional checklist items are to be completed as part of startup \& initial checkout, preparatory to functional testing.

- This checklist does not take the place of the manufacturer's recommended checkout and startup procedures or report.

- Items that do not apply shall be noted with the reasons on this form (N/A = not applicable, $B O=$ by others).

- If this form is not used for documenting, one of similar rigor shall be used.

- Contractors assigned responsibility for sections of the checklist shall be responsible to see that checklist items by their subcontractors are completed and checked off.

- "Contr." column or abbreviations in brackets to the right of an item refer to the contractor responsible to verify completion of this item. $\mathrm{A} / \mathrm{E}=$ architect/engineer, $\mathrm{All}=$ all contractors, $\mathrm{CA}=$ commissioning agent $\mathrm{CC}=$ controls contractor, $\mathrm{EC}=$ electrical contractor, $\mathrm{GC}=$ general contractor, $\mathrm{MC}=$ mechanical contractor, $\mathrm{SC}=$ sheet metal contractor, $\mathrm{TAB}=$ test and balance contractor, $=$

Approvals. This filled-out checklist has been reviewed. Its completion is approved with the exceptions noted below.

Notes: 


\section{Requested documentation submitted}

Check if Okay. Enter comment or note number if deficient.

\begin{tabular}{|l|l|l|l|l|l|l|}
\hline \multicolumn{1}{|c|}{ Check Equip Tag-s } & & & & & & Contr. \\
\hline Manufacturer's cut sheets & & & & & & \\
\hline Performance data (fan curves, coil data, etc.) & & & & & & \\
\hline Installation and startup manual and plan & & & & & & \\
\hline Sequences and control strategies & & & & & & \\
\hline O\&M manuals & & & & & &. \\
\hline
\end{tabular}

\section{- Documentation complete as per contract documents. \\ YES

\section{Model verification}

[Contr $=$

$1=$ as specifled, $2=$ as submitted, $3=$ as installed. Check if Okay. Enter note number if deficient.

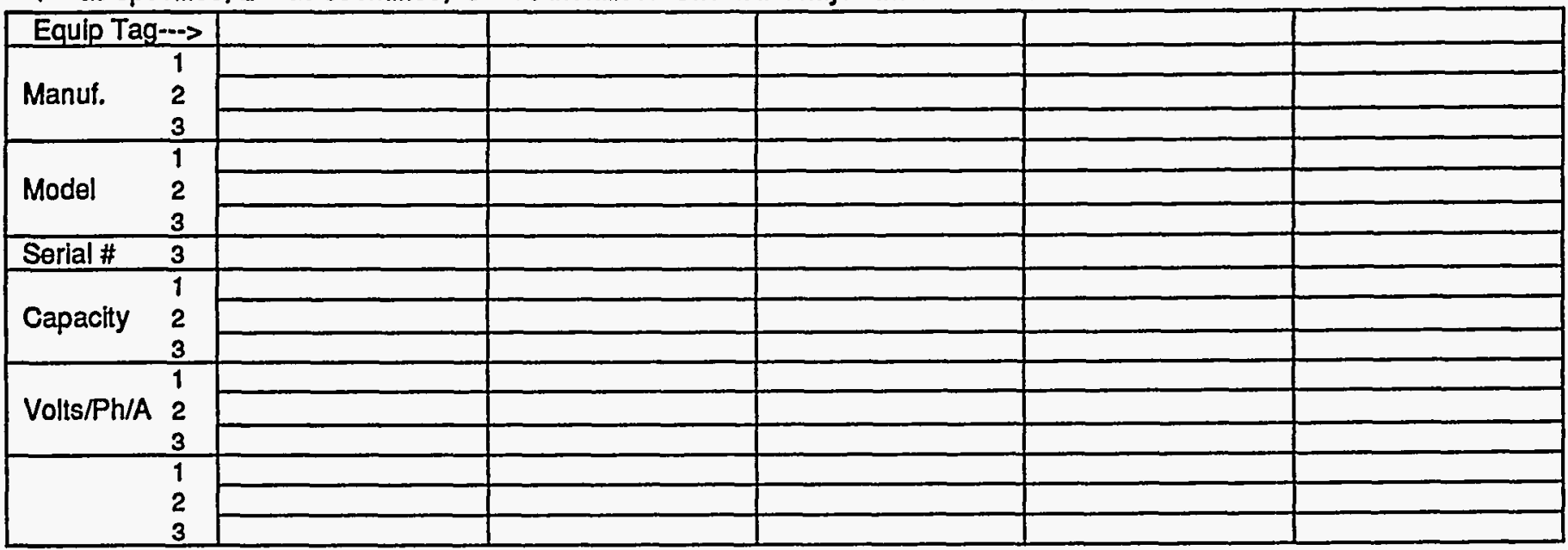

- The equipment installed matches the specifications for given trade.........__ YES __ NO

\section{Physical Installation Checks}

Check if Okay. Enter comment or note number if deficient.

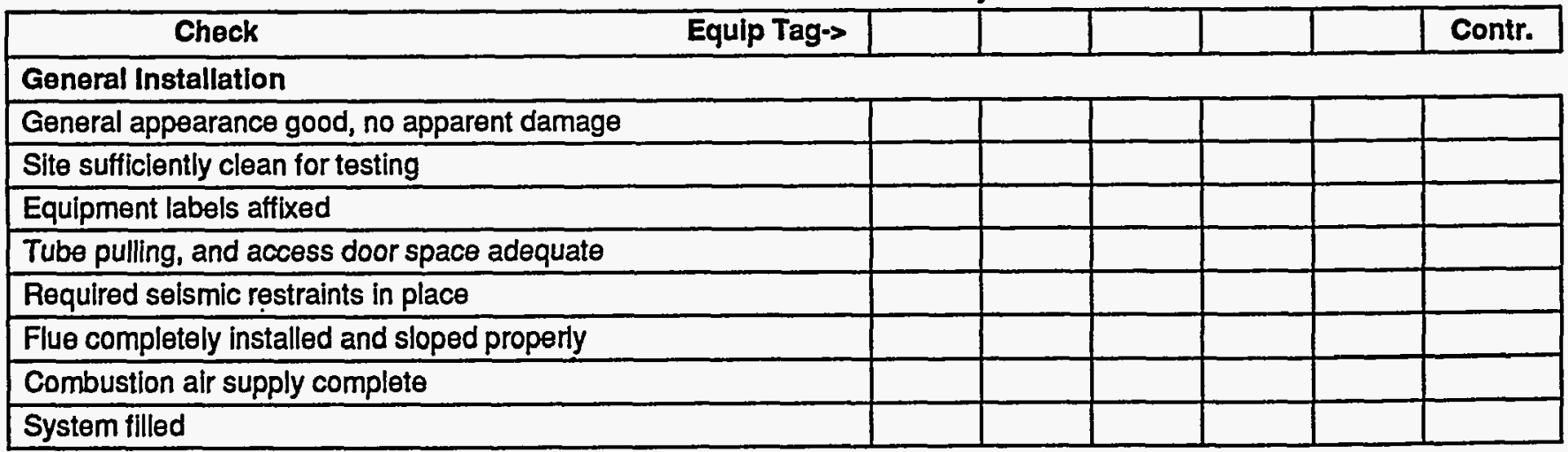

\section{Notes:}


Check if Okay. Enter comment or note number if deficient.

\begin{tabular}{|l|l|l|l|l|l|l|}
\hline \multicolumn{1}{|c|}{ Check } & & & & Contr. \\
\hline Pressure gages installed & & & & & & \\
\hline Thermometers installed & & & & & & \\
\hline Pressure gages installed & & & & & & \\
\hline P/T plugs installed as per drawings & & & & & & \\
\hline Multiple boiler interlocks completed & & & & & & \\
\hline
\end{tabular}

Plping (Immedlately around unit. Full piping in HW Piping Checklist.)

Gas piping installed and tested (supply is at proper pressure)

Hydronic piping complete, including blowdown system, makeup water piping and safety reliefs

Hydronic system flushing complete and strainers cleaned Isolation valves and balancing valves installed Pipe fittings and accessories complete

Test ports installed near all control sensors and per spec

Flow switch installed as required

Flow meters installed as required

Piping type and flow direction labeled on piping

Chemical treatment system or plan installed

ASME pressue vessel data sheet or certification tag posted and inspection complete for each expansion tank

Expansion tanks verified to not be air bound and system completely full of water

Air vents and bleeds at high points of systems functional

\section{Electrical and Controls}

Power to unit and disconnect installed

All electrical components grounded

Sensors calibrated (see below)

Control system interlocks hooked up and functional

All control devices, pneumatic tubing and wiring complete

Motorized valves, dampers and float switches functional

Fire and smoke sensing components functional

\section{Final}

Startup report completed with this checklist attached

Startup report includes written certification from boiler

manufacturer that all specifled features, controls and safeties have

been installed and are functioning properiy and that the installation

and application comply with the manufacturer's recommendations.

\section{Notes:}


Check if Okay. Enter comment or note number if deficient.

\begin{tabular}{|l|l|l|l|l|l|l|}
\hline \multicolumn{1}{|c|}{ Check } & & & & Contr. \\
\hline $\begin{array}{l}\text { Safeties installed and safe operating ranges for this equipment } \\
\text { provided to the commissioning agent }\end{array}$ & & & & & & \\
\hline $\begin{array}{l}\text { Heating water piping and pumps prefunctional checklists } \\
\text { completed }\end{array}$ & & & & & & \\
\hline & & & & & & \\
\hline
\end{tabular}

- The checklist items of Part 4 are all successfully completed for given trade. YES NO

$\bullet$

5. Operational Checks (These augment mir's list. This is not the functional performance testing.)



- The checklist items of Part 5 are all successfully completed for given trade. YES NO

\section{Sensor Calibration}

All field-installed temperature, relative humidity, $\mathrm{CO}, \mathrm{CO}_{2}$ and pressure sensors and gages on this piece of equipment shall be calibrated using the methods described below. All test instruments shall have had a certified calibration within the last 12 months: $\mathrm{Y} / \mathrm{N}$ Sensors installed in the unit at the factory with calibration certification provided need not be field calibrated. All actuators should also be calibrated, per the above checklist.

\begin{tabular}{|c|c|c|c|c|c|c|c|c|c|c|c|}
\hline $\begin{array}{l}\text { Sensor \& } \\
\text { Location }\end{array}$ & $\begin{array}{l}\text { Loc- } \\
\text { ation } \\
\text { OK }\end{array}$ & $\begin{array}{c}\text { 1st } \\
\text { Gage } \\
\text { or BAS } \\
\text { Value }\end{array}$ & $\begin{array}{l}\text { Instr. } \\
\text { Meas'd } \\
\text { Value }\end{array}$ & $\begin{array}{c}\text { Final } \\
\text { Gage } \\
\text { or BAS } \\
\text { Value }\end{array}$ & $\begin{array}{l}\text { Pass } \\
\text { Y/N? }\end{array}$ & $\begin{array}{l}\text { Sensor \& } \\
\text { Location }\end{array}$ & $\begin{array}{l}\text { Loc- } \\
\text { ation } \\
\text { OK }\end{array}$ & $\begin{array}{c}\text { 1st } \\
\text { Gage } \\
\text { or BAS } \\
\text { Value }\end{array}$ & $\begin{array}{l}\text { Instr. } \\
\text { Meas'd } \\
\text { Value }\end{array}$ & $\begin{array}{c}\text { Final } \\
\text { Gage } \\
\text { or BAS } \\
\text { Value }\end{array}$ & $\begin{array}{l}\text { Pass } \\
\text { Y/N? }\end{array}$ \\
\hline & & & & & & & & & & & \\
\hline & & & & & & & & & & & \\
\hline
\end{tabular}

The Contractor's own sensor check-out sheets may be used in lieu of the above, if the same recording fields are included and the procedures below are followed.

- All sensors are calibrated within required tolerances.......................................__ YES NO Notes: 


\section{Misc. Procedures (Referenced above)}

\subsection{Sensor Callbration Methods}

All Sensors. Verify that all sensor locations are appropriate and away from causes of erratic operation. Verify that sensors with shielded cable, are grounded only at one end. For sensor pairs that are used to determine a temperature or pressure dfference, make sure they are reading within $0.2^{\circ} \mathrm{F}$ of each other for temperature and within a tolerance equal to $2 \%$ of the reading, of each other, for pressure. Tolerances for critical applications may be tighter.

A. Sensors Without Transmitters--Standard Application. Make a reading with a calibrated test instrument within 6 inches of the site sensor. Verify that the sensor reading (via the permanent thermostat, gage or building automation system (BAS)) is within the tolerances in the table below of the instrument-measured value. If not, install offset in BAS, calibrate or replace sensor.

B. Sensors With Transmitters--Standard Application. Disconnect sensor. Connect a signal generator in place of sensor. Connect ammeter in series between transmitter and BAS control panel. Using manufacturer's resistance-temperature data, simulate minimum desired temperature. Adjust transmitter potentiometer zero until $4 \mathrm{~mA}$ is read by the ammeter. Repeat for the maximum temperature matching $20 \mathrm{~mA}$ to the potentiometer span or maximum and verify at the BAS. Record all values and recalibrate controller as necessary to conform with specified control ramps, reset schedules, proportional relationship, reset relationship and P/I reaction. Reconnect sensor. Make a reading with a calibrated test instrument within 6 inches of the site sensor. Verify that the sensor reading (via the permanent thermostat, gage or building automation system (BAS)) is within the tolerances in the table below of the instrument-measured value. If not, replace sensor and repeat. For pressure sensors, perform a similar process with a suitable signal generator.

C. Critical Applications. For critical applications (process, manufacturing, etc.) more rigorous calibration techniques may be required for selected sensors. Describe any such methods used on an attached sheet.

\begin{tabular}{|c|c|c|c|}
\hline & Required & & Required \\
\hline Sensor & Tolerance $(+/-)$ & Sensor & Tolerance $(t /-)$ \\
\hline $\begin{array}{l}\text { Cooling coil, chilled and condenser } \\
\text { water temps }\end{array}$ & $0.3 \mathrm{~F}$ & Flow rates, water & $4 \%$ of design \\
\hline AHU wet bulb or dew point & $1.0 \mathrm{~F}$ & Combustion flue temps & $5.0 \mathrm{~F}$ \\
\hline Hot water coil and boiler water temp & $1.0 \mathrm{~F}$ & Oxygen or $\mathrm{CO}_{2}$ monitor & $0.1 \%$ pts \\
\hline Outside air, space air, coil air temps & $0.5 \mathrm{~F}$ & $\mathrm{CO}$ monitor & $0.01 \% \mathrm{pts}$ \\
\hline Watthour, voltage \& amperage & $1 \%$ of design & Natural gas and oil flow rate & $1 \%$ of design \\
\hline Pressures, air, water and gas & $3 \%$ of design & Steam flow rate & $3 \%$ of design \\
\hline Flow rates, air & $10 \%$ of design & Barometric pressure & $0.1 \mathrm{in.}$ of $\mathrm{Hg}$ \\
\hline
\end{tabular}

\subsection{Coll Valve Leak Check}

A. Method 1-Water Temperature With 2-Way Valve. Calibrate water temperature sensors on each side af coil to be within $0.5^{\circ} \mathrm{F}$ of each other. Turn off air handler fans and close OSA dampers. Make sure appropriate coil dampers are open. Normally closed valves will close. Override normally open valves to the closed position. After 10 minutes observe water delta $T$ across coil. If it is greater than $2^{\circ} \mathrm{F}$, leakage is probably occuring. Reset valve stroke to close tighter. Repeat test until compliance.

B. Method 2--Air Temperature With 2 or 3-Way Valve. Calibrate air temperature sensors on each side of coil to be within $0.5^{\circ} \mathrm{F}$ of each other. Change mixed or discharge air setpoint, override values or bleed or squeeze bulb pneumatic controller to cause the valve to close. Air handler fans should be on. After 5 minutes observe air delta $T$ across coil. If it is greater than $1^{\circ} \mathrm{F}$, leakage is probably occuring. Reset valve stroke to close tighter. Repeat test until compliance.

\subsection{Valve Stroke Setup and Check}

For all valve and actuator positions checked, verify the actual position against the BAS readout.

Set pumps to normal operating mode. Command valve closed, verify that valve is closed and adjust output zero signal as required. Command valve open, verify position is full open and adjust output signal as required. Command valve to a few Intermediate positions. If actual valve position doesn't reasonably correspond, replace actuator or add pilot positioner (for pneumatics). For heating coil valves (NO): Set heating setpoint $20^{\circ} \mathrm{F}$ above room temperature. Observe valve open.

\section{Notes:}


Remove control air or power from the valve and verify that the valve stem and actuator position do not change. Restore to normal. Set heating setpoint to $20^{\circ} \mathrm{F}$ below room temperature. Observe the valve close. For pneumatics, by override in the EMS, increase pressure to valve by 3 psi (do not exceed actuator pressure rating) and verify valve stem and actuator position does not change. Restore to normal.

For cooling coll valves (NC): Set cooling setpoint $20^{\circ} \mathrm{F}$ above room temperature. Observe the valve close. Remove control air or power from the valve and verify that the valve stem and actuator position do not change. Restore to normal. Set cooling setpoint to $20^{\circ} \mathrm{F}$ below room temperature. Observe valve open. For pneumatics, by override in the EMS, increase pressure to valve by 3 psi (do not exceed actuator pressure rating) and verify valve stem and actuator position does not change. Restore to normal.

\section{- END OF CHECKLIST -}

Notes: 


\section{Prefunctional Checklist}

Project

\section{PC-01_CONDENSER WATER PIPING}

Components Included: All valves, except coil valves

Associated checklists: Chiller, Cooling Tower, CHW Piping, CHW \& CDW Pumps

\section{Submittal / Approvals}

Submittal. The above equipment and systems integral to them are complete and ready for functional testing. The checklist items are complete and have been checked off only by parties having direct knowledge of the event, as marked below, respective to each responsible contractor. This prefunctional checklist is submitted for approval, subject to an attached list of outstanding items yet to be completed. A Statement of Correction will be submitted upon completion of any outstanding areas. None of the outstanding items preclude safe and reliable functional tests being performed. List attached.

Mechanical Contractor

Electrical Contractor
Date

$$
\text { Date }
$$

Date
Controls Contractor

Sheet Metal Contractor

General Contractor
Date

Date

Date

TAB Contractor

Date

Prefunctional checklist items are to be completed as part of startup \& initial checkout, preparatory to functional testing.

- This checklist does not take the place of the manufacturer's recommended checkout and startup procedures or report.

- Items that do not apply shall be noted with the reasons on this form (N/A = not applicable, $B O=$ by others).

- If this form is not used for documenting, one of similar rigor shall be used.

- Contractors assigned responsibility for sections of the checklist shall be responsible to see that checklist items by their subcontractors are completed and checked off.

- "Contr." column or abbreviations in brackets to the right of an item refer to the contractor responsible to verify completion of this item. $\mathrm{A} / \mathrm{E}=$ architect/engineer, $\mathrm{All}=$ all contractors, $\mathrm{CA}=$ commissioning agent $\mathrm{CC}=$ controls contractor, $\mathrm{EC}=$ electrical contractor, $\mathrm{GC}=$ general contractor, $\mathrm{MC}=$ mechanical contractor, $\mathrm{SC}=$ sheet metal contractor, $\mathrm{TAB}=$ test and balance contractor, $=$

Approvals. This filled-out checklist has been reviewed. Its completion is approved with the exceptions noted below.

Notes: 


\section{Requested documentation submitted}

Check if Okay. Enter comment or note number if deficient.

\begin{tabular}{|l|l|l|l|l|l|l|}
\hline \multicolumn{1}{|c|}{ Check Equip Tag-> } & & & & & & Contr. \\
\hline Manufacturer's cut sheets & & & & & & \\
\hline Performance data & & & & & & \\
\hline Flushing and cleaning plan & & & & & & \\
\hline O\&M manuals & & & & & &. \\
\hline
\end{tabular}

- Documentation complete as per contract documents for given trade YES NO

\section{Physical Installation Checks}

\begin{tabular}{|c|c|c|}
\hline Check & $\mathbf{Y} / \mathbf{N}$ & Contr. \\
\hline \multicolumn{3}{|l|}{ Piping } \\
\hline \multicolumn{3}{|l|}{ Pipe fittings complete and pipes properly supported } \\
\hline \multicolumn{3}{|l|}{ Required seismic anchoring installed } \\
\hline \multicolumn{3}{|l|}{ Pipes properly labeled } \\
\hline \multicolumn{3}{|l|}{ Pipes properly insulated } \\
\hline \multicolumn{3}{|l|}{ Strainers in place and clean } \\
\hline \multicolumn{3}{|l|}{ Isolation valves and balancing valves installed } \\
\hline \multicolumn{3}{|l|}{ Test ports $(\mathrm{P} / \mathrm{T})$ installed near all control sensors and as per spec } \\
\hline \multicolumn{3}{|l|}{ Flushing and cleaning plan submitted and approved } \\
\hline \multicolumn{3}{|l|}{$\begin{array}{l}\text { Piping system properly flushed and cleaned and temporary piping } \\
\text { removed (report attached) }\end{array}$} \\
\hline \multicolumn{3}{|l|}{$\begin{array}{l}\text { Piping pressure tested according to contract documents } \\
\text { (report attached) }\end{array}$} \\
\hline \multicolumn{3}{|l|}{ Chemical treatment system or plan installed } \\
\hline \multicolumn{3}{|l|}{ Water treatment report submitted according to contract documents } \\
\hline \multicolumn{3}{|l|}{ No leaking apparent around fittings } \\
\hline \multicolumn{3}{|l|}{$\begin{array}{l}\text { ASME pressue vessel data sheet or certification tag posted and } \\
\text { inspection complete for each expansion tank }\end{array}$} \\
\hline \multicolumn{3}{|l|}{$\begin{array}{l}\text { Expansion tanks verified to not be air bound and system completely full } \\
\text { of water }\end{array}$} \\
\hline \multicolumn{3}{|l|}{ Air vents and bleeds at high points of systems functional } \\
\hline \multicolumn{3}{|l|}{ Valves (except coil valve checklists are with the unit checklist) } \\
\hline \multicolumn{3}{|l|}{ Valve labels permanently affixed } \\
\hline Valves installed in proper direction & & \\
\hline
\end{tabular}

Notes: 


\begin{tabular}{|l|l|l|}
\hline \multicolumn{1}{|c|}{ Check } & $\mathbf{Y} / \mathbf{N}$ & Contr. \\
\hline No leaks & & \\
\hline $\begin{array}{l}\text { Valves stroke fully and easily and spanning is calibrated (see Section } \\
5.2 \text { below) }\end{array}$ & & \\
\hline $\begin{array}{l}\text { Valves that require a positive shut-off are verified to not be leaking } \\
\text { when closed at normal operating pressure }\end{array}$ & & \\
\hline
\end{tabular}

\section{Sensors and Gages}

Temperature, pressure and flow gages and sensors installed

Sensors calibrated (See calibration section below)

\section{TAB}

Installation of system and balancing devices allowed balancing to be completed following specified NEBB or AABC procedures and contract documents

- The checklist items of Part 3 are all successfully completed for given trade.

\section{Sensor Calibration}

All field-installed temperature, relative humidity, $\mathrm{CO}, \mathrm{CO}_{2}$ and pressure sensors and gages on this piece of equipment shall be calibrated using the methods described below. All test instruments shall have had a certified calibration within the last 12 months: $\mathrm{Y} / \mathrm{N}$ Sensors installed in the unit at the factory with calibration certification provided need not be field calibrated. All actuators should also be calibrated, per the above checklist.

\begin{tabular}{|l|l|l|l|l|l|}
\hline $\begin{array}{c}\text { Sensor \& } \\
\text { Location }\end{array}$ & $\begin{array}{c}\text { Loc- } \\
\text { ation } \\
\text { OK }\end{array}$ & $\begin{array}{c}\text { 1st } \\
\text { Gage } \\
\text { OaAS }\end{array}$ & $\begin{array}{c}\text { Instr. } \\
\text { Meas'd } \\
\text { Value }\end{array}$ & $\begin{array}{c}\text { Final } \\
\text { Gage } \\
\text { or BAS } \\
\text { Value }\end{array}$ & $\begin{array}{c}\text { Pass } \\
\text { YN? }\end{array}$ \\
\hline & & & & & \\
\hline & & & & & \\
\hline & & & & & \\
\hline
\end{tabular}

\begin{tabular}{|c|c|c|c|c|c|}
\hline $\begin{array}{c}\text { Sensor \& } \\
\text { Location }\end{array}$ & $\begin{array}{c}\text { Loc- } \\
\text { ation } \\
\text { OK }\end{array}$ & $\begin{array}{c}\text { Gage } \\
\text { or BAS } \\
\text { Value }\end{array}$ & $\begin{array}{c}\text { Instr. } \\
\text { Meas'd } \\
\text { Value }\end{array}$ & $\begin{array}{c}\text { Final } \\
\text { Gage } \\
\text { or BAS } \\
\text { Value }\end{array}$ & $\begin{array}{c}\text { Pass } \\
\text { YNN? }\end{array}$ \\
\hline \hline & & & & & \\
\hline & & & & & \\
\hline & & & & & \\
\hline
\end{tabular}

The Contractor's own sensor check-out sheets may be used in lieu of the above, if the same recording fields are included and the procedures below are followed.

- All sensors are calibrated within required tolerances. YES NO

\section{Notes:}




\section{Misc. Procedures (As referenced above)}

\subsection{Sensor Callibration Methods}

All Sensors. Verify that all sensor locations are appropriate and away from causes of erratic operation. Verify that sensors with shielded cable, are grounded only at one end. For sensor pairs that are used to determine a temperature or pressure difference, make sure they are reading within $0.2^{\circ} \mathrm{F}$ of each other for temperature and within a tolerance equal to $2 \%$ of the reading, of each other, for pressure. Tolerances for critical applications may be tighter.

A. Sensors Without Transmitters--Standard Application. Make a reading with a calibrated test instrument within 6 inches of the site sensor. Verify that the sensor reading (via the permanent thermostat, gage or building automation system (BAS)) is within the tolerances in the table below of the instrument-measured value. If not, install offset in BAS, calibrate or replace sensor.

B. Sensors With Transmitters--Standard Application. Disconnect sensor. Connect. a signal generator in place of sensor. Connect ammeter in series between transmitter and BAS control panel. Using manufacturer's resistance-temperature data, simulate minimum desired temperature. Adjust transmitter potentiometer zero until $4 \mathrm{~mA}$ is read by the ammeter. Repeat for the maximum temperature matching $20 \mathrm{~mA}$ to the potentiometer span or maximum and verify at the BAS. Record all values and recalibrate controller as necessary to conform with specified control ramps, reset schedules, proportional relationship, reset relationship and $\mathrm{P} / \mathrm{l}$ reaction. Reconnect sensor. Make a reading with a calibrated test instrument within 6 inches of the site sensor. Verify that the sensor reading (via the permanent thermostat, gage or building automation system (BAS)) is within the tolerances in the table below of the instrument-measured value. If not, replace sensor and repeat. For pressure sensors, perform a similar process with a suitable signal generator.

C. Critical Applications. For critical applications (process, manufacturing, etc.) more rigorous calibration techniques may be required for selected sensors. Describe any such methods used on an attached sheet.



\subsection{Coll Valve Leak Check}

A. Method 1--Water Temperature With 2-Way Valve. Calibrate water temperature sensors on each side of coil to be within $0.5^{\circ} \mathrm{F}$ of each other. Turn off air handler fans and close OSA dampers. Make sure appropriate coil dampers are open. Normally closed valves will close. Override nomally open valves to the closed position. After 10 minutes observe water delta $T$ across coil. If it is greater than $2^{\circ} \mathrm{F}$, leakage is probably occuring. Reset valve stroke to close tighter. Repeat test until compliance.

B. Method 2--Air Temperature With 2 or 3-Way Valve. Calibrate air temperature sensors on each side of coil to be within $0.5^{\circ} \mathrm{F}$ of each other. Change mixed or discharge air setpoint, override values or bleed or squeeze bulb pneumatic controller to cause the valve to close. Air handler fans should be on. After 5 minutes observe air delta $T$ across coil. If it is greater than $1^{\circ} \mathrm{F}$, leakage is probably occuring. Reset valve stroke to close tighter. Repeat test until compliance.

\subsection{Valve Stroke Setup and Check}

For all valve and actuator positions checked, verify the actual position against the BAS readout.

Set pumps to normal operating mode. Command valve closed, verify that valve is closed and adjust output zero signal as required. Command valve open, verify position is full open and adjust output signal as required. Command valve to a few intermediate positions. If actual valve position doesn't reasonably correspond, replace actuator or add pilot positioner (for pneumatics). For heating coll valves (NO): Set heating setpoint $20^{\circ} \mathrm{F}$ above room temperature. Observe valve open.

\section{Notes:}


Remove control air or power from the valve and verify that the valve stem and actuator position do not change. Restore to normal. Set heating setpoint to $20^{\circ} \mathrm{F}$ below room temperature. Observe the valve close. For pneumatics, by override in the EMS, increase pressure to valve by 3 psi (do not exceed actuator pressure rating) and verify valve stem and actuator position does not change. Restore to normal.

For cooling coil valves (NC): Set cooling setpoint $20^{\circ} \mathrm{F}$ above room temperature. Observe the valve close. Remove control air or power from the valve and verify that the valve stem and actuator position do not change. Restore to normal. Set cooling setpoint to $20^{\circ} \mathrm{F}$ below room temperature. Observe valve open. For pneumatics, by override in the EMS, increase pressure to valve by 3 psi (do not exceed actuator pressure rating) and verify valve stem and actuator position does not change. Restore to normal.

\section{- END OF CHECKLIST -}

Notes: 


\section{Prefunctional Checklist}

Project

PC-01_ CHILLER \#'S

\section{Associated checklists: Cooling Tower, Chilled \& Condenser Water Piping, CHW and CDW Pumps}

\section{Submittal / Approvals}

Submittal. The above equipment and systems integral to them are complete and ready for functional testing. The checklist items are complete and have been checked off only by parties having direct knowledge of the event, as marked below, respective to each responsible contractor. This prefunctional checklist is submitted for approval, subject to an attached list of outstanding items yet to be completed. A Statement of Correction will be submitted upon completion of any outstanding areas. None of the outstanding items preclude safe and reliable functional tests being performed. ___ List attached.

$\begin{array}{llll}\overline{\text { Mechanical Contractor }} & \overline{\text { Date }} & \overline{\text { Controls Contractor }} & \overline{\text { Date }} \\ \overline{\text { Electrical Contractor }} & \overline{\text { Date }} & \overline{\text { Sheet Metal Contractor }} \\ \overline{\text { TAB Contractor }} & \overline{\text { Date }} & \overline{\text { General Contractor }} & \text { Date }\end{array}$

Prefunctional checklist items are to be completed as part of startup \& initial checkout, preparatory to functional testing.

- This checklist does not take the place of the manufacturer's recommended checkout and startup procedures or report.

- Items that do not apply shall be noted with the reasons on this form (N/A = not applicable, $\mathrm{BO}=$ by others).

- If this form is not used for documenting, one of similar rigor shall be used.

- Contractors assigned responsibility for sections of the checklist shall be responsible to see that checklist items by their subcontractors are completed and checked off.

- "Contr." column or abbreviations in brackets to the right of an item refer to the contractor responsible to verify completion of this item. $\mathrm{A} / \mathrm{E}=$ architect/engineer, $\mathrm{All}=$ all contractors, $\mathrm{CA}=$ commissioning agent $\mathrm{CC}=$ controls contractor, $\mathrm{EC}=$ electrical contractor, $\mathrm{GC}=$ general contractor, $\mathrm{MC}=$ mechanical contractor, $\mathrm{SC}=$ sheet metal contractor, $\mathrm{TAB}=$ test and balance contractor, $=$

Approvals. This filled-out checklist has been reviewed. Its completion is approved with the exceptions noted below.

\section{Notes:}




\section{Requested documentation submitted}

Check if Okay. Enter comment or note number if deficient.

\begin{tabular}{|l|l|l|l|l|l|l|}
\hline \multicolumn{1}{|c|}{ Check Equip Tag-> } & & & & & & Contr. \\
\hline Manufacturer's cut sheets & & & & & & \\
\hline Performance data (fan curves, coil data, etc.) & & & & & & \\
\hline Installation and startup manual and plan & & & & & & \\
\hline Sequences and control strategies & & & & & & \\
\hline O\&M manuals & & & & & & \\
\hline
\end{tabular}

- Documentation complete as per contract documents.

YES

NO

3. Model verification

[Contr $=$ ]

$1=$ as specifled, $2=$ as submitted, $3=$ as installed. Check if Okay. Enter note number if deficient.

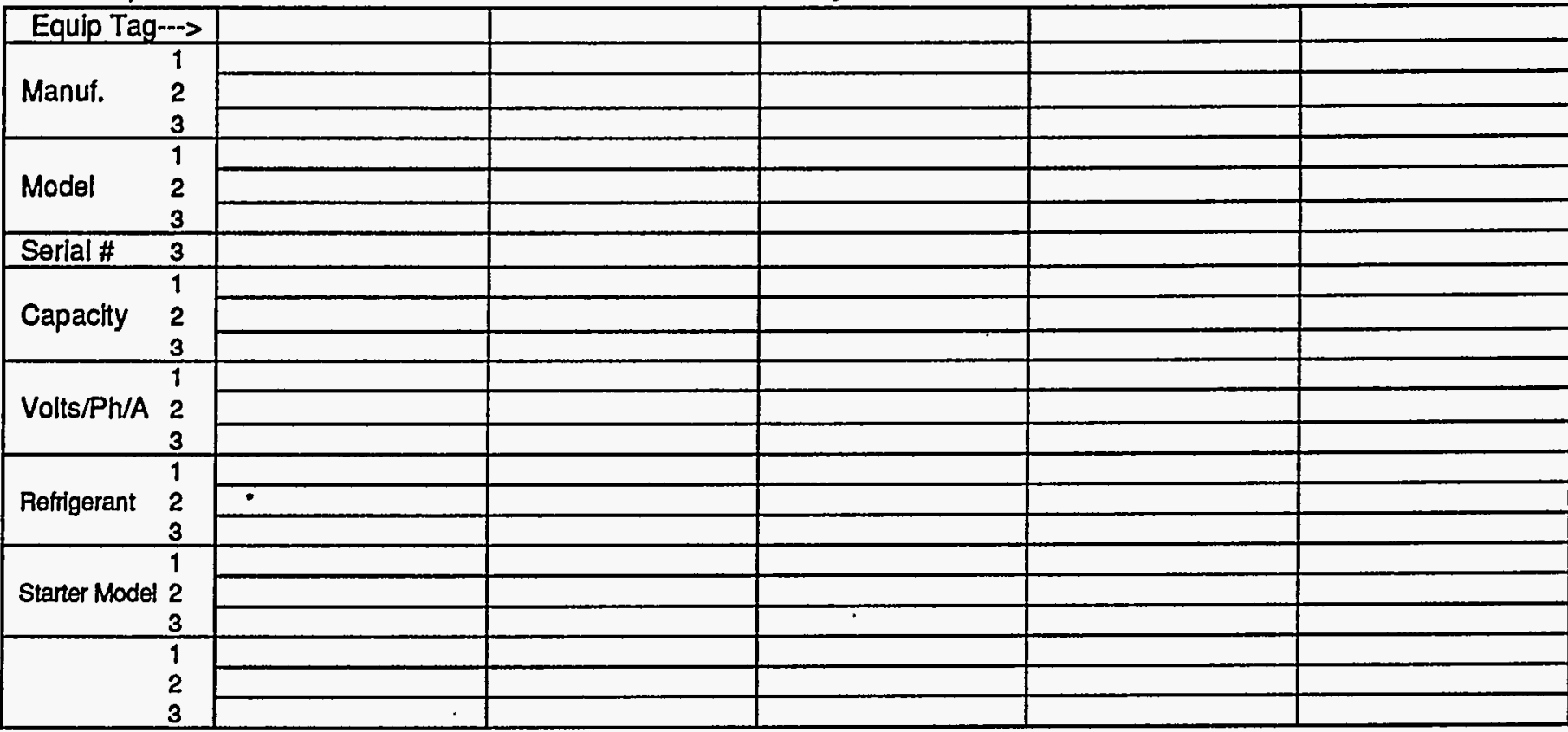

- The equipment installed matches the specifications for given trade..........__ YES NO

\section{Installation Checks}

Check if Okay. Enter comment or note number if deficient.

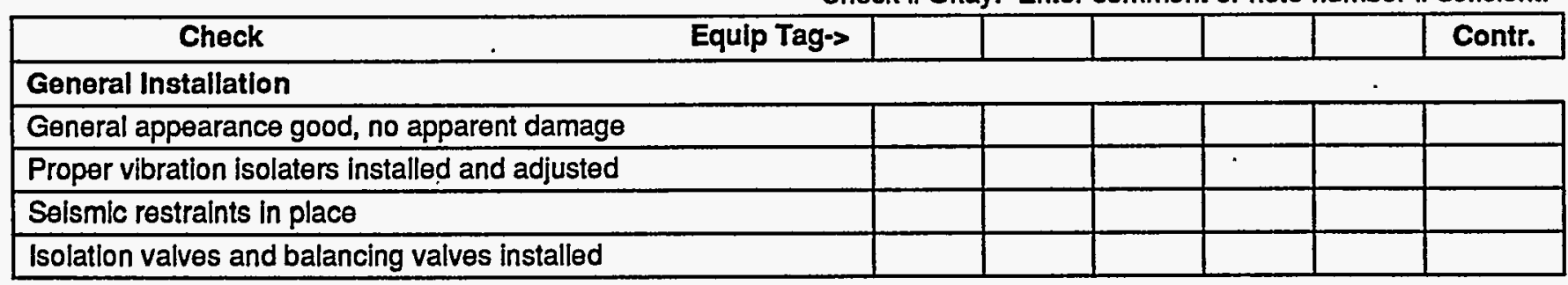

Notes: 
Check if Okay. Enter comment or note number if deficient.

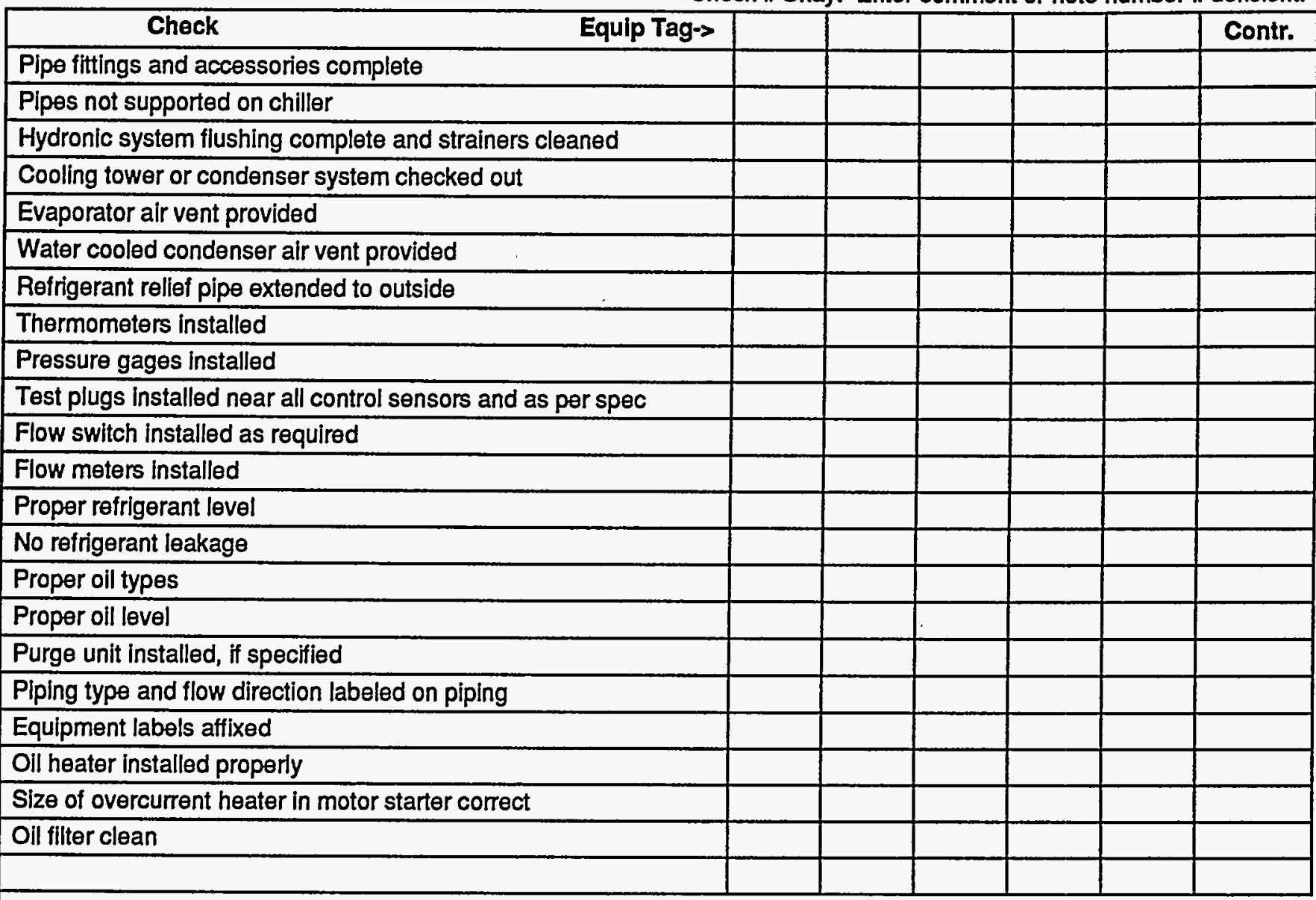

Electrical and Controls

Power wiring installed properly

All electrical components grounded properly

Control wiring and control system hooked up

Sensors calibrated (see calibration section below)

Control system interlocks hooked up and functional

Smoke detectors in place

All control devices, pneumatic tubing and wiring complete

Safetles installed and safe operating ranges for this equipment provided to the commissioning agent

Chilled water piping and pumps prefunctional checklists completed

\begin{tabular}{|l|l|l|l|l|l|l|}
\hline & & & & & & \\
\hline & & & & & & \\
\hline & & & & & & \\
\hline & & & & & & \\
\hline & & & & & & \\
\hline
\end{tabular}

- The checklist items of Part 4 are all successfully completed for given trade.

YES

Notes: 
5. Operational Checks (These augment mir's list. This is not the functional performance testing.)

Check if Okay. Enter comment or note number if deficient.

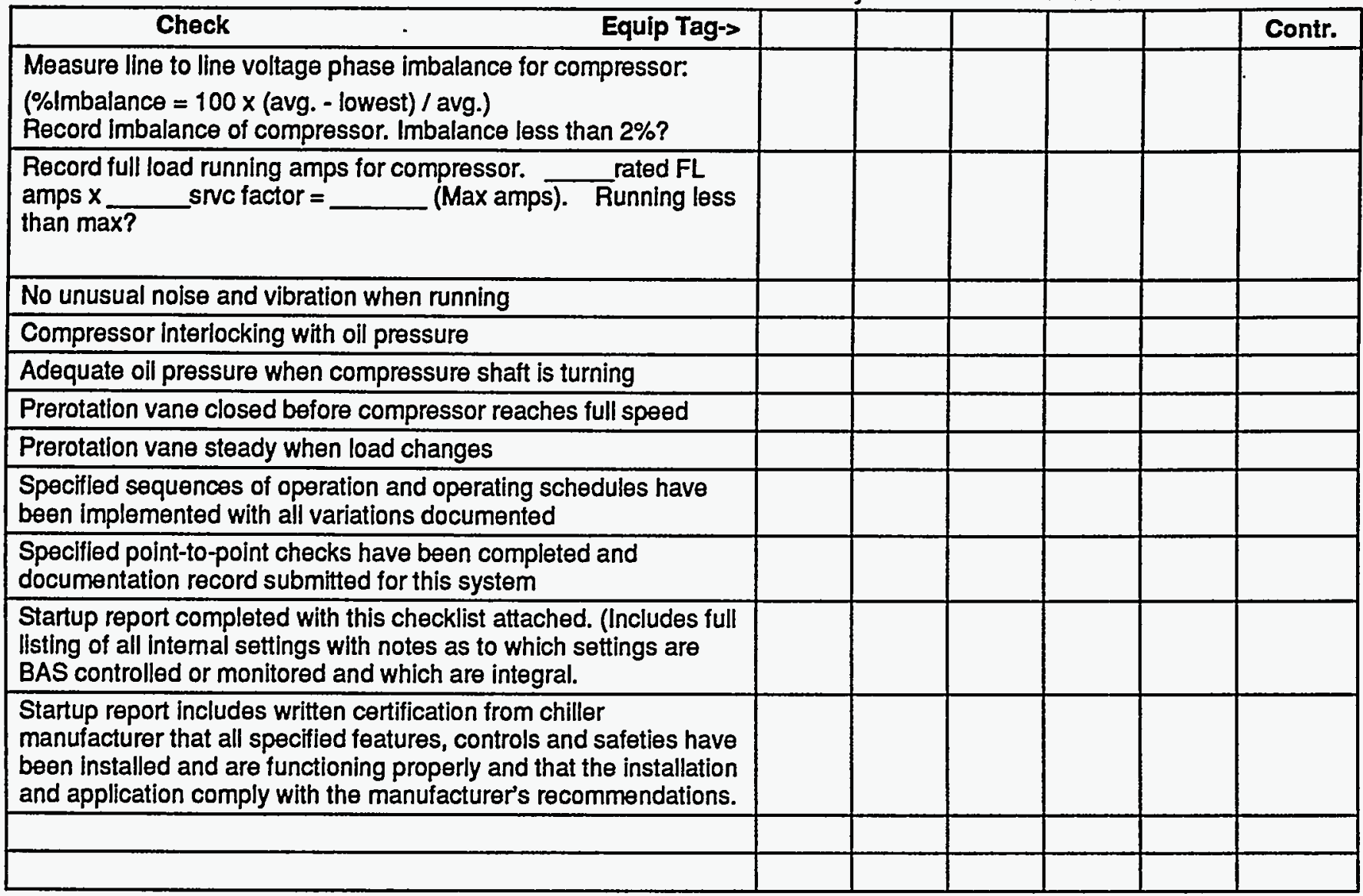

\section{Sensor Calibration}

All field-installed temperature, relative humidity, $\mathrm{CO}, \mathrm{CO}_{2}$ and pressure sensors and gages on this piece of equipment shall be calibrated using the methods described below. All test instruments shall have had a certified calibration within the last 12 months: $\mathrm{Y} / \mathrm{N}$ _. Sensors installed in the unit at the factory with calibration certification provided need not be field calibrated. All actuators should also be calibrated, per the above checklist.

\begin{tabular}{|c|c|c|c|c|c|}
\hline $\begin{array}{c}\text { Sensor \& } \\
\text { Location }\end{array}$ & $\begin{array}{c}\text { Loc- } \\
\text { ation } \\
\text { OK }\end{array}$ & $\begin{array}{c}\text { 1st } \\
\text { Gage } \\
\text { Value }\end{array}$ & $\begin{array}{c}\text { Instr. } \\
\text { Meas'd } \\
\text { Value }\end{array}$ & $\begin{array}{c}\text { Final } \\
\text { Gage } \\
\text { or BAS } \\
\text { Value }\end{array}$ & $\begin{array}{c}\text { Pass } \\
\text { YNN? }\end{array}$ \\
\hline & & & & & \\
\hline & & & & & \\
\hline & & & & & \\
\hline
\end{tabular}

\begin{tabular}{|c|c|c|c|c|c|}
\hline $\begin{array}{c}\text { Sensor \& } \\
\text { Location }\end{array}$ & $\begin{array}{c}\text { Loc- } \\
\text { ation } \\
\text { OK }\end{array}$ & $\begin{array}{c}\text { 1st } \\
\text { Gage } \\
\text { Value }\end{array}$ & $\begin{array}{c}\text { Instr. } \\
\text { Meas'd } \\
\text { Value }\end{array}$ & $\begin{array}{c}\text { Final } \\
\text { Gage } \\
\text { or BAS } \\
\text { Value }\end{array}$ & $\begin{array}{c}\text { Pass } \\
\text { YNN? }\end{array}$ \\
\hline \hline & & & & & \\
\hline & & & & & \\
\hline & & & & & \\
\hline
\end{tabular}

Notes: 
The Contractor's own sensor check-out sheets may be used in lieu of the above, if the same recording fields are included and the procedures below are followed.

- All sensors are calibrated within required tolerances... YES NO

Notes: 


\section{Misc. Procedures (as referenced above)}

\subsection{Sensor Callbration Methods}

All Sensors. Verify that all sensor locations are appropriate and away from causes of erratic operation. Verify that sensors with shielded cable, are grounded only at one end. For sensor pairs that are used to determine a temperature or pressure difference, make sure they are reading within $0.2^{\circ} \mathrm{F}$ of each other for temperature and within a tolerance equal to $2 \%$ of the reading, of each other, for pressure. Tolerances for critical applications may be tighter.

A. Sensors Without Transmilters--Standard Application. Make a reading with a calibrated test instrument within 6 inches of the site sensor. Verify that the sensor reading (via the permanent thermostat, gage or building automation system (BAS)) is within the tolerances in the table below of the instrument-measured value. If not, install offset in BAS, calibrate or replace sensor.

B. Sensors With Transmitters--Standard Application. Disconnect sensor. Connect a signal generator in place of sensor. Connect ammeter in series between transmitter and BAS control panel. Using manufacturer's resistance-temperature data, simulate minimum desired temperature. Adjust transmitter potentiometer zero until $4 \mathrm{~mA}$ is read by the ammeter. Repeat for the maximum temperature matching $20 \mathrm{~mA}$ to the potentiometer span or maximum and verify at the BAS. Record all values and recalibrate controller as necessary to conform with specified control ramps, reset schedules, proportional relationship, reset relationship and $\mathrm{P} / \mathrm{l}$ reaction. Reconnect sensor. Make a reading with a calibrated test instrument within 6 inches of the site sensor. Verify that the sensor reading (via the permanent thermostat, gage or building automation system (BAS)) is within the tolerances in the table below of the instrument-measured value. If not, replace sensor and repeat. For pressure sensors, perform a similar process with a suitable signal generator.

C. Critical Applications. For critical applications (process, manufacturing, etc.) more rigorous calibration techniques may be required for selected sensors. Describe any such methods used on an attached sheet.

\begin{tabular}{|c|c|c|c|}
\hline & Required & & $\frac{\text { Required }}{\text { Tolerance }(t /-)}$ \\
\hline $\begin{array}{l}\text { Sensor } \\
\text { ooling coill, chilled and condenser } \\
\text { ater temps }\end{array}$ & $\frac{\text { Tolerance }(+t-)}{0.3 \mathrm{~F}}$ & Flow rates, water & $\frac{10 \text { lerance }(t+1-]}{4 \% \text { of design }}$ \\
\hline $\begin{array}{l}\text { AHU wet bulb or dew point } \\
\text { Hot water coil and boiler water temp } \\
\text { Outside air, space air, coil air temps } \\
\text { Watthour, voltage \& amperage } \\
\text { Pressures, air, water and gas } \\
\text { Flow rates, air }\end{array}$ & $\begin{array}{l}1.0 \mathrm{~F} \\
1.0 \mathrm{~F} \\
0.5 \mathrm{~F} \\
1 \% \text { of design } \\
3 \% \text { of design } \\
10 \% \text { of design }\end{array}$ & $\begin{array}{l}\text { Combustion flue temps } \\
\text { Oxygen or } \mathrm{CO}_{2} \text { monitor } \\
\mathrm{CO} \text { monitor } \\
\text { Natural gas and oil flow rate } \\
\text { Steam flow rate } \\
\text { Barometric pressure }\end{array}$ & $\begin{array}{l}5.0 \mathrm{~F} \\
0.1 \% \text { pts } \\
0.01 \% \text { pts } \\
1 \% \text { of design } \\
3 \% \text { of design } \\
0.1 \text { in. of } \mathrm{Hg}\end{array}$ \\
\hline
\end{tabular}

\subsection{Coil Valve Leak Check}

A. Method 1-Water Temperature With 2-Way Valve. Calibrate water temperature sensors on each side of coil to be within $0.5^{\circ} \mathrm{F}$ of each other. Turn off air handler fans and close OSA dampers. Make sure appropriate coil dampers are open. Normally closed valves will close. Override normally open valves to the closed position. After 10 minutes observe water delta $T$ across coil. If it is greater than $2^{\circ} \mathrm{F}$, leakage is probably occuring. Reset valve stroke to close tighter. Repeat test until compliance.

B. Method 2--Air Temperature With 2 or 3-Way Valve. Calibrate air temperature sensors on each side of coil to be within $0.5^{\circ} \mathrm{F}$ of each other. Change mixed or discharge air setpoint, override values or bleed or squeeze bulb pneumatic controller to cause the valve to close. Air handler fans should be on. After 5 minutes observe air delta T across coil. If it is greater than $1^{\circ} \mathrm{F}$, leakage is probably occuring. Reset valve stroke to close tighter. Repeat test until compliance.

\subsection{Valve Stroke Setup and Check}

For all valve and actuator positions checked, verify the actual position against the BAS readout.

Set pumps to normal operating mode. Command valve closed, verify that valve is closed and adjust output zero signal as required. Command valve open, verify position is full open and adjust output signal as required. Command valve to a few intermediate positions. If actual valve position doesn't reasonably correspond, replace actuator or add pilot positioner (for pneumatics). For heating coil valves (NO): Set heating setpoint $20^{\circ} \mathrm{F}$ above room temperature. Observe valve open.

\section{Notes:}


Remove control air or power from the valve and verify that the valve stem and actuator position do not change. Restore to normal. Set heating setpoint to $20^{\circ} \mathrm{F}$ below room temperature. Observe the valve close. For pneumatics, by override in the EMS, increase pressure to valve by 3 psi (do not exceed actuator pressure rating) and verify valve stem and actuator position does not change. Restore to normal.

For cooling coil valves (NC): Set cooling setpoint $20^{\circ} \mathrm{F}$ above room temperature. Observe the valve close. Remove control air or power from the valve and verify that the valve stem and actuator position do not change. Restore to normal. Set cooling setpoint to $20^{\circ} \mathrm{F}$ below room temperature. Observe valve open. For pneumatics, by override in the EMS, increase pressure to valve by 3 psi (do not exceed actuator pressure rating) and verify valve stem and actuator position does not change. Restore to normal.

\section{- END OF CHECKLIST -}

Notes: 


\section{-EXAMPLE-}

\section{Documenting Requirements for}

Chiller System

\section{Startup and Initial Checkout}

Project

Date

The purpose of documenting the startup and checkout process is to ensure to the Owner that all recommended startup and initial checkout procedures are completed and that a written record of the work is generated.

\section{PLAN and PROCEDURES:}

1. The prefunctional checklists provided by out and signed (pumps, piping, chillers, cooling towers, water treatment).

2. The following pages shall be copied from the submitted manuals. Each paragraph, installation task or feature on each page listed shall be checked and dated when completed, or written notes shall be provided for why this item was not done or does not apply. A signature and date of the technician shall be provided at the bottom of each page. Settings established or readings made for any of the tasks shall be clearly recorded.

3. This list of references does not constitute a recommendation of the full installation and startup procedures or release the installer from following all factory recommendations, the specifications, applicable codes and good practice. Other pages applicable to this piece of equipment or other procedures completed should be added.

4. Other startup record forms normally used should also be filled out and submitted.

5. All documentation will be submitted to upon completion and is required prior to $\mathrm{TAB}$ or functional testing execution.

Chiller-1 and 2 (each chiller has own pages)

1. McQuay IM 306, p. 4-5, Location and Mounting and Oil Cooler Piping and Vent Piping.

2. McQuay IM 306, p. 5-7, Electrical

3. McQuay IM 306, p. 8, Electrical Testing Control Circuit and Surge Capacitors.

4. McQuay IM 306, p. 10, Factory startup form and warranty registration form (also sent to manufacturer).

5. McQuay IM 306, p. 11 Prestart Checklist.

6. McQuay IM 616, p. 30-31, Pre-Start Checkout.

7. McQuay IM 616, p. 33 Startup.

8. McQuay IM 561, p.7, Installation and Pre-start Checks.

9. McQuay All changes to any Control Menu default values will be listed adjacent to the default values. Significant departures from the defaults will be explained in writing.

\section{Chiller-3}

1. McQuay IM 224 p. 4, Location.

2. McQuay IM 224 p. 5, Vibration Isolators.

3. McQuay IM 224 p. 8 and 9, Water Piping.

4. McQuay IM 224 p. 10, Flow Switch.

5. McQuay IM 224 p.13, Water Pressure Drop.

6. McQuay IM 224 p. 20, Relief Valve Piping.

7. McQuay IM 224 p. 40, Wiring. 


\section{EXAMPLE}

8. McQuay IM 224 p.56, Pre-Start-up and Start-up.

9. McQuay IM 224, p. 71, Factory startup form and warranty registration form (also sent to manufacturer).

10. MCQuay IM 493 p. 25-31, all changes to any Control Menu default values will be listed adjacent to the default values. Significant departures from the defaults will be explained in writing.

\section{Cooling Tower}

1. Baltimore Aircoil M244/1-0AA, p. 4, including "After 24 Hours" requirements.

2. According to $M 244$, p. 4, provide documentation of motor amperage and voltage readings for each phase and compare to nameplate.

Name plate $=480 \mathrm{~V}, 9.1 / 30.0$ FLA.

\begin{tabular}{|r|c|c|c|c|c|c|}
\hline & $\begin{array}{c}\text { Pony- } \\
1\end{array}$ & $\begin{array}{c}\text { Main- } \\
1\end{array}$ & $\begin{array}{c}\text { Pony- } \\
2\end{array}$ & $\begin{array}{c}\text { Main- } \\
2\end{array}$ & $\begin{array}{c}\text { Pony- } \\
3\end{array}$ & $\begin{array}{c}\text { Main- } \\
3\end{array}$ \\
\hline $\mathrm{Ph}-1 \mathrm{~V}$ & & & & & & \\
\hline $\mathrm{Ph}-2 \mathrm{~V}$ & & & & & & \\
\hline Ph-3 V & & & & & & \\
\hline \hline Imbalance* & & & & & \\
\hline $\mathrm{Ph}-1 \mathrm{~A}$ & & & & & & \\
\hline Ph-2 A & & & & & \\
\hline \% Imbalance* & & & & & & \\
\hline
\end{tabular}

*\% Imbalance $=100 \mathrm{x}$ (avg. Volts or amps - lowest phase volts or amps) $/$ avg. volts or amps Avg. $=($ Phase $A+B+C) / 3$

The phase imbalance should be less than $2 \%$.

3. If using a continuous bleed rate, provide calculation and final rate.

4. Provide the following documentation on the sump heaters and vibration alarm checkout, per specification 15710, 3.2.B.






\section{Prefunctional Checklist}

Project

\section{PC-01_CHILLED WATER PIPING}

\section{Components Included: All valves, except coil valves}

Associated checklists: Chiller, Cooling Tower, CDW Piping, CHW \& CDW Pumps

\section{Submittal / Approvals}

Submittal. The above equipment and systems integral to them are complete and ready for functional testing. The checklist items are complete and have been checked off only by parties having direct knowledge of the event, as marked below, respective to each responsible contractor. This prefunctional checklist is submitted for approval, subject to an attached list of outstanding items yet to be completed. A Statement of Correction will be submitted upon completion of any outstanding areas. None of the outstanding items preclude safe and reliable functional tests being performed. List attached.

Mechanical Contractor

Electrical Contractor

TAB Contractor

\section{Date}

\section{Date}

Date
Controls Contractor

Sheet Metal Contractor

General Contractor

\section{Date}

Date

Prefunctional checklist items are to be completed as part of startup \& initial checkout, preparatory to functional testing.

- This checklist does not take the place of the manufacturer's recommended checkout and startup procedures or report.

- Items that do not apply shall be noted with the reasons on this form (N/A = not applicable, $B O=$ by others).

- If this form is not used for documenting, one of similar rigor shall be used.

- Contractors assigned responsibility for sections of the checklist shall be responsible to see that checklist items by their subcontractors are completed and checked off.

- "Contr." column or abbreviations in brackets to the right of an item refer to the contractor responsible to verify completion of this item. $\mathrm{A} / \mathrm{E}=$ architect/engineer, $\mathrm{All}=$ all contractors, $\mathrm{CA}=$ commissioning agent, $\mathrm{CC}=$ controls contractor, $\mathrm{EC}=$ electrical contractor, $\mathrm{GC}=$ general contractor, $\mathrm{MC}=$ mechanical contractor, $\mathrm{SC}=$ sheet metal contractor, $\mathrm{TAB}=$ test and balance contractor, $=$

Approvals. This filled-out checklist has been reviewed. Its completion is approved with the exceptions noted below.

Notes: 


\section{Requested documentation submitted}

Check if Okay. Enter comment or note number if deficient.

\begin{tabular}{|l|l|l|l|l|l|l|}
\hline \multicolumn{1}{|c|}{ Check Equlp Tag-> } & & & & & & Contr. \\
\hline Manufacturer's cut sheets & & & & & & \\
\hline Performance data & & & & & & \\
\hline Flushing and cleaning plan & & & & & & \\
\hline O\&M manuals & & & & & & \\
\hline
\end{tabular}

- Documentation complete as per contract documents for given trade.......

YES NO

\section{Physical Installation Checks}

\begin{tabular}{|c|c|c|}
\hline Check & $\mathbf{Y} / \mathbf{N}$ & Contr. \\
\hline \multicolumn{3}{|l|}{ Piping } \\
\hline \multicolumn{3}{|l|}{ Pipe fittings complete and pipes properly supported } \\
\hline \multicolumn{3}{|l|}{ Required seismic anchoring installed } \\
\hline \multicolumn{3}{|l|}{ Pipes properly labeled } \\
\hline \multicolumn{3}{|l|}{ Pipes properly insulated } \\
\hline \multicolumn{3}{|l|}{ Strainers in place and clean } \\
\hline \multicolumn{3}{|l|}{ Isolation valves and balancing valves installed } \\
\hline \multicolumn{3}{|l|}{ Test ports $(P / T)$ installed near all control sensors and as per spec } \\
\hline \multicolumn{3}{|l|}{ Flushing and cleaning plan submitted and approved } \\
\hline \multicolumn{3}{|l|}{$\begin{array}{l}\text { Piping system properly flushed and cleaned and temporary piping } \\
\text { removed (report attached) }\end{array}$} \\
\hline \multicolumn{3}{|l|}{$\begin{array}{l}\text { Piping pressure tested according to contract documents } \\
\text { (report attached) }\end{array}$} \\
\hline \multicolumn{3}{|l|}{ Chemical treatment system or plan installed } \\
\hline \multicolumn{3}{|l|}{ Water treatment report submitted according to contract documents } \\
\hline \multicolumn{3}{|l|}{ No leaking apparent around fittings } \\
\hline \multicolumn{3}{|l|}{$\begin{array}{l}\text { ASME pressue vessel data sheet or certification tag posted and } \\
\text { inspection complete for each expansion tank }\end{array}$} \\
\hline \multicolumn{3}{|l|}{$\begin{array}{l}\text { Expansion tanks verified to not be air bound and system completely full } \\
\text { of water }\end{array}$} \\
\hline \multicolumn{3}{|l|}{ Air vents and bleeds at high points of systems functional } \\
\hline \multicolumn{3}{|l|}{ Valves (except coll valve checklists are with the unit checklist) } \\
\hline \multicolumn{3}{|l|}{ Valve labels permanently affixed } \\
\hline Valves installed in proper direction & & \\
\hline
\end{tabular}

Notes: 


\begin{tabular}{|l|l|l|}
\hline \multicolumn{1}{|c|}{ Check } & Y/N & Contr. \\
\hline No leaks & & \\
\hline $\begin{array}{l}\text { Valves stroke fully and easily and spanning is calibrated (see Section } \\
5.2 \text { below) }\end{array}$ & & \\
\hline $\begin{array}{l}\text { Valves that require a positive shut-off are verified to not be leaking } \\
\text { when closed at normal operating pressure }\end{array}$ & & \\
\hline Sensors and Gages & & \\
\hline Temperature, pressure and flow gages and sensors installed & & \\
\hline Sensors calibrated (See calibration section below) & & \\
\hline \multicolumn{2}{|c|}{} & \\
\hline TAB & & \\
\hline $\begin{array}{l}\text { Installation of system and balancing devices allowed balancing to be } \\
\text { completed following specified NEBB or AABC procedures and contract } \\
\text { documents }\end{array}$ & & \\
\hline
\end{tabular}

- The checklist items of Part 3 are all successfully completed for given trade.__ YES NO

\section{Sensor Calibration}

All field-installed temperature, relative humidity, $\mathrm{CO}, \mathrm{CO}_{2}$ and pressure sensors and gages on this piece of equipment shall be calibrated using the methods described below. All test instruments shall have had a certified calibration within the last 12 months: Y $\mathbb{N}$ . Sensors installed in the unit at the factory with calibration certification provided need not be field calibrated. All actuators should also be calibrated, per the above checklist.

\begin{tabular}{|c|c|c|c|c|c|}
\hline $\begin{array}{c}\text { Sensor \& } \\
\text { Location }\end{array}$ & $\begin{array}{c}\text { Loc- } \\
\text { ation } \\
\text { OK }\end{array}$ & $\begin{array}{c}\text { 1st } \\
\text { Gage } \\
\text { or BAS }\end{array}$ & $\begin{array}{c}\text { Instr. } \\
\text { Meas'd } \\
\text { Value }\end{array}$ & $\begin{array}{c}\text { Final } \\
\text { Gage } \\
\text { or BAS } \\
\text { Value }\end{array}$ & $\begin{array}{c}\text { Pass } \\
\text { YNN? }\end{array}$ \\
\hline & & & & & \\
\hline & & & & & \\
\hline & & & & & \\
\hline
\end{tabular}

\begin{tabular}{|c|c|c|c|c|c|}
\hline $\begin{array}{c}\text { Sensor \& } \\
\text { Location }\end{array}$ & $\begin{array}{c}\text { Loc- } \\
\text { ation } \\
\text { OK }\end{array}$ & $\begin{array}{c}\text { Ist } \\
\text { or BAS } \\
\text { Value }\end{array}$ & $\begin{array}{c}\text { Instr. } \\
\text { Meas'd } \\
\text { Value }\end{array}$ & $\begin{array}{c}\text { Final } \\
\text { Gage } \\
\text { or BAS } \\
\text { Value }\end{array}$ & $\begin{array}{c}\text { Pass } \\
\text { YN? }\end{array}$ \\
\hline \hline & & & & & \\
\hline & & & & & \\
\hline & & & & & \\
\hline
\end{tabular}

The Contractor's own sensor check-out sheets may be used in lieu of the above, if the same recording fields are included and the procedures below are followed.

- All sensors are calibrated within required tolerances. YES NO

Notes: 


\section{Misc. Procedures (As referenced above)}

\subsection{Sensor Calibration Methods}

All Sensors, Verify that all sensor locations are appropriate and away from causes of erratic operation. Verify that sensors with shielded cable, are grounded only at one end. For sensor pairs that are used to determine a temperature or pressure difference, make sure they are reading within $0.2^{\circ} \mathrm{F}$ of each other for temperature and within a tolerance equal to $2 \%$ of the reading, of each other, for pressure. Tolerances for critical applications may be tighter.

A. Sensors Without Transmitters--Standard Application. Make a reading with a calibrated test instrument within 6 inches of the slte sensor. Verify that the sensor reading (via the permanent thermostat, gage or building automation system (BAS)) Is within the tolerances in the table below of the instrument-measured value. If not, install offset in BAS, calibrate or replace sensor.

B. Sensors With Transmitters--Standard Application. Disconnect sensor. Connect a signal generafor in place of sensor. Connect ammeter in series between transmitter and BAS control panel. Using manufacturer's resistance-temperature data, simulate minimum desired temperature. Adjust transmitter potentiometer zero until $4 \mathrm{~mA}$ is read by the ammeter. Repeat for the maximum temperature matching $20 \mathrm{~mA}$ to the potentiometer span or maximum and verify at the BAS. Record all values and recalibrate controller as necessary to conform with specified control ramps, reset schedules, proportional relationship, reset relationship and P/I reaction. Reconnect sensor. Make a reading with a calibrated test instrument within 6 inches of the site sensor. Verify that the sensor reading (via the permanent thermostat, gage or building automation system (BAS)) is within the tolerances in the table below of the instrument-measured value. If not, replace sensor and repeat. For pressure sensors, perform a similar process with a suitable signal generator.

C. Critical Applications, For critical applications (process, manufacturing, etc.) more rigorous calibration techniques may be required for selected sensors. Describe any such methods used on an attached sheet.

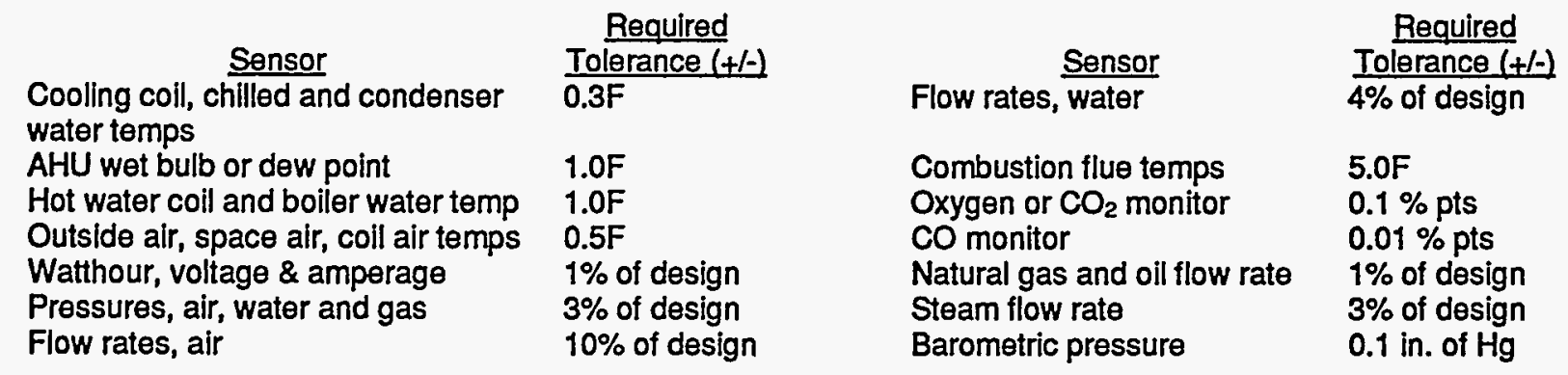

\subsection{Coll Valve Leak Check}

A. Method 1--Water Temperature With 2-Way Valve. Calibrate water temperature sensors on each side of coil to be within $0.5^{\circ} \mathrm{F}$ of each other. Turn off air handler fans and close OSA dampers. Make sure appropriate coil dampers are open. Normally closed valves will close. Override normally open valves to the closed position. After 10 minutes observe water delta $T$ across coil. If it is greater than $2^{\circ} \mathrm{F}$, leakage is probably occuring. Reset valve stroke to close tighter. Repeat test until compliance.

B. Method 2--Air Temperature With 2 or 3-Way Valve. Calibrate air temperature sensors on each side of coil to be within $0.5^{\circ} \mathrm{F}$ of each other. Change mixed or discharge air setpoint, override values or bleed or squeeze bulb pneumatic controller to cause the valve to close. Air handler fans should be on. After 5 minutes observe air clelta T across coil. If it is greater than $1^{\circ} \mathrm{F}$, leakage is probably occuring. Reset valve stroke to close tighter. Repeat test until compliance.

\subsection{Valve Stroke Setup and Check}

For all valve and actuator positions checked, verify the actual position against the BAS readout.

Set pumps to normal operating mode. Command valve closed, verify that valve is closed and adjust output zero signal as required. Command valve open, verify position is full open and adjust output signal as required. Command valve to a few intermediate positions. If actual valve position doesn't reasonably correspond, replace actuator or add pilot positioner (for pneumatics). For heating coil valves (NO): Set heating setpoint $20^{\circ} \mathrm{F}$ above room temperature. Observe valve open.

\section{Notes:}


Remove control air or power from the valve and verify that the valve stem and actuator position do not change. Restore to normal. Set heating setpoint to $20^{\circ} \mathrm{F}$ below room temperature. Observe the valve close. For pneumatics, by override in the EMS, Increase pressure to valve by 3 psi (do not exceed actuator pressure rating) and verify valve stem and actuator position does not change. Restore to normal.

For cooling coil valves (NC): Set cooling setpoint $20^{\circ} \mathrm{F}$ above room temperature. Observe the valve close. Remove control air or power from the valve and verify that the valve stem and actuator position do not change. Restore to normal. Set cooling setpoint to $20^{\circ} \mathrm{F}$ below room temperature. Observe valve open. For pneumatics, by override in the EMS, increase pressure to valve by $3 \mathrm{psi}$ (do not exceed actuator pressure rating) and verify valve stem and actuator position does not change. Restore to normal.

Notes: 


\title{
Prefunctional Checklist
}

Project

\section{PC-06_ COMPUTER ROOM AC UNIT (Inside Section)}

ID\#'s

\author{
Components included: __ Coils _ Valves (CHW) \\ Associated Checklists: __ Outdoor condenser/compressor
}

\section{Submittal / Approvals}

Submittal. The above equipment and systems integral to them are complete and ready for functional testing. The checklist items are complete and have been checked off only by parties having direct knowledge of the event, as marked below, respective to each responsible contractor. This prefunctional checklist is submitted for approval, subject to an attached list of outstanding items yet to be completed. A Statement of Correction will be submitted upon completion of any outstanding areas. None of the outstanding items preclude safe and reliable functional tests being performed. List attached.

Mechanical Contractor

Electrical Contractor

TAB Contractor

\section{Date}

Date

Date

$$
\text { Controls Contractor }
$$

Sheet Metal Contractor

General Contractor
Date

Date

Prefunctional checklist items are to be completed as part of startup \& initial checkout, preparatory to functional testing.

- This checklist does not take the place of the manufacturer's recommended checkout and startup procedures or report.

- Items that do not apply shall be noted with the reasons on this form (N/A = not applicable, $B O=$ by others).

- If this form is not used for documenting, one of similar rigor shall be used.

- Contractors assigned responsibility for sections of the checklist shall be responsible to see that checklist items by their subcontractors are completed and checked off.

- "Contr." column or abbreviations in brackets to the right of an item refer to the contractor responsible to verify completion of this item. $\mathrm{A} / \mathrm{E}=$ architect/engineer, $\mathrm{All}=$ all contractors, $\mathrm{CA}=$ commissioning agent, $\mathrm{CC}=$ controls contractor, $\mathrm{EC}=$ electrical contractor, $\mathrm{GC}=$ general contractor, $\mathrm{MC}=$ mechanical contractor, $\mathrm{SC}=$ sheet metal contractor, $\mathrm{TAB}=$ test and balance contractor, $=$

Approvals. This filled-out checklist has been reviewed. Its completion is approved with the exceptions noted below.

Commissioning Agent

Date

Owner's Representative

Date

Notes: 


\section{Requested documentation submitted}

Check if Okay. Enter comment or note number if deficlent.

\begin{tabular}{|l|l|l|l|l|l|l|}
\hline \multicolumn{1}{|c|}{ Check Equlp Tag-s } & & & & & & Contr. \\
\hline Manufacturer's cut sheets & & & & & & \\
\hline Performance data (fan curves, coll data, etc.) & & & & & & \\
\hline Installation and startup manual and plan & & & & & & \\
\hline Sequences and control strategies & & & & & & \\
\hline O\&M manuals & & & & & & \\
\hline
\end{tabular}

- Documentation complete as per contract documents for given trade......._ YES

NO

\section{Model verification}

[Contr $=$

1 = as specified, 2 = as submitted, $3=$ as installed. Check if Okay. Enter note number if deficient.

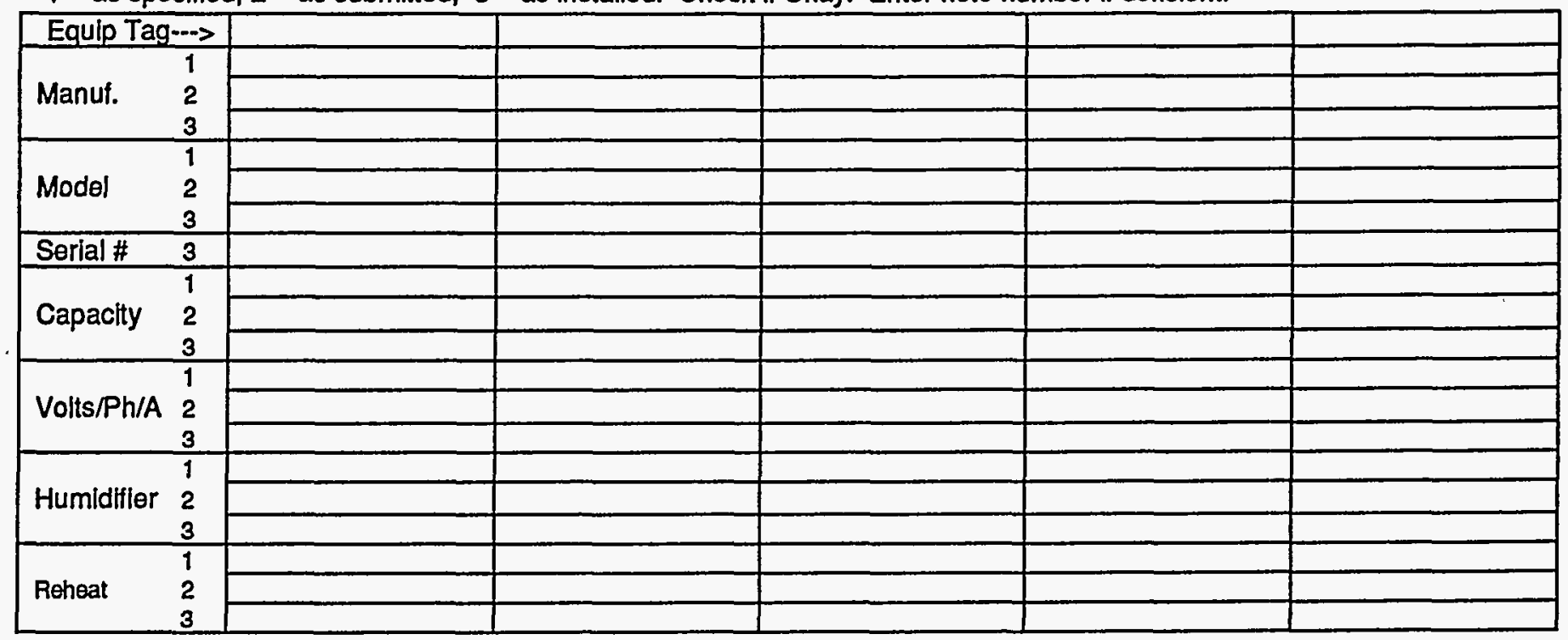

- The equipment installed matches the specifications for given trade.........__ YES _ NO

\section{Physical Installation Checks}

\begin{tabular}{|l|l|l|l|l|l|l|l|}
\hline \multicolumn{1}{|c|}{ Check } & \multicolumn{1}{l|}{} & Contr. \\
\hline Cabinet and General Installation & & & & & \\
\hline Permanent labels affixed, including for fans & & & & & & \\
\hline Casing condition good: no dents, leaks, door gaskets installed & & & & & & \\
\hline Boot between duct and unit tight and in good condition & & & & & & \\
\hline $\begin{array}{l}\text { Vibration isolation equipment installed \& released from shipping } \\
\text { locks }\end{array}$ & & & & & & \\
\hline Maintenance access acceptable for unit and components & & & & & & \\
\hline
\end{tabular}

\section{Notes:}


Check if Okay. Enter comment or note number if deficient.

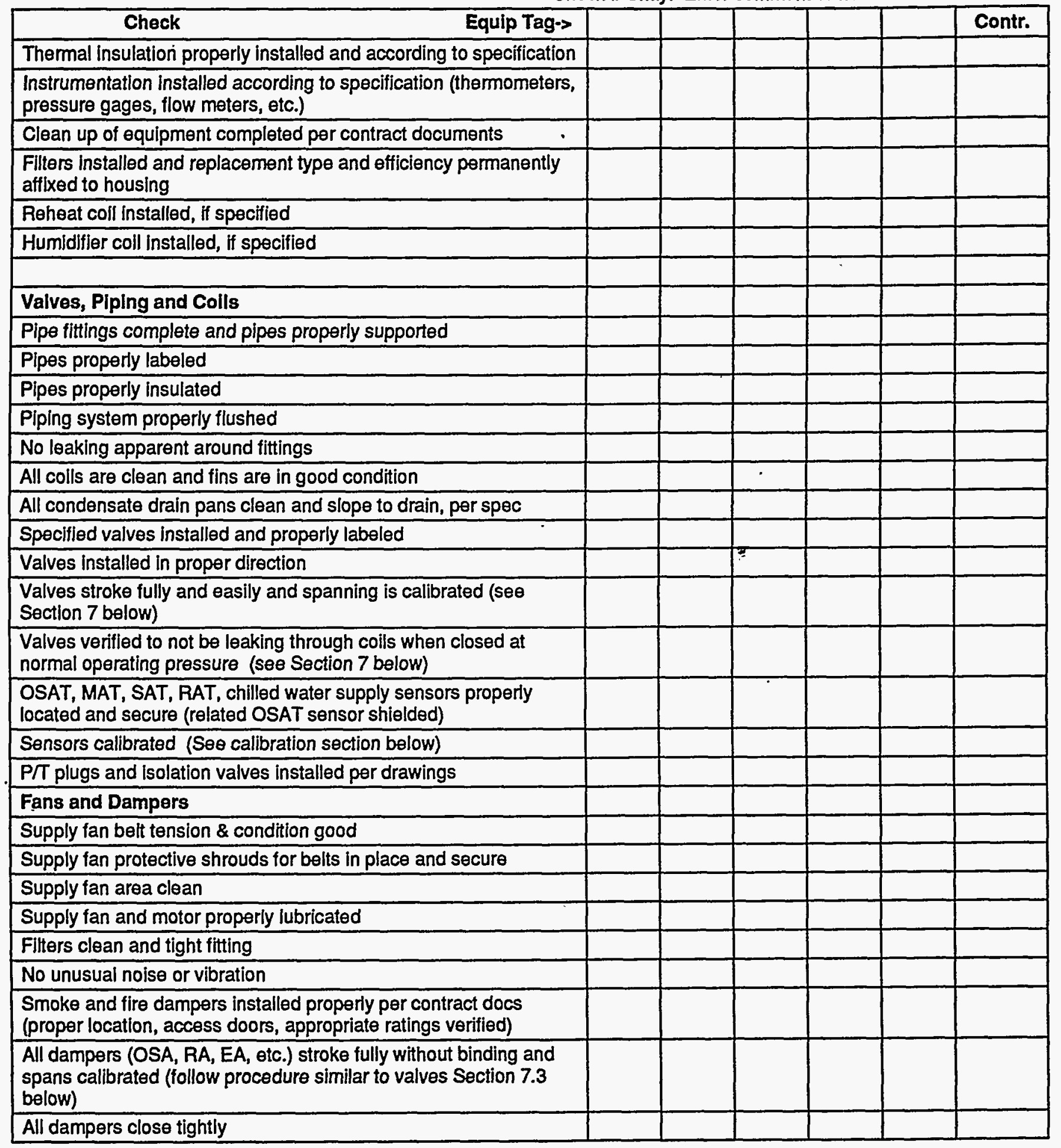

\section{Notes:}


Check if Okay. Enter comment or note number if deficient.



\section{Notes:}


Check if Okay. Enter comment or note number if deficient.

\begin{tabular}{|r|r|r|r|r|r|c|}
\hline Equip Tag-s & & & & & & Contr. \\
\hline
\end{tabular}

- The checklist items of Part 4 are all successfully completed for given trade.___ YES __ NO

5. Operational Checks (These augment mfr's list. This is not the functional performance testing.)

Check if Okay. Enter comment or note number if deficient.

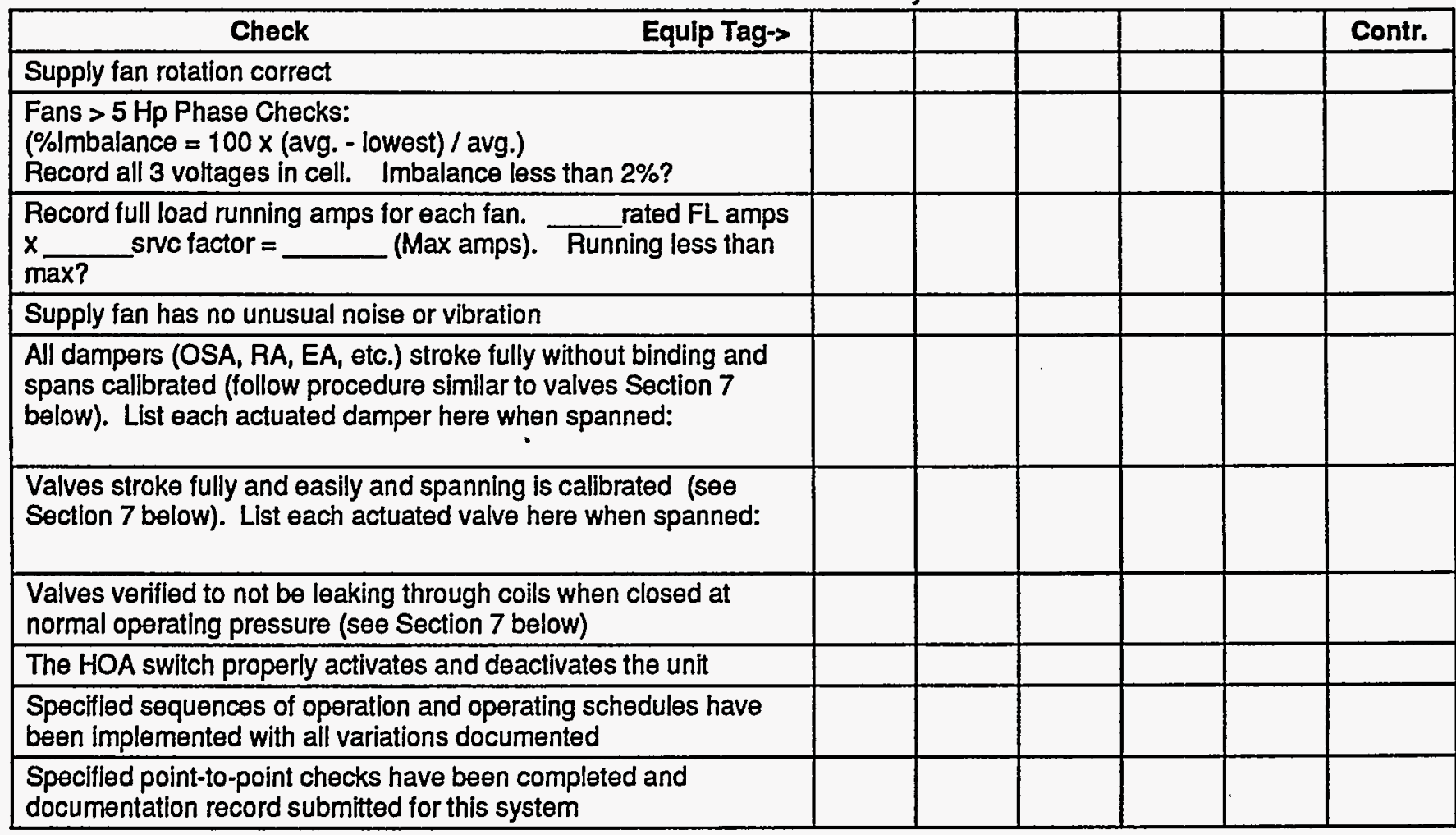

- The checklist items of Part 5 are all successfully completed for given trade.

YES NO

\section{Sensor Calibration}

All field-installed temperature, relative humidity, $\mathrm{CO}, \mathrm{CO}_{2}$ and pressure sensors and gages on this piece of equipment shall be calibrated using the methods described below. All test instruments shall have had a certified calibration within the last 12 months: $\mathrm{Y} / \mathrm{N}$ . Sensors installed in the unit at the factory with calibration certification provided need not be field calibrated. All actuators should also be calibrated, per the above checklist.

Notes:

File: COMPUTAC.PC2

Commissioning Guide Specification -PECI/USDOE: 3/21/97 


\begin{tabular}{|c|c|c|c|c|c|}
\hline $\begin{array}{c}\text { Sensor \& } \\
\text { Location }\end{array}$ & $\begin{array}{c}\text { Loc- } \\
\text { ation } \\
\text { OK }\end{array}$ & $\begin{array}{c}\text { 1st } \\
\text { Gage } \\
\text { Value }\end{array}$ & $\begin{array}{c}\text { instr. } \\
\text { Meas'd } \\
\text { Value }\end{array}$ & $\begin{array}{c}\text { Final } \\
\text { Gage } \\
\text { or BAS } \\
\text { Value }\end{array}$ & $\begin{array}{c}\text { Pass } \\
\text { YNN? }\end{array}$ \\
\hline & & & & & \\
\hline & & & & & \\
\hline & & & & & \\
\hline
\end{tabular}

\begin{tabular}{|c|c|c|c|c|c|}
\hline $\begin{array}{c}\text { Sensor \& } \\
\text { Location }\end{array}$ & $\begin{array}{c}\text { Loc- } \\
\text { ation } \\
\text { OK }\end{array}$ & $\begin{array}{c}\text { 1st } \\
\text { Gage } \\
\text { Value }\end{array}$ & $\begin{array}{c}\text { Instr. } \\
\text { Meas'd } \\
\text { Value }\end{array}$ & $\begin{array}{c}\text { Final } \\
\text { Gage } \\
\text { or BAS } \\
\text { Value }\end{array}$ & $\begin{array}{c}\text { Pass } \\
\text { YN? }\end{array}$ \\
\hline & & & & & \\
\hline & & & & & \\
\hline & & & & & \\
\hline
\end{tabular}

The Contractor's own sensor check-out sheets may be used in lieu of the above, if the same recording fields are included and the procedures below are followed.

- All sensors are calibrated within required tolerances.................................__ YES NO

Notes: 


\section{Misc. Procedures (as referenced above)}

\subsection{Sensar Callbration Methods}

All Sensors. Verify that all sensor locations are appropriate and away from causes of erratic operation. Verity that sensors with shielded cable, are grounded only at one end. For sensor pairs that are used to determine a temperature or pressure difference, make sure they are reading within $0.2^{\circ} \mathrm{F}$ of each other for temperature and within a tolerance equal to $2 \%$ of the reading, of each other, for pressure. Tolerances for critical applications may be tighter.

A. Sensors Without Transmitters--Standard Application. Make a reading with a calibrated test instrument within 6 inches of the site sensor. Verify that the sensor reading (via the permanent thermostat, gage or building automation system (BAS)) is within the tolerances in the table below of the instrument-measured value. If not, install offset in BAS, calibrate or replace sensor.

B. Sensors With Transmitters--Standard Application. Disconnect sensor. Connect a signal generator in place of sensor. Connect ammeter in series between transmitter and BAS control panel. Using manufacturer's resistance-temperature data, simulate minimum desired temperature. Adjust transmitter potentiometer zero until $4 \mathrm{~mA}$ is read by the ammeter. Repeat for the maximum temperature matching $20 \mathrm{~mA}$ to the potentiometer span or maximum and verify at the BAS. Record all values and recalibrate controller as necessary to conform with specified control ramps, reset schedules, proportional relationship, reset relationship and P/I reaction. Reconnect sensor. Make a reading with a calibrated test instrument within 6 inches of the site sensor. Verify that the sensor reading (via the permanent thermostat, gage or building automation system (BAS)) is within the tolerances in the table below of the instrument-measured value. If not, replace sensor and repeat. For pressure sensors, perform a similar process with a suitable signal generator.

C. Critical Applications. For critical applications (process, manufacturing, etc.) more rigorous calibration techniques may be required for selected sensors. Describe any such methods used on an attached sheet.

\begin{tabular}{|c|c|c|c|}
\hline Sensor & $\frac{\text { Required }}{\text { Tolerance }(+/-)}$ & Sensor & $\underset{\text { Tolerance }(+/-)}{\text { Required }}$ \\
\hline $\begin{array}{l}\text { Cooling coil, chilled and condenser } \\
\text { water temps }\end{array}$ & $0.3 \mathrm{~F}$ & Flow rates, water & $4 \%$ of design \\
\hline HU wet bulb or dew point & $1.0 \mathrm{~F}$ & Com & $5.0 \mathrm{~F}$ \\
\hline ot water coil and boller water temp & $1.0 \mathrm{~F}$ & Oxygen or $\mathrm{CO}_{2}$ monitor & $0.1 \%$ pts \\
\hline Itside air, space air, coil air temps & $0.5 \mathrm{~F}$ & CO monitor & $0.01 \% \mathrm{pts}$ \\
\hline Watthour, voltage \& amperage & $1 \%$ of design & Natural gas and oil flow rate & $1 \%$ of design \\
\hline Pressures, air, water and gas & $3 \%$ of design & Steam flow rate & $3 \%$ of design \\
\hline r & $10 \%$ of design & Barometric pressure & $0.1 \mathrm{in}$. of $\mathrm{Hg}$ \\
\hline
\end{tabular}

\subsection{Coll Valve Leak Check}

A. Method 1--Water Temperature With 2-Way Valve. Calibrate water temperature sensors on each side of coil to be within $0.5^{\circ} \mathrm{F}$ of each other. Turn off air handler fans and close OSA dampers. Make sure appropriate coil dampers are open. Normally closed valves will close. Override normally open valves to the closed position. After 10 minutes observe water delta $T$ across coil. If it is greater than $2^{\circ} \mathrm{F}$, leakage is probably occuring. Reset valve stroke to close tighter. Repeat test until compliance.

B. Method 2--Air Temperature With 2 or 3-Way Valve. Calibrate air temperature sensors on each side of coil to be within $0.5^{\circ} \mathrm{F}$ of each other. Change mixed or discharge air setpoint, override values or bleed or squeeze bulb pneumatic controller to cause the valve to close. Air handler fans should be on. After 5 minutes observe air delta T across coil. If it is greater than $1^{\circ} \mathrm{F}$, leakage is probably occuring. Reset valve stroke to close tighter. Repeat test until compliance.

\subsection{Valve Stroke Setup and Check}

For all valve and actuator positions checked, verify the actual position against the BAS readout.

Set pumps to normal operating mode. Command valve closed, verify that valve is closed and adjust output zero signal as required. Command valve open, verify position is full open and adjust output signal as required. Command valve to a few intermediate positions. If actual valve position doesn't reasonably correspond, replace actuator or add pilot positioner (for pneumatics). For heating coil valves (NO): Set heating setpoint $20^{\circ} \mathrm{F}$ above room temperature. Observe valve open.

Notes:

File: COMPUTAC.PC2 
Remove control air or power from the valve and verify that the valve stem and actuator position do not change. Restore to normal. Set heating setpoint to $20^{\circ} \mathrm{F}$ below room temperature. Observe the valve close. For pneumatics, by override in the EMS, increase pressure to valve by 3 psi (do not exceed actuator pressure rating) and verify valve stem and actuator position does not change. Restore to normal.

For cooling coll valves (NC): Set cooling setpoint $20^{\circ} \mathrm{F}$ above room temperature. Observe the valve close. Remove control air or power from the valve and verify that the valve stem and actuator position do not change. Restore to normal. Set cooling setpoint to $20^{\circ} \mathrm{F}$ below room temperature. Observe valve open. For pneumatics, by override in the EMS, increase pressure to valve by 3 psi (do not exceed actuator pressure rating) and verify valve stem and actuator position does not change. Restore to normal.

\section{- END OF CHECKLIST-}

Notes: 


\section{Prefunctional Checklist}

Project

\section{PC-11_ BUILDING AUTOMATION SYSTEM}

\section{Entire Building Only Floor or Zone}

\section{Associated checklists:}

\section{Submittal / Approvals}

Submittal. The above equipment and systems integral to them are complete and ready for functional testing. The checklist items are complete and have been checked off only by parties having direct knowledge of the event, as marked below, respective to each responsible contractor. This prefunctional checklist is submitted for approval, subject to an attached list of outstanding items yet to be completed. A Statement of Correction will be submitted upon completion of any outstanding areas. None of the outstanding items preclude safe and reliable functional tests being performed. List attached.

\begin{tabular}{|c|c|}
\hline Mechanical Contractor & Date \\
\hline Electrical Contractor & Date \\
\hline TAB Contractor & Date \\
\hline
\end{tabular}

$\begin{array}{ll}\overline{\text { Controls Contractor }} & \overline{\text { Date }} \\ \overline{\text { Sheet Metal Contractor }} & \overline{\text { Date }} \\ \overline{\text { General Contractor }} & \text { Date }\end{array}$

Prefunctional checklist items are to be completed as part of startup \& initial checkout, preparatory to functional testing.

- This checklist does not take the place of the manufacturer's recommended checkout and startup procedures or report.

- Items that do not apply shall be noted with the reasons on this form (N/A = not applicable, $B O=$ by others).

- If this form is not used for documenting, one of similar rigor shall be used.

- Contractors assigned responsibility for sections of the checklist shall be responsible to see that checklist items by their subcontractors are completed and checked off.

- "Contr." column or abbreviations in brackets to the right of an item refer to the contractor responsible to verify completion of this item. $\mathrm{A} / \mathrm{E}=$ architect/engineer, $\mathrm{All}=$ all contractors, $\mathrm{CA}=$ commissioning agent, $\mathrm{CC}=$ controls contractor, $\mathrm{EC}=$ electrical contractor, $\mathrm{GC}=$ general contractor, $\mathrm{MC}=$ mechanical contractor, $\mathrm{SC}=$ sheet metal contractor, $\mathrm{TAB}=$ test and balance contractor, $=$

Approvals. This filled-out checklist has been reviewed. Its completion is approved with the exceptions noted below.

\section{Notes:}


2. Documentation submitted and approved:

manufacturer's cut sheets

- installation and checkout manual and plan

_ full written sequences and list of all control strategies

— written copy of all control parameters, settings

and setpoints

_ O\&M manual
_. performance data

- operating manual

_ completed control drawings

— design criteria

— full descriptive points list

- Documentation complete as per contract documents.

3. Model verification

\begin{tabular}{|l|c|c|c|}
\hline & As Specified & As Submitted & As Installed \\
\hline Manufacturer & & & \\
\hline Model No. & & $\mathrm{n} / \mathrm{a}$ & \\
\hline Serial No. & $\mathrm{n} / \mathrm{a}$ & & \\
\hline CPU & & & \\
\hline Monitor & & & \\
\hline $\begin{array}{l}\text { Other primary } \\
\text { features: }\end{array}$ & & & \\
\hline & & & \\
\hline & & & \\
\hline
\end{tabular}

- The equipment installed matches the specifications for given trade.

YES

\section{Initial Setup and Checkout}

\subsection{User Terminal Interface and Sub-Panel Checks}

Check if Okay. Enter comment or note number if deficient.

\begin{tabular}{|l|l|l|}
\hline \multicolumn{1}{|c|}{ Check } & $\mathrm{Y} / \mathrm{N}$ & Contr. \\
\hline General appearance good, no apparent damage & & \\
\hline Equipment labels affixed & & \\
\hline Layout and location of control panels matches drawings & & \\
\hline Areas or equipment panels serve clear in control drawings & & \\
\hline Wiring labeled inside panels (to controlled components) & & \\
\hline Controlled components labeled/tagged & & \\
\hline BAS connection made to labeled terminal(s) as shown on drawings & & \\
\hline Shielded wiring used on electronic sensors & & \\
\hline 110 volt AC power available to panel & & \\
\hline Psig compressed air available to panel (if applicable) & & \\
\hline Battery backup in place and operable & & \\
\hline Panels properly grounded & & \\
\hline
\end{tabular}

Notes: 


\begin{tabular}{|l|c|c|}
\hline \multicolumn{1}{|c|}{ Check } & Y/N & Contr. \\
\hline Environmental conditions according to manufacturer's requirements & & \\
\hline Date and time correct & & \\
\hline & & \\
\hline
\end{tabular}

- The above setup and checkout was successfully completed for given trade_ YES _ NO

\subsection{Device and Point Checkout}

The following procedures are required to be performed and documented for each and every point in the control system. The following procedures are minimum requirements. The control contractor is encouraged to identify better and more comprehensive checkout procedures in their submitted plan. These procedures are not a substitute for the manufacturer's recommended start-up and checkout procedures, but are to be combined with them, as applicable. The documentation may be provided on the vendor's stock form, as long as all the information in the sample table below can be clearly documented on the form.

Similar checkout and calibration requirements are found on the equipment prefunctional checklists. Redundant documentation is not required. Cross reference, by name and form number, to other forms that contain documentation left blank on the current form.

\section{Procedures}

1. [Wire] Verify that the wiring is correct to each point.

2. [Actu] If the device is or has an actuator, verify full free movement through its full range.

3. [Addr] Verify that the software address is correct.

4. [Load] For devices with a controller, verify that current software program with proper setpoints has been downloaded.

5. [DevCal] Device stroke/range calibration. This applies to all controlled valves, dampers, fans, pumps, actuators, etc. Simulate maximum and minimum transmitter signal values and verify minimum and maximum controller output values and positively verify each and every control device minimum and maximum stroke and capacity range. Follow procedure 6.2 below.

6. [SensLoc] Verify that all sensor locations are appropriate and away from causes of erratic operation.

7. [SensCal] Sensor calibration. Calibrate or verify calibration of all sensors and thermostats, including temperature, pressure, flow, current, $\mathrm{kW}, \mathrm{rpm}$, Hertz, etc. Verify that the sensor readings in the control system are within the sensor accuracies specified in this section, using hand-held or other external measuring instruments. Follow procedure 6.1 below.

8. [OperCk] For controlled devices (dampers, valves, actuators, VAV boxes, etc.), after mechanical equipment control becomes operational, perform an operational test of each control loop. Follow procedure 6.2 below. Operational checks are preparatory to the later functional testing.

Other Abbreviations:

[BAS] ...... Building automation system or gage-read value.

[Instru]..... Instrument (calibrated) read value.

[Ofset]...... Offset programmed into the point to correct the calibration.

Notes: 
Controls Checkout Documentation Table -SAMPLE FORM-

\begin{tabular}{|c|c|c|c|c|c|c|c|c|c|c|c|c|c|}
\hline \multirow[b]{2}{*}{$\begin{array}{c}\text { Polnt } \\
\text { ID }\end{array}$} & \multirow[b]{2}{*}{ Object } & \multirow{2}{*}{$\begin{array}{c}\text { Field } \\
\text { Device } \\
\text { Type } \\
\end{array}$} & \multicolumn{3}{|c|}{ Hardware Checks } & \multirow[b]{2}{*}{ Load } & \multirow[b]{2}{*}{$\begin{array}{l}\text { Dov } \\
\text { Cal }\end{array}$} & \multirow[b]{2}{*}{$\begin{array}{l}\text { Sens } \\
\text { Loc }\end{array}$} & \multicolumn{3}{|c|}{ SensCal } & \multicolumn{2}{|c|}{ Final Chock } \\
\hline & & & Wire & Actu & Addr & & & & BAS & Instru & Offset & $\begin{array}{c}\text { Oper } \\
\text { Ck }\end{array}$ & \\
\hline & & & 1 & 2 & 3 & 4 & 5 & 6 & 7 & 7 & 7 & 8 & 9 \\
\hline Al-1 & $\begin{array}{l}\text { ZN-T } \\
\text { (zone T) }\end{array}$ & PhJack & $\sqrt{1}$ & na & $\sqrt{1}$ & na & na & $\sqrt{ }$ & $70.2 F$ & $71.4 \mathrm{~F}$ & $+1.2 F$ & na & \\
\hline $3-2 a$ & $\begin{array}{l}\text { RA-DPR } \\
\text { (damper) }\end{array}$ & PNEU & $\sqrt{ }$ & $\sqrt{ }$ & $\sqrt{ }$ & na & $\sqrt{ }$ & na & na & na & na & $\sqrt{ }$ & \\
\hline & & & & & & & & & & & & & \\
\hline & & & & & & & & & & & & & \\
\hline & & & & & & & & & & & & & \\
\hline & & & & & & & & & & & & & \\
\hline & & & & & & & & & & & & & \\
\hline & & & & & & & & & & & & & \\
\hline & & & & & & & & & & & & & \\
\hline
\end{tabular}

- The initial setup and checkout has been successfully completed as described in Section 4.2 and Section 6 and documented on attached forms YES NO

\section{Pneumatic System Pressure Test}

The entire pneumatic system servicing the controls shall be pressure tested as follows:

5.1. Test the high pressure air piping at $[150 \mathrm{psi}]$ _. Maintain the pressure for 2 hours without loss of pressure. Correct and retest the system if any loss of pressure is indicated.

Pass? (Y/N)

5.2. Test the low pressure control tubing at [ 30 psi] _. Maintain pressure for 2 hours without pumping. If the pressure drops more than 1 psi, correct leak and retest until successful. $\quad$ Pass? (Y/N)

- The pneumatic system pressure tests were successfully completed........__ YES _ NO

6. Misc. Procedures (Referenced above)

\subsection{Sensor Callbration Methods}

All Sensors. Verify that all sensor locations are appropriate and away from causes of erratic operation. Verify that sensors with shielded cable, are grounded only at one end. For sensor pairs that are used to determine a temperature or pressure difference, make sure they are reading within $0.2^{\circ} \mathrm{F}$ of each other for temperature and within a tolerance equal to $2 \%$ of the reading, of each other, for pressure. Tolerances for critical applications may be tighter.

A. Sensors Without Transmitters--Standard Application. Make a reading with a calibrated test instrument within 6 inches of the site sensor. Verify that the sensor reading (via the permanent thermostat, gage or building automation system (BAS)) is within the tolerances in the table below of the instrument-measured value. If not, install offset in BAS, calibrate or replace sensor.

B. Sensors With Transmitters--Standard Application. Disconnect sensor. Connect a signal generator in place of sensor. Connect ammeter in series between transmitter and BAS control panel. Using manufacturer's resistance-temperature data, simulate minimum desired temperature. Adjust transmitter potentiometer zero until $4 \mathrm{~mA}$ is read by the ammeter. Repeat for the maximum temperature matching $20 \mathrm{~mA}$ to the potentiometer span or maximum and verify at the BAS. Record all values and recalibrate controller as necessary to conform with specified control ramps, reset schedules, proportional relationship, reset relationship and $\mathrm{P} / \mathrm{l}$ reaction. Reconnect sensor. Make a reading with a calibrated test instrument within 6 inches of the site sensor. Verify that the sensor reading (via the permanent thermostat, gage or

Notes: 
building automation system (BAS)) is within the tolerances in the table below of the instrument-measured value. If not, replace sensor and repeat. For pressure sensors, perform a similar process with a suitable signal generator.

C. Water and Air Flow Verifications. __Water, _Air flow sensor read out at the BAS will be verifled by a separate test instrument, unless calibration data on the permanent device is provided.

\begin{tabular}{|c|c|c|c|}
\hline$S$ & Required & & Tolequance $(+1-$ - \\
\hline $\begin{array}{l}\text { ooling coll, chilled and condenser } \\
\text { ater temps }\end{array}$ & $\frac{\text { lolera }}{0.3 \mathrm{~F}}$ & Flow rates, water & $4 \%$ of design \\
\hline $\begin{array}{l}\text { AHU wet bulb or dew point } \\
\text { Hot water coil and boller water temp } \\
\text { Outside air, space air, coil air temps } \\
\text { Watthour, voltage \& amperage } \\
\text { Pressures, air, water and gas } \\
\text { Flow rates, air }\end{array}$ & $\begin{array}{l}1.0 \mathrm{~F} \\
1.0 \mathrm{~F} \\
0.5 \mathrm{~F} \\
1 \% \text { of design } \\
3 \% \text { of design } \\
10 \% \text { of design }\end{array}$ & $\begin{array}{l}\text { Combustion flue temps } \\
\text { Oxygen or } \mathrm{CO}_{2} \text { monitor } \\
\text { cO monitor } \\
\text { Natural gas and oil flow rate } \\
\text { Steam flow rate } \\
\text { Barometric pressure }\end{array}$ & $\begin{array}{l}5.0 \mathrm{~F} \\
0.1 \% \text { pts } \\
0.01 \% \text { pts } \\
1 \% \text { of design } \\
3 \% \text { of design } \\
0.1 \text { in. of } \mathrm{Hg}\end{array}$ \\
\hline
\end{tabular}

D. Critical Applications. For critical applications (process, manufacturing, etc.) more rigorous calibration techniques may be required for selected sensors. Describe any such methods used on an attached sheet.

\subsection{Valve Stroke Setup Callibration and Check (Use an analogous procedure for dampers and vanes, motors, otc.)}

Setup and Device Stroke Calibration. Check that valves are installed in the proper direction and that they are normally open or closed as specified. Command valve closed, sight-verify that valve is closed and adjust output zero signal as required. Command valve open, sight-verify that position is full open and adjust output signal as required. In both cases verify that BAS reading corresponds to sight-verified condition. Command valve to a few intermediate positions. If actual valve position doesn't reasonably correspond, replace actuator or add pilot positioner (for pneumatics).

\section{Operational Checks.}

For heating coll valves (NO): Set pumps to normal operating mode. Set heating setpoint $20^{\circ} \mathrm{F}$ above room temperature. Observe valve open. Remove control air from the valve and verify that the valve stem and actuator position do not change. Restore to normal. Set heating setpoint to $20^{\circ} \mathrm{F}$ below room temperature. Observe the valve close. By override in the EMS, increase pressure to valve by 3 psi (do not exceed actuator pressure rating) and verify valve stem and actuator position does not change. Restore to normal. In both conditions verify that BAS reading corresponds to site verified condition. For cooling coil valves (NC): Set pumps to normal operating mode. Set cooling setpoint $20^{\circ} \mathrm{F}$ above room temperature. Observe the valve close. Remove control air from the valve and verify that the valve stem and actuator position do not change. Restore to normal. Set cooling setpoint to $20^{\circ} \mathrm{F}$ below room temperature. Observe valve open. By override in the EMS, increase pressure to valve by 3 psi (do not exceed actuator pressure rating) and verify valve stem and actuator position does not change. Restore to normal. In both conditions verify that BAS reading corresponds to site verified condition.

For VAV Boxes (pressure independent): Start fans. Override space temperature to $55 \mathrm{~F}$, simulating full heating. Verify that BAS flow sensors read the maximum heating flow (cfm) and minimum cooling flow for that box, per box schedule. Verify proper opening of heating coil valve and operation of fan, if applicable. Override the space sensor to read $78 \mathrm{~F}$ to simulate maximum cooling. Verify that BAS flow sensors read the maximum cooling flow (cfm) and minimum heating flow for that box, per box schedule. Verify proper closing of heating coil valve and operation of fan, if applicable. This verifies that the controlled devices are operating under normal control. Document this process on a written form with a cell for recording the check and calibration for each point. Investigate and report anomalies. This is done before balancing and is not a balancing procedure. Additional data may be recorded for each VAV box, such as box number, inlet size, etc.

\section{- END OF CHECKLIST -}

\section{Notes:}




\section{Prefunctional Checklist}

\section{Project \\ PC-01_ COOLING TOWER \#'S}

\section{Associated checklists: Chiller, Chilled Water Piping, CHW Pumps, CDW Pumps}

\section{Submittal / Approvals}

Submittal. The above equipment and systems integral to them are complete and ready for functional testing. The checklist items are complete and have been checked off only by parties having direct knowledge of the event, as marked below, respective to each responsible contractor. This prefunctional checklist is submitted for approval, subject to an attached list of outstanding items yet to be completed. A Statement of Correction will be submitted upon completion of any outstanding areas. None of the outstanding items preclude safe and reliable functional tests being performed. List attached.

$$
\text { Mechanical Contractor }
$$

Electrical Contractor

$$
\text { Date }
$$

Date

Date

$$
\text { Controls Contractor }
$$

Sheet Metal Contractor

General Contractor $\overline{\text { Date }}$

Date

\section{TAB Contractor}

Date

Prefunctional checklist items are to be completed as part of startup \& initial checkout, preparatory to functional testing.

- This checklist does not take the place of the manufacturer's recommended checkout and startup procedures or report.

- Items that do not apply shall be noted with the reasons on this form (N/A = not applicable, $B O=$ by others).

- If this form is not used for documenting, one of similar rigor shall be used.

- Contractors assigned responsibility for sections of the checklist shall be responsible to see that checklist items by their subcontractors are completed and checked off.

- "Contr." column or abbreviations in brackets to the right of an item refer to the contractor responsible to verify completion of this item. $\mathrm{A} / \mathrm{E}=$ architect/engineer, $\mathrm{All}=$ all contractors, $\mathrm{CA}=$ commissioning agent $\mathrm{CC}=$ controls contractor, $\mathrm{EC}=$ electrical contractor, $\mathrm{GC}=$ general contractor, $\mathrm{MC}=$ mechanical contractor, $\mathrm{SC}=$ sheet metal contractor, $\mathrm{TAB}=$ test and balance contractor, $=$

Approvals. This filled-out checklist has been reviewed. Its completion is approved with the exceptions noted below. 


\section{Requested documentation submitted}

Check if Okay. Enter comment or note number if deficient.

\begin{tabular}{|l|l|l|l|l|l|l|}
\hline \multicolumn{1}{|c|}{ Check Equip Tag-> } & & & & & & Contr. \\
\hline Manufacturer's cut sheets & & & & & & \\
\hline Performance data (fan curves, coll data, etc.) & & & & & & \\
\hline Installation and startup manual and plan & & & & & & \\
\hline Sequences and control strategies & & & & & & \\
\hline O\&M manuals & & & & & & \\
\hline
\end{tabular}

- Documentation complete as per contract documents. YES NO

\section{Model verification}

[Contr $=$

$1=$ as specifled, 2 =as submitted, $3=$ as installed. Check if Okay. Enter note number if deficient.

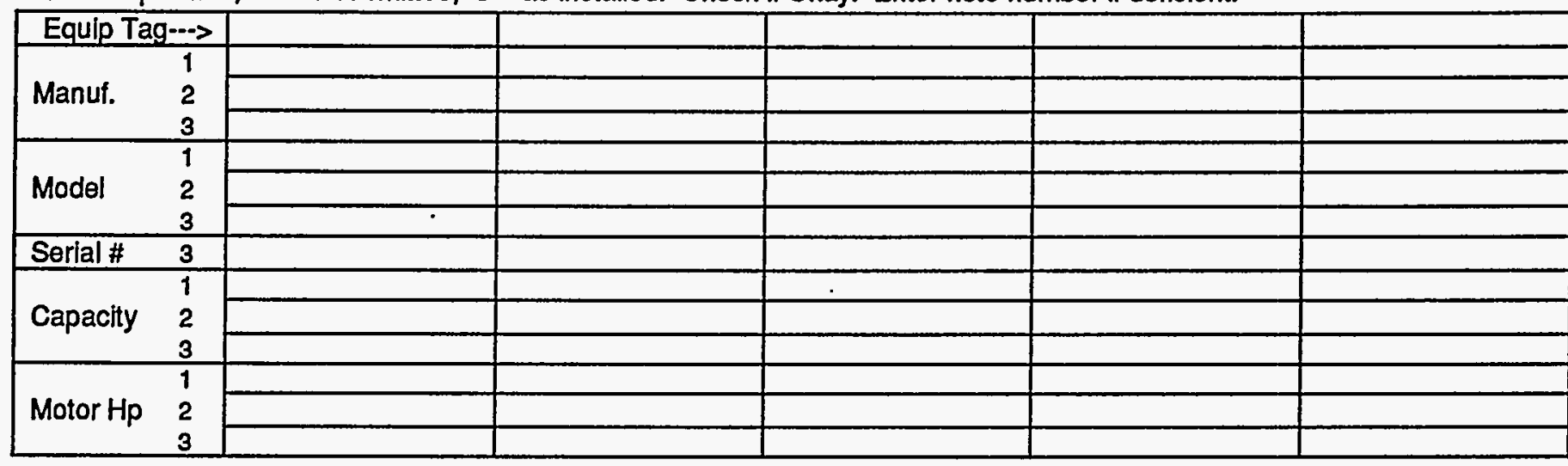

- The equipment installed matches the specifications for given trade........__ YES _ _ NO

\section{Installation Checks}

Check if Okay. Enter comment or note number if deficient.



Notes: 


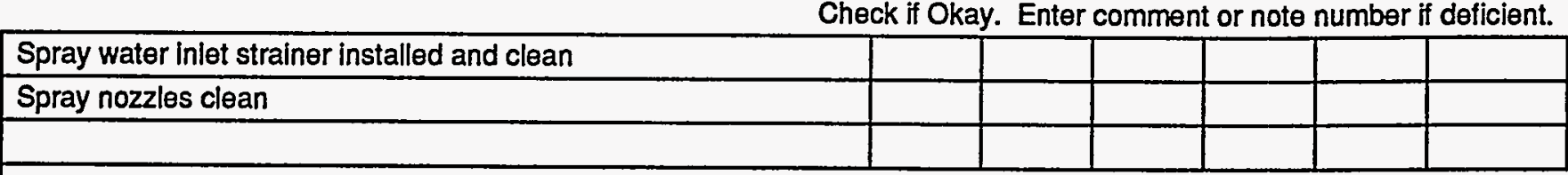

\section{Electrical}

Power to unit and disconnect installed

All electrical components grounded

Power available to sump heater

Motor protection and safeties installed

\section{Controls}

Sensors calibrated (see below)

Control system interlocks hooked up and functional

All control devices, pneumatic tubing and wiring complete

\begin{tabular}{|l|l|l|l|l|l|l|}
\hline & & & & & \\
\hline & & & & & \\
\hline & & & & & & \\
\hline
\end{tabular}

Piping (Imediately around unt. Ful plping in CHW Piping

Piping (lmming
Checkllst.)

Pipe fittings and accessories complete

Makeup water supply piped

Makeup water shut-off valve installed

Pipes are properiy labeled (direction, etc.)

Valves are properly tagged

Chemical treatment system or plan installed

Water treatment report submitted

Distribution header balanced

Test plugs installed

Isolation and balancing valves installed per drawings

\begin{tabular}{|l|l|l|l|l|l|}
\hline & & & & & \\
\hline & & & & & \\
\hline
\end{tabular}

\begin{tabular}{|l|l|l|l|l|l|l|}
\hline & & & & & \\
\hline & & & & & & \\
\hline & & & & & \\
\hline & & & & & \\
\hline & & & & & \\
\hline & & & & & \\
\hline & & & & & \\
\hline
\end{tabular}

\begin{tabular}{|l|l|l|l|l|l|}
\hline & & & & & \\
\hline & & & & & \\
\hline
\end{tabular}

- The checklist items of Part 4 are all successfully completed for given trade.__ YES

5. Operational Checks (These augment mfr's list. This is not the functional performance testing.)

Check if Okay. Enter comment or note number if deficient.

\begin{tabular}{|l|l|l|l|l|l|l|}
\hline \multicolumn{1}{|c|}{ Check Equip Tag $>$ Contr. } \\
\hline Cooling tower starts and runs & & & & & & Cons \\
\hline Fan rotation correct & & & & & & \\
\hline
\end{tabular}

\section{Notes:}


Check if Okay. Enter comment or note number if deficient.

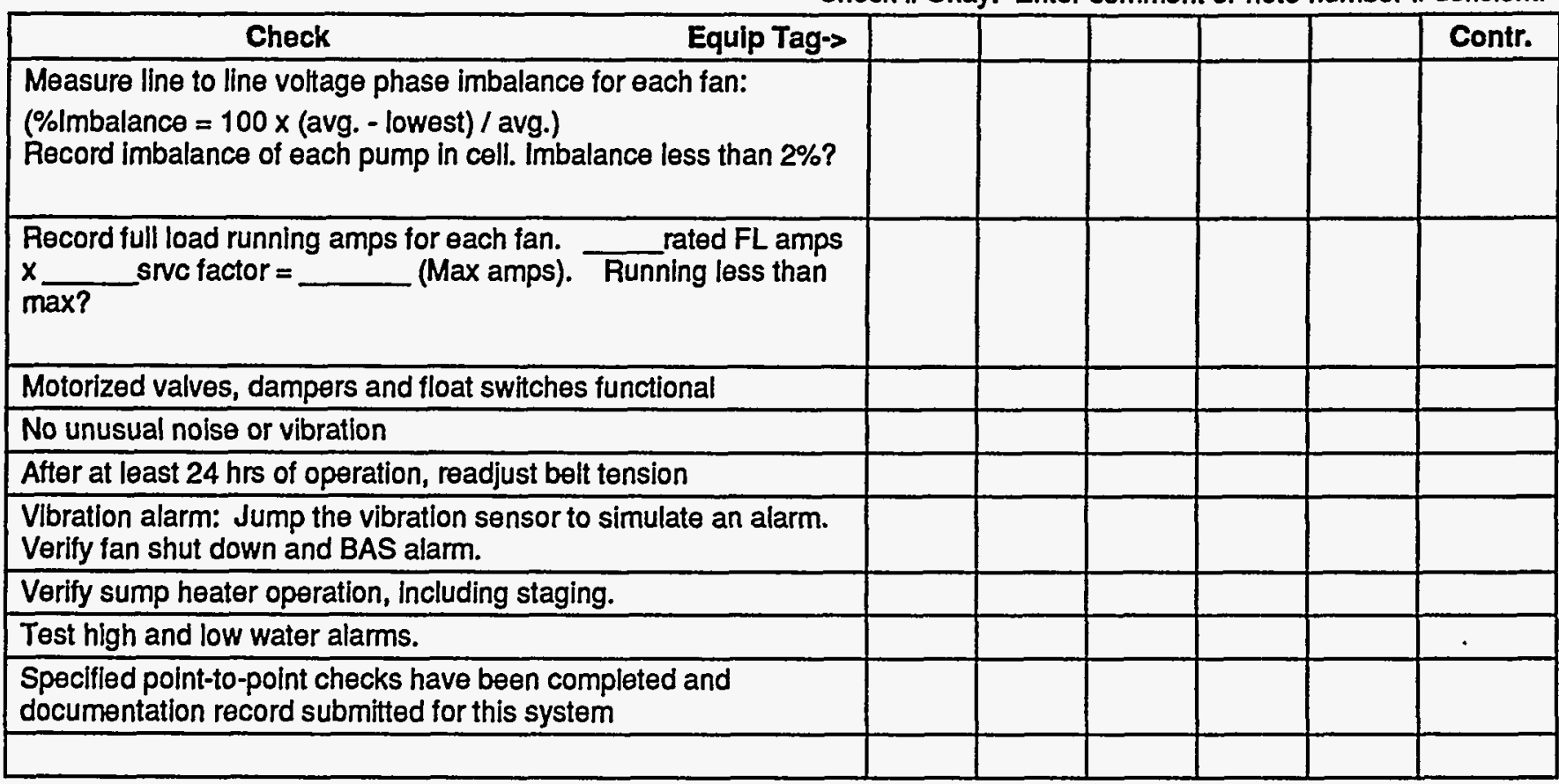

- The checklist items of Part 5 are all successfully completed for given trade. YES NO

\section{Sensor Calibration}

All field-installed temperature, relative humidity, $\mathrm{CO}, \mathrm{CO}_{2}$ and pressure sensors and gages on this piece of equipment shall be calibrated using the methods described below. All test instruments shall have had a certified calibration within the last 12 months: $\mathrm{Y} / \mathrm{N}$ Sensors installed in the unit at the factory with calibration certification provided need not be field calibrated. All actuators should also be calibrated, per the above checklist.

\begin{tabular}{|l|c|c|c|c|c|}
\hline & $\begin{array}{c}18 t \\
\text { Gage } \\
\text { Location }\end{array}$ & $\begin{array}{c}\text { Loc- } \\
\text { ation } \\
\text { OK BAS } \\
\text { Value }\end{array}$ & $\begin{array}{c}\text { Final } \\
\text { Instr. } \\
\text { Meas'd } \\
\text { Value }\end{array}$ & $\begin{array}{c}\text { Gage } \\
\text { or BAS } \\
\text { Value }\end{array}$ & $\begin{array}{c}\text { Pass } \\
\text { Y/N? }\end{array}$ \\
\hline & & & & & \\
\hline & & & & & \\
\hline & & & & & \\
\hline
\end{tabular}

\begin{tabular}{|c|c|c|c|c|c|}
\hline $\begin{array}{c}\text { Sensor \& } \\
\text { Location }\end{array}$ & $\begin{array}{c}\text { Loc- } \\
\text { ation } \\
\text { OK }\end{array}$ & $\begin{array}{c}\text { 1st } \\
\text { Gage } \\
\text { or BAS } \\
\text { Value }\end{array}$ & $\begin{array}{c}\text { Instr. } \\
\text { Meas'd } \\
\text { Value }\end{array}$ & $\begin{array}{c}\text { Final } \\
\text { Gage } \\
\text { or BAS } \\
\text { Value }\end{array}$ & $\begin{array}{c}\text { Pass } \\
\text { YN? }\end{array}$ \\
\hline \hline & & & & & \\
\hline & & & & & \\
\hline & & & & & \\
\hline
\end{tabular}

The Contractor's own sensor check-out sheets may be used in lieu of the above, if the same recording fields are included and the procedures below are followed.

- All sensors are calibrated within required tolerances YES NO

Notes: 


\section{Misc. Procedures (as referenced above)}

\subsection{Sensor Callbratlon Methods}

All Sensors, Verify that all sensor locations are appropriate and away from causes of erratic operation. Verify that sensors with shielded cable, are grounded only at one end. For sensor pairs that are used to determine a temperature or pressure difference, make sure they are reading within $0.2^{\circ} \mathrm{F}$ of each other for temperature and within a tolerance equal to $2 \%$ of the reading, of each other, for pressure. Tolerances for critical applications may be tighter.

A. Sensors Without Transmitters--Standard Application. Make a reading with a calibrated test instrument within 6 inches of the site sensor. Verify that the sensor reading (via the permanent thermostat, gage or building automation system (BAS)) is within the tolerances in the table below of the instrument-measured value. If not, install offset in BAS, calibrate or replace sensor.

B. Sensors With Transmitters--Standard Application. Disconnect sensor. Connect a signal generator in place of sensor. Connect ammeter in series between transmitter and BAS control panel. Using manufacturer's resistance-temperature data, simulate minimum desired temperature. Adjust transmitter potentiometer zero until $4 \mathrm{~mA}$ is read by the ammeter. Repeat for the maximum temperature matching $20 \mathrm{~mA}$ to the potentiometer span or maximum and verify at the BAS. Record all values and recalibrate controller as necessary to conform with specified control ramps, reset schedules, proportional' relationship, reset relationship and $\mathrm{P} / \mathrm{I}$ reaction. Reconnect sensor. Make a reading with a calibrated test instrument within 6 inches of the site sensor. Verify that the sensor reading (via the permanent thermostat, gage or building automation system (BAS)) is within the tolerances in the table below of the instrument-measured value. If not, replace sensor and repeat. For pressure sensors, perform a similar process with a suitable signal generator.

C. Critical Applications. For critical applications (process, manufacturing, etc.) more rigorous calibration techniques may be required for selected sensors. Describe any such methods used on an attached sheet.

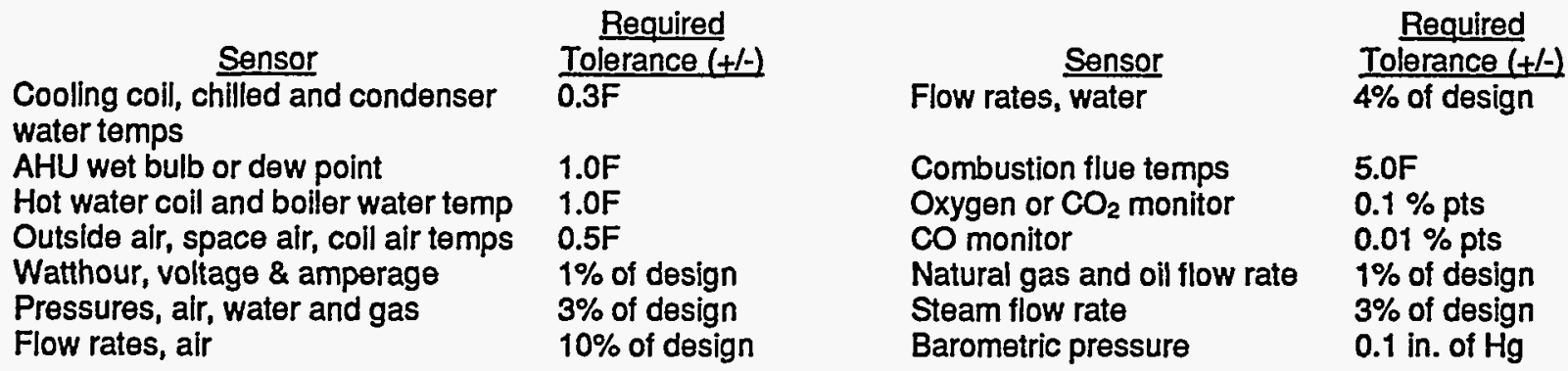

\subsection{Coll Valve Leak Check}

A. Method 1--Water Temperature With 2-Way Valve. Calibrate water temperature sensors on each side of coil to be within $0.5^{\circ} \mathrm{F}$ of each other. Turn off air handler fans and close OSA dampers. Make sure appropriate coil dampers are open. Normally closed valves will close. Override normally open valves to the closed position. After 10 minutes observe water delta $T$ across coil. If it is greater than $2^{\circ} \mathrm{F}$, leakage is probably occuring. Reset valve stroke to close tighter. Repeat test until compliance.

B. Method 2--Air Temperature With 2 or 3-Way Valve. Calibrate air temperature sensors on each side of coil to be within $0.5^{\circ} \mathrm{F}$ of each other. Change mixed or discharge air setpoint, override values or bleed or squeeze bulb pneumatic controller to cause the valve to close. Air handler fans should be on. After 5 minutes observe air delta $T$ across coil. If it is greater than $1^{\circ} \mathrm{F}$, leakage is probably occuring. Reset valve stroke to close tighter. Repeat test until compliance.

\subsection{Valve Stroke Setup and Check}

For all valve and actuator positions checked, verify the actual position against the BAS readout. Set pumps to normal operating mode. Command valve closed, verify that valve is closed and adjust output zero signal as required. Command valve open, verify position is full open and adjust output signal as required. Command valve to a few Intermediate positions. If actual valve position doesn't reasonably correspond, replace actuator or add pilot positioner (for pneumatics). For heating coil valves (NO): Set heating setpoint $20^{\circ} \mathrm{F}$ above room temperature. Observe valve open.

Notes: 
Remove control air or power from the valve and verify that the valve stem and actuator position do not change. Restore to normal. Set heating setpoint to $20^{\circ} \mathrm{F}$ below room temperature. Observe the valve close. For pneumatics, by override in the EMS, Increase pressure to valve by 3 psi (do not exceed actuator pressure rating) and verify valve stem and actuator position does not change. Restore to normal.

For cooling coll valves (NC): Set cooling setpoint $20^{\circ} \mathrm{F}$ above room temperature. Observe the valve close. Remove control alr or power from the valve and verify that the valve stem and actuator position do not change. Restore to normal. Set cooling setpoint to $20^{\circ} \mathrm{F}$ below room temperature. Observe valve open. For pneumatics, by override in the EMS, increase pressure to valve by $3 \mathrm{psi}$ (do not exceed actuator pressure rating) and verify valve stem and actuator position does not change. Restore to normal.

\section{- END OF CHECKLIST -}

Notes: 


\section{Prefunctional Checklist}

Project

\section{PC-}

\section{EXHAUST FANS ID \#'S}

\section{Submittal / Approvals}

Submittal. The above equipment and systems integral to them are complete and ready for functional testing. The checklist items are complete and have been checked off only by parties having direct knowledge of the event, as marked below, respective to each responsible contractor. This prefunctional checklist is submitted for approval, subject to an attached list of outstanding items yet to be completed. A Statement of Correction will be submitted upon completion of any outstanding areas. None of the outstanding items preclude safe and reliable functional tests being performed. List attached.

Mechanical Contractor

Electrical Contractor

\section{Date}

Date

Date

$$
\text { Controls Contractor }
$$

Sheet Metal Contractor

General Contractor
Date

Date

Date

TAB Contractor

Prefunctional checklist items are to be completed as part of startup \& initial checkout, preparatory to functional testing.

- This checklist does not take the place of the manufacturer's recommended checkout and startup procedures or report.

- Items that do not apply shall be noted with the reasons on this form (N/A = not applicable, $B O=$ by others).

- If this form is not used for documenting, one of similar rigor shall be used.

- Contractors assigned responsibility for sections of the checklist shall be responsible to see that checklist items by their subcontractors are completed and checked off.

- "Contr." column or abbreviations in brackets to the right of an item refer to the contractor responsible to verify completion of this item. $\mathrm{A} / \mathrm{E}=$ architect/engineer, $\mathrm{All}=$ all contractors, $\mathrm{CA}=$ commissioning agent $\mathrm{CC}=$ controls contractor, $\mathrm{EC}=$ electrical contractor, $\mathrm{GC}=$ general contractor, $\mathrm{MC}=$ mechanical contractor, $\mathrm{SC}=$ sheet metal contractor, $\mathrm{TAB}=$ test and balance contractor, $=$

Approvals. This filled-out checklist has been reviewed. Its completion is approved with the exceptions noted below.

Notes: 


\section{Requested documentation submitted}

Check if Okay. Enter comment or note number if deficient.

\begin{tabular}{|l|l|l|l|l|l|l|}
\hline Check Equip Tag-s & & & & & & Contr. \\
\hline Manufaclurer's cut sheets & & & & & & \\
\hline Performance data (fan curves, coil data, etc.) & & & & & & \\
\hline Installation and startup manual and plan & & & & & & \\
\hline Sequences and control strategies & & & & & & \\
\hline O\&M manuals & & & & & & \\
\hline
\end{tabular}

- Documentation complete as per contract documents for given trade......._ YES _ NO

\section{Model verification}

[Contr $=$

$1=$ as specified, $2=$ as submitted, $3=$ as installed. Check if Okay. Enter note number if deficient.

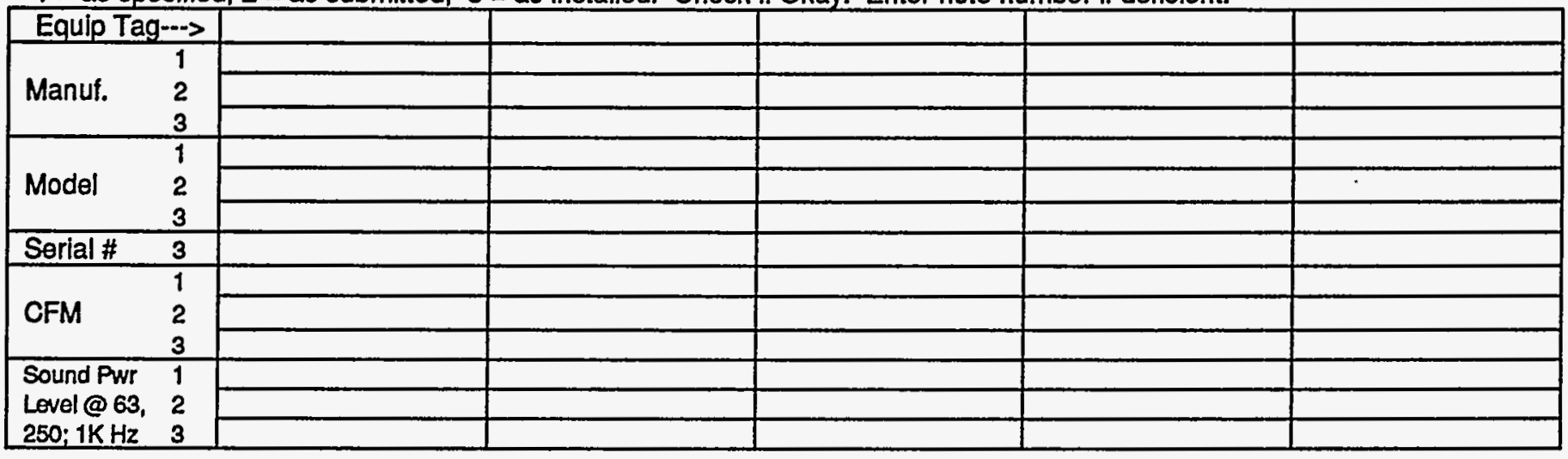

- The equipment installed matches the specifications for given trade.........__ YES _ N NO

\section{Installation Checks}

Check if Okay. Enter comment or note number if deficient.

\begin{tabular}{|l|l|l|l|l|l|l|}
\hline \multicolumn{1}{|c|}{ Check } & & & & Contr. \\
\hline Cablnet and General Installation & & & & & & \\
\hline Permanent labels affixed & & & & & & \\
\hline Casing condition good: no dents, leaks, door gaskets installed & & & & & & \\
\hline Mountings checked and shipping bolts removed & & & & & & \\
\hline Vibration isolators installed & & & & & & \\
\hline Equipment guards installed & & & & & & \\
\hline Pulleys aligned & & & & & & \\
\hline Belt tension correct & & & & & & \\
\hline Plenums clear of debri & & & & & & \\
\hline Fans rotate freely & & & & & & \\
\hline Fire and balance dampers installed & & & & & & \\
\hline
\end{tabular}

\section{Notes:}


Check if Okay. Enter comment or note number if deficient. .

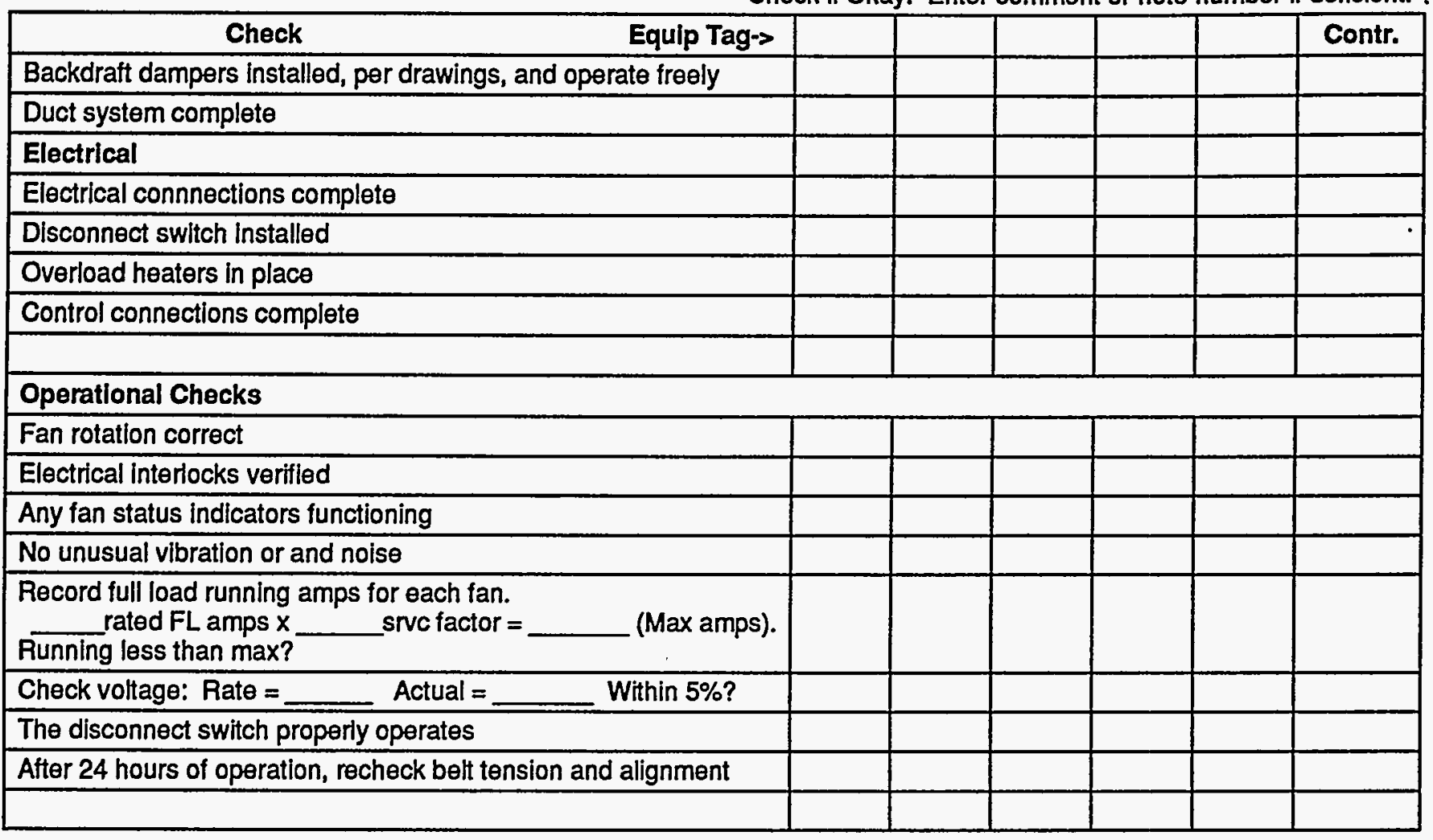

- The checklist items of Part 4 are all successfully completed for given trade.

Notes: 


\section{Prefunctional Checklist}

\section{Project}

\section{PC-07 FAN COIL UNIT, FCU-\#'s}
Components included: _SF, _ Coils, _ Valves (coil), _ VFD _ Dampers Ducts

Associated Checklists: __ CHW, _ HW Piping, __Boiler, __ DX Condenser

\section{Submittal / Approvals}

Submittal. The above equipment and systems integral to them are complete and ready for functional testing. The checklist items are complete and have been checked off only by parties having direct knowledge of the event, as marked below, respective to each responsible contractor. This prefunctional checklist is submitted for approval, subject to an attached list of outstanding items yet to be completed. A Statement of Correction will be submitted upon completion of any outstanding areas. None of the outstanding items preclude safe and reliable functional tests being performed. List attached.

Mechanical Contractor

Electrical Contractor

\section{Date}

\section{Date}

Date
Controls Contractor

Sheet Metal Contractor

General Contractor
Date

$\overline{\text { Date }}$

TAB Contractor

$\overline{\text { Date }}$

Prefunctional checklist items are to be completed as part of startup \& initial checkout, preparatory to functional testing.

- This checklist does not take the place of the manufacturer's recommended checkout and startup procedures or report.

- Items that do not apply shall be noted with the reasons on this form (N/A = not applicable, $B O=$ by others).

- If this form is not used for documenting, one of similar rigor shall be used.

- Contractors assigned responsibility for sections of the checklist shall be responsible to see that checklist items by their subcontractors are completed and checked off.

- "Contr." column or abbreviations in brackets to the right of an item refer to the contractor responsible to verify completion of this item. $\mathrm{A} / \mathrm{E}=$ architect/engineer, $\mathrm{All}=$ all contractors, $\mathrm{CA}=$ commissioning agent $\mathrm{CC}=$ controls contractor, $\mathrm{EC}=$ electrical contractor, $\mathrm{GC}=$ general contractor, $\mathrm{MC}=$ mechanical contractor, $\mathrm{SC}=$ sheet metal contractor, $\mathrm{TAB}=$ test and balance contractor, $=$

Approvals. This filled-out checklist has been reviewed. Its completion is approved with the exceptions noted below. 


\section{Requested documentation submitted}

Check if Okay. Enter comment or note number if deficient.

\begin{tabular}{|l|l|l|l|l|l|l|}
\hline \multicolumn{1}{|c|}{ Check Equip Tag-> } & & & & & & Contr. \\
\hline Manufacturer's cut sheets & & & & & & \\
\hline Performance data (fan curves, coil data, etc.) & & & & & & \\
\hline Installatlon and startup manual and plan & & & & & & \\
\hline Sequences and control strategies & & & & & & \\
\hline O\&M manuals & & & & & & \\
\hline
\end{tabular}

- Documentation complete as per contract documents for given trade.......__ YES

\section{Model verification}

1 = as specified, $2=$ as submitted, $3=$ as installed. Check if Okay. Enter note number if deficient.

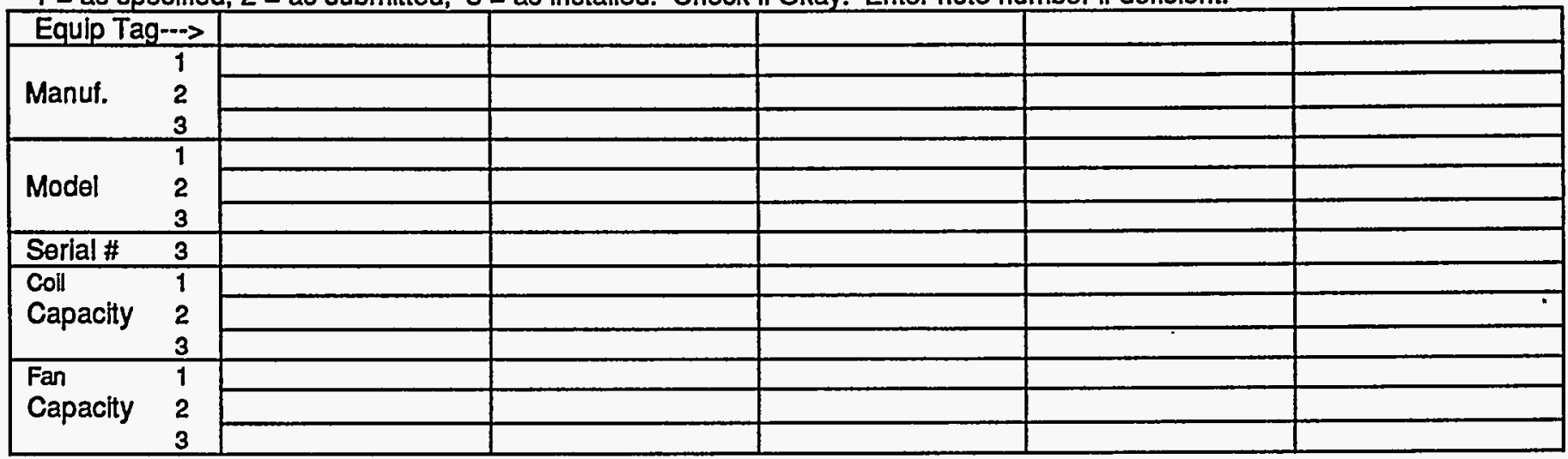

- The equipment installed matches the specifications for given trade.........__ YES _ NO

\section{Installation Checks}

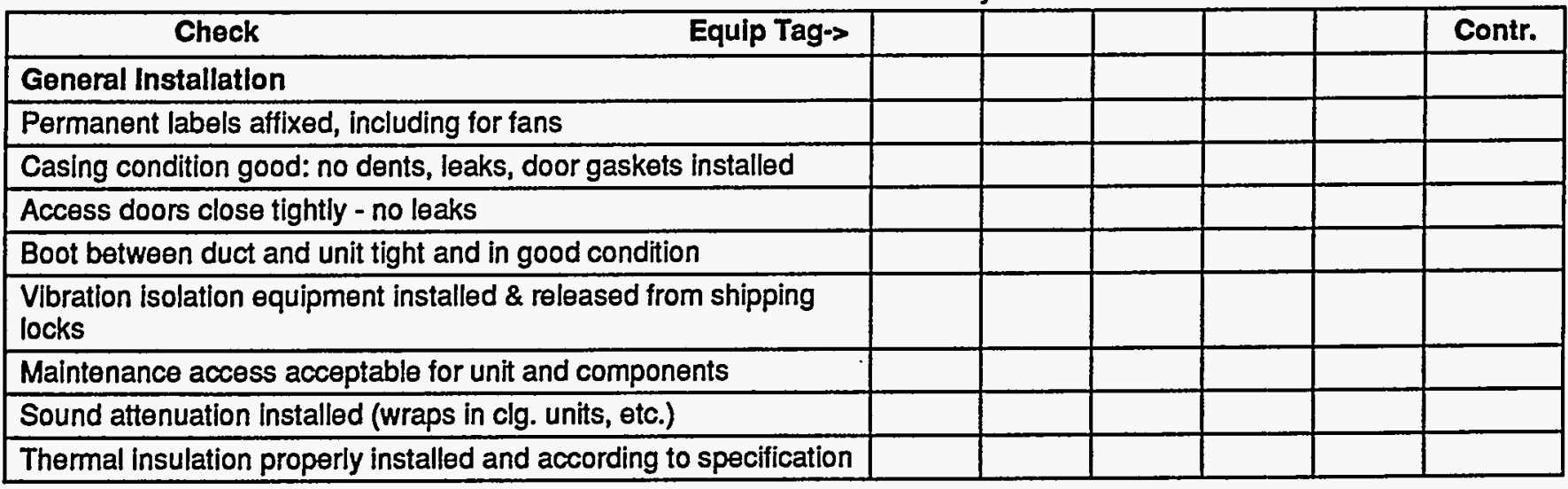

\section{Notes:}


Check if Okay. Enter comment or note number if deficient.

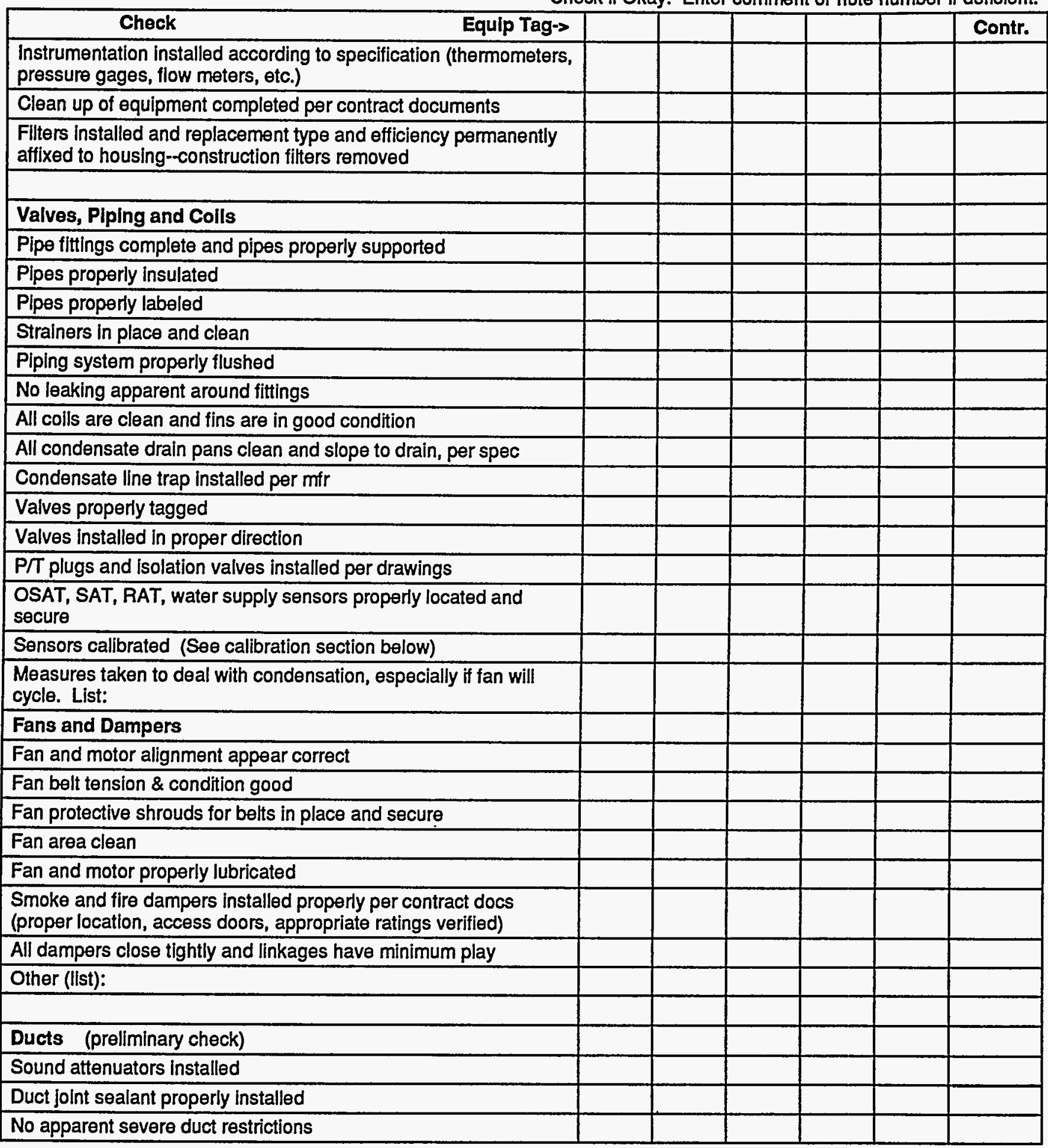

\section{Notes:}


Check if Okay. Enter comment or note number if deficient.

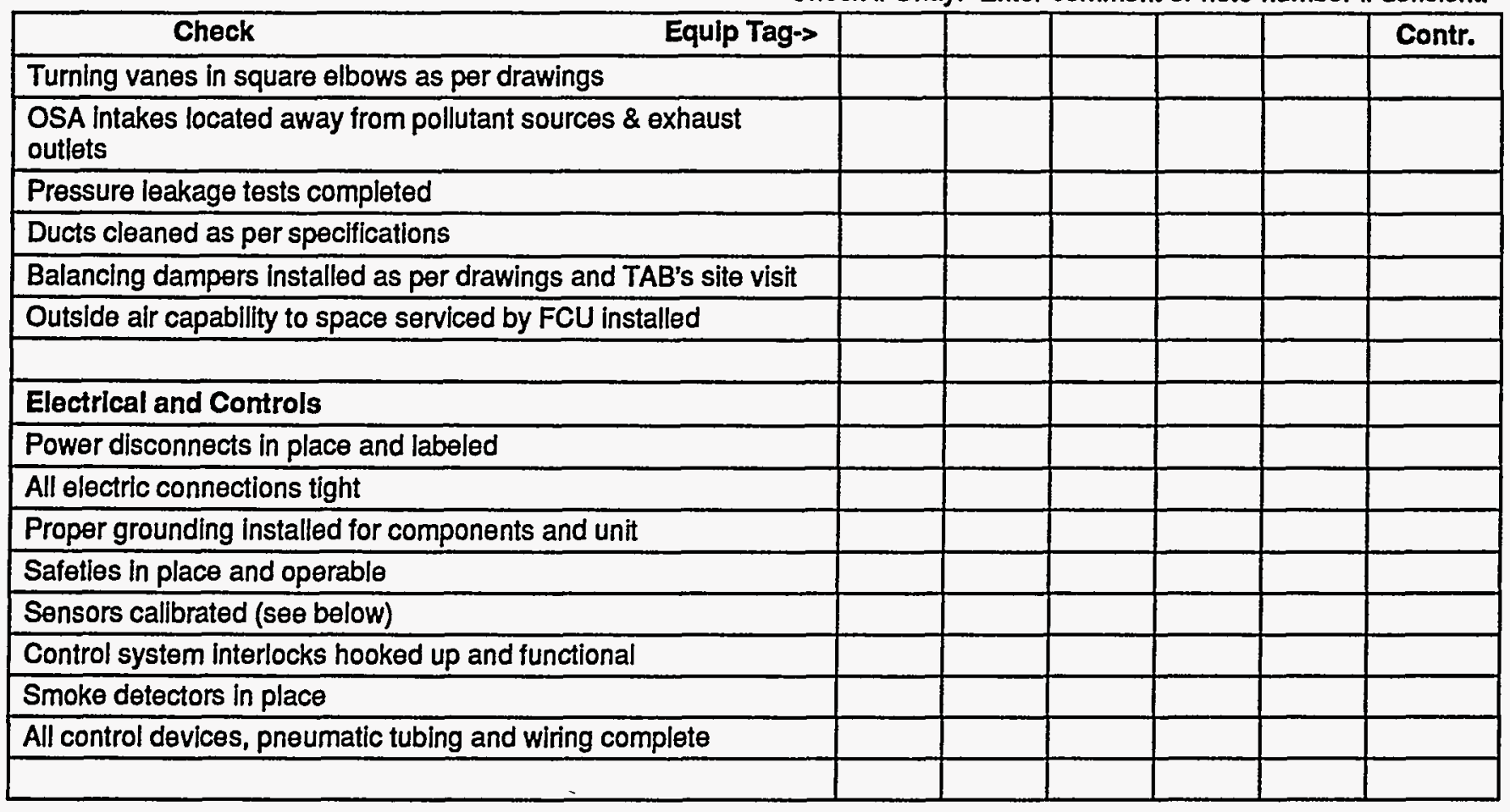

- The checklist items of Part 4 are all successfully completed for given trade.

YES

5. Operational Checks (These augment mfr's list. This is not the functional performance testing.)

Check if Okay. Enter comment or note number if deficient.

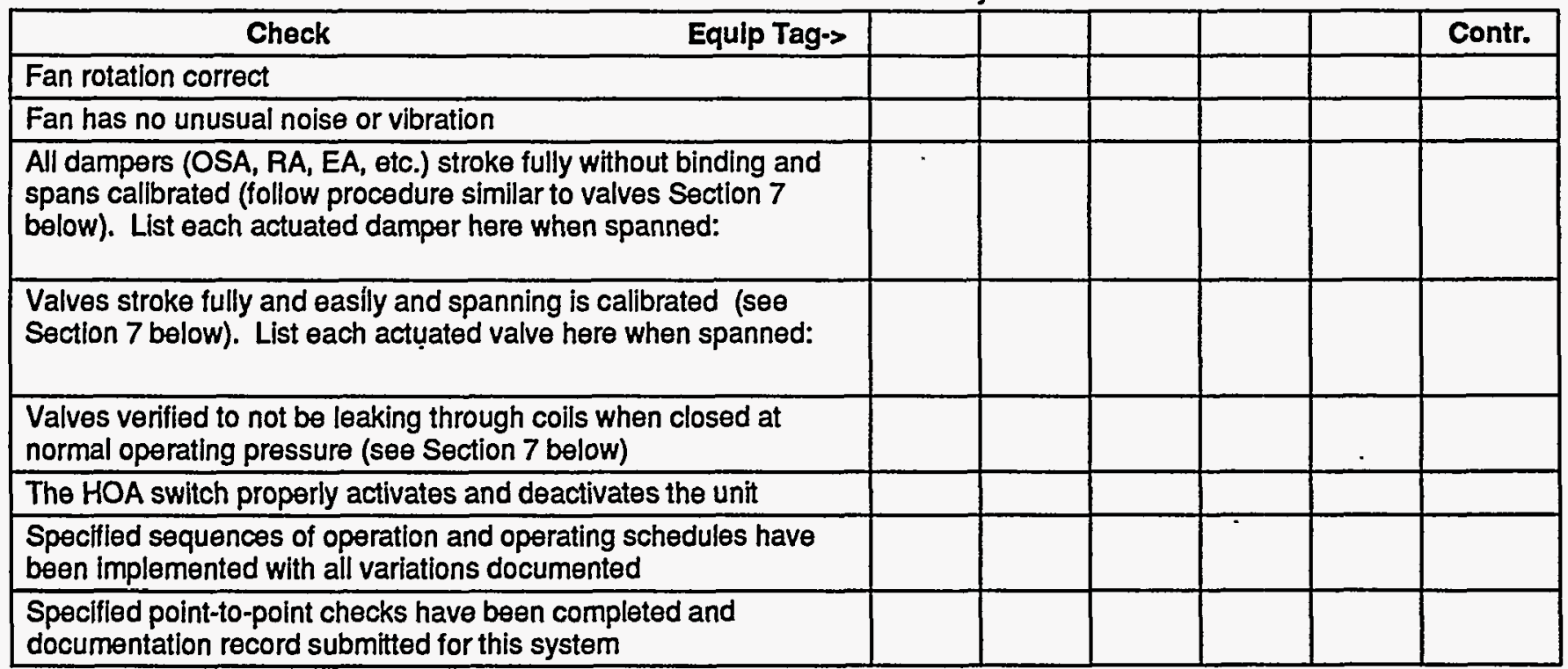

Notes:

File: FANCOILU.PC2

Commissioning Guide Specification -PECI/USDOE: 3/21/97 


\section{Sensor and Actuator Calibration}

All field-installed temperature, relative humidity, $\mathrm{CO}, \mathrm{CO}_{2}$ and pressure sensors and gages on this piece of equipment shall be calibrated using the methods described below. All test instruments shall have had a certified calibration within the last 12 months: $\mathrm{Y} / \mathrm{N}$ Sensors installed in the unit at the factory with calibration certification provided need not be field calibrated. All actuators should also be calibrated, per the above checklist.

\begin{tabular}{|c|c|c|c|c|c|c|c|c|c|c|c|}
\hline $\begin{array}{l}\text { Sensor \& } \\
\text { Location }\end{array}$ & $\begin{array}{c}\text { Loc- } \\
\text { ation } \\
\text { OK }\end{array}$ & $\begin{array}{c}\text { 1st } \\
\text { Gage } \\
\text { or BAS } \\
\text { Value }\end{array}$ & $\begin{array}{l}\text { Instr. } \\
\text { Meas'd } \\
\text { Value }\end{array}$ & $\begin{array}{c}\text { Final } \\
\text { Gage } \\
\text { or BAS } \\
\text { Value }\end{array}$ & $\begin{array}{l}\text { Pass } \\
\text { Y/N? }\end{array}$ & $\begin{array}{l}\text { Sensor \& } \\
\text { Location }\end{array}$ & $\begin{array}{l}\text { Loc- } \\
\text { ation } \\
\text { OK }\end{array}$ & $\begin{array}{c}\text { 1st } \\
\text { Gage } \\
\text { or BAS } \\
\text { Value }\end{array}$ & $\begin{array}{l}\text { Instr. } \\
\text { Meas'd } \\
\text { Value }\end{array}$ & $\begin{array}{c}\text { Final } \\
\text { Gage } \\
\text { or BAS } \\
\text { Value }\end{array}$ & $\begin{array}{l}\text { Pass } \\
\text { YNN? }\end{array}$ \\
\hline & & & & & & & & & & & \\
\hline & & & & & & & & & & & \\
\hline & & & & & & & & & & & \\
\hline
\end{tabular}

The Contractor's own sensor check-out sheets may be used in lieu of the above, if the same recording fields are included and the procedures below are followed.

- All sensors are calibrated within required tolerances. YES NO

\section{Misc. Procedures (Referenced above)}

\subsection{Sensor Callbration Methods}

All Sensors, Verify that all sensor locations are appropriate and away from causes of erratic operation. Verify that sensors with shielded cable, are grounded only at one end. For sensor pairs that are used to determine a temperature or pressure difference, make sure they are reading within $0.2^{\circ} \mathrm{F}$ of each other for temperature and within a tolerance equal to $2 \%$ of the reading, of each other, for pressure. Tolerances for critical applications may be tighter.

A. Sensors Without Transmitters--Standard Application. Make a reading with a calibrated test instrument within 6 inches of the site sensor. Verify that the sensor reading (via the permanent thermostat, gage or building automation system (BAS)) is within the tolerances in the table below of the instrument-measured value. If not, install offset in BAS, calibrate or replace sensor.

B. Sensors With Transmitters--Standard Application. Disconnect sensor. Connect a signal generator in place of sensor. Connect ammeter in series between transmitter and BAS control panel. Using manufacturer's resistance-temperature data, simulate minimum desired temperature. Adjust transmitter potentiometer zero until $4 \mathrm{~mA}$ is read by the ammeter. Repeat for the maximum temperature matching $20 \mathrm{~mA}$ to the potentiometer span or maximum and verify at the BAS. Record all values and recalibrate controller as necessary to conform with specified control ramps, reset schedules, proportional relationship, reset relationship and P/I reaction. Reconnect sensor. Make a reading with a calibrated test instrument within 6 inches of the site sensor. Verify that the sensor reading (via the permanent thermostat, gage or building automation system (BAS)) is within the tolerances in the table below of the instrument-measured value. If not, replace sensor and repeat. For pressure sensors, perform a similar process with a suitable signal generator.

C. Critical Applications. For critical applications (process, manufacturing, etc.) more rigorous calibration techniques may be required for selected sensors. Describe any such methods used on an attached sheet.

Notes: 


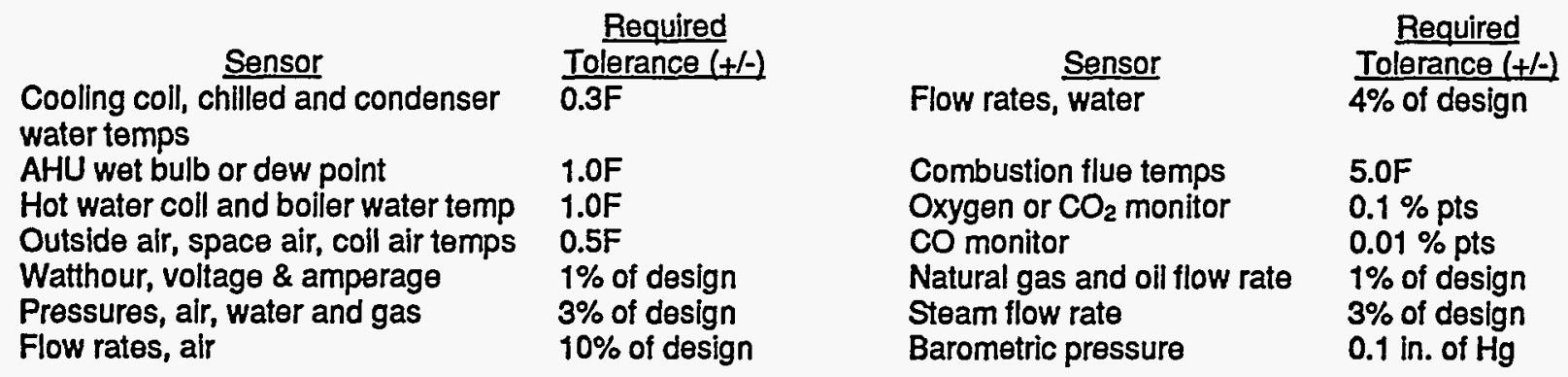

\subsection{Coll Valve Leak Check}

A. Method 1--Water Temperature With 2-Way Valve. Calibrate water temperature sensors on each side of coil to be within $0.5^{\circ} \mathrm{F}$ of each other. Turn off air handler fans and close OSA dampers. Make sure appropriate coil dampers are open. Normally closed valves will close. Override normally open valves to the closed position. After 10 minutes observe water delta $T$ across coil. If it is greater than $2^{\circ} \mathrm{F}$, leakage is probably occuring. Reset valve stroke to close tighter. Repeat test until compliance.

B. Method 2--Air Temperature With 2 or 3-Way Valve. Calibrate air temperature sensors on each side of coil to be within $0.5^{\circ} \mathrm{F}$ of each other. Change mixed or discharge air setpoint, override values or bleed or squeeze bulb pneumatic controller to cause the valve to close. Air handler fans should be on. After 5 minutes observe air delta $T$ across coil. If it is greater than $1^{\circ} \mathrm{F}$, leakage is probably occuring. Reset valve stroke to close tighter. Repeat test until compliance.

C. Method 3 Coil Drain Down (not for 3-way valves). Put systems in normal mode. If cooling coil valve, remove all call for cooling or if heating coil valve put system in full cooling. Close isolation valve on supply side of coil, open air bleed cap, open drain-down cock and drain water from coil. Water should stop draining, else there may be a leak through the control valve. Return all to normal when done.

\subsection{Valve Stroke Setup and Check}

For all valve and actuator positions checked, verify the actual position against the BAS readout.

Set pumps to normal operating mode. Command valve closed, verify that valve is closed and adjust output zero signal as required. Command valve open, verify position is full open and adjust output signal as required. Command valve to a few intermediate positions. If actual valve position doesn't reasonably correspond, replace actuator or add pilot positioner (for pneumatics). For heating coil valves (NO): Set heating setpoint $20^{\circ} \mathrm{F}$ above room temperature. Observe valve open. Remove control air or power from the valve and verify that the valve stem and actuator position do not change. Restore to normal. Set heating setpoint to $20^{\circ} \mathrm{F}$ below room temperature. Observe the valve close. For pneumatics, by override in the EMS, increase pressure to valve by 3 psi (do not exceed actuator pressure rating) and verify valve stem and actuator position does not change. Restore to normal.

For cooling coil valves (NC): Set cooling setpoint $20^{\circ} \mathrm{F}$ above room temperature. Observe the valve close. Remove control air or power from the valve and verify that the valve stem and actuator position do not change. Restore to normal. Set cooling setpoint to $20^{\circ} \mathrm{F}$ below room temperature. Observe valve open. For pneumatics, by override in the EMS, increase pressure to valve by 3 psi (do not exceed actuator pressure rating) and verify valve stem and actuator position does not change. Restore to normal.

\section{- END OF CHECKLIST-}

\section{Notes:}




\section{Prefunctional Checklist}

Project

\section{PC-02 HEATING WATER PIPING}

Components included: All valves, except coil valves

Associated checklists: Boiler, HW Pumps

\section{Submittal / Approvals}

Submittal. The above equipment and systems integral to them are complete and ready for functional testing. The checklist items are complete and have been checked off only by parties having direct knowledge of the event, as marked below, respective to each responsible contractor. This prefunctional checklist is submitted for approval, subject to an attached list of outstanding items yet to be completed. A Statement of Correction will be submitted upon completion of any outstanding areas. None of the outstanding items preclude safe and reliable functional tests being performed. List attached.

$\begin{array}{llll}\overline{\text { Mechanical Contractor }} & \overline{\text { Date }} & \overline{\text { Controls Contractor }} \\ \overline{\text { Electrical Contractor }} & \overline{\text { Date }} & \overline{\text { Sheet Metal Contractor }} \\ \overline{\text { TAB Contractor }} & \overline{\text { Date }} & \overline{\text { General Contractor }}\end{array}$

Prefunctional checklist items are to be completed as part of startup \& initial checkout, preparatory to functional testing.

- This checklist does not take the place of the manufacturer's recommended checkout and startup procedures or report.

- Items that do not apply shall be noted with the reasons on this form (N/A = not applicable, BO = by others).

- If this form is not used for documenting, one of similar rigor shall be used.

- Contractors assigned responsibility for sections of the checklist shall be responsible to see that checklist items by their subcontractors are completed and checked off.

- "Contr." column or abbreviations in brackets to the right of an item refer to the contractor responsible to verify completion of this item. $\mathrm{A} / \mathrm{E}=$ architect/engineer, $\mathrm{All}=$ all contractors, $\mathrm{CA}=$ commissioning agent $\mathrm{CC}=$ controls contractor, $\mathrm{EC}=$ electrical contractor, $\mathrm{GC}=$ general contractor, $\mathrm{MC}=$ mechanical contractor, $\mathrm{SC}=$ sheet metal contractor, $\mathrm{TAB}=$ test and balance contractor, $=$

Approvals. This filled-out checklist has been reviewed. Its completion is approved with the exceptions noted below.

Notes: 


\section{Requested documentation submitted}

Check if Okay. Enter comment or note number if deficient.

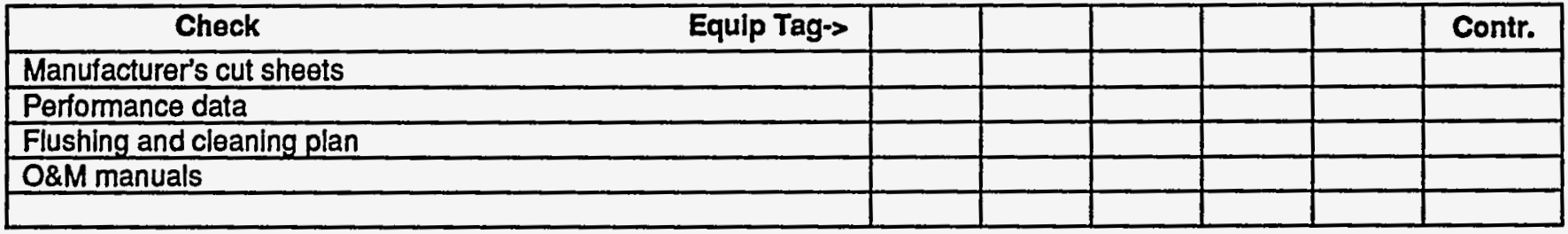

- Documentation complete as per contract documents for given trade ........ YES NO

\section{Physical Installation Checks}

\begin{tabular}{|c|c|c|c|}
\hline Check & $\mathbf{Y} / \mathbf{N}$ & Contr. & Note \\
\hline \multicolumn{4}{|l|}{ Piping } \\
\hline \multicolumn{4}{|l|}{ Pipe fittings complete and pipes properly supported } \\
\hline \multicolumn{4}{|l|}{ Seismic anchoring installed } \\
\hline \multicolumn{4}{|l|}{ Pipes properly labeled } \\
\hline \multicolumn{4}{|l|}{ Pipes properly insulated } \\
\hline \multicolumn{4}{|l|}{ Strainers in place and clean } \\
\hline \multicolumn{4}{|l|}{ Isolation valves and balancing valves installed } \\
\hline \multicolumn{4}{|l|}{ Test ports (P/T) installed near all control sensors and as per spec } \\
\hline \multicolumn{4}{|l|}{ Flushing and cleaning plan submitted and approved } \\
\hline \multicolumn{4}{|l|}{$\begin{array}{l}\text { Piping system properly flushed and cleaned and temporary piping } \\
\text { removed (report attached) }\end{array}$} \\
\hline \multicolumn{4}{|l|}{$\begin{array}{l}\text { Piping pressure tested according to contract documents } \\
\text { (report attached) }\end{array}$} \\
\hline \multicolumn{4}{|l|}{ Chemical treatment system or plan installed } \\
\hline \multicolumn{4}{|l|}{ Water treatment report submitted according to contract documents } \\
\hline \multicolumn{4}{|l|}{ No leaking apparent around fittings } \\
\hline \multicolumn{4}{|l|}{$\begin{array}{l}\text { ASME pressue vessel data sheet or certification tag posted and } \\
\text { inspection complete for each expansion tank }\end{array}$} \\
\hline \multicolumn{4}{|l|}{$\begin{array}{l}\text { Expansion tanks verified to not be air bound and system completely full } \\
\text { of water }\end{array}$} \\
\hline \multicolumn{4}{|l|}{ Air vents and bleeds at high points of systems functional } \\
\hline \multicolumn{4}{|l|}{ Valves (except coil valve checklists are with the unit checklist) } \\
\hline \multicolumn{4}{|l|}{ Valve labels permanently affixed } \\
\hline \multicolumn{4}{|l|}{ Valves installed in proper direction } \\
\hline No leaks & & & \\
\hline
\end{tabular}

Notes: 


\begin{tabular}{|l|l|l|l|}
\hline \multicolumn{1}{|c|}{ Check } & Y/N & Contr. & Note \\
\hline $\begin{array}{l}\text { Valves stroke fully and easily and spanning is calibrated (see Section } \\
5.2 \text { below) }\end{array}$ & & & \\
\hline $\begin{array}{l}\text { Valves that require a positive shut-off are verified to not be leaking } \\
\text { when closed at normal operating pressure }\end{array}$ & & & \\
\hline & & & \\
\hline Sensors and Gages & & & \\
\hline Temperature, pressure and flow gages and sensors installed & & & \\
\hline Sensors calibrated (See calibration section below) & & & \\
\hline & & & \\
\hline TAB & & & \\
\hline $\begin{array}{l}\text { Installation of system and balancing devices allowed balancing to be } \\
\text { completed following specified NEBB or AABC procedures and contract } \\
\text { documents }\end{array}$ & & & \\
\hline
\end{tabular}

- The checklist items of Part 3 are all successfully completed for given trade. YES

\section{Sensor Calibration}

All field-installed temperature, relative humidity, $\mathrm{CO}, \mathrm{CO}_{2}$ and pressure sensors and gages on this piece of equipment shall be calibrated using the methods described below. All test instruments shall have had a certified calibration within the last 12 months: $\mathrm{Y} / \mathrm{N}$ . Sensors installed in the unit at the factory with calibration certification provided need not be field calibrated. All actuators should also be calibrated, per the above checklist.

\begin{tabular}{|l|l|c|c|c|c|}
\hline $\begin{array}{c}\text { Sensor \& } \\
\text { Location }\end{array}$ & $\begin{array}{c}\text { Loc- } \\
\text { ation } \\
\text { OK }\end{array}$ & $\begin{array}{c}\text { 1st } \\
\text { Gage } \\
\text { or BAS } \\
\text { Value }\end{array}$ & $\begin{array}{c}\text { Instr. } \\
\text { Meas'd } \\
\text { Value }\end{array}$ & $\begin{array}{c}\text { Final } \\
\text { Gage } \\
\text { or BAS } \\
\text { Value }\end{array}$ & $\begin{array}{c}\text { Pass } \\
\text { YNN? }\end{array}$ \\
\hline & & & & & \\
\hline & & & & & \\
\hline & & & & & \\
\hline
\end{tabular}

\begin{tabular}{|c|c|c|c|c|c|}
\hline $\begin{array}{c}\text { Sensor \& } \\
\text { Location }\end{array}$ & $\begin{array}{c}\text { Loc- } \\
\text { ation } \\
\text { OK }\end{array}$ & $\begin{array}{c}\text { 1st } \\
\text { Gage } \\
\text { Value }\end{array}$ & $\begin{array}{c}\text { Instr. } \\
\text { Meas'd } \\
\text { Value }\end{array}$ & $\begin{array}{c}\text { Final } \\
\text { Gage } \\
\text { or BAS } \\
\text { Value }\end{array}$ & $\begin{array}{c}\text { Pass } \\
\text { YNN? }\end{array}$ \\
\hline & & & & & \\
\hline & & & & & \\
\hline & & & & & \\
\hline
\end{tabular}

The Contractor's own sensor check-out sheets may be used in lieu of the above, if the same recording fields are included and the procedures below are followed.

- All sensors are calibrated within required tolerances YES NO

\section{Notes:}




\section{Misc. Procedures (as referenced above)}

\subsection{Sensor Calibration Methods}

All Sensors, Verify that all sensor locations are appropriate and away from causes of erratic operation. Verify that sensors with shielded cable, are grounded only at one end. For sensor pairs that are used to determine a temperature or pressure difference, make sure they are reading within $0.2^{\circ} \mathrm{F}$ of each other for temperature and within a tolerance equal to $2 \%$ of the reading, of each other, for pressure. Tolerances for critical applications may be tighter.

A. Sensors Without Transmitters--Standard Application. Make a reading with a calibrated test instrument within 6 inches of the site sensor. Verify that the sensor reading (via the permanent thermostat, gage or building automation system (BAS)) is within the tolerances in the table below of the instrument-measured value. If not, install offset in BAS, calibrate or replace sensor.

B. Sensors With Transmitters--Standard Application. Disconnect sensor. Connect a signal generator in place of sensor. Connect ammeter in series between transmitter and BAS control panel. Using manufacturer's resistance-temperature data, simulate minimum desired temperature. Adjust transmitter potentiometer zero until $4 \mathrm{~mA}$ is read by the ammeter. Repeat for the maximum temperature matching $20 \mathrm{~mA}$ to the potentiometer span or maximum and verify at the BAS. Record all values and recalibrate controller as necessary to conform with specified control ramps, reset schedules, proportional relationship, reset relationship and $\mathrm{P} / \mathrm{l}$ reaction. Reconnect sensor. Make a reading with a calibrated test instrument within 6 inches of the site sensor. Verify that the sensor reading (via the permanent thermostat, gage or building automation system (BAS)) is within the tolerances in the table below of the instrument-measured value. If not, replace sensor and repeat. For pressure sensors, perform a similar process with a suitable signal generator.

C. Critical Applications. For critical applications (process, manufacturing, etc.) more rigorous calibration techniques may be required for selected sensors. Describe any such methods used on an attached sheet.



\subsection{Coll Valve Leak Check}

A. Method 1-Water Temperature With 2-Way Valve. Calibrate water temperature sensors on each side of coil to be within $0.5^{\circ} \mathrm{F}$ of each other. Turn off air handler fans and close OSA dampers. Make sure appropriate coil dampers are open. Normally closed valves will close. Override normally open valves to the closed position. After 10 minutes observe water delta $\mathrm{T}$ across coll. If it is greater than $2^{\circ} \mathrm{F}$, leakage is probably occuring. Reset valve stroke to close tighter. Repeat test until compliance.

B. Method 2-Air Temperature With 2 or 3-Way Valve. Calibrate air temperature sensors on each side of coil to be within $0.5^{\circ} \mathrm{F}$ of each other. Change mixed or discharge air setpoint, override values or bleed or squeeze bulb pneumatic controller to cause the valve to close. Air handler fans should be on. After 5 minutes observe air delta T across coil. If it is greater than $1^{\circ} \mathrm{F}$, leakage is probably occuring. Reset valve stroke to close tighter. Repeat test until compliance.

\subsection{Valve Stroke Setup and Check}

For all valve and actuator positions checked, verify the actual position against the BAS readout.

Set pumps to normal operating mode. Command valve closed, verify that valve is closed and adjust output zero signal as required. Command valve open, verify position is full open and adjust output signal as required. Command valve to a few intermediate positions. If actual valve position doesn't reasonably correspond, replace actuator or add pilot positioner (for pneumatics). For heating coil valves (NO): Set heating setpoint $20^{\circ} \mathrm{F}$ above room temperature. Observe valve open.

\section{Notes:}


Remove control air or power from the valve and verify that the valve stem and actuator position do not change. Restore to normal. Set heating setpoint to $20^{\circ} \mathrm{F}$ below room temperature. Observe the valve close. For pneumatics, by override in the EMS, increase pressure to valve by 3 psi (do not exceed actuator pressure rating) and verify valve stem and actuator position does not change. Restore to normal.

For cooling coil valves (NC): Set cooling setpoint $20^{\circ} \mathrm{F}$ above room temperature. Observe the valve close. Remove control air or power from the valve and verify that the valve stem and actuator position do not change. Restore to normal. Set cooling setpoint to $20^{\circ} \mathrm{F}$ below room temperature. Observe valve open. For pneumatics, by override in the EMS, increase pressure to valve by 3 psi (do not exceed actuator pressure rating) and verify valve stem and actuator position does not change. Restore to normal.

\section{- END OF CHECKLIST -}

Notes: 


\section{Prefunctional Checklist}

Project

\section{PC-04_ PACKAGED DX AIR CONDITIONING or HEAT PUMP, ID}

Components included: _supply fans, __return \& exhaust fans, __coils, valves, _VFD, _ dampers, _ compressors, _ condensers

Associated Checklists:

\section{Submittal / Approvals}

Submittal. The above equipment and systems integral to them are complete and ready for functional testing. The checklist items are complete and have been checked off only by parties having direct knowledge of the event, as marked below, respective to each responsible contractor. This prefunctional checklist is submitted for approval, subject to an attached list of outstanding items yet to be completed. A Statement of Correction will be submitted upon completion of any outstanding areas. None of the outstanding items preclude safe and reliable functional tests being performed. List attached.

Mechanical Contractor

Electrical Contractor

TAB Contractor

\section{Date}

Date

Date
Controls Contractor

Sheet Metal Contractor

General Contractor
Date

Date

Date

Prefunctional checklist items are to be completed as part of startup \& initial checkout, preparatory to functional testing.

- This checklist does not take the place of the manufacturer's recommended checkout and startup procedures or report.

- Items that do not apply shall be noted with the reasons on this form (N/A = not applicable, $B O=$ by others).

- If this form is not used for documenting, one of similar rigor shall be used.

- Contractors assigned responsibility for sections of the checklist shall be responsible to see that checklist items by their subcontractors are completed and checked off.

- "Contr." column or abbreviations in brackets to the right of an item refer to the contractor responsible to verify completion of this item. $\mathrm{A} / \mathrm{E}=$ architect/engineer, $\mathrm{All}=$ all contractors, $\mathrm{CA}=$ commissioning agent, $\mathrm{CC}=\mathrm{controls}$ contractor, $\mathrm{EC}=$ electrical contractor, $\mathrm{GC}=$ general contractor, $\mathrm{MC}=$ mechanical contractor, $\mathrm{SC}=$ sheet metal contractor, $\mathrm{TAB}=$ test and balance contractor, $=$

Approvals. This filled-out checklist has been reviewed. Its completion is approved with the exceptions noted below.

Notes: 


\section{Requested documentation submitted}

Check if Okay. Enter comment or note number if deficient.

\begin{tabular}{|l|l|l|l|l|l|l|}
\hline Check Equip Tag-> & & & & & & Contr. \\
\hline Manufacturer's cut sheets & & & & & & \\
\hline Performance data (fan curves, coil data, etc.) & & & & & & \\
\hline Installation and startup manual and plan & & & & & &. \\
\hline Sequences and control strategles & & & & & & \\
\hline O\&M manuals & & & & & \\
\hline
\end{tabular}

\section{- Documentation complete as per contract documents for given trade......._ YES _ NO}

\section{Model verification}

1 = as specified, 2 = as submitted, 3 = as installed. Enter information and check if Okay. Enter note number if deficient.



- The equipment installed matches the specifications for given trade........._ YES _ NO

\section{Installation Checks}

Check if Okay. Enter comment or note number if deficient.



Notes: 
Check if Okay. Enter comment or note number if deficient.

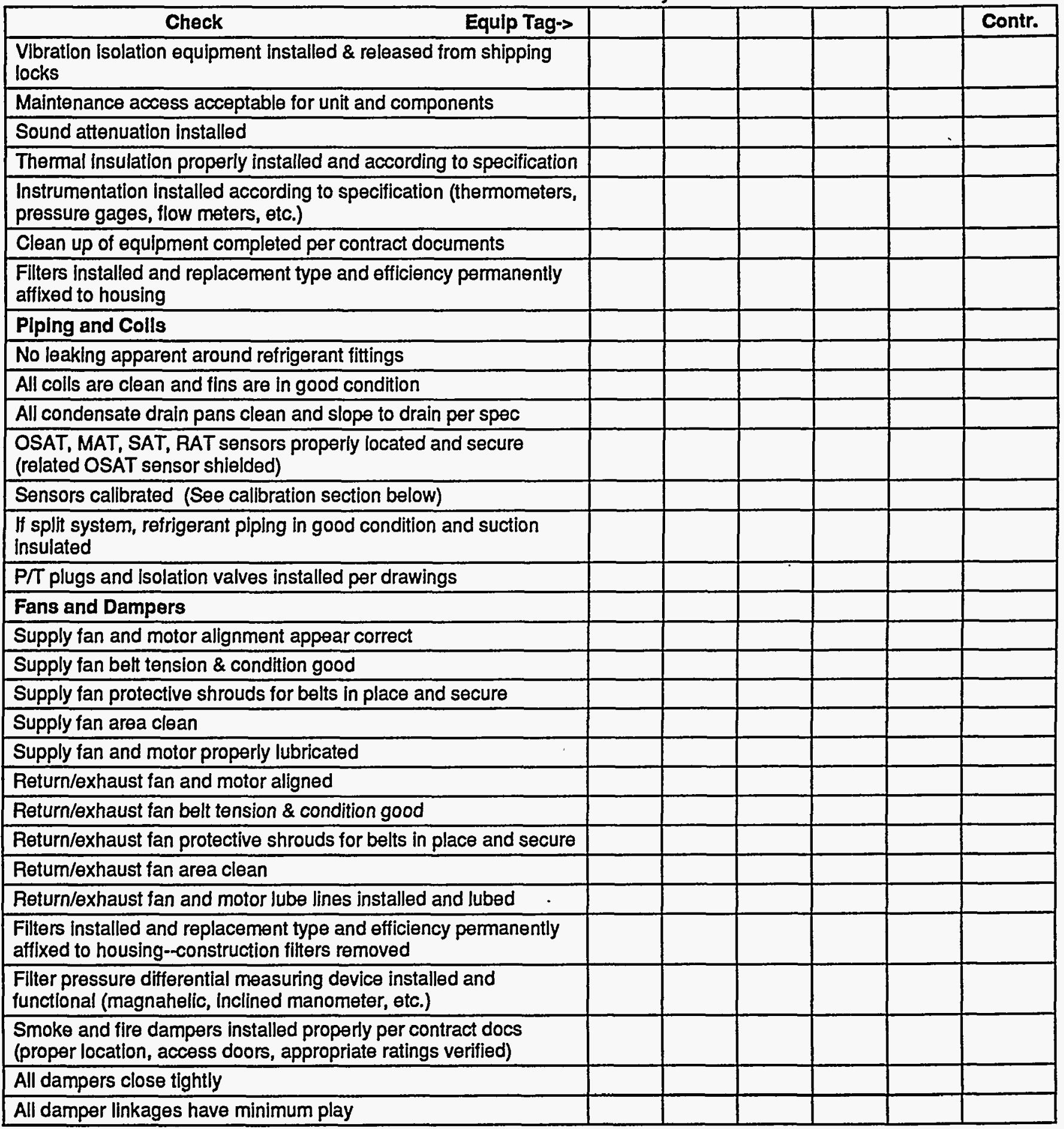

\section{Notes:}


Check if Okay. Enter comment or note number if deficient.

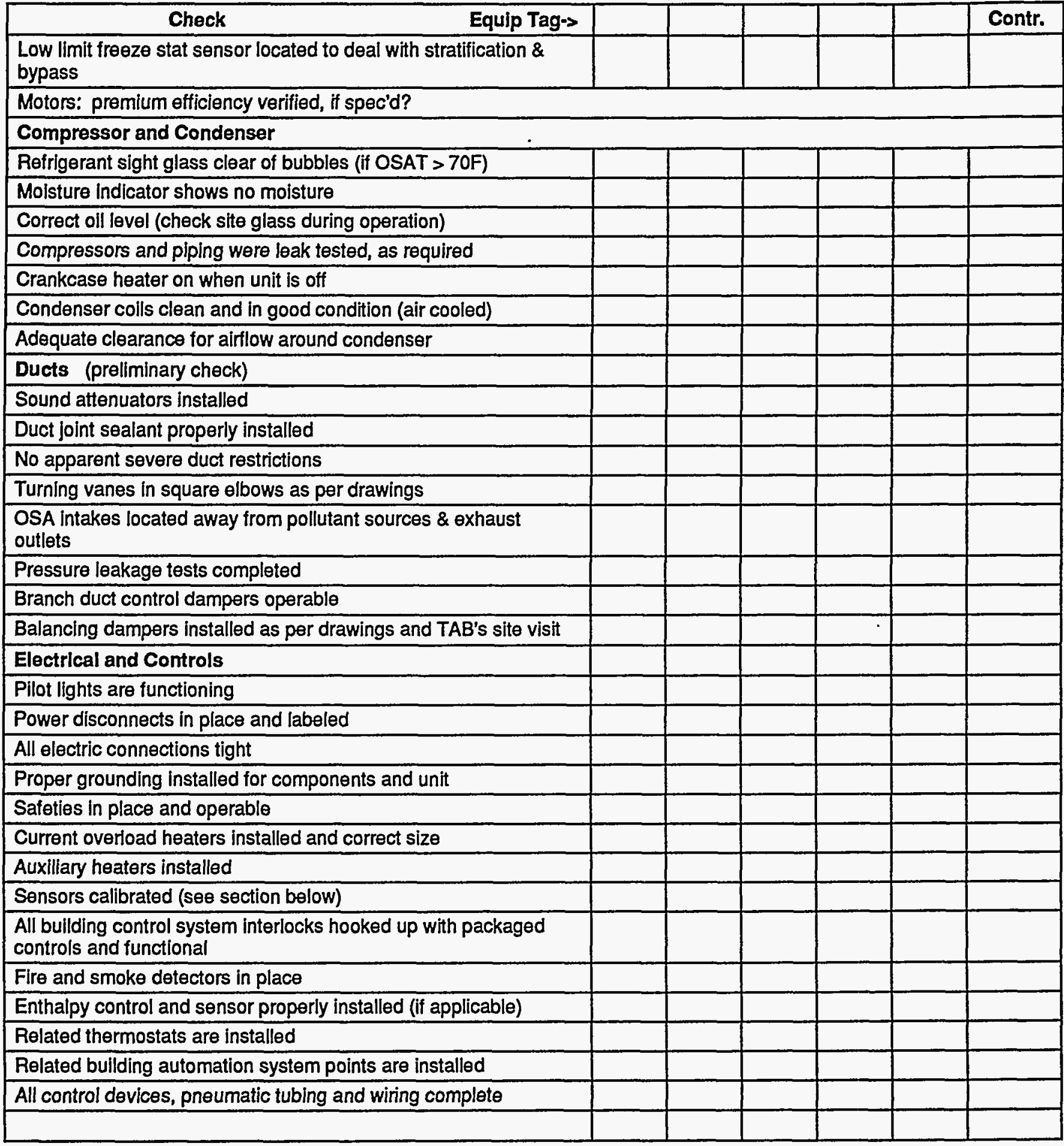

Notes:

File: PKGUNIT.PC6 
Check if Okay. Enter comment or note number if deficient.

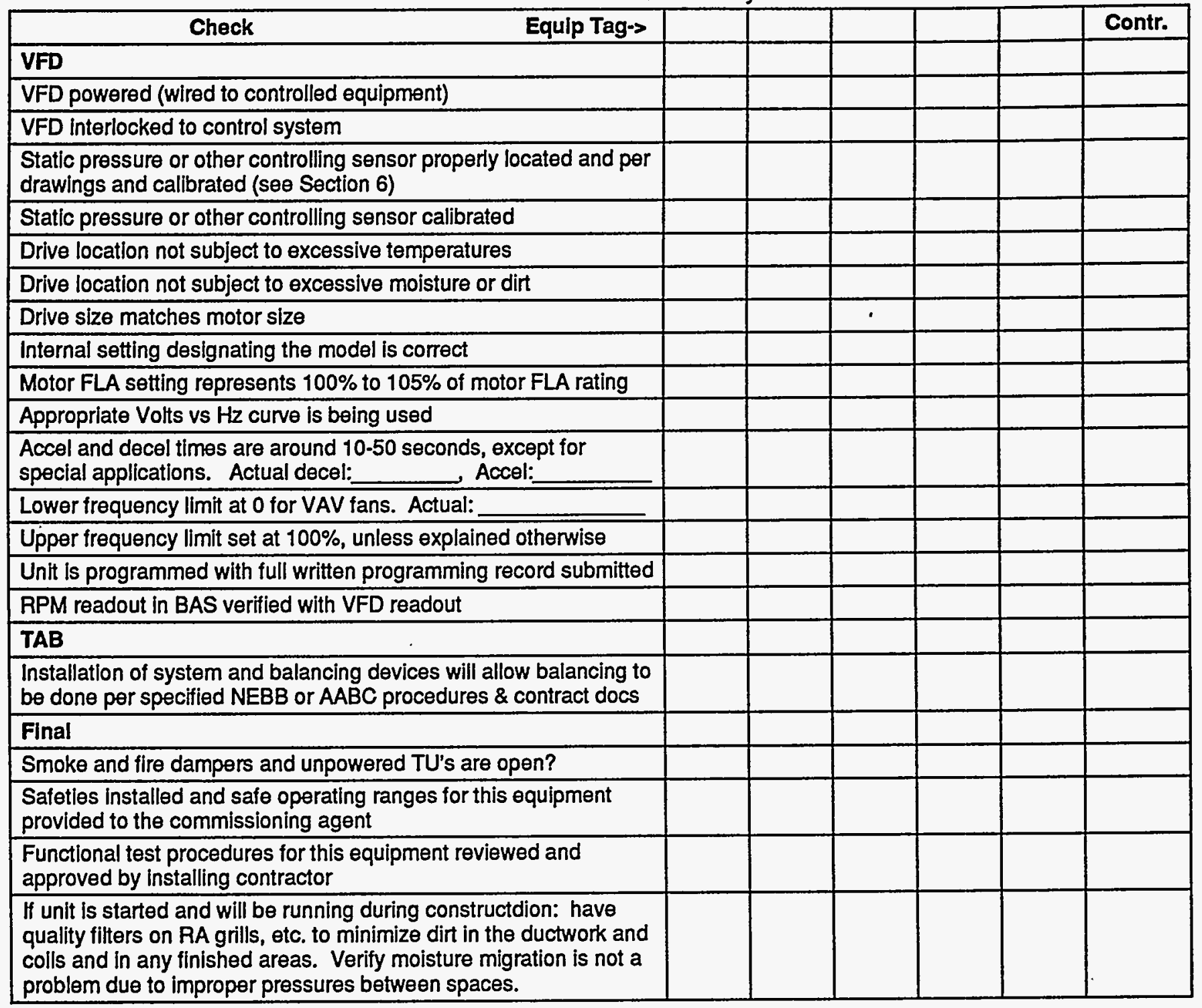

- The checklist items of Part 4 are all successfully completed for given trade.

\section{Operational Checks (These augment mfr's list. This is not the functional performance testing.)}

Check if Okay. Enter comment or note number if deficient.

\begin{tabular}{|l|l|l|l|l|l|l|}
\hline \multicolumn{1}{|c|}{ Check } & & & & & Contr. \\
\hline Supply fan rotation correct & 1 & & & & & \\
\hline Return / exhaust fan rotation correct & 2 & & & & & \\
\hline No unusual noise or vibration in supply and exhaust fans & & & & & & \\
\hline
\end{tabular}

\section{Notes:}




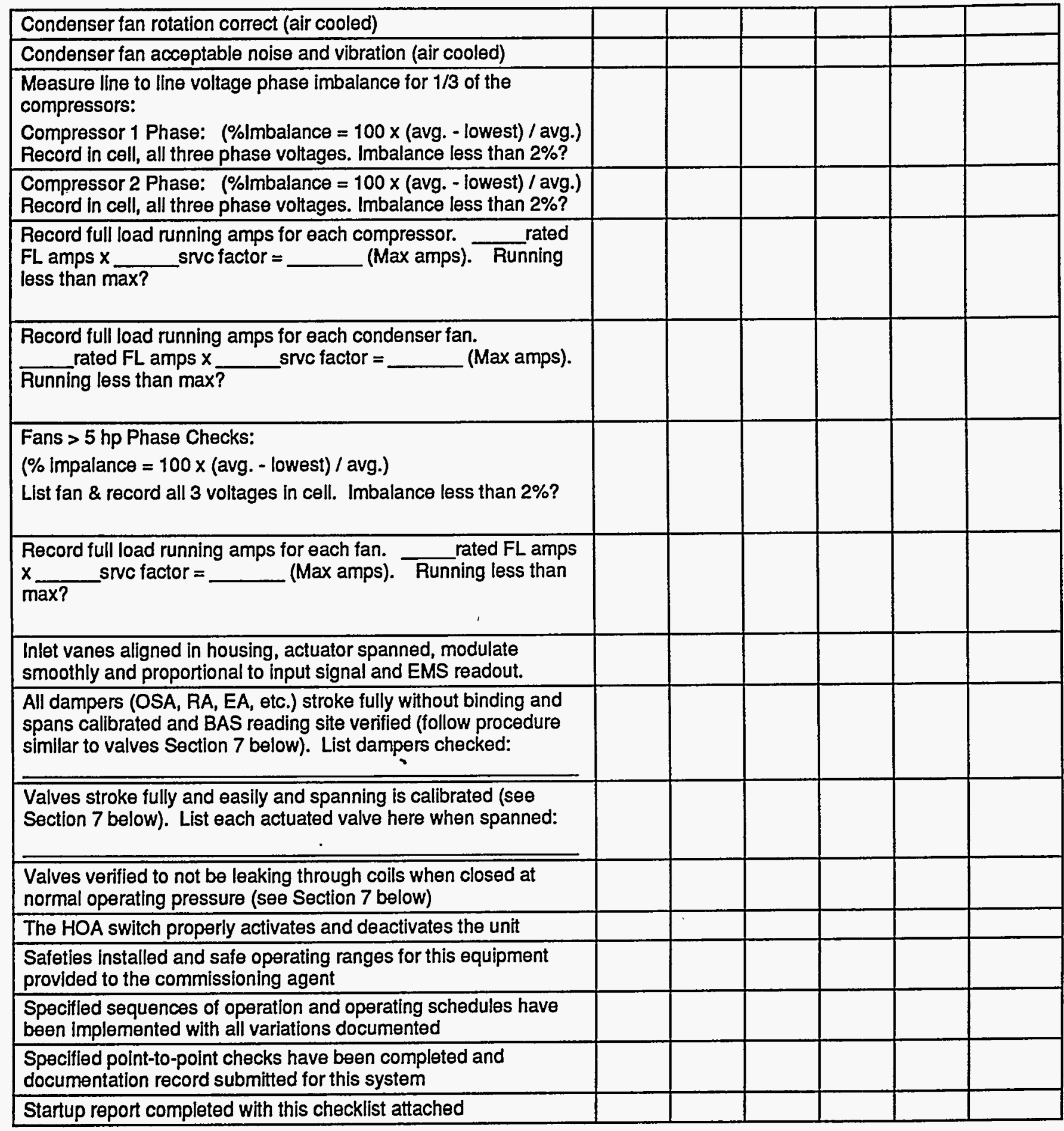

- The checklist items of Part 5 are all successfully completed for given trade.__ YES _ NO

\section{Notes:}




\section{Sensor Calibration}

All field-installed temperature, relative humidity, $\mathrm{CO}, \mathrm{CO}_{2}$ and pressure sensors and gages on this piece of equipment shall be calibrated using the methods described below. All test instruments shall have had a certified calibration within the last 12 months: $\mathrm{Y} / \mathrm{N}$ Sensors installed in the unit at the factory with calibration certification provided need not be field calibrated. All actuators should also be calibrated, per the above checklist.

\begin{tabular}{|c|c|c|c|c|c|}
\hline $\begin{array}{c}\text { Sensor \& } \\
\text { Location }\end{array}$ & $\begin{array}{c}\text { Loc- } \\
\text { ation } \\
\text { OK }\end{array}$ & $\begin{array}{c}\text { 1st } \\
\text { Gage } \\
\text { OaAS }\end{array}$ & $\begin{array}{c}\text { Instr. } \\
\text { Veas'd } \\
\text { Value }\end{array}$ & $\begin{array}{c}\text { Final } \\
\text { Gage } \\
\text { or BAS } \\
\text { Value }\end{array}$ & $\begin{array}{c}\text { Pass } \\
\text { YNN? }\end{array}$ \\
\hline & & & & & \\
\hline & & & & & \\
\hline & & & & & \\
\hline
\end{tabular}

\begin{tabular}{|c|c|c|c|c|c|}
\hline $\begin{array}{c}\text { Sensor \& } \\
\text { Location }\end{array}$ & $\begin{array}{c}\text { Loc- } \\
\text { ation } \\
\text { OK }\end{array}$ & $\begin{array}{c}\text { Ist } \\
\text { Gage } \\
\text { Or BAS }\end{array}$ & $\begin{array}{c}\text { Instr. } \\
\text { Value } \\
\text { Value }\end{array}$ & $\begin{array}{c}\text { Flnal } \\
\text { Gage } \\
\text { or BAS } \\
\text { Value }\end{array}$ & $\begin{array}{c}\text { Pass } \\
\text { YNN? }\end{array}$ \\
\hline \hline & & & & & \\
\hline & & & & 1 & \\
\hline & & & & & \\
\hline
\end{tabular}

The Contractor's own sensor check-out sheets may be used in lieu of the above, if the same recording fields are included and the procedures below are followed.

- All sensors and actuators are calibrated within required tolerances......... YES NO

\section{Misc. Procedures (as referenced above)}

\subsection{Sensor Calibration Mothods}

All Sensors. Verify that all sensor locations are appropriate and away from causes of erratic operation. Verify that sensors with shielded cable, are grounded only at one end. For sensor pairs that are used to determine a temperature or pressure difference, make sure they are reading within $0.2^{\circ} \mathrm{F}$ of each other for temperature and within a tolerance equal to $2 \%$ of the reading, of each other, for pressure. Tolerances for critical applications may be tighter.

A. Sensors Without Transmitters--Standard Application. Make a reading with a calibrated test instrument within 6 inches of the site sensor. Verify that the sensor reading (via the permanent thermostat, gage or building automation system (BAS) Is within the tolerances in the table below of the instrument-measured value. If not, install offset in BAS, calibrate or replace sensor.

B. Sensors With Transmitters--Standard Application. Disconnect sensor. Connect a signal generator in place of sensor. Connect ammeter in series between transmitter and BAS control panel. Using manufacturer's resistance-temperature data, simulate minimum desired temperature. Adjust transmitter potentiometer zero until $4 \mathrm{~mA}$ is read by the ammeter. Repeat for the maximum temperature matching $20 \mathrm{~mA}$ to the potentiometer span or maximum and verify at the BAS. Record all values and recalibrate controller as necessary to conform with specified control ramps, reset schedules, proportional relationship, reset relationship and P/I reaction. Reconnect sensor. Make a reading with a calibrated test instrument within 6 inches of the site sensor. Verify that the sensor reading (via the permanent thermostat, gage or building automation system (BAS)) is within the tolerances in the table below of the instrument-measured value. If not, replace sensor and repeat. For pressure sensors, perform a similar process with a suitable signal generator.

c. Critical Applications. For critical applications (process, manufacturing, etc.) more rigorous calibration techniques may be required for selected sensors. Describe any such methods used on an attached sheet.

\section{Notes:}




\begin{tabular}{|c|c|c|c|}
\hline \multicolumn{3}{|c|}{ Required } & \multirow{2}{*}{$\frac{\text { Required }}{\text { Jerance }(t /-)}$} \\
\hline Sensor & Tolerance $(+1-)$ & Sensor & \\
\hline $\begin{array}{l}\text { Cooling coll, chilled and condenser } \\
\text { water temps }\end{array}$ & $\overline{0.3 F}$ & Flow rates, water & $4 \%$ of design \\
\hline $\begin{array}{l}\text { AHU wet bulb or dew point } \\
\text { Hot water coil and boiler water temp } \\
\text { Outside air, space air, coil air temps }\end{array}$ & $\begin{array}{l}1.0 \mathrm{~F} \\
1.0 \mathrm{~F} \\
0.5 \mathrm{~F}\end{array}$ & $\begin{array}{l}\text { Combustion flue temps } \\
\text { Oxygen or } \mathrm{CO}_{2} \text { monitor } \\
\mathrm{CO} \text { monitor }\end{array}$ & $\begin{array}{l}5.0 \mathrm{~F} \\
0.1 \% \mathrm{pts} \\
0.01 \% \mathrm{pts}\end{array}$ \\
\hline Watthour, voltage \& amperage & $1 \%$ of design & Natural gas and oil flow rate & $1 \%$ of design \\
\hline $\begin{array}{l}\text { Pressures, air, water and gas } \\
\text { Flow rates, air }\end{array}$ & $\begin{array}{l}3 \% \text { of design } \\
10 \% \text { of design }\end{array}$ & $\begin{array}{l}\text { Steam flow rate } \\
\text { Barometric pressure }\end{array}$ & $\begin{array}{l}3 \% \text { of design } \\
0.1 \text { in. of } \mathrm{Hg}\end{array}$ \\
\hline
\end{tabular}

\subsection{Coll Valve Leak Check}

A. Method 1--Water Temperature With 2-Way Valve. Calibrate water temperature sensors on each side of coil to be within $0.5^{\circ} \mathrm{F}$ of each other. Turn off air handler fans and close OSA dampers. Make sure appropriate coll dampers are open. Normally closed valves will close. Override normally open valves to the closed position. After 10 minutes observe water delta $T$ across coll. If it is greater than $2^{\circ} \mathrm{F}$, leakage is probably occuring. Reset valve stroke to close tighter. Repeat test until compliance.

B. Method 2--Air Temperature With 2 or 3-Way Valve. Calibrate air temperature sensors on each side of coil to be within $0.5^{\circ} \mathrm{F}$ of each other. Change mixed or discharge air setpoint, override values or bleed or squeeze bulb pneumatic controller to cause the valve to close. Air handler fans should be on. After 5 minutes observe air delta $T$ across coil. If it is greater than $1^{\circ} \mathrm{F}$, leakage is probably occuring. Reset valve stroke to close tighter. Repeat test until compliance.

C. Method 3 Coil Drain Down (not for 3-way valves). Put systems in normal mode. If cooling coil valve, remove all call for cooling or if heating coil valve put system in full cooling. Close isolation valve on supply side of coil, open air bleed cap, open drain-down cock and drain water from coil. Water should stop draining, else there may be a leak through the control valve. Return all to normal when done.

\subsection{Valve Stroke Setup and Check}

For all valve and actuator positions checked, verify the actual position against the BAS readout.

Set pumps to normal operating mode. Command valve closed, verify that valve is closed and adjust output zero signal as required. Command valve open, verify position is full open and adjust output signal as required. Command valve to a few intermediate positions. If actual valve position doesn't reasonably correspond, replace actuator or add pilot positioner (for pneumatics). For heating coil valves (NO): Set heating setpoint $20^{\circ} \mathrm{F}$ above room temperature. Observe valve open. Remove control air or power from the valve and verify that the valve stem and actuator position do not change. Restore to normal. Set heating setpoint to $20^{\circ} \mathrm{F}$ below room temperature. Observe the valve close. For pneumatics, by override in the EMS, increase pressure to valve by 3 psi (do not exceed actuator pressure rating) and verify valve stem and actuator position does not change. Restore to normal.

For cooling coil valves (NC): Set cooling setpoint $20^{\circ} \mathrm{F}$ above room temperature. Observe the valve close. Remove control air or power from the valve and verify that the valve stem and actuator position do not change. Restore to normal. Set cooling setpoint to $20^{\circ} \mathrm{F}$ below room temperature. Observe valve open. For pneumatics, by override in the EMS, increase pressure to valve by 3 psi (do not exceed actuator pressure rating) and verify valve stem and actuator position does not change. Restore to normal.

\section{- END OF CHECKLIST-}

Notes: 


\section{Prefunctional Checklist}

Project

PC-___ PUMP \#'S

Included components: VFD's

Associated checklists: _Chiller, Cooling Tower, CHW \& CDW Piping, _Boiler and HW Piping, _Other

\section{Submittal / Approvals}

Submittal. The above equipment and systems integral to them are complete and ready for functional testing. The checklist items are complete and have been checked off only by parties having direct knowledge of the event, as marked below, respective to each responsible contractor. This prefunctional checklist is submitted for approval, subject to an attached list of outstanding items yet to be completed. A Statement of Correction will be submitted upon completion of any outstanding areas. None of the outstanding items preclude safe and reliable functional tests being performed. List attached.

Mechanical Contractor

Electrical Contractor

\section{Date}

Date

$$
\text { Controls Contractor }
$$

Sheet Metal Contractor

General Contractor
Date

Date

\section{TAB Contractor}

\section{Date}

General Contractor

Prefunctional checklist items are to be completed as part of startup \& initial checkout, preparatory to functional testing.

- This checklist does not take the place of the manufacturer's recommended checkout and startup procedures or report.

- Items that do not apply shall be noted with the reasons on this form (N/A = not applicable, $B O=b y$ others).

- If this form is not used for documenting, one of similar rigor shall be used.

- Contractors assigned responsibility for sections of the checklist shall be responsible to see that checklist items by their subcontractors are completed and checked off.

- "Contr." column or abbreviations in brackets to the right of an item refer to the contractor responsible to verify completion of this item. $\mathrm{A} / \mathrm{E}=$ architect/engineer, $\mathrm{All}=$ all contractors, $\mathrm{CA}=$ commissioning agent, $\mathrm{CC}=$ controls contractor, $\mathrm{EC}=$ electrical contractor, $\mathrm{GC}=$ general contractor, $\mathrm{MC}=$ mechanical contractor, $\mathrm{SC}=\mathrm{sheet} \mathrm{metal}$ contractor, $\mathrm{TAB}=$ test and balance contractor, $=$

Approvals. This filled-out checklist has been reviewed. Its completion is approved with the exceptions noted below.

Commissioning Agent

Date
Owner's Representative
Date

\section{Notes:}




\section{Requested documentation submitted}

Check if Okay. Enter comment or note number if deficient.

\begin{tabular}{|l|l|l|l|l|l|l|}
\hline \multicolumn{1}{|c|}{ Check Equip Tag-> } & & & & & & Contr. \\
\hline Manufacturer's cut sheets & & & & & & \\
\hline Performance data (fan curves, coil data, etc.) & & & & & & \\
\hline Installation and startup manual and plan & & & & & & \\
\hline Sequences and control strategies & & & & & & \\
\hline O\&M manuals & & & & & & \\
\hline
\end{tabular}

- Documentation complete as per contract documents for given trade.......__ YES _ NO

3. Model verification

[Contr =

$1=$ as specified, $2=$ as submitted, $3=$ as installed. Check if Okay. Enter note number if deficient.

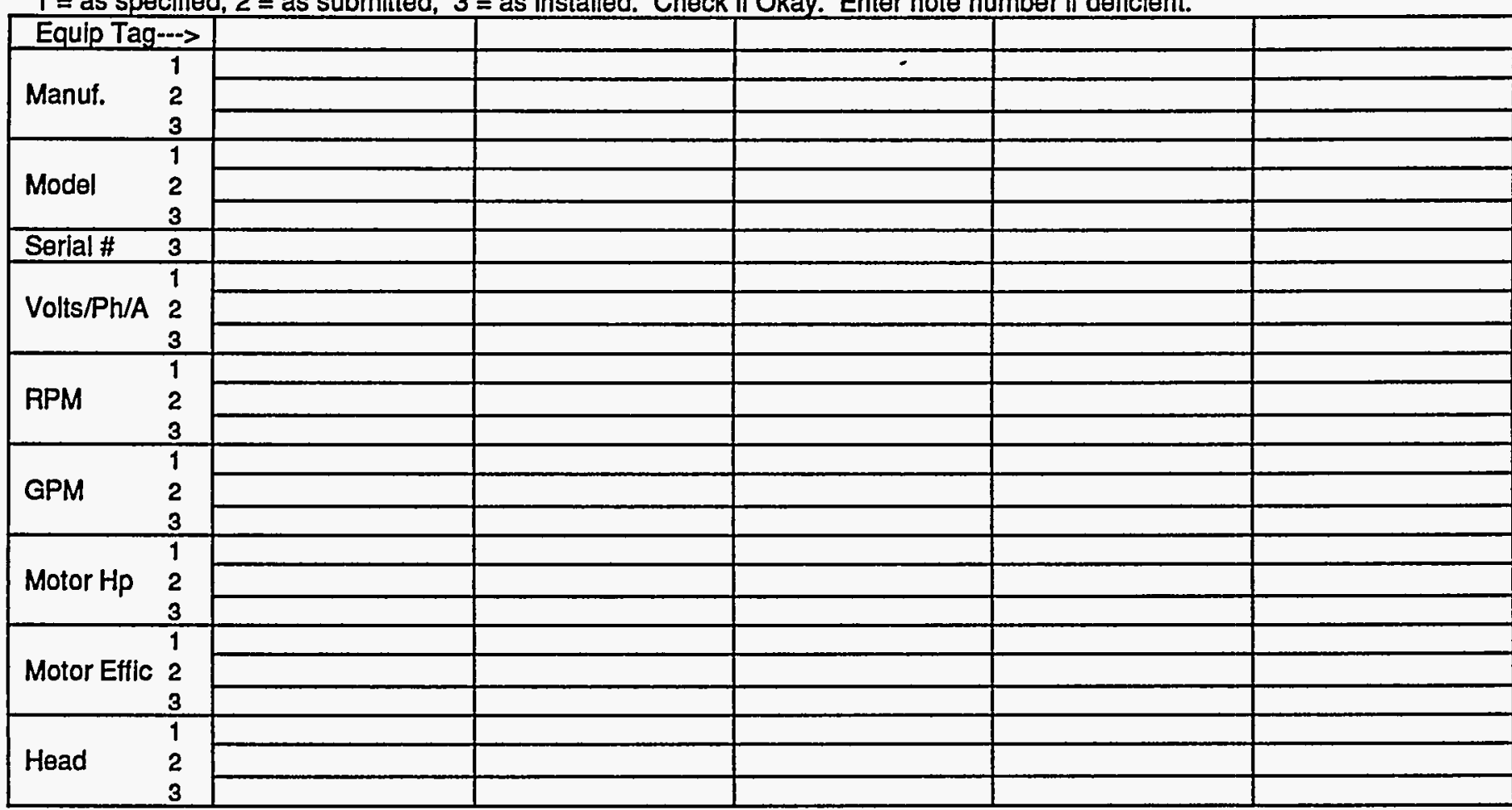

- The equipment installed matches the specifications for given trade........._ YES _ NO

\section{Physical Installation Checks}

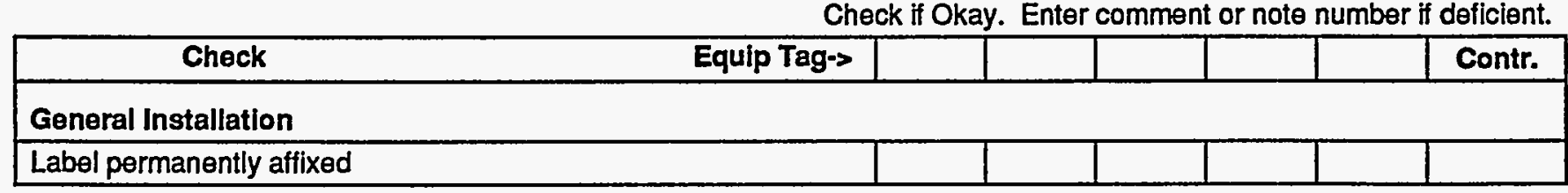

Notes: 
Check if Okay. Enter comment or note number if deficient.

\begin{tabular}{|l|l|l|l|l|l|l|}
\hline \multicolumn{1}{|c|}{ Check } & & & & Contr. \\
\hline Pumps In place and properly grouted & & & & & & \\
\hline Vibration isolation devices Installed and functional & & & & & & \\
\hline Factory allgnment appears correct & & & & & & \\
\hline Field alignment, if required, completed & & & & & & \\
\hline Selsmic anchoring installed & & & & & & \\
\hline Temperature, pressure and flow gages and sensors installed & & & & & & \\
\hline Pump lubricated & & & & & & \\
\hline & & & & & & \\
\hline
\end{tabular}

Plping (immediately around pump, see full piping checklist)

Pipe fittings complete and pipes properiy supported

Pipes properly labeled

Pipes properiy insulated

Strainers in place and clean

Piping system properly flushed

Valves properly tagged

Sensors calibrated (See calibration section below)

Electrical and Controls

Power disconnects in place and labeled

All electric connections tight

Proper grounding installed for components and unit

Motor safetles in place and operable

Control system interlocks hooked up and functional

All control devices, pneumatic tubing and wiring complete

VFD

VFD powered (wired to controlled equipment)

VFD interlocked to control system

Pressure or other controlling sensor properly located and per

drawings and calibrated

Pressure or other controlling sensor calibrated

Drive location not subject to excessive temperatures

Drive location not subject to excessive moisture or dirt

Drive size matches motor size

Internal setting designating the model is correct

Input of motor FLA represents $100 \%$ to $105 \%$ of motor FLA rating

Appropriate Volts vs $\mathrm{Hz}$ curve is being used

Accel and decel times are around 10-50 seconds, except for

special applications. Actual decol $=$

Actual accel $=$

\section{Notes:}


Check if Okay. Enter comment or note number if deficient.

\begin{tabular}{|l|l|l|l|l|l|l|}
\hline Check Equip Tag-> & & & & & & Contr. \\
\hline $\begin{array}{l}\text { Lower frequency limit at } 0 \text { for VAV fans and around 10-30\% for } \\
\text { chilled water pumps. Actual }=\end{array}$ & & & & & & \\
\hline Upper frequency limit set at 100\%, unless explained otherwise & & & & & & \\
\hline Unit Is programmed with full written programming record on site & & & & & & \\
\hline
\end{tabular}

\section{TAB}

Installation of system and balancing devices allowed balancing to be completed following specifled NEBB or AABC procedures and contract documents

Final

Startup report completed with this checklist attached

Safeties installed and safe operating ranges for this equipment provided to the commissioning agent

- The checklist items of Part 4 are all successfully completed for given trade.

5. Operational Checks (These augment mfr's list. This is not the functional performance testing.)

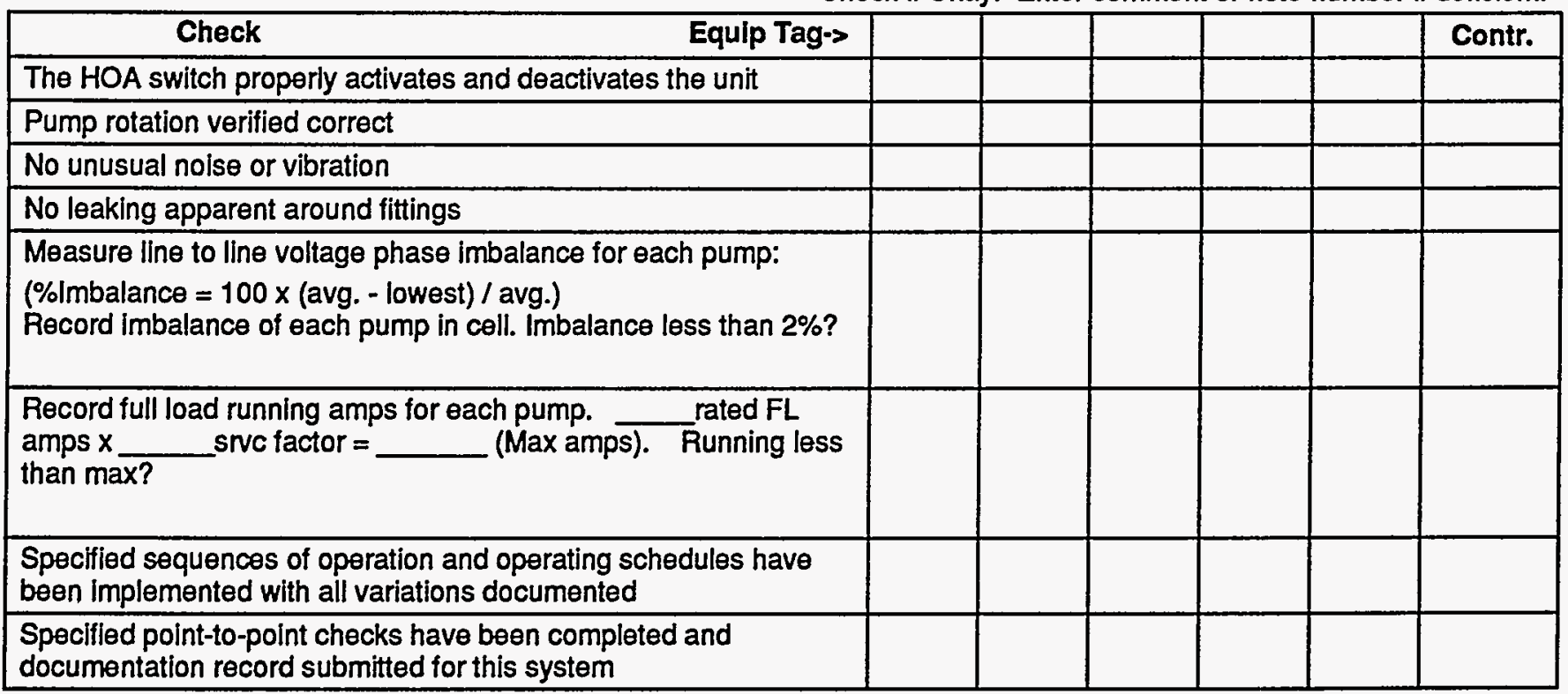

- The checklist items of Part 5 are all successfully completed for given trade.

YES

Notes: 


\section{Sensor Calibration}

All field-installed temperature and pressure sensors and gages on this piece of equipment shall be calibrated using the methods described below. Sensors installed in the unit at the factory with calibration certification provided by manufacturer need not be field calibrated.

Calibrating instrument, air pressure: Certified calibration within last 12 mo's.

Calibrating instrument, water pressure: Certified calibration within last 12 mo's.

Calibrating instrument, temperature: Certified calibration within last 12 mo's.

\begin{tabular}{ccccc}
$\begin{array}{c}\text { Sensor and } \\
\text { Location }\end{array}$ & $\begin{array}{c}\text { Gage or } \\
\text { BAS } \\
\text { Value }\end{array}$ & $\begin{array}{c}\text { If NO, } \\
\text { Calib'd } \\
\text { to }\end{array}$ \\
\hline
\end{tabular}

The Contractor's own sensor check-out sheets may be used in lieu of the above, if the same recording fields are included and the procedures below are followed.

- All sensors are calibrated within required tolerances.......................................__ YES _ NO

\section{Misc. Procedures (as referenced above)}

\subsection{Sensor Calibration Methods}

All Sensors. Verify that all sensor locations are appropriate and away from causes of erratic operation. Verify that sensors with shielded cable, are grounded only at one end. For sensor pairs that are used to determine a temperature or pressure difference, make sure they are reading within $0.2^{\circ} \mathrm{F}$ of each other for temperature and within a tolerance equal to $2 \%$ of the reading, of each other, for pressure. Tolerances for critical applications may be tighter.

A. Sensors Without Transmitters--Standard Application. Make a reading with a calibrated test instrument within 6 inches of the site sensor. Verify that the sensor reading (via the permanent thermostat, gage or building automation system (BAS)) is within the tolerances in the table below of the instrument-measured value. If not, install offset in BAS, calibrate or replace sensor.

Notes: 
B. Sensors With Transmitters--Standard Application. Disconnect sensor. Connect a signal generator in place of sensor. Connect ammeter in series between transmitter and BAS control panel. Using manufacturer's resistance-temperafure data, simulate minimum desired temperature. Adjust transmitter potentiometer zero until $4 \mathrm{~mA}$ is read by the ammeter. Repeat for the maximum temperature matching $20 \mathrm{~mA}$ to the potentiometer span or maximum and verify at the BAS. Record all values and recalibrate controller as necessary to conform with specified control ramps, reset schedules, proportional relationship, reset relationship and $\mathrm{P} / \mathrm{I}$ reaction. Reconnect sensor. Make a reading with a calibrated test Instrument within 6 inches of the site sensor. Verify that the sensor reading (via the permanent thermostat, gage or bullding automation system (BAS)) is within the tolerances in the table below of the instrument-measured value. If not, replace sensor and repeat. For pressure sensors, perform a similar process with a suitable signal generator.

C. Critical Applications. For critical applications (process, manufacturing, etc.) more rigorous calibration techniques may be required for selected sensors. Describe any such methods used on an attached sheet.

\begin{tabular}{|c|c|c|c|}
\hline Sensor & $\frac{\text { Required }}{\text { Tolerance }(+/-)}$ & Sensor & Tolerance $(+t-)$ \\
\hline $\begin{array}{l}\text { Cooling coll, chilled and condenser } \\
\text { water temps }\end{array}$ & $0.3 \mathrm{~F}$ & Flow rates, water & $4 \%$ of design \\
\hline $\begin{array}{l}\text { AHU wet bulb or dew point } \\
\text { Hot water coil and boiler water temp } \\
\text { Outside air, space air, coil air temps }\end{array}$ & $\begin{array}{l}1.0 \mathrm{~F} \\
1.0 \mathrm{~F} \\
0.5 \mathrm{~F}\end{array}$ & $\begin{array}{l}\text { Combustion flue temps } \\
\text { Oxygen or } \mathrm{CO}_{2} \text { monitor } \\
\mathrm{CO} \text { monitor }\end{array}$ & $\begin{array}{l}5.0 \mathrm{~F} \\
0.1 \% \text { pts } \\
0.01 \% \text { pts }\end{array}$ \\
\hline Watthour, voltage \& amperage & $1 \%$ of design & Natural gas and oil flow rate & $1 \%$ of design \\
\hline Pressures, air, water and gas & $3 \%$ of design & Steam flow rate & $3 \%$ of design \\
\hline Flow rates, air & $10 \%$ of design & Barometric pressure & $0.1 \mathrm{in.} \mathrm{of} \mathrm{Hg}$ \\
\hline
\end{tabular}

\section{- END OF CHECKLIST -}

Notes: 


\title{
Plan and Documenting Requirements for Startup and Initial Checkout
}

\author{
Primary Equipment and Tag: \\ Component or Related Equipment Included:
}

Project:

Date:

The purpose of documenting the startup and checkout process is to ensure to the Owner that all recommended startup and initial checkout procedures are completed and that a written record of the work is generated.

\section{PLAN and REQUIRED PROCEDURES:}

1. The prefunctional checklists provided by filled out and signed for the above primary and related equipment. should be

2. The manufacturer recommended field startup and checkout sheets should be fully filled out. These startup and checkout sheets are attached, are not attached.

3. On the manufacturer field startup and checkout sheets, the recommended ranges for readings taken shall be added to each reading field and an explanation given for any variances.

\section{Additional documentation:}

Further documentation beyond the above is required as follows:

The attached pages have been copied from the manuals submitted to They have had paragraphs and sections identified and marked with a signature lines in the margins. Separately for each piece of equipment, during startup and checkout, the technician should check and date each check box and initial and date each line made for that purpose, signifying completion of the task. All readings and settings shall be recorded, not just checked. Provide clear, written notes at the bottom, margin or back-side of each page, as necessary. Written notes shall be provided for why an item was not done or does not apply. A signature and date of the startup technician shall be provided at the end of the startup and checkout documents. Other pages applicable to this piece of equipment in . the installation manual or any other procedures completed should be added.

No further documentation beyond the attached checklist and the manufacturer's installation and startup sheets are required:

This list of procedures does not constitute a recommendation of the full installation and startup procedures or release the installer from following all factory recommendations, the specifications, applicable codes and good practice. All stock startup record forms normally generated should be filled out and submitted.

All documentation should be submitted to upon completion and is required prior to the execution of functional testing. 


\section{TAB Plan--Review Checklist}

Project

PC-10_ TAB PLAN--REVIEW CHECKLIST

Components included: __ Airside, _Water Side

\section{Associated Checklists: TAB Prerequisites}

Contractor filling out this form

The purpose of this checklist is to verify that necessary components of the TAB Plan have been included.

\section{Submittal / Approvals}

Submittal. The TAB Plan has been developed and reviewed against the checklist below.

This plan is submitted for approval, subject to the attached list of outstanding items yet to be completed.

TAB Contractor

Date

General Contractor

$\overline{\text { Date }}$

- The TAB Plan checklist does not take the place of the any recommended formats or procedures in standards referenced in the specifications, but is intended to augment them.

- Items that do not apply shall be noted with the reasons'on this form (N/A = not applicable, $B O=$ by others).

Approvals. This filled-out checklist and the TAB Plan have been reviewed. Their completion is approved with the exceptions noted below.

\section{TAB Plan Checklist}

Check if included in Plan. Enter comment number if deficient.

\begin{tabular}{|c|c|c|c|}
\hline Check & $\begin{array}{l}\text { Air } \\
\text { Side }\end{array}$ & $\begin{array}{l}\text { Heating } \\
\text { Water }\end{array}$ & $\begin{array}{l}\text { Chilled } \\
\text { Water }\end{array}$ \\
\hline Specifled qualifications and certifications of parties performing TAB work submitted & & & \\
\hline $\begin{array}{l}\text { TAB contractor has reviewed drawings and walked through the site and verified that there are sufficient } \\
\text { balancing dampers and valves, isolation dampers and valves and test ports installed to perform TAB per } \\
\text { spec. Any deficiencles in design or installation that will adversely affect or predude proper TAB have been } \\
\text { reported. }\end{array}$ & & - & \\
\hline $\begin{array}{l}\text { TAB contractor has reviewed the construction documents and the systems with the design engineers and } \\
\text { contractors to sufficiently understand the design intent for each system }\end{array}$ & & & \\
\hline
\end{tabular}

\section{Comments:}


PC-

\begin{tabular}{|c|c|c|c|}
\hline Check & $\begin{array}{l}\text { Air } \\
\text { Side }\end{array}$ & $\begin{array}{l}\text { Heating } \\
\text { Water }\end{array}$ & $\begin{array}{l}\text { Chilled } \\
\text { Water }\end{array}$ \\
\hline \multicolumn{4}{|l|}{ Prior to plan, TAB contractor had planning meeting with controls contractor to discuss using BAS for TAB } \\
\hline \multicolumn{4}{|l|}{ All field checkout sheets and logs provided as part of plan } \\
\hline \multicolumn{4}{|l|}{ Final test report sheets to be used provided as part of plan } \\
\hline \multicolumn{4}{|l|}{$\begin{array}{l}\text { Fiold and final test report sheets list each piece of equipment to be tested, adjusted and balanced with the } \\
\text { data cells to be gathered for each }\end{array}$} \\
\hline \multicolumn{4}{|l|}{ Discussion of what notations and markings will be made on the duct and piping drawings. } \\
\hline \multicolumn{4}{|l|}{$\begin{array}{l}\text { List of all air flow, water flow, sound level, system capacity and efficiency measurements to be performed } \\
\text { and provide a description of specific test procedures, parameters, formulas and test instrument type to be } \\
\text { used for the measurements Sample forms have been included. }\end{array}$} \\
\hline \multicolumn{4}{|l|}{$\begin{array}{l}\text { Detalled step-by-step procedures fro TAB work: terminal flow calibration (for each terminal type), diffuser } \\
\text { proportioning, branch / submain proportioning, total flow calculations, rectecking, etc. Similar for water } \\
\text { side. }\end{array}$} \\
\hline \multicolumn{4}{|l|}{$\begin{array}{l}\text { Detalls of how total flow will be determined (Air: sum of terminal flows via BAS calibrated readings or via } \\
\text { hood read of all terminals, supply (SA) and return air (RA) pitot traverse, SA or RA flow stations. Water: } \\
\text { pump curves, circuit setter, flow station, ultrasonic, etc.) }\end{array}$} \\
\hline \multicolumn{4}{|l|}{$\begin{array}{l}\text { Specific procedures that will ensure (and which can be verfitied) that both air and water side are operating at } \\
\text { the lowest possible pressures. }\end{array}$} \\
\hline \multicolumn{4}{|l|}{ Outside alr ventilation criteria under all conditions clearly understood by TAB contractor } \\
\hline \multicolumn{4}{|l|}{ Details of if and how min. outside air cfm will be verified and set and for what level (total bldg, zone, etc.) } \\
\hline \multicolumn{4}{|l|}{ Details of how building static and exhaust fan / relief damper capacity will be checked. } \\
\hline \multicolumn{4}{|l|}{ The identification and types of measurement instruments to be used and their most recent calibration date } \\
\hline \multicolumn{4}{|l|}{ Proposed selection points for sound measurements } \\
\hline \multicolumn{4}{|l|}{ Detalls of any TAB work to be done in phases (by floor, etc.), or of areas to be buitt out later } \\
\hline \multicolumn{4}{|l|}{ Details regarding specified deferred or seasonal TAB work } \\
\hline \multicolumn{4}{|l|}{ Detalls of any specified false loading of sytstems to complete TAB work } \\
\hline $\begin{array}{l}\text { Details of all exhaust fan balancing and capacity verifications, including any required room pressure } \\
\text { differentials. }\end{array}$ & & na & ma \\
\hline \multicolumn{4}{|l|}{$\begin{array}{l}\text { Plan for hand-written field tectnician logs of discrepancies, deficient or uncompleted work by others, } \\
\text { contract interpretation requests and lists of completed tests (scope and frequency) }\end{array}$} \\
\hline \multicolumn{4}{|l|}{ Plan for formal progress reports (scope and frequencty) } \\
\hline Plan for formal deficlency reports (scope, frequency and distribution) & & & \\
\hline & & & \\
\hline
\end{tabular}

- The checklist items of Part 2 are all successfully completed.

\section{Comments:}




\title{
Prefunctional Checklist Approvals and Procedures
}

\author{
Project \\ PC-05_ Terminal Units
}

\section{Submittal}

\section{Associated checklists}

- For the items assigned to the Contractor(s) signing below, the checklist items are complete as marked and ready for functional testing. The checklist items have been checked off only by parties having direct knowledge of the event. "This checklist is submitted for approval for the TU list attached, subject to the attached list of outstanding items yet to be completed. A Statement of Correction will be submitted upon deficiency correction. None of the outstanding items preclude safe and reliable functional testing of other TU's.

\begin{tabular}{l}
\hline Controls Contractor \\
\begin{tabular}{rl|l|l|} 
& & \\
General Contractor & Date \\
2. Requested Documentation Submitted: & \\
\hline Document & Y/N & Contr. \\
\hline Manufacturer's cut sheets & & \\
\hline Installation and checkout manual & & \\
\hline O\&M manual & & \\
\hline
\end{tabular}
\end{tabular}

Sheet Metal Contractor
Mechanical Contractor

$\overline{\text { Date }}$

Date

Documentation complete as per contract documents.

\begin{tabular}{|c|c|c|}
\hline Document & Y/N & Contr. \\
\hline Completed control drawings & & \\
\hline Full written sequences of operation & & \\
\hline All control parameters, deadbands \& setpoints & & \\
\hline
\end{tabular}

\section{Checkout Record}

Prefunctional checklist items are to be completed on each TU as part of startup \& initial checkout, preparatory to functional testing. Further instructions and an explanation of each checklist item, by column number, are found below. See attached sheets for actual checkout record. This checklist does not take the place of the manufacturer's recommended checkout and startup procedures or report. The installing contractor's startup and checkout plan shall make reference to incorporating this checklist or have it attached when submitting the plan to the commissioning agent for approval, prior to execution.

Col. \# CHECKOUT PROCEDURES AND KEY: (refers to column number of TU record)

1 Application and installation in conformance with mfrs recommendations and job specs. Specified sound wrapping and joint sealant installed.

2 Any high pressure ducting upstream has been leak and pressure tested, cleaned and approved prior to setting TU.

3 Model and tag checked against plans and equipment list. Tag or mark affixed.

4 Unit secured per manufacturer's recommendations, contract documents and seizmic requirements.

5 Unit has sufficient clearance to be serviced.

6 Inlet conditions OK: Smooth, round, straight duct for at least 3 duct diameters when possible and 2 diameters minimum for velocity pressure sensor for flow readings and 3 to 5 diameters for single point electronic sensors, else airflow straighteners, OR per manufacturer's recommendation.

7 All balancing devices have been provided in compliance with the contract documents.

8 Any hot or chilled water piping installation complete with valves tagged. Auto-flow control valves checked to ensure proper model.

9 Controls Hardware Check: a) Wiring checked to each point. b) Software pt. address input into box and checked for all points (zone temp. pressures for flow calcs, damper position, fan status, supply air temp., valve position, etc.). c) Release actuator clutch and verify free dami

10 Controls Software Load. Power up unit and download approved software program.

Notes: 
11 Operational Check. a) Start air handler fans. b) Override space temp. to be 55F to simulate tull heating. Verify that BAS flow sensors rear the maximum heating flow and minimum cooling flow for that box per box schedule. Verify proper opening of heating coil valve, if applicable. c) Override space temp. to be $80 \mathrm{~F}$ to simulate full cooling. Verify that BAS flow sensors read the maximum cooling flow and minimum heating flow for that box per box schedule. Verify by observation, the proper closing of heating coil valve, if applicable. During the above sequencing, if box is fan powered, verify no unusual sound or vibration and verify proper fan staging.

12 Sensor Calibrations. All Sensors: a) Verify that all sensor locations are appropriate and away from causes of erratic operation. Verify that sensors with shielded cable, are grounded only at one end. b) For sensor pairs that are used to determine temperature or pressure differences, make sure they are reading within $0.2 F$ of each other for temperature and within a tolerance equal to $2 \%$ of the reading, of $8 a c h$ other, for pressure. Critical applications may be tighter. Sensor Without Transmitters: Make a reading with a calibrated test instrument within 6 inches of the site sensor. Verify that t; he sensor reading (via the permanent thermostat, gage or BAS is within 0.5F for temps and within $3 \%$ of design for pressures of the instrument- measured value. If not, install an offset in the BAS, calibrate or replace sensor.

* Fully document procedures 9-12 on a separate form for each terminal unit. The form should have a cell to record each check and calibration for each sensor and BAS point, including max and min cfms. Other data may also be included (inlet size, $k$ factor, etc.). The above procedures are not a substitute for the manufacturer's recommended start-up and checkout procedures, but are to be combined with them , as applicable.

13 All AVE punch list items related to this TU have been corrected.

14 The system has been balanced in accordance with required proceduresand the TAB has been approved for the AHU of this TU. 15 Required pipe cleaning to this unit, pipe flushing and pressure testing has been completed successfully.

16 Construction filter has been removed and final filter installed, if applicable.

\section{Approvals}

This filled-out checklist has been reviewed. Its completion is approved with the exceptions noted below.

Notos: 


\section{Prefunctional Checklist Record}

\section{Project \\ PC- Terminal Units Associated checklists \\ Contractor filling out this form}

\section{Approvals and Documentation records are found on an attached sheet.}

\section{Checkout Record}

Prefunctional checklist items are to be completed as part of startup \& initial checkout, preparatory to functional testing. Further instructions and an explanation of each checklist item, by column number, are attached to the checklist. In each cell, enter the date the check was completed. Footnote explanations as needed. Items that do not apply shall be noted with the reasons on this form (N/A $=$ not applicable, BO = by others). - If this form is not used for documenting, one of similar rigor shall be used. - Contractors assigned responsibility for sections of the checklist shall be responsible to see that checklist items by their subcontractors are completed and checked off. "Contr." column or abbreviations in brackets to the right of an item refer to the contractor responsible to verify completion

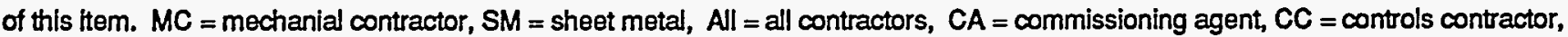
$T A B=$ test and balance

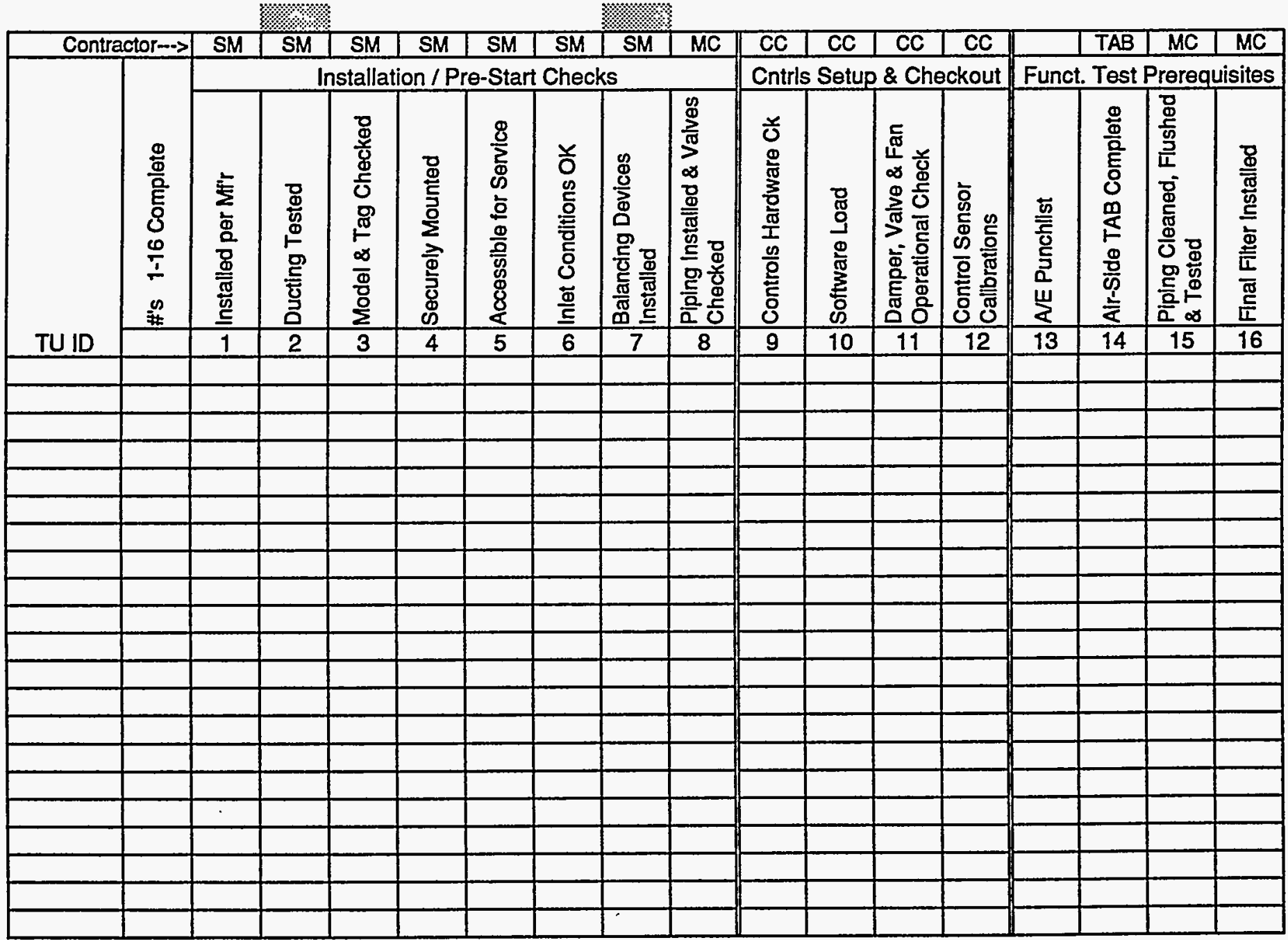


$P C$ -

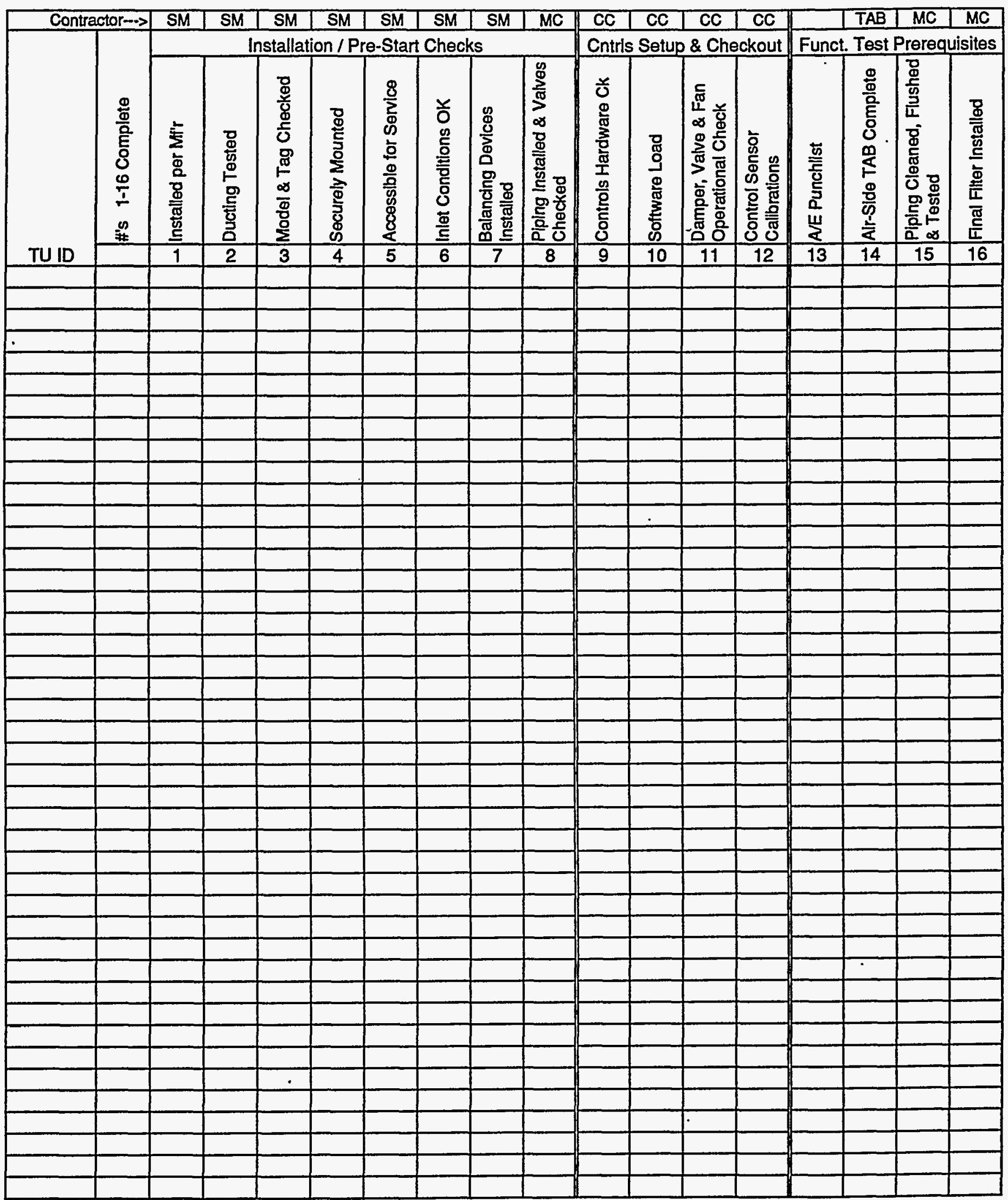




\section{Prefunctional Checklist}

Project

\section{PC-_ VARIABLE FREQUENCY DRIVE on}

\section{Submittal / Approvals}

Submittal. The above equipment and systems integral to them are complete and ready for functional testing. The checklist items are complete and have been checked off only by parties having direct knowledge of the event, as marked below, respective to each responsible contractor. This prefunctional checklist is submitted for approval, subject to an attached list of outstanding items yet to be completed. A Statement of Correction will be submitted upon completion of any outstanding areas. None of the outstanding items preclude safe and reliable functional tests being performed. List attached.

Mechanical Contractor

Electrical Contractor

TAB Contractor

\section{Date}

Date

Date
Controls Contractor

Sheet Metal Contractor

General Contractor
Date

Date

Date

Prefunctional checklist items are to be completed as part of startup \& initial checkout, preparatory to functional testing.

- This checklist does not take the place of the manufacturer's recommended checkout and startup procedures or report.

- Items that do not apply shall be noted with the reasons on this form (N/A = not applicable, $B O=$ by others).

- If this form is not used for documenting, one of similar rigor shall be used.

- Contractors assigned responsibility for sections of the checklist shall be responsible to see that checklist items by their subcontractors are completed and checked off.

- "Contr." column or abbreviations in brackets to the right of an item refer to the contractor responsible to verify completion of this item. $\mathrm{A} / \mathrm{E}=$ architect/engineer, $\mathrm{All}=$ all contractors, $\mathrm{CA}=$ commissioning agent, $\mathrm{CC}=\mathrm{controls}$ contractor, $\mathrm{EC}=$ electrical contractor, $\mathrm{GC}=$ general contractor, $\mathrm{MC}=$ mechanical contractor, $\mathrm{SC}=$ sheet metal contractor, $\mathrm{TAB}=$ test and balance contractor, $=$

Approvals. This filled-out checklist has been reviewed. Its completion is approved with the exceptions noted below.

Notes: 


\section{Requested documentation submitted}

Check if Okay. Enter comment or note number if deficient.

\begin{tabular}{|l|l|l|l|l|l|l|}
\hline \multicolumn{1}{|c|}{ Check Equip Tag-> } & & & & & & Contr. \\
\hline Manufacturer's cut sheets & & & & & & \\
\hline Performance data (fan curves, coll data, etc.) & & & & & & \\
\hline Installation and startup manual and plan & & & & & & \\
\hline Sequences and control strategies & & & & & & \\
\hline O\&M manuals & & & & & \\
\hline
\end{tabular}

- Documentation complete as per contract documents for given trade......._ YES _ NO

\section{Model verification}

[Contr $=$

$1=$ as specified, 2 = as submitted, $3=$ as installed. Check if Okay. Enter note number if deficient.

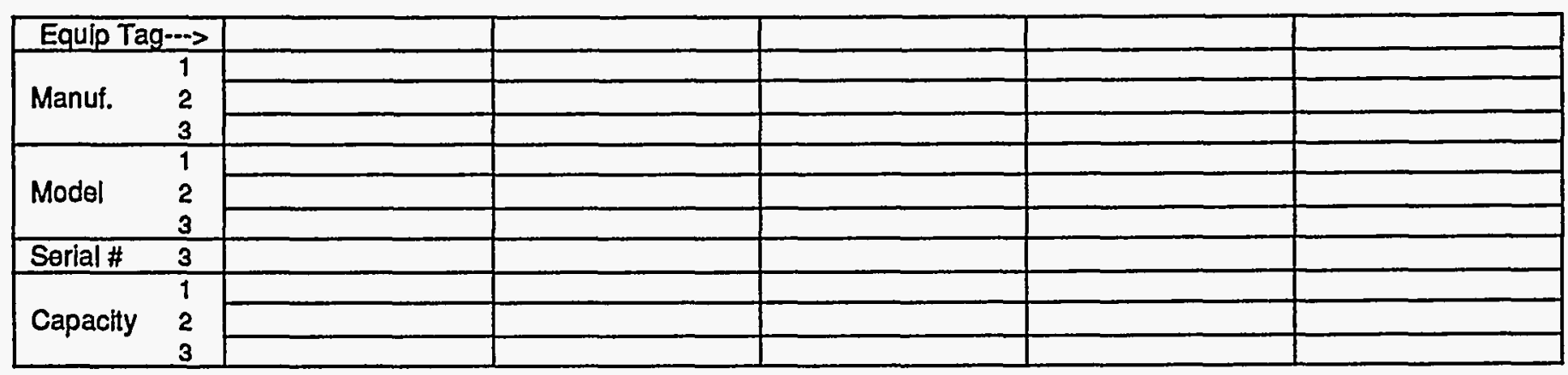

- The equipment installed matches the specifications for given trade.........__ YES __ NO

\section{Installation Checks}

Check if Okay. Enter comment or note number if deficient.

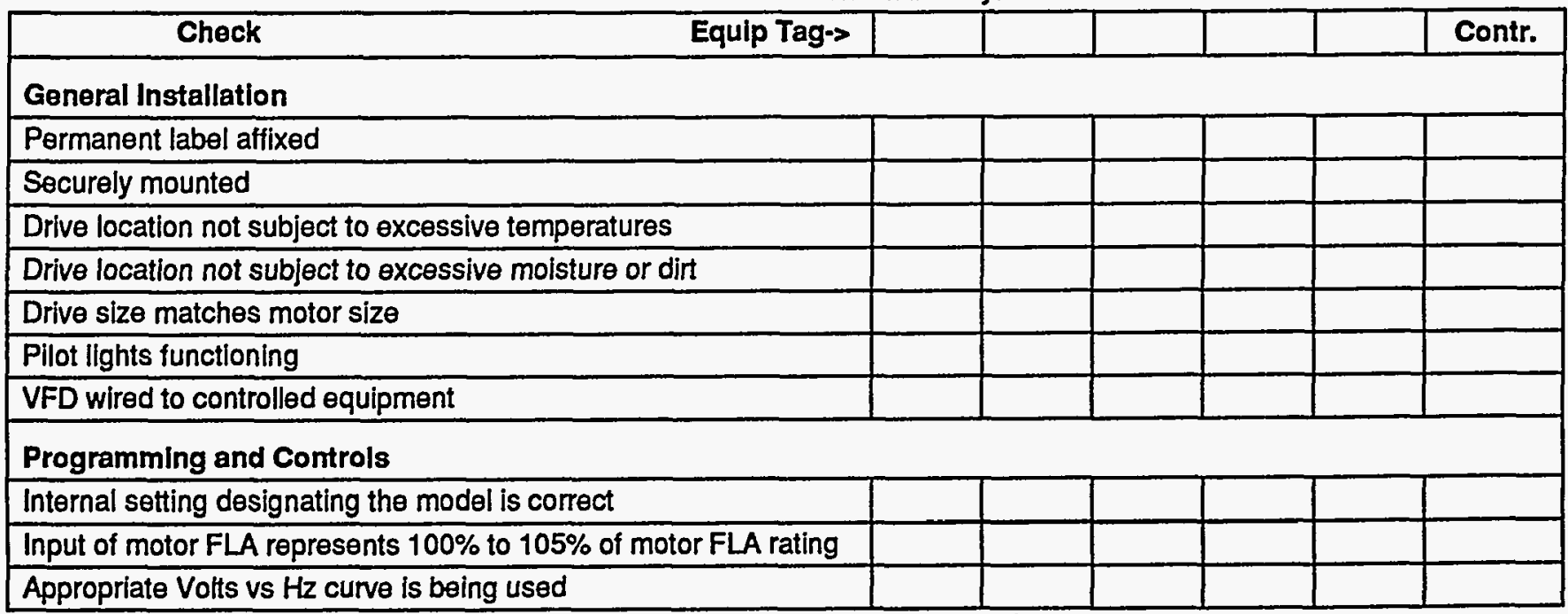

Notes: 
Check if Okay. Enter comment or note number if deficient.

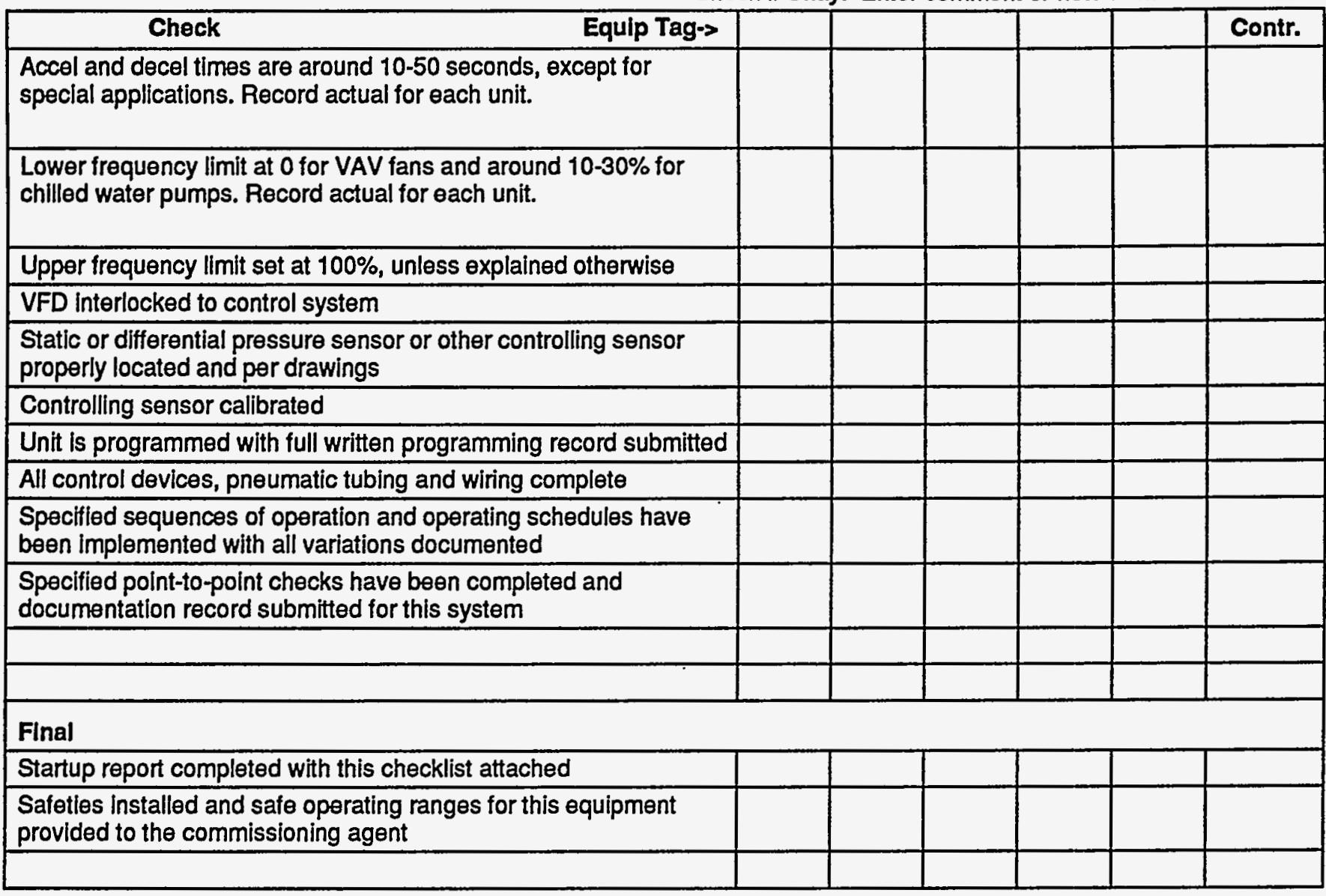

- The checklist items of Part 4 are all successfully completed for given trade.

YES

\section{- END OF CHECKLIST -}

\section{Notes:}




\title{
COMMISSIONING GUIDE SPECIFICATIONS
}

\author{
SECTION 15999 \\ SAMPLE FUNCTIONAL TEST PROCEDURES
}

\section{MECHANICAL}

\section{Spec writer:}

The following example functional test procedures are provided for reference and do not necessarily reflect equipment or conditions in this project. The commissioning agent will write specific functional test procedures for this project.

\section{SECTION 15999}

\section{SAMPLE FUNCTIONAL TEST PROCEDURES}

\section{MECHANICAL}

\section{A. GENERAL}

This section contains sample Functional performance Test procedures in a form format (FT).

The sample FT procedures displayed in a form format here, are to provide contractors and CA with an example of a format and an indication of the rigor of the required testing and documentation for various equipment types. They were not developed for this project. Other forms and formats are acceptable if they comply with the rigor, clarity and intent of all the commissioning specifications. The CA will use the functional testing requirements in Sections 15997 and 16997 and the testing protocols specified in Section 17100 for developing site-specific functional test procedures and forms for this project. For illustrative purposes, sequences of operation associated with a few pieces of the equipment for which tests are included are also provided.

\section{B. SAMPLE FUNCTIONAL TESTS (Examples only, not for this project)}

This guide specification section continues with functional tests for the following equipment. The tests are provided in electronic file format (Word 6.0 for Windows 3.1). The file name is at the bottom of each page. The file name extension " $f$ _ " stands for Functional Test and the last digit is the version number. Any MS Excel spreadsheet files are noted with their usual xls extension. Some of the equipment also has a file with full sequences of operation, for reference when viewing the test procedures, and to illustrate the desired rigor of sequences of operation.

Division 16 functional test examples are found in Section 16999. 


\section{SYSTEM}

Air handler unit (cooling only)

Air compressor (smoke damper)

Boiler (packaged for heating water)

Boiler system sequences

Boiler system (multiple HW)

Cabinet unit heater

Chiller system

Chiller system sequences

Economizer (airside)

Fin tube radiator

Heating fan coil unit

Packaged rooftop AC unit

Small service water circ. pump

Split air conditioner (small)

Service water heater

Terminal unit (with HW reheat, 1-duct)

Terminal unit (cooling only 1-duct)

Terminal unit (dual duct VAV)

Terminal unit (dual duct fan series)

Unit heater

Variable speed drive (fan)

Variable speed drive (pump)

\section{ELECTRONIC FILE NAME}

ahu_cool.ft aircompr.ft boilerhw.ft boilerseq. 004 boilersys.ft cabunhtr.ft_ chiller.ft_ chiller.seq econtest.ft fintube.t htfncoil.ft pkg_rtu.ft smlcpump.ft_ split_ac.ft srve_wh.ft_ tu_rehet.ft_ tu_clg.ft_ tu_ddvav.ft_ tu_ddfan.ft_ unit_htr.ft_ vfdfan.ft vfdpump.ft_

See section 16999 for functional tests of electrical equipment.

\section{SUGGESTED NUMBERING KEY FOR COMMISSIONING PROCEDURES}

The checklists, functional tests, documentation and training use the following identification numbering:

At the beginning of the identification number is a text abbreviation for the following:

Document or Event Abbreviations

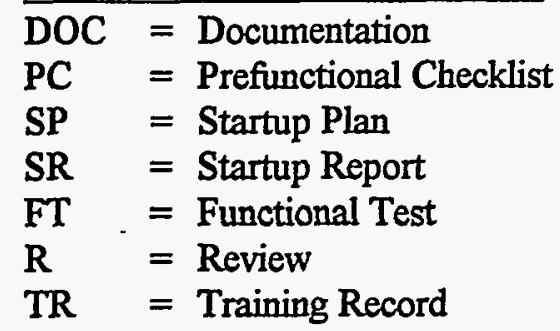

Numbering Key

FT-0102.3: The first four digits uniquely identify the piece of equipment to the component level. The first 2 digits are the System Type, the second 2 digits are an arbitrary component number (not necessarily the same as the specified $\mathrm{ID}$ number). The number after the decimal is the test number. For example, FT-0102.3 = Functional Test 3 of system Type 1, component number 2 (e.g., 0102.3 = Chiller \#2, FT \#3, because chillers are system Type 1). Other components

File: 15999. VO5 
under chillers are: additional chillers, pumps, valves, piping, VFDs. The component number of 00 means "general" or "all" components, as with the entire system. All tests, procedures, trainings and records should have the same first 4 digits for any given equipment component.

Another example is TUs. If there was only 1 TU type, then tests would be numbered FT$0500.1,0500.2$, etc. If there were 2 types of TUs: FT-0501.1, 0501.2, etc and 0502.1, 0502.2, etc.

An example of the number system follows:

0100

Chilled Water System
0101 Chiller 1
0102 Chiller 2
0103 Cooling tower 1
0104 Cooling tower 2
0105 Pump CHWP-1
0106 Pump CHWP-2
0107 CHW piping
0108 CDW piping
0109 Sensor calibration

0200 Boiler System 0201 Boiler 1 0202 Boiler 2 0203 Pump HWP-1 0204 Pump HWP-2 $0205 \mathrm{HW}$ piping 0206 Sensor calibration

\section{Numbers for Primary System Types and Components}

Components are in parentheses.

01 Chilled water system (chillers, cooling towers, pumps, condensers, piping, valves)

02 Hot water system (boilers, hot water pumps, valves, piping)

03 Air handler units (SF, RF, coils, valves, VFD, ducts, dampers)

04 Packaged, AC or HP units (SF, RF, coils, valves, VFD, ducts, dampers, compressors, condensers)

05 Terminal units

06 Computer room AC units

07 Unit heaters or AC spot coolers

08 Heat exchangers

09 Service water system

10 Test and balance (TAB)

11 Building automation system (controls)

12 Lighting controls

13 Specialty fans

14 Fume hoods

\section{END OF SECTION}




\title{
Functional Test
}

\section{Project:}

\section{FT-__ SMOKE DAMPER AIR COMPRESSOR}

\section{Participants}

\section{Party}

\author{
Participation
}

Party filling out this form and witnessing testing

Date of test

\section{Prerequisite Checklist}

a. The following have been started up and startup reports and prefunctional checklists submitted and approved ready for functional testing: _ Smoke dampers

b. All control system functions for this and all interlocking systems are programmed and operable per contract documents, including final setpoints, schedules, debugging, loop tuning and sensor calibrations complete.

Controls Contractor Signature or Verbal $\quad \overline{\text { Date }}$

c. All A/E punchlist items for this equipment corrected.

d. - Safeties and operating ranges reviewed.

e. - Test requirements and sequences of operation attached.

f. - Schedules and setpoints attached.

g. - BAS Program Review. Review the BAS software control program(s) for this equipment. Parameters, setpoints and logic sequences appear to follow the specified written sequences.

h. Packaged Control Program Review. Review the packaged control program(s) for this equipment. Parameters, setpoints and logic sequences appear to follow the specified written sequences.

i. Record of All Values for Current Setpoints (SP), Control Parameters, Limits, Delays, Lockouts, Schedules, Etc. Changed to Accommodate Testing:

\begin{tabular}{|l|l|c|}
\hline \multicolumn{1}{|c|}{ Parameter } & $\begin{array}{c}\text { Pre-Test } \\
\text { Values }\end{array}$ & $\begin{array}{c}\text { Retumed } \\
\text { to Pre-Test } \\
\text { Values } \sqrt{ }\end{array}$ \\
\hline Compr. ON pressure & & \\
\hline BAS alarm setpoint & & \\
\hline
\end{tabular}

3. Sensor Calibration Checks. Check the sensors listed below for calibration and adequate location. This is a sampling check of calibrations done during prefunctional checklisting. Test the packaged controls and BAS readings. -NONE-

\section{Device Calibration Checks.}

\section{Notes:}


-NONE--

\section{Verification of Misc. Prefunctional Checks.}

Misc. site checks of the prefunctional checklist and startup reports completed successfully. Pass? Y / N

_ Unit mounted securely. _ Unit accessible for servicing. _ No unusual noise or vibration in fan.

_Condensate accumulator or air drier functioning

6. Functional Testing Record

\begin{tabular}{|c|c|c|c|c|}
\hline $\begin{array}{l}\text { Proced. } \\
\text { No. \& } \\
\text { Spec. } \\
\text { Seg. ID' }\end{array}$ & $\begin{array}{c}\text { Req ID } \\
\text { No. }^{2}\end{array}$ & $\begin{array}{l}\text { Test Procedure } \\
\text { (including special conditions) }\end{array}$ & $\begin{array}{l}\text { Expected and Actual Response } \\
\text { [Write ACTUAL response in } \\
\text { brackets or circle] }\end{array}$ & $\begin{array}{c}\text { Pass } \\
Y \text { YN } \\
\& \text { Note } \\
\text { N } \\
\end{array}$ \\
\hline $\begin{array}{c}1 \\
\text { Seq. } 1\end{array}$ & & $\begin{array}{l}\text { Bleed off air from the system between the } \\
\text { compressor and regulator until it reaches } \\
\text { the setpoint (currently ON at } \\
\text { and OFF at_ psi). }\end{array}$ & Compressor starts. & \\
\hline $\begin{array}{c}2 \\
\text { Seq. } 1\end{array}$ & & $\begin{array}{l}\text { Low Pressure Alarm. Continue bleeding air } \\
\text { until the pressure read by the gage is equal } \\
\text { to the BAS alarm setpoint (currently } \\
\text { psi). }\end{array}$ & $\begin{array}{l}\text { An alarm is registered in the BAS. } \\
\text { All air handlers shut OFF. }\end{array}$ & \\
\hline $\begin{array}{c}3 \\
\text { Seq. } 1\end{array}$ & & Remove bleed. & $\begin{array}{l}\text { Observe compressor build } \\
\text { pressure to OFF setpoint, then } \\
\text { shut OFF. }\end{array}$ & \\
\hline 4 & & $\begin{array}{l}\text { TREND LOG. Temporarily change the BAS } \\
\text { Low Pressure Alarm setpoint to be 4psi } \\
\text { above the ON compressor setpoint so an } \\
\text { alarm will be generated every time the } \\
\text { compressor comes ON (actually it will alarm } \\
\text { twice, once on the way down and once on } \\
\text { the way up). Track this for } 24 \text { hours during } \\
\text { a week day. }\end{array}$ & $\begin{array}{l}\text { Determine the compressor cycling } \\
\text { frequency and make } \\
\text { recommendations as to adequacy } \\
\text { of the current design. }\end{array}$ & \\
\hline 4 & - & $\begin{array}{l}\text { Return all changed control parameters } \\
\text { and conditions to their pre-test values }\end{array}$ & $\begin{array}{l}\text { Check off in Section } 2 \text { above } \\
\text { when completed }\end{array}$ & \\
\hline
\end{tabular}

Record Foot Notes

${ }^{7}$ Sequences of operation specified in Contract Documents (attached).

${ }^{2}$ Mode or function ID being tested, per testing requirements section of the project Specifications.

${ }^{3}$ Step-by-step procedures for manual testing, trend logging or data-logger monitoring.

${ }^{4}$ Include tolerances for a passing condition.

${ }^{5}$ Record any permanently changed parameter values and submit to Owner.

Notes: 


\section{Functional Test}

\section{Project:}

FT-03

COOLING AIR HANDLING UNIT AHU

And Associated Equipment Including:

Return Fans, RF

Outside Air Handling Unit, AHU

Related Tests:

\section{Participants}

\section{Party}

\section{Participation}

Party filling out this form and witnessing testing

Date of test

\section{Prerequisite Checklist}

a. The following have been started up and startup reports and prefunctional checklists submitted and approved ready for functional testing:

_ Chilled Water System

Connected Terminal Units

Cooling towers
Condenser water pumps

Chilled water piping and valves

- Variable speed drives for pumps

b. All control system functions for this and all interlocking systems are programmed and operable per contract documents, including final setpoints and schedules with debugging, loop tuning and sensor calibrations completed.

c. - Piping system flushing complete and required reports approved.

d. - Water treatment system complete and operational.

e. - Vibration control report approved (if required).

\section{Notes:}


f. - Test and balance (TAB) completed and approved for the hydronic systems and terminal units connected.

g. - All A/E punchlist items for this equipment corrected.

h. - These functional test procedures reviewed and approved by installing contractor.

i. - Safeties and operating ranges reviewed.

j. - Test requirements and sequences of operation attached.

k. - Schedules and setpoints attached.

1. - False loading equipment, system and procedures ready (boilers, preheat or reheat coils, control loops, override on OSA dampers, etc.)

m. Have all energy savings control strategies, setpoints and schedules been incorporated that this equipment and control system are capable of? If not, list recommendations below.

n. -Control Program Review. Review the software control program(s) for this equipment. Parameters, setpoints and logic sequences appear to follow the specified written sequences.

o. _Record of All Values for Current Setpoints (SP), Control Parameters, Limits, Delays, Lockouts, Schedules, Etc. Changed to Accommodate Testing:

\begin{tabular}{|l|l|l|l|l|l|}
\hline \multicolumn{1}{|c|}{ Parameter } & \multicolumn{1}{|c|}{$\begin{array}{c}\text { Pre-Test } \\
\text { Values }\end{array}$} & $\begin{array}{c}\text { Returned } \\
\text { to Pre-Test } \\
\text { Values } \sqrt{ }\end{array}$ \\
\hline $\begin{array}{l}\text { Discharge air static } \\
\text { pressure (SP)P }\end{array}$ & & & Parameter & $\begin{array}{c}\text { Pre-Test } \\
\text { Values }\end{array}$ & $\begin{array}{c}\text { Returned } \\
\text { to Pre-Test } \\
\text { Values } \sqrt{ }\end{array}$ \\
\hline Discharge air temp. & & & & \\
\hline $\begin{array}{l}\text { Static P. reset } \\
\text { schedule }\end{array}$ & & & Bldg. static P. & & \\
\hline $\begin{array}{l}\text { Discharge air reset } \\
\text { schedule }\end{array}$ & & & & & \\
\hline OSA CFM & & & & & \\
\hline & & & & \\
\hline
\end{tabular}

3. Sensor Calibration Checks. Check the sensors listed below for calibration and adequate location. This is a sampling check of calibrations done during prefunctional checklisting.

"In calibration" means making a reading with a calibrated test instrument within 6 inches of the site sensor. Verify that the sensor reading (via the permanent thermostat, gage or building automation system (BAS)) compared to the test instrument-measured value is within the tolerances specified in the prefunctional checklist requirements ( ). If not, install offset in BAS, calibrate or replace sensor. Use the same test instruments as used for the original calibration, if possible.

Notes: 


\begin{tabular}{|c|c|c|c|c|c|}
\hline $\begin{array}{l}\text { Sensor \& } \\
\text { Location }\end{array}$ & $\begin{array}{l}\text { Loc- } \\
\text { ation } \\
\text { OK }^{1}\end{array}$ & $\begin{array}{c}\text { 1st } \\
\text { Gage } \\
\text { or } \\
\text { BAS } \\
\text { Value }\end{array}$ & $\begin{array}{l}\text { Instr. } \\
\text { Meas'd } \\
\text { Value }\end{array}$ & $\begin{array}{c}\text { Final } \\
\text { Gage } \\
\text { or } \\
\text { BAS } \\
\text { Value }\end{array}$ & $\begin{array}{l}\text { Pass } \\
\text { Y/N? }\end{array}$ \\
\hline \multicolumn{6}{|l|}{$\overline{\mathrm{DAT}}$} \\
\hline \multicolumn{6}{|l|}{ RAT } \\
\hline OSAT & & & & & \\
\hline
\end{tabular}

\begin{tabular}{|l|l|c|c|c|c|}
\hline $\begin{array}{c}\text { Sensor \& } \\
\text { Location }\end{array}$ & $\begin{array}{c}\text { 1st } \\
\text { Lage } \\
\text { ation } \\
\text { Or } \\
\text { OK }\end{array}$ & $\begin{array}{c}\text { BAS } \\
\text { Value }\end{array}$ & $\begin{array}{c}\text { Instr. } \\
\text { Meas'd } \\
\text { Value }\end{array}$ & $\begin{array}{c}\text { Gage } \\
\text { or } \\
\text { BAS } \\
\text { Value }\end{array}$ & $\begin{array}{c}\text { Pass } \\
\text { YIN? }\end{array}$ \\
\hline \hline Disch. SP & & & & & \\
\hline & & & & & \\
\hline & & & & & \\
\hline
\end{tabular}

${ }^{1}$ Sensor location is appropriate and away from causes of erratic operation.

4. Device Calibration Checks. The actuators or devices listed below checked for calibration. This is a spot check on a sample of the calibrations done during prefunctional checklisting and startup.

"In calibration" means observing a readout in the BAS and going to the actuator or controlled device and verifying that the BAS reading is correct. For items out of calibration or adjustment, fix now if easy, via an offset in the BAS, or a mechanical fix.

\begin{tabular}{|c|c|c|c|c|c|}
\hline Device or Actuator \& Location & Procedure / State & $\begin{array}{c}\text { 1st } \\
\text { BAS Value }\end{array}$ & $\begin{array}{c}\text { Site } \\
\text { Observation }\end{array}$ & $\begin{array}{c}\text { Final BAS } \\
\text { Reading }\end{array}$ & $\begin{array}{l}\text { Pass } \\
\text { Y/N }\end{array}$ \\
\hline \multirow{5}{*}{$\begin{array}{l}\text { Cooling coil valve (CCV) } \\
\text { position or command and } \\
\text { stroke* }\end{array}$} & 1. Intermediate positions & & & & \\
\hline & 2. Full open & & & & \\
\hline & 3. Increse pressure (open) & & & & \\
\hline & 4. Closed & & & & \\
\hline & 5. Remove power or air (closed) & & & & \\
\hline \multirow[t]{2}{*}{ Relief damper position ** } & 1. Closed & & & & \\
\hline & 2. Full open & & & & \\
\hline \multirow[t]{2}{*}{ Mixed air damper position ** } & 1. Closed & & & & \\
\hline & 2. Full open & & & & \\
\hline \multirow[t]{2}{*}{ Main OSA damper position** } & 1. Closed & & & & \\
\hline & 2. Full open & & & & \\
\hline \multirow[t]{2}{*}{ Min. OSA damper position ${ }^{* *}$} & 1. Closed & & & & \\
\hline & 2. Full open & & & & \\
\hline & & & & & \\
\hline
\end{tabular}

* Set pumps to normal mode. Procedure 1 . Command valve to a few intermediate positions. Verify that readings in BAS reasonably correspond to the actual positions. For cooling coil valves (NC): Procedure 2. Lower space setpoint to 20F below space temperature. Verify BAS reading says CCV is $100 \%$ open. Visually verify valve is $100 \%$ open. Procedure 3. For pneumatic actuators, by override in the EMS, increase pressure to valve by $3 \mathrm{psi}$ (do not exceed actuator rating). Verify valve stem \& actuator position does not change. Restore to normal. Procedure 4. Set space setpoint to $20 \mathrm{~F}$ above space temperature. Verify BAS reading says CCV is closed. Visually verify valve is closed. Procedure 5. Remove control air or electricity from the valve and verify that the valve stem and actuator position do not change.

**1. Command damper closed and verify that damper is shut and BAS reads shut. 2. Do the same, commanding damper fully open.

\section{Notes:}




\section{Verification of Misc. Prefunctional Checks.}

Misc. site checks of the prefunctional checklist and startup reports completed successfully. Pass? Y / N

General Conditions of Test

Notes: 


\section{Functional Testing Record}

\begin{tabular}{|c|c|c|c|c|c|}
\hline $\begin{array}{c}\text { Seq. } \\
\text { ID } \\
\text { From } \\
\text { Specs } 1\end{array}$ & Mode ID ${ }^{2}$ & $\begin{array}{l}\text { Test Procedure } \\
\text { (including special conditions) }\end{array}$ & Expected Response ${ }^{4}$ & $\begin{array}{l}\text { Pass } \\
\text { YNN }\end{array}$ & $\begin{array}{c}\text { Not } \\
\text { e }\end{array}$ \\
\hline 1 & FAN OFF & $\begin{array}{l}\text { Standby Check. With Units } \\
\text { Commanded off by BAS. }\end{array}$ & $\begin{array}{l}\text { Verify by visual inspection that: } \\
\text { Return Air Dampers in AHU } 3 \& 4 \\
\text { are Open } \\
\text { Outside Air Dampers in AHU- } \\
3 \& 4 \text { are Closed } \\
\text { Isolation Dampers on AHU-9\&10 } \\
\text { are Closed. } \\
\text { Relief Dampers in RF-3 and RF- } \\
4 \text { are Closed } \\
\text { Cooling Coil Valves on Cooling } \\
\text { Coils of AHU--3\&4 are Closed }\end{array}$ & & \\
\hline 1 & UNIT STARTUP & With Units Commanded on by BAS & $\begin{array}{l}\text { Supply Fan Isolation Dampers } \\
\text { Open in AHU-3\&4(Both Supply } \\
\text { Fans in each Unit) } \\
\text { Supply Fan start through VSDs } \\
\text { Supply Fan Isolation Dampers in } \\
\text { AHU 9\&10 Open } \\
\text { AHU-9\&10 Fans Start } \\
\text { RF-3\&4 Isolation Dampers Open } \\
\text { RF-3\&4 Fans start through } \\
\text { VSDs } \\
\text { Exhaust Fans EF-5,6,7,8,9\&12 } \\
\text { start. }\end{array}$ & & \\
\hline 2 & $\begin{array}{l}\text { RF VOLUME } \\
\text { CONTROL }\end{array}$ & $\begin{array}{l}\text { 1. Verify RF Volume, utilizing air flow } \\
\text { meters in Retum Fans RF3\&4, } \\
\text { Supply Fans in AHU-3\&4 and Garage } \\
\text { Exhaust Fan EF-1, and TAB } \\
\text { established CFMs for Exhaust Fans } \\
\text { EF--5,6,7,8,9,12, TAB established } \\
\text { Fixed Differential, make the following } \\
\text { calculation: Return Air } \\
\text { Flow=1/2\{Supply Air Flow(AHU- } \\
\text { 3Flow+AHU-4 Flow) - EF5 Flow-EF6 } \\
\text { Flow-EF7 Flow-EF8 Flow-EF9 Flow- } \\
\text { EF-12 Flow--SF1 Flow-Fixed } \\
\text { Differential\} } \\
\text { 2. Trend Log RF3\&4, AHU } 3 \& 4 \text {, and } \\
\text { SF-1 air flow rates at } 5 \text { min. intervals. } \\
\text { Command off EF-5,6,7,8,9 and } 12 \\
\text { sequentially at } 5 \text { min. Intervals. }\end{array}$ & $\begin{array}{l}\text { Verify that RF air flow meter } \\
\text { readings continue to correspond } \\
\text { to calculation }\end{array}$ & & \\
\hline
\end{tabular}

Notes: 


\begin{tabular}{|c|c|c|c|c|c|}
\hline $\begin{array}{l}\text { Seq. } \\
\text { ID } \\
\text { From } \\
\text { Specs }\end{array}$ & Mode ID' & $\begin{array}{l}\text { Test Procedure } \\
\text { (including special conditions) }\end{array}$ & Expected Response ${ }^{4}$ & $\begin{array}{l}\text { Pass } \\
\text { Y/N }\end{array}$ & $\begin{array}{c}\text { Not } \\
0\end{array}$ \\
\hline 3 & $\begin{array}{l}\text { TEMPERATURE } \\
\text { CONTROL-- } \\
\text { ECONOMIZER }\end{array}$ & $\begin{array}{l}\text { 1. Utilizing BAS, Record OSA Temp. } \\
\text { and OSA Dewpoint. } \\
\text { 2. Calculate Enthalpy of OSA. } \\
\text { 3. Utilizing Enthalpy calculations, } \\
\text { reset DAT setpoint such that } \\
\text { Enthalpy of OSA is less than } \\
\text { Enthalpy of Supply Air at revised } \\
\text { conditions. }\end{array}$ & $\begin{array}{l}\text { Outdoor Air Dampers and } \\
\text { Return Air Dampers should } \\
\text { modulate in sequence to } \\
\text { maintain DAT setpoint. Cooling } \\
\text { Coil Valves should be closed. }\end{array}$ & & \\
\hline 3 & $\begin{array}{l}\text { TEMPERATURE } \\
\text { CONTROL--- } \\
\text { ECONOMIZER }\end{array}$ & $\begin{array}{l}\text { 1. Utilizing Enthalpy calculations } \\
\text { above, reset DAT setpoint such that } \\
\text { the Enthalpy of Supply Air is less } \\
\text { than that of OSA. } \\
\text { 2. Return to normal operation. } \\
\text { Utilizing BAS trend logging } \\
\text { capabilities, record OSA temperature, } \\
\text { Return Air Temperature, OSA } \\
\text { Dewpoint, DAT setpoint and DAT at } \\
15 \text { min intervals for an } 8 \text { hr. period }\end{array}$ & $\begin{array}{l}\text { OSA Dampers should close, } \\
\text { Return Air Dampers should } \\
\text { open, Chilled Water Coil Valves } \\
\text { should modulate to maintain } \\
\text { discharge Temp. } \\
\text { Unit should attempt to utilize } \\
\text { economizer cycle when possible } \\
\text { for cooling. }\end{array}$ & & \\
\hline$\overline{4}$ & $\begin{array}{l}\text { STATIC } \\
\text { PRESSURE } \\
\text { CONTROL }\end{array}$ & $\begin{array}{l}\text { Disable Static Pressure Reset } \\
\text { utilizing BAS Software. Adjust space } \\
\text { temperature setpoint on significant } \\
\text { quantity of zones to be well below } \\
\text { observed reading. }\end{array}$ & $\begin{array}{l}\text { Verify that VSD's modulate as } \\
\text { required to maintain SP setpoint } \\
\text { without hunting or overshooting } \\
\text { setpoint }\end{array}$ & & \\
\hline 4 & $\begin{array}{l}\text { HIGH STATIC } \\
\text { PRESSURE } \\
\text { ALARM AND } \\
\text { SHUTDOWN } \\
\end{array}$ & $\begin{array}{l}\text { With units running at low flow } \\
\text { condition, utilizing a squeeze bulb, } \\
\text { simulate an increase in discharge air } \\
\text { static pressure. }\end{array}$ & $\begin{array}{l}\text { Verify that BAS indicates an } \\
\text { alarm condition at } 3.6^{n} W G \text { and } \\
\text { shuts fans down at } 4^{n} W G\end{array}$ & & \\
\hline 4 & $\begin{array}{l}\text { STATIC } \\
\text { PRESSURE } \\
\text { RESET }\end{array}$ & $\begin{array}{l}\text { 1. For PerimeterTerminal Units on } \\
\text { floors 9-16, Reset space temperature } \\
\text { setpoints to be below space } \\
\text { temperatures. Utiliziing BAS trend } \\
\text { logging capablilities, Record at } 5 \text { min. } \\
\text { intervals, Discharge Air SP Spt, } \\
\text { Perimeter TU Units in saturation. } \\
\text { 2. Reset space temperature setpoints } \\
\text { to be above space temperatures. } \\
\text { Utilizing the same Trending as above, } \\
\text { Record the same data points. }\end{array}$ & $\begin{array}{l}\text { Verify that DA SP Spts increase } \\
\text { by } 0.10^{n} \text { WG at } 5 \text { min intervals } \\
\text { until only one Perimeter TU } \\
\text { remains in saturation. Verify } \\
\text { that setpoints are met and } \\
\text { maintained without excessive } \\
\text { hunting. } \\
\text { Verify that DA SP Spt decreases } \\
\text { by } 0.10^{n} W G \text { at } 5 \text { min intervals } \\
\text { until one Perimeter TU reaches } \\
\text { saturation. }\end{array}$ & & \\
\hline
\end{tabular}

Notes: 


\begin{tabular}{|c|c|c|c|c|c|}
\hline $\begin{array}{l}\text { Seq. } \\
\text { ID } \\
\text { From } \\
\text { Specs }\end{array}$ & Mode $I^{2}$ & $\begin{array}{l}\text { Test Procedure } \\
\text { (including special conditions) }\end{array}$ & Expected Response ${ }^{4}$ & $\begin{array}{l}\text { Pass } \\
\text { YN }\end{array}$ & $\begin{array}{c}\text { Not } \\
\text { e }\end{array}$ \\
\hline 5 & $\begin{array}{l}\text { DISCHARGE } \\
\text { TEMPERATURE } \\
\text { RESET }\end{array}$ & $\begin{array}{l}\text { 1. For Perimeter Terminal Units } \\
\text { Floors 9-16, Reset space sensor } \\
\text { setpoints to be above space } \\
\text { temperatures. Utilizing BAS Trend } \\
\text { Logging, at } 6 \text { min intervals, record } \\
\text { DAT setpoint, DAT, and perimeter TU } \\
\text { cooling Flow rates. } \\
\text { 2. For Perimeter Terminal Units } \\
\text { Floors } 9-16 \text {, Reset space sensor } \\
\text { setpoints to be below space } \\
\text { temperatures. Utilizing BAS Trend } \\
\text { Logging, at } 6 \text { min intervals, record } \\
\text { DAT setpoint, DAT, and perimeter TU } \\
\text { cooling Flow rates. }\end{array}$ & $\begin{array}{l}\text { Verify that Discharge Air } \\
\text { Temperature Setpoint is reset } \\
\text { upwards at } 2 \text { deg increments } \\
\text { every } 6 \text { min to maintain design } \\
\text { cooling CFM at } 5 \text { perimeter TUs } \\
\text { to maintain design cooling CFM } \\
\\
\text { Verify that Discharge Air } \\
\text { Temperature Setpoint is reset } \\
\text { downwards at } 2 \text { deg increments } \\
\text { every } 6 \text { min to reach design } \\
\text { cooling CFM at only } 5 \text { perimeter } \\
\text { Tus. Both should happen } \\
\text { without excessive hunting. }\end{array}$ & & \\
\hline 6 & $\begin{array}{l}\text { SMOKE } \\
\text { CONDITIONS }\end{array}$ & $\begin{array}{l}\text { Interfacing with EC, simulate a fire } \\
\text { mode with the Fire Alarm System }\end{array}$ & $\begin{array}{l}\text { Verify that AHU System returns } \\
\text { to FAN OFF Status., with OSA } \\
\text { and Relief Dampers in a Closed } \\
\text { Position. }\end{array}$ & & \\
\hline 7 & $\begin{array}{l}\text { WARMUP } \\
\text { CONTROL }\end{array}$ & $\begin{array}{l}\text { Place Units BAS Control Mode into } \\
\text { Warmup. Ovenwrite RAT Sensor } \\
\text { Reading to be } 65 \text { Deg. F. }\end{array}$ & $\begin{array}{l}\text { Verify that dampers assume a } \\
100 \% \text { Return Air Mode. }\end{array}$ & & \\
\hline 7 & $\begin{array}{l}\text { WARMUP } \\
\text { CONTROL }\end{array}$ & $\begin{array}{l}\text { Place Units BAS Control Mode in } \\
\text { Warmup. Overwrite RAT Sensor } \\
\text { Reading to be } 72 \text { Deg. F. }\end{array}$ & $\begin{array}{l}\text { Verify that unit returns to Normal } \\
\text { Operation Mode }\end{array}$ & & \\
\hline 11 & $\begin{array}{l}\text { FREEZE } \\
\text { CONDITION }\end{array}$ & $\begin{array}{l}\text { Overwrite Low Limit Detection } \\
\text { Thermostat reading to be } 38 \text { Deg. F. }\end{array}$ & $\begin{array}{l}\text { Verify that system alarms, fans } \\
\text { stop, OSA Dampers close, } \\
\text { Relief Dampers Close, and RA } \\
\text { dampers open. }\end{array}$ & & \\
\hline 13 & $\begin{array}{l}\text { RETURN FAN } \\
\text { STATIC } \\
\text { PRESSURE }\end{array}$ & $\begin{array}{l}\text { With AHU Units } 3 \& 4 \text { Units running at } \\
\text { low air flow condition, Overwrite RF } 3 \\
\text { or } 4 \text { return air fan inlet SP to a } \\
\text { reading below }-1.5^{\prime \prime} \text { W.G. }\end{array}$ & $\begin{array}{l}\text { Verify that system alarms and } \\
\text { that all Fans are shut down. }\end{array}$ & & \\
\hline
\end{tabular}

Notes: 


\begin{tabular}{|c|c|c|c|c|c|}
\hline $\begin{array}{l}\text { Seq. } \\
\text { ID } \\
\text { From } \\
\text { Specs }\end{array}$ & Mode ID ${ }^{2}$ & $\begin{array}{l}\text { Test Procedure } \\
\text { (including special conditions) }\end{array}$ & Expected Response ${ }^{4}$ & $\begin{array}{l}\text { Pass } \\
\text { YNN }\end{array}$ & $\begin{array}{c}\text { Not } \\
0\end{array}$ \\
\hline 14 & NIGHT PURGE & $\begin{array}{l}\text { With Units in Night Low Limit Mode, } \\
\text { Select a space temperature sensor at } \\
\text { random and overwrite this value to be } \\
82 \text { Deg. F. Overwrite OSA } \\
\text { temperature value to } 63 \text { Deg. F. } \\
\text { Overwrite Relief Air Temp. Sensor to } \\
\text { a value of } 82 \text { Deg. F., after } 15 \\
\text { minutes, Overwrite Rellef Air Temp } \\
\text { Sensor to a Value of } 75 \text { Deg. F. }\end{array}$ & $\begin{array}{l}\text { Verify that Unit Starts, Return } \\
\text { Air Dampers Close, Heating } \\
\text { Control Valves remain Closed, } \\
\text { OSA Dampers open, flushing } \\
\text { space with OSA, When Retum } \\
\text { Air Temperature reaches a value } \\
\text { of } 75 \text { Deg. F., Purge Cycle } \\
\text { should terminate, }\end{array}$ & & \\
\hline 15 & $\begin{array}{l}\text { MANUAL } \\
\text { SMOKE } \\
\text { PRESSURIZ. } \\
\text { SYSTEM }\end{array}$ & $\begin{array}{l}\text { With Fire Alarm System in alarm, } \\
\text { utilizing control panel in Fireman } \\
\text { Control Center, select a floor and } \\
\text { place floor into purge mode }\end{array}$ & $\begin{array}{l}\text { Verify that Single Fan operates, } \\
\text { lsolation dampers open only on } \\
\text { selected Fans, Return Fans are } \\
\text { off, Outside Air Handling Units } \\
\text { are off, OSA dampers open, and } \\
\text { retum air dampers close. }\end{array}$ & & \\
\hline B1 & $\begin{array}{l}\text { MIN OSA UNIT } \\
\text { FAN OFF }\end{array}$ & Command AHU-1\&2 System off & $\begin{array}{l}\text { Verify that AHU } 9 \& 10 \text { isolation } \\
\text { dampers are closed, and if OSA } \\
\text { temperature is above } 35 \text { Deg. } F \text {, } \\
\text { heating coil control valve is } \\
\text { closed. }\end{array}$ & & \\
\hline B1 & $\begin{array}{l}\text { MIN OSA UNIT } \\
\text { FAN OFF }\end{array}$ & $\begin{array}{l}\text { Simulate a OSA temperature below } \\
35 \text { Deg. F. }\end{array}$ & $\begin{array}{l}\text { Verify that heating coil control } \\
\text { valve opens }\end{array}$ & & \\
\hline $\mathrm{B} 2$ & $\begin{array}{l}\text { MIN OSA UNIT } \\
\text { TEMPERATURE } \\
\text { CONTROL }\end{array}$ & $\begin{array}{l}\text { Utilizing BAS software, reset } \\
\text { discharge air setpoint to } 80 \text { Deg. F. }\end{array}$ & $\begin{array}{l}\text { Verify that Face and Bypass } \\
\text { Dampers and Heating Coil } \\
\text { Control Valves modulate in } \\
\text { sequence to maintain } 80 \text { Deg. F. } \\
\text { Setpoint. }\end{array}$ & & \\
\hline \multirow[t]{3}{*}{ B3 } & $\begin{array}{l}\text { MIN OSA UNIT } \\
\text { FREEZE } \\
\text { CONDITION }\end{array}$ & $\begin{array}{l}\text { Simulate a condition at low limit } \\
\text { detection thermostat of below } 40 \\
\text { Deg. F. }\end{array}$ & $\begin{array}{l}\text { Verify that BAS system goes } \\
\text { into alarm, AHU } 7 \& 8 \text { Fans Shut } \\
\text { Down, AHU-7\&8 Isolation } \\
\text { Dampers Close, and Heating } \\
\text { Valve Opens. }\end{array}$ & & \\
\hline & $\begin{array}{l}\text { ON-FLOOR } \\
\text { RETURN FAN } \\
\text { OPERATION }\end{array}$ & $\begin{array}{l}\text { Place AHU-3\&4 in normal operating } \\
\text { mode }\end{array}$ & $\begin{array}{l}\text { Verify that RAF } 9-1,9-2,10-1,10- \\
2,11-1,11-2,12-1,12-2,13-1,13- \\
2,14-1,14-2,15-1,15-2 \text { Start and } \\
\text { Run }\end{array}$ & & \\
\hline & $\begin{array}{l}\text { AHU FILTER } \\
\text { DROP }\end{array}$ & $\begin{array}{l}\text { Reset the Filter Differential Pressure } \\
\text { to exceed the settting recommended } \\
\text { by the filter manufacturer. }\end{array}$ & $\begin{array}{l}\text { Verify that the BAS reports an } \\
\text { alarm. }\end{array}$ & & \\
\hline
\end{tabular}

Notes: 


\begin{tabular}{|c|c|c|c|c|c|}
\hline $\begin{array}{l}\text { Seq. } \\
\text { ID } \\
\text { From } \\
\text { Specs }\end{array}$ & Mode $I D^{2}$ & $\begin{array}{l}\text { Test Procedure } \\
\text { (including special conditions) }\end{array}$ & Expected Response ${ }^{4}$ & $\begin{array}{l}\text { Pass } \\
\text { YNN }\end{array}$ & Not \\
\hline- & $\begin{array}{l}\text { CHILLED } \\
\text { WATER VALVE } \\
\text { CLOSING } \\
\text { EFFICIENCY }\end{array}$ & $\begin{array}{l}\text { 1. Utilizing BAS, place AHU Units in } \\
\text { WARMUP Mode. } \\
\text { 2. Manually close isolation Valve in } \\
\text { Chilled Water Supply to AHU Coil. } \\
\text { 3. Place thermometer in Chilled } \\
\text { Water Retum Piping adjacent to } \\
\text { AHU. Record temp. at } 1 \text { min. } \\
\text { intervals for } 15 \text { min. } \\
\text { 4. Manually open isolation Valve in } \\
\text { Chilled Water Supply to AHU Coil. } \\
\text { 5. Repeat Step } 3 . \\
\text { 6. Graph Results on Temperature- } \\
\text { Time Basis. }\end{array}$ & $\begin{array}{l}\text { Chilled Water Return Temp. } \\
\text { should approach RAT. If } \\
\text { significant divergence is noted, } \\
\text { review specified performance } \\
\text { requirements of Chilled Water } \\
\text { Control Valves. }\end{array}$ & & \\
\hline- & $\begin{array}{l}\text { SUPPLYFAN } \\
\text { ISOLATION } \\
\text { DAMPER } \\
\text { FUNCTION }\end{array}$ & $\begin{array}{l}\text { Utilizing BAS, Command AHU-1, SF- } \\
1 \text { into the off position }\end{array}$ & $\begin{array}{l}\text { Verify that AHU-1, SF-1 Isolation } \\
\text { Dampers Close. }\end{array}$ & & \\
\hline & REVIEW & $\begin{array}{l}\text { Reveiw schedules, current setpoints } \\
\text { and sequences with Specification } \\
\text { Section } 15950-3.3 \mathrm{~A} \text { and Control } \\
\text { Drawings prepared by CC }\end{array}$ & $\begin{array}{l}\text { Submit approved differences to } \\
\text { be incorporated into as-buitts. }\end{array}$ & & \\
\hline
\end{tabular}

\section{Record Foot Notes}

Sequences of operation specified in Contract Documents (attached).

${ }^{2}$ Mode or function ID being tested from testing requirements section of the project Specifications.

${ }^{3}$ Step-by-step procedures for manual testing, trend logging or data-logger monitoring.

${ }^{4}$ Include tolerances for a passing condition.

${ }^{5}$ Record any permanently changed parameter values and submit to Owner.

\section{- END OF TEST -}

Notes: 


\section{Functional Performance Test}

\section{Air-Side Economizer}

Date:

Building Name:

Address:

Phone:

Equipment Name:

Manufacturer:

ECM No.

ECM Name:

New/Retrofit:

Testing Agent:

Assisted by:

\begin{tabular}{clll} 
Unit ID & AHU ID & Size (tons) & Zone \\
\hline 1 & - & - & \\
2 & - &
\end{tabular}

Documentation. Installation and user's manuals on site $(\mathrm{Y} / \mathrm{N})$ ?

Installation. Note any anomalies about the installations.

Space and OSA temperature sensors have been calibrated and OSA sensor located in open air, shaded, but not enclosed (where there may be heat buildup from the sun). (Y/N)?

Control Sequence Tests.

Unit 1 Unit 2 Unit 3 Unit 4

\section{General Information}

1. What is current space temperature setpoint?Cooling:

(enter: occupied / unoccupied) Heating:

Unit 1 Unit 2 Unit 3 Unit 4


3. What type of building pressure relief is there? (FL = fixed link to OSA damper, BD = barometric RA damper, $\mathrm{EF}=$ exhaust fan)

4. What are the current economizer setpoints (changeover temperatures)?

(If OSA is below this, econ. will open)Package setting:

(PK+ types will have both settings) EMS enable pt::

\section{Mode 1. Test Damper Position in AHU OFF Status}

1. Turn unit OFF.

2. Are dampers completely shut?

OSA:

Relief:

3. Is return damper at maximum open?

Does the system comply in this mode?

\section{Mode 2. Test Damper Position With AHU in ON Status; Compressor (or coil valve) and Econ. OFF}

1. Turn cooling setpoint to $85 \mathrm{~F}$.

2. Turn heating setpoint to $60 \mathrm{~F}$.

3. Turn unit ON.

4. Are dampers at a minimum?

OSA:

Relief:

5. Is return air damper at maximum open?

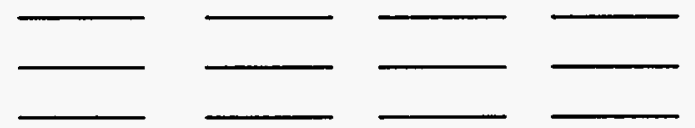

6. NO in either of the above two questions denotes noncompliance.

Does the system comply in this mode?

\section{Mode 3. Test Dampers in First Stage of Cooling (Econ. ON, Compressor or coil valve ON or OFF)}

1. Adjust economizer setpoint or EMS OSA temperature values so economizer will turn on if cooling is called for.

For DB economizers, OSA temp. must be, or be simulated to read by keyboard edit in EMS, below the economizer setpoint and above any DA low limit (usually $\sim 55^{\circ} \mathrm{F}$ if used). If OSA is too hot or too cold and there is no EMS system, use a wet rag or hair blower on OSA sensor OR come back at a time when OSA is appropriate, OR use jumper method of testing, OR use "canned" automatic testing sequence in unit, if any. The last two methods give only a partial assurrance that the economizer is functioning. For enthalpy type economizers, locate the enthalpy of the space air and the OSA on a psychometric chart. Simulate conditions for either so that the OSA has less enthalpy than the inside air or use alternate methods above.

Describe method used: 
2. Adjust cooling setpoint or space temp. until setpoint is $1^{\circ} \mathrm{F}$ below space temp. for integrated economizers (deadband $+1^{\circ}$ for integrated types). Record:

3. Cooling set point:

4. OSA temperatures (actual or simulated, circle): DB: (for enthalpy types) Wet bulb:

5. Space temperature (actual or simulated, circle): DB: (for enthalpy types) Wet bulb:

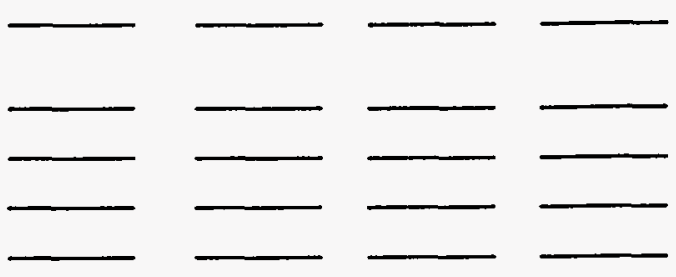

6. Do dampers open properly?

(Full open for dry bulb econ., partial for enthalpy type. If

OSA: OSA is below a functioning DA low limit, OSA damper Relief: will not be full open. Integrated economizers may not open full or at all in cold weather)

7. Is return air damper closing proportionately?

8. Any NO answers in the above two questions denote noncompliance.

Does the system comply in this mode?

\section{Mode 4. Test if Economizer Is Integrated (Economizer ON, Compressor} (or coil valve ON)

1. Continuing from Mode 3, did compressor come on?

(It is best if it doesn't)

2. If compressor does not come on, lower cooling setpoint $2^{\circ}$ at a time (or raise space temp.) until compressor comes on. (circle action taken)

3. What is the temp. of the changed parameter?

4. Do dampers stay open and not at min.?

(If Yes, its integrated)

Is RA proportionately closed?

OSA:

Relief:

RA:

5. Any NO answers in the last question denote noncompliance.

Does the system comply in this mode?

\section{Mode 5. Test if Dampers Go to Minimum When OSA is Above Economizer Setpoint}

1. Return economizer settings to original, if changed.

2. For DB type, lower econ. setpoint or heat up OSA sensor, or simulate OSA in EMS, until the OSA is $1^{\circ} \mathrm{F}$ above the economizer setpoint or changeover temperature. For enthalpy types, change conditions so that the space enthalpy on the psychometric chart is lower than the OSA enthalpy. If dampers don't close, increase OSA temp. until they do. 


\section{Unit 1 Unit 2 Unit 3 Unit 4}

3. Do dampers close to minimum?

OSA:

Relief:

4. Does the RA damper open to maximum?

5. What are the OSA temperatures being used to cause damper closure (this may be a real or simulated value)?

DB:

(for enthalpy types) Wet bulb:

6. Is the OSA DB temperature being used, within $2^{\circ}$ of what the economizer setpoint said it should be?

(use psychometric chart and manufacture's specs for enthalpy types)

7. For DB types, is this OSA temperature between $2-5^{\circ} \mathrm{F}$ below space temp. setpoint?

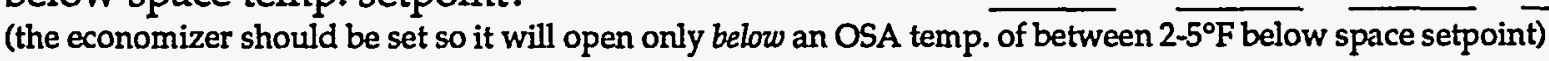

8. Any NO answers in the above five questions denote noncompliance. Does the system comply in this mode?

\section{Mode 6. Test if Dampers Go to Min. When Mixed Air Temp. (MAT) is Below Min. Setting}

1. Cool down MAT sensor, or simulate MAT in EMS, until it is below the MAT setting. ( 45$55^{\circ} \mathrm{F}$ )

2. Do dampers close to minimum?

OSA:

3. Does the RA damper open full?

Relief:

4. What is the MAT temperature being used to cause damper closure (this may be a real or an EMS simulated value)?

5. Is the MAT temperature being used within $2^{\circ}$ of what the specs say the setpoint temperature should be?

6. Any NO answers in the above three denote noncompliance.

Does the system comply in this mode?

Restore all adjustments to their original settings, unless desired as a permanent change. Make a permanent mark on any economizer local controllers showing where the appropriate setting should be. $\mathrm{Y} / \mathrm{N}$

Abbreviations: SA = supply air, RA = return air, DA = discharge air, OSA = outside air, EMS = energy management system 


\title{
Functional Test
}

Project:

FTCABINET UNIT HEATER CUH-1; 2

1. Participants

\author{
Related Tests: Boilers
}

Party

Participation

Party filling out this form and witnessing testing

Date of test

\section{Prerequisite Checklist}

a. The following have been started up and startup reports and prefunctional checklists submitted and approved ready for functional testing: __ CHU-1;2

b. Boilers $1 ; 2$ have successfully completed functional testing.

c. - All control system functions for this and all interlocking systems are programmed and operable per contract documents, including final setpoints, schedules, debugging, loop tuning and sensor calibrations complete.

\section{Controls Contractor Signature or Verbal $\quad \overline{\text { Date }}$}

d. _ All A/E punchlist items for this equipment corrected.

e. - Safeties and operating ranges reviewed.

f. - Test requirements and sequences of operation attached.

g. - Schedules and setpoints attached.

h. - Have all energy savings control strategies, setpoints and schedules been incorporated that this equipment and control system are capable of? If not, list recommendations below.

i. - BAS Program Review. Review the BAS software control program(s) for this equipment. Parameters, setpoints and logic sequences appear to follow the specified written sequences.

j. _ Packaged Control Program Review. Review the packaged control program(s) for this equipment. Parameters, setpoints and logic sequences appear to follow the specified written sequences.

k. - Record of All Values for Current Setpoints (SP), Control Parameters, Limits, Delays, Lockouts, . . Schedules, Etc. Changed to Accommodate Testing:

\begin{tabular}{|l|l|l|l|l|l|}
\hline \multicolumn{1}{|c|}{ Parameter } & $\begin{array}{c}\text { Pre-Test } \\
\text { Values }\end{array}$ & $\begin{array}{c}\text { Returned to } \\
\text { Pre-Test } \\
\text { Values V }\end{array}$ \\
\hline CUH-1 ON setpoint & & & Parameter & $\begin{array}{c}\text { Pre-Test } \\
\text { Values }\end{array}$ & $\begin{array}{c}\text { Returned to } \\
\text { Pre-Test } \\
\text { Values } \sqrt{ }\end{array}$ \\
\hline CUH-1 OFF setpoint & & & & \\
\hline CUH-2 ON setpoint & & \\
\hline CUH-2 OFF setpoint & & \\
\hline
\end{tabular}

Notes: 
3. Sensor Calibration Checks. Check the sensors listed below for calibration and adequate location. This is a sampling check of calibrations done during prefunctional checklisting. Test the packaged controls and BAS readings.

"In calibration" means making a reading with a calibrated test instrument within 6 inches of the site sensor. Verify that the sensor reading (via the permanent thermostat, gage, packaged control panel or building automation system (BAS)) compared to the test instrument-measured value is within the tolerances specified in the prefunctional checklist requirements

\begin{tabular}{|l|c|l|l|l|l|}
\hline Sensor \& Location & $\begin{array}{c}\text { Loc- } \\
\text { ation } \\
\text { OK }^{1}\end{array}$ & $\begin{array}{c}\text { 1st Gage or } \\
\text { Pkg \& BAS } \\
\text { Values }\end{array}$ & $\begin{array}{c}\text { Instru. } \\
\text { Meas'd } \\
\text { Value }\end{array}$ & $\begin{array}{c}\text { Final Gage or } \\
\text { Pkg \& BAS } \\
\text { Values }\end{array}$ & $\begin{array}{c}\text { Pass } \\
\text { Y/N? }\end{array}$ \\
\hline \hline CUH-1;2 stat temp. & & Stat: & & Stat: & \\
\hline
\end{tabular}

${ }^{1}$ Sensor location is appropriate and away from causes of erratic operation.

\section{Device Calibration Checks.}

\section{-NONE--}

\section{Verification of Misc. Prefunctional Checks.}

Misc. site checks of the prefunctional checklist and startup reports completed successfully. Pass? Y / N _ Unit mounted securely. __ Unit accessible for servicing. _ No unusual noise or vibration in fan.

\section{Functional Testing Record}

\begin{tabular}{|c|c|c|c|c|}
\hline $\begin{array}{l}\text { Proced. } \\
\text { No. \& } \\
\text { Spoc. } \\
\text { Seq. ID' }\end{array}$ & $\begin{array}{c}\text { Req ID } \\
\text { No. }^{2}\end{array}$ & $\begin{array}{l}\text { Test Procedure } \\
\text { (including special conditions) }\end{array}$ & $\begin{array}{c}\text { Expected and Actual Response } \\
\text { [Write ACTUAL response in } \\
\text { brackets or circle] }\end{array}$ & $\begin{array}{c}\text { Pass } \\
\text { Y/N } \\
\text { \& Note } \\
\# \\
\end{array}$ \\
\hline \multirow[t]{3}{*}{$\begin{array}{c}1 \\
\text { Seq. } 1\end{array}$} & & $\begin{array}{l}\text { Adjust CUH-1 ON setpoint until it is } 1 \mathrm{~F} \\
\text { above the space temp. }\end{array}$ & 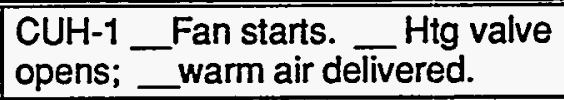 & \\
\hline & & $\begin{array}{l}\text { Adjust CUH-2 ON setpoint until it is } 1 \mathrm{~F} \\
\text { above the space temp. }\end{array}$ & $\begin{array}{l}\text { CUH-2__Fan starts. } \quad \text { Htg valve } \\
\text { opens; _ warm air delivered. }\end{array}$ & \\
\hline & & $\begin{array}{l}\text { Adjust CUH-2 OFF setpoint until it is } 1 F \\
\text { below the space temp. }\end{array}$ & $\begin{array}{l}\text { CUH-2__Fan stops. _ _ Htg valve } \\
\text { closes. }\end{array}$ & \\
\hline $\begin{array}{c}2 \\
\text { Seq. } 1\end{array}$ & & $\begin{array}{l}\text { Adjust CUH-1 OFF setpoint until it is } 1 F \\
\text { below the space temp. }\end{array}$ & $\begin{array}{l}\text { CUH-1__Fan stops. _ Htg valve } \\
\text { closes. }\end{array}$ & \\
\hline 3 & - & $\begin{array}{l}\text { Return all changed control parameters } \\
\text { and conditions to their pre-test values }\end{array}$ & $\begin{array}{l}\text { Check off in Section } 2 \text { above } \\
\text { when completed }\end{array}$ & \\
\hline
\end{tabular}

Record Foot Notes

'Sequences of operation specified in Contract Documents (attached).

${ }^{2}$ Mode or function ID being tested, per testing requirements section of the project Specifications.

${ }^{3}$ Step-by-step procedures for manual testing, trend logging or data-logger monitoring.

${ }^{4}$ Include tolerances for a passing condition.

${ }^{5}$ Record any permanently changed parameter values and submit to Owner.

- END OF TEST -

Notes: 
Chiller System Sequences

\title{
Chilled Water System Sequence of Operations
}

\author{
Original 10/2/96 Sequence 6, CHWST Reset Revised 11/2/96
}

\section{Overview}

The chiller system is comprised of three chillers: two larger centrifugals ( $\mathrm{CH}-1$ and 2) with good part load efficiency down to $25 \%$ and one reciprocating chiller (CH-3) about $1 / 3$ the size of the centrifugals which has excellent part load efficiencies with eight stages of unloading. ${ }^{1}$ There is no automatic chiller staging/selection optimization controls. The preferred sequence of chiller staging may vary by season. The primary pumps and condenser pumps run at constant flow. There is a secondary chilled water supply loop with variable speed drives on the pumps controlled from differential pressure, which is reset incrementally to operate at the lowest speed and pressure possible to satisfy the current load. There are three cooling towers, each assigned to one chiller. There is also a heat exchanger in the condenser water loop that rejects heat from ACU-1-10 and CRU-1, which requires the lead cooling tower to operate year-round. The building automation system (BAS) controls many of the chiller functions and setpoints and just enables others, and monitors a number of points through the chiller interface. BAS in brackets denotes where the BAS has control over the setting or parameter, rather than the local chiller packaged control panel.

${ }^{3}$ Including pump energy, at high loads (75\% - $100 \%$ of chiller capacity) the centrifugals are more efficient, at $50 \%$ the centrifugals and reciprocating chillers are about equal and at $25 \%$ load the reciprocating chiller is more efficient. Since $25 \%$ load on the small CH-3 is expected to rarely be encountered for any period of time, $\mathrm{CH}-1$ and 2 should primarily be used.

\section{Chillers (CH-1, 2; 3)}

1. Software [BAS] lead lag selector to allow any of the chillers to act as the lead machíne.

2. Chiller will only be enabled to operate in AUTO upon the following conditions:

a) Chiller scheduled ON [by BAS]

b) OSAT > 56F [BAS]

c) There are no active alarms that initiate a shutdown (reported to BAS and chiller panel)

d) The chiller sump temperature is above its minimum [BAS and chiller panel]

e) There is a call for cooling [BAS]

f) Chilled and condenser water flows are verified [BAS and chiller panel]

3. Upon a call for cooling ${ }^{2}$, the lead primary CHW pump starts and the pump status is confirmed ON via a current sensor in the BAS and flow is confirmed through a flow switch. Then the assigned lead chiller oil pump starts, then the lead condenser water pump starts and the pump status is confirmed $O N$ via a current sensor in the BAS and flow is confirmed through a flow switch. There are 30-60 second delays between these pumps, per the chiller integral programmed settings (adjustable). The lead secondary CHWP then starts, ramping up from the minimum RPM of via the variable frequency drive (VFD), [per BAS or VFD??]

${ }^{2}$ A call for cooling is when a cooling coil valve (CCV) on one of the ON AHU's (AHU 1, 2, 3 or 4) is at least $15 \%$ open for at least 10 minutes. It is noted that the chiller packaged controls designate a call for cooling to be when the CHWST SPt is $\underline{\mathrm{xx}}$ degrees lower than actual CHWT. This is inactive by being set to 0 .

4. The lead chiller then starts with the prerotation vanes closed, which begin to open (closed to full open in $\sim 3$ minutes and full open to closed in $\sim 1$ minute). 
5. The chiller maintains the CHW supply temperature at the setpoint [BAS] which ranges from $42 \mathrm{~F}$ to $48 \mathrm{~F}$, based on a reset schedule, by modulating chiller capacity. $\mathrm{CH}-1$ and $\mathrm{CH}-2$ utilize prerotation vanes for capacity control, while the reciprocating chiller, $\mathrm{CH}-3$, utilizes 8 stages of unloading.

6. Chilled water supply temperature (CHWST) reset [BAS]. The CHWST will have a default of 44F. The chilled water temperature will be reset only when the secondary pumps' speeds are at their minimum (as described in sequence 33). This is because, lowering pump speed with the differential pressure reset strategy (sequence 33) will save more energy than resetting the chilled water temperature up, per ton of cooling. When the pump speed is at its minimum allowed, start the CHWST reset routine and continue it until one or more pumps are above their minimum speed, then hold the CHWST setpoint where it is until the pumps are at their minimums. Include a differential or time delay to prevent hunting. When enabled, the CHWST reset sequence is: when all CCV's are less than $90 \%$ open, the CHWST setpoint (SPt) is at its highest value of a proportional range (48F). When three or more CCVs are $90 \%$ or more open, the CHWS SPt is at its lowest value (42F).

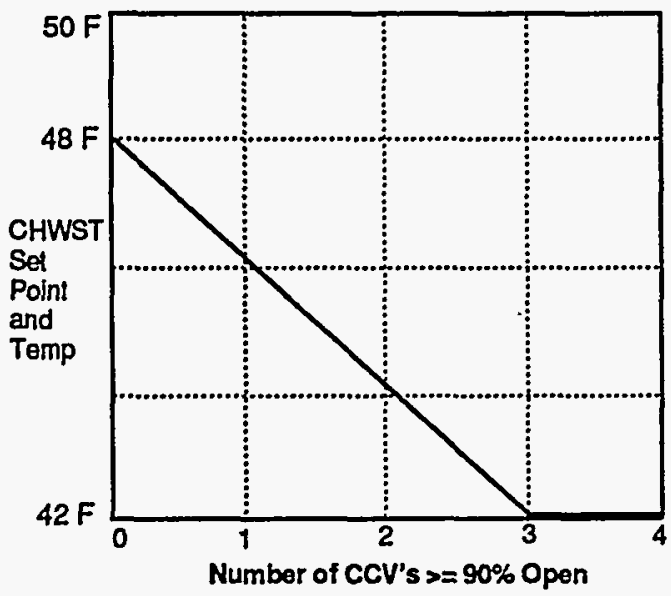

7. The CHWST reset will not increase when the return air relative humidity rises above $50 \%$ [BAS].

8. Chiller Staging. [All in BAS] There is no automatic chiller staging/selection optimization controls. The first lag chiller will be called for whenever the secondary CHW flow exceeds the primary CHW flow for 20 minutes (adjustable) as determined by flow meters AND the lead chiller is $95 \%$ loaded (by $\%$ of rated current). ${ }^{1}$ For reference, each secondary $\mathrm{CHW}$ pump is design rated at $765 \mathrm{gpm}$. After a call has been maintained for the 20 minutes, the first lag chiller and pump sequence start as described above for the lead chiller. The second lag chiller will start under the same conditions and sequences. Whenever a lag chiller starts, all running chillers load and unload as necessary to be running within 5\% of the same \% load (based on rated current).

${ }^{1}$ This $95 \%$ load parameter will allow CH-3 to operate as the lead chiller, if desired, up to its full load before the much larger chillers (CH-1 and 2) start, since there is such a difference in primary CHW flow between $\mathrm{CH}-1$ or 2 and $\mathrm{CH}-3$, but no difference in the secondary $\mathrm{CHW}$ pump flows for the different chillers.

9. The last selected lag chiller and associated pumps stage OFF when the total primary CHW flow exceeds the total secondary CHW flow by the capacity (flow) of the last selected chiller's primary CHW pump for a 20 minute duration (adjustable).

10. All chillers and pumps will turn OFF when OSAT is $\angle 55^{\circ} \mathrm{F}$ for minutes [BAS], OR when all CCV's are less than $15 \%$ open for 10 minutes [BAS], OR when all air handlers are OFF [BAS], OR when an unoccupied schedule occurs (subject to night low limit conditions not being met) [BAS], OR when failure alarms are registered (BAS and chiller controls). 


\section{Misc. Chiller Features}

11. Chillers will not cycle ON and OFF more than three times in a one hour period (chiller controls).

12. Alarm on chiller failure. Failure alarms must be manually reset. See other alarm modes in chiller operator's manual [alarms created by chiller controls, shutdown by chiller controls, message sent to BAS].

13. Demand limiting. [BAS] Demand limiting setpoint adjustment may be made through building automation system [BAS]. The demand limit (in sum of all chillers $\mathrm{kW}$ ), when met will delay the start of the next chiller for one hour (adjustable). This sequence is different than the disabled stock sequence in the chiller packaged controls.

14. The BAS will monitor $\mathrm{kW}$ and calculate the load on the chiller using evaporator $\mathrm{CHW}$ flow and temperature differentials [BAS].

15. Provide emergency stop switch located adjacent to chiller room mandoor exit to stop all equipment in chiller room, except ventilation system. Ventilation fan to automatically operate on purge mode with activation of emergency stop switch.

\section{Primary Chilled Water Pumps (CHWP 1, 2, 3 for CH-1 \& 2 and CHWP 4; 5 for CH-3)}

16. Each primary $\mathrm{CHW}$ pump is assigned to one chiller [BAS]. Lead primary $\mathrm{CHW}$ pump starts upon a call for cooling per above chiller sequences. Lag primary CHW pump starts upon a call for the lag chiller per above chiller sequences [BAS]

17. Primary $\mathrm{CHW}$ pumps to operate continuously when their associated chiller is running. Primary $\mathrm{CHW}$ pumps provide constant flow through the chiller according to the manufacturer's recommendations: $675 \mathrm{gpm}$ for $\mathrm{CH}-1$ and $\mathrm{CH}-2$ and $180 \mathrm{gpm}$ for $\mathrm{CH}-3$. Check balancing report for finals.

18. A standby (redundant) primary $\mathrm{CHW}$ pump is provided for $\mathrm{CH}-1$ and 2 together and can be operated as active pumps after opening manual valves. A standby primary $\mathrm{CHW}$ pump for $\mathrm{CH}-3$ will automatically change over [detected by BAS and chiller controller; pump control by BAS].

19. a) CHWP 1, 2; 3: Alarm on pump failure detected via a motor current switch and flow switch. Upon failure of lead pump, chiller shuts down and lag chiller should start automatically to meet load [BAS]. b) CHWP 4; 5: Alarm on pump failure detected via a motor current switch and flow switch. Upon failure of lead pump, standby pump automatically starts [detected by BAS and chiller controller; pump control by BAS].

\section{Chiller Condenser Water Pumps (CDP 1, 2, 3, 4; 5)}

20. $\mathrm{CD}$ pumps $\mathrm{CDP} 1,2,3$ for $\mathrm{CH}-1$ and $\mathrm{CH}-2$ and $\mathrm{CDP} 4$, and 5 for $\mathrm{CH}-3$ to operate continuously when their associated chiller is running. $C D$ pumps provide constant flow through the chiller condenser according to the manufacturer's recommendations: $1350 \mathrm{gpm}$ for $\mathrm{CH}-1$ and $\mathrm{CH}-2$ and $360 \mathrm{gpm}$ for $\mathrm{CH}-3$.

21. A standby (redundant) $\mathrm{CD}$ pump is provided for $\mathrm{CH}-1$ and 2 together. The pumps can be operated as active pumps after opening manual valves. A standby pump is provided for $\mathrm{CH}-3$ and will automatically changeover [BAS].

22. a) CDP 1,$2 ; 3$ (CH-1;2): Alarm on pump failure detected via a motor current switch and flow switch. Upon failure of lead pump, chiller shuts down and lag chiller should start automatically to meet 
load [detected by BAS and chiller controller; pump control by BAS].

b) CDP 4; 5 (CH-3): Alarm on pump failure detected via a motor current switch and flow switch. Upon failure of lead pump, standby pump automatically starts [detected by BAS and chiller controller; pump control by BAS].

\section{Cooling Tower (CT-1, 2; 3)}

21. Cooling towers operate with operation of their associated condenser water pump. With operation of a pump, open selected tower supply valve and allow tower temperature control to function [BAS].

22. Software selector to allow any tower to be the lead tower, second tower or third tower [BAS].

23. CT Sequences. [All BAS] The CT during the normal cooling season rejects heat from the chillers and returns as cool of water as possible to the chiller's condenser, down to $65^{\circ} \mathrm{F}$. The CT will try and maintain a $65^{\circ} \mathrm{F}$ return temperature (ECDWT) by first modulating the normally open bypass valve, with no water going over the top of the tower. When the valve is full open AND the ECDWT is greater than the ECDWT setpoint $\left(65^{\circ} \mathrm{F}\right)$, the bypass valve begins to close and the normally closed CT control valve associated with the respective $\mathrm{CT}$ and $\mathrm{CDW}$ pump, opens $100 \%$ and water goes over the respective CT. The bypass valve continues to modulate open to try and maintain the ECDWT setpoint without the CT fans. When the ECDWT reaches $69^{\circ} \mathrm{F}$, the bypass valve will be fully closed and the pony motor CT fan turns ON. When the ECDWT reaches $73^{\circ} \mathrm{F}$, the main CT fan turns ON. As the ECDWT decreases, the main fan turns OFF at $69^{\circ} \mathrm{F}$ and the pony motor fan turns OFF at ECDWT of $65^{\circ} \mathrm{F}$. All parameters are adjustable. There is an eight minute delay between each stage.

\begin{tabular}{|c|c|c|}
\hline \multirow[b]{2}{*}{ Fan Spd } & \multicolumn{2}{|c|}{ ECDWT } \\
\hline & ON ( $\left.{ }^{\circ} \mathrm{F}\right)$ & $\mathrm{OFF}\left({ }^{\circ} \mathrm{F}\right)$ \\
\hline OFF & $<69$ & $\ldots$ \\
\hline \multicolumn{3}{|c|}{ (modulation of bypass valve) } \\
\hline *Low & 69 & 65 \\
\hline *High & 73 & 69 \\
\hline
\end{tabular}

24. When a lag chiller comes on line, its condenser water pump and associated CT come on line [BAS].

25. A multiple position CT sump or basin level sensor provides the following information to the BAS:
a) High water alarm
b) Low water alarm
c) Open make up water valve
d) Closed make up water valve
e) System shutdown

Alarm on heatér stage failure detected via current sensing switch.

26. Cooling tower sump two stage heaters shall be controlled to maintain a sump temperature of $45^{\circ} \mathrm{F}$ with the following schedule [BAS]:

\begin{tabular}{lll} 
& \multicolumn{1}{c}{ ON $\left({ }^{\circ} \mathrm{F}\right)$} & OFF $\left({ }^{\circ} \mathrm{F}\right)$ \\
\cline { 3 - 3 } Stage 1 & 45 & 43 \\
Stage 2 & 47 & 45
\end{tabular}

Each CT basin has a temperature sensor and separate??? heaters.

27. Cooling tower makeup valve (one for all three CT's) to maintain sump water level. Upon sensing a drop in water level, slowly open makeup valve in industrial cold water line [level sensor by BAS]. 
28. Alarm on pony and main motor upon motor failure detected via current sensing relay. Upon failure of fan motor, lag CT starts automatically [BAS].

29. Alarm on excessive vibration detected via vibration limit switch. Upon failure of fan, lag CT starts automatically [BAS].

30. The lead cooling tower operate during periods, when the chillers are OFF (even during winter) to maintain a heat rejection source for the heat exchanger $\mathrm{HE}-1$, which serves approximately 40 tons of cooling from ACU-1 thru 10 and CRU-1. See sequences for CDP 6, 7, 8; 9.

\section{Secondary Chilled Water Pumps (CHWP 6, 7;8)}

31. Software lead/lag function allows any of the secondary pumps to act as the lead pump [BAS].

32. Lead secondary CHW pump starts upon a call for cooling per above chiller sequences. Lag secondary CHW pump starts upon a call for the lag chiller per above chiller sequences [BAS].

33. Differential pressure control. [All BAS] The objective is to always have one CCV $80 \%$ open so the pumps operate at the lowest speed and pressure possible to satisfy the current load. Every 5 minutes the CCV's are polled. A PI loop that changes the secondary pump discharge differential pressure setpoint to maintain the remote (local on 8th floor) DP setpoint to maintain the most open CCV at $80 \%$ open (with a deadband of $+/-$ ). For example: When the most open CCV is more than $80 \%$ open, a PI signal is calculated and changes the local DP setpoint upward. When the local DP setpoint is not being met, a PI signal is calculated and sent to the pump discharge pressure setpoint and it is raised accordingly. Through another PI loop, the variable speed (frequency) drive (VFD) increases the pump motor speed to meet the raised pump differential (discharge) pressure setpoint.

The remote DP setpoint will be maintained between maximum and minimum pressures. The maximum pressure limit is the pressure required to provide full flow to all CCV's simultaneously (per TAB). The minimum pressure limit is the pressure correlating to the lowest speed the pump motor is allowed to be operated at (per motor manuf. and TAB). Maximum pressure limit: psi. Mininum pressure limit: psi.

The VFD internal settings will allow the VFD to run the pumps to their minimums. Number of remote DP sensors: Locations:

34. Pump Staging. [BAS] With one secondary CHW pump running, when the total secondary CHW gpm exceeds the lead secondary $\mathrm{CHW}$ pump design gpm AND the discharge differential pressure drops more than 2 psi below the setpoint for 10 minutes (all adjustable), start the first lag pump. Both pumps converge and run at similar speeds and gpm to maintain the common discharge pressure differential setpoint and the remote DP setpoints. If the total secondary gpm exceeds the total design gpm of the running pumps (lead and 1st lag) AND the discharge differential pressure drops more than 2 psi below the setpoint for 10 minutes, start the second lag pump. All three pumps converge and run at similar speeds and gpm to maintain the common discharge pressure differential setpoint and the remote DP setpoints.

35. During reducing load as the DP increases: when the total secondary CHW gpm has reduced to be equal to or less than the sum of the first two selected pumps' gpm for 10 minutes (adjustable), the second lag secondary CHW pump shuts OFF. Similarly, when the total secondary CHW gpm, with two pumps $\mathrm{ON}$, has reduced to be equal to or less than the gpm of the lead CHW pump for 10 minutes, the first lag pump shuts OFF. 
36. The controller shall monitor rpm and gpm of the pumps and shall not allow operation of the pumps at or beyond their published "End of Curve" [BAS].

37. Alarm on pump failure detected via current sensing switch. Upon failure of pump, next lag pump starts automatically (BAS and chiller controller).

38. Alarm on failure of VFD [BAS].

39. The rpm of secondary CHW pumps to be monitored by BAS.

40. For coil freeze protection during smoke exhaust system operation, pumps CHWP-6, 7; 8 to run under NORMAL control and all cooling coil valves to open with operation of respective AHU when smoke exhaust system (EF-10) is in operation AND outside air temperature is below $40^{\circ} \mathrm{F}$ [BAS].

\section{ACU Condenser Water Pumps (CDP 6, 7 and 8; 9) and HE-1}

41. The lead cooling tower operates during periods, when the chillers are OFF (even during winter) to maintain a heat rejection source for the heat exchanger HE-1, which serves approximately 40 tons of cooling from ACU-1 thru 10 and CRU-1. CDP 6 or 7 (one is redundant) provides water from the heat exchanger to the cooling towers. CDP 8 or 9 (one is redundant) services the ACU's and CRU-1 from HE-1. The selected CD pump for each loop (CDP 6 or 7 AND 8 or 9) operate continuously [BAS].

42. During chiller OFF periods, the ECDWT setpoint and CT bypass valve and fan staging parameters remain the same as during chiller ON periods (see above).

43. Alarm on pump failure detected via current sensing switch. Upon failure of any pump, standby pump automatically starts [BAS].

\section{General Chiller Operation During Unoccupied Periods}

44. Unoccupied Operation. During scheduled unoccupied hours at night or weekends, the chiller system is in standby, except the cooling tower operates as required to maintain $65^{\circ} \mathrm{F}$ condenser water to the heat exchanger HE-1 for heat rejection of ACU-1 thru 10 and CRU-1.

45. Winter Operation. During winter, the chiller system is in standby, except the cooling tower operates as required to maintain $65^{\circ} \mathrm{F}$ condenser water to the heat exchanger HE-1 for heat rejection of ACU-1 thru 10 and CRU-1. 


\section{Functional Test}

Project

FT-01-01 CHILLERS 1 thru 3

And Chiller System Including:

Cooling Towers 1 thru 3

CHW Pumps 1 thru 8, including variable speed drives

CD Pumps 1 thru 9 and Piping

HE-1 (heat exchanger)

Related Tests:

1. Participants

Party

Participation

Party filling out this form and witnessing testing

Dates of tests

Dates of tests

Dates of tests

Dates of tests

\section{Test Prerequisites}

a. - The following have been started up and startup reports* and prefunctional checklists submitted and approved ready for functional testing:

_ Chiller

- Chilled water pumps

_ Cooling towers
_Condenser water pumps

- Chilled water piping and valves

_ Variable speed drives for pumps

*The written chiller startup report must contain a full listing of all adjustable internal program settings.

Notes: 
b. All control system functions for this and all interlocking systems are programmed and operable per contract documents, including final setpoints and schedules and with debugging, loop tuning and sensor and device calibrations completed.

$$
\text { Controls Contractor Signature or Verbal }
$$

c. Piping system flushing complete and required report approved.

d. - Water treatment system complete and operational.

e. - Vibration control report approved (if required).

f. - Test and balance (TAB) complete and approved for the hydronic system.

g. - All A/E punchlist items for this equipment corrected.

h. - These functional test procedures reviewed and approved by installing contractor.

i. - Safeties and operating ranges reviewed.

j. - Test requirements and sequences of operation attached.

k. - Schedules and setpoints attached.

1. - False loading equipment, system and procedures ready (cross-over piping, preheat or reheat coils, control loops, over-ride on OSA dampers, etc.)

m. - Sufficient clearance around equipment for servicing.

n. _ Sump or crankcase heaters have been on long enough to allow immediate starting of chillers.

o. - Have all energy savings control strategies, setpoints and schedules been incorporated that this chiller and control system are capable of? If not, list recommendations below.

p. Control Program Review. Review the software control program(s) for this equipment. Parameters, setpoints and logic sequences appear to follow the specified written sequences.

Notes: 
q. L Record made of All Values for Current Setpoints (SPt), Control Parameters, Limits, Delays, Lockouts, Schedules, Etc. Changed to Accomodate Testing:

\begin{tabular}{|c|c|c|}
\hline Parameter & $\begin{array}{l}\text { Pre-Test } \\
\text { Values }\end{array}$ & $\begin{array}{l}\text { Retumed } \\
\text { to Pre-Test } \\
\text { Values } V\end{array}$ \\
\hline Space Temp. Setpts & & \\
\hline $\begin{array}{l}\text { Economizer damper } \\
\text { and changeover } \\
\text { settings }\end{array}$ & & \\
\hline $\begin{array}{l}\text { Preheat coil valve } \\
\text { (auto, manual) }\end{array}$ & & \\
\hline $\begin{array}{l}\text { Min. OSA preheat } \\
\text { coil DAT setpoint }\end{array}$ & & \\
\hline $\begin{array}{l}\text { Boiler enable, } \\
\text { heating water temp. } \\
\text { etc. }\end{array}$ & & \\
\hline CHWS SPt temp & & \\
\hline $\begin{array}{l}\text { Lead chiller ID: } \\
\text { Lag } 1 \text { ID: } \\
\text { Lag } 2 \text { ID: }\end{array}$ & & \\
\hline
\end{tabular}

\begin{tabular}{|c|c|c|}
\hline Parameter & $\begin{array}{c}\text { Pre-Test } \\
\text { Values }\end{array}$ & $\begin{array}{l}\text { Returned } \\
\text { to Pre-Test } \\
\text { Values } \sqrt{ }\end{array}$ \\
\hline $\begin{array}{r}\text { Primary CHW Pumps } \\
\text { CHWP-1 } \\
\text { CHWP-2 } \\
\text { CHWP-3 } \\
\text { CHWP-4 } \\
\text { CHWP-5 } \\
\text { (hand, off, auto) }\end{array}$ & & \\
\hline $\begin{array}{l}\text { Manual piping \& } \\
\text { valving for standby } \\
\text { PCHWP }\end{array}$ & & \\
\hline $\begin{array}{l}\text { EF-10 } \\
\text { (hand, off, auto) }\end{array}$ & & \\
\hline $\begin{array}{l}\text { Secondary } \text { CHW } \\
\text { Pumps } \\
\\
\text { CHWP-6 } \\
\text { CHWP-7 } \\
\text { CHWP-8 } \\
\text { (hand, off, auto) }\end{array}$ & & \\
\hline $\begin{array}{r}\text { Condenser Pumps } \\
\text { CDP-1 } \\
\text { CDP-2 } \\
\text { CDP-3 } \\
\text { CDP-4 } \\
\text { CDP-5 } \\
\text { CDP-6 } \\
\text { CDP-7 } \\
\text { CDP-8 } \\
\text { CDP-9 }\end{array}$ & - & \\
\hline $\begin{array}{lr}\text { VFD } & \text { CHWP-6 } \\
& \text { CHWP-7 } \\
\text { CHWP-8 } & \\
& \text { (hand, off, auto) }\end{array}$ & & \\
\hline $\begin{array}{ll}\text { Demand Limit } & \\
& \mathrm{CH}-1: \\
& \mathrm{CH}-2: \\
& \mathrm{CH}-3:\end{array}$ & & \\
\hline
\end{tabular}

Notes: 


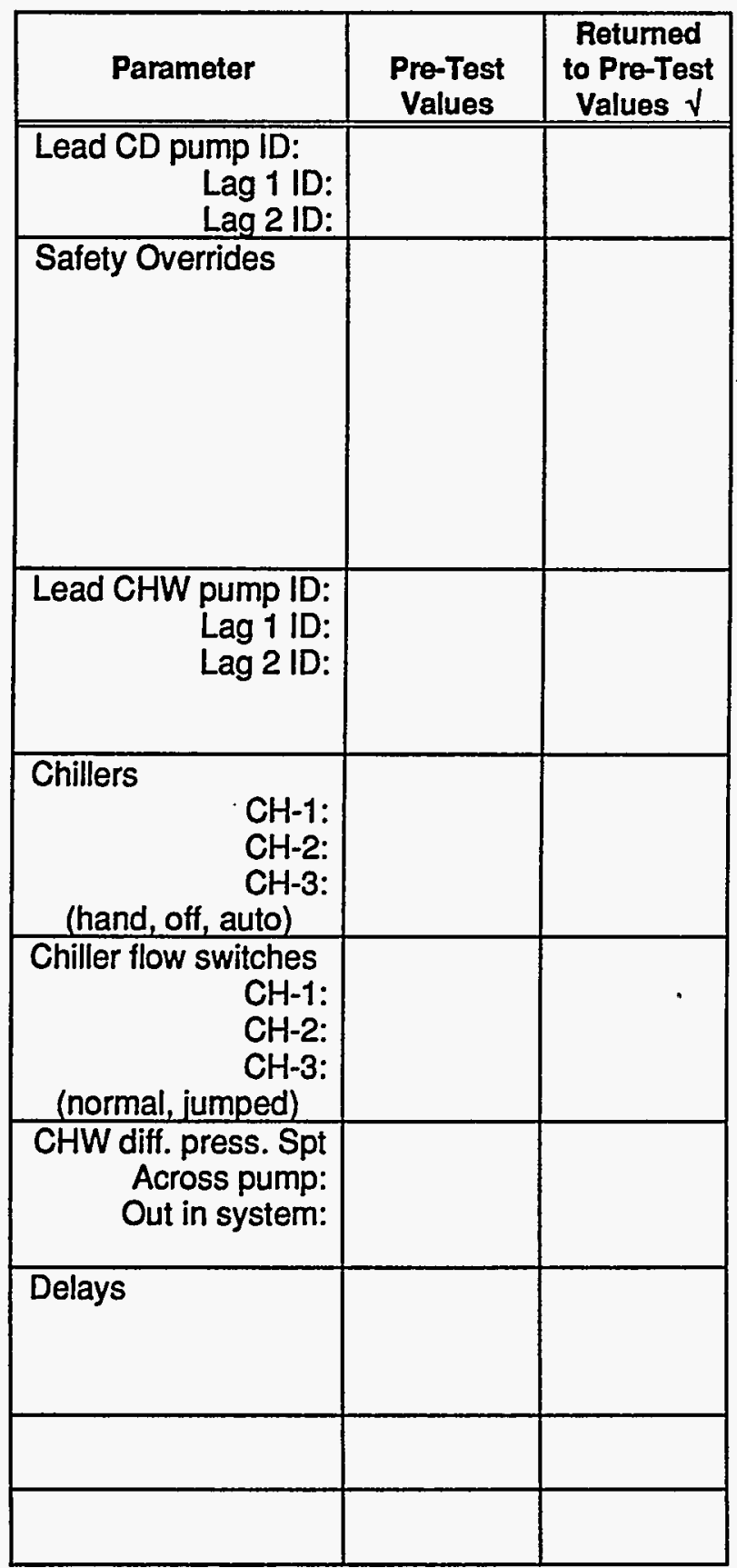

\begin{tabular}{|c|c|c|}
\hline Parameter & $\begin{array}{c}\text { Pre-Test } \\
\text { Values }\end{array}$ & $\begin{array}{l}\text { Returned } \\
\text { to Pre-Test } \\
\text { Values } \sqrt{ }\end{array}$ \\
\hline $\begin{array}{l}\text { CT tans } \\
\qquad \begin{array}{r}\text { CT-1 } \\
\text { CT-2 } \\
\text { CT-3 }\end{array} \\
\text { (hand, off, auto) }\end{array}$ & & \\
\hline $\begin{array}{r}\text { CT vibration sensors } \\
\text { CT-1 } \\
\text { CT-2 } \\
\text { CT-3 }\end{array}$ & & . \\
\hline $\begin{array}{r}\text { CT sump overflow } \\
\text { CT-1 } \\
\text { CT-2 } \\
\text { CT-3 } \\
\text { (normal, plugged) }\end{array}$ & & \\
\hline $\begin{array}{ll}\text { CT makeup valve } & \\
& \text { CT-1 } \\
\text { CT-2 } & \text { CT-3 } \\
\text { (auto, manual) }\end{array}$ & & \\
\hline $\begin{array}{r}\text { Occupied schedule } \\
\text { Start } \\
\text { Stop }\end{array}$ & & \\
\hline & & \\
\hline & & \\
\hline & & \\
\hline
\end{tabular}

Notes: 
3. Sensor Calibration Checks. The sensors listed below checked for calibration and adequate location. This is a spot check on a sample of the calibrations done during prefunctional checklisting.*

"In calibration" means making a reading with a calibrated test instrument within 6 inches of the site sensor. Verify that the sensor reading (via the permanent thermostat, gage or building automation system (BAS)) compared to the test instrument-measured value is within the tolerances specified in the prefunctional checklist requirements. If not, install offset in BAS, calibrate or replace sensor. Use the same test instruments as used for the original calibration, if possible.

Test instrument, air pressure:

Test instrument, water pressure:

Test instrument, temperature:

\begin{tabular}{|l|l|c|c|c|c|}
\hline $\begin{array}{l}\text { Sensor \& } \\
\text { Location }\end{array}$ & $\begin{array}{c}\text { Loc- } \\
\text { ation } \\
\text { OK }\end{array}$ & $\begin{array}{c}\text { Gage } \\
\text { or } \\
\text { BAS } \\
\text { Value }\end{array}$ & $\begin{array}{c}\text { Meas'd } \\
\text { Instr. } \\
\text { Value }\end{array}$ & $\begin{array}{c}\text { Fage } \\
\text { or } \\
\text { BAS } \\
\text { Value }\end{array}$ & $\begin{array}{l}\text { Pass } \\
\text { Y/N? }\end{array}$ \\
\hline \hline ECDWT & & & & & \\
\hline $\begin{array}{l}\text { Pump dP } \\
\text { sensor }\end{array}$ & & & & & \\
\hline CT-1 sump T. & & & & & \\
\hline
\end{tabular}

Certified calibration within last $12 \mathrm{mo}$ 's. Certified calibration within last $12 \mathrm{mo}$ 's. Certified calibration within last $12 \mathrm{mo}$ 's.

\begin{tabular}{|l|l|c|c|c|c|}
\hline $\begin{array}{c}\text { Sensor \& } \\
\text { Location }\end{array}$ & $\begin{array}{c}\text { 1st } \\
\text { Loc- } \\
\text { ation } \\
\text { OK }^{1}\end{array}$ & $\begin{array}{c}\text { or } \\
\text { BAS } \\
\text { Value }\end{array}$ & $\begin{array}{c}\text { Instr. } \\
\text { Meas'd } \\
\text { Value }\end{array}$ & $\begin{array}{c}\text { Final } \\
\text { Gage } \\
\text { or } \\
\text { BAS } \\
\text { Value }\end{array}$ & $\begin{array}{c}\text { Pass } \\
\text { Y/N? }\end{array}$ \\
\hline \hline CT-2 sump T. & & & & & \\
\hline CHWST & & & & & \\
\hline & & & & & \\
\hline
\end{tabular}

${ }^{1}$ Sensor location is appropriate and away from causes of erratic operation.

*For every sensor originally found out of calibration, check one additional sensor not listed.

4. Device Calibration Checks. The actuators or devices listed below checked for calibration. This is a spot check on a sample of the calibrations done during prefunctional checklisting and startup.**

"In calibration" means observing a readout in the BAS and going to the actuator or controlled device and verifying that the BAS reading is correct. For items out of calibration or adjustment, fix now if easy, via an offset in the BAS, or a mechanical fix.

\begin{tabular}{|l|c|c|c|c|}
\hline $\begin{array}{c}\text { Device or } \\
\text { Actuator \& } \\
\text { Location }\end{array}$ & $\begin{array}{c}\text { 1st } \\
\text { BAS } \\
\text { Reading }\end{array}$ & $\begin{array}{c}\text { Site } \\
\text { Observ- } \\
\text { ation }\end{array}$ & $\begin{array}{c}\text { Final } \\
\text { BAS } \\
\text { Reading }\end{array}$ & $\begin{array}{c}\text { Pass } \\
\text { Y/N }\end{array}$ \\
\hline $\begin{array}{l}\text { CHWP-6 } \\
\text { rpm }\end{array}$ & & & & \\
\hline $\begin{array}{l}\text { CHWP-7 } \\
\mathrm{rpm}\end{array}$ & & & & \\
\hline $\begin{array}{l}\text { CHWP-8 } \\
\mathrm{rpm}\end{array}$ & & & & \\
\hline & & & & \\
\hline & & & & \\
\hline
\end{tabular}

\begin{tabular}{|l|c|c|c|c|}
\hline $\begin{array}{c}\text { Device or } \\
\text { Actuator \& } \\
\text { Location }\end{array}$ & $\begin{array}{c}\text { 1st } \\
\text { BAS } \\
\text { Reading }\end{array}$ & $\begin{array}{c}\text { Site } \\
\text { Observ- } \\
\text { ation }\end{array}$ & $\begin{array}{c}\text { Final } \\
\text { BAS } \\
\text { Reading }\end{array}$ & $\begin{array}{c}\text { Pass } \\
\text { Y/N }\end{array}$ \\
\hline \hline CT-1 & $\begin{array}{c}\text { fan } \\
\text { stage 1 }\end{array}$ & & & \\
\hline CT-1 & $\begin{array}{c}\text { fan } \\
\text { stage 2 }\end{array}$ & & & \\
\hline CT-2 & $\begin{array}{c}\text { fan } \\
\text { stage 1 }\end{array}$ & & & \\
\hline CT-2 & $\begin{array}{c}\text { fan } \\
\text { stage 2 }\end{array}$ & & $\cdot$ & \\
\hline CT-3 & $\begin{array}{c}\text { fan } \\
\text { stage 1 }\end{array}$ & & & \\
\hline
\end{tabular}

\section{Notes:}




\begin{tabular}{|c|c|c|c|c|}
\hline $\begin{array}{c}\text { Device or } \\
\text { Actuator \& } \\
\text { Location }\end{array}$ & $\begin{array}{c}\text { 1st } \\
\text { BAS } \\
\text { Reading }\end{array}$ & $\begin{array}{c}\text { Site } \\
\text { Observ- } \\
\text { ation }\end{array}$ & $\begin{array}{c}\text { Final } \\
\text { BAS } \\
\text { Reading }\end{array}$ & $\begin{array}{c}\text { Pass } \\
\text { Y/N }\end{array}$ \\
\hline \hline & & & & \\
\hline & & & & \\
\hline
\end{tabular}

\begin{tabular}{|c|c|c|c|c|}
\hline $\begin{array}{c}\text { Device or } \\
\text { Actuator \& } \\
\text { Location }\end{array}$ & $\begin{array}{c}\text { 1st } \\
\text { BAS' } \\
\text { Reading }\end{array}$ & $\begin{array}{c}\text { Site } \\
\text { Observ- } \\
\text { ation }\end{array}$ & $\begin{array}{c}\text { Final } \\
\text { BAS } \\
\text { Reading }\end{array}$ & $\begin{array}{c}\text { Pass } \\
\text { Y/N }\end{array}$ \\
\hline \hline $\begin{array}{l}\text { CT Bypass } \\
\text { valve }\end{array}$ & & & & \\
\hline & & & & \\
\hline
\end{tabular}

**For every actuator or device originally found out of calibration, check one additional one not listed.

\section{Verification of Misc. Prefunctional Checks.}

Misc. site checks of the prefunctional checklist and startup reports completed successfully. Pass? Y/N

\section{Notes on Methods Used to False Load Chiller (for reference, see Note 6 at end of test)}

\section{Seasonal Testing and General Conditions of Test}

Due to the building completion being during winter, this test will be completed in two stages. The first testing will occur prior to substantial completion, during cold weather. The objective of this first stage test is to provide reasonable assurance that the chiller will function properly during lower load conditions. This will prepare the chiller for operation during the beginning of the cooling season. As many of the test procedures as possible will be executed during this first test, through the use of the methods of false loading noted above and in Note 6 at the end of the test. Tests of all chillers close to full load and full cooling tower fan staging will not be able to be executed until summer. Chiller safeties will be tested prior to occupancy and cooling tower winter operation and sump heater tests will be performed during cold weather of the first test.

At the beginning of the cooling season, the chiller will be started and operated, without further testing, unless problems arise. Then, when conditions are warmer (approximately $80 \mathrm{~F}-85 \mathrm{~F}$ ), the second test will be performed. This will likely require some false loading to create close to full load conditions and subsequently may need to be

\section{Notes:}


executed on a weekend to minimize discomfort to occupants. During this second test, some of the sequences performed during the first test will be retested and recorded, as necessary, to get to the staging and full load tests not performed during the first test. Also, the benchmarking and trending will be completed during the second test period.

\section{Test Procedure Table of Contents}

Procedure \#

Chiller system (including cooling tower) startup and staging ON and OFF (with lead chiller)

Chiller system staging with lag chiller $1-8,14$

Heat exchanger (HE-1) $1 b-8 b$ (after 56)

Variable speed drives and CHWP6, 7;8 9-10

Misc. chiller functions (lockouts, pump failures, chiller standby, etc.

CHW supply reset 15-27

CHW pressure control

Interlock with EF-10 30-32

Reciprocating chiller staging (CH-3) . .33

Chiller safety controls .34

Other cooling tower functions. $.36-48$

Efficiency testing and benchmarking $49-56$

Monitoring / Trending $14,17,29,31,34,57$

Notes: 


\section{Testing Procedures and Record}

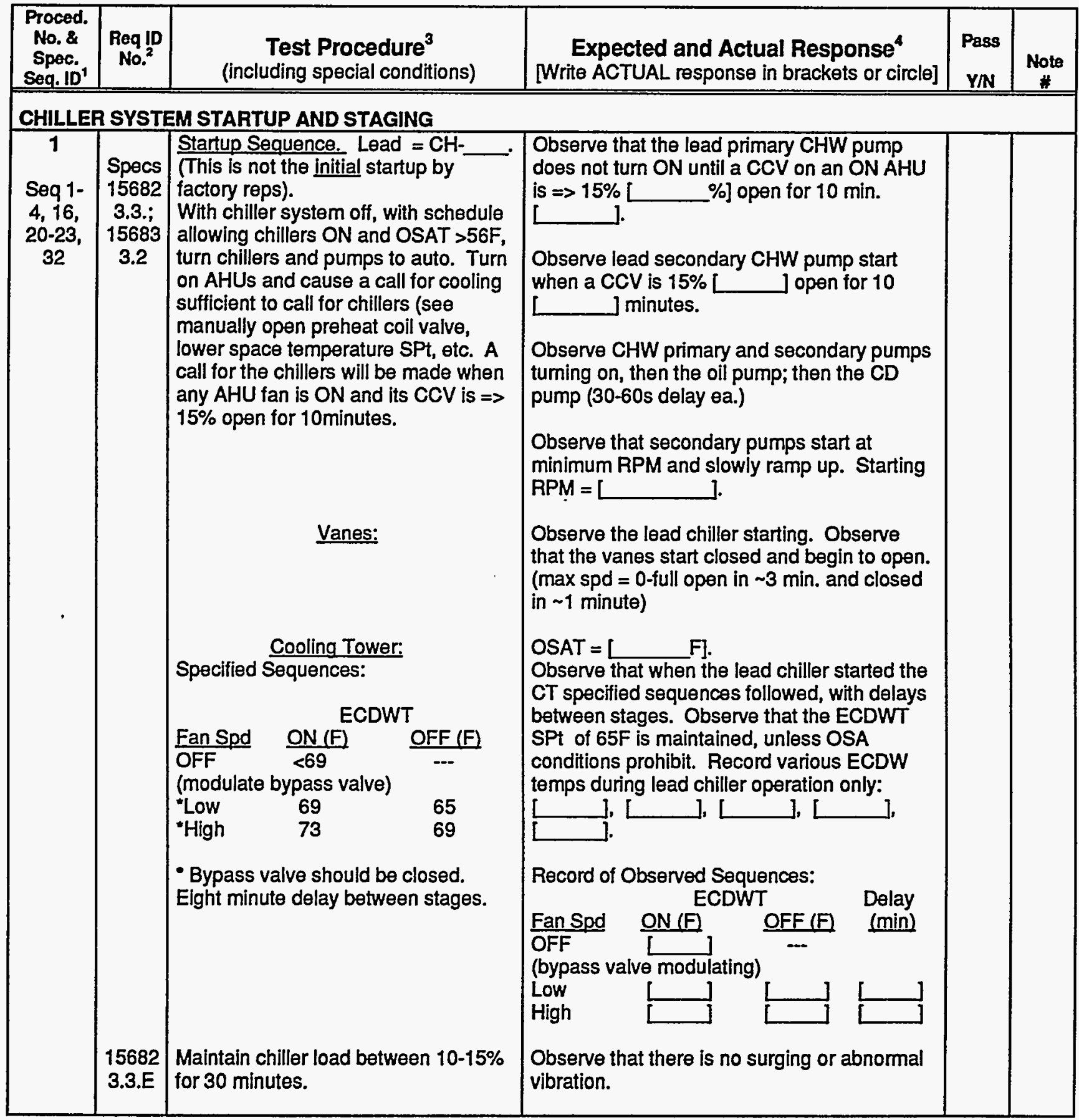

Notes:

File: CHILLER.FT5, 3/21/97 


\begin{tabular}{|c|c|c|c|c|c|}
\hline $\begin{array}{l}\text { Proced. } \\
\text { No. } 8 \\
\text { Spec. } \\
\text { Seg. ID' }\end{array}$ & $\begin{array}{c}\text { Req ID } \\
\text { No. }^{2}\end{array}$ & $\begin{array}{l}\text { Test Procedure } \\
\text { (including special conditions) }\end{array}$ & $\begin{array}{c}\text { Expected and Actual Response } \\
\text { [Write ACTUAL response in brackets or circle] }\end{array}$ & $\begin{array}{l}\text { Pass } \\
\text { Y/N }\end{array}$ & $\begin{array}{c}\text { Noto } \\
\#\end{array}$ \\
\hline $\begin{array}{c}2 \\
\text { Seq } 8\end{array}$ & $\begin{array}{c}\text { Specs } \\
15682 \\
3.3 . ; \\
15683 \\
3.2\end{array}$ & $\begin{array}{l}\text { 1st Lag Chiller Staging ON. } \\
\text { Staging sequence: } \mathrm{CH}- \\
\rightarrow \mathrm{CH}- \\
\text { With chillers in auto, and loaded such } \\
\text { that only lead chiller is running, lower } \\
\text { space setpoints so CCVs open. Wait } \\
\sim 10 \text { minutes. Record time that } \\
\text { primary flow and secondary flow } \\
\text { become equal. Wait } 20 \text { minutes. }\end{array}$ & $\begin{array}{l}\text { Total primary flow = [ gpm]. } \\
\text { Secondary CHW flow => primary CHW flow = } \\
\text { gpm] and lead chiller is at least } 95 \% \\
\text { loaded (by \% of rated current), [ } \\
\text { amps]. Time: [ } \\
\text { minutes, 1st lag chiller should start (PCHWP - } \\
\text { oil pump - CDP - chiller). Time when 1st lag } \\
\text { chiller started = [ } \\
\text { Observe that the amps on both chillers are } \\
\text { within } 5 \% \text { of each other. }\end{array}$ & & \\
\hline $\begin{array}{c}3 \\
\text { Seq 8; } \\
32-34\end{array}$ & $\begin{array}{c}\text { Specs } \\
15683 \\
3.3 . F . \\
2\end{array}$ & $\begin{array}{l}\text { 1st Lag Secondary CHWP } \\
\text { Staging ON. } \\
\text { Continue increasing cooling load, if } \\
\text { necessary, to cause CCVs to open } \\
\text { further. }\end{array}$ & 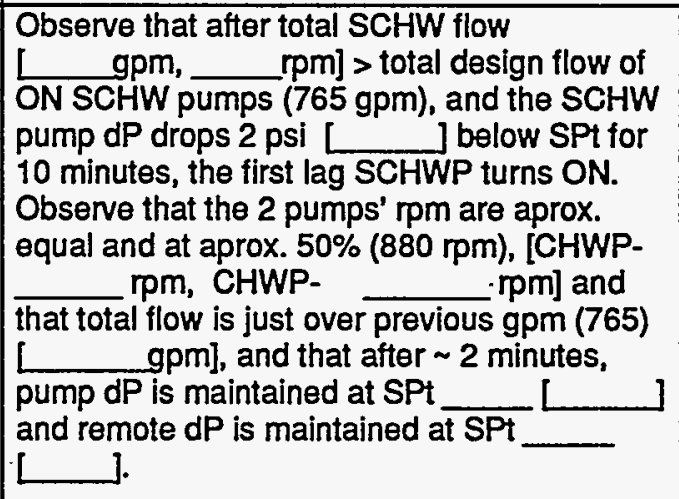 & & \\
\hline $\begin{array}{c}4 \\
\text { Seq } 8 \\
21-24\end{array}$ & $\begin{array}{c}\text { Specs } \\
15682 \\
3.3 . ; \\
15683 \\
3.2\end{array}$ & $\frac{\text { 1st Lag Cooling Tower Staging ON. }}{\text { During the preceding sequences: }}$ & $\begin{array}{l}\text { OSAT = }[\text { F]. } \\
\text { Obsene that when the 1st lag chiller started } \\
\text { the CT specified sequences followed, with } \\
\text { delays between stages. Observe that the } \\
\text { ECDWT SPt of 65F is maintained, unless } \\
\text { OSA conditions prohibit. Record various } \\
\text { ECDW temps when both chillers are } \\
\text { operating: [ } \\
\text { Record of Observed Sequences: } \\
\text { Fan Spd } \\
\text { OFF ON (F) } \\
\text { (bypass valve modulating) } \\
\text { Low } \\
\text { High }\end{array}$ & & \\
\hline
\end{tabular}

\section{Notes:}




\begin{tabular}{|c|c|c|c|c|c|}
\hline $\begin{array}{l}\text { Proced. } \\
\text { No. \& } \\
\text { Spac. } \\
\text { Sog. } 10^{1}\end{array}$ & $\begin{array}{c}\text { Req ID } \\
\text { No. }^{2}\end{array}$ & $\begin{array}{l}\text { Test Procedure } \\
\text { (including special conditions) }\end{array}$ & $\begin{array}{c}\text { Expected and Actual Response } \\
\text { [Write ACTUAL response in brackets or circle] }\end{array}$ & $\begin{array}{l}\text { Pass } \\
\text { Y/N }\end{array}$ & $\begin{array}{c}\text { Noto } \\
*\end{array}$ \\
\hline $\begin{array}{c}5 \\
\text { Seq } 8\end{array}$ & $\begin{array}{c}\text { Specs } \\
15682 \\
3.3 . ; \\
15683 \\
3.2\end{array}$ & $\begin{array}{l}\text { 2nd Lag Chiller Staging ON Cont. } \\
\text { After second chiller starts, continue } \\
\text { calling for more cooling to start third } \\
\text { chiller. }\end{array}$ & 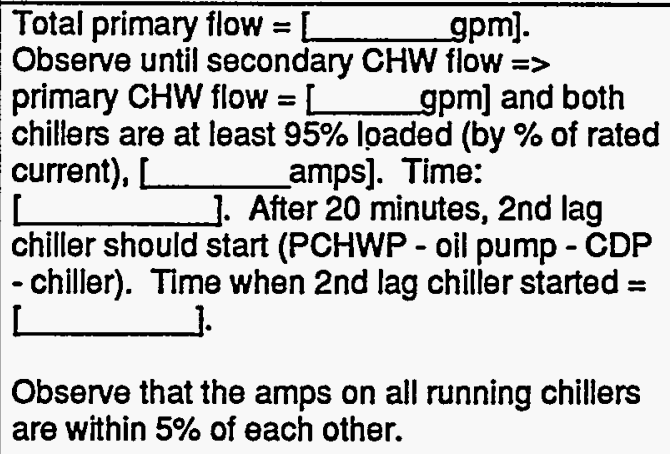 & & \\
\hline $\begin{array}{c}6 \\
\text { Seq 8; } \\
32-34\end{array}$ & \begin{tabular}{c|} 
Specs \\
15682 \\
$3.3 . ;$ \\
15683 \\
3.2
\end{tabular} & $\begin{array}{l}\text { 2nd Lag Secondary CHWP } \\
\text { Staging ON Cont. } \\
\text { Continue increasing cooling load, if } \\
\text { necessary, to cause CCVs to open } \\
\text { further. }\end{array}$ & 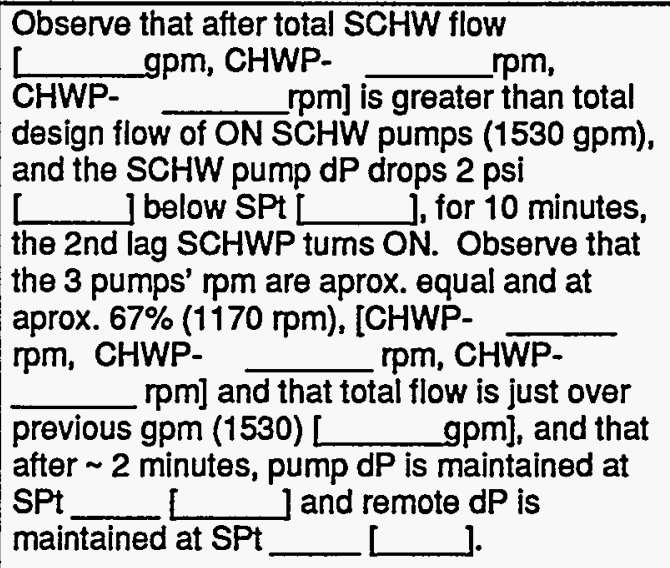 & & \\
\hline
\end{tabular}

Notes: 


\begin{tabular}{|c|c|c|c|c|c|}
\hline $\begin{array}{l}\text { Proced. } \\
\text { No. \& } \\
\text { Spoc. } \\
\text { Seq. ID }\end{array}$ & $\begin{array}{c}\text { Req !D } \\
\text { No. }^{2}\end{array}$ & $\begin{array}{l}\text { Test Procedure } \\
\text { (including special conditions) }\end{array}$ & $\begin{array}{l}\text { Expected and Actual Response } \\
\text { [Write ACTUAL response in brackets or circle] }\end{array}$ & $\begin{array}{l}\text { Pass } \\
\text { Y/N }\end{array}$ & $\begin{array}{c}\text { Nato } \\
\text { \# }\end{array}$ \\
\hline $\begin{array}{c}7 \\
\text { Seq 8; } \\
21-24\end{array}$ & \begin{tabular}{|c|} 
Specs \\
15682 \\
$3.3 . ;$ \\
15683 \\
3.2 \\
\end{tabular} & $\begin{array}{l}\text { 2nd Lag Cooling Tower Staging ON. } \\
\text { During the preceding sequences: }\end{array}$ & 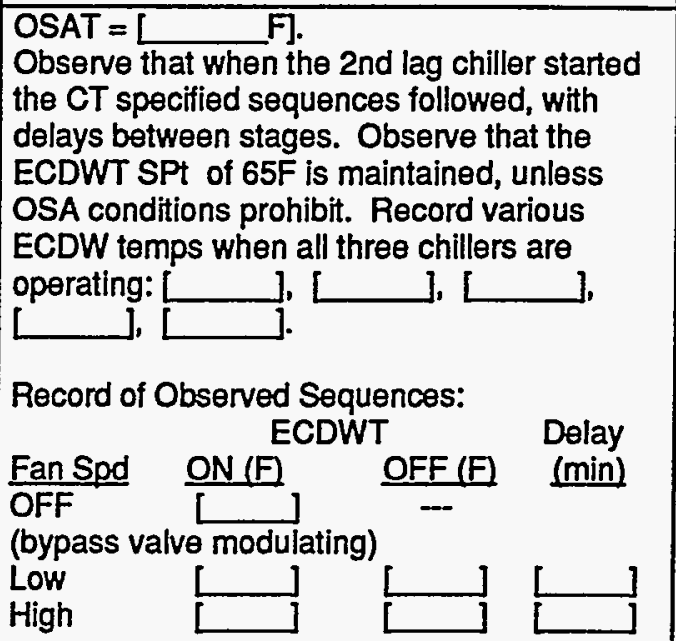 & & \\
\hline
\end{tabular}

Notes: 


\begin{tabular}{|c|c|c|c|c|c|}
\hline $\begin{array}{l}\text { Proced. } \\
\text { No. \& } \\
\text { Spec. } \\
\text { Seq. } 10^{1}\end{array}$ & $\underset{\mathrm{Req} \text { ID }}{\mathrm{No}^{2}}$ & $\begin{array}{l}\text { Test Procedure } \\
\text { (including special conditions) }\end{array}$ & $\begin{array}{c}\text { Expected and Actual Response } \\
\text { [Write ACTUAL response in brackets or circle] }\end{array}$ & $\begin{array}{l}\text { Pass } \\
\text { Y/N }\end{array}$ & $\begin{array}{l}\text { Note } \\
\#\end{array}$ \\
\hline $\begin{array}{c}8 \\
\text { Seq } 9 \\
10 ; 35\end{array}$ & \begin{tabular}{|c|} 
Specs \\
15682 \\
$3.3 . ;$ \\
15683 \\
3.2
\end{tabular} & $\begin{array}{l}\text { Chillers Staging OFF. } \\
\text { Raise space setpoints so CCVs close, } \\
\text { or shut off some or all AHU's. Wait } \\
\sim 10 \text { minutes. Record time that } \\
\text { primary flow exceeds secondary flow } \\
\text { by capacity of last selected pump. } \\
\text { Wait thru } 20 \text { min. delay. (CHWP } 1-3 \\
=675 \mathrm{gpm} \text { ea., CHWP } 4 ; 5=180 \mathrm{gpm} \\
\text { ea.) } \\
\text { Repeat to see } 1 \text { st lag chiller stage off. } \\
\text { Repeat to see lead chiller stage off. }\end{array}$ & 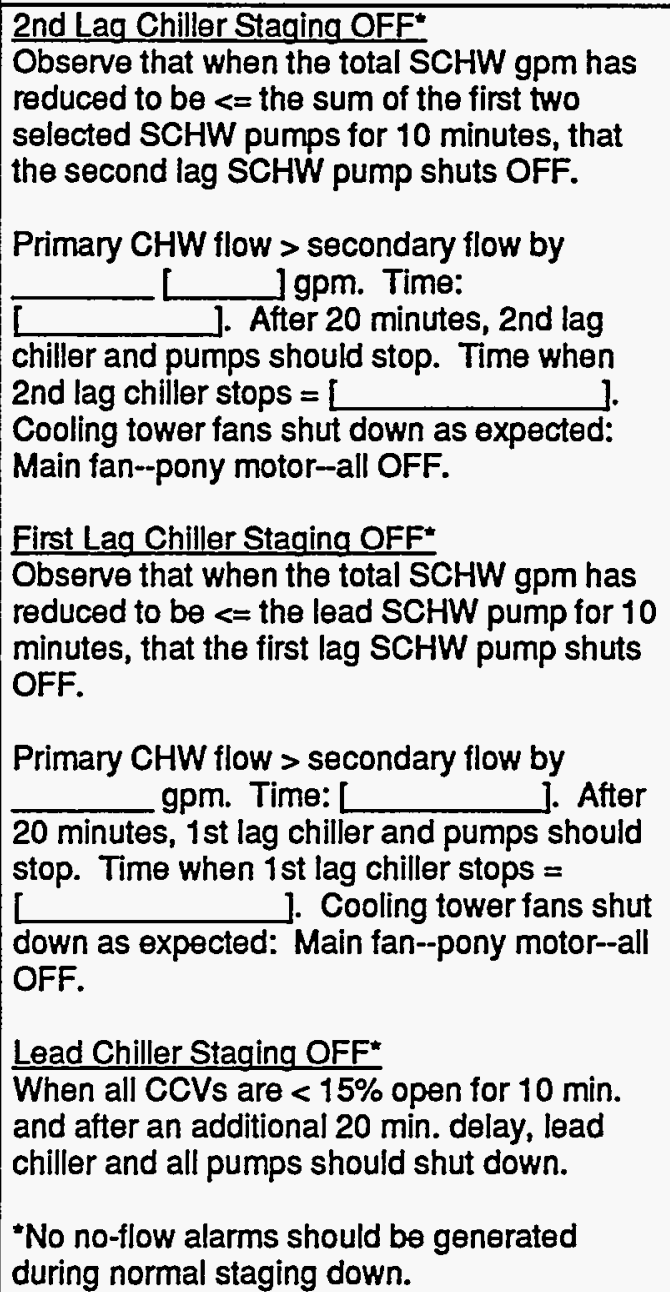 & & \\
\hline $\begin{array}{c}9 \\
\text { Seq } 41 \\
42\end{array}$ & \begin{tabular}{|c|} 
Specs \\
15682 \\
$3.3 . ;$ \\
15683 \\
3.2
\end{tabular} & $\begin{array}{l}\text { CDP 6:7 and HE-1. } \\
\text { Continuing with the last sequence of } \\
\text { staging OFF the chillers: } \\
\text { When the lead chiller shuts down CDP } \\
6 \text { or } 7 \text { still function. }\end{array}$ & $\begin{array}{l}\text { Observe that the CDP- } 6 \text { or } 7 \text { and CDP } 8 \text { or } 9 \\
\text { still run and that the CDWT remains the } \\
\text { constant. }\end{array}$ & & \\
\hline
\end{tabular}

Notes: 


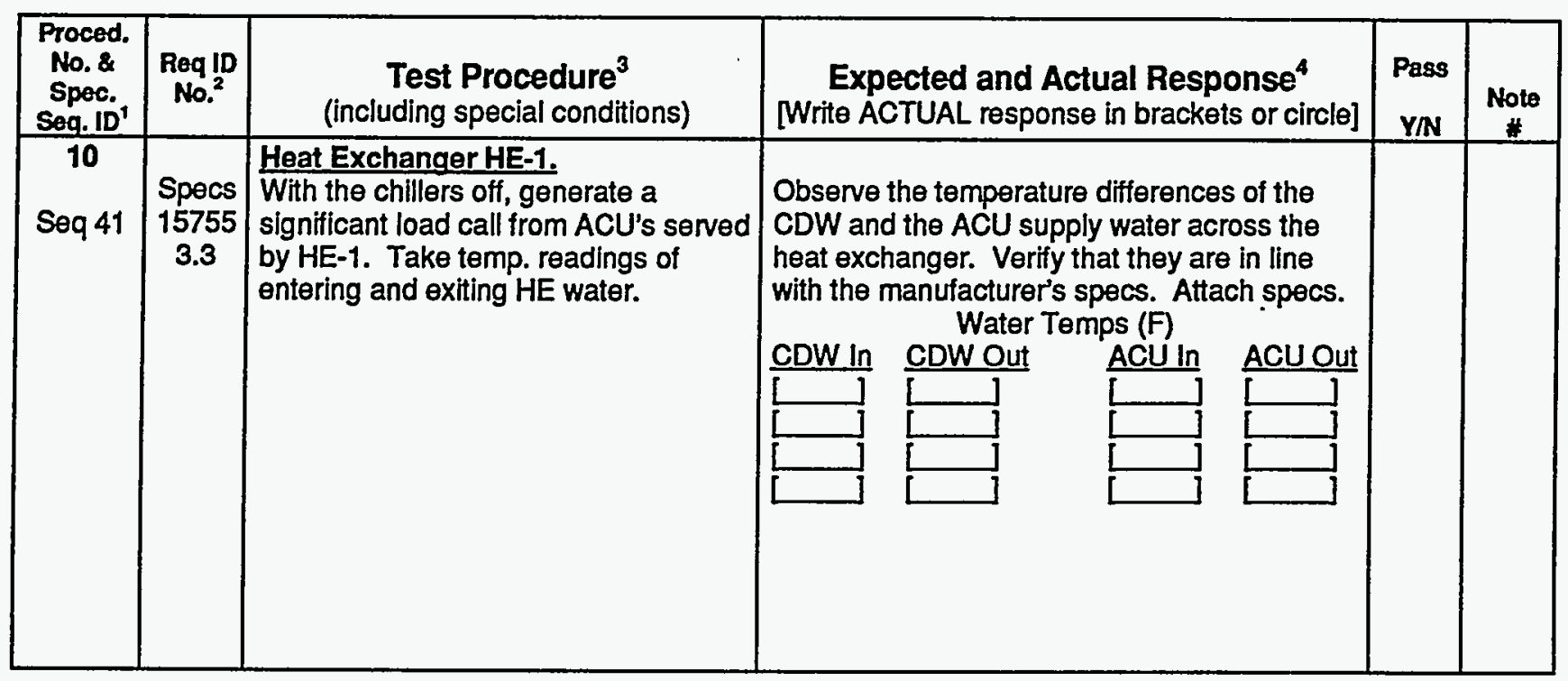

Notes: 


\begin{tabular}{|c|c|c|c|c|c|}
\hline $\begin{array}{c}\text { Proced. } \\
\text { No. \& } \\
\text { Spec. } \\
\text { Seg. } 10^{1}\end{array}$ & $\begin{array}{c}\text { Req ID } \\
\text { No. }^{2}\end{array}$ & $\begin{array}{l}\text { Test Procedure } \\
\text { (Including special conditions) }\end{array}$ & $\begin{array}{l}\text { Expected and Actual Response } \\
\text { [Write ACTUAL response in brackets or circle] }\end{array}$ & $\begin{array}{l}\text { Pass } \\
\text { YNN }\end{array}$ & $\begin{array}{c}\text { Noto } \\
*\end{array}$ \\
\hline $\begin{array}{c}11 \\
\text { Seq } 33- \\
35\end{array}$ & \begin{tabular}{|c|} 
Specs \\
15682 \\
$3.3 . ;$ \\
15683 \\
3.2
\end{tabular} & $\begin{array}{l}\text { Variable Speed Drive (VFD) on } \\
\text { CHWP-6. } \\
\text { (Note: VFD operation with multiple } \\
\text { SCHW pumps operating is tested in } \\
\text { procedure } 3 \text { and } 6 . \\
\text { 1. Carefully go over prefunctional } \\
\text { checklist and programming record and } \\
\text { identify anomalies. Record the low } \\
\text { limits. } \\
\text { 2. With only chiller associated with } \\
\text { CHWP-6 running and other chillers } \\
\text { manually OFF, reduce all cooling load } \\
\text { or manually lower pump and remote } \\
\text { differential pressure setpoints. See } \\
\text { how low VFD will go. } \\
\text { 4. Call for maximum cooling or } \\
\text { increase differential pressure setpoints } \\
\text { (keeping only } 1 \text { chiller ON). } \\
\text { 3. Call for moderate cooling or } \\
\text { increase differential pressure } \\
\text { setpoints. }\end{array}$ & $\begin{array}{l}\text { Motor manufacturer's recommended speed } \\
\text { low limit = L_ \% of max.]. } \\
\text { 1. Low limit setting in drive: L } \\
\text { rpm = of maximum]. Provide } \\
\text { reasons for low limit not being at motor mfr's } \\
\text { low limit. } \\
\text { List any anomalies noticed in programming: } \\
\text { 2. Lowest speed drive will go: L } \\
\text { ipm]. } \\
\text { Is this within } 3 \text { Hz of the low limit setting (or } \\
\text { within a range equal to } 5 \% \text { of maximum } \\
\text { speed)? } \\
\text { Is pump and remote dP SP maintained } \\
\text { without hunting? } \\
\text { 3. Does VFD motor ramp up accordingly in a } \\
\text { reasonable time? } \\
\text { Is pump and remote dP SPt maintained } \\
\text { without hunting? } \\
\text { 4. Does VFD motor ramp to full speed in a } \\
\text { reasonable time? } \\
\text { Is pump and remote dP SPt maintained } \\
\text { without hunting? }\end{array}$ & & \\
\hline
\end{tabular}

Notes: 


\begin{tabular}{|c|c|c|c|c|c|}
\hline $\begin{array}{l}\text { Proced. } \\
\text { No. \& } \\
\text { Spec. } \\
\text { Seg. ID }\end{array}$ & $\begin{array}{c}\text { Req ID } \\
\text { No.? }\end{array}$ & $\begin{array}{l}\text { Test Procedure } \\
\text { (including special conditions) }\end{array}$ & $\begin{array}{l}\text { Expected and Actual Response } \\
\text { [Write ACTUAL response in brackets or circle] }\end{array}$ & $\begin{array}{l}\text { Pass } \\
\text { Y/N }\end{array}$ & $\begin{array}{c}\text { Noto } \\
*\end{array}$ \\
\hline $\begin{array}{c}12 \\
\text { Seq } 33- \\
35\end{array}$ & $\begin{array}{c}\text { Specs } \\
15682 \\
3.3 . ; \\
15683 \\
3.2\end{array}$ & $\begin{array}{l}\text { Variable Speed Drive (VFD) on } \\
\text { CHWP-7. } \\
\text { (Note: VFD operation with multiple } \\
\text { SCHW pumps operating is tested in } \\
\text { procedure } 3 \text { and } 6 . \\
\text { 1. Carefully go over prefunctional } \\
\text { checklist and programming record and } \\
\text { Identify anomalies. Record the low } \\
\text { limits. } \\
\\
\text { 2. With only chiller associated with } \\
\text { CHWP-7 running and other chillers } \\
\text { manually OFF, reduce all cooling load } \\
\text { or manually lower pump and remote } \\
\text { differential pressure setpoints. See } \\
\text { how low VFD will go. } \\
\text { 3. Call for moderate cooling or } \\
\text { increase differential pressure } \\
\text { setpoints. } \\
\text { increase differential pressure setpoints } \\
\text { (keeping only } 1 \text { chiller ON). }\end{array}$ & $\begin{array}{l}\text { Motor manufacturer's recommended speed } \\
\text { low limit = L of max.]. } \\
\text { 1. Low limit setting in drive: [ } \\
\text { rpm = of maximum]. Provide } \\
\text { reasons for low limit not being at motor mfr's } \\
\text { low limit. } \\
\text { List any anomalies noticed in programming: } \\
\text { 2. Lowest speed drive will go: L L } \\
\text { rpm]. } \\
\text { is this within } 3 \mathrm{~Hz} \text { of the low limit setting (or } \\
\text { within a range equal to 5\% of maximum } \\
\text { speed)? } \\
\text { Is pump and remote dP SP maintained } \\
\text { without hunting? } \\
\text { 3. Does VFD motor ramp up accordingly in a } \\
\text { reasonable time? } \\
\text { Is pump and remote dP SPt maintained } \\
\text { without hunting? } \\
\text { 4. Does VFD motor ramp to full speed in a } \\
\text { reasonable time? } \\
\text { Is pump and remote dP SPt maintained } \\
\text { without hunting? }\end{array}$ & & \\
\hline
\end{tabular}

Notes: 


\begin{tabular}{|c|c|c|c|c|c|}
\hline $\begin{array}{c}\text { Proced. } \\
\text { No. \& } \\
\text { Spec. } \\
\text { Seq. ID' }\end{array}$ & $\begin{array}{c}\text { Req ID } \\
\text { No. }^{2}\end{array}$ & $\begin{array}{l}\text { Test Procedure } \\
\text { (including special conditions) }\end{array}$ & $\begin{array}{c}\text { Expected and Actual Response } \\
\text { [Write ACTUAL response in brackets or circle] }\end{array}$ & $\begin{array}{c}\text { Pass } \\
\text { YN }\end{array}$ & Note \\
\hline $\begin{array}{c}13 \\
\text { Seq } 33- \\
35\end{array}$ & \begin{tabular}{|c|} 
Specs \\
15682 \\
$3.3 . ;$ \\
15683 \\
3.2
\end{tabular} & $\begin{array}{l}\text { Varlable Speed Drive (VFD) on } \\
\text { CHWP-8. } \\
\text { (Note: VFD operation with multiple } \\
\text { SCHW pumps operating is tested in } \\
\text { procedure T-3 and T-6. } \\
\text { 1. Carefully go over prefunctional } \\
\text { checklist and programming record and } \\
\text { identify anomalies. Record the low } \\
\text { limits. } \\
\\
\text { 2. With only chiller associated with } \\
\text { CHWP-8 running and other chillers } \\
\text { manually OFF, reduce all cooling load } \\
\text { or manually lower pump and remote } \\
\text { differential pressure setpoints. See } \\
\text { how low VFD will go. } \\
\text { 3. Call for moderate cooling or } \\
\text { increase differential pressure } \\
\text { setpoints. } \\
\text { 4. Call for maximum cooling or } \\
\text { increase differential pressure setpoints } \\
\text { (keeping only } 1 \text { chiller ON). }\end{array}$ & $\begin{array}{l}\text { Motor manufacturer's recommended speed } \\
\text { low limit = L of max.]. } \\
\text { 1. Low limit setting in drive: } \\
\text { rpm }=\% \text { of maximum]. Provide } \\
\text { reasons for low limit not being at motor mir's } \\
\text { low limit. } \\
\text { List any anomalies noticed in programiming: } \\
\text { 2. Lowest speed drive will go: L } \\
\text { rpm]. } \\
\text { Is this within } 3 \text { Hz of the low limit setting (or } \\
\text { within a range equal to } 5 \% \text { of maximum } \\
\text { speed)? } \\
\text { Is SP maintained without hunting? } \\
\text { 3. Does VFD motor ramp up accordingly in a } \\
\text { reasonable time? } \\
\text { is SP SPt maintained without hunting? } \\
\text { 4. Does VFD motor ramp to full speed in a } \\
\text { reasonable time? } \\
\text { Is SP SPt maintained without hunting? }\end{array}$ & & \\
\hline $\begin{array}{c}14 \\
\text { Seq } 8 \\
21-24 ; \\
32-35\end{array}$ & \begin{tabular}{|c|} 
Specs \\
15682 \\
$3.3 . ;$ \\
15683 \\
3.2 \\
\end{tabular} & \begin{tabular}{|l|} 
General Staging. \\
By Monitoring: \\
For each chiller, trend the status of \\
CH, PCHWP, SCHWP, CDWP, CT \\
pony fan, CT main fan, OSAT, \\
CHWST, ECDWT, primary gpm, \\
secondary gpm, VFD rpm for each \\
pump. \\
(Start all points simultaneously, 5 min. \\
time step for 3 days, including \\
weekend during a period of significant \\
cooling. Provide text file (ASCII).
\end{tabular} & $\begin{array}{l}\text { Observe that there are no anomalies in } \\
\text { operation, comparing to the specified } \\
\text { sequences and staging. This is not a detailed } \\
\text { "to the minute" staging verification, which was } \\
\text { done manually above. } \\
\text { Attach representative graphs or columnar data } \\
\text { and explanatory analysis to this test report. }\end{array}$ & & \\
\hline
\end{tabular}

Notes: 


\begin{tabular}{|c|c|c|c|c|c|}
\hline $\begin{array}{l}\text { Proced. } \\
\text { No. \& } \\
\text { Spec. } \\
\text { Seq. ID' }\end{array}$ & $\begin{array}{c}\text { Req ID } \\
\text { No. }^{2}\end{array}$ & $\begin{array}{c}\text { Test Procedure } \\
\text { (including special conditions) }\end{array}$ & $\begin{array}{c}\text { Expected and Actual Response } \\
\text { [Write ACTUAL response in brackets or circle] }\end{array}$ & $\begin{array}{l}\text { Pass } \\
\text { YNN }\end{array}$ & $\begin{array}{c}\text { Noto } \\
\quad\end{array}$ \\
\hline \multicolumn{6}{|c|}{ MISC. CHILLER SYSTEM FUNCTIONS } \\
\hline $\begin{array}{l}15 \\
\operatorname{Seq} 13\end{array}$ & \begin{tabular}{|c|} 
Specs \\
15682 \\
$3.3 . ;$ \\
15683 \\
3.2
\end{tabular} & $\begin{array}{l}\text { Demand Limiting. } \\
\text { With one chiller running, enable the } \\
\text { demand limiting routine and } \\
\text { temporarily reduce the limiting delay } \\
\text { from } 1 \text { hour to } 20 \text { minutes. Lower the } \\
\mathrm{kW} \text { limit to be equal to } 90 \% \text { of the } \\
\text { lead chiller design } \mathrm{kW} \text {. Initiate } \\
\text { sufficient load to call for two chillers. }\end{array}$ & $\begin{array}{l}\text { Observe that CCV's run to } 100 \% \text { open, } \\
\text { indicating a call for cooling and an unsatisfied } \\
\text { condition. Note that the lag chiller is called } \\
\text { for, but does not turn on until the programmed } \\
\text { delay is over. }\end{array}$ & & \\
\hline $\begin{array}{l}16 \\
\text { Seq } 1\end{array}$ & \begin{tabular}{|c|} 
Specs \\
15682 \\
$3.3 . ;$ \\
15683 \\
3.2 \\
\end{tabular} & $\begin{array}{l}\text { OSAT Lockout. } \\
\text { With chiller(s) running in auto, } \\
\text { overwrite OSAT sensor to be } 55 \mathrm{~F} \text {. }\end{array}$ & $\begin{array}{l}\text { Observe a shutdown of the chillers, including } \\
\text { secondary CHW pumps.. }\end{array}$ & & \\
\hline $\begin{array}{l}17 \\
\text { Seq } 1\end{array}$ & $\begin{array}{c}\text { Specs } \\
15682 \\
3.3 . \\
15683 \\
3.2\end{array}$ & $\begin{array}{l}\text { OSAT Lockout. } \\
\text { By Monitoring. } \\
\text { During chilled water pressure control } \\
\text { monitoring: }\end{array}$ & $\begin{array}{l}\text { Observe a shutdown of the chillers, including } \\
\text { secondary CHW pumps, whenever the OSAT } \\
\text { is less than 55F } \\
\text { Attach representative graphs or columnar data } \\
\text { and explanatory analysis to this test report. }\end{array}$ & & \\
\hline Seq 19 & \begin{tabular}{|c|} 
Specs \\
15682 \\
$3.3 . ;$ \\
15683 \\
3.2
\end{tabular} & $\begin{array}{l}\text { Primary CHW Pump Failure, } \mathrm{CH}-1: 2 \text {. } \\
\text { With only the lead chiller running (in } \\
\text { auto), manually shut off the lead } \\
\text { primary CHW pump }\end{array}$ & $\begin{array}{l}\text { Operating chiller should stop and go into } \\
\text { failure alarm. The lag chiller then becomes } \\
\text { the lead chiller and should start. }\end{array}$ & & \\
\hline $\operatorname{Seq} .19$ & \begin{tabular}{|c|} 
Specs \\
15682 \\
$3.3 . ;$ \\
15683 \\
3.2 \\
\end{tabular} & $\begin{array}{l}\text { Primary CHW Pump Failure, } \mathrm{CH}-3 . \\
\text { With the chiller running in auto, } \\
\text { manually shut off the primary } \mathrm{CHW} \\
\text { pump. }\end{array}$ & $\begin{array}{l}\text { An alarm should register and the standby } \\
\text { primary CHW pump should start } \\
\text { automatically. }\end{array}$ & & \\
\hline $\begin{array}{c}20 \\
\operatorname{Seq} 22\end{array}$ & \begin{tabular}{|c|} 
Specs \\
15682 \\
$3.3 . ;$ \\
15683 \\
3.2 \\
\end{tabular} & $\begin{array}{l}\text { CD Pump Failure, } \mathrm{CH}-1 ; 2 \\
\text { With only the lead chiller running (in } \\
\text { auto), manually shut off the CD pump. }\end{array}$ & $\begin{array}{l}\text { Operating chiller should stop and go into } \\
\text { failure alarm. The lag chiller then becomes } \\
\text { the lead chiller and should start. }\end{array}$ & & \\
\hline $\begin{array}{c}21 \\
\text { Seq } 22\end{array}$ & \begin{tabular}{|c|} 
Specs \\
15682 \\
$3.3 . ;$ \\
15683 \\
3.2 \\
\end{tabular} & $\begin{array}{l}\text { CD Pump Failure, } \mathrm{CH}-3 \text {, } \\
\text { With the chiller running in auto, } \\
\text { manually shut off the primary } \mathrm{CD} \\
\text { pump. }\end{array}$ & $\begin{array}{l}\text { An alarm should register and the standby CD } \\
\text { pump should start automatically. }\end{array}$ & & \\
\hline
\end{tabular}

\section{Notes:}




\begin{tabular}{|c|c|c|c|c|c|}
\hline $\begin{array}{l}\text { Proced. } \\
\text { No. \& } \\
\text { Spec. } \\
\text { Seq. ID } \\
\end{array}$ & $\begin{array}{c}\text { Req ID } \\
\mathrm{No}^{2}{ }^{2}\end{array}$ & $\begin{array}{l}\text { Test Procedure } \\
\text { (including special conditions) }\end{array}$ & $\begin{array}{c}\text { Expected and Actual Response } \\
\text { [Write ACTUAL response in brackets or circle] }\end{array}$ & $\begin{array}{l}\text { Pass } \\
Y \mathbb{N}\end{array}$ & $\begin{array}{c}\text { Noto } \\
\#\end{array}$ \\
\hline $\begin{array}{c}22 \\
\text { Seq } 37\end{array}$ & \begin{tabular}{|c|} 
Specs \\
15682 \\
$3.3 . ;$ \\
15683 \\
3.2 \\
\end{tabular} & $\begin{array}{l}\text { Secondary CHWP Failure. } \\
\text { With at least one chiller and pumps in } \\
\text { auto, and running, shut off variable } \\
\text { speed drive to lead SCHWP. }\end{array}$ & Observe that lag or standby SCHWP starts. & & \\
\hline 23 & \begin{tabular}{|c|} 
Specs \\
15682 \\
$3.3 . ;$ \\
15683 \\
3.2
\end{tabular} & $\begin{array}{l}\text { Chiller Standby } 1 \text {. With chillers } \\
\text { manually OFF, turn } 1 \text { st lag chiller to } \\
\text { Auto and cause a call for the chillers. }\end{array}$ & $\begin{array}{l}\text { Lead primary CHWP pump should start and } \\
\text { orig. lead chiller should try and start, but fail. } \\
\text { CHWP should shut off. After } \\
\text { minutes DDC should start the lag CHW pump, } \\
\text { etc. and 1st lag chiller and function as lead. } \\
\text { (shorten delays for test, if desired) }\end{array}$ & & \\
\hline 24 & \begin{tabular}{|c|} 
Specs \\
15682 \\
$3.3 . ;$ \\
15683 \\
3.2 \\
\end{tabular} & $\begin{array}{l}\text { Chiller Standby 2. Repeat above to } \\
\text { test 2nd lag chiller as lead. }\end{array}$ & $\begin{array}{l}\text { First two chillers remain off. 2nd lag chiller } \\
\text { starts. }\end{array}$ & & \\
\hline $\begin{array}{c}25 \\
\text { Seq } 21\end{array}$ & \begin{tabular}{|c|} 
Specs \\
15682 \\
$3.3 . ;$ \\
15683 \\
3.2 \\
\end{tabular} & $\begin{array}{l}\text { Manual Standby CDP- for } \mathrm{CH}-1 \text { \& } \\
2 . \\
\text { With chillers OFF, manually operate } \\
\text { valves to allow standby CDP to } \\
\text { function and assign as lead pump. } \\
\text { Turn chillers to auto with CH-1 or } 2 \text { as } \\
\text { lead. Initiate a call for the chillers. }\end{array}$ & $\begin{array}{l}\text { Observe that standby CDP operates and that } \\
\text { gpm is as per design, } 1350 \mathrm{gpm} \\
\text { gmp]. }\end{array}$ & & \\
\hline $\begin{array}{c}26 \\
\text { Seq } 18\end{array}$ & \begin{tabular}{|c|} 
Specs \\
15682 \\
$3.3 . ;$ \\
15683 \\
3.2
\end{tabular} & $\begin{array}{l}\text { Manual Standby PCHWP- for } \mathrm{CH}-1 \\
\text { \& } 2 \text {. } \\
\text { With chillers OFF, manually operate } \\
\text { valves to allow standby primary } \\
\text { CHWP to function and assign it as } \\
\text { lead pump. Turn chillers to auto with } \\
\mathrm{CH}-1 \text { or } 2 \text { as lead. Initiate a call for } \\
\text { the chillers. }\end{array}$ & $\begin{array}{l}\text { Observe that standby PCHWP operates as } \\
\text { lead and that gpm is as per design, } 675 \mathrm{gpm} \\
\text { [_[pm]. }\end{array}$ & & \\
\hline $\begin{array}{c}27 \\
\text { Seq } 43\end{array}$ & \begin{tabular}{|c|} 
Specs \\
15682 \\
$3.3 . ;$ \\
15683 \\
3.2
\end{tabular} & $\begin{array}{l}\left.\frac{\text { CDP 6: } 7 \text { Failure }}{\text { Lead }=\text { CDP- }} \text { (6 or } 7\right) \\
\text { With system in auto and running, } \\
\text { manually shut down lead pump. } \\
\text { CDP 8: } 9 \text { Failure } \\
\text { Lead = CDP- } \\
\text { With system in auto and running, } \\
\text { manually shut down lead pump. }\end{array}$ & $\begin{array}{l}\text { Observe that an alarm is registered and that } \\
\text { the lag pump starts. } \\
\text { Observe that an alarm is registered and that } \\
\text { the lag pump starts. }\end{array}$ & & \\
\hline
\end{tabular}

Notes: 


\begin{tabular}{|c|c|c|c|c|c|}
\hline $\begin{array}{l}\text { Proced. } \\
\text { No. \& } \\
\text { Spec. } \\
\text { Seq. ID } \\
\end{array}$ & $\begin{array}{c}\text { Req ID } \\
\text { No. }^{2}\end{array}$ & $\begin{array}{l}\text { Test Procedure } \\
\text { (including special conditions) }\end{array}$ & $\begin{array}{c}\text { Expected and Actual Response } \\
\text { [Write ACTUAL response in brackets or circle] }\end{array}$ & $\begin{array}{l}\text { Pass } \\
\text { YN } \\
\end{array}$ & $\begin{array}{c}\text { Note } \\
\text { \# }\end{array}$ \\
\hline $\begin{array}{c}28 \\
\text { Seq } 6 ; 7\end{array}$ & \begin{tabular}{c|} 
Specs \\
15682 \\
$3.3 . ;$ \\
15683 \\
3.2
\end{tabular} & $\begin{array}{l}\text { CHWS Reset. } \\
\text { With one or more chillers running in } \\
\text { auto, change conditions to provide } \\
\text { data points near both ends of the line } \\
\text { and one near the middle of the chart } \\
\text { below. } \\
\text { A. Mark current SPt conditions on } \\
\text { chart with a star and CHWSTemp with } \\
\text { a dot. } \\
\text { B. Increase cooling demand by } \\
\text { lowering space setpoints } 8^{\circ} \mathrm{F} \text { in all } \\
\text { zones or by manually opening preheat } \\
\text { coil valves. } \\
\text { In BAS, observe CCV's opening for } \\
\text { AHU } 1,2,3 ; 4 \text { and CHWS setpoint } \\
\text { lowering. Mark SPt values on chart } \\
\text { with a star. } \\
\text { Observe that the CHWST meets } \\
\text { setpoint w/o excessive hunting. Mark } \\
\text { CHWST values on chart with a dot. } \\
\text { C. Remove cooling demand by } \\
\text { raising space setpoints } 8^{\circ} \mathrm{F} \text { above } \\
\text { normal in all zones or by other } \\
\text { suitable method. } \\
\text { Observe CCV's closing for AHU } 1,2 \text {, } \\
3 ; 4 \text { and CHWS setpoint raising. Mark } \\
\text { SPt values on chart with a star. } \\
\text { Observe that the CHWST meets } \\
\text { setpoint w/o excessive hunting. Mark } \\
\text { CHWT values on chart with a dot. } \\
\text { D. In condition B, Overwrite RA RH to } \\
\text { be } 53 \% \text {. }\end{array}$ & $\begin{array}{l}\text { C. Values in the top left of chart; near the } \\
\text { line. } \\
\text { D. Observe that the SPI does not change } \\
\text { further. }\end{array}$ & & \\
\hline
\end{tabular}

Notes: 


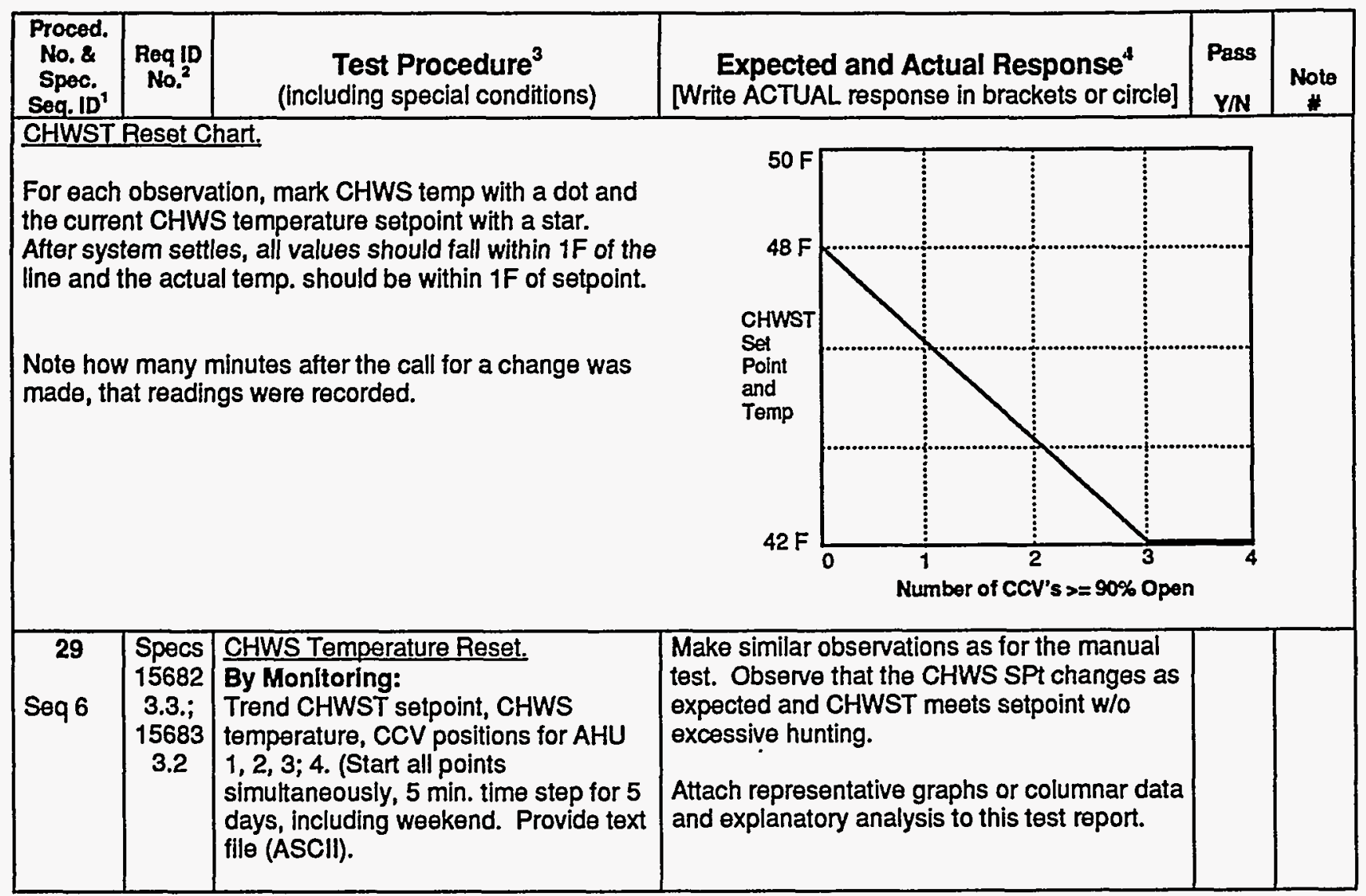

Notes: 


\begin{tabular}{|c|c|c|c|c|c|}
\hline $\begin{array}{c}\text { Proced. } \\
\text { No. \& } \\
\text { Spec. } \\
\text { Seq. ID' }\end{array}$ & $\begin{array}{c}\text { Req ID } \\
\text { No. }^{2}\end{array}$ & $\begin{array}{l}\text { Test Procedure } \\
\text { (including special conditions) }\end{array}$ & $\begin{array}{c}\text { Expected and Actual Response } \\
\text { [Write ACTUAL response in brackets or circle] }\end{array}$ & $\begin{array}{l}\text { Pass } \\
\text { Y/N }\end{array}$ & $\begin{array}{c}\text { Noto } \\
\text { \# }\end{array}$ \\
\hline $\begin{array}{c}30 \\
\text { Seq } 33\end{array}$ & \begin{tabular}{|c|} 
Specs \\
15682 \\
$3.3 . ;$ \\
15683 \\
3.2
\end{tabular} & $\begin{array}{l}\text { Chilled Water Pressure Control. } \\
\text { Setpoint is to have one CCV } 80 \% \\
\text { open. } \\
\text { With one or more chillers running in } \\
\text { auto and with all CCV's less than } 80 \% \\
\text { open. } \\
\text { Increase the call for cooling by } \\
\text { lowering DAT or space temperature } \\
\text { setpoint. } \\
\text { Increase the call for cooling by } \\
\text { lowering DAT or space temperature } \\
\text { setpoint. } \\
\\
\text { Significantly increase the call for } \\
\text { cooling by lowering DAT or space } \\
\text { temperature setpoint. }\end{array}$ & 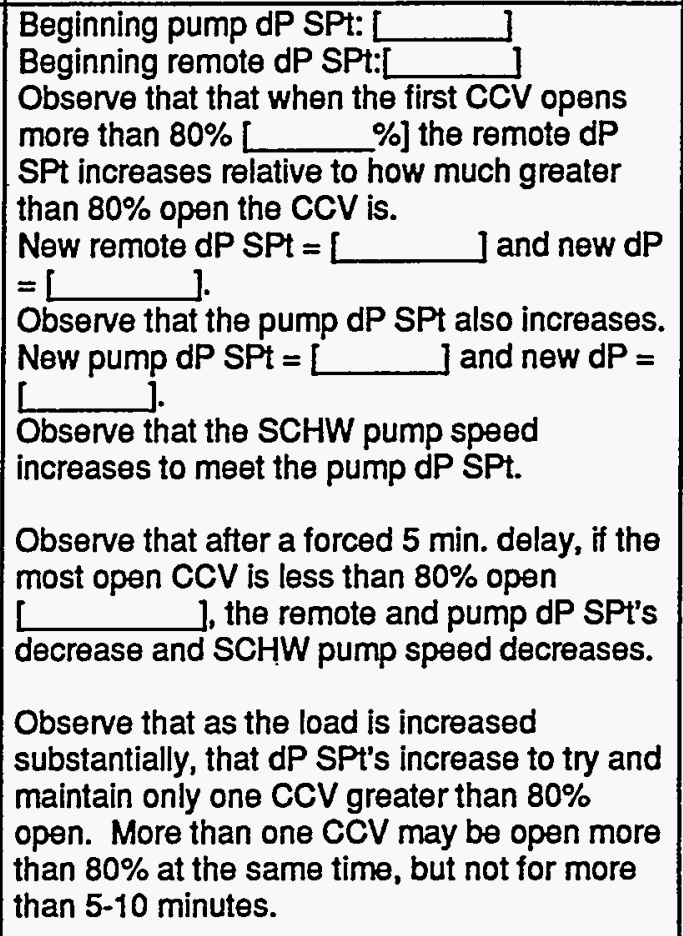 & & \\
\hline $\begin{array}{c}1 \\
\text { Seq } 33\end{array}$ & \begin{tabular}{|c|} 
Specs \\
15682 \\
$3.3 . ;$ \\
15683 \\
3.2
\end{tabular} & $\begin{array}{l}\text { Chilled Water Pressure Control. } \\
\text { By Monitoring. } \\
\text { Trend all CCV positions, pump } \\
\text { discharge differential pressure and } \\
\text { setpoint, remote pressure and } \\
\text { setpoint, VFD rpm on each CHW } \\
\text { pump; OSAT. } \\
\text { Trend during season of moderate to } \\
\text { significant cooling for } 3 \text { days at a } \\
\text { sampling rate of every } 5 \text { minutes; } \\
\text { 24hrs per day with output in ASCll file } \\
\text { columnar format. }\end{array}$ & $\begin{array}{l}\text { Observe that there is generally only one CCV } \\
\text { more than } 80 \% \text { open. At times, not lasting } \\
\text { more than about } 10 \text { minutes, there could be } \\
\text { more than one CCV more than } 80 \% \text { open. } \\
\text { The goal is to have one, and only one, CCV } \\
80 \% \text { open at all times. } \\
\text { Attach representative graphs or columnar data } \\
\text { and explanatory analysis to this test report. }\end{array}$ & & \\
\hline $\begin{array}{c}32 \\
\text { Seq } 5\end{array}$ & $\begin{array}{c}\text { Specs } \\
15682 \\
3.3 . ; \\
15683 \\
3.2\end{array}$ & $\begin{array}{l}\text { System Stabilization. Analyze CHW } \\
\text { reset and pressure control monitoring } \\
\text { data. }\end{array}$ & $\begin{array}{l}\text { Verify that the CHWS temperature is stable } \\
\text { and maintains the CHWS SPt within 0.5F over } \\
\text { a range of conditions and days. }\end{array}$ & & \\
\hline
\end{tabular}

Notes: 


\begin{tabular}{|c|c|c|c|c|c|}
\hline $\begin{array}{l}\text { Proced. } \\
\text { No. } \& \\
\text { Spec. } \\
\text { Seg. ID' }\end{array}$ & $\begin{array}{c}\text { Req ID } \\
\text { No. }^{2}\end{array}$ & $\begin{array}{l}\text { Test Procedure }{ }^{3} \\
\text { (including special conditions) }\end{array}$ & $\begin{array}{c}\text { Expected and Actual Response } \\
\text { [Write ACTUAL response in brackets or circle] }\end{array}$ & $\begin{array}{l}\text { Pass } \\
\text { Y/N } \\
\end{array}$ & $\begin{array}{c}\text { Noto } \\
\# \\
\end{array}$ \\
\hline $\begin{array}{c}33 \\
\text { Seq } 40\end{array}$ & \begin{tabular}{|c|} 
Specs \\
15682 \\
$3.3 . ;$ \\
15683 \\
3.2 \\
\end{tabular} & $\begin{array}{l}\text { Secondary Pumps for Freeze } \\
\text { Protection. } \\
\text { With chillers in auto, but not running, } \\
\text { manually start smoke exhaust system } \\
\text { EF- } 10 \text { and overwrite OSAT to be } 38 F \text {. }\end{array}$ & $\begin{array}{l}\text { Observe that SCHW pumps operate normally. } \\
\text { (EF-10-associated AHU CCV's should also be } \\
\text { open). }\end{array}$ & & \\
\hline $\begin{array}{l}34 \\
\operatorname{Seq} 5\end{array}$ & $\begin{array}{c}\text { Spocs } \\
15683 \\
3.2\end{array}$ & $\begin{array}{l}\text { CH-3 (Reciprocating) Staging. } \\
\text { By Monltoring. } \\
\text { Temporarily program the BAS to } \\
\text { readout and trend the stage of } \mathrm{CH}-3 \text {. } \\
\text { With } \mathrm{CH}-3 \text { as lead chiller in auto, call } \\
\text { for chlllers using a suitable method. } \\
\text { After CH-3 is fully loaded, remove all } \\
\text { load. } \\
\text { During the above, trend the CH-3 } \\
\text { stage, the CHWST and the CHWST } \\
\text { Spt at } 2 \text { min. intervals for } 1 \text { hour or } \\
\text { until chiller is fully loaded and then } \\
\text { unloads to stop. Provide tabular or } \\
\text { graphical documentation. }\end{array}$ & $\begin{array}{l}\text { Loading: } \\
\text { The trends should follow the } 8 \text { staging } \\
\text { sequences of stage vs CHWST offset from } \\
\text { setpoint (accounting for programmed delays), } \\
\text { etc. as per the programmed sequences. } \\
\text { Unloading: } \\
\text { The trends should follow the staging } \\
\text { sequences of stage vs CHWST offset from } \\
\text { setpoint (accounting for programmed delays), } \\
\text { etc. as per the programmed sequences. } \\
\text { Attach representative graphs or columnar data } \\
\text { and explanatory analysis to this test report. }\end{array}$ & & \\
\hline 35 & -- & $\begin{array}{l}\text { For all chiller and cooling tower } \\
\text { components, review current setpoints } \\
\text { and sequences with specifications and } \\
\text { control drawings. Submit approved } \\
\text { differences to be incorporated in } \\
\text { asbuilts. }\end{array}$ & $\begin{array}{l}\text { Setpoints and sequences are the same as } \\
\text { original specs. } \\
\text { OR } \\
\text { Differences submitted for asbuilts. }\end{array}$ & & \\
\hline \multicolumn{6}{|c|}{ CHILLER SAFETY CONTROLS } \\
\hline 36 & \begin{tabular}{|c|} 
Specs \\
15682 \\
$3.3 . ;$ \\
15683 \\
3.2
\end{tabular} & $\begin{array}{l}\text { CHW Flow Switch CH-1. } \\
\text { If PCHW pump is wired in series with } \\
\text { proof of flow switch, jumper pump out } \\
\text { of this loop. With chillers manually } \\
\text { off, but under conditions that will call } \\
\text { for chillers, manually turn off PCHW } \\
\text { pump. Turn Chiller } 1 \text { to auto. }\end{array}$ & $\begin{array}{l}\text { Obsene that chiller won't start because of no } \\
\text { CHW flow and that an alarm is generated. }\end{array}$ & & \\
\hline $\begin{array}{l}37 \\
\text { Seq } 2 \\
3\end{array}$ & \begin{tabular}{|c|} 
Specs \\
15682 \\
$3.3 . ;$ \\
15683 \\
3.2
\end{tabular} & $\begin{array}{l}\text { CHW Flow Switch CH-2. } \\
\text { If PCHW pump is wired in series with } \\
\text { proof of flow switch, jumper pump out } \\
\text { of this loop. With chillers manually } \\
\text { off, but under conditions that will call } \\
\text { for chillers, manually turn off PCHW } \\
\text { pump. Turn Chiller } 2 \text { to auto. }\end{array}$ & $\begin{array}{l}\text { Observe that chiller won't start because of no } \\
\text { CHW flow and that an alarm is generated. }\end{array}$ & & \\
\hline
\end{tabular}

\section{Notes:}




\begin{tabular}{|c|c|c|c|c|c|c|}
\hline $\begin{array}{l}\text { Proced. } \\
\text { No. \& } \\
\text { Spec. } \\
\text { Seq. ID' } \\
\end{array}$ & $\begin{array}{c}\text { Req ID } \\
\mathrm{No}^{2}\end{array}$ & \multicolumn{2}{|l|}{$\begin{array}{l}\text { Test Procedure } \\
\text { (including special conditions) }\end{array}$} & $\begin{array}{c}\text { Expected and Actual Response } \\
\text { [Write ACTUAL response in brackets or circle] }\end{array}$ & $\begin{array}{l}\text { Pass } \\
\text { YN }\end{array}$ & $\begin{array}{c}\text { Note } \\
\text { * }\end{array}$ \\
\hline $\begin{array}{l}38 \\
\text { Seq 2; } \\
3\end{array}$ & $\begin{array}{c}\text { Specs } \\
15682 \\
3.3 . ; \\
15683 \\
3.2\end{array}$ & \multicolumn{2}{|c|}{$\begin{array}{l}\text { CHW Flow Switch CH-3. } \\
\text { If PCHW pump is wired in series with } \\
\text { proof of flow switch, jumper pump out } \\
\text { of this loop. With chillers manually } \\
\text { off, but under conditions that will call } \\
\text { for chillers, manually turn off PCHW } \\
\text { pump. Turn Chiller } 3 \text { to auto. }\end{array}$} & $\begin{array}{l}\text { Observe that chiller won't start because of no } \\
\mathrm{CHW} \text { flow and that an alarm is generated. }\end{array}$ & & \\
\hline $\begin{array}{l}\text { MoQuay } \\
\text { O\&M }\end{array}$ & \begin{tabular}{c|} 
Specs \\
15682 \\
$3.3 . ;$ \\
15683 \\
3.2
\end{tabular} & \multicolumn{2}{|c|}{$\begin{array}{l}\text { Low evap. refrigerant temp/pressure } \\
\text { TBD } \\
\\
\\
\mathrm{CH}-1 \\
\mathrm{CH}-2 \\
\mathrm{CH}-3 \\
\end{array}$} & $\begin{array}{l}\text { Indicator lights for alarms, cutouts and normal } \\
\text { running function properly. } \\
\text { Compressor does not restart after cutout. }\end{array}$ & & \\
\hline $\begin{array}{l}\text { MoQuay } \\
\text { O\&M }\end{array}$ & $\begin{array}{c}\text { Specs } \\
15682 \\
3.3 . ; \\
15683 \\
3.2\end{array}$ & \multicolumn{2}{|c|}{$\begin{array}{|ll|}\text { High condenser pressure } & \\
\text { TBD } & \\
& \\
& \mathrm{CH}-1 \\
& \mathrm{CH}-2 \\
& \mathrm{CH}-3 \\
\end{array}$} & $\begin{array}{l}\text { Indicator lights for alarms, cutouts and normal } \\
\text { running function properly. } \\
\text { Compressor does not restart after cutout. }\end{array}$ & & \\
\hline $\begin{array}{l}\text { MoQuay } \\
\text { O\&M }\end{array}$ & $\begin{array}{c}\text { Specs } \\
15682 \\
3.3 . ; \\
15683 \\
3.2\end{array}$ & \multicolumn{2}{|c|}{$\begin{array}{|ll|}\text { High motor winding temperature } & \\
\text { TBD } & \\
& \mathrm{CH}-1 \\
& \mathrm{CH}-2 \\
& \mathrm{CH}-3 \\
\end{array}$} & $\begin{array}{l}\text { Indicator lights for alarms, cutouts and normal } \\
\text { running function properly. } \\
\text { Compressor does not restart after cutout. }\end{array}$ & & \\
\hline $\begin{array}{l}\text { MoQuay } \\
\text { O\&M }\end{array}$ & \begin{tabular}{c|} 
Specs \\
15682 \\
$3.3 . ;$ \\
15683 \\
3.2
\end{tabular} & \multicolumn{2}{|c|}{$\begin{array}{|ll|}\text { Low differential oil pressure } & \\
\text { TBD } & \\
& \\
& \mathrm{CH}-1 \\
& \mathrm{CH}-2 \\
& \mathrm{CH}-3 \\
\end{array}$} & $\begin{array}{l}\text { Indicator lights for alarms, cutouts and normal } \\
\text { running function properly. } \\
\text { Compressor does not restart after cutout. }\end{array}$ & & \\
\hline $\begin{array}{c}\text { MoQuay } \\
\text { O\&M }\end{array}$ & $\begin{array}{c}\text { Specs } \\
15682 \\
3.3 . ; \\
15683 \\
3.2\end{array}$ & \multicolumn{2}{|c|}{$\begin{array}{ll}\text { Low differential oil pressure } & \\
\text { TBD } & \\
& \\
& \mathrm{CH}-1 \\
& \mathrm{CH}-2 \\
& \mathrm{CH}-3 \\
\end{array}$} & $\begin{array}{l}\text { Indicator lights for alarms, cutouts and normal } \\
\text { running function properly. } \\
\text { Compressor does not restart after cutout. }\end{array}$ & & \\
\hline
\end{tabular}

Notes: 


\begin{tabular}{|c|c|c|c|c|c|c|}
\hline $\begin{array}{l}\text { Proced. } \\
\text { No. \& } \\
\text { Spec. } \\
\text { Seq. ID' }\end{array}$ & $\begin{array}{c}\text { Req ID } \\
\text { No. }^{2}\end{array}$ & $\begin{array}{l}\text { Test Procedure } \\
\text { (including special conditions) }\end{array}$ & & $\begin{array}{l}\text { Expected and Actual Response } \\
\text { [Write ACTUAL response in brackets or circle] }\end{array}$ & $\begin{array}{l}\text { Pass } \\
Y / N\end{array}$ & $\begin{array}{c}\text { Note } \\
*\end{array}$ \\
\hline $\begin{array}{l}\text { MoQuay } \\
\text { O\&M }\end{array}$ & \begin{tabular}{|c|} 
Specs \\
15682 \\
$3.3 . ;$ \\
15683 \\
3.2
\end{tabular} & Loss of any electrical power phase & $\begin{array}{l}\mathrm{CH}-1 \\
\mathrm{CH}-2 \\
\mathrm{CH}-3\end{array}$ & $\begin{array}{l}\text { Indicator lights for alarms, cutouts and normal } \\
\text { running function properly. } \\
\text { Compressor does not restart after cutout. }\end{array}$ & & \\
\hline $\begin{array}{c}45 \\
\text { MoQuay } \\
\text { O\&M }\end{array}$ & \begin{tabular}{|c|} 
Specs \\
15682 \\
$3.3 . ;$ \\
15683 \\
3.2
\end{tabular} & High oil temperataure & $\begin{array}{l}\mathrm{CH}-1 \\
\mathrm{CH}-2 \\
\mathrm{CH}-3\end{array}$ & $\begin{array}{l}\text { Indicator lights for alarms, cutouts and normal } \\
\text { running function properly. } \\
\text { Compressor does not restart after cutout. }\end{array}$ & & \\
\hline $\begin{array}{c}46 \\
\text { MoQuay } \\
\text { O\&M }\end{array}$ & \begin{tabular}{|c|} 
Specs \\
15682 \\
$3.3 . ;$ \\
15683 \\
3.2
\end{tabular} & $\begin{array}{l}\text { High bearing temperature } \\
\text { TBD }\end{array}$ & $\begin{array}{l}\mathrm{CH}-1 \\
\mathrm{CH}-2 \\
\mathrm{CH}-3\end{array}$ & $\begin{array}{l}\text { Indicator lights for alarms, cutouts and normal } \\
\text { running function properly. } \\
\text { Compressor does not restart after cutout. }\end{array}$ & & \\
\hline $\begin{array}{c}47 \\
\text { MoQuay } \\
\text { O\&M }\end{array}$ & \begin{tabular}{|c|} 
Specs \\
15682 \\
$3.3 . ;$ \\
15683 \\
3.2
\end{tabular} & $\frac{\text { Ground fault protection }}{\text { TBD }}$ & $\begin{array}{l}\mathrm{CH}-1 \\
\mathrm{CH}-2 \\
\mathrm{CH}-3\end{array}$ & $\begin{array}{l}\text { Indicator lights for alarms, cutouts and normal } \\
\text { running function properly. } \\
\text { Compressor does not restart after cutout. }\end{array}$ & & \\
\hline 48 & \begin{tabular}{|c|} 
Specs \\
15682 \\
$3.3 . ;$ \\
15683 \\
3.2 \\
\end{tabular} & $\begin{array}{l}\text { Interlocking of chillers and pumps } \\
\text { This is demonstrated in procedure } \\
\text { above (not the safeties). }\end{array}$ & & & & \\
\hline \multicolumn{7}{|c|}{ OTHER COOLING TOWER FUNCTIONS } \\
\hline $\begin{array}{c}49 \\
\text { Seq } 28\end{array}$ & \begin{tabular}{|c|} 
Specs \\
15682 \\
$3.3 . ;$ \\
15710 \\
2.2
\end{tabular} & $\begin{array}{l}\text { CT-1 Fan Failure Alarm. } \\
\text { With CT running, manually shut of } \\
\text { either of its fan motors. }\end{array}$ & & $\begin{array}{l}\text { Observe that an alarm is registered. Lag CT } \\
\text { comes on line automatically??? Manually??? }\end{array}$ & & \\
\hline $\begin{array}{c}50 \\
\text { Seq } 28\end{array}$ & \begin{tabular}{|c|} 
Specs \\
15682 \\
$3.3 . ;$ \\
15710 \\
2.2
\end{tabular} & $\begin{array}{l}\text { CT-2 Fan Failure Alarm. } \\
\text { With CT running, manually shut of } \\
\text { either of its fan motors. }\end{array}$ & & $\begin{array}{l}\text { Observe that an alarm is registered. Lag CT } \\
\text { comes on line automatically??? Manually??? }\end{array}$ & & \\
\hline
\end{tabular}

Notes: 


\begin{tabular}{|c|c|c|c|c|c|}
\hline $\begin{array}{l}\text { Procod. } \\
\text { No. \& } \\
\text { Spec. } \\
\text { Seq. ID' } \\
\end{array}$ & $\begin{array}{c}\text { Req ID } \\
\text { No. }^{2}\end{array}$ & $\begin{array}{l}\text { Test Procedure } \\
\text { (including special conditions) } \\
\end{array}$ & $\begin{array}{c}\text { Expected and Actual Response } \\
\text { [Write ACTUAL response in brackets or circle] }\end{array}$ & $\begin{array}{l}\text { Pass } \\
\text { Y/N } \\
\end{array}$ & $\begin{array}{c}\text { Noto } \\
\vdots\end{array}$ \\
\hline $\begin{array}{c}51 \\
\text { Seq } 28\end{array}$ & \begin{tabular}{|c|} 
Specs \\
15682 \\
$3.3 . ;$ \\
15710 \\
2.2 \\
\end{tabular} & $\begin{array}{l}\text { CT-3 Fan Failure Alarm. } \\
\text { With CT running, manually shut off } \\
\text { either of its fan motors. }\end{array}$ & $\begin{array}{l}\text { Observe that an alarm is registered. Lag CT } \\
\text { comes on line automatically??? Manually??? }\end{array}$ & & \\
\hline $\begin{array}{c}52 \\
\text { Seq } 29\end{array}$ & \begin{tabular}{|c|} 
Specs \\
15682 \\
$3.3 . ;$ \\
15710 \\
2.2
\end{tabular} & $\begin{array}{l}\text { CT Vibration Alarm. } \\
\text { (if not documented during startup) } \\
\text { Jump the vibration sensor to simulate } \\
\text { a vibration alarm. } \\
\qquad \frac{\text { CT-1: }}{\text { CT-2: }} \\
\text { CT-3: }\end{array}$ & $\begin{array}{l}\text { Observe that an alarm is registered and that } \\
\text { the CT fan shuts off. Lag CT comes on line } \\
\text { automatically??? Manually??? }\end{array}$ & & \\
\hline $\begin{array}{c}53 \\
\text { Seq } 25\end{array}$ & \begin{tabular}{|c|} 
Specs \\
15682 \\
$3.3 . ;$ \\
15710 \\
2.2
\end{tabular} & $\begin{array}{l}\text { CT High Water Alarm. } \\
\text { Plug sump overflow and override the } \\
\text { makeup valve, causing the CT sump } \\
\text { to over-fill. }\end{array}$ & $\begin{array}{l}\text { Observe that a high water limit alarm is } \\
\text { registered. }\end{array}$ & & \\
\hline $\begin{array}{c}54 \\
\text { Seg } 27\end{array}$ & \begin{tabular}{|c|} 
Specs \\
15682 \\
$3.3 . ;$ \\
15710 \\
2.2
\end{tabular} & $\begin{array}{l}\text { CT Low Water Alarm and Makeup } \\
\text { Override the makeup valve, causing } \\
\text { the CT sump to not-fill. Drain the } \\
\text { sump below the alarm level. } \\
\text { Return makeup valve to auto. }\end{array}$ & $\begin{array}{l}\text { Observe that a low water limit alarm is } \\
\text { registered. } \\
\text { Observe makeup valve open slowly and fill } \\
\text { sump until proper level; then close. }\end{array}$ & & \\
\hline $\begin{array}{c}55 \\
\text { Seq } 30\end{array}$ & \begin{tabular}{|c|} 
Specs \\
15682 \\
$3.3 . ;$ \\
15710 \\
2.2
\end{tabular} & $\begin{array}{l}\text { Winter Operation. } \\
\text { During weather with OSAT below 25F, } \\
\text { inspect CT. }\end{array}$ & $\begin{array}{l}\text { Observe the functioning of the heat tape, } \\
\text { verify that the sump temperature is above } \\
\text { setpoint, verify that freezing water on the } \\
\text { media is not excessive. Be sure that the fans } \\
\text { do not come on when water is going over the } \\
\text { tower (as only } 60 \mathrm{~F} \text { need be achieved). }\end{array}$ & & \\
\hline
\end{tabular}

Notes: 


\begin{tabular}{|c|c|c|c|c|c|c|c|}
\hline $\begin{array}{l}\text { Proced. } \\
\text { No. \& } \\
\text { Spoc. } \\
\text { Sog. } 1 D^{1}\end{array}$ & $\begin{array}{c}\text { Req ID } \\
\text { No. }^{2}\end{array}$ & $\begin{array}{l}\text { Test Procedure } \\
\text { (including special conditions) }\end{array}$ & $\underset{\text { Write A }}{\text { Ex }}$ & $\begin{array}{l}\text { ected an } \\
\text { STUAL res }\end{array}$ & $\begin{array}{l}\text { Jal Response } \\
\text { in brackets or circle] }\end{array}$ & $\begin{array}{l}\text { Pass } \\
\text { Y/N }\end{array}$ & Noto \\
\hline $\begin{array}{c}56 \\
\text { Seq } 26\end{array}$ & $\begin{array}{c}\text { Specs } \\
15682 \\
3.3 . ; \\
15710 \\
2.2\end{array}$ & 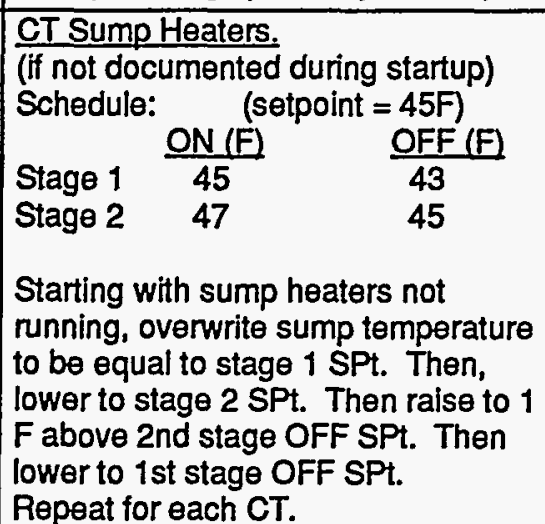 & $\begin{array}{l}\text { Actual: } \\
\text { CT-1 } \\
\text { Stage 1 } \\
\text { Stage 2 } \\
\text { CT-2 } \\
\text { Stage 1 } \\
\text { Stage 2 } \\
\text { CT-3 } \\
\text { Stage 1 } \\
\text { Stage 2 }\end{array}$ & $\begin{array}{l}\text { ON (F) } \\
\square \\
\square \\
\square \\
\square \\
\square \\
\square \\
\square\end{array}$ & $\begin{array}{l}\text { OFF (F) } \\
\square \\
\square \\
\square \\
\square\end{array}$ & & \\
\hline
\end{tabular}

Notes: 


\begin{tabular}{|c|c|c|c|c|c|}
\hline $\begin{array}{c}\text { Proced. } \\
\text { No. \& } \\
\text { Spec. } \\
\text { Seq. ID }\end{array}$ & $\begin{array}{c}\text { Req ID } \\
\text { No. }^{2}\end{array}$ & $\begin{array}{c}\text { Test Procedure } \\
\text { (including special conditions) }\end{array}$ & $\begin{array}{c}\text { Expected and Actual Response } \\
\text { Write ACTUAL response in brackets or circle] }\end{array}$ & $\begin{array}{c}\text { Pass } \\
\text { YNN }\end{array}$ & $\begin{array}{c}\text { Noto } \\
\text { W }\end{array}$ \\
\hline
\end{tabular}

\section{REPEAT PROCEDURES 1-8 WITH CHILLER 2 AS LEAD:}

\section{CHILLER SYSTEM STARTUP AND STAGING (2nd chiller as lead)}

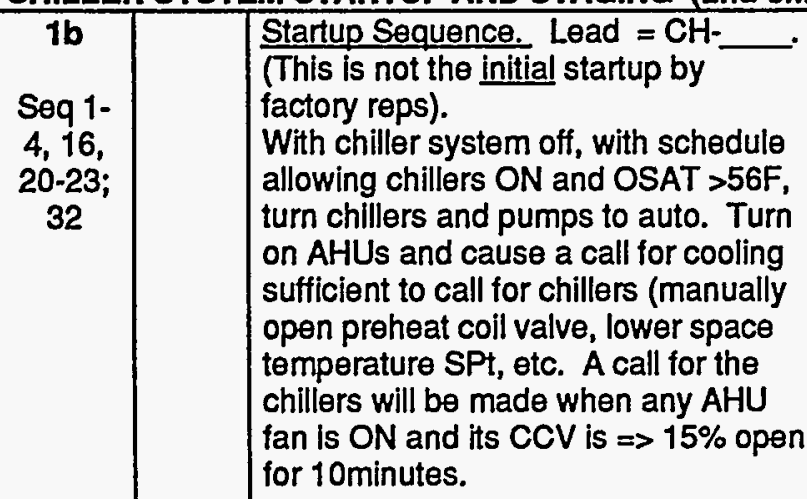

Vanes:

Specified Sequences:

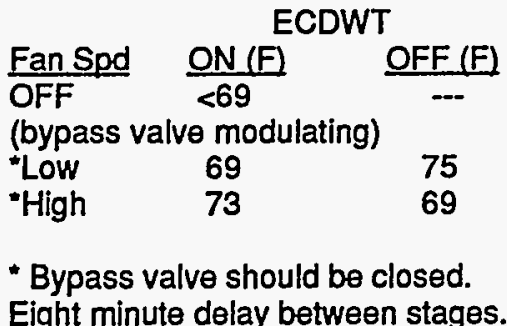

Maintain chiller load between $10-15 \%$ for 30 minutes.
Observe that the lead primary CHW pump does not furn ON until a CCV on an ON AHU is $=>15 \%$ $\%$ lopen for $10 \mathrm{~min}$. ].

Observe lead secondary CHW pump start when a CCV is $15 \%$ L ] open for 10 [__ minutes.

Observe CHW primary and secondary pumps tuming on, then the oil pump; then the CD pump (30-60s delay ea.)

Observe that secondary pumps start at minimum RPM and slowly ramp up. Starting $\mathrm{RPM}=$ ].

Observe the lead chiller starting. Observe that the vanes start closed and begin to open. (max spd = 0-full open in $\sim 3 \mathrm{~min}$. and closed in $\sim 1$ minute)

OSAT $=$ F]. Observe that when the lead chiller started the CT specified sequences followed, with delays between stages. Observe that the ECDWT SPt of $65 \mathrm{~F}$ is maintained, unless OSA conditions prohibit. Record various ECDW temps during lead chiller operation only:



Record of Observed Sequences:

Fan Spd
OFF
(bypass valve modulating)
Low
High
Observe that there is no surging or abnormal
vibration.

\section{Notes:}




\begin{tabular}{|c|c|c|c|c|c|}
\hline $\begin{array}{l}\text { Proced. } \\
\text { No. \& } \\
\text { Spec. } \\
\text { Seq. ID' }\end{array}$ & $\begin{array}{l}\text { Req iD } \\
\text { No. }\end{array}$ & $\begin{array}{l}\text { Test Procedure } \\
\text { (including special conditions) }\end{array}$ & $\begin{array}{l}\text { Expected and Actual Response } \\
\text { [Write ACTUAL response in brackets or circle] }\end{array}$ & $\begin{array}{l}\text { Pass } \\
\text { Y/N }\end{array}$ & $\begin{array}{c}\text { Note } \\
\text { \# }\end{array}$ \\
\hline $\begin{array}{c}2 b \\
\text { Seq } 8\end{array}$ & & $\begin{array}{l}\text { 1st Lag Chiller Staging ON. } \\
\text { Staging sequence: } \mathrm{CH}- \\
\rightarrow \mathrm{CH}- \\
\text { With chillers in auto, and loaded such } \\
\text { that only lead chiller is running, lower } \\
\text { space setpoints so CCVs open. Wait } \\
\sim 10 \text { minutes. Record time that } \\
\text { primary flow and secondary flow } \\
\text { become equal. Wait } 20 \text { minutes. }\end{array}$ & $\begin{array}{l}\text { Total primary flow = L gpm]. } \\
\text { Secondary CHW flow => primary CHW flow = } \\
\text { gpm] and lead chiller is at least } 95 \% \\
\text { loaded (by \% of rated cument), [ } \\
\text { amps]. Time: [ } \\
\text { minutes, 1st lag chiller should start (PCHWP - } \\
\text { oil pump - CDP - chiller). Time when 1st lag } \\
\text { chiller started = [ } \\
\text { Observe that the amps on both chillers are } \\
\text { within } 5 \% \text { of each other. }\end{array}$ & & \\
\hline $\begin{array}{c}3 b \\
\text { Seq 8; } \\
32-34\end{array}$ & & $\begin{array}{l}\text { Ist Lag Secondary CHWP } \\
\text { Staging ON. } \\
\text { Continue increasing cooling load, if } \\
\text { necessary, to cause CCVs to open } \\
\text { further. }\end{array}$ & 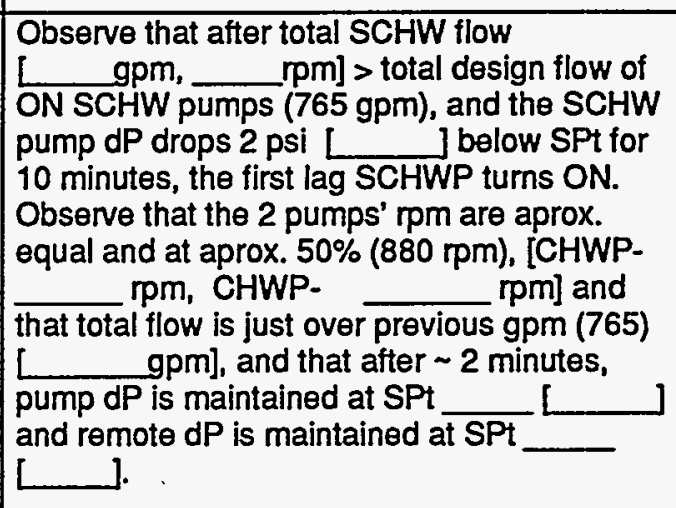 & & \\
\hline $\begin{array}{c}4 b \\
\text { Seq 8; } \\
21-24\end{array}$ & & $\begin{array}{l}\text { 1st Laq Cooling Tower Staging ON. } \\
\text { During the preceding sequences: }\end{array}$ &  & & \\
\hline
\end{tabular}

\section{Notes:}




\begin{tabular}{|c|c|c|c|c|c|}
\hline $\begin{array}{c}\text { Proced. } \\
\text { No. \& } \\
\text { Spoc. } \\
\text { Sog. ID }\end{array}$ & $\begin{array}{c}\text { Req ID } \\
\mathrm{No}^{2}\end{array}$ & $\begin{array}{l}\text { Test Procedure } \\
\text { (including special conditions) }\end{array}$ & $\begin{array}{l}\text { Expected and Actual Response } \\
\text { [Write ACTUAL response in brackets or circle] }\end{array}$ & $\begin{array}{l}\text { Pass } \\
\text { Y/N }\end{array}$ & $\begin{array}{c}\begin{array}{c}\text { Note } \\
\text { \# }\end{array} \\
\end{array}$ \\
\hline $\begin{array}{c}5 b \\
\text { Seq } 8\end{array}$ & & $\begin{array}{l}\text { 2nd Lag Chiller Staging ON Cont. } \\
\text { After second chiller starts, continue } \\
\text { calling for more cooling to start third } \\
\text { chiller. }\end{array}$ &  & & \\
\hline $\begin{array}{c}6 b \\
\text { Seq 8; } \\
32-34\end{array}$ & & $\begin{array}{l}\text { 2nd Lag Secondary CHWP } \\
\text { Staging ON Cont. } \\
\text { Continue increasing cooling load, if } \\
\text { necessary, to cause CCVs to open } \\
\text { further. }\end{array}$ &  & & \\
\hline
\end{tabular}

Notes: 


\begin{tabular}{|c|c|c|c|c|c|}
\hline $\begin{array}{c}\text { Proced. } \\
\text { No. } 8 \\
\text { Spec. } \\
\text { Seq. ID' }\end{array}$ & $\begin{array}{c}\text { Req ID } \\
\text { No. }^{2}\end{array}$ & $\begin{array}{l}\text { Test Procedure } \\
\text { (including special conditions) }\end{array}$ & $\begin{array}{l}\text { Expected and Actual Response } \\
\text { [Write ACTUAL response in brackets or circle] }\end{array}$ & $\begin{array}{l}\text { Pass } \\
\text { YN } \\
\end{array}$ & $\begin{array}{c}\text { Note } \\
\#\end{array}$ \\
\hline $\begin{array}{c}7 b \\
\text { Seq } 8 \\
21-24\end{array}$ & & $\begin{array}{l}\text { 2nd Lag Cooling Tower Staging ON. } \\
\text { During the preceding sequences: }\end{array}$ & $\begin{array}{l}\text { OSAT = } \mathrm{F}] \text {. } \\
\text { Observe that when the 2nd lag chiller started } \\
\text { the CT specified sequences followed, with } \\
\text { delays between stages. Observe that the } \\
\text { ECDWT SPt of } 65 \mathrm{~F} \text { is maintained, unless } \\
\text { OSA conditions prohibit. Record various } \\
\text { ECDW temps when all three chillers are } \\
\text { operating: [ } \\
\text { Record of Observed Sequences: } \\
\text { Fan Spd } \\
\text { OFF ON (F) } \\
\text { (bypass valve modulating) } \\
\text { Low } \\
\text { High }\end{array}$ & & \\
\hline
\end{tabular}

Notes: 


\begin{tabular}{|c|c|c|c|c|c|}
\hline $\begin{array}{c}\text { Proced. } \\
\text { No. \& } \\
\text { Spoc. } \\
\text { Seg. ID' }\end{array}$ & $\begin{array}{l}\text { Req ID } \\
\text { No. }^{2}\end{array}$ & $\begin{array}{c}\text { Test Procedure } \\
\text { (Including special conditions) } \\
\end{array}$ & $\begin{array}{c}\text { Expected and Actual Response } \\
\text { Write ACTUAL response in brackets or circle] } \\
\end{array}$ & $\begin{array}{l}\text { Pass } \\
\text { YNN }\end{array}$ & $\begin{array}{c}\text { Note } \\
\#\end{array}$ \\
\hline $\begin{array}{c}8 b \\
\text { Seq 9; } \\
10 ; 35\end{array}$ & & $\begin{array}{l}\text { Chillers Staging OFF. } \\
\text { Raise space setpoints so CCVs close, } \\
\text { or shut off some or all AHU's. Wait } \\
\sim 10 \text { minutes. Record time that } \\
\text { primary flow exceeds secondary flow } \\
\text { by capacity of last selected pump. } \\
\text { Wait thru } 20 \text { min. delay. (CHWP } 1-3 \\
=675 \mathrm{gpm} \text { ea., CHWP } 4 ; 5=180 \mathrm{gpm} \\
\text { ea.) } \\
\text { Repeat to see 1st lag chiller stage off. } \\
\text { Repeat to see lead chiller stage off. }\end{array}$ & $\begin{array}{l}\text { 2nd Lag Chiller Staging OFF* } \\
\text { Observe that when the total SCHW gpm has } \\
\text { reduced to be }<=\text { the sum of the first two } \\
\text { selected SCHW pumps for } 10 \text { minutes, that } \\
\text { the second lag SCHW pump shuts OFF. } \\
\text { Primary CHW flow > secondary flow by } \\
\text { chiller and pumps should stop. Time when } \\
\text { 2nd lag chiller stops = [ } \\
\text { Cooling tower fans shut down as expected: } \\
\text { Main fan--pony motor-all OFF. } \\
\text { First Lag Chiller Staging OFF* } \\
\text { Observe that when the total SCHW gpm has } \\
\text { reduced to be }<=\text { the lead SCHW pump for } 10 \\
\text { minutes, that the first lag SCHW pump shuts } \\
\text { OFF. } \\
\text { Primary CHW flow > secondary flow by } \\
\text { 20 minutes, } 1 \text { st lag chiller and pumps should } \\
\text { stop. Time when 1st lag chiller stops = } \\
\text { L. Cooling tower fans shut } \\
\text { down as expected: Main fan--pony motor-all } \\
\text { OFF. } \\
\text { Lead Chiller Staging OFF* } \\
\text { When all CCVs are < 15\% open for } 10 \text { min. } \\
\text { and after an additional } 20 \text { min. delay, lead } \\
\text { chiller and all pumps should shut down. } \\
\text { "No no-flow alarms should be generated } \\
\text { during normal staging down. }\end{array}$ & & \\
\hline
\end{tabular}

Notes: 


\begin{tabular}{|c|c|c|c|c|c|}
\hline $\begin{array}{l}\text { Proced. } \\
\text { No. \& } \\
\text { Spoc. } \\
\text { Seq. } 10^{1} \\
\end{array}$ & $\begin{array}{l}\text { Req ID } \\
\text { No. }^{2}\end{array}$ & $\begin{array}{c}\text { Test Procedure } \\
\text { (including special conditions) } \\
\end{array}$ & $\begin{array}{c}\text { Expected and Actual Response } \\
\text { [Write ACTUAL response in brackets or circle] }\end{array}$ & $\begin{array}{l}\text { Pass } \\
\text { YNN }\end{array}$ & $\begin{array}{l}\text { Note } \\
\# \\
\end{array}$ \\
\hline 57 & $\begin{array}{c}15682 \\
3.3 . C ; \\
D\end{array}$ & \multicolumn{2}{|c|}{$\begin{array}{l}\text { Chlller Efflciency Testlng and Benchmarking. } \\
\text { The efficlency and capacity testing specified shall be substituted with the following } \\
\text { efficiency benchmarking. In summary this will consist of: } \\
\text { A. Obtain calculated kw/ton values from the mf'r for each chiller model for all possible } \\
\text { combinations of } 4 \text { ECDW temps, } 4 \text { LCHW temps and 100, 75, } 50 \text { and } 25 \% \text { loads, } \\
\text { totalling } 60 \text { points. Plot kw/ton vs \% Load. Perform a regression based on DOE-2 } \\
\text { chiller curve equation forms through the data, using the PG\&E Chiller Performance } \\
\text { Evaluation Tool. Use the same equation form for each chiller model. } \\
\text { B. During a near design day and a moderate cooling day, trend the LCHWT, ECDWT, } \\
\text { kw, RCHWT, CHW gpm at } 15 \text { min. intervals over the occupied period. Calculate \% } \\
\text { load and tons at each point. Trend each chiller as needed to establish a good variety } \\
\text { of load, ECDWT and reset CHWT. Plot kw/ton vs \% Load. Perform a regression based } \\
\text { on the same curve forms as for the mf't data. } \\
\text { C. Compare the chiller plots in B. to mir's plots in A. Significant difference between } \\
\text { mi'r data in A and actual data plots in B may indicate problems. If the ARI APLV } \\
\text { (Application Part Load Value) kw/ton efficiency calculated in the PG\&E tool, for the } \\
\text { actual chiller is more than } 15 \% \text { greater than the calculated APLV from the mf'r data, } \\
\text { then full site verification and testing of full and part load efficiencies at ARI conditions, } \\
\text { as per the original specs, will be necessary, unless the reason for inefficiency can be } \\
\text { traced to site installation problems and remedied. } \\
\text { D. Compare the chiller plots in B for the identical chillers. Significant differences } \\
\text { between CH-1 and CH-2 actual plots in B may indicate problems with one of the } \\
\text { chillers. } \\
\text { E. The plots in B provide the efficiency benchmark for these chillers. Similar tests can } \\
\text { be completed annually to verify and ensure continued efficient chiller operation by } \\
\text { comparing curve fit regressions of current operation with that of the original } \\
\text { benchmarks. } \\
\text { The commissioning consultant (PECI) shall perform all data analysis for the } \\
\text { benchmarking and submit a full report of the process and results. }\end{array}$} & & \\
\hline 58 & - & $\begin{array}{l}\text { Return all changed control } \\
\text { parameters and conditions to } \\
\text { their pre-test values }\end{array}$ & & & \\
\hline
\end{tabular}

\section{SEQUENCES AND COMPONENTS NOT TESTED}

\begin{tabular}{|l|l|l|l|l|}
\hline 59 & & $\frac{\text { Vibration Isolators. }}{\text { Not tested. }}$ & & \\
\hline 60 & & $\frac{\text { Capacity Testing }}{\text { Not tested. }}$ & & \\
\hline
\end{tabular}

\section{Notes:}




\begin{tabular}{|l|l|l|}
\hline 61 & $\begin{array}{l}\text { SCHW Pump End of Curve Safety. } \\
\text { Not tested (from examining the pump } \\
\text { curves and operating points, pumps } \\
\text { are sufficiently oversized to make an } \\
\text { end of curve event highly unlikely) }\end{array}$ & $\mid$ \\
\hline MONITORING AND TREND LOGGING & \\
Monitoring via BAS trend logs are required per test procedures 14, 17, 29, 31, 34; 57. Attach representative graphs or \\
Columnar data and explanatory analysis to this test report.
\end{tabular}

"Abbreviations; SCHW = secondary chilled water, PCHW = primary chilled water. $d P=d i f f$. pressure, $S P t=$ setpoint CHWS = chilled water supply, CT = cooling tower, BAS = bullding automation system.

${ }^{1}$ Sequences of operation attached to this test.

${ }^{2}$ Mode or function ID being tested from testing requirements section of the project Specifications.

${ }^{3}$ Step-by-step procedures for manual testing, trend logging or data-logger monitoring.

4 Include tolerances for a passing condition. Fill-in spaces or lines not in brackets denote sequence parameters still to be specified by the AVE, conrols contractor or vendor. Write "Via BAS" for verifications of device position from BAS readout or "Via obs" for actual observation or from test instrument reading.

${ }^{6}$ Record any permanently changed parameter values and submit changes to Owner.

Methods to False Load Chillers

1) If OSAT is less than 75F, prevent economizer cool OSA from entering the building.

a) Manually close the economizer OSA dampers, OR

b) Lower the changeover economizer setpoint below the OSAT (if DB type), OR lastly

c) Ovenwrite the OSAT value to be $80 \mathrm{~F}$ or more so dampers won't open.

2) Use OSA preheat coils to heat incoming OSA.

Enable the boiler by removing any lockouts, etc. Manually open the min. OSA preheat coil valve to preheat the OSA. Increase the min. OSA discharge temperature setpoint and the heating water supply temperature, as necessary.

3) Lower the space temperature setpoint.

4) Prior to the chiller test, manually preheat the building space temperature to $78 \mathrm{~F}-80 \mathrm{~F}$.

5) Lower the chilled water supply temperature setpoint.

False Loading Cooling Towers

1) False load the chiller (see above)

\section{A SUMMARY OF DEFICIENCIES IDENTIFIED DURING TESTING IS ATTACHED}

\section{- END OF TEST -}

Notes: 


\title{
Functional Test
}

\section{Project:}

FT-__ HEATING FAN COIL FCU-1, Room B-102

\section{Participants}

\author{
Related Tests: Boilers
}

Party

Participation

Party filling out this form and witnessing testing

Date of test

\section{Prerequisite Checklist}

a. The following have been started up and startup reports and prefunctional checklists submitted and approved ready for functional testing:_ FCU-1

b. Boilers $1 ; 2$ have successfully completed functional testing.

c. - All control system functions for this and all interlocking systems are programmed and operable per contract documents, including final setpoints, schedules, debugging, loop tuning and sensor calibrations complete.

\section{Controls Contractor Signature or Verbal $\quad \overline{\text { Date }}$}

d. _ All A/E punchlist items for this equipment corrected.

e. - Safeties and operating ranges reviewed.

f. - Test requirements and sequences of operation attached.

g. - Schedules and setpoints attached.

h. - Have all energy savings control strategies, setpoints and schedules been incorporated that this equipment and control system are capable of? If not, list recommendations below.

i. BAS Program Review. Review the BAS software control program(s) for this equipment. Parameters, setpoints and logic sequences appear to follow the specified written sequences.

j. Packaged Control Program Review. Review the packaged control program(s) for this equipment. Parameters, setpoints and logic sequences appear to follow the specified written sequences.

k. Record of All Values for Current Setpoints (SP), Control Parameters, Limits, Delays, Lockouts, Schedules, Etc. Changed to Accommodate Testing:

\begin{tabular}{|c|c|c|}
\hline Parameter & $\begin{array}{c}\text { Pre-Test } \\
\text { Values }\end{array}$ & $\begin{array}{c}\text { Retumed } \\
\text { to Pre-Test } \\
\text { Values } \sqrt{ }\end{array}$ \\
\hline FCU-1 setpoint & & \\
\hline
\end{tabular}

\begin{tabular}{|c|c|c|}
\hline Parameter & $\begin{array}{c}\text { Pro-Test } \\
\text { Values }\end{array}$ & $\begin{array}{c}\text { Retumed } \\
\text { to Pre-Test } \\
\text { Values } \checkmark\end{array}$ \\
\hline & & \\
\hline
\end{tabular}

Notes: 
3. Sensor Calibration Checks. Check the sensors listed below for calibration and adequate location. This is a sampling check of calibrations done during prefunctional checklisting. Test the packaged controls and BAS readings.

"In calibration" means making a reading with a calibrated test instrument within 6 inches of the site sensor. Verify that the sensor reading (via the permanent thermostat, gage, packaged control panel or building automation system (BAS)) compared to the test instrument-measured value is within the tolerances specified in the prefinctional checklist requirements ( ). If not, install offset in BAS, calibrate or replace sensor. Use the same test instruments as used for the original calibration, if possible.

\begin{tabular}{|l|c|c|c|c|c|}
\hline Sensor \& Location & $\begin{array}{c}\text { Loc- } \\
\text { ation } \\
\text { OK }\end{array}$ & $\begin{array}{c}\text { 1st Gage or } \\
\text { Pkg \& BAS } \\
\text { Values }\end{array}$ & $\begin{array}{c}\text { Instru. } \\
\text { Meas'd } \\
\text { Value }\end{array}$ & $\begin{array}{c}\text { Final Gage or } \\
\text { Pkg \& BAS } \\
\text { Values }\end{array}$ & $\begin{array}{c}\text { Pass } \\
\text { YNN? }\end{array}$ \\
\hline \hline FCU-1 stat temp. & & Stat: & & Star: & \\
\hline
\end{tabular}

${ }^{1}$ Sensor location is appropriate and away from causes of erratic operation.

\section{Device Calibration Checks.}

\section{-NONE--}

\section{Verification of Misc. Prefunctional Checks.}

Misc. site checks of the prefunctional checklist and startup reports completed successfully. Pass? Y / N Unit mounted securely. _ Unit accessible for servicing. _ No unusual noise or vibration in fan.

\section{Functional Testing Record}

\begin{tabular}{|c|c|c|c|c|}
\hline $\begin{array}{c}\text { Proced. } \\
\text { No. \& } \\
\text { Spec. } \\
\text { Sog. } 1 D^{\top} \\
\end{array}$ & $\begin{array}{c}\text { Req ID } \\
\mathrm{No}^{2}\end{array}$ & $\begin{array}{c}\text { Test Procedure } \\
\text { (including special conditions) }\end{array}$ & $\begin{array}{c}\text { Expected and Actual Response } \\
\text { [Write ACTUAL response in } \\
\text { brackets or circle] }\end{array}$ & $\begin{array}{c}\text { Pass } \\
\text { Y/N } \\
\text { \& Note } \\
\text { \# } \\
\end{array}$ \\
\hline $\begin{array}{c}1 \\
\text { Seq. } 1\end{array}$ & & $\begin{array}{l}\text { Adjust the stat setpoint until it is equal to the } \\
\text { space temp. }\end{array}$ & $\begin{array}{l}\text { Fan starts. _ Heating coil valve } \\
\text { opens; _ _warm air delivered. }\end{array}$ & \\
\hline $\begin{array}{c}2 \\
\text { Seq. } 1 \\
\end{array}$ & & $\begin{array}{l}\text { Adjust the stat setpoint until it is } 4 \mathrm{~F} \text { below } \\
\text { the space temp. }\end{array}$ & $\begin{array}{l}\text { Fan stops. } \\
\text { Heating coil valve closes. }\end{array}$ & \\
\hline 3 & - & $\begin{array}{l}\text { Return all changed control parameters } \\
\text { and conditions to their pre-test values }{ }^{5}\end{array}$ & $\begin{array}{l}\text { Check off in Section } 2 \text { above } \\
\text { when completed }\end{array}$ & \\
\hline
\end{tabular}

Record Foot Notes

${ }^{3}$ Sequences of operation specified in Contract Documents (attached).

${ }^{2}$ Mode or function ID being tested, per testing requirements section of the project Specifications.

${ }^{3}$ Step-by-step procedures for manual testing, trend logging or data-logger monitoring.

${ }^{4}$ Include tolerances for a passing condition.

${ }^{5}$ Record any permanently changed parameter values and submit to Owner.

\section{- END OF TEST -}

\section{Notes:}




\section{Functional Test}

\section{Project:}

\section{FT- $\quad$ FIN TUBE RADIATOR FT}

(There are fin tubes in this project and will be tested.)

Related Tests: Boilers, Interlocked TU-

\section{Participants}

Party

Participation

Party filling out this form and witnessing testing

Date of test

\section{Prerequisite Checklist}

a. The following have been started up and startup reports and prefunctional checklists submitted and approved ready for functional testing: TU's

b. - Boilers have successfully completed functional testing.

c. - All control system functions for this and all interlocking systems are programmed and operable per contract documents, including final setpoints, schedules, debugging, loop tuning and sensor calibrations complete.

\section{Controls Contractor Signature or Verbal Date}

d. _ All A/E punchlist items for this equipment corrected.

e. - Safeties and operating ranges reviewed.

f. - Test requirements and sequences of operation attached.

g. - Schedules and setpoints attached.

h. - Have all energy savings control strategies, setpoints and schedules been incorporated that this equipment and control system are capable of? If not, list recommendations below.

i. BAS Program Review. Review the BAS software control program(s) for this equipment. Parameters, setpoints and logic sequences appear to follow the specified written sequences.

j. Record of All Values for Current Setpoints (SP), Control Parameters, Limits, Delays, Lockouts, Schedules, Etc. Changed to Accommodate Testing:

3. Sensor Calibration Checks. Check the sensors listed below for calibration and adequate location. This is a sampling check of calibrations done during prefunctional checklisting. Test the packaged controls and BAS readings. -NONE-

Notes: 
4. Device Calibration Checks. Check the actuators or devices listed below for calibration.

"In calibration" means observing a readout in the BAS and going to the actuator or controlled device and verifying that the BAS reading is correct. For items out of calibration or adjustment, fix now if easy, via an offset in the BAS, or a mechanical fix.

Heating coil valve (HCV): Set pumps to normal mode. Procedure 1. Command valve to a few intermediate positions. Verify that reading in BAS reasonably correspond to the actual positions. For heating coil valves (NO): Procedure $2 a$. Set heating setpoint $20^{\circ} \mathrm{F}$ above room temperature. Verify BAS reading says $100 \%$ open. Visually verify valve is fully open. $2 b$. Remove control air or electricity from the valve and verify that the valve stem and actuator position do not change. Procedure 3 . Restore to normal. Set heating setpoint to $20^{\circ} \mathrm{F}$ below room temperature. Observe the valve close. 4. For pneumatic actuators, by override in the EMS, increase pressure to valve by $3 \mathrm{psi}$ (do not exceed actuator rating). Verify valve stem \& actuator position does not change. Restore to normal.

\begin{tabular}{|c|c|c|c|c|c|}
\hline $\begin{array}{l}\text { Device or Actuator \& } \\
\text { Location }\end{array}$ & Procedure / State & BAS Value & $\begin{array}{c}\text { Site } \\
\text { Osservation }\end{array}$ & Corrections & $\begin{array}{l}\text { Pass } \\
\text { Y/N }\end{array}$ \\
\hline \multirow{5}{*}{$\begin{array}{l}\text { Heating coil valve (HCV) } \\
\text { position or command and } \\
\text { stroke }\end{array}$} & 1. Intermediate positions & & & & \\
\hline & 2a. Full open & & & & \\
\hline & 2b. Remove power or air (full open) & & & & \\
\hline & 3. Closed & & & & \\
\hline & 4. Increase pressure (close) & & & & \\
\hline & & & & & \\
\hline & & & & & \\
\hline
\end{tabular}

\section{Verification of Misc. Prefunctional Checks.}

Misc. site checks of the prefunctional checklist and startup reports completed successfully. Pass? Y /N Unit mounted securely. _ Valves and unit accessible for servicing.

Notes: 


\section{Functional Testing Record}

\begin{tabular}{|c|c|c|c|c|}
\hline $\begin{array}{l}\text { Proced. } \\
\text { No. \& } \\
\text { Spec. } \\
\text { Seq. ID' }\end{array}$ & $\begin{array}{c}\text { Req ID } \\
\text { No. }\end{array}$ & $\begin{array}{l}\text { Test Procedure } \\
\text { (including special conditions) }\end{array}$ & $\begin{array}{c}\text { Expected and Actual Response } \\
\text { [Write ACTUAL response in } \\
\text { brackets or circle] }\end{array}$ & $\begin{array}{l}\text { Pass } \\
\text { YN } \\
\text { Note } \\
\text { \# }\end{array}$ \\
\hline$\overline{1}$ & & $\begin{array}{l}\text { General Sequencing. } \\
\text { a. With boilers in normal mode and ON, } \\
\text { increase space setpoint } 20 F \text { fof TU- } \\
\text { (interlocked to the fin tube). If OSAT is not > } \\
40 F \text {, overwrite it to be > 4OF. Ovenwrite space } \\
\text { temp to be } 3 F \text { below main setpoint (cooling) } \\
\text { F and observe in BAS that there is } \\
\text { heating deck flow and cooling flow goes to } \\
\text { minimum. Observe that the fin tube or radiant } \\
\text { panels remain OFF. } \\
\text { b. Change the space temp. to be 5F below } \\
\text { main setpoint (cooling) } \\
\text { the radiant panels or fin tubes remain OFF. } \\
\text { c. Change the OSAT to be < } 40 F \text {. Observe } \\
\text { that the radiant panels or fin tubes start } \\
\text { heating. } \\
\text { Return all parameters to normal. }\end{array}$ & $\begin{array}{l}\text { a. TU goes into heating mode. } \\
\text { Fin tube HCV's remain closed. } \\
\text { b. TU remains in heating mode. } \\
\text { Fin tube HCV's remain closed. } \\
\text { c. TU remains in heating mode. } \\
\text { Fin tube HCV's open. }\end{array}$ & \\
\hline 2 & & $\begin{array}{l}\text { Lower space setpoint to } 20 \mathrm{~F} \text { below space } \\
\text { temperature of TU- }\end{array}$ & $\begin{array}{l}\text { TU goes into cooling mode. } \\
\text { Fin tube heating valve closes } \\
\text { equally with TU heating command } \\
\text { (TU HCV or dual duct heating } \\
\text { damper). }\end{array}$ & \\
\hline 3 & & $\begin{array}{l}\text { Valve Leakage Test. After } 1 \text { hour or more } \\
\text { with fin tube heating valve closed, verify } \\
\text { that no hot water is leaking through valve by } \\
\text { feeling fin tube } 3 \text { feet from valve. }\end{array}$ & $\begin{array}{l}\text { Tube should be near room } \\
\text { temperature. }\end{array}$ & \\
\hline 4 & & Trend Logs. NONE & & \\
\hline 5 & & & & \\
\hline 6 & - & $\begin{array}{l}\text { Return all changed control parameters } \\
\text { and conditions to their pre-test values }\end{array}$ & $\begin{array}{l}\text { Check off in Section } 2 \text { above } \\
\text { when completed }\end{array}$ & \\
\hline
\end{tabular}

Record Foot Notes

${ }^{1}$ Sequences of operation specified in Contract Documents (attached).

${ }^{2}$ Mode or function ID being tested, per testing requirements section of the project Specifications.

${ }^{3}$ Step-by-step procedures for manual testing, trend logging or data-logger monitoring.

${ }^{4}$ Include tolerances for a passing condition.

${ }^{5}$ Record any permanently changed parameter values and submit to Owner.

\section{- END OF TEST -}

Notes: 


\section{Functional Test}

Project:

FT-04

PACKAGED ROOFTOP DX AIR CONDITIONING UNIT RTU

Including integral equipment: supply fans, inlet vanes, __ variable speed drive

Related Tests:

\section{Participants}

Party

Participation

Party filling out this form and witnessing testing

Date of test

\section{Prerequisite Checklist}

a. The following have been started up and startup reports and prefunctional checklists submitted and approved ready for functional testing:

- Duct system

_ Connected Terminal Units

b. All control system functions for this and all interlocking systems are programmed and operable per contract documents, including final setpoints and schedules with debugging, loop tuning and sensor calibrations completed.

Controls Contractor Signature or Verbal $\quad \overline{\text { Date }}$

c. - Vibration control report approved (if required).

d. - Test and balance (TAB) completed and approved for the hydronic systems and terminal units connected.

e. - All A/E punchlist items for this equipment corrected.

f. - These functional test procedures reviewed and approved by installing contractor.

g. - Safeties and operating ranges reviewed.

h. - Test requirements and sequences of operation attached.

i. - Schedules and setpoints attached.

Notes: 
j. False loading equipment, system and procedures ready (boilers, preheat or reheat coils, control loops, override on OSA dampers, etc.)

k. _ Have all energy savings control strategies, setpoints and schedules been incorporated that this equipment and control system are capable of? If not, list recommendations below.

1. BAS Program Review. Review the BAS software control program(s) for this equipment. Parameters, setpoints and logic sequences appear to follow the specified written sequences.

m. Packaged Control Program Review. Review the packaged control program(s) for this equipment. Parameters, setpoints and logic sequences appear to follow the specified written sequences.

n. Record of All Values for Current Setpoints (SP), Control Parameters, Limits, Delays, Lockouts, Schedules, Etc. Changed to Accommodate Testing:

\begin{tabular}{|l|l|l|}
\hline \multicolumn{1}{|c|}{ Parameter } & \multicolumn{1}{c|}{$\begin{array}{c}\text { Pre-Test } \\
\text { Values }\end{array}$} & $\begin{array}{c}\text { Retumed } \\
\text { to Pre-Test } \\
\text { Values V }\end{array}$ \\
\hline Supply air temp. & & \\
\hline $\begin{array}{l}\text { Discharge static } \\
\text { pressure (SP) }\end{array}$ & & \\
\hline $\begin{array}{l}\text { Supply air reset } \\
\text { schedule }\end{array}$ & & \\
\hline Bldg. static P. & & \\
\hline Low ambient lockout & & \\
\hline NLL return air setpt. & & \\
\hline & & \\
\hline & & \\
\hline
\end{tabular}

\begin{tabular}{|l|r|r|}
\hline \multicolumn{1}{|c|}{ Parameter } & $\begin{array}{c}\text { Pre-Test } \\
\text { Values }\end{array}$ & $\begin{array}{c}\text { Returned } \\
\text { to Pre-Test } \\
\text { Values V }\end{array}$ \\
\hline High duct SP alarm & $\%$ & $\%$ \\
\hline $\begin{array}{l}\text { Econ. min. when VFD } \\
\text { or IGV @ 0\% }\end{array}$ & $\%$ & $\%$ \\
\hline $\begin{array}{l}\text { Econ. min. when VFD } \\
\text { or IGV @ 100\% }\end{array}$ & $\%$ & $\%$ \\
\hline Space temp. setpoint & & \\
\hline NLL space temp. setpt. & & \\
\hline & & \\
\hline & & \\
\hline & & \\
\hline
\end{tabular}

3. Sensor Calibration Checks. Check the sensors listed below for calibration and adequate location. This is a sampling check of calibrations done during prefunctional checklisting. Test the packaged controls and BAS readings.

"In calibration" means making a reading with a calibrated test instrument within 6 inches of the site sensor. Verify that the sensor reading (via the permanent thermostat, gage, packaged control panel or building automation system (BAS)) compared to the test instrument-measured value is within the tolerances specified in the prefunctional checklist requirements as used for the original calibration, if possible.

). If not, install offset in BAS, calibrate or replace sensor. Use the same test instruments

Notes: 


\begin{tabular}{|l|l|l|l|l|l|}
\hline $\begin{array}{c}\text { Sensor \& } \\
\text { Location }\end{array}$ & $\begin{array}{c}\text { Loc- } \\
\text { ation } \\
\text { OK }\end{array}$ & $\begin{array}{l}\text { 1st Gage or } \\
\text { Pkg \& BAS } \\
\text { Values }\end{array}$ & $\begin{array}{c}\text { Instru. } \\
\text { Meas'd } \\
\text { Value }\end{array}$ & $\begin{array}{l}\text { Final Gage or } \\
\text { Pkg \& BAS } \\
\text { Values }\end{array}$ & $\begin{array}{l}\text { Pass } \\
\text { Y/N? }\end{array}$ \\
\hline \hline SAT & & $\begin{array}{l}\text { Pkg: } \\
\text { BAS: }\end{array}$ & & $\begin{array}{l}\text { Pkg: } \\
\text { BAS: }\end{array}$ & \\
\hline RAT & & $\begin{array}{l}\text { Pkg: } \\
\text { BAS: }\end{array}$ & & $\begin{array}{l}\text { Pkg: } \\
\text { BAS: }\end{array}$ & \\
\hline OSAT & & $\begin{array}{l}\text { Pkg: } \\
\text { BAS: }\end{array}$ & & $\begin{array}{l}\text { Pkg: } \\
\text { BAS: }\end{array}$ & \\
\hline Disch. SP & & $\begin{array}{l}\text { Pkg: } \\
\text { BAS: }\end{array}$ & & $\begin{array}{l}\text { Pkg: } \\
\text { BAS: }\end{array}$ & \\
\hline Enthalpy & & Pkg: & & Pkg: & \\
\hline
\end{tabular}

${ }^{1}$ Sensor location is appropriate and away from causes of erratic operation.

4. Device Calibration Checks. The actuators or devices listed below checked for calibration. This is a spot check on a sample of the calibrations done during prefunctional checklisting and startup.

"In calibration" means observing a readout in the BAS and going to the actuator or controlled device and verifying that the BAS reading is correct. For items out of calibration or adjustment, fix now if easy, via an offset in the BAS, or a mechanical fix.

\begin{tabular}{|c|c|c|c|c|c|}
\hline $\begin{array}{l}\text { Device or Actuator \& Location } \\
\text {. }\end{array}$ & Procedure / State & $\begin{array}{c}\text { 1st } \\
\text { Pkg'd Value }\end{array}$ & $\begin{array}{c}\text { Site } \\
\text { Observation }\end{array}$ & $\begin{array}{l}\text { Final Pkg'd } \\
\text { Reading }\end{array}$ & $\begin{array}{l}\text { Pass } \\
\text { YNN }\end{array}$ \\
\hline \multirow[t]{2}{*}{ Inlet guide vane position* } & 1. Closed & & & & \\
\hline & 2. Full open & & & & \\
\hline \multirow{2}{*}{$\begin{array}{l}\text { Variable frequency drive speed* } \\
\text { (VFD) }\end{array}$} & 1. Min.: & & & & \\
\hline & 2. Max.: & & & & \\
\hline \multirow[t]{2}{*}{ OSA damper position** } & 1. Closed & & & & \\
\hline & 2. Full open & & & & \\
\hline & & & & & \\
\hline
\end{tabular}

*Vanes or VFD: Procedure 1. Lower the controlling static pressure setpoint (duct or discharge) to be $1 / 4$ of its current value. Verify that the vanes are shut, or fan speed is at minimum for VFD and packaged controller reads the same. Return the static pressure setpoint to normal. Procedure 2. Lower the space temperature setpoint to be 20F below space temp. and cause TU dampers to go to full cooling. Raise the static pressure setpoint as necessary to cause the setpoint to not be met. Verify that the inlet vanes are fully open or the fan speed is at its $\max$. and verify that the packaged controller reades the same. Return all to normal.

**OSA Damper. Procedure 1. Change minimum OSA damper position setting to $0 \%$. Change economizing parameter as necessary to cause damper to go to minimum. Verify that the damper is shut. Change the minimum OSA damper position setting to $100 \%$. Verify that the damper is fully open. Return all to normal.

\section{Notes:}




\section{Verification of Misc. Prefunctional Checks.}

Misc. site checks of the prefunctional checklist and startup reports completed successfully. Pass? Y / N

\section{General Conditions of Test}

\section{Functional Testing Record}

\begin{tabular}{|c|c|c|c|c|}
\hline $\begin{array}{c}\text { Proced. } \\
\text { No. \& } \\
\text { Spec. } \\
\text { Seq. ID' } \\
\end{array}$ & $\begin{array}{c}\text { Req ID } \\
\text { No. }\end{array}$ & $\begin{array}{l}\text { Test Procedure } \\
\text { (including special conditions) }\end{array}$ & $\begin{array}{c}\begin{array}{c}\text { Expected and Actual Response } \\
\text { [Write ACTUAL response in } \\
\text { brackets or circle] }\end{array} \\
\end{array}$ & $\begin{array}{c}\text { Pass } \\
\text { Y/N } \\
\text { \& Noto } \\
\# \\
\end{array}$ \\
\hline $\begin{array}{c}1 \\
\text { Seq. } 1 \\
31-33\end{array}$ & & Observe the unit in OFF condition. & $\begin{array}{l}\text { Inlet vanes closed, [ }] \text {, } \\
\text { relief and OSA dampers closed, } \\
\text { RA dampers open [ ] } \\
\text { Associated exhaust fan(s) are } \\
\text { OFF. }\end{array}$ & \\
\hline $\begin{array}{c}2 \\
\text { Seq. } 2 \text {; } \\
3 ; 31- \\
33\end{array}$ & & $\begin{array}{l}\text { Disable optimum start. With the ASU in } \\
\text { auto and with the schedule in unoccupied, } \\
\text { change schedule to be occupied in a few } \\
\text { minutes. Change the warm-up mode } \\
\text { setpoint to be 3F greater than the RA } \\
\text { temperature. }\end{array}$ & $\begin{array}{l}\text { Upon the occpied time the unit } \\
\text { should start. Observe that the inlet } \\
\text { vanes are closed [L] when } \\
\text { the unit starts. } \\
\text { Associated exhaust fan(s) are ON. }\end{array}$ & \\
\hline $\begin{array}{c}3 \\
\text { Seq. } 5 \\
22 ; 34\end{array}$ & & $\begin{array}{l}\text { Warm-up Mode. Continuing with the last } \\
\text { procedure observe the startup. }\end{array}$ & $\begin{array}{l}\text { 1) Economizer dampers are shut. } \\
\text { 2) Perimeter TU box reheat valves } \\
\text { open (observe } 1 / 2 \text { of designated } \\
\text { perimeter TU's thru BAS). } \\
\text { 3) Associated exhaust fan(s) are } \\
\text { OFF. }\end{array}$ & \\
\hline $\begin{array}{c}4 \\
\text { Seq. } 6\end{array}$ & & $\begin{array}{l}\text { Wait until the RA temperature rises } \\
\text { sufficiently, or change the warmup mode } \\
\text { setpoint to be = to RA temperature + any } \\
\text { offset. }\end{array}$ & $\begin{array}{l}\text { Perimeter reheat valves return to } \\
\text { normal. } \\
\text { Economizer damper retums to } \\
\text { normal (minimum position). (Note: } \\
\text { min. position varies with fan inlet } \\
\text { vane position.) }\end{array}$ & \\
\hline
\end{tabular}

Notes: 


\begin{tabular}{|c|c|c|c|c|}
\hline $\begin{array}{l}\text { Proced. } \\
\text { No. \& } \\
\text { Spec. } \\
\text { Seq. ID' } \\
\end{array}$ & $\begin{array}{l}\text { Req ID } \\
\text { No. }^{2}\end{array}$ & $\begin{array}{c}\text { Test Procedure } \\
\text { (including special conditions) } \\
\end{array}$ & $\begin{array}{c}\text { Expected and Actual Response } \\
\text { [Write ACTUAL response in } \\
\text { brackets or circle] }\end{array}$ & $\begin{array}{r}\text { Pass } \\
\text { Y/N } \\
\text { \& Note } \\
\text { \# } \\
\end{array}$ \\
\hline $\begin{array}{l}5 \\
\text { Seq. } 7\end{array}$ & & $\begin{array}{l}\text { Volume Capacity Control. Return all } \\
\text { settings to normal. Record discharge static } \\
\text { pressure. } \\
\text { Command all TU dampers to minimum (via } \\
\text { direct command or by raising the space } \\
\text { temp. setpoint } 20 \mathrm{~F} \text { above space temp). } \\
\\
\text { Command all TU dampers to max. cooling } \\
\text { (via direct command or by lowering the } \\
\text { space temperature setpoint 20F below } \\
\text { space temp.). }\end{array}$ & 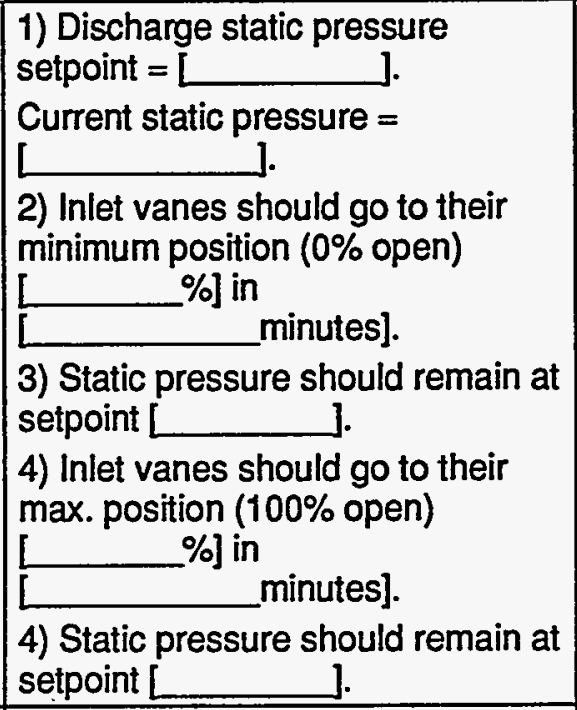 & \\
\hline $\begin{array}{c}6 \\
\text { Seq. } 7\end{array}$ & & $\begin{array}{l}\text { TREND LQG } 1 \text { Volume Capacity Control. } \\
\text { Since the discharge pressure is not } \\
\text { monitored, trend the inlet vane position } \\
\text { command and OSAT for } 8 \text { hours in } 1 \text { minute } \\
\text { intervals, with all systems in normal mode. } \\
\text { Include transition from unoccupied to } \\
\text { occupied periods. Attach occupied } \\
\text { schedule. See Monitoring section at the end } \\
\text { of this test. }\end{array}$ & $\begin{array}{l}\text { Verify that the inlet vanes are not } \\
\text { hunting excessively in trying to } \\
\text { maintain the static pressure } \\
\text { setpoint. If there is not a wide } \\
\text { enough range of vane positions } \\
\text { logged, repeat the trend with some } \\
\text { simulated load conditions being } \\
\text { applied. }\end{array}$ & \\
\hline $\begin{array}{c}7 \\
\text { Seq. } 8\end{array}$ & & $\begin{array}{l}\text { Lower the ASU high static setpoint to be } 0.1 \\
\text { inch lower than the current discharge static } \\
\text { pressure. When done, return setpoint to } \\
\text { normal. }\end{array}$ & $\begin{array}{l}\text { ASU should shut down } \\
\text { L }\end{array}$ & \\
\hline
\end{tabular}

Notes: 


\begin{tabular}{|c|c|c|c|c|}
\hline $\begin{array}{l}\text { Proced. } \\
\text { No. \& } \\
\text { Spec. } \\
\text { Seq. ID' }\end{array}$ & $\underset{N^{2} .^{2}}{R e q ~ I D}$ & $\begin{array}{l}\text { Test Procedure } \\
\text { (including special conditions) }\end{array}$ & $\begin{array}{c}\text { Expected and Actual Response } \\
\text { Write ACTUAL response in } \\
\text { brackets or circle] }\end{array}$ & $\begin{array}{c}\text { Pass } \\
\text { YNN } \\
\text { \& Note } \\
\text { \# }\end{array}$ \\
\hline $\begin{array}{c}8 \\
\text { Seq. } \\
12 ; 18 ; \\
20\end{array}$ & & $\begin{array}{l}\text { Cooling Capacity Staging. } \\
\text { a) Shut the ASU OFF. Raise the space } \\
\text { temperature setpoints } 10 \mathrm{~F} \text { above space } \\
\text { temperatures. If the OSAT is >55F, } \\
\text { overwrite the OSAT sensor, that controls } \\
\text { the economizer, to be 55F. Turn ASU ON. } \\
\text { b) Change SAT reset parameters so that at } \\
\text { full economy, the SAT setpoint will still not } \\
\text { be met upon a call for full cooling (so SAT } \\
\text { setpoint will be >OSAT). Record changes } \\
\\
\\
\text { c) Lower the space temperature setpoints } \\
\text { to } 20 \mathrm{~F} \text { below space temperatures. }\end{array}$ & 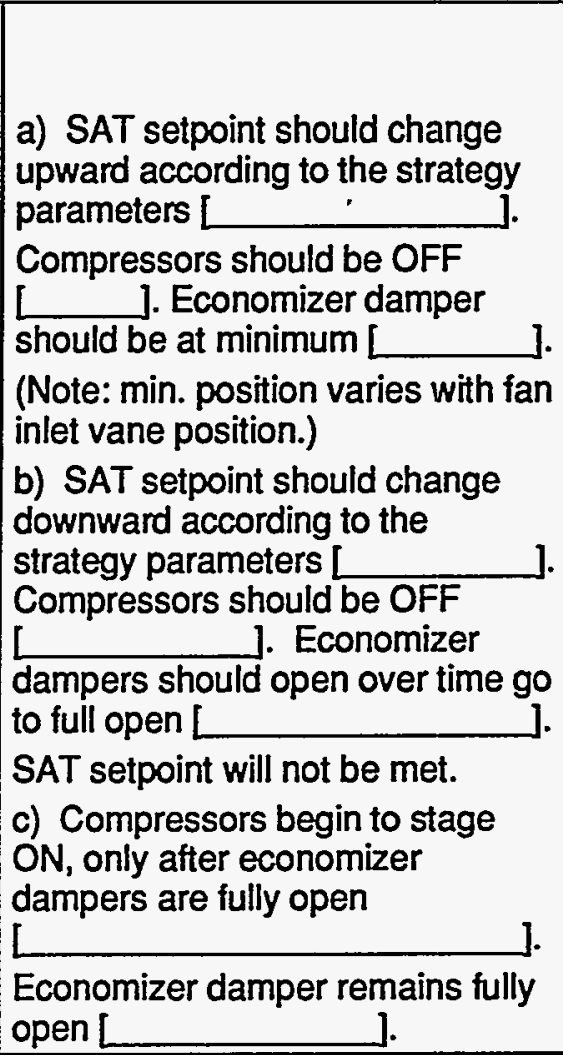 & \\
\hline $\begin{array}{l}8 \text { cont. } \\
\text { Seq. } \\
12\end{array}$ & & $\begin{array}{l}\text { Continuing from above: } \\
\text { If temperatures are so low that the OSA with } \\
\text { only the lower stages of mechanical will } \\
\text { meet the SAT setpoint, lower the enthalpy } \\
\text { changeover setpoint to } 10 \text { Btu/lb, so } \\
\text { economizer damper will go to minimum. }\end{array}$ & $\begin{array}{l}\text { Observe the staging ON of } \\
\text { multiple compressors and their } \\
\text { condenser fans. } \\
\text { Observe that SAT setpoint is met } \\
\text { at all times, within 1F either side of } \\
\text { the current deadband (+/-4F). } \\
\text { Maximum deviation observed } \\
\text { If OSAT is too cold for full } \\
\text { compressor staging, repeat this } \\
\text { sequence in warmer weather. }\end{array}$ & \\
\hline
\end{tabular}

Notes: 


\begin{tabular}{|c|c|c|c|c|}
\hline $\begin{array}{l}\text { Proced. } \\
\text { No. \& } \\
\text { Spec. } \\
\text { Seq. ID' }\end{array}$ & $\begin{array}{c}\text { Req ID } \\
\mathrm{No}^{2}\end{array}$ & $\begin{array}{l}\text { Test Procedure } \\
\text { (including special conditions) }\end{array}$ & $\begin{array}{c}\text { Expected and Actual Response } \\
\text { [Write ACTUAL response in } \\
\text { brackets or circle] }\end{array}$ & $\begin{array}{l}\text { Pass } \\
\text { YNN } \\
\text { \& Note } \\
\vdots \\
\end{array}$ \\
\hline $\begin{array}{c}9 \\
\text { Seq. } \\
14\end{array}$ & & $\begin{array}{l}\text { Compressor Lockout. Continuing from } \\
\text { above, change the compressor lockout } \\
\text { temperature to be 3F below the current } \\
\text { OSAT. } \\
\text { Change the compressor lockout } \\
\text { temperature to be 1F above the current } \\
\text { OSAT. Return all settings to normal. }\end{array}$ & $\begin{array}{l}\text { Compressors should remain ON. } \\
\text { Compressors should shut OFF. }\end{array}$ & \\
\hline $\begin{array}{c}10 \\
\text { Seq. } \\
12 ; 16- \\
20\end{array}$ & & $\begin{array}{l}\text { TREND LOG 2. Cooling Capacity Staging } \\
\text { and Economizer. With all systems in } \\
\text { normal mode, trend the OSAT, RAT, SAT, } \\
\text { SAT setpoint, ASU inlet vane position } \\
\text { command and datalog the compressor } \\
\text { current. Synchronize datalogger and BAS } \\
\text { time and starts. Sample at } 5 \text { min. intervals } \\
\text { for } 48 \text { hours during weather near design } \\
\text { cooling. Provide occupied schedule. See } \\
\text { Monitoring section at the end of this test. }\end{array}$ & $\begin{array}{l}\text { Observe that SAT setpoint is met } \\
\text { at all times, within 1F either side of } \\
\text { the current deadband }(+1-4 \mathrm{~F}) \text {. } \\
\text { Observe that economizer is tirst } \\
\text { stage of cooling and that } \\
\text { compressors stage ON and OFF } \\
\text { according to need to maintain SAT } \\
\text { setpoint. Verify that the } \\
\text { compressors comply with the min. } \\
\text { ON and OFF time of } 3 \text { minutes. }\end{array}$ & \\
\hline $\begin{array}{c}11 \\
\text { Seq. } \\
15\end{array}$ & & $\begin{array}{l}\text { SAT Reset. a) With all systems in auto, } \\
\text { make sure all polled zones are within 4F of } \\
\text { space setpoint. Record the zone farthest } \\
\text { above its setpoint. } \\
\text { b) Ovenwrite a zone space temp to be } 5 \mathrm{~F} \\
\text { above its setpoint. Record the BAS SA } \\
\text { setpoint. Observe the SA meet setpoint. } \\
\text { c) Overwrite a zone space temp to be } 10 \mathrm{~F} \\
\text { below its setpoint. Observe the SA meet } \\
\text { setpoint. } \\
\qquad \frac{\text { Reset Schedule }}{\text { Worst }} \\
\frac{\text { Zone (1) }}{5 \mathrm{~F}} \\
\begin{array}{l}\text { SA } \\
-10 \mathrm{~F}\end{array} \\
\text { (1) Farthest zone above its setpoint) }\end{array}$ & $\begin{array}{l}\text { a) } \\
\text { b) Setpoint goes to } 50 \mathrm{~F}[ \\
\text { SA temp meets } 50 \mathrm{~F} \text { without } \\
\text { excessive hunting. } \\
\text { c) Setpoint goes to } 70 \mathrm{~F} \\
\text { SA temp meets } 70 \mathrm{~F} \text { without } \\
\text { excessive hunting. Compressors } \\
\text { should shut OFF. }\end{array}$ & $r$ \\
\hline
\end{tabular}

Notes: 


\begin{tabular}{|c|c|c|c|c|}
\hline $\begin{array}{l}\text { Proced. } \\
\text { No. \& } \\
\text { Spec. } \\
\text { Seg. ID' } \\
\end{array}$ & $\begin{array}{c}\text { Req ID } \\
\text { No. }^{2}\end{array}$ & $\begin{array}{l}\text { Test Procedure } \\
\text { (including special conditions) }\end{array}$ & $\begin{array}{c}\text { Expected and Actual Response } \\
\text { [Write ACTUAL response in } \\
\text { brackets or circle] }\end{array}$ & $\begin{array}{l}\text { Pass } \\
\text { Y/N } \\
\& \text { Noto } \\
\#\end{array}$ \\
\hline $\begin{array}{c}12 \\
\text { Seq. } \\
15\end{array}$ & & $\begin{array}{l}\text { TREND LOG } 3 \text {, SAT Reset. } \\
\text { With all systems in normal mode, trend the } \\
\text { five typical warmest zones space temps, the } \\
\text { SAT and the SAT setpoint. Verify the reset } \\
\text { schedule is being met, per procedure } 12 \text {. } \\
\text { Trend at } 5 \text { minute intervals for } 48 \text { hours, } \\
\text { during the week. } \\
\text { See Monitoring section at the end of this } \\
\text { test. }\end{array}$ & $\begin{array}{l}\text { Data indicates SA reset strategy is } \\
\text { working. }\end{array}$ & \\
\hline $\begin{array}{c}13 a \\
\text { Seq. } \\
16-19 \\
21\end{array}$ & & 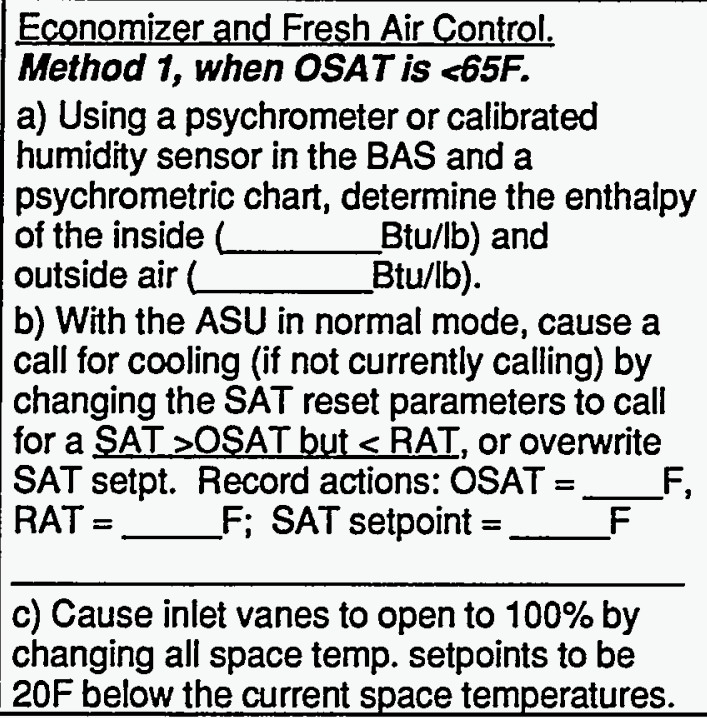 & & . \\
\hline
\end{tabular}

Notes: 


\begin{tabular}{|c|c|c|c|c|}
\hline $\begin{array}{l}\text { Proced. } \\
\text { No. \& } \\
\text { Spec. } \\
\text { Seq. ID } \\
\end{array}$ & $\begin{array}{c}\text { Req ID } \\
\mathrm{No}^{2}{ }^{2}\end{array}$ & $\begin{array}{l}\text { Test Procedure } \\
\text { (including special conditions) }\end{array}$ & $\begin{array}{c}\text { Expected and Actual Response } \\
\text { [Write ACTUAL response in } \\
\text { brackets or circle] }\end{array}$ & $\begin{array}{c}\text { Pass } \\
\text { YNN } \\
\text { \& Note } \\
\text { \# }\end{array}$ \\
\hline $\begin{array}{c}13 a \\
\text { Seq. } \\
16-19 \\
21\end{array}$ & & $\begin{array}{l}\text { e) Cause inlet vanes to close to } 0 \% \text { open by } \\
\text { changing all space temp. setpoints to be } \\
20 \mathrm{~F} \text { above the current space temperatures. } \\
\text { f) Change the economizer changeover } \\
\text { setpoint in the ASU to be } 3 \text { Btu/lb above the } \\
\text { current OSA enthalpy. } \\
\text { g) Change conditions or overwrite so the } \\
\text { SAT setpoint is < OSAT. OSAT = } \\
\text { SAT setpoint = } \\
\text { Return economizer setpoint, SAT reset and } \\
\text { space setpoints to normal. }\end{array}$ & $\begin{array}{l}\text { Fresh Air Control: } \\
\text { d) Economizer damper should go } \\
\text { to minimum. Observe that inlet } \\
\text { vanes are } 100 \% \text { open [ } \\
\text { Verify that damper minimum is } \\
\text { according to the Fresh Air Control } \\
\text { OSA Compensation schedule: } \\
\% \text { open, [ } \\
\text { for this inlet vane position. } \\
\text { e) Economizer damper minimum } \\
\text { should change. Observe that inlet } \\
\text { vanes are 0\% open [ } \\
\text { Verify that damper minimum is } \\
\text { according to the Fresh Air Control } \\
\text { OSA Compensation schedule: } \\
\% \% \text { open, L } \\
\text { for this inlet vane position. } \\
\text { f) Econen] } \\
\text { begin to open and maintain SAT } \\
\text { setpoint within 1F on both sides of } \\
\text { the current SAT deadband of }+1- \\
\text { 4F. Damper should not be fully } \\
\text { open. L } \\
\text { g) Economizer damper should go } \\
\text { to full open [ } \\
\text { RA damper modulates opposite of } \\
\text { economizer damper. } \\
\text { Parameters put back to normal. }\end{array}$ & \\
\hline
\end{tabular}

Notes: 


\begin{tabular}{|c|c|c|c|c|}
\hline $\begin{array}{l}\text { Proced. } \\
\text { No. \& } \\
\text { Spoc. } \\
\text { Seq. } 10^{1} \\
\end{array}$ & $\begin{array}{c}\text { Req ID } \\
\mathrm{No}^{2}\end{array}$ & $\begin{array}{l}\text { Test Procedure } \\
\text { (including special conditions) }\end{array}$ & $\begin{array}{c}\text { Expected and Actual Response } \\
\text { [Write ACTUAL response in } \\
\text { brackets or circle] }\end{array}$ &  \\
\hline $\begin{array}{l}13 b \\
\text { Seq. } \\
16-19 \\
21\end{array}$ & & 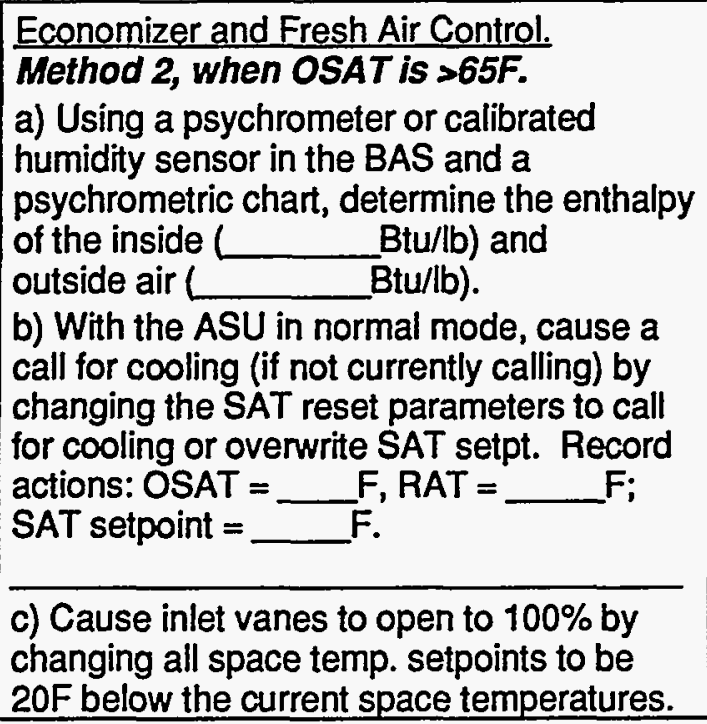 & & \\
\hline $\begin{array}{c}13 b \\
\text { Seq. } \\
16-19 \\
21\end{array}$ & & $\begin{array}{l}\text { Continuing from previous: } \\
\text { d) Change the economizer changeover } \\
\text { setpoint in the ASU to be } 3 \text { Btu/lb below the } \\
\text { current OSA enthalpy, so economizer won't } \\
\text { open. } \\
\text { e) Cause inlet vanes to close to } 0 \% \text { open by } \\
\text { changing all space temp. setpoints to be } \\
20 \mathrm{~F} \text { above the current space temperatures. }\end{array}$ & $\begin{array}{l}\text { Fresh Air Control: } \\
\text { d) Economizer damper should go } \\
\text { to minimum. Observe that inlet } \\
\text { vanes are } 100 \% \text { open [ } \\
\text { Verify that damper minimum is } \\
\text { according to the Fresh Air Control } \\
\text { OSA Compensation schedule: } \\
\% \text { open, [ \% open] } \\
\text { for this inlet vane position. } \\
\text { e) Economizer damper minimum } \\
\text { should change. Observe that inlet } \\
\text { vanes are 0\% open [L } \\
\text { Verify that damper minimum is } \\
\text { according to the Fresh Air Control } \\
\text { OSA Compensation schedule: } \\
\% \text { open, [ \% open] } \\
\text { for this inlet vane position. }\end{array}$ & \\
\hline
\end{tabular}

Notes: 


\begin{tabular}{|c|c|c|c|c|}
\hline $\begin{array}{l}\text { Proced. } \\
\text { No. \& } \\
\text { Spec. } \\
\text { Seq. ID' } \\
\end{array}$ & $\begin{array}{l}\text { Req ID } \\
\text { No. }^{2}\end{array}$ & $\begin{array}{l}\text { Test Procedure } \\
\text { (Including special conditions) }\end{array}$ & $\begin{array}{c}\text { Expected and Actual Response } \\
\text { Write ACTUAL response in } \\
\text { brackets or circle] }\end{array}$ & $\begin{array}{c}\begin{array}{c}\text { Pass } \\
\text { YN } \\
\text { \& Note } \\
\text { \# }\end{array} \\
\end{array}$ \\
\hline $\begin{array}{c}13 b \\
\text { Seq. } \\
16-19 \\
21\end{array}$ & & $\begin{array}{l}\text { Continuing from previous: } \\
\text { f) Change the economizer changeover } \\
\text { setpoint in the ASU to be } 3 \text { Btu/lb above the } \\
\text { current OSA enthalpy. Overwrite the SAT } \\
\text { to be > SAT setpoint by } 10 \mathrm{~F} \text {. } \\
\text { Return economizer setpoint, SAT reset and } \\
\text { space setpoints to normal. }\end{array}$ & $\begin{array}{l}\text { f) Economizer damper should } \\
\text { begin to open and eventually go to } \\
\text { full open. } \\
\text { Setpoint will not be met. } \\
\text { Compressors will come on and } \\
\text { economizer damper will remain } \\
\text { fully open. } \\
\\
\text { RA damper modulates opposite of } \\
\text { economizer damper. } \\
\text { Parameters put back to normal. } \\
\end{array}$ & \\
\hline $\begin{array}{c}14 \\
\text { Seq. } \\
23-26 \\
34\end{array}$ & & $\begin{array}{l}\text { Unoccupied Night Low Limit Mode. } \\
\text { a) With ASU in normal mode, change the } \\
\text { schedule so unoccupied mode will begin in } \\
5 \text { minutes. } \\
\text { b) After the ASU shuts OFF, change the RA } \\
\text { NLL setpoint to be 10F above current RA } \\
\text { temp. Overwrite one of the polled perimeter } \\
\text { zone space temp. to be 1Fabove the space } \\
\text { NLL heating setpoint, currently } \\
\text { c) Overwrite one of the polled perimeter } \\
\text { zone space temp. to be 3Fbelow the space } \\
\text { NLL heating setpoint. } \\
\text { d) Change the RA NLL setpoint to be within } \\
\text { the bias or deadband range of the current } \\
\text { RA temp. } \\
\text { e) Return schedules, NLL RA setpoint and } \\
\text { space overwritten values to normal. }\end{array}$ & $\begin{array}{l}\text { a) When the schedule is met, the } \\
\text { ASU shuts OFF. } \\
\text { b) ASU and boiler does not come } \\
\text { ON. } \\
\text { c) The ASU and boilers come ON. } \\
\text { Heating coil valves operate } \\
\text { normally. } \\
\text { Economizer dampers are shut and } \\
\text { exhaust fans are OFF. } \\
\text { d) The ASU and boilers shut OFF. } \\
\text { e) Values returned to normal. }\end{array}$ & \\
\hline
\end{tabular}

Notes: 


\begin{tabular}{|c|c|c|c|c|}
\hline $\begin{array}{l}\text { Proced. } \\
\text { No. \& } \\
\text { Spec. } \\
\text { Seq. ID' }\end{array}$ & $\begin{array}{c}\text { Req ID } \\
\mathrm{No}^{2}{ }^{2}\end{array}$ & $\begin{array}{l}\text { Test Procedure } \\
\text { (including special conditions) }\end{array}$ & $\begin{array}{c}\text { Expected and Actual Response } \\
\text { [Write ACTUAL response in } \\
\text { brackets or circle] }\end{array}$ & $\begin{array}{l}\text { Pass } \\
\text { Y/N } \\
\text { \&oto } \\
\text { Note }\end{array}$ \\
\hline $\begin{array}{l}15 \\
\text { Seq. } \\
27-30 \\
34\end{array}$ & & $\begin{array}{l}\text { Unoccupied Night High Limit Mode. } \\
\text { a) With ASU in normal mode, change the } \\
\text { schedule so unoccupied mode will begin in } \\
5 \text { minutes. } \\
\text { b) After the ASU shuts OFF, change the RA } \\
\text { NHL setpoint to be } 10 \mathrm{~F} \text { below current RA } \\
\text { temp. Change the space NHL cooling } \\
\text { setpoint to be } 65 F \text { (so no unoccupied } \\
\text { cooling or heating is called for). Overwrite } \\
\text { one of the polled perimeter zone space } \\
\text { temp. to be 1Fbelow the space temporary } \\
\text { NHL cooling setpoint, currently } \\
\text { c) Change economizer changeover enthalpy } \\
\text { as necessary to allow economizer damper } \\
\text { to open. } \\
\text { d) Overwrite one of the polled perimeter } \\
\text { zone space temp. to be } 3 F b e l o w \text { the } \\
\text { temporary space NHL cooling setpoint. . } \\
\text { e) Change the RA NHL setpoint to be within } \\
\text { the bias or deadband range of the current } \\
\text { RA temp. } \\
\text { f) Return schedules, NHL RA, NHL space } \\
\text { setpoint and space overwritten values to } \\
\text { normal. }\end{array}$ & $\begin{array}{l}\text { a) When the schedule is met, the } \\
\text { ASU shuts OFF. } \\
\text { b) ASU does not come ON. } \\
\text { c; d) The ASU comes ON and } \\
\text { economizer goes above minimum. } \\
\text { Exhaust fans and boiler remain } \\
\text { OFF. } \\
\text { e) The ASU shuts OFF. } \\
\text { f) Values returned to normal. }\end{array}$ & \\
\hline $\begin{array}{l}16 \\
\text { Seq. } \\
23-26\end{array}$ & & $\begin{array}{l}\text { TREND LOG 4. Unoccupied NHL. } \\
\text { During a period of weather with nights below } \\
40 F \text {, with all systems in normal mode, trend } \\
\text { the inlet vane position command (surragate } \\
\text { for ASU status), RA temp, highest and } \\
\text { lowest polled space temp., SAT, boiler } \\
\text { status, HWST and OSAT. Trend at } 15 \text { min. } \\
\text { intervals for } 3 \text { days. Provide occupied } \\
\text { schedule. See Monitoring section at the end } \\
\text { of this test. }\end{array}$ & $\begin{array}{l}\text { Verify the proper sequencing per } \\
\text { Procedure } 14 \text {. }\end{array}$ & \\
\hline
\end{tabular}

Notes: 


\begin{tabular}{|c|c|c|c|c|}
\hline $\begin{array}{l}\text { Proced. } \\
\text { No. \& } \\
\text { Spec. } \\
\text { Seq. ID' }\end{array}$ & $\begin{array}{c}\text { Req ID } \\
\text { No. }^{2}\end{array}$ & $\begin{array}{l}\text { Test Procedure } \\
\text { (including special conditions) }\end{array}$ & $\begin{array}{c}\text { Expected and Actual Response } \\
\text { [Write ACTUAL response in } \\
\text { brackets or circle] }\end{array}$ & $\begin{array}{c}\text { Pass } \\
\text { YNN } \\
\text { \& Note } \\
\text { \# }\end{array}$ \\
\hline $\begin{array}{c}17 \\
\text { Seq. } \\
27-30\end{array}$ & & $\begin{array}{l}\text { TREND LOG } 5 \text {, Unoccupied NLL. } \\
\text { During a period of weather with nights below } \\
40 F \text {, with all systems in normal mode, trend } \\
\text { the inlet vane position command (surragate } \\
\text { for ASU status), RA temp, highest and } \\
\text { lowest polled space temp., SAT, boiler } \\
\text { status, HWST and OSAT. Trend at } 15 \text { min. } \\
\text { intervals for } 3 \text { days. Provide occupied } \\
\text { schedule. See Monitoring section at the end } \\
\text { of this test. }\end{array}$ & $\begin{array}{l}\text { Verify the proper sequencing per } \\
\text { Procedure } 15 .\end{array}$ & \\
\hline $\begin{array}{c}18 \\
\text { Seq. } \\
35\end{array}$ & & $\begin{array}{l}\text { Misc. Alarms. a) Filter alarm. In the BAS, } \\
\text { lower the filter alarm setpoint until it equals } \\
\text { the filter differential pressure. } \\
\text { b) Compressor failure. With an ASU } \\
\text { compressor running, shut off the breaker to } \\
\text { the compressor. Reset when done. }\end{array}$ & $\begin{array}{l}\text { a) An alarm is registered in the } \\
\text { BAS. } \\
\text { b) An alarm is registered in the } \\
\text { BAS. } \\
\text { Breaker reset. }\end{array}$ & \\
\hline $\begin{array}{c}19 \\
\text { Seq. } \\
36\end{array}$ & & $\begin{array}{l}\text { External Shutdowns and Alarms. } \\
\text { a) High duct static pressure. In the BAS, } \\
\text { lower the high duct static pressure alarm } \\
\text { setpoint to the current duct static pressure. } \\
\text { b) Supply duct smoke detector. Spray } \\
\text { "smoke" on the SA duct sensor. } \\
\text { c) Return duct smoke detector. Spray } \\
\text { "smoke" on the RA duct sensor. } \\
\text { d) Turn the emergency shutdown switch in } \\
\text { on the BAS ASU controller in the } \\
\text { Penthouse. }\end{array}$ & $\begin{array}{l}\text { a) The ASU should shut OFF and } \\
\text { register an alarm. } \\
\text { b) The ASU should shut OFF and } \\
\text { register an alarm in the BAS and } \\
\text { generate a fire alarm. (see fire } \\
\text { alarm response matrix). } \\
\text { c) The ASU should shut OFF and } \\
\text { register an alarm in the BAS and } \\
\text { generate a fire alarm. (see fire } \\
\text { alarm response matrix). } \\
\text { d) The ASU should shut OFF and } \\
\text { register an alarm. }\end{array}$ & \\
\hline $\begin{array}{l}20 \\
\text { Seq. } \\
37\end{array}$ & & $\begin{array}{l}\text { Fire Alarm Shutdown. Initiate a fire alarm } \\
\text { through the following: general smoke, pull } \\
\text { station, sprinkler flow (jumper contacts). }\end{array}$ & $\begin{array}{l}\text { All ASU's should shut OFF. } \\
\text { General smoke alarm: } \\
\text { Pull station: } \\
\text { Sprinkler flow: } \\
\text { Duct smoke detector: (done above) }\end{array}$ & \\
\hline
\end{tabular}

Notes: 


\begin{tabular}{|c|c|c|c|c|}
\hline $\begin{array}{l}\text { Proced. } \\
\text { No. \& } \\
\text { Spec. } \\
\text { Seg. } 10^{1}\end{array}$ & $\begin{array}{c}\text { Req ID } \\
\text { No. }^{2}\end{array}$ & $\begin{array}{l}\text { Test Procedure } \\
\text { (including special conditions) }\end{array}$ & $\begin{array}{c}\text { Expected and Actual Response } \\
\text { [Write ACTUAL response in } \\
\text { brackets or circle] }\end{array}$ & $\begin{array}{l}\text { Pass } \\
\text { Y/N } \\
\text { \& Note } \\
\text { \# }\end{array}$ \\
\hline $\begin{array}{l}21 \\
\text { Seq. } \\
38\end{array}$ & & $\begin{array}{l}\text { Telecom Rm C-104 Interlock. a) Change } \\
\text { schedule to be in unoccupied mode. } \\
\text { b) Overwrite the RA temp. to be } 5 \mathrm{~F} \text { less } \\
\text { than the RA unoccupied NHL setpoint to } \\
\text { simulate a NHL satisfied condition. }\end{array}$ & $\begin{array}{l}\text { a) ASU should shut OFF and } \\
\text { remain OFF. }\end{array}$ & \\
\hline & & $\begin{array}{l}\text { c) Lower theTelecom Rm unoccupied TU-1- } \\
43 \text { setpoint (initially } 80 \mathrm{~F} \text { ) to the current } \\
\text { Telecom room space temp. }\end{array}$ & $\begin{array}{l}\text { c) ASU should start and run, not in } \\
\text { night high limit mode, but run until } \\
\text { the unoccupied setpoint of TU-1-43 } \\
\text { is satisfied. }\end{array}$ & \\
\hline $\begin{array}{l}22 \\
\text { Seq. } \\
39\end{array}$ & & $\begin{array}{l}\text { BAS Monitored and Adjustable Points. } \\
\text { Verify that the monitored and adjustable } \\
\text { points specified in the sequences are } \\
\text { actually operable in the BAS. }\end{array}$ & All points as per spec. & \\
\hline $\begin{array}{c}23 \\
\text { Seq. } \\
40\end{array}$ & & $\begin{array}{l}\text { Terminal Boxes. Verify where in the BAS } \\
\text { that the specified perimeter boxes are } \\
\text { designated. Match to specs. }\end{array}$ & $\begin{array}{l}\text { TU perimeter schedules match } \\
\text { spec. }\end{array}$ & \\
\hline $\begin{array}{c}24 \\
\text { Seq. }\end{array}$ & & $\begin{array}{l}\text { TREND LOG } 6 \text {. Optimum Stant. } \\
\text { Trend the ASU static pressure (surrogate for } \\
\text { ON condition), the OSA temperature and } \\
\text { the average temperature used for the } \\
\text { optimum start routine and the RA temp } \\
\text { during weather with night time lows } 30-40 F \text {, } \\
\text { for three consecutive days in } 5 \text { minute } \\
\text { intervals. Trend again when night time lows } \\
\text { are } 60-70 \mathrm{~F} \text {. }\end{array}$ & $\begin{array}{l}\text { Observe that the start times vary } \\
\text { per the optimum start routine and } \\
\text { that the RA temp is met by the } \\
\text { schedule. }\end{array}$ & \\
\hline 25 & - & $\begin{array}{l}\text { Return all changed control parameters } \\
\text { and conditions to their pre-test values }\end{array}$ & $\begin{array}{l}\text { Check off in Section } 2 \text { above } \\
\text { when completed }\end{array}$ & \\
\hline
\end{tabular}

MONITORING AND TREND LOGGING. Five monitoring via BAS trend logs are required per test Procedures 6, 10, $12,16,17,24$. Trend logs all shall be provided in electronic continuous columnar spreadsheet compatible format. Trends all shall be provided in hard tabular format (continuous columnar with time in left column and at least four columns of point values in adjacent columns). All points for a given trend will begin at exactly the same time. Provide a key to all abbreviations. Attach representative graphs or columnar data and explanatory analysis to this test report.

Record Foot Notes

${ }^{7}$ Sequences of operation specified in Contract Documents (attached).

${ }^{2}$ Mode or function ID being tested, per testing requirements section of the project Specifications.

${ }^{3}$ Step-by-step procedures for manual testing, trend logging or data-logger monitoring.

${ }^{4}$ Include tolerances for a passing condition.

${ }^{5}$ Record any permanently changed parameter values and submit to Owner.

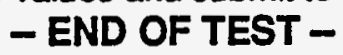

Notes: 


\section{Functional Test}

Project

\section{FT-0201 PACKAGED BOILER \\ And Boiler System Including HW Pumps 1 \& 2}

Related Tests:

\section{Participants}

Party

Participation

Party filling out this form and witnessing testing

Dates of tests

Dates of tests

Dates of tests

\section{Test Prerequisites}

a. - The following have been started up and startup reports and prefunctional checklists submitted and approved ready for functional testing:

_Boiler

_Heating water pumps

Heating water piping and valves

b. All control system functions for this and all interlocking systems are programmed and operable per contract documents, including final setpoints and schedules and with debugging, loop tuning and sensor and device calibrations completed.

$$
\text { Controls Contractor Signature or Verbal }
$$

c. Piping system flushing complete and required report approved.

d. - Water treatment system complete and operational.

e. - Vibration control report approved (if required).

f. - Test and balance (TAB) complete and approved for the hydronic system.

g. - All A/E punchlist items for this equipment corrected.

h. - These functional test procedures reviewed and approved by installing contractor.

i. - Safeties and operating ranges reviewed.

j. - Test requirements and sequences of operation attached.

k. - Schedules and setpoints attached.

1. - Sufficient clearance around equipment for servicing.

\section{Notes:}


m. Have all energy savings control strategies, setpoints and schedules been incorporated that this boiler and control system are capable of? If not, list recommendations below.

n. - BAS Program Review. Review the BAS software control program(s) for this equipment. Parameters, setpoints and logic sequences appear to follow the specified written sequences.

o. Packaged Control Program Review. Review the packaged control program(s) for this equipment. Parameters, setpoints and logic sequences appear to follow the specified written sequences.

p. _Record made of All Values for Current Setpoints (SPt), Control Parameters, Limits, Delays, Lockouts, Schedules, Etc. Changed to Accomodate Testing:

\begin{tabular}{|r|l|l|}
\hline \multicolumn{1}{|c|}{ Parameter } & $\begin{array}{c}\text { Pro-Test } \\
\text { Values }\end{array}$ & $\begin{array}{c}\text { Returned to Pre } \\
\text { Tost Values V }\end{array}$ \\
\hline Space Temp. Setpts & & \\
\hline Boiler enable OSAT setpoint & & \\
\hline $\begin{array}{c}\text { Boiler-1: } \\
\text { High limit of firing rate controlsetpoint } \\
\text { Operating control setpoint } \\
\text { Operating control setpoint differential }\end{array}$ & & \\
\hline $\begin{array}{c}\text { Boiler-2: } \\
\text { Low limit of firing rate control setpoint } \\
\text { High limit of firing rate control setpoint } \\
\text { Operating control setpoint }\end{array}$ & & \\
Operating control setpoint differential & & \\
\hline Mixed HWT Reset & $\begin{array}{l}\text { OSAT1 } \\
\text { HWT1 } \\
\text { OSAT2 } \\
\text { HWT2 }\end{array}$ & \\
\hline
\end{tabular}

3. Sensor Calibration Checks. Check the sensors listed below for calibration and adequate location. This is a sampling check of calibrations done during prefunctional checklisting.

"In calibration" means making a reading with a calibrated test instrument within 6 inches of the site sensor. Verify that the sensor reading (via the permanent thermostat, gage or building automation system (BAS)) compared to the test instrument-measured value is within the tolerances specified in the prefunctional checklist requirements ( ). If not, install offset in BAS, calibrate or replace sensor. Use the same test instruments as used for the original calibration, if possible.

\begin{tabular}{|c|c|c|c|c|c|}
\hline Sensor \& Location & $\begin{array}{l}\text { Location } \\
\text { OK }^{1}\end{array}$ & $\begin{array}{c}\text {-1st Gage or } \\
\text { BAS Value }\end{array}$ & $\begin{array}{c}\text { Instrument } \\
\text { Measured Value }\end{array}$ & $\begin{array}{l}\text { Final Gage or } \\
\text { BAS Value }\end{array}$ & $\begin{array}{l}\text { Pass } \\
\text { YIN? }\end{array}$ \\
\hline \multicolumn{6}{|l|}{$\overline{\mathrm{OSAT}}$} \\
\hline \multicolumn{6}{|l|}{ HWST (bldg loop) } \\
\hline \multicolumn{6}{|l|}{ HWRT (bldg loop) } \\
\hline Boiler Packaged Contro & sors) & B-1 & B-1 & B-2 & \\
\hline
\end{tabular}

\section{Notes:}




\begin{tabular}{|c|c|c|c|c|c|}
\hline Sensor \& Location & $\begin{array}{l}\text { Location } \\
\text { OK }^{1}\end{array}$ & $\begin{array}{l}\text { 1st Gage or } \\
\text { BAS Value }\end{array}$ & $\begin{array}{c}\text { Instrument } \\
\text { Measured Value }\end{array}$ & $\begin{array}{c}\text { Flnal Gage or } \\
\text { BAS Value }\end{array}$ & $\begin{array}{l}\text { Pass } \\
\text { Y/N? }\end{array}$ \\
\hline Gage temperature & & & & & \\
\hline High limit control ${ }^{2}$ & & & & & \\
\hline Operating control $^{2}$ & & & & & \\
\hline Firing rate control ${ }^{2}$ & & & & & \\
\hline
\end{tabular}

${ }^{1}$ Sensor location is appropriate and away from causes of erratic operation.

${ }^{2}$ Rotate setpoint dial on each controller and compare temperature when controller clicks with the temperature gage value. Within $5 \mathrm{~F}$ is acceptable.

4. Device Calibration Checks. The actuators or devices listed below checked for calibration. This is a spot check on a sample of the calibrations done during prefunctional checklisting and startup.

"In calibration" means observing a readout in the BAS and going to the actuator or controlled device and verifying that the BAS reading is correct. For items out of calibration or adjustment, fix now if easy, via an offset in the BAS, or a mechanical fix.

\begin{tabular}{|c|c|c|c|c|c|}
\hline $\begin{array}{l}\text { Device or } \\
\text { Actuator \& } \\
\text { Location }\end{array}$ & Procedure / State & $\begin{array}{l}\text { Expected } \\
\text { Value }\end{array}$ & $\begin{array}{c}\text { Site } \\
\text { Observation }\end{array}$ & Final Values & $\begin{array}{l}\text { Pass } \\
\text { Y/N }\end{array}$ \\
\hline $\begin{array}{l}\text { 3-way mixing } \\
\text { valve }\end{array}$ & $\begin{array}{l}\text { With one or both boilers ON, drive valve to } \\
\text { full bypass (closed), manually or by } \\
\text { lowering the HWST resets. }\end{array}$ & $\begin{array}{l}\text { HWST }= \\
\text { HWRT } \\
(+/-2 F) \\
\end{array}$ & $\begin{array}{l}\text { HWST }=[ \\
\text { HRST }=[\end{array}$ & $\begin{array}{l}\text { HWST }=L \\
\text { HRST }=[\end{array}$ & \\
\hline $\begin{array}{l}\text { 3-way mixing } \\
\text { valve }\end{array}$ & $\begin{array}{l}\text { With both boilers ON, drive valve } 100 \% \\
\text { open ( } 0 \% \text { bypass, all return thru boilers), } \\
\text { manually or by lowering the HWST resets. }\end{array}$ & $\begin{array}{l}\text { HWST = boiler } \\
\text { temp. (gage) } \\
(+/-2 F)\end{array}$ & $\begin{array}{l}\text { HWST }=[ \\
\text { Boiler }=[\end{array}$ & $\begin{array}{l}\text { HWST }=L \\
\text { Boiler }=[\end{array}$ & \\
\hline
\end{tabular}

\section{Verification of Misc. Prefunctional Checks.}

Misc. site checks of the prefunctional checklist and startup reports completed successfully. Pass? Y / N

\section{General Conditions of Test and Seasonal Testing}

The primary testing will occur during typical winter weather. Because the boiler will be operated year-round, Sequences 14-16; 20 will be trended again (Procedure 11), to ensure that boiler use is minimized during the offseason.

Notes: 
6. Testing Procedures and Record

\begin{tabular}{|c|c|c|c|c|c|}
\hline $\begin{array}{c}\text { Proced. } \\
\text { No. \& } \\
\text { Spec. } \\
\text { Seq. ID' }\end{array}$ & $\begin{array}{c}\text { Req ID } \\
\text { No. }\end{array}$ & $\begin{array}{c}\text { Test Procedure } \\
\text { (including special conditions) }^{3}\end{array}$ & $\begin{array}{c}\begin{array}{c}\text { Expected and Actual Response } \\
\text { Write ACTUAL response in brackets or circle] }\end{array} \\
\end{array}$ & $\begin{array}{r}\text { Pass } \\
\text { YNN } \\
\end{array}$ & $\begin{array}{c}\text { Note } \\
\#\end{array}$ \\
\hline \multicolumn{6}{|c|}{ Burner Control Sequencing } \\
\hline $\begin{array}{c}1 \\
\text { Seq. } 1 \\
2,13 \\
14\end{array}$ & & $\begin{array}{l}\text { 1) Manually shut OFF boilers and } \\
\text { keep pumps running on manual to } \\
\text { lower boiler water temperature to < } \\
\text { 140F. } \\
\text { 2) Lower the HWST reset parameters } \\
\text { so the } 3 \text {-way valve is providing } 100 \% \\
\text { retum, or manually fix } 3 \text {-way valve to } \\
\text { do the same. } \\
\text { 3) If no gage, install a temperature } \\
\text { sensor in a thermowell of the boiler. } \\
\text { 4) With the boilers OFF, and boiler } \\
\text { water temperature < } 140 F \text {, lower the } \\
\text { lag boiler OSAT setpoint so that the } \\
\text { OSAT is } 3 F<\text { the OSAT, so both } \\
\text { boilers are enabled. Turn all systems } \\
\text { to auto. } \\
\text { Continue allowing water temp. to } \\
\text { climb. }\end{array}$ & 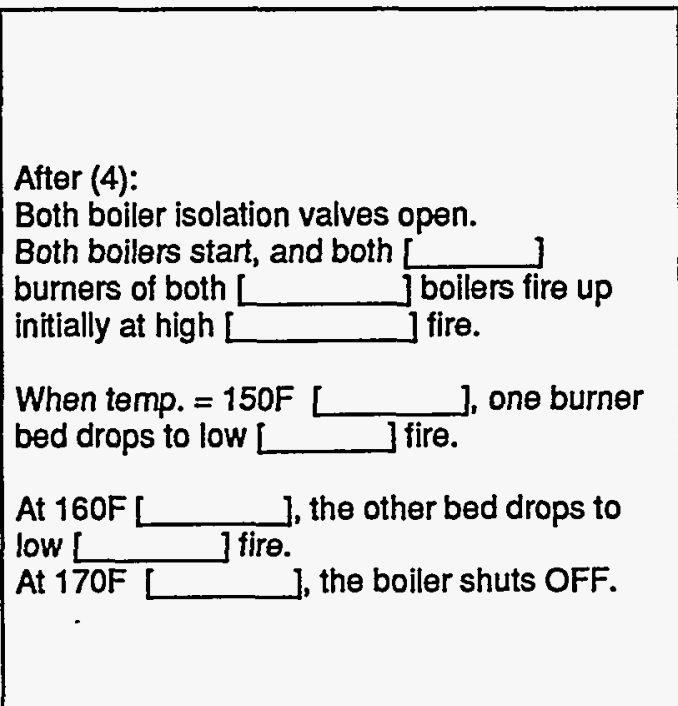 & & \\
\hline $\begin{array}{l}\text { Seq. } 6 \\
\text { Seq. } 7\end{array}$ & & $\begin{array}{l}\text { Raise the HWST resets, so that the 3- } \\
\text { way valve is at } 0 \% \text { return water (all } \\
\text { thru boller). } \\
\text { Allow the water in the boiler to cool. } \\
\text { Raise the HWST resets, and space } \\
\text { temperature setpoints, as necessary, } \\
\text { to keep boiler water cooling. }\end{array}$ & 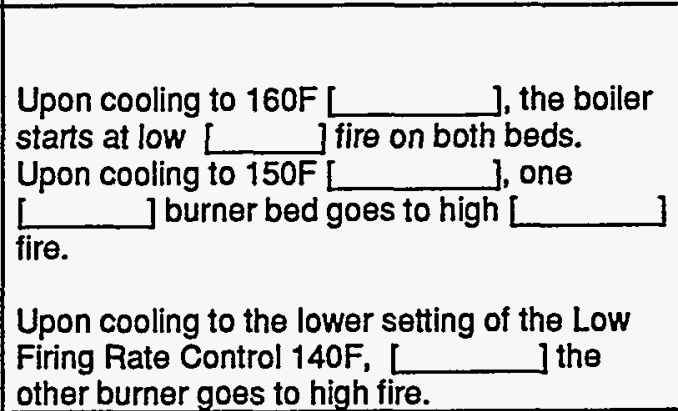 & & \\
\hline $\begin{array}{c}3 \\
\text { Seq. } 14\end{array}$ & & $\begin{array}{l}\text { With both bollers still running, lower } \\
\text { the lag boiler OSAT setpoint to be } 3 F \\
\text { lower than the OSAT. }\end{array}$ & $\begin{array}{l}\text { The lag boiler isolation valve closes and lag } \\
\text { boiler and pump shuts OFF. }\end{array}$ & & \\
\hline \multicolumn{6}{|l|}{ Safeties } \\
\hline $\begin{array}{c}4 \\
\text { Seg. } 8\end{array}$ & & $\begin{array}{l}\text { Loss of power. With boilers ON, shut } \\
\text { OFF power to them. }\end{array}$ & $\begin{array}{l}\text { Boiler burners shut OFF and an alarm is } \\
\text { generated in the BAS. }\end{array}$ & & \\
\hline $\begin{array}{ll}5 \\
5 \\
\text { Seg. } 9\end{array}$ & & $\begin{array}{l}\text { Low water. Unhook the wire to the low } \\
\text { water sensor to initiate an alarm. }\end{array}$ & $\begin{array}{l}\text { Boiler burners shutt OFF and an alarm is } \\
\text { generated in the BAS. }\end{array}$ & & \\
\hline $\begin{array}{c}6 \\
\text { Seg. } 10 \\
\end{array}$ & & $\begin{array}{l}\text { High limit. Lower the high limit setting } \\
\text { to the current water temperature to } \\
\text { initiate an alarm and shutdown. }\end{array}$ & $\begin{array}{l}\text { Boiler bumers shut OFF and an alarm is } \\
\text { generated in the BAS. }\end{array}$ & & \\
\hline Seq. 12 & & $\begin{array}{l}\text { Flame safety. Sufficiently tested } \\
\text { during startup. }\end{array}$ & DONE & & \\
\hline
\end{tabular}

Notes: 


\begin{tabular}{|c|c|c|c|c|c|}
\hline \begin{tabular}{|l|} 
Proced. \\
No. \& \\
Spec. \\
Seg. ID' \\
\end{tabular} & $\begin{array}{c}\text { Req ID } \\
\mathrm{No}^{2}\end{array}$ & $\begin{array}{c}\text { Test Procedure } \\
\text { (Including special conditions) } \\
\end{array}$ & \begin{tabular}{|c}
$\begin{array}{c}\text { Expected and Actual Response } \\
\text { [Write ACTUAL response in brackets or circle] }\end{array}$ \\
\end{tabular} & $\begin{array}{l}\text { Pass } \\
\text { Y/N }\end{array}$ & $\begin{array}{c}\text { Noto } \\
*\end{array}$ \\
\hline \multicolumn{6}{|c|}{ BAS Controlled Sequences } \\
\hline $\begin{array}{c}8 \\
\text { Seg. } 14 \\
\end{array}$ & & Done with procedure for Sequence 1. & & & \\
\hline \begin{tabular}{c|}
9 \\
Seq. 13 \\
\end{tabular} & & $\begin{array}{l}\text { Lead Boiler. Retum all boiler settings } \\
\text { and building parameters to normal. } \\
\text { Change the lead boiler OSAT setpoint } \\
\text { to be 3F > the OSAT. }\end{array}$ & $\begin{array}{l}\text { Lead boiler starts. } \\
\text { Only lead pump runs. } \\
\text { Isolation valve to lag boiler is closed. }\end{array}$ & & \\
\hline $\begin{array}{c}10 \\
\text { Seg. } 15 \\
\end{array}$ & & $\begin{array}{l}\text { Continuing from the last procedure: } \\
\text { Manually shut off the lead pump. }\end{array}$ & $\begin{array}{l}\text { After } 30 \text { seconds L } \\
\text { starts. No change in boiler isolation valves. }\end{array}$ & & \\
\hline $\begin{array}{c}11 \\
\text { Seq. } 16\end{array}$ & & $\begin{array}{l}\text { Return lead pump to auto. Lower the } \\
\text { high limit setpt on boiler, until boiler } \\
\text { goes OFF on high limit. }\end{array}$ & $\begin{array}{l}\text { After } 30 \text { seconds [ }[\text { ], the lag boiler } \\
\text { isolation valve opens, lead valve closes and } \\
\text { lag boiler should start. }\end{array}$ & & \\
\hline $\begin{array}{l}12 \\
\text { Seq. } \\
13-14 ; \\
17 ; 18\end{array}$ & & $\begin{array}{l}\text { Trend Log. Trend the OSAT, the } \\
\text { status of both boilers and pumps, } \\
\text { HWRT and the mixed HW supply } \\
\text { temperature for } 5 \text { days, including a } \\
\text { weekend at } 10 \text { minute intervals. } \\
\text { Provide the occupied schedule for this } \\
\text { period. }\end{array}$ & \begin{tabular}{|l} 
Verify Sequence 13. \\
Verify Sequence 14. \\
Verify Sequence 17. \\
Verify Sequence 18.
\end{tabular} & & \\
\hline $\begin{array}{c}13 \\
\text { Seq. } 17\end{array}$ & & $\begin{array}{l}\text { Unoccupied Night Low Limit Mode. } \\
\text { a) With RTU air handler (ASU) in } \\
\text { normal mode, change the schedule so } \\
\text { unoccupled mode will begin in } 5 \\
\text { minutes. } \\
\text { b) After the ASU shuts OFF, change } \\
\text { the RA NLL setpoint to be } 10 \mathrm{~F} \text { above } \\
\text { current RA temp. Overwrite one of the } \\
\text { polled perimeter zone space temp. to } \\
\text { be } 1 \text { Fabove the space NLL heating } \\
\text { setpoint, currently } \\
\text { c) Overwrite one of the polled } \\
\text { perimeter zone space temp. to be } \\
\text { 3Fbelow the space NLL heating } \\
\text { setpoint. } \\
\text { d) Change the RA NLL setpoint to be } \\
\text { within the bias or deadband range of } \\
\text { the current RA temp. } \\
\text { e) Retum schedules, NLL RA setpoint } \\
\text { and space overwritten values to } \\
\text { normal. }\end{array}$ & $\begin{array}{l}\text { c) The ASU and boilers come ON. } \\
\text { Heating coil valves operate normally. } \\
\text { Economizer dampers are shut and exhaust } \\
\text { fans are OFF. } \\
\text { d) The ASU and boilers shut OFF. } \\
\text { e) Values retumed to normal. }\end{array}$ & & \\
\hline
\end{tabular}

Notes: 


\begin{tabular}{|c|c|c|c|c|c|}
\hline $\begin{array}{l}\text { Proced. } \\
\text { No. \& } \\
\text { Spec. } \\
\text { Seq. ID' }\end{array}$ & $\begin{array}{c}\text { Req ID } \\
\text { No. }^{2}\end{array}$ & $\begin{array}{l}\text { Test Procedure } \\
\text { (Including special conditions) }\end{array}$ & $\begin{array}{l}\text { Expected and Actual Response } \\
\text { [Write ACTUAL response in brackets or circle] }\end{array}$ & $\begin{array}{l}\text { Pass } \\
\text { Y/N }\end{array}$ & $\begin{array}{c}\text { Note } \\
\#\end{array}$ \\
\hline $\begin{array}{c}14 \\
\text { Misc. }\end{array}$ & & $\begin{array}{l}\text { Pump speed. With both boilers } \\
\text { running, raise the space temperature } \\
\text { setpoint in all zones to put all boxes in } \\
\text { full heating. Wait } 10 \text { minutes to } \\
\text { ensure that all valves are fully open. } \\
\text { Check the amps on the pump motors. } \\
\text { Repeat with } 1 \text { pump and } 1 \text { boiler. }\end{array}$ & $\begin{array}{l}\text { Pump amps should be less than the rated full } \\
\text { load amps } \times \text { service factor of the pumps which } \\
\text { is: } \\
\text { [P-1 } \\
\text { On-2 } \\
\text { One Pump, P-1: } \\
\text { One Pump, P-2: }\end{array}$ & & \\
\hline $\begin{array}{c}15 \\
\text { Seq. } 18\end{array}$ & & $\begin{array}{l}\text { HWST reset. Using the trend log } \\
\text { above, plot the trend data in a } \\
\text { spreadsheet graph in the form below, } \\
\text { or plot } 20 \text { values thru both ends of the } \\
\text { range of trend data on the chart below. }\end{array}$ & & & \\
\hline
\end{tabular}

Notes: 


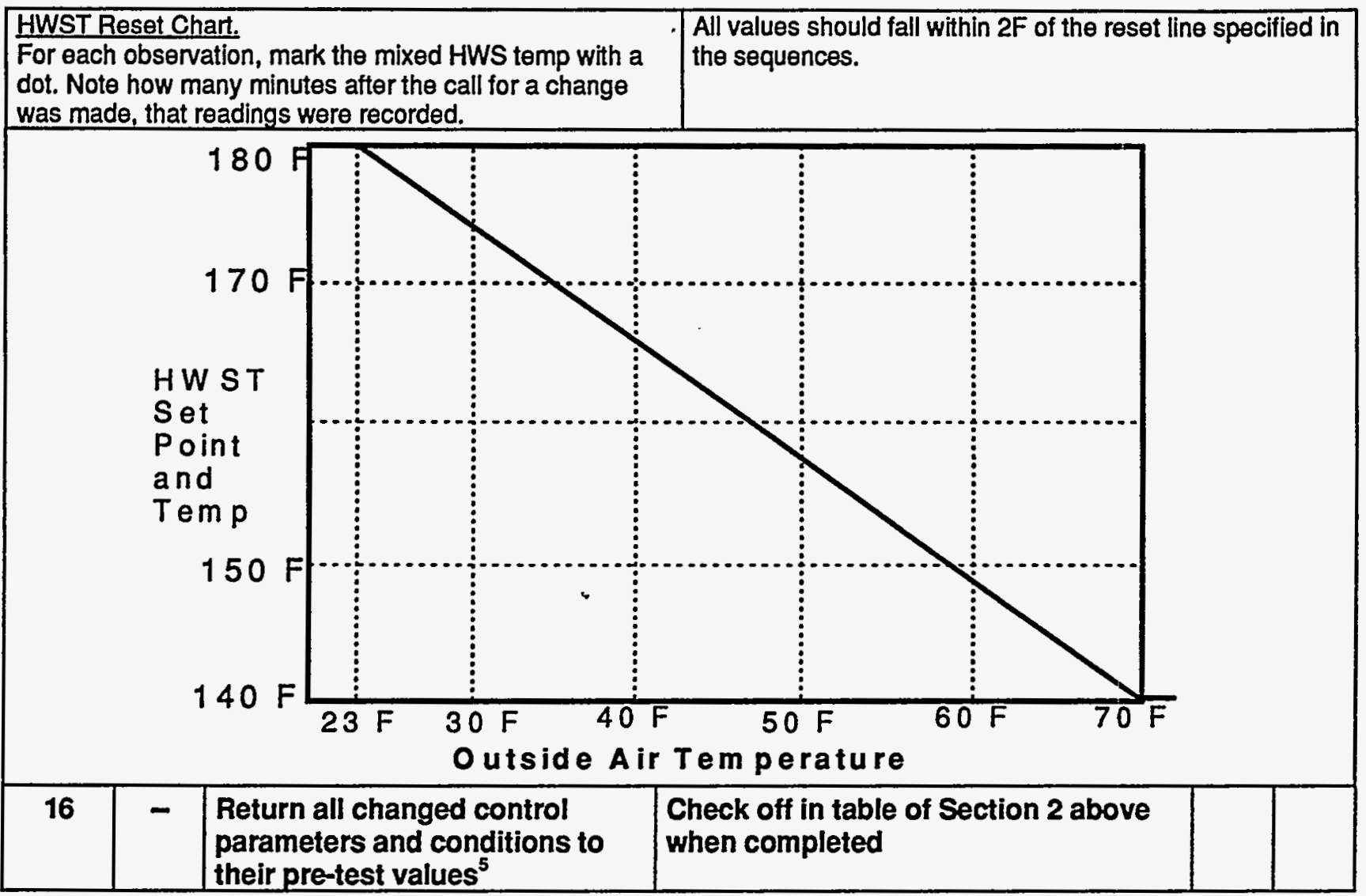

MONITORING AND TREND LOGGING. Monitoring via BAS trend logs are required per test Procedures 12. Attach representative graphs or columnar data and explanatory analysis to this test report.

*Abbreviations: HWST = mixed hot water supply temperature, BWST $=$ boiler hot water supply temperature, SPt $=$ setpoint, BAS = building automation system.

'Sequences of operation attached to this test.

${ }^{2}$ Mode or function ID being tested from testing requirements section of the project Specifications.

${ }^{3}$ Step-by-step procedures for manual testing, trend logging or data-logger monitoring.

${ }^{4}$ Include tolerances for a passing condition. Fill-in spaces or lines not in brackets denote sequence parameters still to be specified by the A/E, conrols contractor or vendor. Write "Via BAS" for verifications of device position from BAS readout or "Vla obs" for actual observation or from test instrument reading.

${ }^{5}$ Record any permanently changed parameter values and submit changes to Owner.

A summary of deficiencies identified during testing is attached

- END OF TEST -

Notes: 


\section{Functional Test}

Project

\section{FT- \\ SERVICE WATER HEATER (GAS)}

Related Tests: Small Service Water Heater Circulating Pumps

\section{Participants}

Party filling out this form and witnessing testing Dates of tests

\section{Test Prerequisites}

a. The following have been started up and startup reports and prefunctional checklists submitted and approved ready for functional testing:
Hot water heaters (GWH-1 and 2)
Service hot water piping

b. - All control system functions for this and all interlocking systems are programmed and operable per contract documents, including final setpoints and schedules and with debugging, loop tuning and sensor and device calibrations completed.

Controls Contractor Signature or Verbal

\section{Date}

c. _ Piping system flushing complete and required report approved.

g. - All $\mathrm{A} / \mathrm{E}$ punchlist items for this equipment corrected.

h. - These functional test procedures reviewed and approved by installing contractor.

i. - Safeties and operating ranges reviewed.

j. - Test requirements and sequences of operation attached.

k. - Schedules and setpoints attached.

1. - Sufficient clearance around equipment for servicing.

m. Have all energy savings control strategies, setpoints and schedules been incorporated that this water heater and control system are capable of? Is the temperature setpoint as low as it could practically be?

n. - Sensor Calibration Checks. The sensors listed below checked for calibration and adequate location. This is a spot check on a sample of the calibrations done during prefunctional checklisting.*

"In calibration" means making a reading with a calibrated test instrument within 6 inches of the site sensor. Verify that the sensor reading (via the permanent thermostat, gage or building automation system (BAS)) compared to the test instrument-measured value is within the tolerances specified in the prefunctional checklist requirements. If not, install offset in BAS, calibrate or replace sensor. Use the same test instruments as used for the original calibration, if possible.

Notes: 


\begin{tabular}{|l|c|c|c|c|c|}
\hline \multicolumn{1}{|c|}{ Sensor \& Location } & $\begin{array}{c}\text { Location } \\
\text { OK }\end{array}$ & $\begin{array}{c}\text { 1st Gage or } \\
\text { BAS Value }\end{array}$ & $\begin{array}{c}\text { Instrument } \\
\text { Measured Value }\end{array}$ & $\begin{array}{c}\text { Final Gage or } \\
\text { BAS Value }\end{array}$ & $\begin{array}{c}\text { Pass } \\
\text { Y/N? }\end{array}$ \\
\hline \hline HWST thermometer & & & & & \\
\hline HWRT thermometer & & & & & \\
\hline
\end{tabular}

${ }^{1}$ Sensor location is appropriate and away from causes of erratic operation.

o. _- Other misc. checks of the prefunctional checklist and startup reports completed successfully.

p. _ Record made of all values for current setpoints, etc. that may be changed to accomodate testing:

\begin{tabular}{|c|c|c|}
\hline Parameter & $\begin{array}{c}\text { Pre-Test } \\
\text { Values }\end{array}$ & $\begin{array}{c}\text { Retumed } \\
\text { to Pro-Test } \\
\text { Values } \sqrt{ }\end{array}$ \\
\hline \hline $\begin{array}{l}\text { Hot water temperature setpoint GWH-1 } \\
\text { Hot water temperature setpoint GWH-2 }\end{array}$ & & \\
\hline
\end{tabular}

\section{Testing Procedures and Record}

\begin{tabular}{|c|c|c|c|c|c|c|}
\hline $\begin{array}{c}\text { Proced. } \\
\text { No. \& } \\
\text { Spec. } \\
\text { Seq. ID' } \\
\end{array}$ & $\begin{array}{l}\text { Req ID } \\
\text { No. }{ }^{2}\end{array}$ & $\begin{array}{c}\text { Test Procedure } \\
\text { (including special conditions) } \\
\end{array}$ & $\begin{array}{r}\text { Expected and Actual Respo } \\
\text { [Write ACTUAL response in brackets }\end{array}$ & $\begin{array}{l}\text { onse } \\
\text { s or circle] }\end{array}$ & $\begin{array}{l}\text { Pass } \\
\text { YN } \\
\end{array}$ & $\begin{array}{c}\text { Note } \\
\# \\
\end{array}$ \\
\hline \multicolumn{7}{|c|}{ Boiler Bumer Control Sequencing } \\
\hline 1 & & $\begin{array}{l}\text { With the heaters in auto, but in } \\
\text { standby, drain hot water via PRV } \\
\text { to call for heat, or adjust the HW } \\
\text { temperature setpoint to be } 4 \\
\text { degrees above the HWT (from the } \\
\text { thermometers). Flue damper } \\
\text { should be shut. }\end{array}$ & $\begin{array}{l}\text { Flue damper opens. } \\
\text { Spark ignition lights pilot light. } \\
\text { Main burners fire after pilot is lit. }\end{array}$ & $\begin{array}{l}\text { GWH-1. } \\
\text { GWH-2 } \\
\text { GWH-1 } \\
\text { GWH-2 } \\
\text { GWH-1 } \\
\text { GWH-2 }\end{array}$ & & \\
\hline 2 & & -continued & $\begin{array}{l}\text { When HW temperature meets se } \\
\text { pilot \& burners shut OFF; } \\
\text { Flue damper closes. }\end{array}$ & $\begin{array}{l}\text { tpoint, } \\
\text { GWH-1 } \\
\text { GWH-2 } \\
\text { GWH-1 } \\
\text { GWH-2 }\end{array}$ & & \\
\hline 3 & & $\begin{array}{l}\text { Power failure. With WH satisfied } \\
\text { and burner OFF, shut OFF power } \\
\text { to flue damper. }\end{array}$ & Flue damper should open. & $\begin{array}{l}\text { GWH-1 } \\
\text { GWH-2 }\end{array}$ & & \\
\hline 4 & & $\begin{array}{l}\text { Observe the typical loop dT } \\
\text { (HWST - HWRT). }\end{array}$ & It should be less than $8 F$ & & & \\
\hline 5 & & $\begin{array}{l}\text { Pressure relief valve. Test the } \\
\text { presssure relief valve. }\end{array}$ & Water should be released. & $\begin{array}{l}\text { GWH-1 } \\
\text { GWH-2 }\end{array}$ & & \\
\hline
\end{tabular}

Notes: 


\begin{tabular}{|c|c|c|c|c|c|}
\hline $\begin{array}{l}\text { Procod. } \\
\text { No. \& } \\
\text { Spec. } \\
\text { Seg. ID' }\end{array}$ & $\begin{array}{c}\text { Req ID } \\
\text { No. }^{2}\end{array}$ & $\begin{array}{l}\text { Test Procedure } \\
\text { (including special conditlons) }\end{array}$ & $\begin{array}{c}\text { Expected and Actual Response } \\
\text { [Write ACTUAL response in brackets or circle] }\end{array}$ & $\begin{array}{c}\text { Pass } \\
\text { Y/N }\end{array}$ & $\begin{array}{c}\text { Note } \\
\text { \# }\end{array}$ \\
\hline 6 & & $\begin{array}{l}\text { Inspect for flammables around } \\
\text { WH. }\end{array}$ & There should be no flammables near WH. & & \\
\hline 7 & & $\begin{array}{l}\text { Does quality and quantity of } \\
\text { makeup air appear adequate? }\end{array}$ & Appears adequate. & & \\
\hline 8 & - & $\begin{array}{l}\text { Return all changed parameters } \\
\& \text { conditions to pre-test values }\end{array}$ & $\begin{array}{l}\text { Check off in table of Section } 2 \text { above } \\
\text { when completed }\end{array}$ & & \\
\hline
\end{tabular}

${ }^{1}$ Sequences of operation attached to this test.

${ }^{2}$ Mode or function ID being tested from testing requirements section of the project Specifications.

${ }^{3}$ Step-by-step procedures for manual testing, trend logging or data-logger monitoring.

${ }^{4}$ Include tolerances for a passing condition. Fill-in spaces or lines not in brackets denote sequence parameters still to be specified by the AVE, conrols contractor or vendor. Write "Via BAS" for verifications of device position from BAS readout or "Vla obs" for actual observation or from test instrument reading.

${ }^{5}$ Record any permanently changed parameter values and submit changes to Owner.

A summary of deficiencies identified during testing is attached.

\section{- END OF TEST -}

Notes: 


\section{Functional Test}

Project:

FT-

SMALL SERVICE HOT WATER CIRCULATING PUMPS CP-1; 2

1. Participants

Party
Related Tests: Gas HW Heaters

Participation

Party filling out this form and witnessing testing

Date of test

2. Prerequisite Checklist

a. The following have been started up and startup reports and prefunctional checklists submitted and approved ready for functional testing: _ CP-1; 2

b. Boilers $1 ; 2$ have successfully completed functional testing.

c. - All control system functions for this and all interlocking systems are programmed and operable per contract documents, including final setpoints, schedules, debugging, loop tuning and sensor calibrations complete.

Controls Contractor Signature or Verbal $\quad \overline{\text { Date }}$

d. All A/E punchlist items for this equipment corrected.

e. - Safeties and operating ranges reviewed.

f. - Test requirements and sequences of operation attached.

g. - Schedules and setpoints attached.

h. - Have all energy savings control strategies, setpoints and schedules been incorporated that this equipment and control system are capable of? If not, list recommendations below.

i. BAS Program Review. Review the BAS software control program(s) for this equipment. Parameters, setpoints and logic sequences appear to follow the specified written sequences.

j. Lecord of All Values for Current Setpoints (SP), Control Parameters, Limits, Delays, Lockouts, Schedules, Etc. Changed to Accommodate Testing:

\begin{tabular}{|c|c|c|c|c|c|}
\hline Parameter & $\begin{array}{c}\text { Pre-Test } \\
\text { Values }\end{array}$ & $\begin{array}{c}\text { Returned to } \\
\text { Pro-Test } \\
\text { Values } \sqrt{ }\end{array}$ & Parameter & $\begin{array}{c}\text { Pre-Test } \\
\text { Values }\end{array}$ & $\begin{array}{l}\text { Returned to } \\
\text { Pre-Test } \\
\text { Values } \sqrt{ }\end{array}$ \\
\hline CP-1; 2 schedule & & & & & \\
\hline
\end{tabular}

Notes: 
3. Sensor Calibration Checks. Check the sensors listed below for calibration and adequate location. This is a sampling check of calibrations done during prefunctional checklisting. Test the packaged controls and BAS readings.

-NONE-

4. Device Calibration Checks.

-NONE--

\section{Verification of Misc. Prefunctional Checks.}

Misc. site checks of the prefunctional checklist and startup reports completed successfully. Pass?'Y/N

_ Unit mounted securely.

6. Functional Testing Record

\begin{tabular}{|c|c|c|c|c|}
\hline $\begin{array}{l}\text { Proced. } \\
\text { No. \& } \\
\text { Spec. } \\
\text { Seq. ID' }\end{array}$ & $\begin{array}{c}\text { Req ID } \\
\text { No. }^{2}\end{array}$ & $\begin{array}{c}\text { Test Procedure } \\
\text { (including special conditions) }\end{array}$ & $\begin{array}{l}\text { Expected and Actual Response } \\
\text { [Write ACTUAL response in } \\
\text { brackets or circle] }\end{array}$ & 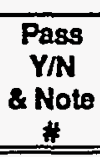 \\
\hline 1 & & $\begin{array}{l}\text { Pump speed. Check the amperage of the } \\
\text { circulating pumps. }\end{array}$ & $\begin{array}{l}\text { Amperage should be less than the } \\
\text { rated amps. Rated = }\end{array}$ & \\
\hline 2 & & $\begin{array}{l}\text { Change the schedule so the pumps should } \\
\text { be OFF. }\end{array}$ & Pumps turn OFF. & \\
\hline 3 & & $\begin{array}{l}\text { Schedule the pumps to be ON. } \\
\text { Return schedule to normal. }\end{array}$ & $\begin{array}{l}\text { Pumps start. } \\
\text { Schedule returned to normal }\end{array}$ & \\
\hline 4 & - & $\begin{array}{l}\text { Return all changed control parameters } \\
\text { and conditions to their pre-test values }\end{array}$ & $\begin{array}{l}\text { Check off in Section } 2 \text { above } \\
\text { when completed }\end{array}$ & \\
\hline
\end{tabular}

Record Foot Notes

${ }^{1}$ Sequences of operation specified in Contract Documents (attached).

${ }^{2}$ Mode or function ID being tested, per testing requirements section of the project Specifications.

${ }^{3}$ Step-by-step procedures for manual testing, trend logging or data-logger monitoring.

${ }^{4}$ Include tolerances for a passing condition.

${ }^{5}$ Record any permanently changed parameter values and submit to Owner.

\section{- END OF TEST -}

Notes: 


\section{Functional Test}

Project:

\section{FT-__ SPLIT AC UNIT AC-1; FCU-2 including \\ TELECOM ROOM C-104 SPACE TEMPERATURE CONTROL Including integral equipment: ASU-4; TU-1-43 \\ Related Tests: ASU-4}

\section{Participants}

Party

Participation

Party filling out this form and witnessing testing

Date of test

\section{Prerequisite Checklist}

a. The following have been started up and startup reports and prefunctional checklists submitted and approved ready for functional testing:

- AC-1; FCU-2

b. $-\bar{T}$ U-1-43 has successfully completed functional testing.

c. _ ASU-4 has successfully completed functional testing

d. All control system functions for this and all interlocking systems are programmed and operable per contract documents, including final setpoints and schedules with debugging, loop tuning and sensor calibrations completed.

$$
\text { Controls Contractor Signature or Verbal } \quad \overline{\text { Date }}
$$

e. - Vibration control report approved (if required).

f. - Test and balance (TAB) completed and approved for the hydronic systems and terminal units connected.

g. - All $\mathrm{A} / \mathrm{E}$ punchlist items for this equipment corrected.

h. - These functional test procedures reviewed and approved by installing contractor.

i. - Safeties and operating ranges reviewed.

j. - Test requirements and sequences of operation attached.

k. _ Schedules and setpoints attached.

\section{Notes:}


1. False loading equipment, system and procedures ready (boilers, preheat or reheat coils, control loops, override on OSA dampers, etc.)

m. _ Have all energy savings control strategies, setpoints and schedules been incorporated that this equipment and control system are capable of? If not, list recommendations below.

n. BAS Program Review. Review the BAS software control program(s) for this equipment. Parameters, setpoints and logic sequences appear to follow the specified written sequences.

o. _ Packaged Control Program Review. Review the packaged control program(s) for this equipment. Parameters, setpoints and logic sequences appear to follow the specified written sequences.

p. _Record of All Values for Current Setpoints (SP), Control Parameters, Limits, Delays, Lockouts, Schedules, Etc. Changed to Accommodate Testing:

\begin{tabular}{|l|l|l|}
\hline \multicolumn{1}{|c|}{ Parameter } & \multicolumn{1}{c|}{$\begin{array}{c}\text { Pre-Test } \\
\text { Values }\end{array}$} & $\begin{array}{c}\text { Retumed } \\
\text { to Pr-Test } \\
\text { Values V }\end{array}$ \\
\hline $\begin{array}{l}\text { Occupied mode TU } \\
\text { setpoint }\end{array}$ & & \\
\hline $\begin{array}{l}\text { Unoccupied mode TU } \\
\text { setpoint }\end{array}$ & & \\
\hline $\begin{array}{l}\text { Occupied FCU-2 } \\
\text { setpoint }\end{array}$ & & \\
\hline & & \\
\hline & & \\
\hline
\end{tabular}

\begin{tabular}{|l|r|r|}
\hline \multicolumn{1}{|c|}{ Parameter } & $\begin{array}{c}\text { Pre-Test } \\
\text { Values }\end{array}$ & $\begin{array}{c}\text { Returned } \\
\text { to Pre-Test } \\
\text { Values V }\end{array}$ \\
\hline $\begin{array}{l}\text { Unoccupied FCU-2 } \\
\text { setpoint }\end{array}$ & & \\
\hline $\begin{array}{l}\text { Security Co. occupied } \\
\text { alarm setpoint }\end{array}$ & $\%$ & $\%$ \\
\hline $\begin{array}{l}\text { Security Co. } \\
\text { unoccupied alarm } \\
\text { setpoint }\end{array}$ & & \\
\hline & $\%$ & $\%$ \\
\hline & \multicolumn{2}{|c|}{} \\
\hline
\end{tabular}

3. Sensor Calibration Checks. Check the sensors listed below for calibration and adequate location. This is a sampling check of calibrations done during prefunctional checklisting. Test the packaged controls and BAS readings.

"In calibration" means making a reading with a calibrated test instrument within 6 inches of the site sensor. Verify that the sensor reading (via the permanent thermostat, gage, packaged control panel or building automation system (BAS)) compared to the test instrument-measured value is within the tolerances specified in the prefunctional checklist requirements as used for the original calibration, if possible.

). If not, install offset in BAS, calibrate or replace sensor. Use the same test instruments

\begin{tabular}{|l|l|l|l|l|l|}
\hline Sensor \& Location & $\begin{array}{c}\text { Loc- } \\
\text { ation } \\
\text { OK' }\end{array}$ & $\begin{array}{c}\text { 1st Gage or } \\
\text { Pkg \& BAS } \\
\text { Values }\end{array}$ & $\begin{array}{c}\text { Instru. } \\
\text { Meas'd } \\
\text { Value }\end{array}$ & $\begin{array}{l}\text { Final Gage or } \\
\text { Pkg \& BAS } \\
\text { Values }\end{array}$ & $\begin{array}{l}\text { Pass } \\
\text { Y/N? }\end{array}$ \\
\hline \hline TU stat temp. & & BAS: & & BAS: & \\
\hline FCU-2 stat temp. & & Stat: & & Stat: & \\
\hline Security Co. Stat temp. & & Stat: & & Stat: & \\
\hline
\end{tabular}

'Sensor location is appropriate and away from causes of erratic operation.

\section{Notes:}


4. Device Calibration Checks. The actuators or devices listed below checked for calibration. This is a spot check on a sample of the calibrations done during prefunctional checklisting and startup.

"In calibration" means observing a readout in the BAS and going to the actuator or controlled device and verifying that the BAS reading is correct. For items out of calibration or adjustment, fix now if easy, via an offset in the BAS, or a mechanical fix.

\begin{tabular}{|l|l|l|l|l|l|}
\hline Device or Actuator \& Location & Procedure / State & $\begin{array}{c}\text { 1st } \\
\text { Pkg'd Value }\end{array}$ & $\begin{array}{c}\text { Site } \\
\text { Observation }\end{array}$ & $\begin{array}{c}\text { Final Pkg'd } \\
\text { Reading }\end{array}$ & $\begin{array}{c}\text { Pass } \\
\text { Y/N }\end{array}$ \\
\hline \hline $\begin{array}{l}\text { TU-1-43 shall be one of the } \\
\text { selected units in the TU } \\
\text { functional test sample } \\
\text { previously completed. }\end{array}$ & & & & & \\
\hline
\end{tabular}

\section{Verification of Misc. Prefunctional Checks.}

Misc. site checks of the prefunctional checklist and startup reports completed successfully. Pass? Y / N

\section{General Conditions of Test}

\section{Functional Testing Record}

\begin{tabular}{|c|c|c|c|c|}
\hline $\begin{array}{l}\text { Proced. } \\
\text { No. \& } \\
\text { Spec. } \\
\text { Seq. ID' }\end{array}$ & $\begin{array}{c}\text { Req ID } \\
\mathrm{No}^{2}\end{array}$ & $\begin{array}{l}\text { Test Procedure } \\
\text { (including special conditions) }\end{array}$ & $\begin{array}{c}\text { Expected and Actual Response } \\
\text { [Write ACTUAL response in } \\
\text { brackets or circle] }\end{array}$ & $\begin{array}{c}\text { Pass } \\
\text { YNN } \\
\& \text { Note } \\
\# \\
\end{array}$ \\
\hline $\begin{array}{c}1 \\
\text { Seq. } 1\end{array}$ & & $\begin{array}{l}\text { TU Occupied Mode. During occupied } \\
\text { mode, verify that the TU is maintaining the } \\
\text { space to the TU setpoint, by lowering the } \\
\text { TU setpoint } 5 F \text { and observing the TU } \\
\text { dampers open and meet setpoint. } \\
\text { Return TU setpoint to normal. }\end{array}$ & $\begin{array}{l}\text { The new setpoint is met. } \\
\text { (Additional testing on this TU was } \\
\text { performed with the TU's functional } \\
\text { testing.) } \\
\text { Setpoint returned to normal. }\end{array}$ & \\
\hline $\begin{array}{c}2 \\
\text { Seq. } 1\end{array}$ & & $\begin{array}{l}\text { FCU-2: AC-1 Occupied Mode. a) In } \\
\text { occupied mode, lower the FCU-2 setpoint to } \\
\text { be = current space temp. } \\
\text { b) Lower the setpoint to } 5 \text { F below the space } \\
\text { temp. } \\
\text { c) Lower the Security Co. setpoint to be = to } \\
\text { the space temp. } \\
\text { d) Return FCU-2 and Security Co. setpoints } \\
\text { to normal. }\end{array}$ & $\begin{array}{l}\text { a) FCU-2 starts. } \\
\text { AC-1 starts and -55F air is } \\
\text { delivered to space. } \\
\text { An alarm is registered in the BAS. } \\
\text { b) FCU-2 and AC-1 run until space } \\
\text { is cooled to new setpoint and then } \\
\text { cycle OFF. } \\
\text { c) An alarm is registered by the } \\
\text { Security Co. Obtain a fax of the } \\
\text { alarm. } \\
\text { d) Setpoints returned to normal. }\end{array}$ & \\
\hline
\end{tabular}

Notes: 


\begin{tabular}{|c|c|c|c|c|}
\hline $\begin{array}{l}\text { Proced. } \\
\text { No. \& } \\
\text { Spec. } \\
\text { Seq. ID } \\
\end{array}$ & $\begin{array}{c}\text { Req ID } \\
\text { No. }^{2}\end{array}$ & $\begin{array}{l}\text { Test Procedure } \\
\text { (including special conditions) }\end{array}$ & $\begin{array}{c}\text { Expected and Actual Response } \\
\text { [Write ACTUAL response in } \\
\text { brackets or circle] }\end{array}$ & $\begin{array}{l}\text { Pass } \\
\text { YN } \\
\text { \& Note } \\
\text { : }\end{array}$ \\
\hline $\begin{array}{c}3 \\
\text { Seq. } 2\end{array}$ & & $\begin{array}{l}\text { FCU-2; AC-1 Unoccupied Mode. a) In } \\
\text { unoccupied mode, lower the FCU-2 setpoint } \\
\text { to be = current space temp. } \\
\text { b) Lower the setpoint to } 5 F \text { below the space } \\
\text { temp. } \\
\text { c) Lower the Security Co. setpoint to be = to } \\
\text { the space temp. } \\
\text { d) Lower the Security Co. setpoint to } 5 F \\
\text { below space temp. } \\
\text { e) Return FCU-2 and Security Co. setpoints } \\
\text { to normal. }\end{array}$ & $\begin{array}{l}\text { a) FCU-2 starts. } \\
\text { AC-1 starts and } \sim 55 F[\text { _ } \\
\text { delivered to space. } \\
\text { An alarm is NOT registered in the } \\
\text { BAS. } \\
\text { b) FCU-2 and AC-1 run until space } \\
\text { is cooled to new setpoint and then } \\
\text { cycle OFF. } \\
\text { c) An alarm is registed by the } \\
\text { Security Co. and by the BAS. } \\
\text { Obtain a fax of the alarm. } \\
\text { ASU-4 starts and TU delivers } ~ \\
\text { J5F } \\
\text { d) TU and FCU-2 deliver air until } \\
\text { the Security Co. setpoint is met; } \\
\text { then ASU-4 shuts OFF. } \\
\text { e) Setpoints returned to normal. }\end{array}$ & \\
\hline 4 & & $\begin{array}{l}\text { Low Temp. Operation. During outdoor } \\
\text { weather between } 20 \mathrm{~F} \text { and } 30 \mathrm{~F} \text {, verify that } \\
\text { the unit functions and does not shut down } \\
\text { on safeties. }\end{array}$ & $\begin{array}{l}\text { Unit operates at specified low } \\
\text { ambient temperatures. }\end{array}$ & \\
\hline $\begin{array}{c}5 \\
\text { Seq. } 1 \\
2\end{array}$ & & $\begin{array}{l}\text { TREND LOG 1. During near design } \\
\text { conditions in summer, trend the OSAT, TU- } \\
1-43 \text { space temp., ASU-4 status and BAS } \\
\text { alarms, in } 15 \text { min. intervals for } 3 \text { days. }\end{array}$ & $\begin{array}{l}\text { Verify proper functioning of } \\
\text { systetm per sequences and above } \\
\text { test parameters. }\end{array}$ & \\
\hline 6 & - & $\begin{array}{l}\text { Return all changed control parameters } \\
\text { and conditions to their pre-test values }\end{array}$ & $\begin{array}{l}\text { Check off in Section } 2 \text { above } \\
\text { when completed }\end{array}$ & \\
\hline
\end{tabular}

MONITORING AND TREND LOGGING. Five monitoring via BAS trend logs are required per test Procedure 4. Trend logs none shall be provided in electronic continuous columnar spreadsheet compatible format. Trends all shall be provided in hard tabular format (continuous columnar with time in left column and at least four columns of point values in adjacent columns). All points for a given trend will begin at exactly the same time. Provide a key to all abbreviations. Attach representative graphs or columnar data and explanatory analysis to this test report.

\section{Record Foot Notes}

Sequences of operation specified in Contract Documents (attached).

${ }^{2}$ Mode or function ID being tested, per testing requirements section of the project Specifications.

${ }^{3}$ Step-by-step procedures for manual testing, trend logging or data-logger monitoring.

${ }^{4}$ Include tolerances for a passing condition.

${ }^{5}$ Record any permanently changed parameter values and submit to Owner.

\section{- END OF TEST -}

\section{Notes:}




\section{Functional Test (Cover Sheet)}

Project

FT-

TERMINAL UNITS (VAV w/ hot water reheat, single duct) DATA COMMON FOR ALL UNITS

\section{Participants (fill out once, to cover all TU's) Party

Party filling out this form and witnessing testing

Dates of tests

Dates of tests

2. Test Prerequisites (fill out once, to cover all TU's)

a. The following have been started up and startup reports and prefunctional checklists submitted and approved:

_ All terminal units, except

- All air handlers serving terminal units, except

_Hot water pumps

b. All control system functions for this and all interlocking systems are programmed and operable per contract documents, including final setpoints and schedules and with debugging, loop tuning and sensor and device calibrations completed.

\section{Controls Contractor Signature or Verbal}

Date

c. Piping system flushing complete, water treatment system complete and required report approved.

d. - Airside test and balance calibration of BAS readings of TU flows complete (system total flow need not be complete).

e. _ All $\mathrm{A} / \mathrm{E}$ punchlist items for this equipment corrected.

f. - These functional test procedures reviewed and approved by installing contractor.

g. - Test requirements and sequences of operation attached.

h. - Schedules and setpoints attached.

i. - Have all energy savings control strategies, setpoints and schedules been incorporated that this TU and control system are capable of? If not, list recommendations below.

j. - The controller \& actuator runtime accumulator set to 0 after prefunctional checkout of the entire system.

k. - Obtain and review the full program of 5\% (randomly chosen) of all TU's of each type (parameters \& setpoints, etc.). Examine variances. Clarify as needed, reconcile and document differences with controls contractor. If too many corrections exist with this sample, controls contractor shall recheck all programming.

\section{Sampling and Additional Testing.}

The terminal unit testing requirements in the specifications call for a random sample of $\%$ of all TU's of each type to be tested. Total number to be tested of this type $=$ The specifications also require that if

$\%$ of the sampled TU's fail in the testing (any No Pass items), then another $\%$ of the total population must be tested. This applies to the subsections of the test, i.e., if sub-sections fail, only subsections of additional TU's need to be tested. Record results in the table below.

\begin{tabular}{|l|l|l|}
\hline \multicolumn{1}{|c|}{ Sub-Section } & $\begin{array}{c}\% \text { Failed of } \\
\text { 1st Sample }\end{array}$ & $\begin{array}{c}\text { \% Failed of } \\
\text { 2nd Sample }\end{array}$ \\
\hline I. Sensor calibration & & \\
\hline II. Actuator calibration & & \\
\hline III. Static inspections & & \\
\hline
\end{tabular}

\begin{tabular}{|l|c|c|}
\hline \multicolumn{1}{|c|}{ Sub-Section } & $\begin{array}{c}\text { \% Failed of } \\
\text { 1st Sample }\end{array}$ & $\begin{array}{c}\text { \% Failed of } \\
\text { 2nd Sample }\end{array}$ \\
\hline IV. Programming & & . \\
\hline V. Functional tests & & \\
\hline & & \\
\hline
\end{tabular}




\section{Testing of TU 3-Way Valves}

All TU 3-way heating valves shall be verified to have been programmed and setup properly. When programmed or wired backwards, the valve will open when being commanded to close, causing the space to overheat. To verify proper wiring and programming, during a period of general cooling, verify that the actual space temperature is within $2 \mathrm{~F}$ of the (setpoint plus any user adjustment), unless in a fluctuating area (entry, etc.). Space temperatures more than $2 \mathrm{~F}$ above the net setpoint indicate possible 3-way valve problems. Investigate.

\section{TU Space Temperature Control for TU's With Three-Way Valves}

\begin{tabular}{|c|c|c|c|c|}
\hline TU ID & $\begin{array}{c}\text { Actual } \\
\text { Space } \\
\text { Temp. }\end{array}$ & Setpoint & $\begin{array}{c}\text { User } \\
\text { Adjust- } \\
\text { ment }\end{array}$ & OK? \\
\hline & & & & \\
\hline & & & & \\
\hline & & & & \\
\hline & & & & \\
\hline & & & & \\
\hline & & & & \\
\hline & & & & \\
\hline & & & & \\
\hline & & & & \\
\hline
\end{tabular}

\begin{tabular}{|c|c|c|c|c|}
\hline TU ID & $\begin{array}{c}\text { Actual } \\
\text { Space } \\
\text { Temp. }\end{array}$ & Setpoint & $\begin{array}{c}\text { User } \\
\text { Adjust- } \\
\text { ment }\end{array}$ & $\begin{array}{c}\text { OK } \\
?\end{array}$ \\
\hline & & & & \\
\hline & & & & \\
\hline & & & & \\
\hline & & & & \\
\hline & & & & \\
\hline & & & & \\
\hline & & & & \\
\hline & & & & \\
\hline & & & & \\
\hline
\end{tabular}

Notes: 


\section{Functional Test Record}

Project

FT-___ TERMINAL UNIT (VAV w/ hot water reheat, single duct)

Common values for all terminal units are recorded on the Cover Sheet. The following five pages of procedures are to be filled out for each TU tested.

\section{Seasonal Testing and General Conditions of Test}

Air handler or rooftop unit and boiler (if applicable) should be running in normal and occupied mode, unless noted. The tests may be performed in any season, if any temperature lockouts can be overridden.

\section{Testing Procedures and Record}

Computer printout or list made and attached of the current TU setpoints and control parameters and schedules, lockouts, etc. of other systems that may be changed to accomodate testing.

I. Sensor Calibration Checks. Check the sensors listed below for calibration and adequate location.

"In calibration" means making a reading with a calibrated test instrument within 6 inches of the site sensor. Verify that the sensor reading (via the permanent thermostat, gage or building automation system (BAS)) compared to the test instrument-measured value is within the tolerances specified in the prefunctional checklist requirements ). If not, install offset in BAS, calibrate or replace sensor. Use the same test instruments as used for the original calibration, if possible.

\begin{tabular}{|l|c|c|c|c|c|}
\hline $\begin{array}{c}\text { Sensor \& } \\
\text { Location }\end{array}$ & $\begin{array}{c}\text { Location } \\
\text { OK }^{1}\end{array}$ & $\begin{array}{c}\text { 1st Gage or } \\
\text { BAS Value }\end{array}$ & $\begin{array}{c}\text { Instrument } \\
\text { Measured Value }\end{array}$ & $\begin{array}{c}\text { Final Gage or } \\
\text { BAS Value }\end{array}$ & $\begin{array}{c}\text { Pass } \\
\text { Y/N? }\end{array}$ \\
\hline \hline Space temp. & & & & & \\
\hline & & & & & \\
\hline
\end{tabular}

${ }^{1}$ Sensor location is appropriate and away from causes of erratic operation.

II. Device Calibration Checks. Check the actuators or devices listed below for calibration. "In calibration" means observing a readout in the BAS and going to the actuator or controlled device and verifying that the BAS reading is correct. For items out of calibration or adjustment, fix now if easy, via an offset in the BAS, or a mechanical fix.

HCV: Set pumps to normal mode. Procedure 1. Command valve to a few intermediate positions. Verify that reading in BAS reasonably correspond to the actual positions. For heating coil valves (NO): Procedure $2 a$. Set heating setpoint $20^{\circ} \mathrm{F}$ above room temperature. Verify BAS reading says $100 \%$ open. Visually verify valve is fully open. $2 b$. Remove control air or electricity from the valve and verify that the valve stem and actuator position do not change. Procedure 3. Restore to normal. Set heating setpoint to $20^{\circ} \mathrm{F}$ below room temperature. Observe the valve close. 4. For pneumatic actuators, by override in the EMS, increase pressure to valve by 3 psi (do not exceed actuator rating). Verify valve stem \& actuator position does not change. Restore to normal.

Damper or Flow: -Checked during Functional Testing Section.

\begin{tabular}{|l|l|l|l|l|l|}
\hline \multicolumn{1}{|c|}{$\begin{array}{c}\text { Device or Actuator \& } \\
\text { Location }\end{array}$} & \multicolumn{1}{|c|}{ Procedure / State } & BAS Value & \multicolumn{1}{c|}{$\begin{array}{c}\text { Site } \\
\text { Observation }\end{array}$} & Corrections & $\begin{array}{c}\text { Pass } \\
\text { Y/N }\end{array}$ \\
\hline \hline \multirow{2}{*}{$\begin{array}{l}\text { Heating coil valve (HCV) } \\
\text { position or command and } \\
\text { stroke }\end{array}$} & 1. Intermediate positions & & & & \\
\cline { 2 - 6 } & 2a. Full open & & & & \\
\hline & 2b. Remove power or air (full open) & & & & \\
\hline & 3. Closed & & & & \\
\hline & 4. Increase pressure (close) & & & & \\
\hline & & & & & \\
\hline
\end{tabular}




\begin{tabular}{|c|c|c|c|c|}
\hline $\begin{array}{l}\text { Proced } \\
\text {. No. \& } \\
\text { Spec. } \\
\text { Seg. } \\
\text { ID }\end{array}$ & $\begin{array}{l}\text { Req } \\
\text { ID } \\
\text { No. }\end{array}$ & $\begin{array}{l}\text { Test Procedure } \\
\text { (including special conditions) }\end{array}$ & $\begin{array}{l}\text { Expected and Actual Response } \\
\text { [Write ACTUAL response or finding } \\
\text { in brackets or circle] }\end{array}$ & $\begin{array}{l}\text { Pass } \\
\text { Y/N } \\
\& \\
\text { Note \# }\end{array}$ \\
\hline \multicolumn{5}{|c|}{ III. STATIC INSPECTIONS } \\
\hline 1. & & \multicolumn{2}{|c|}{ Verify sufficient clearance around equipment for servicing. } & \\
\hline 2. & & \multicolumn{2}{|c|}{ Verify installation of specified sound wrapping and joint sealant. } & \\
\hline 3. & & \multicolumn{2}{|l|}{ Unit secured per spec. } & \\
\hline 4. & & \multicolumn{2}{|c|}{ Model and tag checked against plans \& equipment list. TU \& valve tags affixed. } & \\
\hline 5. & & \multicolumn{2}{|c|}{$\begin{array}{l}\text { Verify that inlet conditions are OK: Smooth, round, straight duct for at least } 3 \text { duct } \\
\text { diameters when possible and } 2 \text { diameters minimum for velocity pressure sensor and } 3 \\
\text { to } 5 \text { diameters for single point electronic sensors, else airflow straighteners. }\end{array}$} & \\
\hline 6. & & $\begin{array}{l}\text { (Verify for only } 1 / 2 \text { of the tested TU's) } \\
\text { For autoflow control valves, with water system } \\
\text { in normal, check pressure drop across valve. } \\
\text { Compare with valve requirements. }\end{array}$ & $\begin{array}{l}\text { Pressure drop should be in the range } \\
\text { of to If out of range, } \\
\text { investigate. }\end{array}$ & \\
\hline 7. & & $\begin{array}{l}\text { Verify for the other } 1 / 2 \text { of the tested TU's that } \\
\text { didn't have valve pressure drops checked.) } \\
\text { Valve off TU. Remove and check strainer for } \\
\text { cleanliness.. }\end{array}$ & $\begin{array}{l}\text { To pass, basket strainers must have } \\
\text { an unclogged area }>=80 \% \text { of the } \\
\text { strainer area. In-line strainers with } \\
\text { area = to pipe cross section must be } \\
90 \% \text { clean. }\end{array}$ & \\
\hline 8. & & $\begin{array}{l}\text { Auto TU Diagnostics. In the control system } \\
\text { diagnostics, check the controller and actuator } \\
\text { accumulated run times, the moving avg. flow } \\
\text { error and moving avg. space temp. deviation } \\
\text { from setpoint. }\end{array}$ & \begin{tabular}{|l|} 
The ratio of actuator to controller \\
runtime should be ideally <3\% \& $<$ \\
$5 \%$ is acceptable. L \%]. \\
Moving avg. flow error should be $<$ \\
$10 \%$ of max. cooling cfm [ $\%$ ]. \\
The moving avg. space temp. \\
deviation should be < 3F [ F].
\end{tabular} & \\
\hline \multicolumn{5}{|c|}{$\begin{array}{l}\text { IV. CONTROL PROGRAMMING. } \\
\text { In the procedures of this sectlon, compare specified written sequences and parameters with that found } \\
\text { programmed in the TU or BAS. Variances that, in the CA's opinion, reduce performance, must be } \\
\text { corrected. Variances that make no difference or enhance performance pass. Document all variances. }\end{array}$} \\
\hline 9. & & Control drawing sequences of operation & Per spec and detail adequate. & \\
\hline 10. & & $\begin{array}{l}\text { Verify that the TU address matches the TU } \\
\text { location and ID on the plan drawings and } \\
\text { control drawings. }\end{array}$ & Address matches. & \\
\hline 11. & & $\begin{array}{l}\text { Verify that the TU max and min setpoints in the } \\
\text { BAS match (within } 10 \% \text { ) the latest plan } \\
\text { drawings and balance report (TAB). }\end{array}$ & 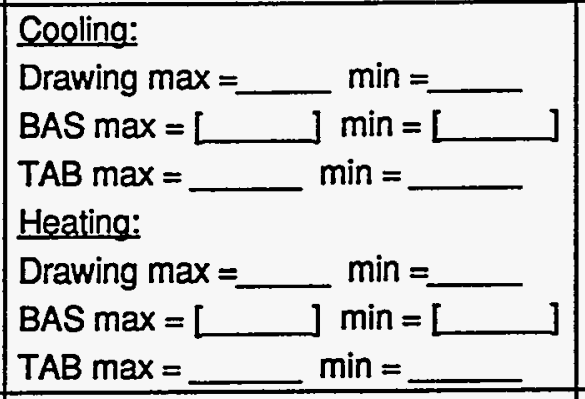 & \\
\hline 12. & & $\begin{array}{l}\text { Verify that BAS TU K factor is within } 20 \% \text { of } K \\
\text { on the submitted control drawings, unless } \\
\text { explained by TAB. }\end{array}$ & $\begin{array}{l}\text { Drawing } \mathrm{K}=\square \\
\text { BAS K=L TAB K = }\end{array}$ & \\
\hline
\end{tabular}

Notes: 


\begin{tabular}{|c|c|c|c|c|}
\hline \begin{tabular}{|l|} 
Proced \\
. No. \& \\
Spec. \\
Seq. \\
ID' \\
\end{tabular} & $\begin{array}{l}\text { Req } \\
\text { ID } \\
\text { No.2 }\end{array}$ & $\begin{array}{l}\text { Test Procedure } \\
\text { (including special conditions) }\end{array}$ & $\begin{array}{l}\text { Expected and Actual Response } \\
\text { [Write ACTUAL response or finding } \\
\text { in brackets or circle] }\end{array}$ & \begin{tabular}{|c|} 
Pass \\
Y/N \\
$\&$ \\
Note \#
\end{tabular} \\
\hline 13. & & $\begin{array}{l}\text { Temperature adjustment range by tenants } \\
\text { (indicate if a setting was spec'd) }\end{array}$ & $\begin{array}{l}\text { Spec'd or reasonable value } \\
\text { Found [L }\end{array}$ & \\
\hline 14. & & $\begin{array}{l}\text { Cooling-- occupied zone temp. setpoint } \\
\text { (indicate if a setting was spec'd) }\end{array}$ & $\begin{array}{l}\text { Spec'd or reasonable value } \\
\text { Found [L }\end{array}$ & \\
\hline 15. & & $\begin{array}{l}\begin{array}{l}\text { Heating-occupied zone temp. setpoint } \\
\text { (indicate if a setting was spec'd) }\end{array} \\
\end{array}$ & $\begin{array}{l}\text { Spec'd or reasonable value } \\
\text { Found [ }\end{array}$ & \\
\hline 16. & & $\begin{array}{l}\text { Unoccupied zone temperature setpoint } \\
\text { (indicate if a setting was spec'd) }\end{array}$ & $\begin{array}{l}\text { Spec'd or reasonable value } \\
\text { Found [ }\end{array}$ & \\
\hline 17. & & $\begin{array}{l}\text { Occupied zone temp. bias (deadband) } \\
\text { (indicate if a setting was spec'd) }\end{array}$ & $\begin{array}{l}\text { Spec'd or reasonable value } \\
\text { Found [ }\end{array}$ & \\
\hline 18. & & $\begin{array}{l}\text { Unnuccupied zone temp. bias (deadband) } \\
\text { (indicate if a setting was spec'd) }\end{array}$ & $\begin{array}{l}\text { Spec'd or reasonable value } \\
\text { Found [ }\end{array}$ & \\
\hline 19. & & $\begin{array}{l}\text { Heating coil valve stroke time (for incremental } \\
\text { valves) }\end{array}$ & $\begin{array}{l}\text { Actual timed } \\
\text { Input found in BAS }\end{array}$ & \\
\hline 20. & & $\begin{array}{l}\text { Cooling space setpoint proportional band } \\
\text { (indicate if a setting was spec'd) }\end{array}$ & $\begin{array}{l}\text { Spec'd or reasonable value } \\
\text { Found [ }\end{array}$ & \\
\hline 21. & & $\begin{array}{l}\text { Heating space setpoint proportional band } \\
\text { (indicate if a setting was spec'd) }\end{array}$ & $\begin{array}{l}\text { Spec'd or reasonable value } \\
\text { Found [ }\end{array}$ & \\
\hline 22. & & $\begin{array}{l}\text { Cooling cfm proportional band } \\
\text { (indicate if a setting was spec'd) }\end{array}$ & $\begin{array}{l}\text { Spec'd or reasonable value } \\
\text { Found [L }\end{array}$ & \\
\hline 23. & & Duct area (si) & From prints __ Found [_] & \\
\hline 24. & & $\begin{array}{l}\text { Damper stroke time (Spec'd value comes } \\
\text { from controller spec, unless oval duct, which } \\
\text { should then be timed) }\end{array}$ & Spec'd____ Found L & \\
\hline 25. & & Auto-zero function schedule set and enabled. & Set and enabled. & \\
\hline 26. & & & & \\
\hline \multicolumn{5}{|c|}{ V. FUNCTIONAL TESTING. } \\
\hline 27. & & $\begin{array}{l}\text { CFM Capacity Test, Cooling. With the duct SP } \\
\text { setpoint being met, lower the space temp. } \\
\text { setpoint } 20 \mathrm{~F} \text {. Verify in the BAS that the } \\
\text { specified max. cfm is achieved (within } \\
\text { deadband). } \\
\text { For TU's controlled by damper position only, } \\
\text { observe that the damper goes to max. as } \\
\text { expected. }\end{array}$ & $\begin{array}{l}\text { Specified max. cooling } \mathrm{cfm}= \\
\text { Achieved cfm or position }=[ \\
\text { Within deadband? }\end{array}$ & \\
\hline 28. & & $\begin{array}{l}\text { CFM Capacity Test. Heating. With the duct SP } \\
\text { setpoint being met, raise the space temp. } \\
\text { setpoint } 20 \mathrm{~F} \text {. Verify in the BAS that the } \\
\text { specified min. or heating cfm is achieved } \\
\text { (within deadband). } \\
\text { For TU's controlled by damper position only, } \\
\text { observe that the damper goes to min. as } \\
\text { expected. }\end{array}$ & $\begin{array}{l}\text { Specified min. or heating } \mathrm{cfm}= \\
\text { Achieved cfm or position= } \\
\text { Within deadband? }\end{array}$ & \\
\hline
\end{tabular}

Notes: 


\begin{tabular}{|c|c|c|c|c|}
\hline $\begin{array}{l}\text { Proced } \\
\text {. No. \& } \\
\text { Spec. } \\
\text { Seq. } \\
\text { ID' } \\
\end{array}$ & $\begin{array}{l}\text { Req } \\
\text { ID } \\
\text { No. }\end{array}$ & $\begin{array}{l}\text { Test Procedure } \\
\text { (including special conditions) }\end{array}$ & $\begin{array}{l}\text { Expected and Actual Response } \\
\text { [Write ACTUAL response or finding } \\
\text { in brackets or circle] }\end{array}$ & $\begin{array}{l}\text { Pass } \\
\text { Y/N } \\
\& \\
\text { Note \# }\end{array}$ \\
\hline 29. & & $\begin{array}{l}\text { (Verify for only } 1 / 2 \text { of the tested TU's) } \\
\text { Warmup cycle-heating. Adjust schedule or } \\
\text { time so TU will be in warmup mode. Adjust the } \\
\text { space setpoint to be } 5 \mathrm{~F} \text { above space. }\end{array}$ & $\begin{array}{l}\text { Does the TU damper go to heating } \\
\text { minimum? } \\
\text { Does HCV go to full open? }\end{array}$ & \\
\hline 30. & & $\begin{array}{l}\text { (Verify for only } 1 / 2 \text { of the tested TU's) } \\
\text { Warmup cycle--cooling. Adjust schedule or } \\
\text { time so TU will be in warmup mode. Adjust the } \\
\text { space setpoint to be 5F below space. }\end{array}$ & $\begin{array}{l}\text { Does the TU damper go to cooling } \\
\text { maximum? }\end{array}$ & \\
\hline 31. & & $\begin{array}{l}\text { HCV leakage. Method 1. Use any of three } \\
\text { methods. With the TU in cooling, with the } \\
\text { damper in a stable position, using matched } \\
\text { sensors, measure the duct air temperature } \\
\text { within } 4 \mathrm{ft} \text {. upstream and downstream of the } \\
\text { coil. }\end{array}$ & $\begin{array}{l}\text { Upstream: } \_ \text {F Down: } \frac{F}{\text { The temperature down stream should }} \\
\text { not be warmer than the air up stream. } \\
\text { if more than 1.0F greater, unit fails. } \\
\text { Investigate. }\end{array}$ & \\
\hline 32. & & $\begin{array}{l}\text { HCV leakage. Method } 2 \text {. Use any of three } \\
\text { methods. Turn off the air handler during test. } \\
\text { Command HCV open. After } 5 \text { min., slide temp. } \\
\text { sensor } 3 / 4^{n} \text { underneath insulation near } \\
\text { actuated valve. Shut isolation valves to stop } \\
\text { flow. Record ambient \& initial pipe temp. and } \\
\text { temp. after } 10 \text { min. Open isolation valves, } \\
\text { allow temp. to reach within } 3 F \text { of initial temp. } \\
\text { and record pipe and ambient temp. Command } \\
\text { HCV closed. Record temp. after } 10 \text { min. }\end{array}$ & 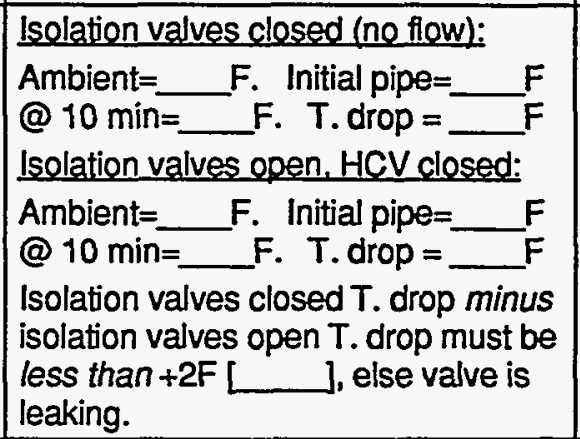 & \\
\hline 33. & & $\begin{array}{l}\text { HCV leakage. Method 3. Use any of three } \\
\text { methods. With the heating water system in } \\
\text { normal and the TU in full cooling, close coil } \\
\text { supply isolation valve, open air bleed cap, open } \\
\text { drain-down cock and drain water from coil. } \\
\text { Return all to normal. This method is not } \\
\text { applicable for 3-way valves. }\end{array}$ & $\begin{array}{l}\text { Water should stop draining, else } \\
\text { there may be a leak through the } \\
\text { control valve. }\end{array}$ & \\
\hline 34. & & Unoccupied Mode--Night Low Limit. & & \\
\hline 35. & & Unoccupied Mode-Night High Limit. & & \\
\hline 36. & & $\begin{array}{l}\text { Trending: HCV and Damper Control. } \\
\text { Over an } 8 \text { hour occupied period, trend at } 1 \mathrm{~min} \text {. } \\
\text { intervals, the HCV position, the HCV } \\
\text { command, the damper positon or cfm, the } \\
\text { damper or cfm command, the space } \\
\text { temperature and the duct static pressure at the } \\
\text { controlling sensor. }\end{array}$ & $\begin{array}{l}\text { Compare to the space temperature } \\
\text { to the setpoint. Observe that there is } \\
\text { little or no overshoot of space } \\
\text { temperature or hunting of the damper } \\
\text { or valve. }\end{array}$ & \\
\hline
\end{tabular}

Notes: 


\begin{tabular}{|c|c|c|c|c|}
\hline $\begin{array}{l}\text { Proced } \\
\text {. No. \& } \\
\text { Spec. } \\
\text { Seg. } \\
\text { ID }^{1}\end{array}$ & $\begin{array}{l}\text { Req } \\
\text { ID } \\
\text { No. }{ }^{2}\end{array}$ & $\begin{array}{l}\text { Test Procedure } \\
\text { (including special conditions) }\end{array}$ & $\begin{array}{l}\text { Expected and Actual Response } \\
\text { [Write ACTUAL response or finding } \\
\text { in brackets or circle] }\end{array}$ & $\begin{array}{l}\text { Pass } \\
\text { Y/N } \\
\& \\
\text { Note \# }\end{array}$ \\
\hline 37. & & $\begin{array}{l}\text { (Trend for only } 1 / 2 \text { of the tested TU's) } \\
\text { Trending. Over a } 3 \text { day period, during near } \\
\text { design conditions for heating and cooling, trend } \\
\text { space temp. at } 10 \text { minute intervals. Omit this } \\
\text { test if auto diagnostics has a moving avg. } \\
\text { space temp. deviation log and it was } \\
\text { completed. }\end{array}$ & $\begin{array}{l}\text { Observe that the space temp. does } \\
\text { not drift more than } 1^{\circ} \mathrm{F} \text { outside the } \\
\text { deadband range around the setpoint. }\end{array}$ & \\
\hline 38. & - & $\begin{array}{l}\text { Retum all changed control parameters and } \\
\text { conditions to their pre-test values }\end{array}$ & $\begin{array}{l}\text { Check off in program printout } \\
\text { when completed }\end{array}$ & \\
\hline
\end{tabular}

\section{MONITORING AND TAEND LOGGING}

Monitoring via BAS trend logs are required for test procedures 36; 37. Attach representative graphs or columnar data and explanatory analysis to this test report. The data should have time down the left column and four to six columns of parameters to the right. Provide a key to all abbreviations and attach setpoints and schedules for all trended parameters.

"*Abbreviations: BAS = building automation system, $\mathrm{CA}=$ commissioning agent, $\mathrm{HCV}=$ heating coil valve, $\mathrm{TU}=$ terminal unit, $S A=$ supply air, plan drawing = building drawings and schedules from design engineer.

'Sequences of operation attached to this test.

${ }^{2}$ Mode or function ID being tested from testing requirements section of the project Specifications.

${ }^{3}$ Step-by-step procedures for manual testing, trend logging or data-logger monitoring.

${ }^{4}$ Include tolerances for a passing condition. Fill-in spaces or lines not in brackets denote sequence parameters still to be specified by the AVE, conrols contractor or vendor. Write "Via BAS" for verifications of device position from BAS readout or "Via obs" for actual observation or from test instrument reading.

${ }^{5}$ Record any permanently changed parameter values and submit changes to Owner.

\section{A SUMMARY OF DEFICIENCIES IDENTIFIED DURING TESTING IS ATTACHED}

\section{- END OF TEST -}

Notes: 


\section{Functional Test (Cover Sheet)}

Project
FT-
TERMINAL UNITS (VAV Dual Duct, no coil) DATA COMMON FOR ALL UNITS

\section{Participants (fill out once, to cover all TU's) Party \\ Participation}

Party

Participation

Party filling out this form and witnessing testing

Dates of tests

Dates of tests

2. Test Prerequisites (fill out once, to cover all TU's)

a. The following have been started up and startup reports and prefunctional checklists submitted and approved:

All terminal units, except

_ All air handlers serving terminal units, except

b. All control system functions for this and all interlocking systems are programmed and operable per contract documents, including final setpoints and schedules and with debugging, loop tuning and sensor and device calibrations completed.

$$
\text { Controls Contractor Signature or Verbal }
$$

Date

c. Airside test and balance calibration of BAS readings of TU flows complete (system total flow need not be complete).

d. All A/E punchlist items for this equipment corrected.

e. - These functional test procedures reviewed and approved by installing contractor.

f. - Test requirements and sequences of operation attached.

g. - Schedules and setpoints attached.

h. - Have all energy savings control strategies, setpoints and schedules been incorporated that this TU and control system are capable of? If not, list recommendations below.

i. - The controller \& actuator runtime accumulator set to 0 after prefunctional checkout of the entire system.

j. _ Obtain and review the full program of 5\% (randomly chosen) of all TU's of each type (parameters \& setpoints, etc.). Examine variances. Clarify as needed, reconcile and document differences with controls contractor. If too many corrections exist with this sample, controls contractor shall recheck all programming.

\section{Sampling and Additional Testing.}

The terminal unit testing requirements in the specifications call for a random sample of ___ \% of all TU's of each type to be tested. Total number to be tested of this type = . The specifications also require that if

. \% of the sampled TU's fail in the testing (any No Pass items), then another ___ \% of the total population must be tested. This applies to the subsections of the test, i.e., if sub-sections fail, only subsections of additional TU's need to be tested. Record results in the table below.

\begin{tabular}{|l|l|l|}
\hline \multicolumn{1}{|c|}{ Sub-Section } & $\begin{array}{c}\text { \% Failed of } \\
\text { 1st Sample }\end{array}$ & $\begin{array}{c}\text { \% Failed of } \\
\text { 2nd Sample }\end{array}$ \\
\hline I. Sensor calibration & & \\
\hline II. Actuator calibration & & \\
\hline III. Static inspections & & \\
\hline
\end{tabular}

\begin{tabular}{|l|l|l|}
\hline \multicolumn{1}{|c|}{ Sub-Section } & $\begin{array}{c}\% \text { Failed of } \\
\text { 1st Sample }\end{array}$ & $\begin{array}{c}\% \text { Failed of } \\
\text { 2nd Sample }\end{array}$ \\
\hline IV. Programming & & \\
\hline V. Functional tests & & \\
\hline & & \\
\hline
\end{tabular}




\section{Functional Test Record}

\section{Project}

FT-_ TERMINAL UNIT (DD, VAV Dual Duct)

Common values for all terminal units are recorded on the Cover Sheet. The following pages of procedures are to be filled out for each TU tested.

\section{Seasonal Testing and General Conditions of Test}

Air handler or rooftop unit and boiler (if applicable) should be running in normal and occupied mode, unless noted. The tests may be performed in any season, if any temperature lockouts can be overridden.

\section{Testing Procedures and Record}

Computer printout or list made and attached of the current TU setpoints and control parameters and schedules, lockouts, etc. of other systems that may be changed to accomodate testing.

I. Sensor Calibration Checks. Check the sensors listed below for calibration and adequate location. "In calibration" means making a reading with a calibrated test instrument within 6 inches of the site sensor. Verify that the sensor reading (via the permanent thermostat, gage or building automation system (BAS)) compared to the test instrument-measured value is within the tolerances specified in the prefunctional checklist requirements ). If not, install offset in BAS, calibrate or replace sensor. Use the same test instruments as used for the original calibration, if possible.

\begin{tabular}{|l|l|l|l|l|l|}
\hline $\begin{array}{c}\text { Sensor \& } \\
\text { Location }\end{array}$ & $\begin{array}{c}\text { Location } \\
\text { OK }^{1}\end{array}$ & $\begin{array}{c}\text { 1st Gage or } \\
\text { BAS Value }\end{array}$ & $\begin{array}{c}\text { Instrument } \\
\text { Measured Value }\end{array}$ & $\begin{array}{c}\text { Final Gage or } \\
\text { BAS Value }\end{array}$ & $\begin{array}{c}\text { Pass } \\
\text { Y/N? }\end{array}$ \\
\hline \hline Space temp. & & & & & \\
\hline & & & & & \\
\hline
\end{tabular}

${ }^{1}$ Sensor location is appropriate and away from causes of erratic operation.

\section{Device Calibration Checks.}

1. Heating Damper Minimum Positive Closure Verification. For terminal units with a 0 (zero) cfm minimum heating cfm setpoint: With hot and cold decks operating, lower the space temperature setpoint $20 \mathrm{~F}$. Visually verify that the heating damper is shut tight and feel that no warm air is passing through damper. If damper is not accessible, close the return air isolation damper, measure the temperature at the cold duct inlet to the box and compare to the temperature at the discharge. If discharge temperature is more than $0.5 \mathrm{~F}$ greater than the cooling inlet, leakage may be occurring and the unit fails this test.

PASS? (Y/N)

\begin{tabular}{|l|l|l|l|c|}
\hline $\begin{array}{c}\text { Proced } \\
\text { No. \& } \\
\text { Spec. } \\
\text { Seq. } \\
\text { ID }\end{array}$ & $\begin{array}{c}\text { Req } \\
\text { ID } \\
\text { No. }\end{array}$ & \multicolumn{1}{|c|}{$\begin{array}{c}\text { Test Procedure } \\
\text { (including special conditions) }\end{array}$} & $\begin{array}{c}\text { Expected and Actual Response } \\
\text { [Write ACTUAL response or finding } \\
\text { in brackets or circle] }\end{array}$ & $\begin{array}{c}\text { Pass } \\
\text { Y/N } \\
\text { \& } \\
\text { Note \# }\end{array}$ \\
\hline III. STATIC INSPECTIONS & & \\
\hline 1. & & Verify sufficient clearance around equipment for servicing. & \\
\hline 2. & & Verify installation of specified sound wrapping and joint sealant. & \\
\hline 3. & & Unit secured per spec. & \\
\hline 4. & & Model and tag checked against plans \& equipment list. TU \& valve tags affixed. & \\
\hline 5. & & $\begin{array}{l}\text { Verify that inlet conditions are OK: Smooth, round, straight duct for at least } 3 \text { duct } \\
\text { diameters when possible and 2 diameters minimum for velocity pressure sensor and } 3 \\
\text { to } 5 \text { diameters for single point electronic sensors, else airflow straighteners. }\end{array}$ & \\
\hline
\end{tabular}




\begin{tabular}{|c|c|c|c|c|}
\hline $\begin{array}{l}\text { Proced } \\
\text { No. \& } \\
\text { Spec. } \\
\text { Seq. } \\
\text { ID' }\end{array}$ & $\begin{array}{c}\text { Req } \\
\text { iD } \\
\text { No. }\end{array}$ & $\begin{array}{l}\text { Test Procedure } \\
\text { (including special conditions) }\end{array}$ & $\begin{array}{l}\text { Expected and Actual Response } \\
\text { [Write ACTUAL response or finding } \\
\text { in brackets or circle] }\end{array}$ & $\begin{array}{l}\text { Pass } \\
\text { Y/N } \\
\& \\
\text { Note \# }\end{array}$ \\
\hline 6. & & $\begin{array}{l}\text { Aute TU Diagnostics. In the control system } \\
\text { diagnostics, check the controller and actuator } \\
\text { accumulated run times, the moving avg. flow } \\
\text { error and moving avg. space temp. deviation } \\
\text { from setpoint. }\end{array}$ & $\begin{array}{l}\text { The ratio of actuator to controller } \\
\text { runtime should be ideally }<3 \% \text { \& }< \\
5 \% \text { is acceptable. L } \%] \text {. } \\
\text { Moving avg. flow error should be }< \\
10 \% \text { of max. cooling cfm [ } \%] \text {. } \\
\text { The moving avg. space temp. } \\
\text { deviation should be }<3 F[\text { F]. }\end{array}$ & \\
\hline \multicolumn{5}{|c|}{$\begin{array}{l}\text { IV. CONTROL PROGRAMMING. } \\
\text { In the procedures of this section, compare specified written sequences and parameters with that found } \\
\text { programmed in the TU or BAS. Variances that, in the CA's opinion, reduce performance, must be } \\
\text { corrected. Variances that make no difference or enhance performance pass. Document all variances. }\end{array}$} \\
\hline 7. & & Control drawing sequences of operation & Per spec and detail adequate. & \\
\hline 8. & & $\begin{array}{l}\text { Verify that the TU address matches the TU } \\
\text { location and ID on the plan drawings and } \\
\text { control drawings. }\end{array}$ & Address matches. & \\
\hline 9. & & $\begin{array}{l}\text { Verify that the TU max and min setpoints in the } \\
\text { BAS match the latest plan drawings and } \\
\text { balance report (TAB). }\end{array}$ & 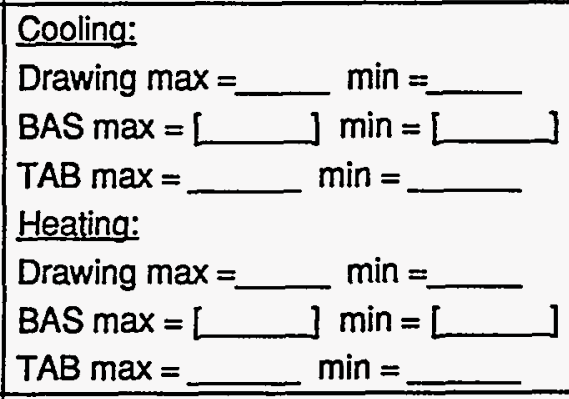 & \\
\hline 10. & & $\begin{array}{l}\text { Temperature adjustment range by tenants } \\
\text { (indicate if a setting was spec'd) }\end{array}$ & $\begin{array}{l}\text { Spec'd or reasonable value } \\
\text { Found [ }\end{array}$ & \\
\hline 11. & & $\begin{array}{l}\text { Cooling-- occupied zone temp. setpoint } \\
\text { (indicate if a setting was spec'd) }\end{array}$ & $\begin{array}{l}\text { Spec'd or reasonable value } \\
\text { Found [ }\end{array}$ & \\
\hline 12. & & $\begin{array}{l}\text { Unoccupied zone temperature setpoint } \\
\text { (indicate if a setting was spec'd) }\end{array}$ & $\begin{array}{l}\text { Spec'd or reasonable value } \\
\text { Found [ ] }\end{array}$ & \\
\hline 13. & & $\begin{array}{l}\text { Occupied zone temp. bias (deadband) } \\
\text { (indicate if a setting was spec'd) }\end{array}$ & $\begin{array}{l}\text { Spec'd or reasonable value } \\
\text { Found [ }\end{array}$ & \\
\hline 14. & & $\begin{array}{l}\text { Unnuccupied zone temp. bias (deadband) } \\
\text { (indicate if a setting was spec'd) }\end{array}$ & $\begin{array}{l}\text { Spec'd or reasonable value } \\
\text { Found [ }\end{array}$ & \\
\hline 15. & & $\begin{array}{l}\text { Cooling space setpoint proportional band } \\
\text { (indicate if a setting was spec'd) }\end{array}$ & $\begin{array}{l}\text { Spec'd or reasonable value } \\
\text { Found [ }\end{array}$ & \\
\hline 16. & & $\begin{array}{l}\text { Heating space setpoint proportional band } \\
\text { (indicate if a setting was spec'd) }\end{array}$ & $\begin{array}{l}\text { Spec'd or reasonable value } \\
\text { Found [L] }\end{array}$ & \\
\hline 17. & & $\begin{array}{l}\text { Cooling cim proportional band } \\
\text { (indicate if a setting was spec'd) }\end{array}$ & $\begin{array}{l}\text { Spec'd or reasonable value } \\
\text { Found [ }\end{array}$ & \\
\hline 18. & & $\begin{array}{l}\text { Heating cfm proportional band } \\
\text { (indicate if a setting was spec'd) }\end{array}$ & $\begin{array}{l}\text { Spec'd or reasonable value } \\
\text { Found [ }\end{array}$ & \\
\hline 19. & & Auto-zero function schedule set and enabled. & Set and enabled. & \\
\hline
\end{tabular}

Notes: 


\begin{tabular}{|c|c|c|c|c|}
\hline \begin{tabular}{c|} 
Proced \\
. No. \& \\
Spec. \\
Seq. \\
ID \\
\end{tabular} & $\begin{array}{l}\text { Req } \\
\text { ID } \\
\text { No. }\end{array}$ & $\begin{array}{l}\text { Test Procedure } \\
\text { (including special conditions) }\end{array}$ & $\begin{array}{l}\text { Expected and Actual Response } \\
\text { [Write ACTUAL response or finding } \\
\text { in brackets or circle] }\end{array}$ & \begin{tabular}{|c|} 
Pass \\
Y/N \\
$\&$ \\
Note \#
\end{tabular} \\
\hline 20. & & Duct area at flow station (sf) & 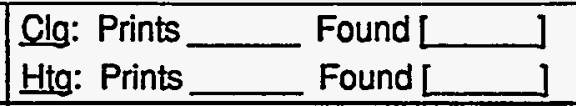 & \\
\hline 21. & & $\begin{array}{l}\text { Verify that BAS TU K factor is within } 20 \% \text { of } K \\
\text { on the submitted control drawings, unless } \\
\text { explained by TAB. }\end{array}$ & $\begin{array}{l}\text { Cooling: Drawing } \mathrm{K}= \\
\mathrm{BASK}=[\quad \mathrm{TABK}= \\
\text { Heating: Drawing } \mathrm{K}= \\
\mathrm{BASK}=[\quad \mathrm{TABK}=\end{array}$ & \\
\hline 22. & & $\begin{array}{l}\text { Damper stroke time (Spec'd value comes } \\
\text { from controller spec, unless oval duct, which } \\
\text { should then be timed) }\end{array}$ & Spec'd _____ Found [ & \\
\hline 23. & & & & \\
\hline \multicolumn{5}{|c|}{ V. FUNCTIONAL TESTING. } \\
\hline 24. & & $\begin{array}{l}\text { CFM Capacity Test. Cooling. For TU's } \\
\text { controlled from DDC flow stations: } \\
\text { With the duct SP setpoint being met, lower } \\
\text { space setpoint } 20 \mathrm{~F} \text { and observe in BAS that } \\
\text { cooling flow goes to maximum and heating flow } \\
\text { goes to minimum. } \\
\text { For TU's controlled by damper position only, } \\
\text { observe that the damper goes to min. and max. } \\
\text { as expected. }\end{array}$ & $\begin{array}{l}\text { Specified max. cooling cfm }= \\
\text { Achieved cfm or position }=[ \\
\text { Within deadband (if DDC)? } \\
\text { Specified min. heating cfm }= \\
\text { Achieved cfm or position }=[ \\
\text { Within deadband? (if DDC) }\end{array}$ & \\
\hline 25. & & $\begin{array}{l}\text { CFM Capacity Test. Heating. For TU's } \\
\text { controlled from DDC flow stations: } \\
\text { With the duct SP setpoint being met, raise } \\
\text { space setpoint } 20 \text { F and observe in BAS that } \\
\text { heating flow goes to maximum and cooling flow } \\
\text { goes to minimum. } \\
\text { For TU's controlled by damper position only, } \\
\text { observe that the damper goes to min. and max. } \\
\text { as expected. } \\
\text { Retum setpoints to normal. }\end{array}$ & $\begin{array}{l}\text { Specified max. htg cfm }= \\
\text { Achieved cfm or position }=[ \\
\text { Within deadband (if } \mathrm{DDC}) ? \\
\text { Specified min. clg cfm }= \\
\text { Achieved cfm or position }=[ \\
\text { Within deadband? (if } \mathrm{DDC} \text { ) }\end{array}$ & \\
\hline 26. & & $\begin{array}{l}\text { (Verify for only } 1 / 2 \text { of the tested TU's) } \\
\text { Warmup cycle-heating. Adjust schedule or } \\
\text { time so TU will be in warmup mode. Adjust the } \\
\text { space setpoint to be } 5 F \text { above space. }\end{array}$ & $\begin{array}{l}\text { Does the TU damper go to heating } \\
\text { minimum? }\end{array}$ & \\
\hline 27. & & $\begin{array}{l}\text { (Verify for only } 1 / 2 \text { of the tested TU's) } \\
\text { Warmup cycle--cooling. Adjust schedule or } \\
\text { time so TU will be in warmup mode. Adjust the } \\
\text { space setpoint to be 5F below space. }\end{array}$ & $\begin{array}{l}\text { Does the TU damper go to cooling } \\
\text { maximum? }\end{array}$ & \\
\hline 28. & & $\begin{array}{l}\text { Interlocks. This unit is interlocked with radiant } \\
\text { panel or fin tube heating (Y/N) } \\
\text { Yes, the fin tube or radiant panel functional } \\
\text { tests will verify the interlocks with the TU. }\end{array}$ & $\begin{array}{l}\text { TU operates normally during cycling } \\
\text { ON and OFF of radiant panels and fin } \\
\text { tubes. }\end{array}$ & \\
\hline
\end{tabular}

Notes: 


\begin{tabular}{|c|c|c|c|c|}
\hline $\begin{array}{l}\text { Proced } \\
\text { No. \& } \\
\text { Spec. } \\
\text { Seq. } \\
\text { ID } \\
\end{array}$ & $\begin{array}{l}\text { Req } \\
\text { ID } \\
\text { No. }\end{array}$ & $\begin{array}{l}\text { Test Procedure } \\
\text { (including special conditions) }\end{array}$ & $\begin{array}{l}\text { Expected and Actual Response } \\
\text { [Write ACTUAL response or finding } \\
\text { in brackets or circle] }\end{array}$ & $\begin{array}{c}\text { Pass } \\
\text { Y/N } \\
\& \\
\text { Note \# }\end{array}$ \\
\hline 29. & & $\begin{array}{l}\text { Night High Limit Operation. Schedule the } \\
\text { space so it is in unoccupied mode. Change the } \\
\text { NHL setpoint } \\
\text { NHL functions. } \\
\text { a. Change the zone unoccupied setpoint to be } \\
20 \text { F below the space temp. Observe in BAS } \\
\text { that cooling flow goes to maximum and heating } \\
\text { flow goes to minimum. } \\
\text { b. Change the zone unoccupied setpoint (if } \\
\text { used, else use occupied setpoint) to be = to the } \\
\text { space temp. Observe in the BAS that the } \\
\text { cooling and heating flows go to min. } \\
\text { For TU's controlled by damper position only, } \\
\text { observe that the dampers go to their expected } \\
\text { positions. }\end{array}$ & $\begin{array}{l}\text { a. Specified max. unoccupied } \\
\text { cooling cfm = } \\
\text { Achieved cfm or position = } \\
\text { Within deadband (if DDC)? } \\
\text { Specified min. heating cfm = } \\
\text { Achieved cfm or position = [ } \\
\text { Within deadband? (if DDC) } \\
\text { b. Cooling and heating flows or } \\
\text { postions go to minimum. L } \\
\text { c. TU remains in normal mode until } \\
\text { NHL setpoint minus offset is reached } \\
\text { by the determining zones, when AHU } \\
\text { and TU will shut down. }\end{array}$ & \\
\hline 30. & & $\begin{array}{l}\text { Night Low Limit Operation. Schedule the } \\
\text { space so it is in unoccupied mode. Change the } \\
\text { NLL setpoint L so it engages the NLL } \\
\text { functions. } \\
\text { a. Change the zone unoccupied setpoint (if } \\
\text { used, else use occupied setpoint) to be } 20 \mathrm{~F} \\
\text { above the space temp. Observe in BAS that } \\
\text { heating flow goes to maximum and cooling flow } \\
\text { goes to minimum. } \\
\text { b. Change the zone unoccupied setpoint to be } \\
\text { = to the space temp. Observe in the BAS that } \\
\text { the cooling and heating flows go to min. } \\
\text { For TU's controlled by damper position only, } \\
\text { observe that the dampers go to their expected } \\
\text { positions. }\end{array}$ & $\begin{array}{l}\text { a. Specified max. unoccupied } \\
\text { heating cfm = } \\
\text { Achieved cfm or position = [ } \\
\text { Within deadband (if DDC)? } \\
\text { Specified min. cooling cfm = } \\
\text { Achieved cfm or position = } \\
\text { Within deadband? (if DDC) } \\
\text { b. Cooling and heating flows or } \\
\text { postions go to minimum. [ } \\
\text { c. TU remains in normal mode until } \\
\text { NLL setpoint + offset is reached by } \\
\text { the determining zones, when AHU } \\
\text { and TU will shut down. }\end{array}$ & \\
\hline 31. & & $\begin{array}{l}\text { Trending: Damper Control. } \\
\text { Over an } 8 \text { hour occupied period, trend at } 1 \text { min. } \\
\text { intervals, the hot and cold damper positons or } \\
\text { cfm, the dampers or cfm commands, the } \\
\text { space temperature and the duct static pressure } \\
\text { at the controlling sensor. } \\
\end{array}$ & $\begin{array}{l}\text { Compare to the space temperature } \\
\text { to the setpoint. Observe that there is } \\
\text { little or no overshoot of space } \\
\text { temperature or hunting of the } \\
\text { damper. }\end{array}$ & \\
\hline 32. & & $\begin{array}{l}\text { (Trend for only } 1 / 2 \text { of the tested TU's) } \\
\text { Trending General. Over a } 3 \text { day period, during } \\
\text { near design conditions for heating and cooling, } \\
\text { trend space temp. at } 10 \text { minute intervals. } \\
\text { Omit this test if auto diagnostics has a moving } \\
\text { avg. space temp. deviation log and it was } \\
\text { completed. }\end{array}$ & $\begin{array}{l}\text { Observe that the space temp. does } \\
\text { not drift more than } 1^{\circ} \mathrm{F} \text { outside the } \\
\text { deadband range around the setpoint. }\end{array}$ & \\
\hline
\end{tabular}

Notes: 


\begin{tabular}{|c|c|c|c|c|}
\hline $\begin{array}{c}\text { Proced } \\
\text { No. \& } \\
\text { Spec. } \\
\text { Seq. } \\
\text { ID }^{1}\end{array}$ & $\begin{array}{c}\text { Req } \\
\text { ID } \\
\text { No. }^{2}\end{array}$ & $\begin{array}{c}\text { Test Procedure } \\
\text { (including special conditions) }\end{array}$ & $\begin{array}{c}\text { Expected and Actual Response } \\
\text { [Write ACTUAL response or finding } \\
\text { in brackets or circle] }\end{array}$ & $\begin{array}{c}\text { Pass } \\
\text { Y/N } \\
\& \\
\text { Note \# }\end{array}$ \\
\hline \hline 33. & & & & \\
\hline 34. & - & $\begin{array}{l}\text { Return all changed control parameters and } \\
\text { conditions to thelr pre-test values }\end{array}$ & $\begin{array}{l}\text { Check off in program printout } \\
\text { when completed }\end{array}$ & \\
\hline
\end{tabular}

\section{MONITORING AND TREND LOGGING}

Monitoring via BAS trend logs are required for test procedures 31 and 32. Attach representative graphs or columnar data and explanatory analysis to this test report. The data should have time down the left column and four to six columns of parameters to the right. Provide a key to all abbreviations and attach setpoints and schedules for all trended parameters.

"*Abbreviations: $\mathrm{BAS}=$ building automation system, $\mathrm{CA}=$ commissioning agent, $\mathrm{HCV}=$ heating coil valve, $\mathrm{TU}=$ terminal unit, $S A=$ supply air, plan drawing = building drawings and schedules from design engineer.

${ }^{1}$ Sequences of operation attached to this test.

${ }^{2}$ Mode or function ID being tested from testing requirements section of the project Specifications.

${ }^{3}$ Step-by-step procedures for manual testing, trend logging or data-logger monitoring.

${ }^{4}$ Include tolerances for a passing condition. Fill-in spaces or lines not in brackets denote sequence parameters still to be specified by the AVE, conrols contractor or vendor. Write "Via BAS" for verifications of device position from BAS readout or "Via obs" for actual observation or from test instrument reading.

${ }^{5}$ Record any permanently changed parameter values and submit changes to Owner.

\section{A SUMMARY OF DEFICIENCIES IDENTIFIED DURING TESTING IS ATTACHED}

\section{- END OF TEST -}

\section{Notes:}




\title{
Functional Test (Cover Sheet)
}

\author{
Project
}

FTTERMINAL UNITS (VAV Dual Duct with Series Fan, no coil)
DATA COMMON FOR ALL UNITS

1. Participants (fill out once, to cover all TU's) Party

Participation

Party

Participation

Party filling out this form and witnessing testing

Dates of tests

Dates of tests

2. Test Prerequisites (fill out once, to cover all TU's)

a. The following have been started up and startup reports and prefunctional checklists submitted and approved: - All terminal units, except All air handlers serving terminal units, except

b. - All control system functions for this and all interlocking systems are programmed and operable per contract documents, including final setpoints and schedules and with debugging, loop tuning and sensor and device calibrations completed.

c. Airside TAB calibration of BAS readings of TU flows complete (system total flow need not be complete).

d. - All A/E punchlist items for this equipment corrected.

e. - These functional test procedures reviewed and approved by installing contractor.

f. - Test requirements and sequences of operation attached.

g. - Schedules and setpoints attached.

h. - Have all energy savings control strategies, setpoints and schedules been incorporated that this TU and control system are capable of? If not, list recommendations below.

i. - The controller \& actuator runtime accumulator set to 0 after prefunctional checkout of the entire system.

j. - Obtain and review the full program of 5\% (randomly chosen) of all TU's of each type (parameters \& setpoints, etc.). Examine variances. Clarify as needed, reconcile and document differences with controls contractor. If too many corrections exist with this sample, controls contractor shall recheck all programming.

k. - Verify that the unit and controls contain all specified fan backward rotation prevention devices and any specified backdraft dampers.

\section{Sampling and Additional Testing.}

The terminal unit testing requirements in the specifications call for a random sample of $\%$ of all TU's of each type to be tested. Total number to be tested of this type = . The specifications also require that if $\%$ of the sampled TU's fail in the testing (any No Pass items), then another ___ \% of the total population must be tested. This applies to the subsections of the test, i.e., if sub-sections fail, only subsections of additional TU's need to be tested. Record results in the table below.

\begin{tabular}{|l|l|l|}
\hline \multicolumn{1}{|c|}{ Sub-Section } & $\begin{array}{c}\text { \% Failed of } \\
\text { 1st Sample }\end{array}$ & $\begin{array}{c}\text { \% Failed of } \\
\text { 2nd Sample }\end{array}$ \\
\hline I. Sensor calibration & & \\
\hline II. Actuator calibration & & \\
\hline III. Static inspections & & \\
\hline
\end{tabular}

\begin{tabular}{|l|l|l|}
\hline \multicolumn{1}{|c|}{ Sub-Section } & $\begin{array}{c}\text { \% Failed of } \\
\text { 1st Sample }\end{array}$ & $\begin{array}{c}\text { \% Failed of } \\
\text { 2nd Sample }\end{array}$ \\
\hline IV. Programming & & \\
\hline V. Functional tests & & \\
\hline & & \\
\hline
\end{tabular}




\title{
Functional Test Record
}

\author{
Project
}

FT-

TERMINAL UNIT

(VAV Dual Duct with Series Fan, no

coil)

Common values for all terminal units are recorded on the Cover Sheet. The following pages of procedures are to be filled out for each TU tested.

\section{Seasonal Testing and General Conditions of Test}

Air handler or rooftop unit and boiler (if applicable) should be running in normal and occupied mode, unless noted. The tests may be performed in any season, if any temperature lockouts can be overridden.

\section{Testing Procedures and Record}

Computer printout or list made and attached of the current TU setpoints and control parameters and schedules, lockouts, etc. of other systems that may be changed to accomodate testing.

I. Sensor Calibration Checks. Check the sensors listed below for calibration and adequate location.

"In calibration" means making a reading with a calibrated test instrument within 6 inches of the site sensor. Verify that the sensor reading (via the permanent thermostat, gage or building automation system (BAS)) compared to the test instrument-measured value is within the tolerances specified in the prefunctional checklist requirements ). If not, install offset in BAS, calibrate or replace sensor. Use the same test instruments as used for the original calibration, if possible.

\begin{tabular}{|l|c|c|c|c|c|}
\hline $\begin{array}{c}\text { Sensor \& } \\
\text { Location }\end{array}$ & $\begin{array}{c}\text { Location } \\
\text { OK }^{1}\end{array}$ & $\begin{array}{c}\text { 1st Gage or } \\
\text { BAS Value }\end{array}$ & $\begin{array}{c}\text { Instrument } \\
\text { Measured Value }\end{array}$ & $\begin{array}{c}\text { Fnal Gage or } \\
\text { BAS Value }\end{array}$ & $\begin{array}{c}\text { Pass } \\
\text { Y/N? }\end{array}$ \\
\hline \hline Space temp. & & & & & \\
\hline & & & & & \\
\hline
\end{tabular}

${ }^{1}$ Sensor location is appropriate and away from causes of erratic operation.

\section{Device Calibration Checks.}

1. Heating Damper Minimum Positive Closure Verification. For terminal units with a 0 (zero) cfm minimum heating cfm setpoint: With hot and cold decks operating, lower the space temperature setpoint $20 \mathrm{~F}$. Visually verify that the heating damper is shut tight and feel that no warm air is passing through damper. If damper is not accessible, close the return air isolation damper, measure the temperature at the cold duct inlet to the box and compare to the temperature at the discharge. If discharge temperature is more than $0.5 \mathrm{~F}$ greater than the cooling inlet, leakage may be occurring and the unit fails this test.

PASS? (Y/N)

\begin{tabular}{|l|c|c|c|c|}
\hline $\begin{array}{c}\text { Proced } \\
\text { No. \& } \\
\text { Spec. } \\
\text { Seg. } \\
\text { ID }\end{array}$ & $\begin{array}{c}\text { Req } \\
\text { ID } \\
\text { No. }^{2}\end{array}$ & $\begin{array}{c}\text { Test Procedure } \\
\text { (including special conditions) }\end{array}$ & $\begin{array}{c}\text { Expected and Actual Response } \\
\text { [Write ACTUAL response or finding } \\
\text { in brackets or circle] }\end{array}$ & $\begin{array}{c}\text { Pass } \\
\text { Y/N } \\
\text { \& } \\
\text { Note \# }\end{array}$ \\
\hline \hline \\
\hline III. STATIC INSPECTIONS & & \\
\hline 1. & & Verify sufficient clearance around equipment for servicing. & \\
\hline 2. & & Verify installation of specified sound wrapping and joint sealant. & \\
\hline 3. & & Unit secured per spec. & \\
\hline 4. & & Model and tag checked against plans \& equipment list. TU \& valve tags affixed. & \\
\hline
\end{tabular}




\begin{tabular}{|c|c|c|c|c|}
\hline $\begin{array}{l}\text { Proced } \\
\text {. No. \& } \\
\text { Spec. } \\
\text { Seq. } \\
\text { ID }\end{array}$ & $\begin{array}{l}\text { Req } \\
\text { ID } \\
\text { No. }\end{array}$ & $\begin{array}{l}\text { Test Procedure } \\
\text { (including special conditions) }\end{array}$ & $\begin{array}{l}\text { Expected and Actual Response } \\
\text { [Write ACTUAL response or finding } \\
\text { in brackets or circle] }\end{array}$ & $\begin{array}{l}\text { Pass } \\
\text { Y/N } \\
\& \\
\text { Note \# }\end{array}$ \\
\hline 5. & & \multicolumn{2}{|c|}{$\begin{array}{l}\text { Verify that inlet conditions are OK: Smooth, round, straight duct for at least } 3 \text { duct } \\
\text { diameters when possible and } 2 \text { diameters minimum for velocity pressure sensor and } 3 \\
\text { to } 5 \text { diameters for single point electronic sensors, else airflow straighteners. }\end{array}$} & \\
\hline 6. & & \multicolumn{2}{|c|}{ Visually verify that the return air isolation or balancing damper is open. } & \\
\hline 7. & & $\begin{array}{l}\text { Auto TU Diagnostics. In the control system } \\
\text { diagnostics, check the controller and actuator } \\
\text { accumulated run times, the moving avg. flow } \\
\text { error and moving avg. space temp. deviation } \\
\text { from setpoint. }\end{array}$ & $\begin{array}{l}\text { The ratio of actuator to controller } \\
\text { runtime should be ideally < } 3 \% \text { \& }< \\
5 \% \text { is acceptable. [ } \% \text { \%]. } \\
\text { Moving avg. flow error should be }< \\
10 \% \text { of max. cooling cfm L } \\
\text { The moving avg. space temp. } \\
\text { deviation should be }<3 \text { F L F. F. }\end{array}$ & \\
\hline \multicolumn{5}{|c|}{$\begin{array}{l}\text { IV. CONTROL PROGRAMMING. } \\
\text { In the procedures of this section, compare specified written sequences and parameters with that found } \\
\text { programmed in the TU or BAS. Variances that, in the CA's opinion, reduce performance, must be } \\
\text { corrected. Variances that make no difference or enhance performance pass. Document all variances. }\end{array}$} \\
\hline 8. & & Control drawing sequences of operation & Per spec and detail adequate. & \\
\hline 9. & & $\begin{array}{l}\text { Verify that the TU address matches the TU } \\
\text { location and ID on the plan drawings and } \\
\text { control drawings. }\end{array}$ & Address matches. & \\
\hline 10. & & $\begin{array}{l}\text { Verify that the TU max and min setpoints in the } \\
\text { BAS match the latest plan drawings and } \\
\text { balance report (TAB). }\end{array}$ & 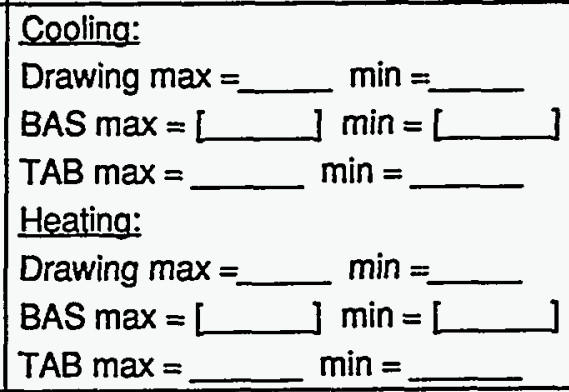 & \\
\hline 11. & & $\begin{array}{l}\text { Temperature adjustment range by tenants } \\
\text { (indicate if a setting was spec'd) }\end{array}$ & $\begin{array}{l}\text { Spec'd or reasonable value } \\
\text { Found [ }\end{array}$ & \\
\hline 12. & & $\begin{array}{l}\text { Cooling-- occupied zone temp. setpoint } \\
\text { (indicate if a setting was spec'd) }\end{array}$ & $\begin{array}{l}\text { Spec'd or reasonable value } \\
\text { Found [ }\end{array}$ & \\
\hline 13. & & $\begin{array}{l}\text { Unoccupied zone temperature setpoint } \\
\text { (indicate if a setting was spec'd) }\end{array}$ & $\begin{array}{l}\text { Spec'd or reasonable value } \\
\text { Found [ }\end{array}$ & \\
\hline 14. & & $\begin{array}{l}\text { Occupied zone temp. bias (deadband) } \\
\text { (indicate if a setting was spec'd) }\end{array}$ & $\begin{array}{l}\text { Spec'd or reasonable value } \\
\text { Found [ }\end{array}$ & \\
\hline 15. & & $\begin{array}{l}\text { Unnuccupied zone temp. bias (deadband) } \\
\text { (indicate if a setting was spec'd) }\end{array}$ & $\begin{array}{l}\text { Spec'd or reasonable value } \\
\text { Found [ }\end{array}$ & \\
\hline 16. & & $\begin{array}{l}\text { Cooling space setpoint proportional band } \\
\text { (indicate if a setting was spec'd) }\end{array}$ & $\begin{array}{l}\text { Spec'd or reasonable value } \\
\text { Found [ }\end{array}$ & \\
\hline 17. & & $\begin{array}{l}\text { Heating space setpoint proportional band } \\
\text { (indicate if a setting was spec'd) }\end{array}$ & $\begin{array}{l}\text { Spec'd or reasonable value } \\
\text { Found [ }\end{array}$ & \\
\hline 18. & & $\begin{array}{l}\text { Cooling cfm proportional band } \\
\text { (indicate if a setting was spec'd) }\end{array}$ & $\begin{array}{l}\text { Spec'd or reasonable value } \\
\text { Found [ }\end{array}$ & \\
\hline
\end{tabular}

Notes: 


\begin{tabular}{|c|c|c|c|c|}
\hline $\begin{array}{l}\text { Proced } \\
\text {. No. \& } \\
\text { Spec. } \\
\text { Seq. } \\
\text { ID. }\end{array}$ & $\begin{array}{l}\text { Req } \\
\text { ID } \\
\text { No.2 }\end{array}$ & $\begin{array}{l}\text { Test Procedure } \\
\text { (including special conditions) }\end{array}$ & $\begin{array}{l}\text { Expected and Actual Response } \\
\text { [Write ACTUAL response or finding } \\
\text { in brackets or circle] }\end{array}$ & $\begin{array}{l}\text { Pass } \\
\text { Y/N } \\
\& \\
\text { Note \# }\end{array}$ \\
\hline 19. & & $\begin{array}{l}\text { Heating cfm proportional band } \\
\text { (indicate if a setting was spec'd) }\end{array}$ & $\begin{array}{l}\text { Spec'd or reasonable value } \\
\text { Found [ }\end{array}$ & \\
\hline 20. & & Auto-zero function schedule set and enabled. & Set and enabled. & \\
\hline 21. & & Duct area at flow station (sf) & 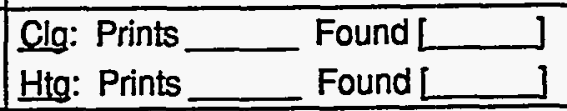 & \\
\hline 22. & & $\begin{array}{l}\text { Verify that BAS TU K factor is within } 20 \% \text { of } K \\
\text { on the submitted control drawings, unless } \\
\text { explained by TAB. }\end{array}$ & $\begin{array}{l}\text { Cooling: Drawing } K= \\
\text { BAS K }=[\quad \text { TAB K }= \\
\text { Heating: Drawing } K= \\
\text { BAS K }=[\quad] \text { TAB K }=\end{array}$ & \\
\hline 23. & - & $\begin{array}{l}\text { Damper stroke time (Spec'd value comes } \\
\text { from controller spec, unless oval duct, which } \\
\text { should then be timed) }\end{array}$ & Spec'd___ Found L L & \\
\hline 24. & & & & \\
\hline \multicolumn{5}{|c|}{ V. FUNCTIONAL TESTING. } \\
\hline 25. & & $\begin{array}{l}\text { Occupied CFM Test \& Fans. Cooling. For TU's } \\
\text { controlled from DDC flow stations: } \\
\text { a. During occupied mode with only a few lights } \\
\text { ON in the zone and with the duct SP setpoint } \\
\text { being met, lower space setpoint } 20 F \text { and } \\
\text { observe in BAS that cooling flow goes to } \\
\text { maximum and heating flow goes to minimum. } \\
\text { b. Turn OFF all lights in the zone. } \\
\text { For TU's controlled by damper position only, } \\
\text { observe that the damper goes to min. and max. } \\
\text { as expected. }\end{array}$ & $\begin{array}{l}\text { a. Fan is ON. } \\
\text { Specified max. cooling cfm }= \\
\text { Achieved cfm or position= } \\
\text { Within deadband (if DDC)? } \\
\text { Specified min. heating cfm }= \\
\text { Achieved cfm or position = } \\
\text { Within deadband? (if DDC) } \\
\text { b. Fan turns OFF. L } \\
\text { Flows remain under previous control } \\
\text { control. [L }\end{array}$ & \\
\hline 26. & & $\begin{array}{l}\text { Occupied CFM Test \& Fans. Heating. For TU's } \\
\text { controlled from DDC flow stations: } \\
\text { a. During occupied mode with only a few lights } \\
\text { ON in the zone and with the duct SP setpoint } \\
\text { being met, raise space setpoint 2OF and } \\
\text { observe in BAS that heating flow goes to } \\
\text { maximum and cooling flow goes to minimum. }\end{array}$ & $\begin{array}{l}\text { a. Fan is ON. } \\
\text { Specified max. htg cfm }= \\
\text { Achieved cfm or position }=L \\
\text { Within deadband (if DDC)? } \\
\text { Specified min. clg cfm }= \\
\text { Achieved cfm or position }=[ \\
\text { Within deadband? (if DDC) }\end{array}$ & \\
\hline 27. & & $\begin{array}{l}\text {-continuing: } \\
\text { b. Turn OFF all lights in zone. } \\
\text { For TU's controlled by damper position only, } \\
\text { observe that the damper goes to min. and max. } \\
\text { as expected. } \\
\text { Return setpoints to normal. }\end{array}$ & $\begin{array}{l}\text { b. Fan turns OFF. [_] } \\
\text { Flows remain under previous control } \\
\text { control. [ }\end{array}$ & \\
\hline
\end{tabular}

\section{Notes:}




\begin{tabular}{|c|c|c|c|c|}
\hline $\begin{array}{l}\text { Proced } \\
\text {. No. \& } \\
\text { Spec. } \\
\text { Seq. } \\
\text { ID' }\end{array}$ & $\begin{array}{l}\text { Req } \\
\text { ID } \\
\text { No. }\end{array}$ & $\begin{array}{l}\text { Test Procedure } \\
\text { (including special conditions) }\end{array}$ & $\begin{array}{l}\text { Expected and Actual Response } \\
\text { [Write ACTUAL response or finding } \\
\text { in brackets or circle] }\end{array}$ & $\begin{array}{l}\text { Pass } \\
\text { Y/N } \\
\& \\
\text { Note \# }\end{array}$ \\
\hline 28. & & $\begin{array}{l}\text { (Verify for only } 1 / 2 \text { of the tested TU's) } \\
\text { Warmup cycle-heating. Adjust schedule or } \\
\text { time so TU will be in warmup mode. Adjust the } \\
\text { space setpoint to be } 5 F \text { above space. }\end{array}$ & $\begin{array}{l}\text { TU damper goes to heating min. } \\
\text { Fan is ON. [ }\end{array}$ & \\
\hline 29. & & $\begin{array}{l}\text { (Verify for only } 1 / 2 \text { of the tested TU's) } \\
\text { Warmup cycle--cooling. Adjust schedule or } \\
\text { time so TU will be in warmup mode. Adjust the } \\
\text { space setpoint to be } 5 \mathrm{~F} \text { below space. }\end{array}$ & $\begin{array}{l}\text { TU damper goes to cooling max. } \\
\text { Fan is ON. L }\end{array}$ & \\
\hline 30. & & $\begin{array}{l}\text { Interlocks. This unit is interlocked with radiant } \\
\text { panel or fin tube heating (YIN) } \\
\text { Yes, the fin tube or radiant panel functional } \\
\text { tests will verify the interlocks with the TU. }\end{array}$ & $\begin{array}{l}\text { TU operates normally during cycling } \\
\text { ON and OFF of radiant panels and fin } \\
\text { tubes. }\end{array}$ & \\
\hline 31. & & $\begin{array}{l}\text { Unoccupied \& Night High Limit Operation. } \\
\text { a. Fans. Schedule the space so it is in } \\
\text { unoccupied mode. Turn all lights OFF in the } \\
\text { zone. Observe that the fan is OFF. } \\
\text { b. Turn a few lights ON in zone. } \\
\text { Change the NHL setpoint } L \text { so it } \\
\text { engages the NHL. }\end{array}$ & $\begin{array}{l}\text { a. Fan is OFF. L } \\
\text { b. Fan is OFF. }[]\end{array}$ & \\
\hline 32. & & $\begin{array}{l}\text {--cont. Unoccupied \& Night High Limit. } \\
\text { c. Change the zone unoccupied setpoint to be } \\
20 \text { F below the space temp. Observe in BAS } \\
\text { that cooling flow goes to maximum and heating } \\
\text { flow goes to minimum. } \\
\text { d. Change the zone unoccupied setpoint to be } \\
\text { = to the space temp. Observe in the BAS that } \\
\text { the cooling and heating flows go to min. } \\
\text { For TU's controlled by damper position only, } \\
\text { observe that the dampers go to their expected } \\
\text { positions. }\end{array}$ & $\begin{array}{l}\text { c. Specified max. unoccupied } \\
\text { cooling cfm = } \\
\text { Achieved cfm or position= } \\
\text { Within deadband (if DDC)? } \\
\text { Specified min. heating cfm = } \\
\text { Achieved cfm or position = L } \\
\text { Within deadband? (if DDC) } \\
\text { Fan is OFF. [ } \\
\text { d. Cooling and heating flows or } \\
\text { postions go to minimum. L } \\
\text { Fan is OFF. L } \\
\text { e. TU remains in normal mode until } \\
\text { NHL setpoint minus offset is reached } \\
\text { by the determining zones, when AHU } \\
\text { and TU will shut down. }\end{array}$ & \\
\hline
\end{tabular}

Notes: 


\begin{tabular}{|c|c|c|c|c|}
\hline $\begin{array}{l}\text { Proced } \\
\text {. No. \& } \\
\text { Spec. } \\
\text { Seq. } \\
\text { ID' }\end{array}$ & $\begin{array}{l}\text { Req } \\
\text { ID } \\
\text { No. }\end{array}$ & $\begin{array}{l}\text { Test Procedure } \\
\text { (including special conditions) }\end{array}$ & $\begin{array}{l}\text { Expected and Actual Response } \\
\text { [Write ACTUAL response or finding } \\
\text { in brackets or circle] }\end{array}$ & $\begin{array}{c}\text { Pass } \\
\text { Y/N } \\
\& \\
\text { Note \# }\end{array}$ \\
\hline 33. & & $\begin{array}{l}\text { Unoccupied \& Night Low Limit Operation. a. } \\
\text { a. Fans. Schedule the space so it is in } \\
\text { unoccupied mode. Turn ON some lights in the } \\
\text { space. Observe that the fan is OFF. } \\
\text { Change the NLL setpoint L so it engages } \\
\text { the NLL functions. } \\
\text { b. Change the zone unoccupied setpoint (if } \\
\text { used, else use occupied) to be } 20 F \text { above the } \\
\text { space temp. Observe in BAS that heating fiow } \\
\text { goes to maximum and cooling flow goes to } \\
\text { minimum. } \\
\text { c. Change the zone unoccupied setpoint (if } \\
\text { used, else use occupied setpoint) to be = to the } \\
\text { space temp. Observe in the BAS that the } \\
\text { cooling and heating flows go to min. } \\
\text { For TU's controlled by damper position only, } \\
\text { observe dampers go to expected positions. }\end{array}$ & $\begin{array}{l}\text { a. Fan is OFF. L } \\
\text { b. Specified max. unoccupied } \\
\text { heating cfm = } \\
\text { Achieved cfm or position= [ } \\
\text { Within deadband (if DDC)? } \\
\text { Specified min. cooling cfm = } \\
\text { Achieved cfm or position = } \\
\text { Within deadband? (if DDC) } \\
\text { Fan is OFF. [ ] } \\
\text { c. Cooling and heating flows or } \\
\text { positions go to minimum. L } \\
\text { Fan is OFF. L } \\
\text { d. TU remains in normal mode until } \\
\text { NLL setpoint + offset is reached by } \\
\text { the determining zones, when AHU } \\
\text { and TU will shut down. }\end{array}$ & \\
\hline 34. & & $\begin{array}{l}\text { Backflow into RA Check. In occupied mode, } \\
\text { with fan ON and return air damper open, lower } \\
\text { the space temp. setpoint 20F. Wait until the } \\
\text { cooling flow goes to maximum and remains } \\
\text { fairly constant. } \\
\text { Measure flows on all diffusers with a flow hood. } \\
\text { (This test may be omitted if the TAB conducted } \\
\text { and documented this procedure in a } \\
\text { satisfactory manner on all fan powered TU's.) }\end{array}$ & $\begin{array}{l}\text { BAS cooling max. design = } \\
\text { Box design = } \\
\text { Fan spec'd cfm }= \\
\text { Sum of diffusers = } \\
\text { Actual cooling flow = } \\
\text { Actual heating flow = } \\
\text { Htg flow }+ \text { clg flow = } \\
\text { This should be within 10\% of box } \\
\text { design } L \quad \text { and less than or } \\
\text { equal to the sum of all diffuser flows, } \\
\text { else some flow is backing into RA } \\
\text { and test fails (fan is undersized). }\end{array}$ & \\
\hline 35. & & Alarms. With fan ON, flip OFF fan switch. & An alarm is registered in the BAS. & \\
\hline 36. & & $\begin{array}{l}\text { Trending: Damper Control and Fans. } \\
\text { Over an } 8 \text { hour occupied period, trend at } 1 \text { min. } \\
\text { intervals, the hot and cold damper positons or } \\
\text { cfm, the dampers or cfm commands, the } \\
\text { space temp., fan status, lighting status and the } \\
\text { duct static pressure at the controlling sensor. }\end{array}$ & $\begin{array}{l}\text { Compare to the space temperature } \\
\text { to the setpoint. Observe that there is } \\
\text { little or no overshoot of space } \\
\text { temperature or hunting of the } \\
\text { damper. } \\
\text { Fan is OFF during unoccupied hours } \\
\text { OR when lights are OFF. }\end{array}$ & \\
\hline
\end{tabular}

\section{Notes:}




\begin{tabular}{|c|c|c|c|c|}
\hline $\begin{array}{c}\text { Proced } \\
\text { No. \& } \\
\text { Spec. } \\
\text { Seq. } \\
\text { ID }\end{array}$ & $\begin{array}{c}\text { Req } \\
\text { ID } \\
\text { No. }\end{array}$ & \multicolumn{1}{|c|}{$\begin{array}{c}\text { Test Procedure } \\
\text { (including special conditions) }\end{array}$} & $\begin{array}{c}\text { Expected and Actual Response } \\
\text { [rite ACTUAL response or finding } \\
\text { in brackets or circle] }\end{array}$ & $\begin{array}{c}\text { Pass } \\
\text { Y/N } \\
\& \\
\text { Note \# }\end{array}$ \\
\hline \hline 37. & & $\begin{array}{l}\text { Trend for only 1/2 of the tested TU's) } \\
\text { Trending. Space Temp. Over a } 3 \text { day period, } \\
\text { during near design conditions for heating and } \\
\text { cooling, trend space temp. at } 10 \text { min. steps. } \\
\text { Omit the space temp. trend if auto diagnostics } \\
\text { has a moving avg. space temp. deviation log } \\
\text { and it was completed. }\end{array}$ & $\begin{array}{l}\text { Observe that the space temp. does } \\
\text { not dritt more than 10F outside the } \\
\text { deadband range around the setpoint. }\end{array}$ & \\
\hline 38. & - & $\begin{array}{l}\text { Retum all changed control parameters and } \\
\text { conditions to their pre-test values }\end{array}$ & $\begin{array}{l}\text { Check off in program printout } \\
\text { when completed }\end{array}$ & \\
\hline
\end{tabular}

\section{MONITORING AND TREND LOGGING}

Monitoring via BAS trend logs are required for test procedures 34 and 35 . Attach representative graphs or columnar data and explanatory analysis to this test report. The data should have time down the left column and four to six columns of parameters to the right. Provide a key to all abbreviations and attach setpoints and schedules for all trended parameters.

"*Abbreviations: $B A S=$ building automation system, $C A=$ commissioning agent, $\mathrm{HCV}=$ heating coil valve, $\mathrm{TU}=$ terminal unit, $\mathrm{SA}=$ supply air, plan drawing = building drawings and schedules from design engineer.

${ }^{1}$ Sequences of operation attached to this test.

${ }^{2}$ Mode or function ID being tested from testing requirements section of the project Specifications.

${ }^{3}$ Step-by-step procedures for manual testing, trend logging or data-logger monitoring.

${ }^{4}$ Include tolerances for a passing condition. Fill-in spaces or lines not in brackets denote sequence parameters still to be specified by the AEE, conrols contractor or vendor. Write "Via BAS" for verifications of device position from BAS readout or "Via obs" for actual observation or from test instrument reading.

${ }^{5}$ Record any permanently changed parameter values and submit changes to Owner.

\section{A SUMMARY OF DEFICIENCIES IDENTIFIED DURING TESTING IS ATTACHED}

\section{- END OF TEST -}

Notes: 


\section{Functional Test (Cover Sheet)}

\section{Project \\ FT- \\ TERMINAL UNITS (VAV cooling only) DATA COMMON FOR ALL UNITS}

1. Participants (fill out once, to cover.all TU's) Party

Participation

Party

Participation

Party filling out this form and witnessing testing

Dates of tests

Dates of tests

2. Test Prerequisites (fill out once, to cover all TU's)

a. The following have been started up and startup reports and prefunctional checklists submitted and approved:

All terminal units, except

_ All air handlers serving terminal units, except

b. All control system functions for this and all interlocking systems are programmed and operable per contract documents, including final setpoints and schedules and with debugging, loop tuning and sensor and device calibrations completed.

Controls Contractor Signature or Verbal

Date

c. Airside test and balance calibration of BAS readings of TU flows complete (system total flow need not be complete).

d _ All A/E punchlist items for this equipment corrected.

e. - These functional test procedures reviewed and approved by installing contractor.

f. - Test requirements and sequences of operation attached.

g. - Schedules and setpoints attached.

h. - Have all energy savings control strategies, setpoints and schedules been incorporated that this TU and control system are capable of? If not, list recommendations below.

i. The controller \& actuator runtime accumulator set to 0 after prefunctional checkout of the entire system.

j. _ Obtain and review the full program of 5\% (randomly chosen) of all TU's of each type (parameters \& setpoints, etc.). Examine variances. Clarify as needed, reconcile and document differences with controls contractor. If too many corrections exist with this sample, controls contractor shall recheck all programming.

\section{Sampling and Additional Testing.}

The terminal unit testing requirements in the specifications call for a random sample of $\%$ of all TU's of each type to be tested. Total number to be tested of this type = The specifications also require that if $\%$ of the sampled TU's fail in the testing (any No Pass items), then another ___ \% of the total population must be tested. This applies to the subsections of the test, i.e., if sub-sections fail, only subsections of additional TU's need to be tested. Record results in the table below.

\begin{tabular}{|l|l|l|}
\hline \multicolumn{1}{|c|}{ Sub-Section } & $\begin{array}{c}\text { \% Failed of } \\
\text { 1st Sample }\end{array}$ & $\begin{array}{c}\text { \% Failed of } \\
\text { 2nd Sample }\end{array}$ \\
\hline I. Sensor calibration & & \\
\hline II. Actuator calibration & & \\
\hline III. Static inspections & & \\
\hline
\end{tabular}

\begin{tabular}{|l|l|l|}
\hline \multicolumn{1}{|c|}{ Sub-Section } & $\begin{array}{c}\text { \% Failed of } \\
\text { 1st Sample }\end{array}$ & $\begin{array}{c}\text { \% Failed of } \\
\text { 2nd Sample }\end{array}$ \\
\hline IV. Programming & & \\
\hline V. Functional tests & & \\
\hline & & \\
\hline
\end{tabular}




\section{Functional Test Record}

\section{Project}

\section{FT-___ TERMINAL UNIT____ (VAV cooling only)}

Common values for all terminal units are recorded on the Cover Sheet. The following five pages of procedures are to be filled out for each TU tested.

\section{Seasonal Testing and General Conditions of Test}

Air handler or rooftop unit and boiler (if applicable) should be running in normal and occupied mode, unless noted. The tests may be performed in any season, if any temperature lockouts can be overridden.

\section{Testing Procedures and Record}

Computer printout or list made and attached of the current TU setpoints and control parameters and schedules, lockouts, etc. of other systems that may be changed to accomodate testing.

I. Sensor Calibration Checks. Check the sensors listed below for calibration and adequate location.

"In calibration" means making a reading with a calibrated test instrument within 6 inches of the site sensor. Verify that the sensor reading (via the permanent thermostat, gage or building automation system (BAS)) compared to the test instrument-measured value is within the tolerances specified in the prefunctional checklist requirements ( ). If not, install offset in BAS, calibrate or replace sensor. Use the same test instruments as used for the original calibration, if possible.

\begin{tabular}{|l|l|l|c|c|c|}
\hline $\begin{array}{c}\text { Sensor \& } \\
\text { Location }\end{array}$ & $\begin{array}{c}\text { Location } \\
\text { OK }\end{array}$ & $\begin{array}{c}\text { 1st Gage or } \\
\text { BAS Value }\end{array}$ & $\begin{array}{c}\text { Instrument } \\
\text { Measured Value }\end{array}$ & $\begin{array}{c}\text { Final Gage or } \\
\text { BAS Value }\end{array}$ & $\begin{array}{c}\text { Pass } \\
\text { Y/N? }\end{array}$ \\
\hline \hline Space temp. & & & & & \\
\hline & & & & & \\
\hline
\end{tabular}

${ }^{I}$ Sensor location is appropriate and away from causes of erratic operation.

II. Device Calibration Checks. -Checked in the Functional Testing Section.

\begin{tabular}{|c|c|c|c|c|}
\hline $\begin{array}{l}\text { Proced } \\
\text {. No. \& } \\
\text { Spec. } \\
\text { Seq. } \\
\text { ID } \\
\end{array}$ & $\begin{array}{l}\text { Req } \\
\text { ID } \\
\text { No. }\end{array}$ & $\begin{array}{l}\text { Test Procedure } \\
\text { (inçuding special conditions) }\end{array}$ & $\begin{array}{l}\text { Expected and Actual Response } \\
\text { [Write ACTUAL response or finding } \\
\text { in brackets or circle] }\end{array}$ & $\begin{array}{l}\text { Pass } \\
\text { Y/N } \\
\& \\
\text { Note \# }\end{array}$ \\
\hline \multicolumn{5}{|c|}{ III. STATIC INSPECTIONS } \\
\hline 1. & & \multicolumn{2}{|c|}{ Verify sufficient clearance around equipment for servicing. } & \\
\hline 2. & & \multicolumn{2}{|c|}{ Verify installation of specified sound wrapping and joint sealant. } & \\
\hline 3. & & \multicolumn{2}{|l|}{ Unit secured per spec. } & \\
\hline 4. & & \multicolumn{2}{|c|}{ Model and tag checked against plans \& equipment list. TU tags affixed. } & \\
\hline 5. & & \multicolumn{2}{|c|}{$\begin{array}{l}\text { Verify that inlet conditions are OK: Smooth, round, straight duct for at least } 3 \text { duct } \\
\text { diameters when possible and } 2 \text { diameters minimum for velocity pressure sensor and } 3 \\
\text { to } 5 \text { diameters for single point electronic sensors, else airflow straighteners. }\end{array}$} & \\
\hline 6. & & $\begin{array}{l}\text { Auto TU Diagnostics. In the control system } \\
\text { diagnostics, check the controller and actuator } \\
\text { accumulated run times, the moving avg. flow } \\
\text { error and moving avg. space temp. deviation } \\
\text { from setpoint. }\end{array}$ & 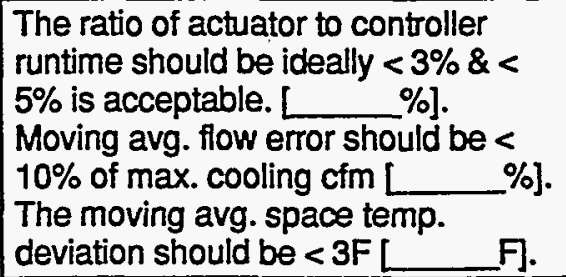 & \\
\hline
\end{tabular}




\begin{tabular}{|c|c|c|c|c|}
\hline $\begin{array}{l}\text { Proced } \\
\text {. No. \& } \\
\text { Spec. } \\
\text { Seq. } \\
\text { ID }^{1}\end{array}$ & $\begin{array}{l}\text { Req } \\
\text { ID } \\
\text { No. }\end{array}$ & $\begin{array}{l}\text { Test Procedure } \\
\text { (including special conditions) }\end{array}$ & $\begin{array}{l}\text { Expected and Actual Response } \\
\text { [Write ACTUAL response or finding } \\
\text { in brackets or circle] }\end{array}$ & $\begin{array}{l}\text { Pass } \\
\text { Y/N } \\
\& \\
\text { Note }\end{array}$ \\
\hline \multicolumn{5}{|c|}{$\begin{array}{l}\text { IV. CONTROL PROGRAMMING. } \\
\text { In the procedures of this section, compare specified written sequences and parameters ivith that found } \\
\text { programmed in the TU or BAS. Variances that, in the CA's opinion, reduce performance, must be } \\
\text { corrected. Variances that make no difference or enhance performance pass. Document all variances. }\end{array}$} \\
\hline 7. & & Control drawing sequences of operation & Per spec and detail adequate. & \\
\hline 8. & & $\begin{array}{l}\text { Verify that the TU address matches the TU } \\
\text { location and ID on the plan drawings and } \\
\text { control drawings. }\end{array}$ & Address matches. & \\
\hline 9. & & $\begin{array}{l}\text { Verify that the TU max and min setpoints in the } \\
\text { BAS match (within } 10 \% \text { ) the latest plan } \\
\text { drawings and balance report (TAB). }\end{array}$ & 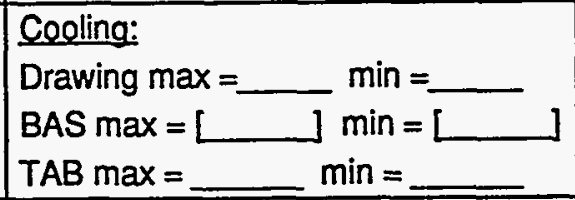 & \\
\hline 10. & & $\begin{array}{l}\text { Verify that BAS TU K factor is within } 20 \% \text { of } K \\
\text { on the submitted control drawings, unless } \\
\text { explained by TAB. }\end{array}$ & 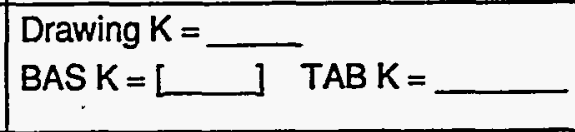 & \\
\hline 11. & & $\begin{array}{l}\text { Temperature adjustment range by tenants } \\
\text { (indicate if a setting was spec'd) }\end{array}$ & $\begin{array}{l}\text { Spec'd or reasonable value } \\
\text { Found [ }\end{array}$ & \\
\hline 12. & & $\begin{array}{l}\text { Cooling-- occupied zone temp. setpoint } \\
\text { (indicate if a setting was spec'd) }\end{array}$ & $\begin{array}{l}\text { Spec'd or reasonable value } \\
\text { Found [ }\end{array}$ & \\
\hline 13. & & $\begin{array}{l}\text { Unoccupied zone temperature setpoint } \\
\text { (indicate if a setting was spec'd) }\end{array}$ & $\begin{array}{l}\text { Spec'd or reasonable value } \\
\text { Found }[\end{array}$ & \\
\hline 14. & & $\begin{array}{l}\text { Occupied zone temp. bias (deadband) } \\
\text { (indicate if a setting was spec'd) }\end{array}$ & $\begin{array}{l}\text { Spec'd or reasonable value } \\
\text { Found [ }\end{array}$ & \\
\hline 15. & & $\begin{array}{l}\text { Unnuccupied zone temp. bias (deadband) } \\
\text { (indicate if a setting was spec'd) }\end{array}$ & $\begin{array}{l}\text { Spec'd or reasonable value } \\
\text { Found [ }\end{array}$ & \\
\hline 16. & & $\begin{array}{l}\text { Cooling space setpoint proportional band } \\
\text { (indicate if a setting was spec'd) }\end{array}$ & $\begin{array}{l}\text { Spec'd or reasonable value } \\
\text { Found [ }\end{array}$ & \\
\hline 17. & & $\begin{array}{l}\begin{array}{l}\text { Cooling cim proportional band } \\
\text { (indicate if a setting was spec'd) }\end{array} \\
\end{array}$ & $\begin{array}{l}\text { Spec'd or reasonable value } \\
\text { Found [ }\end{array}$ & \\
\hline 18. & & Duct area (sf) & From prints _ Found [ & \\
\hline 19. & & $\begin{array}{l}\text { Damper stroke time (Spec'd value comes } \\
\text { from controller spec, unless oval duct, which } \\
\text { should then be timed) }\end{array}$ & Spec'd____ Found L $L$ & \\
\hline 20. & & Auto-zero function schedule set and enabled. & Set and enabled. & \\
\hline 21. & & & & \\
\hline
\end{tabular}

Notes: 


\begin{tabular}{|c|c|c|c|c|}
\hline $\begin{array}{l}\text { Proced } \\
\text { No. \& } \\
\text { Spec. } \\
\text { Seg. } \\
\text { ID } \\
\end{array}$ & $\begin{array}{l}\text { Req } \\
\text { ID } \\
\text { No. }\end{array}$ & $\begin{array}{l}\text { Test Procedure } \\
\text { (including special conditions) }\end{array}$ & $\begin{array}{l}\text { Expected and Actual Response } \\
\text { [Write ACTUAL response or finding } \\
\text { in brackets or circle] }\end{array}$ & $\begin{array}{l}\text { Pass } \\
\text { Y/N } \\
\& \\
\text { Note \# }\end{array}$ \\
\hline 22. & & $\begin{array}{l}\text { CFM Capacity Test. Cooling. With the duct SP } \\
\text { setpoint being met, lower the space temp. } \\
\text { setpoint } 20 \mathrm{~F} \text {. Verify in the BAS that the } \\
\text { specified max. cfm is achieved (within } \\
\text { deadband). } \\
\text { For TU's controlled by damper position only, } \\
\text { observe that the damper goes to max. as } \\
\text { expected. }\end{array}$ & $\begin{array}{l}\text { Specified max. cooling cfm }=[ \\
\text { Achieved } \mathrm{cfm} \text { or position }=[ \\
\text { Within deadband? }\end{array}$ & \\
\hline 23. & & $\begin{array}{l}\text { CFM Capacity Test, Heating. With the duct SP } \\
\text { setpoint being met, raise the space temp. } \\
\text { sepoint } 20 \mathrm{~F} \text {. Verify in the BAS that the } \\
\text { specified min. cfm is achieved (within } \\
\text { deadband). } \\
\text { For TU's controlled by damper position only, } \\
\text { observe that the damper goes to min. as } \\
\text { expected. }\end{array}$ & $\begin{array}{l}\text { Specified } \min . \mathrm{cfm}= \\
\text { Achieved cfm or position }=[ \\
\text { Within deadband? }\end{array}$ & \\
\hline 24. & & $\begin{array}{l}\text { (Verify for only } 1 / 2 \text { of the tested TU's) } \\
\text { Warmup cycle-heating. Adjust schedule or } \\
\text { time so TU will be in warmup mode. Adjust the } \\
\text { space setpoint to be } 5 \mathrm{~F} \text { above space. }\end{array}$ & $\begin{array}{l}\text { Does the TU damper go to } \\
\text { minimum? }\end{array}$ & \\
\hline 25. & & $\begin{array}{l}\text { (Verify for only } 1 / 2 \text { of the tested TU's) } \\
\text { Warmup cycle--cooling. Adjust schedule or } \\
\text { time so TU will be in warmup mode. Adjust the } \\
\text { space setpoint to be 5F below space. }\end{array}$ & $\begin{array}{l}\text { Does the TU damper go to cooling } \\
\text { maximum? }\end{array}$ & \\
\hline 26. & & Unoccupied Mode-Night Low Limit. & & \\
\hline 27. & & Unoccupied Mode-Night High Limit. & & \\
\hline 28. & & $\begin{array}{l}\text { Trending: Damper Control. } \\
\text { Over an } 8 \text { hour occupied period, trend at } 1 \mathrm{~min} \text {. } \\
\text { intervals, the damper positon or cfm, the } \\
\text { damper or cfm command, the space } \\
\text { temperature and the duct static pressure at the } \\
\text { controlling sensor. }\end{array}$ & $\begin{array}{l}\text { Compare to the space temperature } \\
\text { to the setpoint. Observe that there is } \\
\text { little or no overshoot of space } \\
\text { temperature or hunting of the } \\
\text { damper. }\end{array}$ & \\
\hline 29. & & $\begin{array}{l}\text { (Trend for only } 1 / 2 \text { of the tested TU's) } \\
\text { Trending: General. Over a } 3 \text { day period, } \\
\text { during near design conditions for heating and } \\
\text { cooling, trend space temp. at } 10 \text { minute } \\
\text { intervals. Omit this test if auto diagnostics has a } \\
\text { moving avg. space temp. deviation log and it } \\
\text { was completed. }\end{array}$ & $\begin{array}{l}\text { Observe that the space temp. does } \\
\text { not drift more than } 1^{\circ} \mathrm{F} \text { outside the } \\
\text { deadband range around the setpoint. }\end{array}$ & \\
\hline
\end{tabular}

Notes: 


\begin{tabular}{|c|c|c|c|c|}
\hline $\begin{array}{c}\text { Proced } \\
\text { No. \& } \\
\text { Spec. } \\
\text { Seq. } \\
\text { ID }\end{array}$ & $\begin{array}{c}\text { Req } \\
\text { ID } \\
\text { No. }^{2}\end{array}$ & $\begin{array}{c}\text { Test Procedure } \\
\text { (including special conditions) }\end{array}$ & $\begin{array}{c}\text { Expected and Actual Response } \\
\text { [Write ACTUAL response or finding } \\
\text { in brackets or circle] }\end{array}$ & $\begin{array}{c}\text { Pass } \\
\text { Y/N } \\
\& \\
\text { Note \# }\end{array}$ \\
\hline 30. & & & & \\
\hline 31. & - & $\begin{array}{l}\text { Retum all changed control parameters and } \\
\text { conditions to their pre-test values }\end{array}$ & $\begin{array}{l}\text { Check off in program printout } \\
\text { when completed }\end{array}$ & \\
\hline
\end{tabular}

\section{MONITORING AND TREND LOGGING}

Monitoring via BAS trend logs are required for test procedures 28; 29. Attach representative graphs or columnar data and explanatory analysis to this test report. The data should have time down the left column and four to six columns of parameters to the right. Provide a key to all abbreviations and attach setpoints and schedules for all trended parameters.

*Abbreviations: $B A S=$ building automation system, $C A=$ commissioning agent, $\mathrm{HCV}=$ heating coil valve, $T U=$ terminal unit, $S A$ = supply air, plan drawing = building drawings and schedules from design engineer.

'Sequences of operation attached to this test.

${ }^{2}$ Mode or function ID being tested from testing requirements section of the project Specifications.

${ }^{3}$ Step-by-step procedures for manual testing, trend logging or data-logger monitoring.

${ }^{4}$ Include tolerances for a passing condition. Fill-in spaces or lines not in brackets denote sequence parameters still to be specified by the A/E, conrols contractor or vendor. Write "Via BAS" for verifications of device position from BAS readout or "Via obs" for actual observation or from test instrument reading.

${ }^{5}$ Record any permanently changed parameter values and submit changes to Owner.

\section{A SUMMARY OF DEFICIENCIES IDENTIFIED DURING TESTING IS ATTACHED}

Notes: 


\title{
Functional Test
}

\section{Project:}

\section{FT-___ UNIT HEATER UH-1, Penthouse}

\section{Participants}

\author{
Related Tests: Boilers
}

Party

Participation

Party filling out this form and witnessing testing

Date of test

\section{Prerequisite Checklist}

a. The following have been started up and startup reports and prefunctional checklists submitted and approved ready for functional testing:

$$
\text { UH-1 }
$$

b. Boilers $1 ; 2$ have successfully completed functional testing.

c. All control system functions for this and all interlocking systems are programmed and operable per contract documents, including final setpoints, schedules, debugging, loop tuning and sensor calibrations complete.

\section{Controls Contractor Signature or Verbal $\quad$ Date}

d. _ All A/E punchlist items for this equipment corrected.

e. - Safeties and operating ranges reviewed.

f. - Test requirements and sequences of operation attached.

g. - Schedules and setpoints attached.

h. - Have all energy savings control strategies, setpoints and schedules been incorporated that this equipment and control system are capable of? If not, list recommendations below.

i. _ BAS Program Review. Review the BAS software control program(s) for this equipment. Parameters, setpoints and logic sequences appear to follow the specified written sequences.

j. - Packaged Control Program Review. Review the packaged control program(s) for this equipment.

Parameters, setpoints and logic sequences appear to follow the specified written sequences.

k. Record of All Values for Current Setpoints (SP), Control Parameters, Limits, Delays, Lockouts, Schedules, Etc. Changed to Accommodate Testing:

Notes: 


\begin{tabular}{|c|c|c|}
\hline Parameter & $\begin{array}{c}\text { Pre-Test } \\
\text { Values }\end{array}$ & $\begin{array}{c}\text { Returned } \\
\text { to Pre-Test } \\
\text { Values V }\end{array}$ \\
\hline UH-1 setpoint & & \\
\hline
\end{tabular}

\begin{tabular}{|c|c|c|}
\hline Parameter & $\begin{array}{c}\text { Pre-Test } \\
\text { Values }\end{array}$ & $\begin{array}{c}\text { Retumed } \\
\text { to Pro-Test } \\
\text { Values } \sqrt{ }\end{array}$ \\
\hline & & \\
\hline
\end{tabular}

3. Sensor Calibration Checks. Check the sensors listed below for calibration and adequate location. This is a sampling check of calibrations done during prefunctional checklisting. Test the packaged controls and BAS readings.

"In calibration" means making a reading with a calibrated test instrument within 6 inches of the site sensor. Verify that the sensor reading (via the permanent thermostat, gage, packaged control panel or building automation system (BAS)) compared to the test instrument-measured value is within the tolerances specified in the prefunctional checklist requirements

\begin{tabular}{|l|c|c|c|c|c|}
\hline Sensor \& Location & $\begin{array}{c}\text { LoC- } \\
\text { ation } \\
\text { OK }^{1}\end{array}$ & $\begin{array}{c}\text { 1st Gage or } \\
\text { Pkg \& BAS } \\
\text { Values }\end{array}$ & $\begin{array}{c}\text { Instru. } \\
\text { Meas'd } \\
\text { Value }\end{array}$ & $\begin{array}{c}\text { Final Gage or } \\
\text { Pkg \& BAS } \\
\text { Values }\end{array}$ & $\begin{array}{c}\text { Pass } \\
\text { Y/N? }\end{array}$ \\
\hline UH-1 stat temp. & & Stat: & & Stat: & \\
\hline
\end{tabular}

${ }^{1}$ Sensor location is appropriate and away from causes of erratic operation.

\section{Device Calibration Checks.}

\section{-NONE-}

\section{Verification of Misc. Prefunctional Checks.}

Misc. site checks of the prefunctional checklist and startup reports completed successfully. Pass? Y / N

_ Unit mounted securely. _ Unit accessible for servicing. _ No unusual noise or vibration in fan.

\section{Functional Testing Record}

\begin{tabular}{|c|c|c|c|c|}
\hline $\begin{array}{l}\text { Proced. } \\
\text { No. \& } \\
\text { Spec. } \\
\text { Seq. } 10^{4}\end{array}$ & $\begin{array}{l}\text { Req ID } \\
\text { No. }{ }^{2}\end{array}$ & $\begin{array}{l}\text { Test Procedure } \\
\text { (including special conditions) }\end{array}$ & $\begin{array}{c}\text { Expected and Actual Response } \\
\text { [Write ACTUAL response in } \\
\text { brackets or circle] }\end{array}$ & $\begin{array}{c}\text { Pass } \\
\text { Y/N } \\
\text { \& Noto } \\
n \\
*\end{array}$ \\
\hline $\begin{array}{c}1 \\
\text { Seq. } 1\end{array}$ & & $\begin{array}{l}\text { Adjust the stat setpoint until it is equal to the } \\
\text { space temp. }\end{array}$ & $\begin{array}{l}\text { Fan starts. _ Heating coil valve } \\
\text { opens; _ warm air delivered. }\end{array}$ & \\
\hline $\begin{array}{c}2 \\
\text { Seq. } 1\end{array}$ & & $\begin{array}{l}\text { Adjust the stat setpoint until it is } 4 \mathrm{~F} \text { below } \\
\text { the space temp. }\end{array}$ & $\begin{array}{l}\text { Fan stops. } \\
\text { Heating coil valve closes. }\end{array}$ & \\
\hline 3 & - & $\begin{array}{l}\text { Return all changed control parameters } \\
\text { and conditions to their pre-test values }\end{array}$ & $\begin{array}{l}\text { Check off in Section } 2 \text { above } \\
\text { when completed }\end{array}$ & \\
\hline
\end{tabular}

Record Foot Notes

Sequences of operation specified in Contract Documents (attached).

${ }^{2}$ Mode or function ID being tested, per testing requirements section of the project Specifications.

${ }^{3}$ Step-by-step procedures for manual testing, trend logging or data-logger monitoring.

${ }^{4}$ Include tolerances for a passing condition.

${ }^{5}$ Record any permanently changed parameter values and submit to Owner.

\section{- END OF TEST -}

\section{Notes:}




\section{Functional Performance Test}

\section{Variable Frequency Drive (VFD) VAV Fan Application}

\section{Constant Static Pressure Application}

Project:

Date:

Address:

Commissioning Participants:

Commissioning agent:

EMS operator:

VFD technician:

HVAC technician:

Owner's rep.:

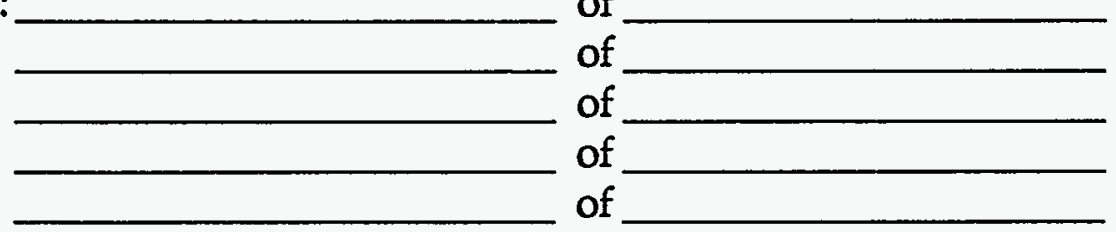

Air handler ID: Supply fan (SF) Hp: Return fan (RF) Hp: CFM: $R P M$ SP RPM $\mathrm{SP}$

VFD brand and model:

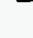

The following functional performance test is for a VFD controlling a VAV air handler to a constant duct static pressure (SP). A check-mark denotes acceptance or compliance.

\section{Design Intent and Documentation Verification}

Review the design documents and the specifications.
Verify that the VFD _ description, specifications, _technical and troubleshooting guide and the installation, __programming record and __balance report are on-site.

From the design documents determine: Location of static pressure sensor:

Nearest duct fitting upstream (fitting and distance):

Nearest duct fitting downstream:

Control strategy for the return fan:

\section{VFD Installation}

Static Pressure Sensor

\section{Linear Position}

Location of sensor in \% of the distance from fan to terminal box:

Normally, the sensor should be located $2 / 3$ to $3 / 4$ the distance from the fan to the terminal box of the most restrictive branch.

Complies?

Pressure Reading Reliability

Nearest duct fitting upstream (fitting and distance): 
Nearest duct fitting downstream:

The SP sensor controlling the VFD must be located so as to properly sense the static pressure in the duct without being adversely affected by changes in flow from duct fittings. This ideally requires the sensor to be at least 10 duct diameters downstream and 5 duct diameters upstream from any duct takeoff or elbow fittings.

\section{Complies?}

\section{Pressure Offset (Po)}

Duct static pressure fan is being controlled to: in. $\mathrm{H}_{2} \mathrm{O}[\mathrm{A}]$.

Pressure rise across supply fan at design conditions (from balance report summary): in. $\mathrm{H}_{2} \mathrm{O}[\mathrm{B}]$. Pressure offset, $\mathrm{Po},[\mathrm{A}] /[\mathrm{B}]$ :

Optimally, Po should be 0.3 or less in order for the VFD and fan to be able to respond to small pressure changes and realize adequate energy savings. If $P o$ is greater than 0.4 , the duct SP sensor is probably located too close to the fan.

\section{Complies?}

\section{Balancing to Lowest Pressure}

Review the HVAC balance report and verify that according to the report, the system was balanced so the VFD controls to the lowest possible duct static pressure (that is, a capacity test was performed). The controlling duct static pressure from balance reports is report is: supply fan (SF): return fan (RF): . Refer to the end of this test for details of the capacity test.

Balanced to lowest static? (this is further verified by \#2 under Section IV)

\section{Turn-Down Ratio}

What is the minimum $\mathrm{Hz}$ the VFD will take the fan to? What is the reason for any limitations?

\section{General Issues}

Verify that any power quality mitigation measures required from the specifications have been completed.

Verify that any inlet vanes or outlet dampers on the fan have been removed or permanently held full open.

Verify verbally that the acceleration and deceleration ramp time of the VFD is between one and four minutes.

Actual ramp time: up ___ min. down ___ min. (too short of ramp times will result in "hunting" and excess modulation by the VFD, typical ramp times are 1 to 4 minutes)

Verify that the lower frequency limit is 0 , unless explained.

Verify that the VFD has been integrated into the EMS as per specification.

Verify that the EMS monitors the duct static pressure or that an in-line "T" in the static pressure hose is extended to near the VFD, from which a magnehelic static pressure reading can be made during testing. 


\section{Functional Performance Test}

This test is not intended to verify that the VAV system is functioning properly, but rather that the VFD is functioning properly.

1. Boxes Partially Open (intermediate CFM). If current conditions are such, that the system is not expected to be in full cooling, nor be at the minimum flow condition:

a. Read the frequency output of the VFDs and record in Table 1 in the "Boxes Partially Open" column for both the supply fan (SF) and return fan (RF) if applicable.

b. Read the duct static pressure and record in the same column.

If the conditions are not in an "intermediate" position, change all space temperature set points to 4 degrees below the actual temperature in the space, to simulate an approaching of thermostat satisfaction and take readings.

2. Boxes to Maximum Open (Full Cooling). Using the (EMS) or other means, change all the space temperature setpoints to at least 10 degrees below the current space temperature so that the entire HVAC system supplied from this fan is in full cooling in all zones and all terminal boxes are open to their maximum "stops."
a. Measure or read the duct static pressure controlling the VFD and record in the "Open to Max. Stop" column in Table 1.
b. Read the frequency output of the VFDs and record in Table 1.

3. Boxes to Minimum Positions. Change all space temperature set points to be equal to the actual space temperatures to simulate a satisfied condition, driving the boxes to their minimum.

a. Take the frequency and static pressure readings and record in Column D.

\section{Analysis}

Table 1.

\begin{tabular}{|c|c|c|c|}
\hline $\begin{array}{l}\text { A } \\
\text { Design static pressure } \\
\text { Design freq. (Hz): } \mathrm{SF} \\
\text { Design RPM: SF }\end{array}$ & $\begin{array}{c}\text { B } \\
\text { Terminal } \\
\text { Boxes Open } \\
\text { to Max. Stop }\end{array}$ & $\begin{array}{c}\text { C } \\
\text { Boxes } \\
\text { Partially } \\
\text { Open }\end{array}$ & $\begin{array}{l}\text { D } \\
\text { Boxes Closed } \\
\text { to Min. Stop }\end{array}$ \\
\hline SP being contolled to now & \begin{tabular}{l|l} 
SF & I \\
RF
\end{tabular} & SF I RF & SF I RF \\
\hline VFD frequency. or RPM & 1 & T & T \\
\hline Static pressure during VFD test & & & \\
\hline Static pressure during capacity test & & \multicolumn{2}{|c|}{ (from $\mathrm{TAB}$ report data form) } \\
\hline
\end{tabular}

1. Fractional variance of SF design frequency or RPM to full open, 1-(B / A): . If the full open $\mathrm{SF}$ frequency or RPM is more than $5 \%$ less than the design value (assuming the design and actual static are equal), all boxes may not be driven full open. Investigate as appropriate.

Less than $5 \%$ variance? 
2. The SP with full open boxes (B) should be significantly less than the SP during the partially loaded conditions and should be within 0.15 inches SP of the SP from the capacity test. If the VFD SP is greater than the capacity test SP, all boxes may not be fully open. If the SP's are not close to each other, the TAB data may be innaccurate. Compliance basically verifies that a capacity test was completed.

Complies?

\section{Is the SP in (C) and (D) within $10 \%$ of the what it's being controlled to in (A)?}

\section{The min. turn down ratio (from Section II) should be close to (freq. D/B) Y/N?}

\section{Return fan RPMs or frequencies track well with changes in SF RPM, accounting for changes in OSA quantities and relief strategy?}

6. Static pressure (SP) readings at the last two conditions should remain within $5 \%$ of each other. If the there is more than a $5 \%$ variance, the sensor may be unstable, possibly from being too close to duct fittings.

Less than $5 \%$ variance?

Collaborative Trending: If the variance is greater than 5\% and if the Pressure Reading Reliability location doesn't comply, from Section III, trending (monitoring) the SP against terminal unit damper position or SF flow is recommended to confidently verify stability. The SP should remain constant $(+/-5 \%)$ regardless of damper position or flow.. SP trended?

Complies? (sensor is stable)

\section{For the frequency or RPM readings in Table 1 , are the values in Col. $B>C>D$ ?}

\section{Training}

The training specified in the design incentive agreement has been completed.

\section{Required Capacity Test}

To insure that energy use is minimized, the HVAC system must be balanced at design conditions at the lowest possible static pressure possible. This requires that the lowest possible static pressure (SP) be found at the sensor that will allow full design flow at the TU most difficult to satisfy. This system minimum SP found is what the VFD should control to. This is accomplished by changing the temperature setpoint for all zones to 55F, causing all terminal units (TU) to be calling for full cooling. Each TU's airflow is then measured against the design flow. The TU that is receiving the lowest fraction of design is identified. The current SP at the controlling sensor is noted. A calculation is made, giving the SP required at the sensor to allow the identified most critical TU box to meet its design flow. The equation is $\mathrm{SP}_{2}=\mathrm{SP}_{1} \times Q_{2}{ }^{2} / \mathrm{Q}_{1}{ }^{2}$. Where $Q_{1}=$ actual or fraction of design flow during capacity test. $Q_{2}$ = design flow or 1.0 if using fractions. $\mathrm{SP}_{1}=\mathrm{SP}$ at sensor. $\mathrm{SP}_{2}=\mathrm{SP}$ to control to. It is noted that if all boxes were calling for full cooling simultaneously, the fan could not maintain the new $\mathrm{SP}_{2}$ value, due to diversity fan size reduction having been made by the design engineer.

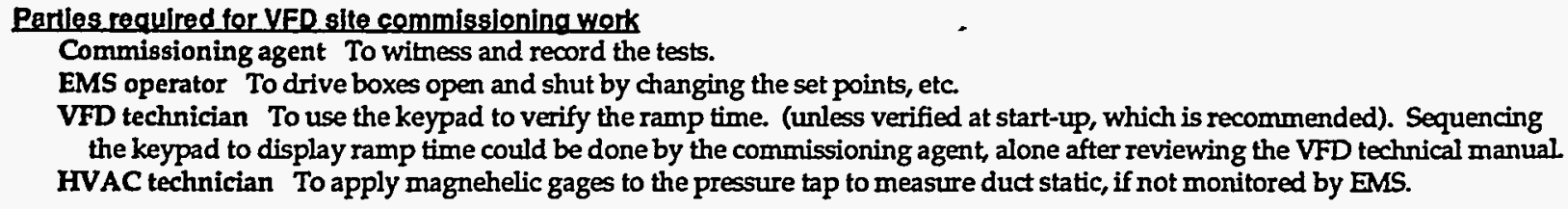




\section{Functional Performance Test}

\section{Variable Frequency Drive (VFD) \\ Pump Application}

Secondary Hydronic Pump Application

Project:

Address:

Date:

Commissioning Participants:

Commissioning agent (CA):

EMS operator:

VFD technician:

HVAC technician:

Owner's rep.:

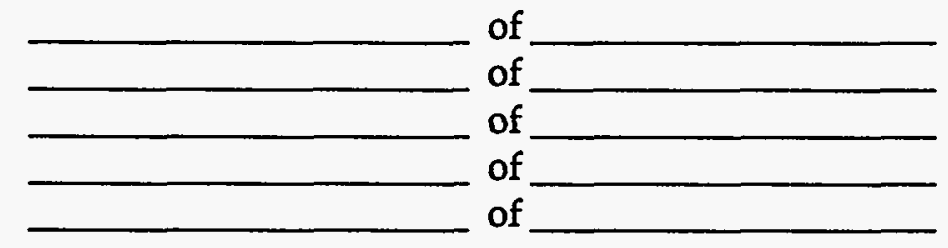

Pumps ID:

Chilled water (CHW) secondary,

Hot water (HW)

Design max.: Hp:

GPM:

Head

Ft

VFD brand and model:

The following functional performance test is for a VFD controlling a variable flow hydronic system to a constant differential pressure (DP). A check-mark denotes acceptance or compliance.

\section{Design Intent and Documentation Verification}

\section{Review the design documents and the specifications.}

_ Verify that the VFD _ description,_specifications, _technical and troubleshooting guide and the installation, __ programming record and __balance report are on-site.

From the design documents determine: Location for the DP measurement:

Control strategy for the pump:

\section{VFD Installation}

Differential Pressure Sensor

Actual location of DP measurement

The measurement should ideally be taken across the coil of the last branch.

Notes: 


\section{Complies?}

Pressure Offset (Po)

DP pump is being controlled to: feet [A].

Conversion: $\mathrm{psi} \times 2.31=\mathrm{ft} \mathrm{H}_{2} \mathrm{O}$

Pressure rise across pump at design conditions (from balance report): feet $[B]$.

Pressure offset, Po, $[\mathrm{A}] \div[\mathrm{B}]=$

Optimally, Po should be 0.3 or less in order for the VFD and pump to be able to respond to small pressure changes and realize adequate energy savings. If Po is greater than 0.4 , the DP sensor is probably located too close to the pump.

\section{Complies?}

\section{Balancing to Lowest Pressure}

Review the HVAC balance report and verify, according to the report, that the system was balanced so the VFD controls to the lowest possible DP (that is a capacity test was performed). The controlling DP from balance reports is feet. At design, the corresponding VFD frequency or pump RPM from the balance report is: Pump-1 report is Pump-2 Balanced to lowest DP?

\section{General Issues}

\section{Verify that any power quality mitigation measures required from the specifications} have been completed.

Verify that there are no 3-way coil valves that may negate the value of the VFD by allowing flow to bypass the coil, except for a very small min. flow bypass.

Verify verbally that the acceleration and deceleration ramp time of the VFD is between one and four minutes. Actual ramp time: up_ min. down __ min. (too short of ramp times will result in "hunting" and excess modulation by the VFD; typical ramp times are 1 to 4 minutes)

Verify that each VFD has been integrated into the EMS as per specification.

Verify that the lower frequency limit is programmed to $10-30 \%$ (the lower the better). Verify that the EMS monitors the DP.

Min.flow bypass with 2-way or constant flow valve, if present, has flow less than $2 \%$ of design flow?

\section{Functional Performance Test}

This test is not intended to verify that the coil valve is functioning properly, but rather that the VFD is functioning properly.

1. Design Flow by Test and Balance (TAB). Record in Condition 1 in Table 1 the speed, DP and total supply flow at design conditions from the TAB report.

Notes: 
2. Intermediate Flow (coil valves partially open). If current conditions are such, that the system is not expected to be in full cooling or full heating, nor be at minimum flow.

a. Read the speed, DP and the total supply flow in the secondary loop and record in Condition 3 in Table 1.

If the conditions are not in an "intermediate" position, change all space temperature set points to 4 degrees below the actual temperature in the space, for CHW pumps OR 4 degrees above for $H W$ pumps (circle one) to simulate an approaching of thermostat satisfaction and take readings.

3. Design Flow (coil valves full open). Using the (EMS) or other means, change all the space temperature set points to at least 10 degrees below the current space temperature for CHW pumps, OR 10 degrees above for HW pumps, so that the entire HVAC system supplied from these pumps is in full cooling (or heating, as appropriate, circle) in all zones. Observe that all coil valves are to their design maximum position (from the TAB report). Wait at least 20 minutes for lag time while observing:

Does the first lag pump turn on (after a delay) when the lead pump exceeds its gpm design flow?

Does the 2nd lag pump turn on (after a delay) when the sum Lead + Lag 1 exceeds the sum of their design, $A N D$ the DP drops to $\%$ or feet? (typically $80 \%$ )

a. Read the speeds, DP and the total supply flow and record in Condition 2.

4. Minimum Flow (Coil valves shut). Change all space temperature set points to be equal to the actual space temperatures to simulate a satisfied condition, driving the boxes to their minimum and the coil valves closed. Wait at least 25 minutes.

Do the lag pumps sequentially turn off (with a delay) when the flow is less than the design of all running pumps?

Does the last pump shut off appropriately?

a. Take the frequency, pressure and flow readings and record in Condition 4.

Notes: 


\section{Analysis}

\begin{tabular}{|c|c|c|c|c|c|c|}
\hline \multirow[b]{2}{*}{ Condition } & \multirow[b]{2}{*}{$\begin{array}{l}\text { Secondary } \\
\text { Pump No. }\end{array}$} & \multicolumn{2}{|c|}{ Speed (Hz or RPM) } & \multicolumn{2}{|c|}{ DP at Sensor (psi) } & \multirow{2}{*}{$\begin{array}{l}\text { Total } \\
\text { Flow } \\
\text { (gpm) }\end{array}$} \\
\hline & & Reading & Average & Reading & Average & \\
\hline \multirow{3}{*}{ 1. At design flow by TAB } & Lead & & & & & \\
\hline & Lag-1 & & & & & \\
\hline & Lag-2 & & & & & \\
\hline \multirow{3}{*}{$\begin{array}{l}\text { 2. At design flow (during } \\
\text { commissioning) }\end{array}$} & Lead & & & & & \\
\hline & Lag-1 & & & & & \\
\hline & Lag-2 & & & & & \\
\hline \multirow{3}{*}{$\begin{array}{l}\text { 3. At intermediate flow } \\
\text { (during commissioning) }\end{array}$} & Lead & & & & & \\
\hline & Lag-1 & & & & & \\
\hline & Lag-2 & & & & & \\
\hline \multirow{3}{*}{$\begin{array}{l}\text { 4. At no flow (during } \\
\text { commissioning) }\end{array}$} & Lead & & & & & \\
\hline & Lag-1 & & & & & \\
\hline & Lag-2 & & & & & \\
\hline
\end{tabular}

1. In Table 1, average the speed and the DP for all pumps at each of the four conditions.

2. If the speed at Condition 1 (TAB test) is not within $10 \%$ of the current test at Condition 2, all the boxes may not have been driven wide open during the $\mathrm{Cx}^{\prime} \mathrm{g}$ test, or the readings were taken before the lag time was complete. Investigate and repeat tests as appropriate. Less than $10 \%$ variance?

3. During operation of lead-lag pump combinations, the average DP readings at all four conditions should remain within $10 \%$ of each other. If the there is more than a $10 \%$ variance, the sensor may be faulty. (During lead-lag pump transition, the DP may appropriately vary by as much as $20 \%$ )

Less than $10 \%$ variance?

4. At no flow, Condition 4, is the flow and DP zero or equal to the min. flow bypass?

5. For the total flow readings in Table 1, are the values in Condition $2>3>4$ ?

6._Collaborative Trending

The system operation will, will not (circle) be trended to further verify the proper operation of the VFD. Points to be trended are listed in the Trending Request Form.

From studying the trends, is the VFD is functioning properly?

Notes: 
7. Additional tests. Refer to the chilled water systems sequence of operations tests for further collaboration on the VFD performance.

\section{Training}

The training specified in the design incentive agreement has been completed.

\section{O\&M Plan}

An acceptable O\&M Plan has been put into place. Describe:

\section{Capacity Test}

To insure that energy use is minimized, the hydronic system must be balanced at design conditions at the lowest possible differential pressure (DP) possible. This requires that the lowest possible DP at the sensor be found that will allow the delivery of design flow through the valve most difficult to satisfy. This system minimum DP found is what the VFD should control to. This is accomplished by changing the temperature setpoint for all zones to $55 \mathrm{~F}$ for cooling coils or $85 \mathrm{~F}$ for heating coils, causing all AHU coil valves to be calling for full cooling or heating, as applicable. Each coil's flow is then measured against the design flow. The coil that is receiving the lowest fraction of design is identified. The current DP at the controlling sensor is noted. A calculation is made, giving the DP required at the sensor to allow the identified most critical coil to meet its design flow. The equation is $D P_{2}=D P_{1} \times Q_{2}^{2} / Q_{1}^{2}$. Where $Q_{1}=$ actual or fraction of design flow during capacity test. $Q_{2}=$ design flow or 1.0 if using fractions. $D P_{1}=D P$ at sensor. $D P_{2}=D P$ to control to. It is noted that if all coils were calling for full cooling simultaneously, the pump could not maintain the new $\mathrm{DP}_{2}$ value, due to diversity pump size reduction having been made by the design engineer.

\section{Partles required for VFD site commissioning work}

Commissioning agent To witness and record the tests.

EMS operator To drive boxes open and shut by changing the set points, etc.

VFD technician To use the keypad to verify the ramp time. (unless verified at start-up, which is recommended). Sequencing the keypad to display ramp time could be done by the commissioning agent, alone after reviewing the VFD technical manual.

Notes: 


\section{COMMISSIONING GUIDE SPECIFICATIONS}

\section{SECTION 16010 \\ ELECTRICAL_GENERAL PROVISIONS}

Spec writer:

The following guide specifications are intended to be reviewed, modified and inserted into the noted specification section to meet the specific commissioning needs and requirements for the current project. Any modifications to these specifications shall only be made after consultation with the Owner's representative and with approval of the engineer of record. Where there are check boxes or fill-in blanks, fill in as appropriate and delete all but the choice(s) that apply. Delete all direction boxes.

In an appropriate section, alert Division 16 that they will be responsible for commissioning according to Section 16995, 17100 and other referenced sections.

Division 16 will be responsible to carry out the commissioning requirements specified in Section 16995,17100 and other sections referenced in 17100 .

END OF GUIDE SPECIFICATION SECTION 


\section{COMMISSIONING GUIDE SPECIFICATIONS}

\section{SECTION 16995 ELECTRICAL SYSTEMS COMMISSIONING}

Spec writer:

The following guide specifications are intended to be reviewed, modified and inserted into the noted specification section to meet the specific commissioning needs and requirements for the current project. Any modifications to these specifications shall only be made after consultation with the Owner's representative and with approval of the engineer of record. Where there are check boxes or fill-in blanks, fill in as appropriate and delete all but the choice(s) that apply. Delete all direction boxes.

\section{SECTION 16995}

\section{ELECTRICAL SYSTEMS COMMISSIONING}

TABLE OF CONTENTS (with selected subheadings)

\subsection{Description}

1.2 Responsibilities
A. Electrical Contractor
B. Electrical Designer

1.3 Related Work

2.1 Test Equipment

3.1 Submittals

\subsection{Startup}

3.3 Functional Performance Tests

3.4 Testing Documentation, Non-Conformance and Approvals

3.5 Operation and Maintenance Manuals

3.6 Training of Owner Personnel

3.7 Deferred Testing

3.8 Written Work Products 


\section{PART 1 - GENERAL}

\subsection{DESCRIPTION}

A. The purpose of this section is to specify Division 16 responsibilities in the commissioning process which are being directed by the $\mathrm{CA}$. Other electrical systems testing is required under the direction of the CM.

B. The list of commissioned equipment and systems is found in Section 17100.1.7.

C. Commissioning requires the participation of Division 16 to ensure that all systems are operating in a manner consistent with the Contract Documents. The general commissioning requirements and coordination are detailed in Division 17. Division 16 shall be familiar with all parts of Division 17 and the commissioning plan issued by the $\mathrm{CA}$ and shall execute all commissioning responsibilities assigned to them in the Contract Documents.

\subsection{RESPONSIBLITIES}

A. Electrical Contractors. The commissioning responsibilities applicable to the electrical contractor are as follows (all references apply to commissioned equipment only):

\section{Construction and Acceptance Phases}

1. Include the cost of commissioning in the contract price, if not yet let.

2. In each purchase order or subcontract written, include requirements for submittal data, O\&M data and training.

3. Attend a commissioning scoping meeting and other necessary meetings scheduled by the CA to facilitate the Cx process.

4. Contractors shall provide normal cut sheets and shop drawing submittals to the CA of commissioned equipment.

5. Provide additional requested documentation, prior to normal O\&M manual submittals, to the CA for development of start-up and functional testing procedures.

a. Typically this will include detailed manufacturer installation and start-up, operating, troubleshooting and maintenance procedures, full details of any owner-contracted tests, fan and pump curves, full factory testing reports, if any, and full warranty information, including all responsibilities of the Owner to keep the warranty in force clearly identified. In addition, the installation and checkout materials that are actually shipped inside the equipment and the actual field checkout sheet forms to be used by the factory or field technicians shall be submitted to the Commissioning Agent.

b. The Commissioning Agent may request further documentation necessary for the commissioning process.

c. This data request may be made prior to normal submittals.

The above information about special commissioning submittals is repeated in Section 01300. Maintain consistency. 
6. Provide a copy of the O\&M manuals submittals of commissioned equipment, through normal channels, to the CA for review and approval.

7. Contractors shall assist (along with the design engineers) in clarifying the operation and control of commissioned equipment in areas where the specifications, control drawings or equipment documentation is not sufficient for writing detailed testing procedures.

8. Provide assistance to the CA in preparation of the specific functional performance test procedures specified in Section 16997. Subs shall review test procedures to ensure feasibility, safety and equipment protection and provide necessary written alarm limits to be used during the tests.

9. Develop a full start-up and initial checkout plan using manufacturer's start-up procedures and the prefunctional checklists from the CA. Submit manufacturer's detailed start-up procedures and the full start-up plan and procedures and other requested equipment documentation to CA for review.

10. During the startup and initial checkout process, execute and document the electrical-related portions of the prefucntional checklists provided by the $\mathrm{CA}$ for all commissioned equipment.

11. Perform and clearly document all completed startup and system operational checkout procedures, providing a copy to the $C A$.

12. Address current $\mathrm{A} / \mathrm{E}$ punch list items before functional testing. Air and water $\mathrm{TAB}$ shall be completed with discrepancies and problems remedied before functional testing of the respective air- or water-related systems.

13. Provide skilled technicians to execute starting of equipment and to execute the functional performance tests. Ensure that they are available and present during the agreed upon schedules and for sufficient duration to complete the necessary tests, adjustments and problemsolving.

14. Perform functional performance testing under the direction of the $\mathrm{CA}$ for specified equipment in Section 16997 and 17100. Assist the CA in interpreting the monitoring data, as necessary.

15. Correct deficiencies (differences between specified and observed performance) as interpreted by the $\mathrm{CA}, \mathrm{CM}$ and $\mathrm{A} / \mathrm{E}$ and retest the equipment.

16. Prepare O\&M manuals according to the Contract Documents, including clarifying and updating the original sequences of operation to as-built conditions.

17. Prepare red-line as-built drawings for all drawings and final as-builts for contractor-generated coordination drawings.

18. Provide training of the Owner's operating personnel as specified.

19. Coordinate with equipment manufacturers to determine specific requirements to maintain the validity of the warranty.

\section{Warranty Period}

1. Execute seasonal or deferred functional performance testing, witnessed by the $\mathrm{CA}$, according to the specifications.

2. Correct deficiencies and make necessary adjustments to $0 \& M$ manuals and as-built drawings for applicable issues identified in any seasonal testing.

\section{B. Electrical Designer/Engineer}

1. Refer to Section $\mathbf{1 7 1 0 0}$ for the responsiblities of the Electrical Designer/Engineer.

\subsection{RELATED WORK}


A. Refer to Section 17100, Part 1.5 for a listing of all sections where commissioning requirements are found.

B. Refer to Section 17100 Part 1.4 for systems to be commissioned and section 17100 Part 1.6 and 16997 for functional testing requirements.

\section{PART 2 - PRODUCTS}

\subsection{TEST EQUIPMENT}
A. Division 16 shall provide all test equipment necessary to fulfill the testing requirements of this Division.

B. Refer to Section 17100 Part 2.1 for additional Division 16 requirements.

\section{PART 3 - EXECUTION}

\subsection{SUBMTTTALS}

A. Division 16 shall provide submital documentation relative to commissioning to the $\mathrm{CA}$ as requested by the CA. Refer to Section 17100 Part 3.3 for additional Division 16 requirements.

\subsection{STARTUP}

A. The electrical contractors shall follow the start-up and initial checkout procedures listed in the Responsibilities list in this section and in 17100 Part 3.4. Division 16 has start-up responsibility and is required to complete systems and sub-systems so they are fully functional, meeting the design objectives of the Contract Documents. The commissioning procedures and functional testing do not relieve or lessen this responsibility or shift that responsibility partially to the commissioning agent or Owner.

B. Functional testing is intended to begin upon completion of a system. Functional testing may proceed prior to the completion of systems, or sub-systems at the discretion of the CA and CM. Beginning system testing before full completion, does not relieve the Contractor from fully completing the system, including all prefunctional checklists as soon as possible.

\subsection{FUNCTIONAL PERFORMANCE TESTS}

A. Refer to Section 17100 Part 1.4 for a list of systems to be commissioned and to Part 3.6 for a description of the process and to Section 16997 for specific details on the required functional performance tests.

\subsection{TESTING DOCUMENTATION, NON-CONFORMANCE AND APPROVALS}

A. Refer to Section 17100 Part 3.4 for specific details on non-conformance issues relating to prefunctional checklists and tests. 
B. Refer to Section 17100 Part 3.7 for issues relating to functional performance tests.

\subsection{OPERATIONS AND MAINTENANCE (O\&M) MANUALS}
A. Division 16 shall compile and prepare documentation for all equipment and systems covered in Division 16 and deliver to the GC for inclusion in the O\&M manuals, according to Section 01730.
B. The CA shall receive a copy of the O\&M manuals for review.

\subsection{TRAINING OF OWNER PERSONNEL}

A. The GC shall be responsible for training coordination and scheduling and ultimately to ensure that training is completed. Refer to Section 17100 for additional details.

B. The CA shall be responsible for overseeing and approving the content and adequacy of the training of Owner personnel for commissioned equipment. Refer to Section 17100 for additional details.

C. Electrical Contractor. The electrical contractor shall have the following training responsibilities:

1. Provide the $\mathrm{CA}$ with a training plan two weeks before the planned training according to the outline described in Section 17100, Part 3.9.

2. Provide designated Owner personnel with comprehensive training in the understanding of the systems and the operation and maintenance of each major piece of commissioned electrical . equipment or system.

3. Training shall start with classroom sessions, if necessary, followed by hands on training on each piece of equipment, which shall illustrate the various modes of operation, including startup, shutdown, fire/smoke alarm, power failure, etc.

4. During any demonstration, should the system fail to perform in accordance with the requirements of the O\&M manual or sequence of operations, the system will be repaired or adjusted as necessary and the demonstration repeated.

5. The appropriate trade or manufacturer's representative shall provide the instructions on each major piece of equipment. This person may be the start-up technician for the piece of equipment, the installing contractor or manufacturer's representative. Practical building operating expertise as well as in-depth knowledge of all modes of operation of the specific piece of equipment are required. More than one party may be required to execute the training.

6. The training sessions shall follow the outline in the Table of Contents of the operation and maintenance manual and illustrate whenever possible the use of the O\&M manuals for reference.

7. Training shall include:

a. Use the printed installation, operation and maintenance instruction material included in the O\&M manuals.

b. Include a review of the written O\&M instructions emphasizing safe and proper operating requirements, preventative maintenance, special tools needed and spare parts inventory suggestions. The training shall include start-up, operation in all modes possible, shutdown, seasonal changeover and any emergency procedures.

c. Discuss relevant health and safety issues and concerns.

d. Discuss warranties and guarantees.

e. Cover common troubleshooting problems and solutions. 
f. Explain information included in the O\&M manuals and the location of all plans and manuals in the facility.

g. Discuss any peculiarities of equipment installation or operation.

h. The format and training agenda in Guidelines for Commissioning HVAC Systems, ASHRAE, 1989R, 1996 is recommended.

i. Classroom sessions shall include the use of overhead projections, slides, video and audio taped material as might be appropriate.

8. Hands-on training shall include start-up, operation in all modes possible, including manual, shut-down and any emergency procedures and maintenance of all pieces of equipment.

9. The electrical contractor shall fully explain and demonstrate the operation, function and overrides of any local packaged controls, not controlled by the central control system.

10. Training shall occur after functional testing is complete, unless approved otherwise by the Project Manager.

11. Duration of Training. The electrical contractor shall provide training on each piece of equipment according to the following schedule.

Fire Alarm System

Lighting Controls

Emergency Generator

UPS

Security System

Telecom and Data

Paging System 
The Spec Writer should list and specify training for all equipment not listed here.

\subsection{DEFERRED TESTING}

A. Refer to Section 17100 , Part 3.10 for requirements of deferred testing.

\subsection{WRITTEN WORK PRODUCTS}

A. Written work products of Contractors will consist of the startup and intitial checkout plan described in Section 17100 and the filled out startup, initial checkout and prefunctional checklists.

\section{END OF SPECIFICATION SECTION}




\section{COMMISSIONING GUIDE SPECIFICATIONS}

\section{SECTION 16997 ELECTRICAL TESTING REQUIREMENTS}

\section{Spec writer:}

The following guide specifications are intended to be reviewed, modified and inserted into the noted specification section to meet these specific commissioning needs and requirements for the current project. Any modifications to these specifications shall only be made after consultation with the Owner's representative and with approval of the engineer of record. Where there are check boxes or fill-in blanks, fill in as appropriate and delete all but the choice(s) that apply. Delete all direction boxes.

Spec Writer: $A / E$ and design phase $C A$ should:

1. Review the functional test requirements and add or change requirements, as necessary, for the current project. Delete requirements for equipment not existing in the current project.

2. Make sure that every piece of mechanical equipment or system has a unique test requirement or is listed as a component of a system with testing requirements given. Use the format of this section for new test requirements.

3. Include intersystem test requirements where significant interactions or interlocks exist between systems.

\section{PART 1 - GENERAL}

\subsection{INCLUDED SYSTEMS AND EQUIPMENT}

A. The following is a list of the equipment and system test requirements included in this section:

1. Lighting sweep controls

2. Daylight dimming controls

3. Emergency power and UPS system

\subsection{DESCRIPTION}

A. This section specifies the functional testing requirements for Division 15 systems and equipment. From these requirements, the Commissioning Agent (CA) shall develop step-by-step procedures to be executed by the Subs. The general functional testing process, requirements and testing methods definitions are described in Section 17100. The test requirements for each piece of equipment or system contain the following:

1. The contractors responsible to execute the tests, under the direction of the $\mathrm{CA}$.

2. A list of the integral components being tested.

3. Prefunctional checklists associated with the components.

4. Functions and modes to be tested.

5. Required conditions of the test for each mode.

6. Special procedures.

7. Required methods of testing. 
8. Required monitoring.

9. Acceptance criteria.

10. Sampling strategies allowed.

\subsection{PREREQUISITES}

The following applicable generic prerequisite checklist items are required to be listed on each written functional test form and be completed and checked off by $\mathrm{CA}$ prior to functional testing.

All related equipment has been started up and start-up reports and prefunctional checklists submitted and approved ready for functional testing:

All control system functions for this and all interlocking systems are programmed and operable per contract documents, including final setpoints and schedules with debugging, loop tuning and sensor calibrations completed.

$$
\text { Controls Contractor Signature or Verbal } \quad \overline{\text { Date }}
$$

All A/E punchlist items for this equipment corrected.

These functional test procedures reviewed and approved by installing contractor.

- Safeties and operating ranges reviewed by the CA.

Test requirements and sequences of operation attached.

Schedules and setpoints attached.

- Sufficient clearance around equipment for servicing.

- Record of all values for pre-test setpoints changed to accommodate testing has been made and a check box provided to verify return to original values (control parameters, limits, delays, lockouts, schedules, etc.).

_Other miscellaneous checks of the prefunctional checklist and start-up reports completed successfully.

\subsection{MONITORING.}

a. Monitoring is a method of testing as a stand-alone method or to augment manual testing.

b. All points listed in the required monitoring section of the test requirements which are control system monitored points shall be trended by the controls contractor. Other points shall be monitored by the CA using dataloggers. At the option of the $\mathrm{CA}$, some control system monitoring may be replaced with datalogger monitoring. At the CA's request, the controls contractor shall trend up to $20 \%$ more points than listed at no extra charge.

c. Hard copies of monitored data must be in columnar format with time down the left column and at least 4 columns of point values on the same page. Graphical output is a desirable option, if the system can produce it.

\section{PART 2 - PRODUCTS}

-NOT APPLICABLE - 


\section{PART 3 - EXECUTION}

\section{LIGHTING SWEEP CONTROLS}

A. Parties Responsible to Execute Functional Test

1. Controls contractor: operate the controls

2. Electrical contractor: assist in testing sequences

B. Integral Components or Related Equipment Being Tested

1. Lighting Sweep Controls

\section{Prefunctional Checklist ID \\ $\mathrm{PC}-$}

C. Prerequisites The applicable prerequisite checklist items listed in the beginning of Section 16997 shall be listed on each functional test form and checked off prior to functional testing.

D. Functions / Modes Required To Be Tested and Test Methods

The following testing requirements are an addition to and do not replace any testing requirements elsewhere in this Division.

\begin{tabular}{|c|c|}
\hline Function / Mode & $\begin{array}{l}\text { Test Method } \\
\text { Manual (demonstration), } \\
\text { Monitoring, Either or } \\
\text { Both }\end{array}$ \\
\hline \multicolumn{2}{|l|}{ MISCELLANEOUS FUNCTIONS } \\
\hline $\begin{array}{l}\text { 1. All specified functions and features are set up, debugged and fully } \\
\text { operable. }\end{array}$ & $\begin{array}{l}\text { Verbal discussion of } \\
\text { features }\end{array}$ \\
\hline 2. Power failure and battery backup and power-up restart functions. & Demonstration \\
\hline 3. Security and access codes. & Demonstration \\
\hline 4. Verify override duration setting. & Demonstration \\
\hline 5. Scheduling features fully functional and setup, including holidays. & $\begin{array}{l}\text { Observation in terminal } \\
\text { screens or printouts }\end{array}$ \\
\hline $\begin{array}{l}\text { 6. Date and time setting in central computer and verify that field panels read } \\
\text { the same time. }\end{array}$ & Demonstration \\
\hline & \\
\hline \multicolumn{2}{|l|}{ SWEEP FUNCTIONS } \\
\hline $\begin{array}{l}\text { 7. } 50 \% \text { of the zones with a minimum of } 2 \text { zones per controller or relay must } \\
\text { be verified by turning on at least } 25 \% \text { of the lights in the zone and } \\
\text { witnessing an actual sweep. }\end{array}$ & Either \\
\hline \multicolumn{2}{|l|}{ OVERRDE FUNCTIONS } \\
\hline $\begin{array}{l}\text { 8. Manual occupant overrides: } 25 \% \text { of the local override switches, with a } \\
\text { minimum of } 4 \text { switches must be verified by turning the override switches } \\
\text { ON after a sweep and seeing the lights turn back on. } 100 \% \text { of the } \\
\text { remainder of the switches should be sight verified to be in place. }\end{array}$ & Either \\
\hline $\begin{array}{l}\text { 9. Telephone and keypad overrides: Test the telephone overrides by calling } \\
\text { in for } 50 \% \text { of the zones. Test } 50 \% \text { of the keypad overrides. }\end{array}$ & Either \\
\hline & \\
\hline
\end{tabular}


E. Special Procedures (other equipment to test with, etc.; reference to function ID)

None

F. Required Monitoring

1. None required, though monitoring can substitute for manual testing for all functions. See section 1.4 above.

G. Acceptance Criteria (referenced by function or mode ID)

1-9 For the conditions, sequences and modes tested, the sweep controls, integral components

(All) and related equipment respond to changing conditions and parameters appropriately as expected, as specified and according to acceptable operating practice.

H. Sampling Strategy for Identical Units ( $x x \%$ Sampling-yy\% Failure Rule is defined in Section 17100, Part 3.6)

1. Sampling is as listed in the table above with a $10 \%$ Failure Rule applying.

END OF REQUIREMENTS FOR SWEEP CONTROL TEST 


\section{DAYLIGHT DIMMING CONTROLS}

A. Parties Responsible to Execute Functional Test

1. Controls contractor: operate the controls

2. Electrical contractor: assist in testing sequences

B. Integral Components or Related Equipment Being Tested

1. Daylight Dimming Controls

\section{Prefunctional Checklist ID \\ $\mathrm{PC}-$}

C. Prerequisites The applicable prerequisite checklist items listed in the beginning of Section 16997 shall be listed on each functional test form and checked off prior to functional testing.

D. Functions / Modes Required To Be Tested and Test Methods

The following testing requirements are an addition to and do not replace any testing requirements elsewhere in this Division.

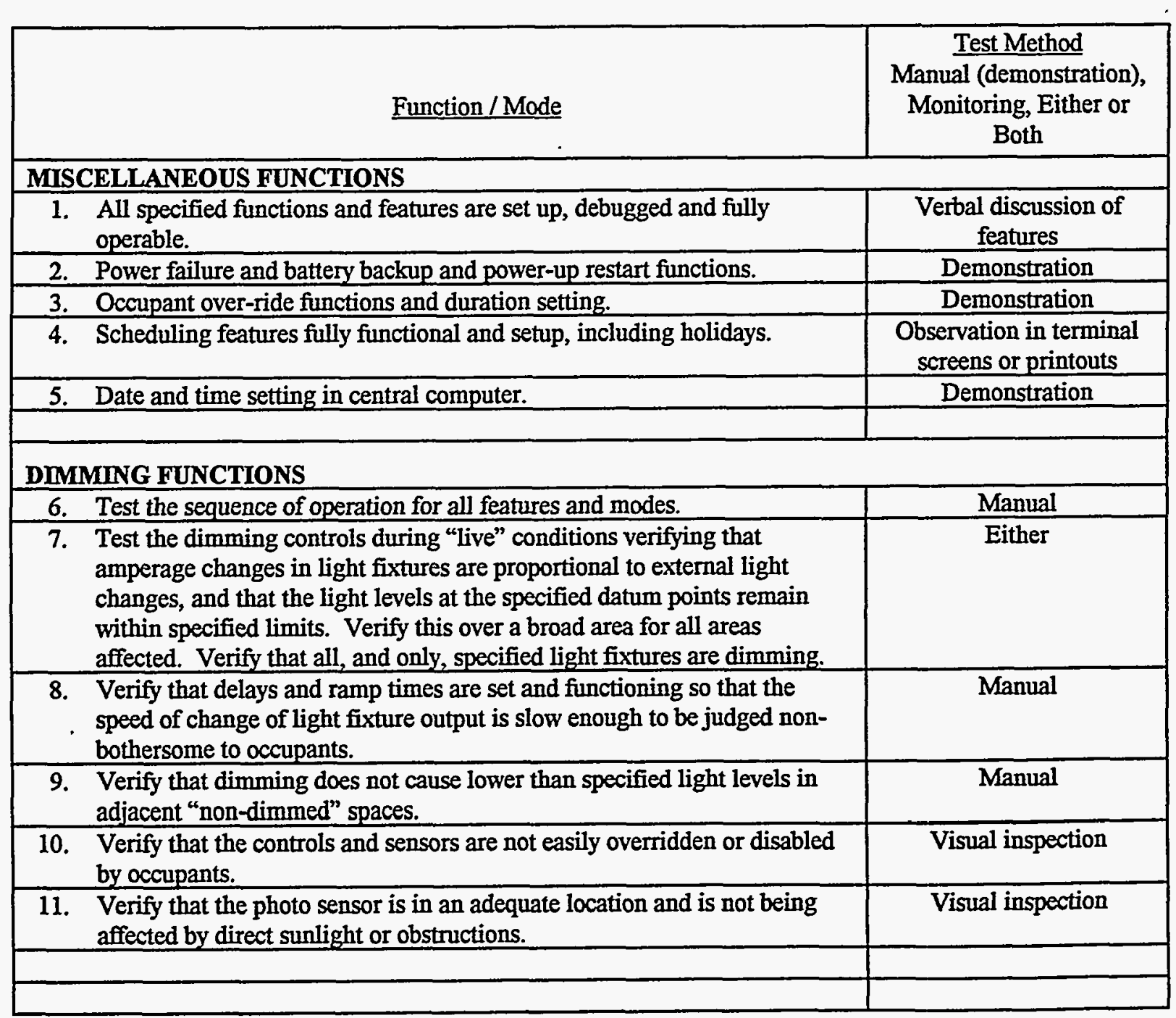

E. Special Procedures (other equipment to test with, etc.; reference to function ID)

None 
F. Required Monitoring

1. None required, though monitoring can substitute for manual testing for most functions. See section 1.4 above.

G. Acceptance Criteria (referenced by function or mode ID)

1-11 For the conditions, sequences and modes tested, the dimming controls, integral

(All) components and related equipment respond to changing conditions and parameters appropriately as expected, as specified and according to acceptable operating practice.

H. Sampling Strategy for Identical Units ( $x x \%$ Sampling-yy\% Failure Rule is defined in Section 17100, Part 3.6)

1. Each photosensor and its controlled zone must be tested (no sampling).

END OF REQUIREMENTS FOR DAYLIGHT DIMMING TEST 


\section{EMERGENCY POWER AND UNINTERRUPTIBLE POWER SUPPLY SYSTEM}

A. Parties Responsible to Execute or Participate in Functional Test

1. Controls contractor: operate the controls

2. Electrical contractor: provide all testing instruments and assist in testing sequences and debugging

3. Mechanical contractor: assist in testing sequences and debugging

4. Electrical design engineer: assist in testing sequences

5. Security system contractor, local and remote monitoring site: report communication response

6. Owner staff at regional monitoring site: report communication response

7. Owner project and facility representatives: assist in testing sequences and debugging

8. Commissioning agent: coordinate testing

B. Integral Components or Related Equipment Being Tested

1. Generator

2. Automatic transfer switch

3. Uninterruptible power supply

4. Building control, HVAC, lighting, fire alarm, telecommunications, elevator and security systems
Prefunctional Checklist ID

$\mathrm{PC}$ -

$\mathrm{PC}-$

$\mathrm{PC}-$

\section{Spec Writer:}

There is a wide variation in the industry as to what is sufficient testing for emergency power systems. More critical emergency power loads and generators feeding UPS systems and critical UPS loads warrant the more rigorous tests. Less critical applications will frequently omit the infrared metering and the powerline load profiler, detailed frequency and voltage stabilization tests mentioned below.

C. Prerequisites The applicable prerequisite checklist items listed in the beginning of Section 16997 shall be listed on each functional test form and checked off prior to functional testing.

D. Functions / Modes Required To Be Tested and Test Methods

The following testing requirements are an addition to and do not replace any testing requirements elsewhere in this Division.

Function / Mode

Test Method Manual (demonstration), Monitoring, Either or Both

Generator and ATS

1. Document and witness startup, checkout and testing by factory representative as specified and including the following:

2. Safeties and alarms (including high and low oil pressure, high temperature, over-speed, derangements, etc.)

3. Sequences of operation with load bank: From a cold start, verify starting functions by recording times for engine start, ATS transfer ON, delay to OFF, engine cool down, etc.

4. Load bank generator to $100 \%$ for 1 hour. Record every 5 min.: volts \& amps (each phase), frequency, using load profiler, engineer coolant temp. and oil pressure. 


\begin{tabular}{|c|c|}
\hline Function / Mode & $\begin{array}{c}\text { Test Method } \\
\text { Manual (demonstration), } \\
\text { Monitoring, Either or } \\
\text { Both }\end{array}$ \\
\hline $\begin{array}{l}\text { 5. Voltage and frequency regulation over various loads. Verify that } \\
\text { frequency and voltage is within specified ranges at steady state and step } \\
\text { loads of } 0 \%-50 \%, 0 \%-100 \%, 100 \%-50 \% \text { and } 50 \%-100 \% \text { in that order } \\
\text { using a power line load profiler. Verify that frequency stability (rate of } \\
\text { change) is adequate. }\end{array}$ & Combination \\
\hline $\begin{array}{l}\text { Using actual building emergency loads, tune the generator output } \\
\text { frequency and voltage for use by the UPS, using a load profiler or } \\
\text { oscilloscope. (This could be done during the Integrated Building Test). }\end{array}$ & Combination \\
\hline 7. Verify annunciations to BAS and remote monitoring sites. & Monitoring \\
\hline $\begin{array}{l}\text { 8. During the above tests use an infrared meter on the ATS contacts and } \\
\text { look for hot spots and significant variations between contracts. }\end{array}$ & Manual \\
\hline $\begin{array}{l}\text { 9. Monitor and instrument as required to make positive observations of test } \\
\text { results. }\end{array}$ & Either \\
\hline 10. Operation during Integrated Test. & Manual \\
\hline \multicolumn{2}{|l|}{ UPS } \\
\hline $\begin{array}{l}11 \text { By actual power outage, verify sequence of operation of UPS. Use actual } \\
\text { UPS loads if possible, else use load bank: at what voltage UPS starts, } \\
\text { time to transfer back to E-power, etc. Verify proper frequency window } \\
\text { and slew rate with powerline analyzer. Tune UPS and generator governor } \\
\text { as necessary. Partially drain batteries and verify charging sequences. }\end{array}$ & Manual \\
\hline $\begin{array}{l}\text { 12. Simulate all alarms critical malfunctions and verify annunciations and } \\
\text { protective device functioning. }\end{array}$ & Manual \\
\hline 13. Verify annunciations to BAS and remote monitoring sites. & Monitoring \\
\hline $\begin{array}{l}\text { 14. During the above tests use an infrared meter on the UPS contacts and look } \\
\text { for hot spots and significant variations between contracts. }\end{array}$ & Manual \\
\hline $\begin{array}{l}\text { 15. Monitor and instrument as required to make positive observations of test } \\
\text { results. }\end{array}$ & Either \\
\hline 16. Operation during Integrated Test. & Manual \\
\hline \multicolumn{2}{|l|}{ Integrated Building Test } \\
\hline $\begin{array}{l}\text { 17. The emergency power and UPS system and all integral components will } \\
\text { be tested together through actual power outages with as much emergency } \\
\text { loads operating as possible. Physical verification of emergency power to } \\
\text { all emergency powered systems and equipment, including lighting, } \\
\text { HVAC, telecommunications, fire alarm, elevator (test actual recall } \\
\text { function), security, lighting and the controls system shall be documented. } \\
\text { Communication responses to remote monitoring reception points, the } \\
\text { local building automation system and visual points within the building } \\
\text { will be documented. Critical voltage sensing, timing, delays, voltages, } \\
\text { amperages and groundings will be documented. }\end{array}$ & Manual \\
\hline & \\
\hline
\end{tabular}

E. Special Procedures (other equipment to test with, etc.; reference to function ID) None, except as noted.

F. Required Monitoring

1. See Requirements 4, 5, 8. See Section 1.4 above. 
G. Acceptance Criteria (referenced by function or mode ID)

1-17 For the conditions, sequences and modes tested, the emergency power and UPS system,

(All) integral components and related equipment respond to changing conditions and parameters appropriately as expected, as specified and according to acceptable operating practice.

H. Sampling Strategy for Identical Units ( $x x \%$ Sampling-yy\% Failure Rule is defined in Section 17100, Part 3.6)

1. None. Test all.

END OF REQUIREMENTS FOR EMERGENCY POWER SYSTEM TEST

END OF THIS GUIDE SPECIFICATION SECTION 


\title{
COMMISSIONING GUIDE SPECIFICATIONS
}

\author{
SECTION 16998 \\ PREFUNCTIONAL CHECKLISTS
}

\section{ELECTRICAL}

\section{Spec writer:}

The following guide specifications are intended to be reviewed, modified and inserted into the noted specification section to meet the specific commissioning needs and requirements for the current project. Any modifications to these specifications shall only be made after consultation with the Owner's representative and with approval of the engineer of record. Where there are check boxes or fill-in blanks, fill in as appropriate and delete all but the choice(s) that apply. Delete all direction boxes.

\section{SECTION 16998}

\section{PREFUNCTIONAL CHECKLISTS}

\section{ELECTRICAL}

\section{A. GENERAL}

All prefunctional checklists for both mechanical and electrical are found in Section 15998.

\section{END OF SECTION}




\title{
COMMISSIONING GUIDE SPECIFICATIONS
}

\section{SECTION 16999 \\ SAMPLE FUNCTIONAL TEST PROCEDURES}

\author{
ELECTRICAL
}

\section{Spec writer:}

The following example functional test procedures are provided for reference and do not necessarily reflect equipment or conditions in this project. The commissioning agent will write specific functional test procedures for this project.

\section{SECTION 16999}

\section{SAMPLE FUNCTIONAL TEST PROCEDURES}

\section{ELECTRICAL}

\section{A. GENERAL}

This section contains sample Functional performance Test procedures in a form format (FT).

The sample FT procedures displayed in a form format here are intended to provide the Subs and CA with an example of a format and an indication of the rigor of the required testing and documentation for various equipment types. They were not developed for this project. Other forms and formats are acceptable if they comply with the rigor, clarity and intent of all the commissioning specifications. The CA will use the functional testing requirements in Sections 15997 and 16997 and the testing protocols specified in Section 17100 for developing site-specific functional test procedures and forms for this project. For illustrative purposes, sequences of operation associated with a few pieces of the equipment for which tests are included are also provided.

\section{B. SAMPLE FUNCTIONAL TESTS (Examples only, not for this project)}

This guide specifications section continues with functional tests for the following equipment. The tests are provided in electronic file format (Word 6.0 for Windows 3.1). The file name is at the bottom of each page. The file name extension " $\mathrm{ft}$ " stands for Functional Test and the last digit is the version number. Any MS Excel spreadsheet files are noted with their usual .xls extension. Some of the equipment also has a file with its full sequences of operation, for reference when viewing the test procedures, and to illustrate the desired rigor of sequences of operation.

Additional example functional tests for mechanical equipment are found in Section 15999. 


\section{$\underline{\text { SYSTEM }}$}

Emergency power and UPS (comprehensive, big)

Emergency power and UPS

Exterior lighting controls

Lighting sweep controls

\section{ELECTRONIC FILE NAME}

e-powbig.ft

e-power.ft

extlight.ft

sweep.t.

\section{SUGGESTED NUMBERING KEY FOR COMMISSIONING PROCEDURES}

The checklists, functional tests, documentation and training use the following identification numbering:

At the beginning of the identification number is a text abbreviation for the following:

Document or Event Abbreviations

DOC = Documentation

$\mathrm{PC} \quad=$ Prefunctional Checklist

$\mathrm{SP} \quad=$ Start-up Plan

SR = Start-up Report

FT = Functional Test

$\mathrm{R} \quad=$ Review

TR = Training Record

Numbering Key

FT-0102.3: The first four digits uniquely identify the piece of equipment to the component level. The first 2 digits are the System Type, the second 2 digits are an arbitrary component number (not necessarily the same as the specified ID number). The number after the decimal is the test number. For example, FT-0102.3 = Functional Test 3 of system Type 1, component number 2 (e.g., 0102.3 = Chiller \#2, FT \#3, because chillers are System Type 1). Other components under chillers are: additional chillers, pumps, valves, piping, VFDs. The component number of 00 means "general" or "all" components, as with the entire system. All tests, procedures, trainings and records should have the same first 4 digits for any given equipment component.

Another example is TUs. If there were only 1 TU type, then tests would be numbered FT$0500.1,0500.2$, etc. If there were 2 types of TUs: FT-0501.1, 0501.2, etc. and 0502.1, 0502.2 , etc.

An example of the number system follows:

0100 Chilled Water System

0101 Chiller 1

0102 Chiller 2

0103 Cooling tower 1

0104 Cooling tower 2

0105 Pump CHWP-1

0106 Pump CHWP-2

$0107 \mathrm{CHW}$ piping

$0108 \mathrm{CDW}$ piping

0109 Sensor calibration
0200 Boiler System

0201 Boiler 1

0202 Boiler 2

0203 Pump HWP-1

0204 Pump HWP-2

$0205 \mathrm{HW}$ piping

0206 Sensor calibration

etc. 


\section{Numbers for Primary System Types and Components}

Components are in parentheses.

01 Chilled water system (chillers, cooling towers, pumps, condensers, piping, valves)

02 Hot water system (boilers, hot water pumps, valves, piping)

03 Air handler units (SF, RF, coils, valves, VFD, ducts, dampers)

04 Packaged, AC or HP units (SF, RF, coils, valves, VFD, ducts, dampers, compressors, condensers)

05 Terminal units

06 Computer room $\mathrm{AC}$ units

07 Unit heaters or AC spot coolers

08 Heat exchangers

09 Service water system

10 Test and balance (TAB)

11 Building automation system (controls)

12 Lighting controls

13 Specialty fans

14 Fume hoods

\section{END OF SECTION}




\section{Functional Test}

Project

\section{FT- EMERGENCY POWER SYSTEM \\ (Short Test Version, less rigorous UPS test) \\ Including Emergency Generator, ATS and UPS}

\section{Related Tests:}

\section{Participants}

\section{Party}

\section{Participation}

Party filling out this form and witnessing testing

Dates of tests

\section{Test Prerequisites}

a. The following have been started up and startup reports and prefunctional checklists submitted and approved ready for functional testing:

Emergency generator and ATS

$$
\text { UPS }
$$

b. All control system functions for this and all interlocking systems are programmed and operable per contract documents, including final setpoints and schedules and with debugging, loop tuning and sensor and device calibrations completed.

$$
\text { Controls Contractor Signature or Verbal } \quad \overline{\text { Date }}
$$

g. - All A/E punchlist items for this equipment corrected.

h. - These functional test procedures reviewed and approved by installing contractor and vendors.

i. - Safeties and operating ranges reviewed.

j. - Test requirements and sequences of operation attached.

o. - Verify that generator gages and meters for voltage, amperage and frequency are calibrated to hand-held or load profiler instrument readings.

p. _ Other misc. checks of the prefunctional checklist and startup reports completed successfully.

q. - Monitoring security company notified of test. Arrangements made to test UPS loads (or load bank).

Notes: 


\section{Testing Procedures and Record}

\begin{tabular}{|c|c|c|c|c|c|}
\hline $\begin{array}{l}\text { Proced. } \\
\text { No. \& } \\
\text { Spec. } \\
\text { Seq. ID }\end{array}$ & $\begin{array}{l}\text { Req ID } \\
\text { No. }^{2}\end{array}$ & $\begin{array}{l}\text { Test Procedure } \\
\text { (Including special conditions) }\end{array}$ & $\begin{array}{c}\text { Expected and Actual Response } \\
\text { [Write ACTUAL response in } \\
\text { brackets or circle] }\end{array}$ & $\begin{array}{l}\text { Pass } \\
\text { YNN }\end{array}$ & $\begin{array}{c}\text { Note } \\
*\end{array}$ \\
\hline \multicolumn{6}{|c|}{ Initial Procedures } \\
\hline A & & $\begin{array}{l}\text { The contractor shall follow the following } \\
\text { acceptance procedure with the engine } \\
\text { cold and no connected load. } \\
\text { With ATS switch in the manual position, } \\
\text { open the ATS breaker. } \\
\text { Restore ATS to automatic position and } \\
\text { close ATS breaker. }\end{array}$ & $\begin{array}{l}\text { Verify that power has been lost from } \\
\text { each load served by emergency } \\
\text { power. }\end{array}$ & & \\
\hline $\bar{B}$ & & $\begin{array}{l}\text { Connect Power Line Disturbance } \\
\text { Monitor (PDM), Load Profiler and } \\
\text { recording Multimeter to UPS and } \\
\text { Backup Generator/ATS. }\end{array}$ & & & \\
\hline \multicolumn{6}{|c|}{ Generator, ATS and Loads } \\
\hline$\overline{1}$ & & $\begin{array}{l}\text { Cold Start. } \\
\text { Open normal power breakers and } \\
\text { immediately connect full load bank load } \\
\text { capacity to ATS units. This connection } \\
\text { must be made before engine generator } \\
\text { is up to speed and transfer to E-power } \\
\text { has been completed. }\end{array}$ & $\begin{array}{l}\text { Observe the system's performance } \\
\text { and record the following data using } \\
\text { a Power Line Disturbance Monitor to } \\
\text { monitor the transient responses. } \\
\text { Compare to specifications. }\end{array}$ & & \\
\hline 2 & & Measure time using PDM. & $\begin{array}{l}\text { Time delay from power failure to } \\
\text { engine start signal should be within } \\
\text { sec., [_ sec]. }\end{array}$ & & \\
\hline 3 & & Measure time using PDM. & 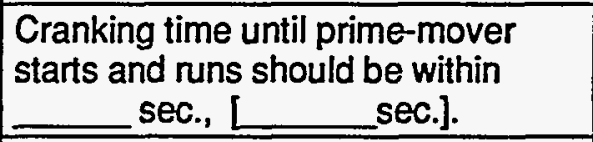 & & \\
\hline 4 & & Measure time using PDM. & $\begin{array}{l}\text { Time until engine-generator is at } \\
\text { proper voltage and frequency should } \\
\text { be within } \\
\text { sec]. }\end{array}$ & & \\
\hline 5 & & Measure time using PDM. & $\begin{array}{l}\text { Total time from power failure until } \\
\text { ATS switch is on E-power should be } \\
\text { within_sec., [r sec]. }\end{array}$ & & \\
\hline 6 & & OPTIONAL: Repeat procedures 1-5. & $\begin{array}{l}\text { Document variances from specified } \\
\text { performance. }\end{array}$ & & \\
\hline
\end{tabular}

Notes: 


\begin{tabular}{|c|c|c|c|c|c|}
\hline $\begin{array}{c}\text { Procod. } \\
\text { No. \& } \\
\text { Spec. } \\
\text { Seq. ID' }\end{array}$ & $\begin{array}{l}\text { Req ID } \\
\text { No. }^{2}\end{array}$ & $\begin{array}{l}\text { Test Procedure } \\
\text { (including special conditions) }\end{array}$ & $\begin{array}{c}\text { Expected and Actual Response } \\
\text { [Write ACTUAL response in } \\
\text { brackets or circle] }\end{array}$ & $\begin{array}{l}\text { Pass } \\
\text { YIN }\end{array}$ & $\begin{array}{c}\text { Noto } \\
*\end{array}$ \\
\hline 7 & & $\begin{array}{l}\text { Full Load Test. } \\
\text { Continue generator operation. Record } \\
\text { voltage and amperage of each phase } \\
\text { and frequency using a load profile } \\
\text { monitor, not generator gages; engine } \\
\text { coolant temperature, oil pressure, and } \\
\text { battery charge rate at } 5 \text { minute intervals } \\
\text { for a period of one hour. } \\
\text { OPTIONAL: Measure the temperature } \\
\text { of all generator and ATS connections } \\
\text { using a laser guided infrared } \\
\text { temperature meter, Raytech or } \\
\text { approved. }\end{array}$ & & & \\
\hline
\end{tabular}

Performance Criteria for Data in Table Below (by Column number).
1) 5 minute intervals
7) Batt. Charge:
2) Volts:
3) Hertz:
4) Amps:
5) Coolant $T$ :
8) Ambient temperature: none
9) ATS Contacts Input Temp.: Note any significant variances between phases.
10) ATS Contacts Output Temp.: Note any significant variances between phases

6) Oil pressure:

\begin{tabular}{|c|c|c|c|c|c|c|c|c|c|c|}
\hline 1 & 2 & 3 & 4 & 5 & 6 & 7 & 8 & 9 & 10 & 11 \\
\hline Time & Volts & Amps & Hertz & $\begin{array}{c}\text { Engine } \\
\text { Coolant } \\
\text { Temp. }\end{array}$ & $\begin{array}{c}\text { Oil } \\
\text { Press }\end{array}$ & $\begin{array}{c}\text { Batt. } \\
\text { Charge }\end{array}$ & $\begin{array}{l}\text { Temp. } \\
\text { @ Gen. }\end{array}$ & $\begin{array}{c}\text { Temp.@ } \\
\text { ATS Input } \\
\text { (list ea. phase) }\end{array}$ & $\begin{array}{c}\text { Temp.@ } \\
\text { ATS } \\
\text { Output } \\
\text { (list ea. phase) }\end{array}$ & $\begin{array}{c}\text { Note } \\
\text { Number }\end{array}$ \\
\hline & & & & & & & & & & \\
\hline & & & & & & & & & & \\
\hline & & & & & & & & & & \\
\hline & & & & & & & & & & \\
\hline & & & & & & & & & & \\
\hline & & & & & & & & & & \\
\hline
\end{tabular}

Notes: 


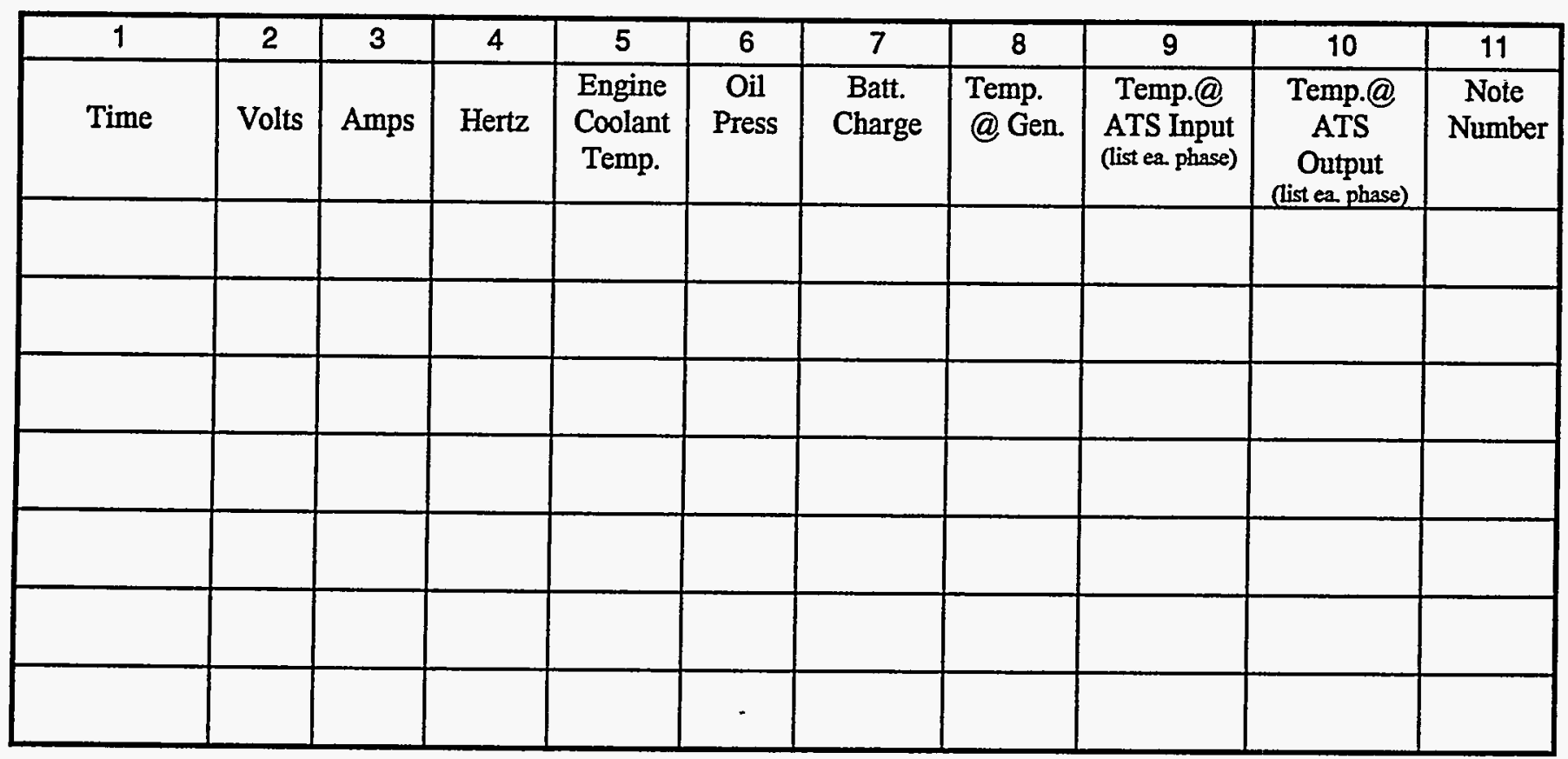

Test Procedures Continued:

\begin{tabular}{|c|c|c|c|c|c|}
\hline $\begin{array}{l}\text { Proced. } \\
\text { No. \& } \\
\text { Spec. } \\
\text { Seq. ID' }\end{array}$ & $\begin{array}{c}\text { Req ID } \\
\text { No. }^{2}\end{array}$ & $\begin{array}{l}\text { Test Procedure } \\
\text { (Including special conditions) }\end{array}$ & $\begin{array}{l}\text { Expected and Actual Response } \\
\text { [Write ACTUAL response in } \\
\text { brackets or circle] }\end{array}$ & $\begin{array}{l}\text { Pass } \\
\text { Y/N }\end{array}$ & $\begin{array}{c}\text { Note } \\
*\end{array}$ \\
\hline 8 & & $\begin{array}{l}\text { Disconnect load bank load from ATS, } \\
\text { before transfer back to normal power. } \\
\text { Restore normal power and record delay } \\
\text { to normal power transfer. }\end{array}$ & $\begin{array}{l}\text { Delay to normal power should be } \\
\text { min., [ min.]. }\end{array}$ & & \\
\hline 9 & & $\begin{array}{l}\text { Record neutral delay time (if applicable) } \\
\text { or verify in-phase monitor is working by } \\
\text { recording voltage differential between } \\
\text { Engine Generator Power and Utility } \\
\text { Power at the time of the transfer back to } \\
\text { normal power. } \\
\end{array}$ & $\begin{array}{c}\text { Neutral delay time should be } \\
\text { sec., L_ L_ec.]. }\end{array}$ & & \\
\hline 10 & & $\begin{array}{l}\text { Record engine cool-down time. (Engine } \\
\text { continues to run after ATS transfer.) }\end{array}$ & $\begin{array}{l}\text { Cool down time should be } \\
\text { min., L } \quad \text { min.]. }\end{array}$ & & \\
\hline
\end{tabular}

Notes: 




Notes: 


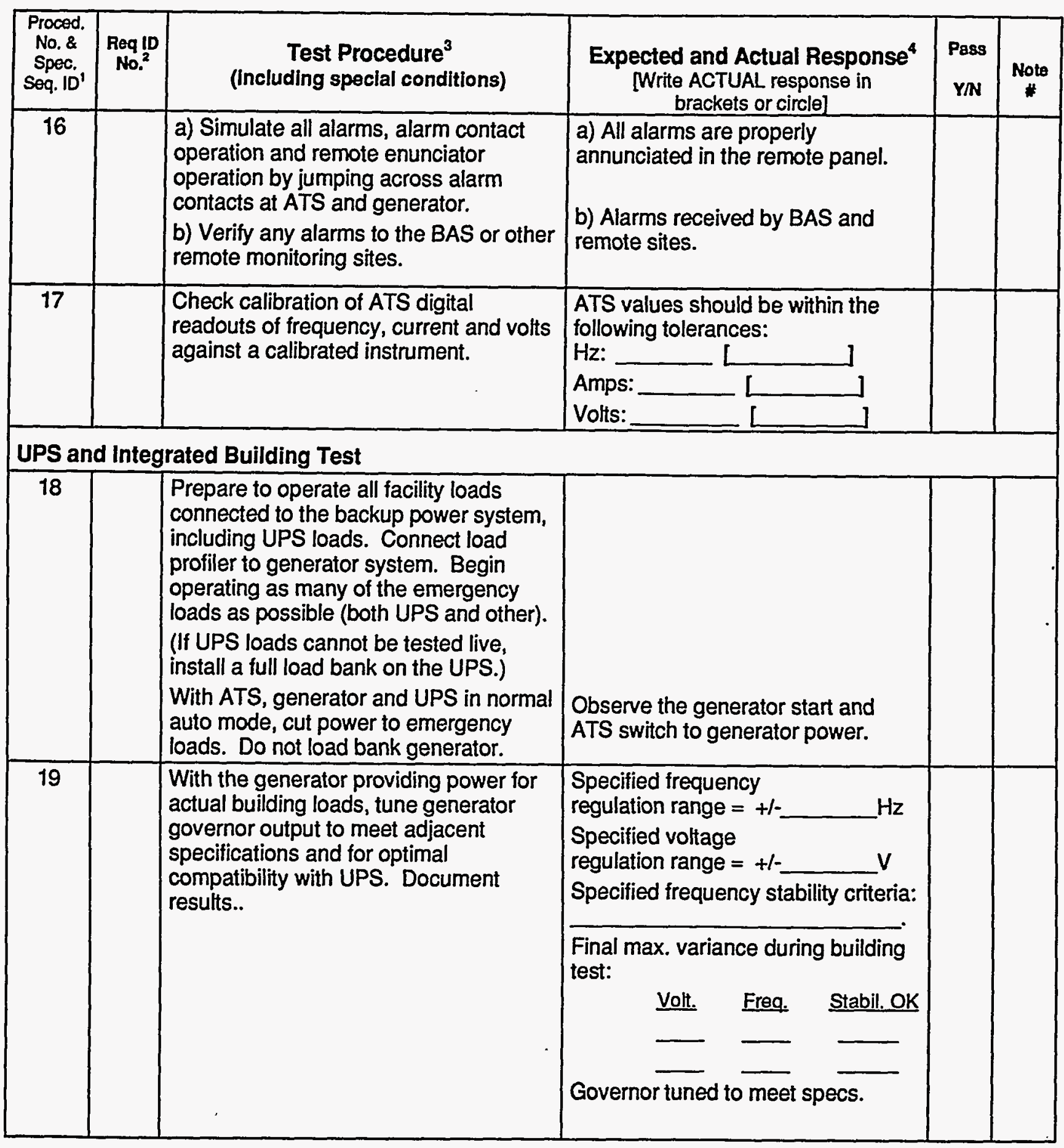

Notes: 


\begin{tabular}{|c|c|c|c|c|c|}
\hline $\begin{array}{l}\text { Proced. } \\
\text { No. \& } \\
\text { Spec. } \\
\text { Seq. ID' }\end{array}$ & $\begin{array}{c}\text { Req ID } \\
\text { No. }^{2}\end{array}$ & $\begin{array}{c}\text { Test Procedure } \\
\text { (including speclal conditions) }\end{array}$ & $\begin{array}{c}\text { Expected and Actual Response } \\
\text { [Write ACTUAL response in } \\
\text { brackets or circle] }\end{array}$ & $\begin{array}{l}\text { Pass } \\
\text { YNN }\end{array}$ & $\begin{array}{c}\text { Note } \\
*\end{array}$ \\
\hline 20 & & \begin{tabular}{|l|} 
UPS \\
Connect load profiler to UPS and \\
monitor the UPS load voltage, \\
frequency and amperage with load \\
profiler, through transition (dynamic) and \\
at steady state.
\end{tabular} & $\begin{array}{l}\text { Verify UPS goes back to generator } \\
\text { power (off battery and stays off), per } \\
\text { spec. } \\
\text { Verify that specified voltage } \\
\text { dynamic regulation is met: } \\
\text { Dynamic voltage overshoot should } \\
\text { be within } \\
\text { Actual: } \\
\text { Steady-state voltage variation } \\
\text { should be within }+1 \text { - } \\
\text { Actual: } \\
\text { Frequency overshoot should be } \\
\text { within } \\
\text { Actual: } \\
\text { THD should be less than } 5 \% \\
\text { Wave form deviation should be } \\
\text { minimal. }\end{array}$ & & \\
\hline $20 \mathrm{a}$ & & $\begin{array}{l}\text { Measure the amperage of each phase } \\
\text { off the UPS. Verify that they are } \\
\text { balanced. }\end{array}$ & $\begin{array}{l}\text { Phase } A=[ \\
\text { Phase } B=[ \\
\text { Phase } C=[ \\
\text { Phase imbalance is within }]\end{array}$ & & \\
\hline 21 & & $\begin{array}{l}\text { Tune UPS opening and closing of } \\
\text { frequency window and slew rate. }\end{array}$ & UPS tuned. & & \\
\hline 22 & & $\begin{array}{l}\text { Simulate all alarms, alarm contact } \\
\text { operation and remote enunciator } \\
\text { operation by jumping across alarms. } \\
\text { List. }\end{array}$ & All alarms are properly annunciated. & & \\
\hline 23 & & $\begin{array}{l}\text { Change ATS to manual and cut } \\
\text { emergency power to UPS. Monitor } \\
\text { UPS. Allow batteries to drain } 25 \% \text { or } \\
\text { more. }\end{array}$ & $\begin{array}{l}\text { Observe that loaded UPS provides } \\
\text { sufficient power. }\end{array}$ & & \\
\hline 24 & & Restore emergency power to UPS. & $\begin{array}{l}\text { Verify that UPS is charging properly } \\
\text { from the generator. }\end{array}$ & & \\
\hline 25 & & Verify function of UPS bypasses. & Bypasses function per spec. & & \\
\hline
\end{tabular}

Notes: 


\begin{tabular}{|c|c|c|c|c|c|}
\hline $\begin{array}{l}\text { Proced. } \\
\text { No. \& } \\
\text { Spec. } \\
\text { Soq. ID' }\end{array}$ & $\begin{array}{c}\text { Req ID } \\
\text { No. }^{2}\end{array}$ & $\begin{array}{l}\text { Test Procedure } \\
\text { (including special conditions) }\end{array}$ & $\begin{array}{l}\text { Expected and Actual Response } \\
\text { [Write ACTUAL response in } \\
\text { brackets or circle] }\end{array}$ & $\begin{array}{l}\text { Pass } \\
\text { YNN }\end{array}$ & Noto \\
\hline 26 & & $\begin{array}{l}\text { Check calibration of UPS digital } \\
\text { readouts of frequency, current and volts } \\
\text { against a calibrated instrument. }\end{array}$ & $\begin{array}{l}\text { UPS values should be within the } \\
\text { following tolerances: } \\
\text { Hz: } \\
\text { Amps: } \\
\text { Volts: }\end{array}$ & & \\
\hline 27 & & $\begin{array}{l}\text { Building Test } \\
\text { Continuing from above, with generator, } \\
\text { ATS and UPS in auto and E-power } \\
\text { circuit open, test the function of all loads } \\
\text { on emergency power, including UPS } \\
\text { loads. } \\
\text { Verify that proper power is delivered to } \\
\text { each device listed in the emergency } \\
\text { panel schedules and that equipment } \\
\text { directly wired functions properly. } \\
\text { Monitor generator output manually every } \\
15 \text { minutes (voltage, amperage, } \\
\text { frequency). }\end{array}$ & $\begin{array}{l}\text { Generator should be nunning at less } \\
\text { than } 100 \% \text { load, L } \\
\text { UPS loads should properly operate } \\
\text { from generator and not transfer to } \\
\text { battery power. } \\
\text { Time Generator } \\
\end{array}$ & & \\
\hline 28 & & $\begin{array}{l}\text { Walk through building and observe that } \\
\text { all emergency lighting is ON. Compare } \\
\text { and reconcile with the prints, any areas } \\
\text { that are unusually dark. }\end{array}$ & $\begin{array}{l}\text { All loads are properly serviced with } \\
\text { power. Full listing and checkoff is } \\
\text { attached. }\end{array}$ & & \\
\hline 29 & & $\begin{array}{l}\text { Using the emergency panel schedule, } \\
\text { verify that any specialty emergency } \\
\text { lighting is ON (oral surgery, telecom, } \\
\text { engineer's room, electrical room, 2nd } \\
\text { floor procedure room lights, elevators). }\end{array}$ & $\begin{array}{l}\text { All loads are properly serviced with } \\
\text { power. Full listing and checkoff is } \\
\text { attached. }\end{array}$ & & \\
\hline 30 & & $\begin{array}{l}\text { Go to each emergency power receptacle } \\
\text { and verify proper power. }\end{array}$ & OK? & & \\
\hline 31 & & $\begin{array}{l}\text { Go to each specialty load on emergency } \\
\text { power and verify proper power and } \\
\text { function: }\end{array}$ & & & \\
\hline
\end{tabular}

Notes: 


\begin{tabular}{|c|c|c|c|c|c|}
\hline $\begin{array}{l}\text { Proced. } \\
\text { No. \& } \\
\text { Spec. } \\
\text { Seq. ID }\end{array}$ & $\begin{array}{c}\text { Req ID } \\
\text { No. }^{2}\end{array}$ & $\begin{array}{l}\text { Test Procedure } \\
\text { (including special conditions) }\end{array}$ & $\begin{array}{c}\text { Expected and Actual Response } \\
\text { [Write ACTUAL response in } \\
\text { brackets or circle] }\end{array}$ & $\begin{array}{l}\text { Pass } \\
\text { Y/N }\end{array}$ & $\begin{array}{c}\text { Nole } \\
*\end{array}$ \\
\hline $31 a$ & & $\begin{array}{l}\text { a. Security panel. Verify that it is } \\
\text { functioning by heating the Security Co. } \\
\text { stat in the Telecom room above its } \\
\text { alarm setpoint }(80 \mathrm{~F}) \text { and having } \\
\text { Security Co. fax the printout of the } \\
\text { trouble report. }\end{array}$ & OK? & & \\
\hline $31 b$ & & $\begin{array}{l}\text { b. Fire alarm panel. Verify that it } \\
\text { is functioning by initiating an alarm and } \\
\text { then resetting. }\end{array}$ & OK? & & \\
\hline $31 \mathrm{c}$ & & $\begin{array}{l}\text { c. Med-gas alarm. Derange the } \\
\text { system and verity that an alarm was } \\
\text { initiated. }\end{array}$ & OK? & & \\
\hline 31d & & \begin{tabular}{|l|} 
d. Dental chairs in rms. \\
to their outlets or try some functions. \\
\end{tabular} & OK? & & \\
\hline $31 e$ & & $\begin{array}{l}\text { e. Telecom HVAC. Using a heat } \\
\text { gun, increase the temperature at the } \\
\text { FCU-2 stat } 5 F \text { above its setpoint ( } \\
77 F \text { ). Observe FCU-2 and ACU-1 start } \\
\text { and deliver cool air to the room. } \\
\text { Remove heat and observe units cycle } \\
\text { OFF. }\end{array}$ & OK? & & \\
\hline $31 f$ & & $\begin{array}{l}\text { f. Telecom System. Verify that } \\
\text { telecom loads are functioning properly } \\
\text { under emergency power (unless UPS } \\
\text { had to be load banked). }\end{array}$ & OK? & & \\
\hline $31 \mathrm{~g}$ & & $\begin{array}{l}\text { g. Elevator. Test the elevator } \\
\text { recall function under emergency power. }\end{array}$ & $\begin{array}{l}\text { Elevator recalls per specified } \\
\text { sequences. }\end{array}$ & & \\
\hline
\end{tabular}

Notes: 


\begin{tabular}{|c|c|c|c|c|c|}
\hline $\begin{array}{l}\text { Proced. } \\
\text { No. \& } \\
\text { Spec. } \\
\text { Seq. ID' }\end{array}$ & $\begin{array}{c}\text { Req ID } \\
\text { No. }^{2}\end{array}$ & $\begin{array}{l}\text { Test Procedure } \\
\text { (Including speclal conditions) }\end{array}$ & $\begin{array}{c}\text { Expected and Actual Response } \\
\text { Write ACTUAL response in } \\
\text { brackets or circle] }\end{array}$ & $\begin{array}{l}\text { Pass } \\
\text { Y/N }\end{array}$ & $\begin{array}{c}\text { Note } \\
*\end{array}$ \\
\hline 32 & & $\begin{array}{l}\text { UPS Monitored Alarms. The following } \\
\text { alarms are monitored by the Security } \\
\text { Co. Verify their function by causing the } \\
\text { alarm, recording the time and having } \\
\text { Security Co. fax a copy of the alarm } \\
\text { report. } \\
\text { a) Electrical failure. Simulate an } \\
\text { electrical failure or malfunction. } \\
\text { b) Detection of power being } \\
\text { switched to the UPS. Verify during one } \\
\text { of the previous transfers. } \\
\text { c) Low Battery. Simulate a low } \\
\text { battery condition. } \\
\text { d) Space temperature above } \\
\text { alarm setpoint. Heat stat above } \\
\text { setpoint. }\end{array}$ & OK? & & \\
\hline
\end{tabular}

Notes: 


\begin{tabular}{|c|c|c|c|c|c|}
\hline $\begin{array}{l}\text { Proced. } \\
\text { No. \& } \\
\text { Spec. } \\
\text { Seq. ID }\end{array}$ & $\begin{array}{c}\text { Req ID } \\
\text { No. }^{2}\end{array}$ & $\begin{array}{l}\text { Test Procedure } \\
\text { (Including special conditions) }\end{array}$ & $\begin{array}{c}\text { Expected and Actual Response } \\
\text { [Write ACTUAL response in } \\
\text { brackets or circle] }\end{array}$ & $\begin{array}{l}\text { Pass } \\
\text { Y/N }\end{array}$ & $\begin{array}{l}\text { Noto } \\
\#\end{array}$ \\
\hline 33 & & \multicolumn{2}{|c|}{$\begin{array}{l}\text { As necessary, provide any attachments and a written report beyond this test } \\
\text { form comparing measurement data with factory and project specifications, in } \\
\text { areas that do not comply or where additional documentation or explanation is } \\
\text { necessary. }\end{array}$} & & \\
\hline 34 & - & $\begin{array}{l}\text { Return all changed control } \\
\text { parameters and conditions to their } \\
\text { pre-test values }\end{array}$ & & & \\
\hline
\end{tabular}

${ }^{1}$ Sequences of operation attached to this test.

${ }^{2}$ Mode or function ID being tested from testing requirements section of the project Specifications.

${ }^{3}$ Step-by-step procedures for manual testing, trend logging or data-logger monitoring.

${ }^{4}$ Include tolerances for a passing condition. Fill-in spaces or lines not in brackets denote sequence parameters still to be speciffled by the AVE, conrols contractor or vendor. Write "Via BAS" for verifications of device position from BAS readout or "Via obs" for actual obsenation or from test instrument reading.

${ }^{6}$ Record any permanently changed parameter values and submit changes to Owner.

\section{A SUMMARY OF DEFICIENCIES IDENTIFIED DURING TESTING IS ATTACHED - END OF TEST -}

Notes: 


\section{Functional Test}

\section{Project:}

\section{FT-___ EXTERIOR LIGHTING CONTROLS}

\section{Participants}

Party

Participation

Party filling out this form and witnessing testing

Date of test

\section{Prerequisite Checklist}

a. All control system functions for this and all interlocking systems are programmed and operable per contract documents, including final setpoints, schedules, debugging and fine tuning of photo-cell parameters.

\section{Controls Contractor Signature or Verbal $\overline{\text { Date }}$}

b. _ All A/E punchlist items for this equipment corrected.

c. - Safeties and operating ranges reviewed.

d. - Test requirements and sequences of operation attached.

e. - Schedules and setpoints attached.

f. - Have all energy savings control strategies, setpoints and schedules been incorporated that this equipment and control system are capable of? If not, list recommendations below.

g. - BAS Program Review. Review the BAS software control program(s) for this equipment. Parameters, setpoints and logic sequences appear to follow the specified written sequences.

h. - Schedule of fixtures on each control type (Parking or Security) has been reviewed.

i. _- Record of All Values for Current Setpoints (SP), Control Parameters, Limits, Delays, Lockouts, Schedules, Etc. Changed to Accommodate Testing:

\begin{tabular}{|l|l|l|}
\hline \multicolumn{1}{|c|}{ Parameter } & \multicolumn{1}{|c|}{$\begin{array}{c}\text { Pro-Test } \\
\text { Values }\end{array}$} & $\begin{array}{c}\text { Retumed } \\
\text { to Pre-Test } \\
\text { Values V }\end{array}$ \\
\hline $\begin{array}{l}\text { Parking lot lights } \\
\text { schedule }\end{array}$ & $\begin{array}{l}\text { ON by photo } \\
\text { cell } \\
\text { OFF by sched: }\end{array}$ & \\
\hline $\begin{array}{l}\text { Photo-cell BAS } \\
\text { parameters }\end{array}$ & & \\
\hline
\end{tabular}

\begin{tabular}{|l|l|l|}
\hline \multicolumn{1}{|c|}{ Parameter } & Pre-Test Values & $\begin{array}{c}\text { Retumed } \\
\text { to Pro-Test } \\
\text { Values } \checkmark\end{array}$ \\
\hline $\begin{array}{l}\text { Exterior security } \\
\text { lights schedule }\end{array}$ & $\begin{array}{l}\text { ON by photo } \\
\text { cell } \\
\text { QFF by photo- } \\
\text { cell }\end{array}$ & \\
\hline & & \\
\hline
\end{tabular}

Notes: 
3. Sensor Calibration Checks. Check the sensors listed below for calibration and adequate location. This is a sampling check of calibrations done during prefunctional checklisting. Test the packaged controls and BAS readings. -NONE-

\section{Device Calibration Checks.}

- NONE-

\section{Verification of Misc. Prefunctional Checks.}

Misc. site checks of the prefunctional checklist and startup reports completed successfully. Pass? Y / N Photo-cell (PC) mounted securely. _ PC mounted where it won't be tampered with. won't become dirty easily. PC accessible for servicing.

\section{Functional Testing Record}

\begin{tabular}{|c|c|c|c|c|}
\hline $\begin{array}{l}\text { Proced. } \\
\text { No. \& } \\
\text { Spoc. } \\
\text { Sog. ID' }\end{array}$ & $\begin{array}{c}\text { Req ID } \\
\text { No. }^{2}\end{array}$ & $\begin{array}{c}\text { Test Procedure } \\
\text { (including special conditions) }\end{array}$ & $\begin{array}{c}\begin{array}{c}\text { Expected and Actual Response } \\
\text { [Write ACTUAL response in } \\
\text { brackets or circle] }\end{array} \\
\end{array}$ & $\begin{array}{c}\text { Pass } \\
\text { YNN } \\
\text { \& Note } \\
\text { \# }\end{array}$ \\
\hline 1 & & $\begin{array}{l}\text { Near dusk, observe exterior lights until they } \\
\text { come ON. } \\
\text { (Witnessed by Owner's Rep: }\end{array}$ & $\begin{array}{l}\text { All exterior lights come on at dusk, } \\
\text { before dark, but not when still very } \\
\text { light. }\end{array}$ & \\
\hline 2 & & $\begin{array}{l}\text { a) Change the Parking Lot light schedule } \\
\text { OFF to be in } 5 \text { minutes. } \\
\text { b) Return schedule to normal. }\end{array}$ & $\begin{array}{l}\text { a) Observe that the parking lot } \\
\text { lights, designated by the approved } \\
\text { schedule, shut OFF. Designated } \\
\text { signage remains ON. } \\
\text { b) Schedule returned to normal. }\end{array}$ & \\
\hline 3 & & $\begin{array}{l}\text { Before daylight in the morning, observe the } \\
\text { security lights ON. Wait until dawn. } \\
\text { (Witnessed by Owner's Rep: }\end{array}$ & $\begin{array}{l}\text { When sufficiently light, Security } \\
\text { Lights and signage lights shut } \\
\text { OFF. }\end{array}$ & \\
\hline 4 & - & $\begin{array}{l}\text { Return all changed control parameters } \\
\text { and conditions to their pre-test values }\end{array}$ & $\begin{array}{l}\text { Check off in Section } 2 \text { above } \\
\text { when completed }\end{array}$ & \\
\hline
\end{tabular}

Record Foot Notes

Sequences of operation specified in Contract Documents (attached).

${ }^{2}$ Mode or function ID being tested, per testing requirements section of the project Specifications.

${ }^{3}$ Step-by-step procedures for manual testing, trend logging or data-logger monitoring.

${ }^{4}$ Include tolerances for a passing condition.

${ }^{5}$ Record any permanently changed parameter values and submit to Owner.

Notes: 


\section{Functional Performance Test}

\section{Lighting Sweep}

Project

Date

Commissioning

Operator executing sweeps of

1. Sweep Controller Type: controllers (give quantity), Brand and model: Type of system: Sweeps off lights until morning. Override timers allow zones to be turned back on.

Sweeps off lights. Any light can than be turned back on by a: standard switch, __ phone call within building separate PC system, stand-alone part of EMS, stand-alone integrated into EMS.

2. Documentation. Verify that full documentation of the controller is permanently on site and includes the following: specifications and features

list of loads and zones each relay controls attached*

_ contact number for additional assistance attached*

_ current written list of sweep schedules for all zones attached*

_ programming instructions attached* controller warranty (in submittals) written instructions for tenants in using the local overrides and a description of the areas they control

*Attached = attached to the controller panel door or if PC computer controlled, in documentation manual

3. Training. If there is a full-time building operator in the building or building complex, they must be trained to fully understand the programming of the sweep controls, the operation of the total override and of the local overrides and have access to the system's full documentation. Full-time operator? No

If Yes, installing contractor performing training

If Yes, individual trained as the "operator"

Review and approve the written instructions distributed to the tenants regarding the operation of the local overrides. Approved and distributed: __ Yes ___ No

4. Verification of capabilities and performance. Verify that the controller has the following features and capabilities: (check-mark denotes acceptance)

4.1. Programming capabilities via keypad or EMS interface. Verify by running through the current program and schedules.

4.2. Back-up power supply (automatically recharged) that will retain program for ___ weeks without power. Verify by viewing specifications and battery pack.

4.3. Lockable controller enclosure or room with key or code-only access for programming and total override or access is in a restricted PC program.

4.4. The controlling time clock is reading the appropriate time. 
4.5. Override duration set to not more than 2 hours

4.6. Each override as tested below, energizes no more than 5000 sf of floor area.

4.7. Verify actual sweep and override operation of each controller as per table below.

Sweep Operation Verification

\begin{tabular}{|c|c|c|c|c|c|}
\hline \multirow{3}{*}{$\begin{array}{l}\text { Day Type and } \\
\text { Sweep No. }\end{array}$} & \multicolumn{5}{|c|}{ Schedule of Sweeps (hour of day) } \\
\hline & ID: & ID: & ID: & ID: & ID: \\
\hline & Relay ID: & Relay ID: & Relay ID: & Relay ID: & Relay ID: \\
\hline Weekdays 1 & & & & & \\
\hline (enter schedules 2 & & & & & \\
\hline In these rows) 3 & & & & & \\
\hline Saturday 1 & & & & & \\
\hline 2 & & & & & \\
\hline $\begin{array}{ll}\text { Sunday } & 1\end{array}$ & & & & & \\
\hline 2 & & & & & \\
\hline $\begin{array}{l}\text { Fixtures/rooms } \\
\text { excluded from } \\
\text { sweep }\end{array}$ & & & & & \\
\hline $\begin{array}{l}\text { Sweep verification } \\
\text { type }^{1}\end{array}$ & & & & & \\
\hline $\begin{array}{l}\text { No. of local } \\
\text { override switches } \\
\text { (actual / spec'd) }\end{array}$ & & & & & \\
\hline $\begin{array}{l}\text { No. of override } \\
\text { switches tested } 2\end{array}$ & & & & & \\
\hline
\end{tabular}

\section{Test Procedures}

1 Sweeps. $50 \%$ of the zones with a minimum of 2 zones per controller or relay must be verified by turning on at least $25 \%$ of the lights in the zone and witnessing an actual sweep. The remainder of the zones must have the programming of their schedules verified.

In the table above, enter all of the following codes that apply:

$\mathbf{0}=$ not verified, $\mathbf{S}=$ verified Schedule in keypad or EMS display, $\mathbf{W}=$ verified operation by Witnessing a sweeping off of the lights at a special scheduled time, $F=$ witnessed sweep, but sweep Failed to function properly. Refer to comments.

2 Overrides. $25 \%$ of the local override switches with a minimum of 4 overrides must be verified by turning the override switches on after a sweep and seeing the lights turn back on. $100 \%$ of the remainder of the switches should be sight verified to be in place. For each Zone, enter the number of override switches where functionality was actually witnessed. Verify that the local override only controls the specified zone.

\section{Comments:}




\section{COMMISSIONING GUIDE SPECIFICATIONS}

\section{SECTION 17100 COMMISSIONING REQUIREMENTS}

\section{Spec writer:}

The following guide specifications are intended to be reviewed and modified to meet the specific commissioning needs and requirements for the current project and systems. Any modifications to this specification shall only be made after consultation with the Owner's representative and with approval of the engineer of record. Where there are check boxes or fill-in blanks, fill in as appropriate and delete all but the choice(s) that apply. Delete all direction boxes.

TABLE OF CONTENTS (with selected subsections)

1.1 Description

A. Commissioning definition

C. Abbreviations

1.2 Coordination
A. Commissioning team
B. Management
C. Scheduling

1.3 Commissioning Process
A. Commissioning plan
B. Commissioning process

1.4 Related Work
A. Related commissioning sections

1.5 Responsibilities
A. Overview
B. All parties
C. Architect
D. Mechanical and Electrical Designers
E. Commissioning Agent
F. Construction Manager-Owner's Representative
G. Owner's Project Manager
H. General Contractor
I. Equipment Suppliers

\subsection{Definitions}

1.7 Systems to be Commissioned 
2.1 Test Equipment

3.1 Meetings

3.2 Reporting

3.3 Submittals

3.4 Startup, Prefunctional Checklists and Initial Checkout
A. Application
B. General
C. Startup Plan
D. Sensor Calibrations
E. Execution
F. Deficiencies and Approvals

3.5 Phased Commissioning

3.6 Functional Performance Testing

D. Objectives and Scope

E. Development of Test Procedures

F. Test Methods

G. Coordination and Scheduling

H. Test Equipment

I. Problem Solving

3.7 Documentation, Non-Conformance and Approval of Tests
A. Documentation
B. Non-Conformance
C. Failure due to Manufacturer Defect
D. Approval

3.8 Operation and Maintenance (O \& M) Manuals
A. Standard O\&M Manuals
B. Commissioning Record in O\&M Manuals

3.9 Training of Owner Personnel

3.10 Deferred Testing

\subsection{Written Work Products}




\section{PART 1 - GENERAL}

\subsection{DESCRIPTION}

A. Commissioning. Commissioning is a systematic process of ensuring that all building systems perform interactively according to the design intent and the owner's operational needs. This is achieved by beginning in the design phase and documenting design intent and continuing through construction, acceptance and the warranty period with actual verification of performance. The commissioning process shall encompass and coordinate the traditionally separate functions of system documentation, equipment startup, control system calibration, testing and balancing, performance testing and training.

Commissioning during the construction phase is intended to achieve the following specific objectives according to the Contract Documents:

1) Verify that applicable equipment and systems are installed according to the manufacturer's recommendations and to industry accepted minimum standards and that they receive adequate operational checkout by installing contractors.

2) Verify and document proper performance of equipment and systems.

3) Verify that O\&M documentation left on site is complete.

4) Verify that the Owner's operating personnel are adequately trained.

B. The commissioning process does not take away from or reduce the responsibility of the system designers or installing contractors to provide a finished and fully functioning product.

C. Abbreviations. The following are common abbreviations used in the Specifications and in the Commissioning Plan. Definitions are found in Section 1.6.

A/E- Architect and design engineers

CA- Commissioning agent

CC Controls contractor

CM- Construction Manager (GSA's representative)

$\mathrm{Cx}$ - Commissioning

Cx Plan- Commissioning Plan document

EC- Electrical contractor
FT- Functional performance test

GC- General contractor (prime)

MC- Mechanical contractor

PC- Prefunctional checklist

PM- Project manager (of GSA)

Subs- Subcontractors to General

TAB- Test and balance contractor 


\subsection{COORDINATION}

A. Commissioning Team. The members of the commissioning team consist of the Commissioning Agent (CA), the GSA Project Manager (PM), the designated representative of the owner's (GSA) Construction Management firm (CM), the General Contractor (GC or Contractor), the architect and design engineers (particularly the mechanical engineer), the Mechanical Contractor (MC), the Electrical Contractor (EC), the TAB representative, the Controls Contractor (CC), any other installing subcontractors or suppliers of equipment. If known, the Owner's building or plant operator/engineer is also a member of the commissioning team.

B. Management. The CA is hired by the CM, GC, A/E, GSA directly. The CA directs and coordinates the commissioning activities and the reports to the $\quad \mathrm{CM}, \quad$ is part of the CM team. All members work together to fulfill their contracted responsibilities and meet the objectives of the Contract Documents. The CA's responsibilities are the same regardless of who hired the CA. Refer to Section 17100 Part 1.6 for additional management details. The following organization chart clarifies the roles.

The following organization charts may assist in making it clear how the CA fits into the management plan for this project. Use or modify one of these in the

Specifications and delete the others.

\section{CA Hired by the GC, Reporting to the CM}

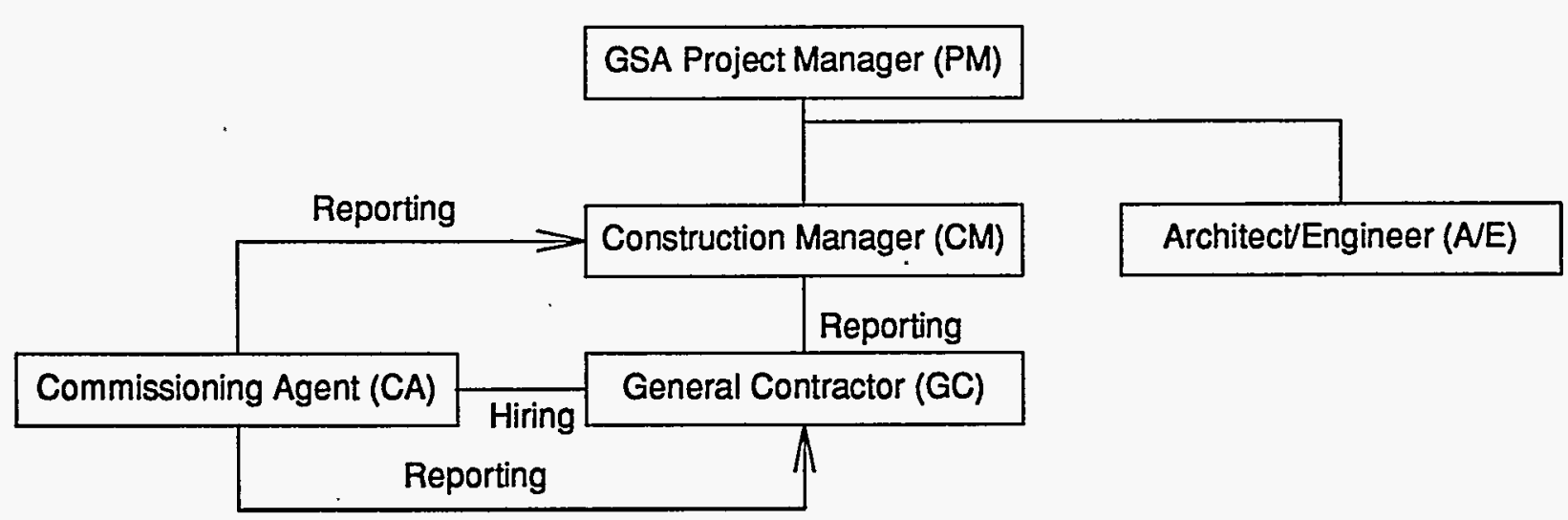




\section{CA Hired by the A/E, Reporting to the CM}

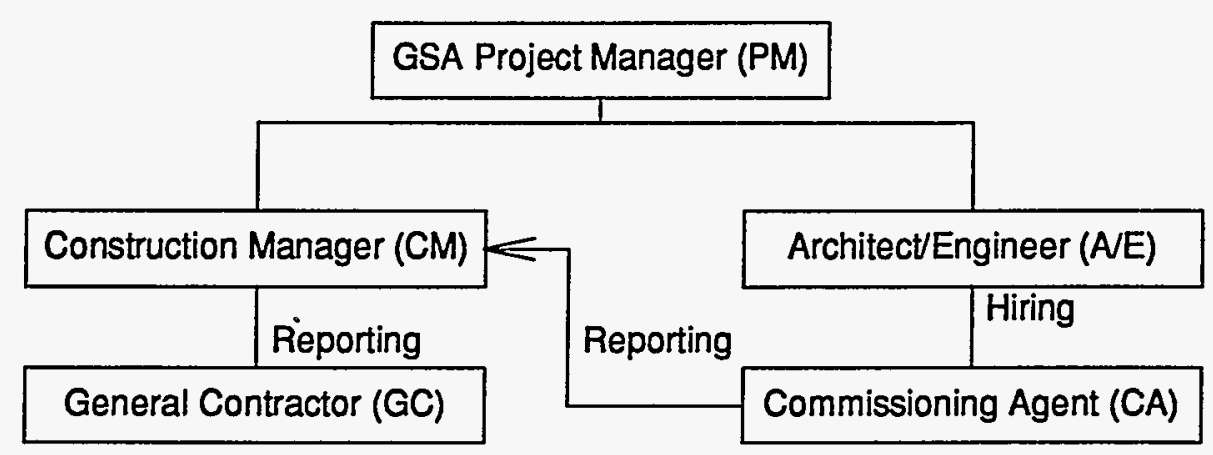

CA Hired by the CM, or Directly by GSA

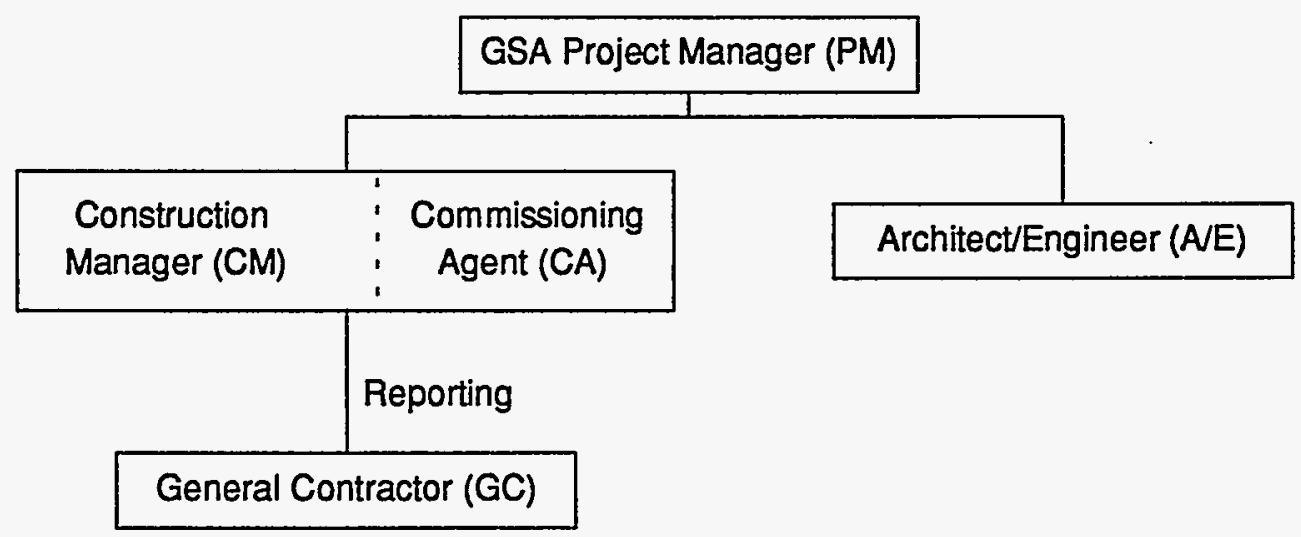

C. Scheduling. The $\mathrm{CA}$ will work with the $\mathrm{CM}$ and $\mathrm{GC}$ according to established protocols to schedule the commissioning activities. The CA will provide sufficient notice to the $\mathrm{CM}$ and $\mathrm{GC}$ for scheduling commissioning activities. The GC will integrate all commissioning activities into the master schedule. All parties will address scheduling problems and make necessary notifications in a timely manner in order to expedite the commissioning process.

The CA will provide the initial schedule of primary commissioning events at the commissioning scoping meeting. The Commissioning Plan-Construction Phase provides a format for this schedule. As construction progresses more detailed schedules are developed by the $\mathrm{CA}$. The Commissioning Plan also provides a format for detailed schedules. 


\subsection{COMMISSIONING PROCESS}

\section{Spec writer:}

If no commissioning plan was issued at bidding, delete the first sentence of the following paragraph

A. Commissioning Plan. The Commissioning Plan, Draft 2, provided as part of the bid documents, is binding on the Contractor. The commissioning plan provides guidance in the execution of the commissioning process. Just after the initial commissioning scoping meeting the CA will update the plan which is then considered the "final" plan, though it will continue to evolve and expand as the project progresses. The Specifications will take precedence over the Commissioning Plan.

B. Commissioning Process. The following narrative provides a brief overview of the typical commissioning tasks during construction and the general order in which they occur.

1. Commissioning during construction begins with a scoping meeting conducted by the CA where the commissioning process is reviewed with the commissioning team members.

2. Additional meetings will be required throughout construction, scheduled by the CA with necessary parties attending, to plan, scope, coordinate, schedule future activities and resolve problems.

3. Equipment documentation is submitted to the CA during normal submittals, including detailed start-up procedures.

4. The CA works with the Subs in developing startup plans and startup documentation formats, including providing the Subs with prefunctional checklists to be completed, during the startup process.

5. In general, the checkout and performance verification proceeds from simple to complex; from component level to equipment to systems and intersystem levels with prefunctional checklists being completed before functional testing.

6. The Subs, under their own direction, execute and document the prefunctional checklists and perform startup and initial checkout. The CA documents that the checklists and startup were completed according to the approved plans. This may include the CA witnessing start-up of selected equipment.

7. The CA develops specific equipment and system functional performance test procedures. The Subs review the procedures.

8. The procedures are executed by the Subs, under the direction of, and documented by the CA.

9. Items of non-compliance in material, installation or setup are corrected at the Sub's expense and the system retested.

10. The $C A$ reviews the $O \& M$ documentation for completeness.

11. Commissioning is completed before Substantial Completion.

12. The $\mathrm{CA}$ reviews, pre-approves and coordinates the training provided by the Subs and verifies that is was completed.

13. Deferred testing is conducted, as specified or required.

\subsection{RELATED WORK}

A. Specific commissioning requirements are given in the following sections of these specifications. All of the following sections apply to the Work of this section. 
00800 Supplementary Conditions Provides for a penalty if commissioning is not completed by the Functional Completion milestone.

* If the commissioning agent is hired by the owner or construction manager, 01040a applies:

01040a Coordination Introduces commissioning and refers to Division 17.

* If the commissioning agent is hired by the general contractor, $01040 \mathrm{~b}$ applies:

01040b Coordination

01300 Submittals

01700 Project Close-out

01730 O\&M Data

15010 Mechanical General

15950 Automatic Controls

15990 TAB

15995 Mechanical Cx

15997 Mechanical Testing Requirements

15998 Mechanical Prefunctional Checklists

15999 Mechanical Functional Tests-Examples

16010 Electrical General

16995 Electrical $\mathrm{Cx}$

16997 Electrical Testing

16998 Electrical Prefunctional Checklists
Introduces commissioning, refers to Division 17 and requires that the $G C$ hire a qualified $C A$.

Alerts all parties that additional detail in submittals may be required and directs to Division 17.

Defines Substantial Completion and Functional Completion milestones, relative to commissioning.

Alerts all parties that O\&M documentation may be more detailed and directs to Division 17.

Alerts the mechanical contractor to $\mathrm{Cx}$ responsibilities in 15995.

Lists special requirements and alerts the controls contractor of the special requirements of the control contractor and control system in 15995.

Alerts the TAB of $\mathrm{Cx}$ responsibilities in 15995.

Describes the $C x$ responsibilities of the mechanical, controls and $\mathrm{TAB}$ contractors and the prefunctional testing and startup responsibilities of each. Points to 15997 for functional testing requirements.

Describes the specific functional testing requirements for Division 15 equipment in the project.

Provides the prefunctional checklists for use on this project, including items for Div. 15 and Div. 16.

Provides example functional test procedures and formats for mechanical equipment.

Alerts the electrical contractor of $\mathrm{Cx}$ responsibilities in $\mathbf{1 6 9 9 5}$.

Describes the $\mathrm{Cx}$ responsibilities of the electrical contractor.

Describes the specific functional testing requirements Requirements for Division 16 equipment in the project.

Points to Section 15998. 
16999 Electrical Functional Tests-Examples

17100 Commissioning
Provides example functional test procedures and formats for electrical equipment.

Describes the commissioning process, responsibilities common to all parties, responsibilities of the A/E, CA, CM, PM, GC and Suppliers, focusing on the $\mathrm{CA}$. The unique $\mathrm{MC}, \mathrm{CC}, \mathrm{TAB}$ and $\mathrm{EC}$ responsibilities are included in Div. 15 and 16.

Spec Writer: List other sections or divisions that have systems commissioned. Include alerts in Section 10 of the division, division commissioning responsibilities in section 995 of the division, and actual test requirements in section 997, all similar to Division 15 .

\subsection{RESPONSIBILITIES}

A. The responsibilities of various parties in the commissioning process are provided in this section. The responsibilities of the mechanical contractor, $\mathrm{TAB}$ and controls contractor are in Division 15 and those of the electrical contractor in Division 16 and those of list other sections where requirements of other divisions are found]. It is noted that the services for the GSA Project Manager, Construction Manager, Architect, HVAC mechanical and electrical designers/engineers, and Commissioning Agent are not provided for in this contract. That is, the Contractor is not responsible for providing their services. Their responsibilities are listed here to clarify the commissioning process.

If the CA is hired by the GC or AVE, delete "Commissioning Agent" in the above paragraph.

Spec writer should make sure that language in the contract and general conditions states that the contractors are paying for their part in the commissioning and testing; the Owner is not paying as an extra.

\section{Spec writer:}

If no commissioning plan was issued at bidding, delete item number 1 under $B$, "Follow the Commissioning Plan."

\section{B. All Parties}

1. Follow the Commissioning Plan.

2. Attend commissioning scoping meeting and additional meetings, as necessary.

C. Architect (of A/E)

Construction and Acceptance Phase

1. Manage the CA contract,_ GC manages the CA contract, __ CM or GSA manages the $\mathrm{CA}$ contract. 
2. Attend the commissioning scoping meeting and selected commissioning team meetings.

3. Perform normal submittal review, construction observation, as-built drawing preparation, O\&M manual preparation, etc., as contracted.

4. Provide any design narrative documentation requested by the $\mathrm{CA}$.

5. Coordinate resolution of system deficiencies identified during commissioning, according to the contract documents.

6. Prepare and submit final as-built design intent documentation for inclusion in the O\&M manuals. Review and approve the O\&M manuals.

\section{Warranty Period}

1. Coordinate resolution of design non-conformance and design deficiencies identified during warranty-period commissioning.

\section{Mechanical and Electrical Designers/Engineers (of the A/E)}

\section{Construction and Acceptance Phase}

1. Perform normal submittal review, construction observation, as-built drawing preparation, etc., as contracted. One site observation should be completed just prior to system startup.

2. Provide any design narrative and sequences documentation requested by the $\mathrm{CA}$. The designers shall assist (along with the contractors) in clarifying the operation and control of commissioned equipment in areas where the specifications, control drawings or equipment documentation is not sufficient for writing detailed testing procedures.

3. Attend commissioning scoping meetings and other selected commissioning team meetings.

4. Participate in the resolution of system deficiencies identified during commissioning, according to the contract documents.

5. Prepare and submit the final as-built design intent and operating parameters documentation for inclusion in the O\&M manuals. Review and approve the O\&M manuals.

6. Provide a presentation at the first training session for the Owner's personnel.

OPTIONAL:

7. - Review, _ Approve the prefunctional checklists for major pieces of equipment for sufficiency prior to their use.

8. _Review, _ Approve the functional test procedure forms for major pieces of equipment for sufficiency prior to their use.

9. Witness testing of selected pieces of equipment and systems:

\section{Warranty Period}

1. Participate in the resolution of non-compliance, non-conformance and design deficiencies identified during commissioning during warranty-period commissioning.

\section{Spec writer:}

If no commissioning plan was issued at bidding, modify as appropriate, any references to the commissioning plan throughout the rest of this section. 


\section{E. Commissioning Agent (CA)}

The CA is not responsible for design concept, design criteria, compliance with codes, design or general construction scheduling, cost estimating, or construction management. The CA may assist with problem-solving non-conformance or deficiencies, but ultimately that responsibility resides with the general contractor and the $\mathrm{A} / \mathrm{E}$. The primary role of the $\mathrm{CA}$ is to develop and coordinate the execution of a testing plan, observe and document performance-that systems are functioning in accordance with the documented design intent and in accordance with the Contract Documents. The Contractors will provide all tools or the use of tools to start, check-out and functionally test equipment and systems, except for specified testing with portable data-loggers, which shall be supplied and installed by the $\mathrm{CA}$.

\section{Construction and Acceptance Phase}

1. Coordinates and directs the commissioning activities in a logical, sequential and efficient manner using consistent protocols and forms, centralized documentation, clear and regular communications and consultations with all necessary parties, frequently updated timelines and schedules and technical expertise.

2. Coordinate the commissioning work and, with the $\mathrm{GC}$ and $\mathrm{CM}$, ensure that commissioning activities are being scheduled into the master schedule.

3. Revise, as necessary, the Draft 2, Commissioning Plan-Construction Phase.

4. Plan and conduct a commissioning scoping meeting.

5. Request and review additional information required to perform commissioning tasks, including O\&M materials, contractor start-up and checkout procedures.

6. Before startup, gather and review the current control sequences and interlocks and work with contractors and design engineers until sufficient clarity has been obtained, in writing, to be able to write detailed testing procedures.

7. Review and approve normal Contractor submittals applicable to systems being commissioned for compliance with commissioning needs, concurrent with the A/E reviews.

8. Write and distribute prefunctional tests and checklists.

9. Develop an enhanced start-up and initial systems checkout plan with Subs.

10. Perform site visits, as necessary, to observe component and system installations. Attend s selected planning and job-site meetings to obtain information on construction progress.

Review construction meeting minutes for revisions/substitutions relating to the commissioning process. Assist in resolving any discrepancies.

11. Witness all or part of the HVAC piping test and flushing procedure, sufficient to be confident that proper procedures were followed. Document this testing and include the documentation in O\&M manuals. Notify owners project manager of any deficiencies in results or procedures.

12. Witness all or part of any ductwork testing and cleaning procedures, sufficient to be confident that proper procedures were followed: Document this testing and include the documentation in O\&M manuals. Notify owner's project manager of any deficiencies in results or procedures.

13. Approve prefunctional tests and checklist completion by reviewing prefunctional checklist reports and by selected site observation and spot checking.

14. Approve systems startup by reviewing start-up reports and by selected site observation.

15. Review $\mathrm{TAB}$ execution plan.

16. Oversee sufficient functional testing of the control system and approve it to be used for TAB, before TAB is executed.

17. Approve air and water systems balancing by spot testing, by reviewing completed reports and by selected site observation.

18. With necessary assistance and review from installing contractors, write the functional performance test procedures for equipment and systems. This may include energy 
management control system trending, stand-alone datalogger monitoring or manual functional testing. Submit to CM for review, and for approval if required.

19. Analyze any functional performance trend logs and monitoring data to verify performance.

20. Coordinate, witness and approve manual functional performance tests performed by installing contractors. Coordinate retesting as necessary until satisfactory performance is achieved.

21. Maintain a master deficiency and resolution $\log$ and a separate testing record. Provide the $\mathrm{CM}$ with written progress reports and test results with recommended actions.

22. Witness performance testing of smoke control systems by others and all other owner contracted tests or tests by manufacturer's personnel over which the CA may not have direct control. Document these tests and include this documentation in Commissioning Record in O\&M manuals.

23. Review equipment warranties to ensure that the Owner's responsibilities are clearly defined.

24. Oversee and approve the training of the Owner's operating personnel.

25. Compile and maintain a commissioning record and building systems book(s).

26. Review and approve the preparation of the O\&M manuals.

27. Provide a final commissioning report.

\section{Warranty Period}

1. Coordinate and supervise required seasonal or deferred testing and deficiency corrections.

2. Return to the site at 10 months into the 12 month warranty period and review with facility staff the current building operation and the condition of outstanding issues related to the original and seasonal commissioning. Also interview facility staff and identify problems or concerns they have operating the building as originally intended. Make suggestions for improvements and for recording these changes in the O\&M manuals. Identify areas that may come under warranty or under the original construction contract. Assist facility staff in developing reports, documents and requests for services to remedy outstanding problems.

3. Optional: Assist in the development of a preventative maintenance plan, a detailed operating plan or an energy and resource management plan or as-built documentation.

\section{F. Construction Manager-O-Owner's Representative (CM)}

\section{Construction and Acceptance Phase}

1. Facilitate the coordination of the commissioning work by the $\mathrm{CA}$, and, with the $\mathrm{GC}$ and $\mathrm{CA}$, ensure that commissioning activities are being scheduled into the master schedule.

2. Review and approve the final Commissioning Plan-Construction Phase.

3. Attend a commissioning scoping meeting and other commissioning team meetings.

4. Perform the normal review of Contractor submittals.

5. Furnish a copy of all construction documents, addenda, change orders and approved submittals and shop drawings related to commissioned equipment to the $\mathrm{CA}$.

6. Review and approve the functional performance test procedures submitted by the $\mathrm{CA}$, prior to testing.

7. When necessary, observe and witness prefunctional checklists, startup and functional testing of selected equipment.

8. Review commissioning progress and deficiency reports.

9. Coordinate the resolution of non-compliance and design deficiencies identified in all phases of commissioning.

10. Sign-off (final approval) on individual commissioning tests as completed and passing. Recommend completion of the commissioning process to the Project Manager.

11. Assist the GC in coordinating the training of owner personnel. 
Note: If the CA is hired by the CM or directly by GSA, some or all of the CM tasks for the commissioning process above become the responsibility of the $\mathrm{CA}$, as the need for oversight of the CA is essentially eliminated. Refer to further detail in the CM definition in Section 1.6, except for the coordination of deficiency resolution.

\section{Warranty Period}
1. Assist the CA as necessary in the seasonal or deferred testing and deficiency corrections required by the specifications.

\section{G. Owner's Project Manager (PM)}

\section{Construction and Acceptance Phase}

1. Manage the contract of the $A / E$ and of the $G C$.

2. Arrange for facility operating and maintenance personnel to attend various field commissioning activities and field training sessions according to the Commissioning Plan-Construction Phase.

3. Provide final approval for the completion of the commissioning work.

\section{Warranty Period}

1. Ensure that any seasonal or deferred testing and any deficiency issues are addressed.

\section{H. General Contractor (GC)}

\section{Construction and Acceptance Phase}

1. Facilitate the coordination of the commissioning work by the $\mathrm{CA}$, and with the $\mathrm{GC}$ and $\mathrm{CA}$ ensure that commissioning activities are being scheduled into the master schedule.

2. Include the cost of commissioning in the contract price.

3. Furnish a copy of all construction documents, addenda, change orders and approved submittals and shop drawings related to commissioned equipment to the $\mathrm{CA}$.

4. In each purchase order or subcontract written, include requirements for submittal data, O\&M data, commissioning tasks and training.

5. Ensure that all Subs execute their commissioning responsibilities according to the Contract Documents and schedule.

6. A representative shall attend a commissioning scoping meeting and other necessary meetings scheduled by the $\mathrm{CA}$ to facilitate the $\mathrm{Cx}$ process.

7. Coordinate the training of owner personnel.

8. Prepare O\&M manuals, according to the Contract Documents, including clarifying and updating the original sequences of operation to as-built conditions.

\section{Warranty Period}

1. Ensure that Subs execute seasonal or deferred functional performance testing, witnessed by the $\mathrm{CA}$, according to the specifications.

2. Ensure that Subs correct deficiencies and make necessary adjustments to O\&M manuals and as-built drawings for applicable issues identified in any seasonal testing. 


\section{Equipment Suppliers}

1. Provide all requested submittal data, including detailed start-up procedures and specific responsibilities of the Owner to keep warranties in force.

2. Assist in equipment testing per agreements with Subs.

3. Include all special tools and instruments (only available from vendor, specific to a piece of equipment) required for testing equipment according to these Contract Documents in the base bid price to the Contractor, except for stand-alone datalogging equipment that may be used by the CA.

4. Provide information requested by $\mathrm{CA}$ regarding equipment sequence of operation and testing procedures.

5. Review test procedures for equipment installed by factory representatives.

\subsection{DEFINITIONS}

Acceptance Phase - phase of construction after startup and initial checkout when functional performance tests, O\&M documentation review and training occurs.

Approval - acceptance that a piece of equipment or system has been properly installed and is functioning in the tested modes according to the Contract Documents.

Architect / Engineer (A/E) - the prime consultant (architect) and sub-consultants who comprise the design team, generally the HVAC mechanical designer/engineer and the electrical designer/engineer.

Basis of Design - The basis of design is the documentation of the primary thought processes and assumptions behind design decisions that were made to meet the design intent. The basis of design describes the systems, components, conditions and methods chosen to meet the intent. Some reiterating of the design intent may be included.

Commissioning Agent (CA) - an independent agent, not otherwise associated with the A/E team members or the Contractor, though he/she may be hired as a subcontractor to them. The CA directs and coordinates the day-to-day commissioning activities. The $\mathrm{CA}$ does not take an oversight role like the CM. The CA is part of the Construction Manager (CM) team or shall report directly to the $C M$.

Commissioning Plan - an overall plan, developed before or after bidding, that provides the structure, schedule and coordination planning for the commissioning process.

Contract Documents - the documents binding on parties involved in the construction of this project (drawings, specifications, change orders, amendments, contracts, $C x$ Plan, etc.).

Contractor - the general contractor or authorized representative.

Control system - the central building energy management control system.

Construction Manager (CM) - a) the Owner's (GSA) representative in the day-to-day activities of construction. In general, the construction management services contractor (CM) is hired by GSA to assist the government in the overall management of the project including supervising and on-site managing authority over a project's construction. The General Contractor reports to the $\mathrm{CM}$. The CM is GSA's on-site representative.

b) When the $\mathrm{CA}$ is hired by the $\mathrm{GC}$ or $\mathrm{A} / \mathrm{E}$, the $\mathrm{CM}$ referred to in the commissioning process is a member of the $\mathrm{CM}$ team (staff or independent contractor) who shall have direct significant mechanical engineering and commissioning experience. That person designated from the $\mathrm{CM}$ team is the owner's representative verifying the adequacy of the commissioning process. In this case, the 


\section{SECTION $17100-14$ COMMISSIONING REQUIREMENTS}

$\mathrm{CM}$ will be more involved in the commissioning work and in witnessing portions of the process (selected start-up and functional tests) and reviewing documents (test approvals, etc.) than in the following case.

c) When the CA is hired by the CM (on staff or as a subcontractor), or directly by GSA, there may not need to be another $\mathrm{CM}$ representative reviewing and approving the work of the $\mathrm{CA}$, other than schedule approvals and consultation during problem solving. In that case, references to the $\mathrm{CM}$ in these Specifications would actually mean the CA, except that CA progress reports would go to the $\mathrm{PM}$ rather than the $\mathrm{CM}$.

Datalogging - monitoring flows, currents, status, pressures, etc. of equipment using stand-alone dataloggers separate from the control system.

Deferred Functional Tests - FTs that are performed later, after substantial completion, due to partial occupancy, equipment, seasonal requirements, design or other site conditions that disallow the test from being performed.

Deficiency - a condition in the installation or function of a component, piece of equipment or system that is not in compliance with the Contract Documents (that is, does not perform properly or is not complying with the design intent).

Design Intent - a dynamic document that provides the explanation of the ideas, concepts and criteria that are considered to be very important to the owner. It is initially the outcome of the programming and conceptual design phases.

Design Narrative or Design Documentation - sections of either the Design Intent or Basis of Design.

Factory Testing - testing of equipment on-site or at the factory by factory personnel with an Owner's representative present.

Functional Performance Test (FT) - test of the dynamic function and operation of equipment and systems using manual (direct observation) or monitoring methods. Functional testing is the dynamic testing of systems (rather than just components) under full operation (e.g., the chiller pump is tested interactively with the chiller functions to see if the pump ramps up and down to maintain the differential pressure setpoint). Systems are tested under various modes, such as during low cooling or heating loads, high loads, component failures, unoccupied, varying outside air temperatures, fire alarm, power failure, etc. The systems are run through all the control system's sequences of operation and components are verified to be responding as the sequences state. Traditional air or water test and balancing (TAB) is not functional testing, in the commissioning sense of the word. TAB's primary work is setting up the system flows and pressures as specified, while functional testing is verifying that which has already been set up. The commissioning agent develops the functional test procedures in a sequential written form, coordinates, oversees and documents the actual testing, which is usually performed by the installing contractor or vendor. FTs are performed after prefunctional checklists and startup are complete.

General Contractor (GC) - the prime contractor for this project. Generally refers to all the GC's subcontractors as well. Also referred to as the Contractor, in some contexts.

GSA - the General Services Administration (of the Federal Government)-the owner.

Indirect Indicators - indicators of a response or condition, such as a reading from a control system screen reporting a damper to be $100 \%$ closed.

Manual Test - using hand-held instruments, immediate control system readouts or direct observation to verify performance (contrasted to analyzing monitored data taken over time to make the "observation").

Monitoring - the recording of parameters (flow, current, status, pressure, etc.) of equipment operation using dataloggers or the trending capabilities of control systems.

Non-Compliance - see Deficiency.

Non-Conformance - see Deficiency. 
Over-written Value - writing over a sensor value in the control system to see the response of a system (e.g., changing the outside air temperature value from $50 \mathrm{~F}$ to $75 \mathrm{~F}$ to verify economizer operation). See also "Simulated Signal."

Owner-Contracted Tests - tests paid for by the Owner outside the GC's contract and for which the CA does not oversee. These tests will not be repeated during functional tests if properly documented.

Phased Commissioning - commissioning that is completed in phases (by floors, for example) due to the size of the structure or other scheduling issues, in order minimize the total construction time.

Prefunctional Checklist (PC) - a list of items to inspect and elementary component tests to conduct to verify proper installation of equipment, provided by the CA to the Sub. Prefunctional checklists are primarily static inspections and procedures to prepare the equipment or system for initial operation (e.g., belt tension, oil levels $\mathrm{OK}$, labels affixed, gages in place, sensors calibrated, etc.). However, some prefunctional checklist items entail simple testing of the function of a component, a piece of equipment or system (such as measuring the voltage imbalance on a three phase pump motor of a chiller system). The word prefunctional refers to before functional testing. Prefunctional checklists augment and are combined with the manufacturer's start-up checklist. Even without a commissioning process, contractors typically perform some, if not many, of the prefunctional checklist items a commissioning agent will recommend. However, few contractors document in writing the execution of these checklist items. Therefore, for most equipment, the contractors execute the checklists on their own. The commissioning agent only requires that the procedures be documented in writing, and does not witness much of the prefunctional checklisting, except for larger or more critical pieces of equipment.

Project Manager (PM) - the contracting and managing authority for GSA over the design and/or construction of the project, a GSA staff position.

Sampling. - functionally testing only a fraction of the total number of identical or near identical pieces of equipment. Refer to Section 17100, Part 3.6, F for details.

Seasonal Performance Tests - FT that are deferred until the system(s) will experience conditions closer to their design conditions.

Simulated Condition - condition that is created for the purpose of testing the response of a system (e.g., applying a hair blower to a space sensor to see the response in a VAV box).

Simulated Signal - disconnecting a sensor and using a signal generator to send an amperage, resistance or pressure to the transducer and DDC system to simulate a sensor value.

Specifications - the construction specifications of the Contract Documents.

Startup - the initial starting or activating of dynamic equipment, including executing prefunctional checklists.

Subs - the subcontractors to the GC who provide and install building components and systems.

Test Procedures - the step-by-step process which must be executed to fulfill the test requirements. The test procedures are developed by the $C A$.

Test Requirements - requirements specifying what modes and functions, etc. shall be tested. The test requirements are not the detailed test procedures. The test requirements are specified in the Contract Documents (Sections 15997; 16997, etc.).

Trending - monitoring using the building control system.

Vendor - supplier of equipment.

Warranty Period - warranty period for entire project, including equipment components. Warranty begins at Substantial Completion and extends for at least one year, unless specifically noted otherwise in the Contract Documents and accepted submittals. 


\subsection{SYSTEMS TO BE COMMISSIONED}

A. The following checked systems will be commissioned in this project.

\begin{tabular}{|c|c|c|c|}
\hline $\begin{array}{l}\text { Equipment } \\
\text { and System }\end{array}$ & $\begin{array}{c}\text { Functional } \\
\text { Test } \\
\text { Requirements } \\
\text { Specified In: }\end{array}$ & $\begin{array}{l}\text { Equipment } \\
\text { and System }\end{array}$ & $\begin{array}{l}\text { Functional } \\
\text { Test } \\
\text { Requirements } \\
\text { Specified In: }\end{array}$ \\
\hline FVAC System & 15997 & Equipment vibration control & 15997 \\
\hline _Chillers & 15997 & Egress pressurization & 15997 \\
\hline _ Pumps & 15997 & Electrical System & \\
\hline _ Cooling tower & 15997 & $\begin{array}{l}\text { Sweep or scheduled lighting } \\
\text { controls }\end{array}$ & 16997 \\
\hline _ Boilers & 15997 & Daylight dimming controls & 16997 \\
\hline Piping systems & 15997 & _Lighting occupancy sensors & 16997 \\
\hline Ductwork & 15997 & Power quality & 16997 \\
\hline _ Variable frequency drives & 15997 & _ Security system & 16997 \\
\hline _ Air handlers & 15997 & _ Emergency power system & 16997 \\
\hline - Packaged units ( $\mathrm{AC}$ and $\mathrm{HP}$ ) & 15997 & _ UPS systems & 16997 \\
\hline _ Terminal units (air) & 15997 & Fire and smoke alarm & 16997 \\
\hline Unit heaters & 15997 & Fire protection systems. & 16997 \\
\hline _ Heat exchangers & 15997 & _Communications system & 16997 \\
\hline _ Computer room units & 15997 & _Public address/paging & 16997 \\
\hline Fume hoods & 15997 & & \\
\hline Lab room pressures & 15997 & Other & \\
\hline Specialty fans & 15997 & Service water heaters & 15997 \\
\hline $\begin{array}{l}\text { Testing, Adjusting and } \\
\text { Balancing work }\end{array}$ & 15997 & - Service water booster pumps & 15997 \\
\hline __ Chemical treatment systems & 15997 & _ Refrigeration systems & 15997 \\
\hline _ HVAC control system & 15997 & _ Medical gas systems & 15997 \\
\hline Fire and smoke dampers & 15997 & & \\
\hline _ Indoor air quality ${ }^{1}$ & 15997 & & \\
\hline Equipment sound control & 15997 & & \\
\hline
\end{tabular}




\section{PART 2 - PRODUCTS}

\subsection{TEST EQUIPMENT}

A. All standard testing equipment required to perform startup and initial checkout and required functional performance testing shall be provided by the Division contractor for the equipment being tested. For example, the mechanical contractor of Division 15 shall ultimately be responsible for all standard testing equipment for the HVAC system and controls system in Division 15, except for equipment specific to and used by $\mathrm{TAB}$ in their commissioning responsibilities. Two-way radios shall be provided by the Division Controller.

B. Special equipment, tools and instruments (only available from vendor, specific to a piece of equipment) required for testing equipment, according to these Contract Documents shall be included in the base bid price to the Contractor and left on site, except for stand-alone datalogging equipment that may be used by the CA.

C. Datalogging equipment and software required to test equipment will be provided by the CA, but shall not become the property of the Owner.

D. All testing equipment shall be of sufficient quality and accuracy to test and/or measure system performance with the tolerances specified in the Specifications. If not otherwise noted, the following minimum requirements apply: Temperature sensors and digital thermometers shall have a certified calibration within the past year and a resolution of + or $-0.1^{\circ} \mathrm{F}$. Pressure sensors shall have an accuracy of + or $-2.0 \%$ of the value range being measured (not full range of meter) and have been calibrated within the last year. All equipment shall be calibrated according to the manufacturer's recommended intervals and when dropped or damaged. Calibration tags shall be affixed or certificates readily available.

E. Refer to Section 17100, Part 3.6 E for details regarding equipment that may be required to simulate required test conditions.

\section{PART 3 - EXECUTION}

\subsection{MEETINGS}

A. Scoping Meeting. Within [60 to 90, depending on bldg size] days of commencement of construction, the $\mathrm{CA}$ will schedule, plan and conduct a commissioning scoping meeting with the entire commissioning team in attendance. Meeting minutes will be distributed to all parties by the CA. Information gathered from this meeting will allow the CA to revise the Draft 2 Commissioning Plan to its "final" version, which will also be distributed to all parties.

B. Miscellaneous Meetings. Other meetings will be planned and conducted by the $\mathrm{CA}$ as construction progresses. These meetings will cover coordination, deficiency resolution and planning issues with particular Subs. The CA will plan these meetings and will minimize unnecessary time being spent by Subs. For large projects, these meetings may be held monthly, until the final 3 months of construction when they may be held as frequently as one per week. 


\section{SECTION $17100-18$ \\ COMMISSIONING REQUIREMENTS}

\subsection{REPORTING}

A. The CA will provide regular reports to the CM or PM, depending on the management structure, with increasing frequency as construction and commissioning progresses. Standard forms are provided and referenced in the Commissioning Plan.

B. The CA will regularly communicate with all members of the commissioning team, keeping them apprised of commissioning progress and scheduling changes through memos, progress reports, etc.

C. Testing or review approvals and non-conformance and deficiency reports are made regularly with the review and testing as described in later sections.

D. A final summary report (about four to six pages, not including backup documentation) by the CA will be provided to the $\mathrm{CM}$ or PM, focusing on evaluating commissioning process issues and identifying areas where the process could be improved. All acquired documentation, logs, minutes, reports, deficiency lists, communications, findings, unresolved issues, etc., will be compiled in appendices and provided with the summary report. Prefunctional checklists, functional tests and monitoring reports will not be part of the final report, but will be stored in the Commissioning Record in the O\&M manuals.

\subsection{SUBMITTALS}

A. The CA will provide appropriate contractors with a specific request for the type of submittal documentation the $\mathrm{CA}$ requires to facilitate the commissioning work. These requests will be integrated into the normal submittal process and protocol of the construction team. At minimum, the request will include the manufacturer and model number, the manufacturer's printed installation and detailed start-up procedures, full sequences of operation, O\&M data, performance data, any performance test procedures, control drawings and details of owner contracted tests. In addition, the installation and checkout materials that are actually shipped inside the equipment and the actual field checkout sheet forms to be used by the factory or field technicians shall be submitted to the Commissioning Agent. All documentation requested by the CA will be included by the Subs in their O\&M manual contributions.

B. The Commissioning Agent will review and approve submittals related to the commissioned equipment for conformance to the Contract Documents as it relates to the commissioning process, to the functional performance of the equipment and adequacy for developing test procedures. This review is intended primarily to aid in the development of functional testing procedures and only secondarily to verify compliance with equipment specifications. The Commissioning Agent will notify the $\mathrm{CM}, \mathrm{PM}$ or $\mathrm{A} / \mathrm{E}$ as requested, of items missing or areas that are not in conformance with Contract Documents and which require resubmission.

C. The CA may request additional design narrative from the $A / E$ and Controls Contractor, depending on the completeness of the design intent documentation and sequences provided with the Specifications.

D. These submittals to the CA do not constitute compliance for O\&M manual documentation. The O\&M manuals are the responsibility of the Contractor, though the CA will review and approve them. 
These guide specifications presume that design documentation and sequences of operation were carefully and completely prepared prior to bid documents being issued. If this was not the case, include language that requires that $A / E$ and Controls Contractor to develop the design narrative and operating parameters according to the Design Phase Commissioning Plan and the format provided in Appendix 1 of that plan.

\subsection{START-UP, PREFUNCTIONAL CHECKLISTS AND INITIAL CHECKOUT}

A. The following procedures apply to all equipment to be commissioned, according to Section 1.7, Systems to be Commissioned. Some systems that are not comprised so much of actual dynamic machinery, e.g., electrical system power quality, may have very simplified PCs and startup.

B. General. Prefunctional checklists are important to ensure that the equipment and systems are hooked up and operational. It ensures that functional performance testing (in-depth system checkout) may proceed without unnecessary delays. Each piece of equipment receives full prefunctional checkout. No sampling strategies are used. The prefunctional testing for a given system must be successfully completed prior to formal functional performance testing of equipment or subsystems of the given system.

C. Start-up and Initial Checkout Plan. The CA shall assist the commissioning team members responsible for startup of any equipment in developing detailed start-up plans for all equipment. The primary role of the $\mathrm{CA}$ in this process is to ensure that there is written documentation that each of the manufacturer-recommended procedures have been completed. Parties responsible for prefunctional checklists and startup are identified in the commissioning scoping meeting and in the checklist forms. Parties responsible for executing functional performance tests are identified in the testing requirements in Sections 15997, 16997 and [list other sections where tests requirements are foundl.

1. The CA adapts, if necessary, the representative prefunctional checklists and procedures from Section 15998. These checklists indicate required procedures to be executed as part of startup and initial checkout of the systems and the party responsible for their execution.

2. These checklists and tests are provided by the CA to the Contractor. The Contractor determines which trade is responsible for executing and documenting each of the line item tasks and notes that trade on the form. Each form will have more than one trade responsible for its execution.

3. The subcontractor responsible for the purchase of the equipment develops the full start-up plan by combining (or adding to) the CA's checklists with the manufacturer's detailed start-up and checkout procedures from the O\&M manual and the normally used field checkout sheets. The plan will include checklists and procedures with specific boxes or lines for recording and documenting the checking and inspections of each procedure and a summary statement with a signature block at the end of the plan.

The full start-up plan could consist of something as simple as:

a. The CA's prefunctional checklists. 
b. The manufacturer's standard written start-up procedures copied from the installation manuals with check boxes by each procedure and a signature block added by hand at the end.

c. The manufacturer's normally used field checkout sheets.

4. The subcontractor submits the full startup plan to the CA for review and approval.

5. The CA reviews and approves the procedures and the format for documenting them, noting any procedures that need to be added.

6. The full start-up procedures and the approval form may be provided to the CM for review and approval, depending on management protocol.

An alternative to the process for developing the start-up plan given in parts 3-5 immediately above consists of the CA doing more of the work as described below.

\section{OPTION FOR 3 - 5 ABOVE:}

a. The CA, (instead of the contractor), copies the manufacturer's startup and initial checkout procedures from O\&M submittals.

b. The CA marks the applicable areas in the procedures and makes initial and date lines at each procedure or section.

c. The CA transmits these procedures and the original prefunctional checklist procedures (see 1 above) to the Contractor as the startup and initial checkout plan.

D. Sensor Calibration. Calibration of all sensors shall be included as part of the prefunctional checklists performed by the Contractors, according to the following procedures:

1. All Sensors. Verify that sensors with shielded cable, are grounded only at one end. For sensor pairs that are used to determine a temperature or pressure difference, make sure they are reading within $0.2^{\circ} \mathrm{F}$ of each other for temperature and within a tolerance equal to $2 \%$ of the reading, of each other, for pressure. Tolerances for critical applications may be tighter.

2. Sensors Without Transmitters-Standard Application. Make a reading with a calibrated test instrument within 6 inches of the site sensor. Verify that the sensor reading (via the permanent thermostat, gage or building automation system (BAS)) is within the tolerances in the table below of the instrument-measured value. If not, install offset in BAS, calibrate or replace sensor.

3. Sensors With Transmitters-Standard Application. Disconnect sensor. Connect a signal generator in place of sensor. Connect ammeter in series between transmitter and BAS control panel. Using manufacturer's resistance-temperature data, simulate minimum desired temperature. Adjust transmitter potentiometer zero until $4 \mathrm{~mA}$ is read by the ammeter. Repeat for the maximum temperature matching $20 \mathrm{~mA}$ to the potentiometer span or maximum and verify at the BAS. Reconnect sensor. Make a reading with a calibrated test instrument within 6 inches of the site sensor. Verify that the sensor reading (via the permanent thermostat, gage or building automation system (BAS)) is within the tolerances in the table below of the instrument-measured value. If not, replace sensor and repeat. For pressure sensors, perform a similar process with a suitable signal generator.

4. Critical Applications. For critical applications (process, manufacturing, etc.) more rigorous calibration techniques may be required for selected sensors. Describe any such methods used on an attached sheet. 


\section{Sensor Required}

Cooling coil, chilled and condenser water temps
$1.0 \mathrm{~F}$

$1.0 \mathrm{~F}$

$0.5 \mathrm{~F}$

$1 \%$ of design

$3 \%$ of design

$10 \%$ of design
Sensor

Flow rates, water

Combustion flue temps

Oxygen or $\mathrm{CO}_{2}$ monitor

$\mathrm{CO}$ monitor

Natural gas and oil flow rate

Steam flow rate

Barometric pressure
Required

Tolerance $(t /-)$

$4 \%$ of design

$5.0 \mathrm{~F}$

$0.1 \% \mathrm{pts}$

$0.01 \%$ pts

$1 \%$ of design

$3 \%$ of design

0.1 in. of $\mathrm{Hg}$

\section{E. Execution of Prefunctional Checklists and Startup.}

1. Four weeks prior to startup, the Subs and vendors schedule startup and checkout with the CM, $\mathrm{GC}$ and $\mathrm{CA}$. The performance of the prefunctional checklists, startup and checkout are directed and executed by the Sub or vendor. When checking off prefunctional checklists, signatures may be required of other Subs for verification of completion of their work.

2. The CA shall observe, at minimum, the procedures for each piece of primary equipment, unless there are multiple units, (in which case a sampling strategy may be used as approved by the CM). In no case will the number of units witnessed be less than four on any one building, nor less than $20 \%$ of the total number of identical or very similar units.

3. For lower-level components of equipment, (e.g., VAV boxes, sensors, controllers), the CA shall observe a sampling of the prefunctional and start-up procedures. The sampling procedures are identified in the commissioning plan.

4. The Subs and vendors shall execute startup and provide the $C A$ with a signed and dated copy of the completed start-up and prefunctional tests and checklists.

5. Only individuals that have direct knowledge and witnessed that a line item task on the prefunctional checklist was actually performed shall initial or check that item off. It is not acceptable for witnessing supervisors to fill out these forms.

\section{F. Deficiencies, Non-Conformance and Approval in Checklists and Startup.}

1. The Subs shall clearly list any outstanding items of the initial start-up and prefunctional procedures that were not completed successfully, at the bottom of the procedures form or on an attached sheet. The procedures form and any outstanding deficiencies are provided to the CA within two days of test completion.

2. The CA reviews the report and submits either a non-compliance report or an approval form to the Sub or CM. The CA shall work with the Subs and vendors to correct and retest deficiencies or uncompleted items. The $\mathrm{CA}$ will involve the $\mathrm{CM}$ and others as necessary. The installing Subs or vendors shall correct all areas that are deficient or incomplete in the checklists and tests in a timely manner, and shall notify the CA as soon as outstanding items have been corrected and resubmit an updated start-up report and a Statement of Correction on the original non-compliance report. When satisfactorily completed, the CA recommends 


\section{COMMISSIONING REQUIREMENTS}

SECTION $17100-22$

approval of the execution of the checklists and startup of each system to the CM using a standard form.

3. Items left incomplete, which later cause deficiencies or delays during functional testing may result in backcharges to the responsible party. Refer to Part 3.7 herein for details.

\subsection{PHASED COMMISSIONING}

A. The project __will require, _will not require startup and initial checkout to be executed in phases. This phasing will be planned and scheduled in a coordination meeting of the $\mathrm{CA}, \mathrm{CM}$, mechanical, TAB and controls and the GC. Results will be added to the master and commissioning schedule.

\subsection{FUNCTIONAL PERFORMANCE TESTING}

A. This sub-section applies to all commissioning functional testing for all divisions.

B. The general list of equipment to be commissioned is found in Section 17100, Part 1.4. The specific equipment and modes to be tested are found in Sections 15997, 16997 and _list other sections where tests requirements are found].

C. The parties responsible to execute each test are listed with each test in Sections 15997, 16997 and [list other sections where tests requirements are found].

D. Objectives and Scope. The objective of functional performance testing is to demonstrate that each system is operating according to the documented design intent and Contract Documents. Functional testing facilitates bringing the systems from a state of substantial completion to full dynamic operation. Additionally, during the testing process, areas of deficient performance are identified and corrected, improving the operation and functioning of the systems.

In general, each system should be operated through all modes of operation (seasonal, occupied, unoccupied, warm-up, cool-down, part- and full-load) where there is a specified system response. Verifying each sequence in the sequences of operation is required. Proper responses to such modes and conditions as power failure, freeze condition, low oil pressure, no flow, equipment failure, etc. shall also be tested. Specific modes required in this project are given in Sections 15997, 16997 and [list other sections where tests requirements are found].

E. Development of Test Procedures. Before test procedures are written, the CA shall obtain all requested documentation and a current list of change orders affecting equipment or systems, including an updated points list, program code, control sequences and parameters. Using the testing parameters and requirements in Sections 15997, 16997 and [list other sections where tests requirements are found] the CA shall develop specific test procedures and forms to verify and document proper operation of each piece of equipment and system. Each Sub or vendor responsible to execute a test, shall provide limited assistance to the $\mathrm{CA}$ in developing the procedures review (answering questions about equipment, operation, sequences, etc.). Prior to execution, the CA shall provide a copy of the test procedures to the Sub(s) who shall review the tests for feasibility, safety, equipment and warranty protection. The $C A$ may submit the tests to the $A / E$ for review, if requested. 
The CA shall review owner-contracted, factory testing or required owner acceptance tests which the $\mathrm{CA}$ is not responsible to oversee, including documentation format, and shall determine what further testing or format changes may be required to comply with the Specifications. Redundancy of testing shall be minimized.

The purpose of any given specific test is to verify and document compliance with the stated criteria of acceptance given on the test form.

Representative test formats and examples (not designed for this facility) are found in the appendices to Divisions 15 and 16. The test procedure forms developed by the CA shall include (but not be limited to) the following information:

1. System and equipment or component name(s)

2. Equipment location and ID number

3. Unique test ID number, and reference to unique prefunctional checklist and start-up documentation $\mathrm{D}$ numbers for the piece of equipment

4. Date

5. Project name

6. Participating parties

7. A copy of the specification section describing the test requirements

8. A copy of the specific sequence of operations or other specified parameters being verified

9. Formulas used in any calculations

10. Required pre-test field measurements

11. Instructions for setting up the test.

12. Special cautions, alarm limits, etc.

13. Specific step-by-step procedures to execute the test, in a clear, sequential and repeatable format

14. Acceptance criteria of proper performance with a Yes / No check box to allow for clearly marking whether or not proper performance of each part of the test was achieved.

15. A section for comments

16. Signatures and date block for the $\mathrm{CA}$

F. Test Methods.

1. Functional performance testing and verification may be achieved by manual testing (persons manipulate the equipment and observe performance) or by monitoring the performance and analyzing the results using the control system's trend log capabilities or by stand-alone dataloggers. Sections 15997, 16997 and [ilst other sections where tests requirements are found] specify which methods shall be used for each test. The CA may substitute specified methods or require an additional method to be executed, other than what was specified, with the approval of the CM. This may require a change order and adjustment in charge to the Owner. The CA will determine which method is most appropriate for tests that do not have a method specified.

2. Simulated Conditions. Simulating conditions (not by an overwritten value) shall be allowed, though timing the testing to experience actual conditions is encouraged wherever practical.

3. Overwritten Values. Overwriting sensor values to simulate a condition, such as overwriting the outside air temperature reading in a control system to be something other than it really is, shall be allowed, but shall be used with caution and avoided when possible. Such testing methods often can only test a part of a system, as the interactions and responses of other 
systems will be erroneous or not applicable. Simulating a condition is preferable. e.g., for the above case, by heating the outside air sensor with a hair blower rather than overwriting the value or by altering the appropriate setpoint to see the desired response. Before simulating conditions or overwriting values, sensors, transducers and devices shall have been calibrated.

4. Simulated Signals. Using a signal generator which creates a simulated signal to test and calibrate transducers and DDC constants is generally recommended over using the sensor to act as the signal generator via simulated conditions or overwritten values.

5. Altering Setpoints. Rather than overwriting sensor values, and when simulating conditions is difficult, altering setpoints to test a sequence is acceptable. For example, to see the AC compressor lockout work at an outside air temperature below 55F, when the outside air temperature is above $55 \mathrm{~F}$, temporarily change the lockout setpoint to be $2 \mathrm{~F}$ above the current outside air temperature.

6. Indirect Indicators. Relying on indirect indicators for responses or performance shall be allowed only after visually and directly verifying and documenting, over the range of the tested parameters, that the indirect readings through the control system represent actual conditions and responses. Much of this verification is completed during prefunctional testing.

7. Setup. Each function and test shall be performed under conditions that simulate actual conditions as close as is practically possible. The Sub executing the test shall provide all necessary materials, system modifications, etc. to produce the necessary flows, pressures, temperatures, etc. necessary to execute the test according to the specified conditions. At completion of the test, the Sub shall return all affected building equipment and systems, due to these temporary modifications, to their pre-test condition.

8. Sampling. Multiple identical pieces of non-life-safety or otherwise non-critical equipment may be functionally tested using a sampling strategy. Significant application differences and significant sequence of operation differences in otherwise identical equipment invalidates their common identity. A small size or capacity difference, alone, does not constitute a difference. The specific recommended sampling rates are specified with each type of equipment in Sections 15997, 16997 and [list other sections where test requirements are found]. It is noted that no sampling by Subs is allowed in prefunctional checklist execution.

A common sampling strategy referenced in the Specifications as the " $\mathrm{xx} \%$ Sampling-yy\% Failure Rule" is defined by the following example.

$x x=$ the percent of the group of identical equipment to be included in each sample. $y y=$ the percent of the sample that if failing, will require another sample to be tested.

The example below describes a 20\% Sampling-10\% Failure Rule.

a. Randomly test at least $20 \%(\mathrm{xx})$ of each group of identical equipment. In no case test less than three units in each group. This $20 \%$, or three, constitute the "first sample."

b. If $10 \%$ (yy) of the units in the first sample fail the functional performance tests, test another $20 \%$ of the group (the second sample).

c. If $10 \%$ of the units in the second sample fail, test all remaining units in the whole group.

d. If at any point, frequent failures are occurring and testing is becoming more troubleshooting than verification, the CA may stop the testing and require the responsible Sub to perform and document a checkout of the remaining units, prior to continuing with functionally testing the remaining units. 
G. Coordination and Scheduling. The Subs shall provide sufficient notice to the CA regarding their completion schedule for the prefunctional checklists and startup of all equipment and systems. The CA will schedule functional tests through the CM, GC and affected Subs. The CA shall direct, witness and document the functional testing of all equipment and systems. The Subs shall execute the tests.

In general, functional testing is conducted after prefunctional testing and startup has been satisfactorily completed. The control system is sufficiently tested and approved by the CA before it is used for TAB or to verify performance of other components or systems. The air balancing and water balancing is completed and debugged before functional testing of air-related or water-related equipment or systems. Testing proceeds from components to subsystems to systems. When the proper performance of all interacting individual systems has been achieved, the interface or coordinated responses between systems is checked.

H. Test Equipment. Refer to Section 17100, Part 2 for test equipment requirements.

I. Problem Solving. The CA will recommend solutions to problems found, however the burden of responsibility to solve, correct and retest problems is with the GC, Subs and A/E. 


\subsection{DOCUMENTATION, NON-CONFORMANCE AND APPROVAL OF TESTS}

A. Documentation. The CA shall witness and document the results of all functional performance tests using the specific procedural forms developed for that purpose. Prior to testing, these forms are provided to the CM for review and approval and to the Subs for review. The CA will include the filled out forms in the O\&M manuals.

\section{B. Non-Conformance.}

1. The CA will record the results of the functional test on the procedure or test form. All deficiencies or non-conformance issues shall be noted and reported to the CM on a standard non-compliance form.

2. Corrections of minor deficiencies identified may be made during the tests at the discretion of the $\mathrm{CA}$. In such cases the deficiency and resolution will be documented on the procedure form.

3. Every effort will be made to expedite the testing process and minimize unnecessary delays, while not compromising the integrity of the procedures. However, the CA will not be pressured into overlooking deficient work or loosening acceptance criteria to satisfy scheduling or cost issues, unless there is an overriding reason to do so at the request of the $\mathrm{CM}$.

4. As tests progress and a deficiency is identified, the CA discusses the issue with the executing contractor.

a. When there is no dispute on the deficiency and the Sub accepts responsibility to correct it:

1) The CA documents the deficiency and the Sub's response and intentions and they go on to another test or sequence. After the day's work, the CA submits the noncompliance reports to the $\mathrm{CM}$ for signature, if required. A copy is provided to the Sub and CA. The Sub corrects the deficiency, signs the statement of correction at the bottom of the non-compliance form certifying that the equipment is ready to be retested and sends it back to the $\mathrm{CA}$.

2) The CA reschedules the test and the test is repeated.

b. If there is a dispute about a deficiency, regarding whether it is a deficiency or who is responsible:

1) The deficiency shall be documented on the non-compliance form with the Sub's response and a copy given to the $\mathrm{CM}$ and to the Sub representative assumed to be responsible.

2) Resolutions are made at the lowest management level possible. Other parties are brought into the discussions as needed. Final interpretive authority is with the A/E. Final acceptance authority is with the Project Manager.

3) The CA documents the resolution process.

4) Once the interpretation and resolution have been decided, the appropriate party corrects the deficiency, signs the statement of correction on the non-compliance form and provides it to the $\mathrm{CA}$. The $\mathrm{CA}$ reschedules the test and the test is repeated until satisfactory performance is achieved.

5. Cost of Retesting.

a. The cost for the $S u b$ to retest a prefunctional or functional test, if they are responsible for the deficiency, shall be theirs. If they are not responsible, any cost recovery for retesting costs shall be negotiated with the GC. 
b. For a deficiency identified, not related to any prefunctional checklist or start-up fault, the following shall apply: The CA and $\mathrm{CM}$ will direct the retesting of the equipment once at no "charge" to the GC for their time. However, the CA's and CM's time for a second retest will be charged to the $\mathrm{GC}$, who may choose to recover costs from the responsible Sub.

c. The time for the $\mathrm{CA}$ and $\mathrm{CM}$ to direct any retesting required because a specific prefunctional checklist or start-up test item, reported to have been successfully completed, but determined during functional testing to be faulty, will be backcharged to the GC, who may choose to recover costs from the party responsible for executing the faulty prefunctional test.

d. Refer to the sampling section of Section 17100, Part 3.6 for requirements for testing and retesting identical equipment.

6. The Contractor shall respond in writing to the $\mathrm{CA}$ and $\mathrm{CM}$ at least as often as commissioning meetings are being scheduled concerning the status of each apparent outstanding discrepancy identified during commissioning. Discussion shall cover explanations of any disagreements and proposals for their resolution.

7. The CA retains the original non-conformance forms until the end of the project.

C. Failure Due to Manufacturer Defect. If $10 \%$, or three, whichever is greater, of identical pieces (size alone does not constitute a difference) of equipment fail to perform to the Contract Documents (mechanically or substantively) due to manufacturing defect, not allowing it to meet its submitted performance spec, all identical units may be considered unacceptable by the CM or PM. In such case, the Contractor shall provide the Owner with the following:

a. Within one week of notification from the CM or PM, the Contractor or manufacturer's representative shall examine all other identical units making a record of the findings. The findings shall be provided to the CM or PM within two weeks of the original notice.

b. Within two weeks of the original notification, the Contractor or manufacturer shall provide a signed and dated, written explanation of the problem, cause of failures, etc. and all proposed solutions which shall include full equipment submittals. The proposed solutions shall not significantly exceed the specification requirements of the original installation.

c. The CM or PM will determine whether a replacement of all identical units or a repair is acceptable.

d. Two examples of the proposed solution will be installed by the Contractor and the CM will be allowed to test the installations for up to one week, upon which the CM or PM will decide whether to accept the solution.

e. Upon acceptance, the Contractor and/or manufacturer shall replace or repair all identical items, at their expense and extend the warranty accordingly, if the original equipment warranty had begun. The replacement/repair work shall proceed with reasonable speed beginning within one week from when parts can be obtained.

D. Approval. The CA notes each satisfactorily demonstrated function on the test form. Formal approval of the functional test is made later after review by the $\mathrm{CA}$ and by the $\mathrm{CM}$, if necessary. The CA recommends acceptance of each test to the $\mathrm{CM}$ using a standard form. The $\mathrm{CM}$ gives final approval on each test using the same form, providing a signed copy to the CA and the Contractor. 
The following O\&M documentation requirements assume that the general contractor is compiling the O\&M manuals, with all Subs compiling their own sections, including some submissions for the $\mathrm{A} / \mathrm{E}$ and $\mathrm{CA}$.

These requirements may need to be merged and edited to follow the protocols and scope of the current agency or project. However, the comprehensiveness and accessibility described herein shall be maintained.

\section{A. Standard O\&M Manuals.}

1. The specific content and format requirements for the standard O\&M manuals are detailed in Section 01730. Special requirements for the controls contractor and TAB contractor are found Section 15995, Part 3.6.

2. $\mathrm{A} / \mathrm{E}$ Contribution. The $\mathrm{A} / \mathrm{E}$ will include in the beginning of the O\&M manuals a separate section describing the systems including:

a. The design intent narrative prepared by the $\mathrm{A} / \mathrm{E}$ and provided as part of the bid documents, updated to as-built status by the A/E.

b. Simplified professionally drawn single line system diagrams on $81 / 2$ " $\times 11^{\prime \prime}$ or $11^{\prime \prime} \times 17$ " sheets. These shall include chillers, water system, condenser water system, heating system, supply air systems, exhaust systems and These shall show major pieces of equipment such as pumps, chillers, boilers, control valves, expansion tanks, coils, service valves, etc.

3. CA Review and Approval. Prior to substantial completion, the CA shall review the O\&M manuals, documentation and redline as-builds for systems that were commissioned and llist other systems documentation that the CA should review] to verify compliance with the Specifications. The CA will communicate deficiencies in the manuals to the CM, PM or A/E, as requested. Upon a successful review of the corrections, the $C A$ recommends approval and acceptance of these sections of the O\&M manuals to the CM, PM or A/E. The CA also reviews each equipment warranty and verifies that all requirements to keep the warranty valid are clearly stated. This work does not supersede the A/E's review of the O\&M manuals according to the $\mathrm{A} / \mathrm{E}$ 's contract.

\section{B. Commissioning Record in O\&M Manuals.}

1. The $\mathrm{CA}$ is responsible to compile, organize and index the following commissioning data by equipment into labeled, indexed and tabbed, three-ring binders and deliver it to the $G C$, to be included with the O\&M manuals. Three copies of the manuals will be provided. The format of the manuals shall be:

Tab 1-1 Commissioning Plan

Tab I-2 Final Commissioning Report

Tab 01 System Type 1 (chiller system, packaged unit, boiler system, etc.)

Sub-Tab A Design narrative and criteria, sequences, approvals for Equipment 1 
Sub-Tab B Startup plan and report, approvals, corrections, blank prefunctional checklists

Colored Separator Sheets - for each equipment type (fans, pumps, chiller, etc.)

Sub-Tab C Functional tests (completed), trending and analysis, approvals and corrections, training plan, record and approvals, blank functional test forms and a recommended recommissioning schedule.

Tab 02 System Type 2......repeat as per System 1

2. Other documentation will be retained by the $\mathrm{CA}$.

\subsection{TRAINING OF OWNER PERSONNEL}

A. The GC shall be responsible for training coordination and scheduling and ultimately for ensuring that training is completed.

B. The CA shall be responsible for overseeing and approving the content and adequacy of the training of Owner personnel for commissioned equipment.

1. The CA shall interview the the facility manager and lead engineer to determine the special . needs and areas where training will be most valuable. The Owner and CA shall decide how rigorous the training should be for each piece of commissioned equipment. The CA shall communicate the results to the Subs and vendors who have training responsibilities.

2. In addition to these general requirements, the specific training requirements of Owner personnel by Subs and vendors is specified in Division 15 and 16 and llist other sections where training requirements are foundl.

3. Each Sub and vendor responsible for training will submit a written training plan to the CA for review and approval prior to training. The plan will cover the following elements:
a. Equipment (included in training)
b. Intended audience
c. Location of training
d. Objectives
e. Subjects covered (description, duration of discussion, special methods, etc.)
f. Duration of training on each subject
g. Instructor for each subject
h. Methods (classroom lecture, video, site walk-through, actual operational demonstrations, written handouts, etc.)
i. Instructor and qualifications

4. For the primary HVAC equipment, the Controls Contractor shall provide a short discussion of the control of the equipment during the mechanical or electrical training conducted by others.

5. The CA develops an overall training plan and coordinates and schedules, with the $\mathrm{CM}$ and $\mathrm{GC}$, the overall training for the commissioned systems. The CA develops criteria for determining that the training was satisfactorily completed, including attending some of the training, etc. The CA recommends approval of the training to the $\mathrm{CM}$ using a standard form. The $\mathrm{CM}$ also signs the approval form.

6. At one of the training sessions, the CA presents a ___ hour presentation discussing the use of 
the blank functional test forms for re-commissioning equipment.

7. Video taping of the training sessions will be provided by the Owner, the CA with tapes cataloged by _ the Owner, _the CA and added to the O\&M manuals.

8. The mechanical design engineer shall at the first training session present the overall system design concept and the design concept of each equipment section. This presentation shall be hours in length and include a review of all systems using the simplified system schematics (one-line drawings) including chilled water systems, condenser water or heat rejection systems, heating systems, fuel oil and gas supply systems, supply air systems, exhaust system and outside air strategies.

\subsection{DEFERRED TESTING}

A. Unforeseen Deferred Tests. If any check or test cannot be completed due to the building structure, required occupancy condition or other deficiency, execution of checklists and functional testing may be delayed upon approval of the PM. These tests will be conducted in the same manner as the seasonal tests as soon as possible. Services of necessary parties will be negotiated.

B. Seasonal Testing. During the warranty period, seasonal testing (tests delayed until weather conditions are closer to the system's design) specified in Section 15997 shall be completed as part of this contract. The CA shall coordinate this activity. Tests will be executed, documented and deficiencies corrected by the appropriate Subs, with facilities staff and the CA witnessing. Any final adjustments to the $O \& M$ manuals and as-builds due to the testing will be made.

\subsection{WRITTEN WORK PRODUCTS}

A. The commissioning process generates a number of written work products described in various parts of the Specifications. The Commissioning Plan-Construction Phase, lists all the formal written work products, describes briefly their contents, who is responsible to create them, their due dates, who receives and approves them and the location of the specification to create them. In summary, the written products are:

Product

1. Final commissioning plan

2. Meeting minutes

3. Commissioning schedules

4. Equipment documentation submittals

5. Sequence clarifications

5. Prefunctional checklists

6. Startup and initial checkout plan

7. Startup and initial checkout forms filled out

8. Final TAB report

9. Issues $\log$ (deficiencies)

10. Commissioning Progress Record

11. Deficiency reports

12. Functional test forms
Developed By

CA

CA

$C A$ with $\mathrm{GC}$ and $\mathrm{CM}$

Subs

Subs and $A / E$ as needed

CA (already in Specs)

Subs and CA (compilation of existing documents)

Subs

TAB

CA

CA

CA

CA 
Product

13. Filled out functional tests

14. O\&M manuals

15. Commissioning record book

16. Overall training plan

17. Specific training agendas

18. Final commissioning report

19. Misc. approvals
Developed By

CA

Subs

CA

$\mathrm{CA}$ and $\mathrm{CM}$

Subs

CA

CA

END OF GUIDE SPECIFICATION SECTION 


\title{
Part IV
}

\section{Model Commissioning Plan --Construction Phase--}

\author{
Sponsored by \\ US Department of Energy \\ Seattle Regional Support Office \\ 800 5th Ave. Suite 3950 \\ Seattle, WA 98104 \\ Prepared by: \\ Portland Energy Conservation, Inc. (PECI) \\ 921 SW Washington, Suite 312 \\ Portland, OR 97205 \\ 503-248-4636, Fax 503-295-0820
}

Version 2.02

March 1997 


\section{Part IV. Model Commissioning Plan-Construction Phase}

\section{Summary}

The Commissioning Plan-Construction Phase is developed in draft form for the specific project during the design phase. During the design phase, the plan provides direction for the development of the site-specific commissioning specifications by the design team. During the construction phase, the plan provides direction for the commissioning tasks during construction. The plan focuses on providing support for the specifications and provides forms for the application of the commissioning process.

\section{Table of Contents}

1. Overview

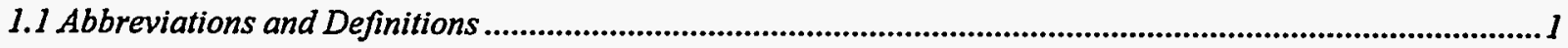

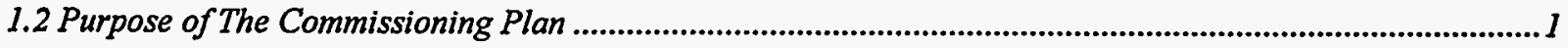

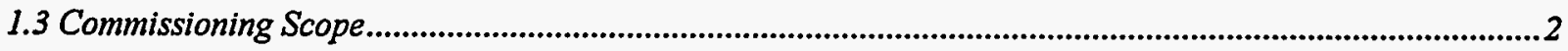

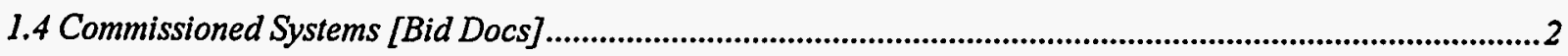

1.5 Forms

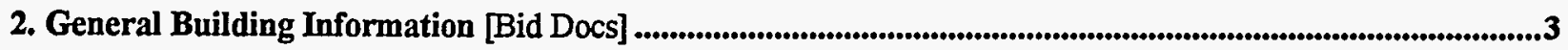

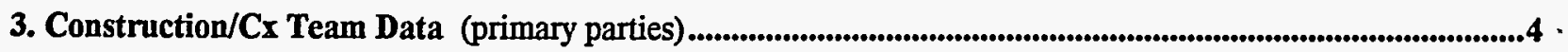

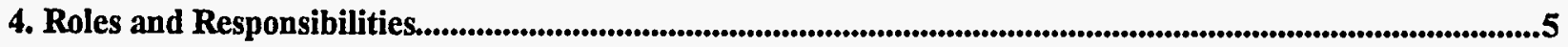

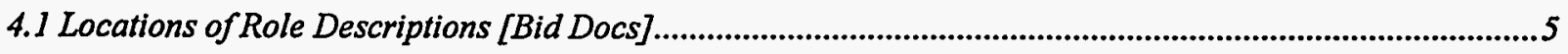

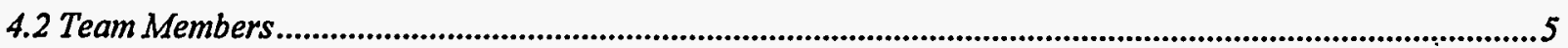

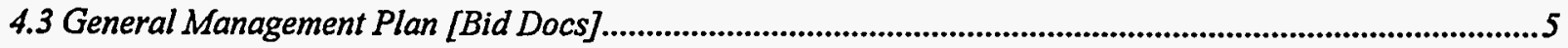



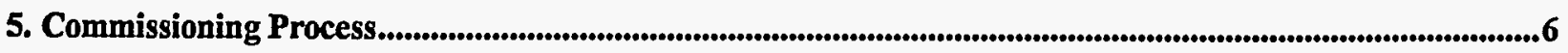

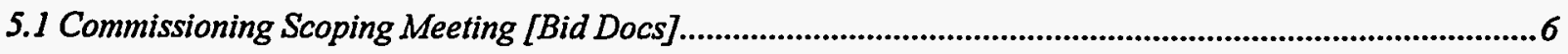

5.2 Final Commissioning Plan-Construction Phase [Bid Docs] ...................................................................6

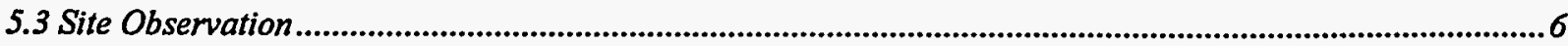

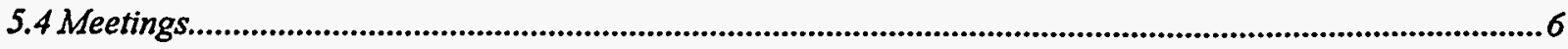

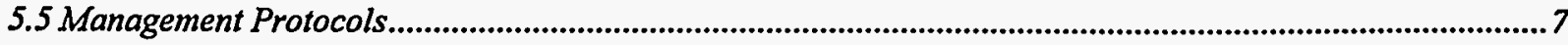

Model Commissioning Plan and Guide Specifications ii

PECIUSDOE CONSPLAN.V10, 01/14197 


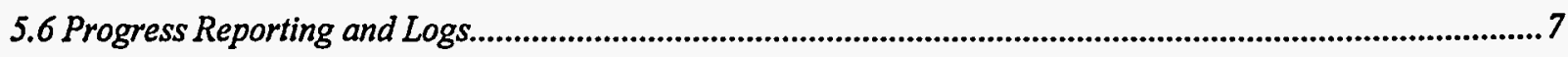

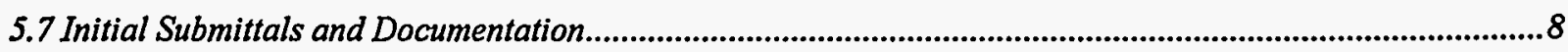



5.7.2 Special Submittals, Notifications and Clarifications..........................................................................

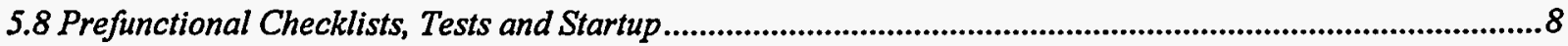

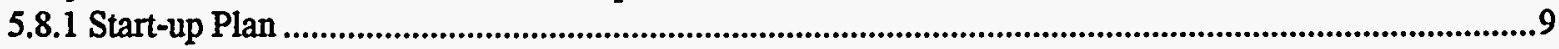

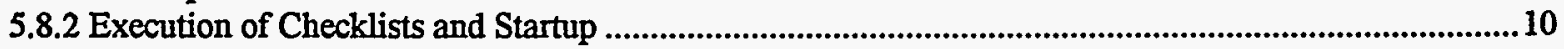

5.8.3 Sampling Strategy for CA Observation of Prefunctional Checkout and Startup....................................... 10

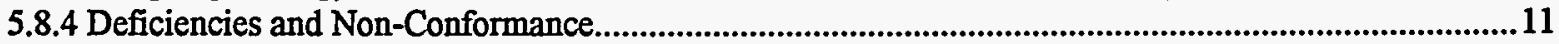



5.8.6 $\mathrm{TAB}$

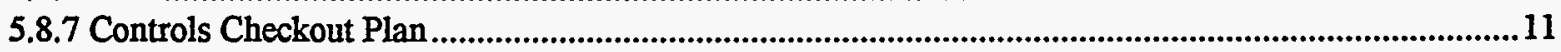

5.9 Development of Functional Test and Verification Procedures.........................................................................12

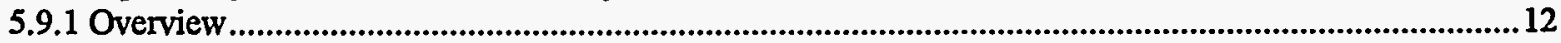

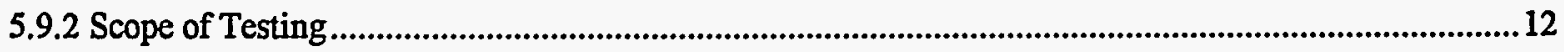

5.9.3 Development Process..........................................................................................................................12

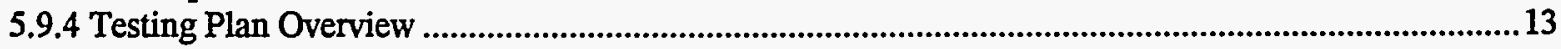

5.10 Execution of Functional Testing Procedures................................................................................................13



5.10.2 Deficiencies and Retesting .............................................................................................................13

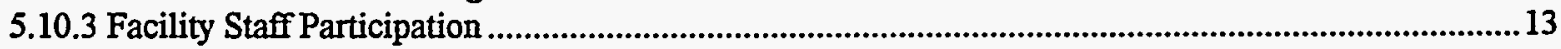

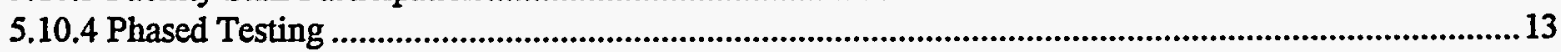

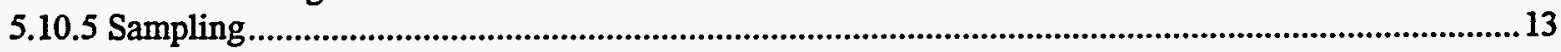



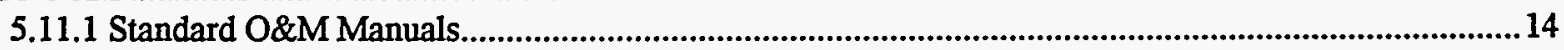

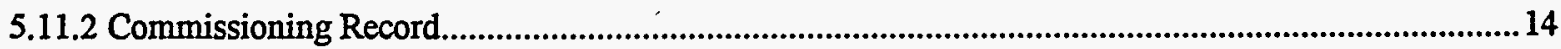

5.12 Training and Orientation of Owner Personnel ........................................................................................14

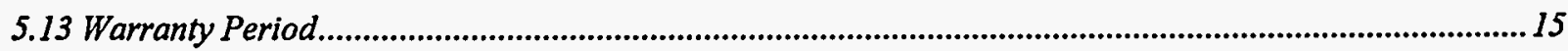

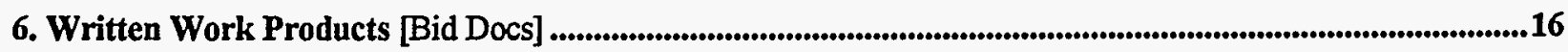

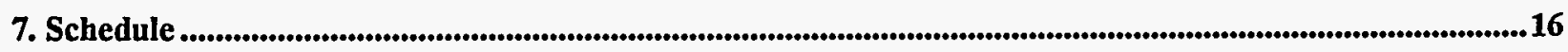

7.1 General Issues [Bid Docs].....................................................................................................................16

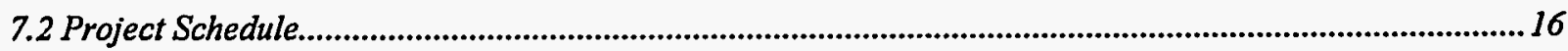

Appendix 1. Construction Phase Application Forms

Appendix 2. Document and Test Development Flow Charts and Submittal Maps 


\section{Commissioning Plan-Construction Phase}


Plan Approved:

Signature

Titie

Date

\section{Overview}

\subsection{Abbreviations and Definitions}

The following are common abbreviations used in this document. Definitions are found in Division 17 of the Specifications.
A/E-
Architect and design engineers
FT-
Functional performance test
CA-
Commissioning agent
GC- General contractor
CC- Controls contractor
MC- Mechanical contractor
CM-
Construction Manager
PC-
Prefunctional checklist
$\mathrm{Cx}-$
Commissioning
PM-
Project manager (GSA)
Cx Plan-
Commissioning Plan document
Subs-
Subcontractors to General
EC-
Electrical contractor
TAB-
Test and balance contractor

Section Headings with "[Bid Docs]" at the right margin denote sections which include blanks that should be filled in prior to construction bidding. Other fill-in blanks are not filled in until after construction begins.

\subsection{Purpose of The Commissioning Plan}

The purpose of the construction phase commissioning plan is to:

1. Provide direction for the development of the $\mathrm{Cx}$ specifications by $\mathrm{A} / \mathrm{E}$, during the latter part of the design phase.

2. Provide direction for the commissioning process during construction, particularly providing resolution for issues and providing details that cannot be, or were not, fully developed during design, such as scheduling, participation of various parties of this particular project, actual lines of reporting and approvals, coordination, etc.

This plan does not provide a detailed explanation of required testing procedures. The detailed testing requirements and procedures are found in the Specifications, Sections 15997, 15998, 16997and 16998. Additionally, this plan does not provide extensive narrative on all commissioning concepts, as may be provided in other commissioning guides. 


\subsection{Commissioning Scope}

Commissioning is a systematic process of ensuring that all building systems perform interactively according to the design intent and the owner's operational needs. 'This is achieved by beginning in the design phase, documenting the design intent and continuing through construction, acceptance and the warranty period with actual verification of performance.

Commissioning during the construction of this project is intended to achieve the following specific objectives:

According to the Contract Documents:

- Ensure that applicable equipment and systems are installed properly and receive adequate operational checkout by installing contractors.

- Verify and document proper performance of equipment and systems.

- Ensure that O\&M documentation left on site is complete.

- Ensure that the Owner's operating personnel are adequately trained.

\subsection{Commissioned Systems}

[Bid Docs]

The following marked systems will be commissioned in this project. Refer to Section 6 for additional details. All general references to equipment in this document refer only to equipment that is to be commissioned.

HVAC System (and all integral equipment controls)

Chiller system (including controls, chillers, cooling towers, piping, pumps and variable speed drives)

Boiler system (including controls, boilers, piping, pumps and variable speed drives)

Pumps

Variable speed drives

Heat exchangers

Piping, cleaning and flushing

Chemical treatment

Ductwork

Air handling units

Roof top packaged DX units (heatpumps or AC)

Split systems

Evaporative coolers

Evaporative condensers

Terminal units

Testing, Adjusting and Balancing work

Unit heaters

Building automation system (controlled devices, control loops and system integration)

\section{Electrical Systems}

Sweep and scheduled lighting controls

Daylighting/dimming controls

Electrical system power quality

Communications system

Security sytem

Emergency power systems 
Part IV. Commissioning Plan-Construction Phase

__ Uninterruptible power supply system

Life Safety Systems

Fire alarm system

Egress pressurization systems

Fire suppression/protection systems

Plumbing

Domestic booster pump

Domestic hot water heaters

Laboratories/Clinics

Fume hoods

Room isolation

Process gas

Other

Elevator

Kitchen exhaust equipment

Refrigeration equipment and systems

Walk-in coolers

Cases

_ Compressors and condensers

Control system

\subsection{Forms}

Forms used during commissioning are referred to in this plan by the format: Form $\mathrm{D}$-xx or $\mathrm{C}$-xx, where

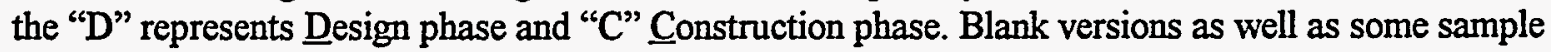
filled- out versions are found in Appendix 1 of this plan.

\section{General Building Information}

[Bid Docs]

Project:

Location:

Building Type (office, court, etc.):

Square Footage:

Number of stories:

Agency:

Tenants:

Const. Period: 
3. Construction/Cx Team Data (primary parties)

\begin{tabular}{|c|c|c|}
\hline Team Member & Co. \& Contact Names & $\begin{array}{l}\text { Voice, office, cell, fax, } \\
\text { email, address }\end{array}$ \\
\hline \multicolumn{3}{|l|}{ Owner } \\
\hline \multicolumn{3}{|l|}{ Project Manager } \\
\hline \multicolumn{3}{|l|}{ Site Engineer } \\
\hline \multicolumn{3}{|l|}{ Property Manager } \\
\hline \multicolumn{3}{|l|}{ Construction Manager } \\
\hline \multicolumn{3}{|l|}{ General Site Contact } \\
\hline \multicolumn{3}{|l|}{ Mechanical } \\
\hline \multicolumn{3}{|l|}{ General Contractor } \\
\hline \multicolumn{3}{|l|}{$\begin{array}{l}\text { Site Supervisor } \\
\text { Site Coordinator }\end{array}$} \\
\hline \multicolumn{3}{|l|}{ Commissioning Agent } \\
\hline \multicolumn{3}{|l|}{ Architect } \\
\hline \multicolumn{3}{|l|}{ Mechanical Designer/Eng. } \\
\hline \multicolumn{3}{|l|}{ Electrical Designer/Eng. } \\
\hline \multicolumn{3}{|l|}{ Tenant Representative } \\
\hline \multicolumn{3}{|l|}{ Mechanical Contractor } \\
\hline \multicolumn{3}{|l|}{ HVAC Site Superv. } \\
\hline \multicolumn{3}{|l|}{ Piping Contractor } \\
\hline \multicolumn{3}{|l|}{ Sheet Metal Contractor } \\
\hline \multicolumn{3}{|l|}{ Electrical Contractor } \\
\hline \multicolumn{3}{|l|}{ Site Supervisor } \\
\hline \multicolumn{3}{|l|}{ TAB Contractor } \\
\hline $\begin{array}{r}\text { Controls Contractor } \\
\text { Project Manager } \\
\text { Project Engineer }\end{array}$ & & \\
\hline
\end{tabular}




\section{Roles and Responsibilities}

4.1 Locations of Role Descriptions

[Bid Docs]

Descriptions and explanations of the roles and responsibilities of those in the commissioning process are found in the following places in the Contract Documents:

List of team members: $\quad$ Cx Plan, 4.2

Management plan outline: Cx Plan, 4.3. Specifications 17100, Pt. 1

General roles: $\quad$ Cx Plan, 4.4 , Specifications 17100, Pt. 1

Specific responsibilities:

$\begin{array}{ll}\begin{array}{l}\text { Information for all parties: } \\ \text { CM, PM: }\end{array} & \begin{array}{l}\text { Cx Plan 5; Specs 17100, Pt. 1 } \\ \text { Cx Plan 5; Specs 17100, Pt. 1 }\end{array} \\ \begin{array}{l}\text { Mechanical contractor, TAB, } \\ \text { controls contractor, subs and mfr's: }\end{array} & \begin{array}{l}\text { Specs Div. } 1^{1}, 15995,15990,15997, \\ 16998,17100\end{array} \\ \text { Electrical contractor, subs and mfr's: } & \begin{array}{l}\text { Specs Div. } 1^{1}, 16995,16997,16998, \\ 17100\end{array} \\ \text { Commissioning agent: } & \text { Specs Div. } 1^{1}, 17100,15 \text { and } 16997 \\ \text { A/E: } & \text { A/E contract, Div. } 1^{1} \text {, Specs } 17100\end{array}$

${ }^{1}$ Division 1 sections include: 00800, 01040, 01300, 01700 and 10730.

\subsection{Team Members}

The members of the commissioning team consist of the CA, GSA PM, assigned members of the CM, GC, $\mathrm{A} / \mathrm{E}$ (particularly the mechanical engineer), the mechanical contractor, electrical contractor, $\mathrm{TAB}$ representative, controls contractor, any other installing subcontractors or suppliers of equipment. If known, the Owner's building or plant operator/ engineer is also a member of the commissioning team.

\subsection{General Management Plan}

[Bid Docs]

The CA was hired by the _CM, _ _ GC, _ _ A/E, _ GSA directly. In general, the CA coordinates the commissioning activities and reports to the _ CM, _ GC, A/E. The CA's responsibilities, along with all other contractors' commissioning responsibilities are detailed in the specifications. The Specifications will take precedence over this Cx Plan. All members work together to fulfill their contracted responsibilities and meet the objectives of the Contract Documents. Refer to the management protocols section below.

\subsection{General Descriptions of Roles}

General descriptions of the commissioning roles are as follows:

CA : Coordinates the $\mathrm{Cx}$ process, writes tests, oversees and documents performance tests

CM : Facilitates the Cx process. Approves test plans and signs-off on performance, if the CA was not hired by the CM.

GC : Facilitates the Cx process, ensures that Subs perform their responsibilities and integrates $\mathrm{Cx}$ into the construction process and schedule 
Subs : Demonstrate proper system performance

A/E : Perform construction observation, approve O\&M manuals and assist in resolving problems

PM : Facilitates and supports the $C x$ process and gives final approval of the $C x$ work

Mfr. : The equipment manufacturers and vendors provide documentation to facilitate the commissioning work and perform contracted startup

\section{Commissioning Process}

This section sequentially details the commissioning process by commissioning task or activity.

\subsection{Commissioning Scoping Meeting}

A commissioning scoping meeting is planned and conducted by the $\mathrm{CA}$ within beginning of construction. In attendance are the respective representatives of the $\mathrm{GC}, \mathrm{CM}, \mathrm{CA}, \mathrm{PM}, \mathrm{A} / \mathrm{E}$ and the mechanical, electrical, controls, and TAB subs. At the meeting commissioning parties are introduced and the commissioning process reviewed, management and reporting lines determined. The flow of documents, how much submital data the $\mathrm{CA}$ will receive, etc. are also being discussed. The $C x$ Plan is reviewed, process questions are addressed, lines of reporting and communications determined and the work products list discussed. Also covered are the general list of each party's responsibilities, who is responsible to develop the startup plan for each piece of equipment (Form C-7, Commissioning Progress Record) and the proposed commissioning schedule. The outcome of the meeting is increased understanding by all parties of the commissioning process and their respective responsibilities. The meeting provides the CA additional information needed to finalize the $C x$ Plan, including the commissioning schedule.

Prior to this meeting the $\mathrm{CA}$ is given, by the $\mathrm{GC}$, all drawings and specifications and the construction schedule by trade. The CA keeps notes from the meeting and distributes them to each team member.

\subsection{Final Commissioning Plan-Construction Phase}

[Bid Docs]

The CA finalizes the draft $C x$ Plan using the information gathered from the scoping meeting. The initial commissioning schedule is also developed (Table 8-1) along with a detailed timeline using Form C-10, Detailed Commissioning Schedule. The timeline is fine-tuned as construction progresses. In particular, [60] days prior to startup of the primary equipment, the $C A$ meets with the $G C$ and $C M$ and develops a detailed commissioning schedule. The commissioning plan is approved by the $\mathrm{CM}$.

\subsection{Site Observation}

The CA, and CM if applicable, makes periodic visits to the site, as necessary, to witness equipment and system installations.

\subsection{Miscellaneous Meetings}

The CA attends selected planning and job-site meetings in order to remain informed on construction progress and to update parties involved in commissioning. The $\mathrm{CM}$ and $\mathrm{GC}$ provide the $\mathrm{CA}$ with information regarding substitutions, change orders and any Architect's Supplemental Instructions (ASI) that may affect commissioning equipment, systems or the commissioning schedule. The CA may review construction meeting minutes, change orders or ASIs for the same purpose.

Later during construction, necessary meetings between various commissioning team parties will be scheduled by the $\mathrm{CA}$, through the $\mathrm{CM}$, as required.

Model Commissioning Plan and Guide Specifications 
Part IV. Commissioning Plan-Construction Phase .

\subsection{Miscellaneous Management Protocols}

The following protocols will be used on this project.

\section{Issue}

For requests for information (RFI) or formal documentation requests:

For minor or verbal information and clarifications:

For notifying contractors of deficiencies:

For scheduling functional tests or training:

For scheduling commissioning meetings:

For making a request for significant changes:

For making small changes in specified sequences of operations:

Subcontractors disagreeing with requests or interpretations by the CA shall:

\section{Protocol}

The CA goes first: direct to Sub or $\mathrm{A} / \mathrm{E}$, _ through the $\mathrm{CM}$, through GC.

The CA goes direct to the informed party.

The CA documents deficiencies through the $\mathrm{CM}$, but may discuss deficiency issues with contractors prior to notifying the CM.

The CA may provide input for and do some coordination of training and testing, but does not do any scheduling.

The CA selects the date and schedules through the:

CM, GC.

The CA schedules and notifies attendees directly.

The CA has no authority to issue change orders.

The CA may make small sequences of operations changes to improve efficiency or control or to correct deficiencies, through the responsible contractor, but shall document the change and provide all changes of specified sequences to the $\mathrm{CM}$ and $\mathrm{A} / \mathrm{E}$.

The CA may not make changes to specified sequences without approval from the $\mathrm{A} / \mathrm{E}$.

Try and resolve with the CA first. Then work through GC who will work with $\mathrm{CA}$ directly or through the $\mathrm{CM}$ to resolve the situation.

Additional protocols regarding the flow of documents and the commissioning process are shown in Appendix 2.

\subsection{Progress Reporting and Logs}

At the beginning of construction, the $\mathrm{CA}$ provides the $\mathrm{CM}$ with monthly commissioning progress reports. Thirty (30) days prior to the startup of the first piece of major equipment, the frequency of progress reports is increased to twice per month, until startup is completed. Thirty (30) days before functional testing of equipment begins, weekly progress reports are required until functional testing and all non-conformance issues are resolved. The CM may adjust the reporting frequency as needed. The progress reports contain: an update of the schedule with list of requested schedule changes and new items added to the schedule, a list of new and outstanding deficiencies, a description of commissioning progress corresponding to the plan, etc. Form C-4, Commissioning Progress Report provides a format for this report. The CA keeps a log of all commissioning-related issues that require current or future attention using Form $\mathrm{C}-1$, Commissioning Issues Log. Form C-7 Commissioning Progress Record provides a form for tracking the status of documentation and testing for each piece of equipment and system (e.g., installer, party responsible for 
startup, approval dates for checklist and testing forms, their completion, training, O\&M documentation review, etc.).

The CA regularly communicates with all members of the commissioning team, keeping them apprised of commissioning progress and scheduling issues through memos, progress reports, etc. (Form C-3e, Commissioning Memorandum).

The CA will keep all commissioning materials in an organized notebook. An example format is illustrated in Form C-17, Sample Commissioning Record Notebook Format, in Appendix 1.

\subsection{Initial Submittals and Documentation}

\subsubsection{Standard Submittals}

The CA provides all Subs responsible for commissioned equipment with commissioning documentation requirements for their respective equipment and systems through the $\mathrm{CM}$. This data request typically coincides with the normal A/E submittal process. At minimum, this equipment data includes installation and start-up procedures, O\&M data, performance data and control drawings. Form C-2, Request for Documentation and Record of Submissions for Commissioning provides documentation request and tracking forms for representative equipment and acts as the tracking mechanism for documentation. It can also be used as the checkoff sheet for part of the final O\&M documentation review.

\subsubsection{Special Submittals, Notifications and Clarifications}

The Subs, GC or A/E notify the CA of any new design intent or operating parameter changes, added control strategies and sequences of operation, or other change orders that may affect commissioned systems. The controls contractor provides the $\mathrm{CA}$ a full points list with details requested by the $\mathrm{CA}$ (see Specs $17100,3.3 ; 01300$ ). Thirty (30) days prior to performing owner-contracted tests, the Subs provide the $\mathrm{CA}$ full details of the procedures. As the phases of the TAB are completed, the draft TAB report is provided to the CA with full explanations of approach, methods, results, data table legends, etc. The final TAB report is provided to the CA upon completion.

These submittals to the CA do not constitute compliance for submittals for the O\&M manuals. Documentation requirements for the O\&M manuals are discussed in Section 5.11, herein.

The CA may request additional design narrative from the $\mathrm{A} / \mathrm{E}$ and from the controls contractor depending on how complete the documentation was which was provided with the bid documents. The CA may submit written RFIs to contractors through the CM, (Form C-3d, Commissioning Request for Information) or address them directly for clarifications, as needed.

\subsection{Prefunctional Checklists, Tests and Startup}

Prefunctional checklists (PC) are important to ensure that the equipment and systems are hooked up and operational and that functional performance testing may proceed without unnecessary delays. Each piece of equipment receives full prefunctional checkout by the Contractor. No sampling strategies are used. In general, the prefunctional testing for a given system, must be successfully completed prior to formal

- functional performance testing of equipment or subsystems of the given system.

Prefunctional checklists are primarily static inspections and procedures to prepare the equipment or system for initial operation (e.g., oil levels $\mathrm{OK}$, fan belt tension, labels affixed, gages in place, sensor calibration, etc.). However, some prefunctional checklist items entail simple testing of the function of a component, a piece of equipment or system (such as measuring the voltage imbalance on a three phase pump motor of a chiller system). The word prefunctional refers to before functional testing. Prefunctional checklists augment and are combined with the manufacturer's start-up checklist. 
Contractors typically already perform some, if not many, of the prefunctional checklist items the commissioning agent will recommend. However, few contractors document in writing the execution of these checklist items. This project requires that the procedures be documented in writing by the installing technician. The CA does not witness much of the prefunctional checklisting, except for testing of larger or more critical pieces of equipment and some spot-checking.

\subsubsection{Start-up Plan}

The CA assists the commissioning team members responsible for startup in developing detailed start-up plans for all equipment. The parties responsible for each part of startup and initial checkout are identified in Form C-7 Commissioning Progress Record and on the prefunctional checklists. Refer to Appendix 2, Chart 1 for a graphic description of how the prefunctional checklist and start-up plans are developed. Chart 3 in Appendix 2 shows a submittal map for reference.

A. The following procedures will be used for this project: (the $\mathrm{CA}$ is responsible for the plan development):

1. The CA adapts and enhances, if necessary, the representative prefunctional checklists (PC) and procedures from the lists in Specification Section 15998, and develops original lists, as necessary.

2. The CA obtains manufacturer installation, startup and checkout data, including actual field checkout sheets used by the field technicians from the contractor (through an RFI).

3. The CA copies all pages with important instructional data and procedures from the startup and checkout manuals not covered in manufacturer field checkout sheets and adds a signature line in the column by each procedure.

4. The copied pages from (2), along with the prefunctional checklist provided by the CA and the manufacturer field checkout sheets become the "Startup and Checkout Plan." Form C-8, Plan and Documenting Requirements for Startup, provides a cover sheet and template for the startup plan.

5. For systems that may not have adequate manufacturer startup and checkout procedures, particularly for components being integrated with other equipment, the Sub should provide the added necessary detail and documenting format to the $\mathrm{CA}$ for approval, prior to execution.

6. The CA transmits the full Startup Plan to the GC, who designates which trade or contractor is responsible to fill out each line item (mark in the "Contr" column) on the Prefunctional Checklist from the CA. The GC then transmits the full start-up plan to the Subs for their review and use. (This usually means that the Prefunctional Checklist, alone, will go to more than one Sub, while the full plan will go to the primary installing contractor.)

$-\mathrm{OR}-$

B. The following procedures will be used for this project: (the Sub is responsible for the plan development):

1. The CA adapts and enhances, if necessary, the representative prefunctional checklists (PC) and procedures from the lists in Specification Section 15998, and develops original lists, as necessary.

2. The $\mathrm{CA}$ transmits them to the $\mathrm{GC}$ who designates which trade or contractor is responsible to fill out each line item (mark in the "Contr" column) on the Prefunctional Checklist from the CA. The GC then transmits the checklist to the responsible Subs. 
3. The Sub designated to develop the Start-up Plan obtains manufacturer installation, start-up and checkout data, including actual field checkout sheets used by the field technicians.

4. The Sub copies all pages with important instructional data and procedures (not covered in manufacturer field checkout sheets) from the start-up and checkout manuals and adds a signature line in the column by each procedure.

5. The copied pages from (2), along with the prefunctional checklist provided by the GC (originally from the CA) and the manufacturer field checkout sheets become the "Start-up and Checkout Plan." Form C-8, Plan and Documenting Requirements for Startup, provides a cover sheet and template for the start-up plan.

6. For systems that may not have adequate manufacturer start-up and checkout procedures, particularly for components being integrated with other equipment, the Sub should provide the added necessary detail and documenting format to the CA for approval, prior to execution.

7. The Sub transmits the full Start-up Plan to the CA for review and approval.

8. The $\mathrm{CA}$ reviews and approves the procedures and the format for documenting them using a standard form (Form C-3a or b, Commissioning Test or Review Approval or Commissioning Prefunctional Checklist and Startup Submittal / Approval), noting any procedures that need to be added, and conveys to the GC. The GC then transmits the full start-up plan to the Subs for their review and use. (This usually means that the Prefunctional Checklist, alone, will go to more than one Sub, while the full plan will go to the primary installing contractor.)

\subsubsection{Execution of Checklists and Startup}

Four weeks prior to startup, the Subs and vendors schedule startup and initial checkout with the CM, GC and CA. The startup and initial checkout are directed and executed by the Sub or vendor. The CA, and CM if necessary, observe, at minimum, the procedures for each piece of primary equipment, unless there are multiple units, when a sampling strategy is used. For components of equipment, (e.g., VAV boxes), the CA observes a sampling of the prefunctional and start-up procedures.

To document the process of startup and checkout, the site technician perfoming the line item task initials and dates each paragraph of procedures in the "Startup Plan" and checks off items on the prefunctional and manufacturer field checkout sheets, as they are completed. Only individuals having direct knowledge of a line item being completed shall check or initial the forms.

The Subs and vendors execute the checklists and tests and submit a signed copy of the completed start-up and prefunctional tests and checklists to the $\mathrm{CA}$, using Form C-3a or b. Further details are found in the Specifications Section 17100, Part 3.4. The CA may review prefunctional checklists in progress, as necessary. On smaller equipment or projects, the checklists (which all contain more than one trade's responsibility), may be passed around to the Subs to fill out. For larger projects, each trade may need a full form and the CA will consolidate them later.

\subsubsection{Sampling Strategy for CA Observation of Prefunctional Checkout and Startup}

The following table provides a tentative list of the equipment and how much of the prefunctional checkout and startup work will be witnessed by the commissioning agent.

\section{Equipment or System}

Central plant (chillers, boilers, cooling tower)

Packaged roof top units

Pumps, VFD's
Fraction To Be

Observed by $C_{A}$

$50 \%$

$50 \%$

$10 \%$ 
Pipe flushing

Terminal units

Building automation system

TAB work

Other misc. equipment
At beginning and end

$2 \%$

Observe _ hours of checkout and calibration

Observe _ hours of TAB

As necessary

\subsubsection{Deficiencies and Non-Conformance}

The Subs clearly list any outstanding items of the initial start-up and prefunctional procedures that were not completed successfully at the bottom of the procedures form or on an attached sheet. The procedures form and deficiencies are provided to the CA within two days of test completion. The CA works with the Subs and vendors to correct and retest deficiencies or uncompleted items, involving the CM and others as necessary. The installing Subs or vendors correct all areas that are deficient or incomplete according to the checklists and tests. The CA recommends approval of the startup and initial checkout of each system to the CM using Form C-3a. Further details are found in the Specifications Section 17100, Part 3. Refer to Appendix 2, Chart 5 for a flow chart of the documentation process.

\subsubsection{Phased Commissioning}

Because of project size, this project __ will require, __will not require startup and initial checkout to be executed in phases. The phasing is summarized in Form C-12, Phased Commissioning, in Appendix 1. Additional resolution of these phases can be found in the detailed commissioning schedule.

\subsubsection{TAB}

The TAB contractor submits the outline of the TAB plan and approach to the $\mathrm{CA}$ and the controls contractor eight weeks prior to starting the TAB. Included in the approach, is an explanation of the intended use of the building control system. The CA reviews the plan and approach for understanding and coordination issues and may comment, but does not "approve." The controls contractor reviews the feasibility of using the building control system for assistance in the TAB work. The TAB submits weekly written reports of discrepancies, contract interpretation requests and lists of completed tests to the $C A$ and CM. This facilitates quicker resolution of problems and will result in a more complete TAB before functional testing begins. A checklist form for reviewing theTAB plan is provided as one of the prefunctional checklists in Specifications Section 15998 (file: tabplan.c03).

TAB work will not begin until the control system has been prefunctionally tested and selective functional tests have been performed and approved by the $\mathrm{CA}$.

\subsubsection{Controls Checkout Plan}

The controls contractor develops and submits a written step-by-step plan to the $\mathrm{CA}$ which describes the process they intend to follow in checking out the control system and the forms on which they will document the process. The controls contractor will also meet with the TAB contractor prior to the start of TAB and review the TAB plan to determine the capabilities of the control system for use in TAB. The controls contractor will provide the TAB with any necessary unique instruments for setting terminal unit boxes and instruct TAB in their use (handheld control system interface for use around the building during TAB, etc.). The controls contractor shall also provide a technician qualified to operate the controls to assist the TAB contractor in performing TAB. Additional details are found in Specifications Section 15995.

All CA-required controls prefunctional checklists, calibrations, start-up and selected functional tests of the system shall be completed and approved by the CA prior to TAB. The controls contractor shall execute the 
tests and trend logs assigned to them in Section 15997 and 16997 and remain on site for assistance for mechanical system functional tests as specified in the same sections.

\subsection{Development of Functional Test and Verification Procedures}

\subsubsection{Overview}

Functional testing is the dynamic testing of systems (rather than just components) under full operation (e.g., the chiller pump is tested interactively with the chiller functions to see if the pump ramps up and down to maintain the differential pressure setpoint). Systems are tested under various modes, such as during low cooling or heating loads, high loads, component failures, unoccupied, varying outside air temperatures, fire alarm, power failure, etc. The systems are run through all of the control system's sequences of operation and components are verified to be responding as the sequences state. The commissioning agent develops the functional test procedures in a sequential written form, coordinates, oversees and documents the actual testing, which is usually performed by the installing contractor or vendor.

\subsubsection{Scope of Testing}

[Bid Docs]

The specification "Testing Requirements" Sections 15997 and 16997 provide specific functional testing scope for each piece of commissioned equipment. A detailed description of the functional and prefunctional testing procedures and process is found in the Specifications, 17100 Part 3. If specific testing requirements were not included in the bid documents and original specifications, they should be developed for this project for each piece of commissioned equipment. Another example format, with less detail than than in the Guide Specifications Sections 15997 and 16997, that may be useful is illustrated in Form C-15, Functional Testing Scope Outline.

\subsubsection{Development Process}

Before test procedures are written, the CA obtains all requested documentation and a current list of change orders affecting equipment or systems, including an updated points list, control sequences and setpoints. The CA develops specific test procedures to verify proper operation of each piece of equipment and system, using the testing requirements in the Specifications, Sections 17100 and Sections 15995, 15997, 16995 and 16997 and the representative test procedure formats found in Sections 15999 and 16999 and other sources. The CA obtains clarification, as needed, from contractors and the A/E regarding sequences and operation to develop these tests. Prior to execution, the CA provides a copy of the primary equipment tests to the installing Sub (via the $\mathrm{GC}$ ) who reviews the tests for feasibility, safety, warranty and equipment protection. Blank copies of the procedures are input into the O\&M manuals for later use by operations staff. Refer to Appendix 2, Chart 2 for an illustration of the development of functional test forms and Chart 4 for the functional test submittal map.

Functional testing and verification may be achieved by manual testing (persons manipulate the equipment and observe performance) or by monitoring the performance and analyzing the results using the control system's trend log capabilities or by stand-alone dataloggers. The CA follows the Specifications when given and uses judgement where needed to determine which method is most appropriate. According to the Specifications, not all pieces of identical equipment receive in-depth testing. The CA reviews ownercontracted, factory or required owner acceptance tests and determines what further testing may be required to comply with the Specifications. Redundancy is minimized.

Form C-13, Owner Contracted Tests, lists the owner-contracted or conducted tests for which the CA does not write procedures or document execution. Included in Form C-13 is the CA's judgement as to the rigor of the tests and the need for more in-depth testing. The CA reviews and approves documentation format of these tests prior to execution, but does not develop the procedures or document their execution, unless so requested by the $\mathrm{CM}$. 


\subsubsection{Testing Plan Overview}

To provide the contractors with a better idea of where functional testing lies in the schedule, what issues are preventing the start of testing, which contractors are needed for each test and how much time might be expected from them, Form C-11, Commissioning Functional Testing Plan Overview, is used. This form is filled out after most equipment has been started up and when functional testing dates are not too far off. The form is provided to the Contractors to assist in moving more efficiently to functional testing.

\subsection{Execution of Functional Testing Procedures}

\subsubsection{Overview and Process}

The CA schedules functional tests through the CM, GC and affected Subs. The CA oversees, witnesses and documents the functional testing of all equipment and systems according to the Specifications and the Cx Plan. The Subs execute the tests. The control system is tested before it is used to verify performance of other components or systems. The air balancing and water balancing is completed and debugged before functional testing of air-related or water-related equipment or systems. Testing proceeds from components to subsystems to systems and finally to interlocks and connections between systems. Refer to Section 6 for details on functional testing scope. Refer to specification section 17100 Part 3 for additional process details and to Appendix 2, Chart 5, for a flow chart of the documentation process.

\subsubsection{Deficiencies and Retesting}

The CA documents the results of the test. Corrections of minor deficiencies identified are made during the tests at the discretion of the CA. The CA records the results of the test on the procedure or test form. Deficiencies or non-conformance issues are noted and reported to the CM on Form C-6 (Commissioning Corrective Action Report). Subs correct deficiencies, notify the CA and return Form C-6 certifying correction. The CA schedules retesting through the $\mathrm{CM}$. Decisions regarding deficiencies and corrections are made at as low a level as possible, preferrably between CA or CM and the Sub. For areas in dispute, final authority, besides the Owner's, resides with the A/E. The CA recommends acceptance of each test to the CM. The CM gives final approval on each test using Form C-3a or b (Commissioning Test or Review Approval or Commissioning Prefunctional Checklist and Startup Submittal / Approval) form. For tracking, Form C-7, Commissioning Progress Record, is provided which lists all tests and their status. Refer to Specifications Section 17100 Part 3.7 for further details.

\subsubsection{Facility Staff Participation}

The Owner's facilities operating staff are encouraged to attend and participate in the testing process. The tables in Form C-14, Facility Staff Participation, summarize the planning of their involvement. This form does not describe their involvement in formal training. The CA will notify the CM, then notify the facility staff when the commissioning events will occur.

\subsubsection{Phased Testing}

Refer to Section 5.8.5 for details regarding testing the equipment or systems in phases.

\subsubsection{Sampling}

Multiple identical pieces of non-life-safety or otherwise non-critical equipment may be functionally tested using a sampling strategy. The Specifications specify the sampling strategies that are used on this project, with a summary listed in Form C-15, Functional Testing Scope Outline, if used. 


\subsection{O\&M Manuals and Warranties}

\subsubsection{Standard O\&M Manuals}

The CA reviews the O\&M manuals, documentation and redline as-builts for systems that were commissioned to verify compliance with the Specifications. The CA recommends approval and acceptance of these sections of the O\&M manuals to the CM. The CA also reviews each equipment warranty and verifies that all requirements to keep the warranty valid are clearly stated. Refer to Specificaions 17100 Part 3.8 for further details.

\subsubsection{Commissioning Record}

The CA will compile, organize and index the following commissioning data by equipment into labeled, indexed and tabbed, three-ring binders and deliver it to the $\mathrm{GC}$, to be included with the O\&M manuals. The correspondence, meeting minutes and progress reports, miscellaneous notes, etc. kept in the Commissioning Record Book during construction will not be retained into this record and the O\&M manuals. The format of the manual follows:

General

Tab I-1 Commissioning Plan

Tab I-2 Final Commissioing Report

Tab I-3 Issues Log (record of deficiencies, Form.C-1)

Tab I-4 Progress Record (Form C-7)

Equipment Specific

Tab 01 System Type 1 (chiller system, packaged unit, boiler system, etc.)

$S u b-T a b A \quad$ Design narrative and criteria, sequences, approvals for Equipment 1

Sub-Tab B Start-up plan and report, approvals, corrections, blank prefunctional checklists Colored Separator Sheets-for each equipment type (fans, pumps, chiller, etc.)

Sub-Tab C Functional tests (completed), trending and analysis, approvals and corrections, training plan, record and approvals, blank functional test forms and a recommended recommissioning schedule.

Tab 02 System Type 2......repeat as per System One

\subsection{Training and Orientation of Owner Personnel}

Owner training and orientation on equipment and systems provided by the Contractor is accomplished in three general steps using three forms.

1. Overall Plan. After reviewing the specifications, and after interviewing facility staff, if necessary, the Owner and Commissioning Agent (CA) fill out a table listing all the equipment for which training or orientation will be provided, on Form C-5a, Project Training Plan-General Scope and Responsible Parties. This form lists, among other things, the type and number of trainees, rigor of training desired by the Owner, the primary responsible subcontractor, the trainer's company and columns for tracking training agendas. The Commissioning agent provides this form to the Contractor for reference.

2. Specific Training Agendas. For each piece of equipment or system for which training is provided, the Owner and CA fill out Section 1 of the Training and Orientation Agenda, Form C-5b. This section includes some of the information from Form C-5a, regarding the scope of training and the intended audience, for reference by the trainer in developing the training agenda. The CA develops a plan for including in the training session contractors / trainers from different disciplines, when appropriate, by listing their company names in Section 2 of the form. In particular, the controls contractor will provide brief training on controls in the same session with the mechanical training for equipment controlled by the building automation system. 
This form is then submitted to the Contractor who has the trainer fill out the rest of Sections 2 and 3 of the form (Form C-5b), describing the subjects covered, duration of each subject and the methods that will be used in the training, along with the name and qualifications of the trainer(s). The trainer returns this form to the Contractor, who submits it to the Owner and CA. The Owner and CA review the agenda; make comments; approve the form subject to the comments; and submit back to the Contractor. The Contractor provides the approved agenda to the trainer to use during the training. The trainer provides a copy of the agenda to each trainee.

3. Training Record. For each piece of equipment, prior to training, the Contractor provides each trainer Form C-5c, Training and Orientation Record. On this form, the trainer documents each training session (duration and general subjects covered). The trainer signs for the session and obtains the signature of each trainee. The trainer also checks off subjects covered on the Agenda (Form C-5b). When the training is complete, the Contractor provides a copy of the Training and Orientation Record, Form C-5c, and the trainer's Agenda, Form C-5b to the Owner and CA. The Owner and CA review $\mathrm{C}-5 \mathrm{c}$ and make final approval by signing it. The CA may witness any of the training sessions. Refer to Specifications 17100 Part 3.10 for further details.

\subsubsection{Special Training and Orientation}

The following checked orientation and trainings will be completed by the $\mathrm{CA}$ and $\mathrm{A} / \mathrm{E}$ according to the specifications:

Recommissioning. The commissioning agent will provide instruction on the use of blank functional test forms for periodic recommissioning of equipment and systems, per the specification.

Architect. The architect will provide a general overview of the facility, its use, special features, tenant and public considerations, etc.

Mechanical Design Engineer. The mechanical designer will provide an overview of the major systems and equipment in the facility, including for each system: the design intent, why the system was chosen, an overview of its operation, and interactions with other systems, any special areas to be aware of, issues regarding future expansion and remodeling, etc.

Electrical Design Engineer. The electrical designer will provide an overview of the major electrical systems and equipment in the facility, particularly the lighting control systems, fire alarm, security and emergency power, focusing on the design intent, why the system was chosen, an overview of its operation, and interactions with other systems, any special areas to be aware of, issues regarding future expansion and remodeling, etc.

\subsection{Warranty Period}

During the warranty period, seasonal testing and other deferred testing required is completed according to the Specifications. The CA coordinates this activity. Tests are executed and deficiencies corrected by the appropriate Subs, witnessed by facilities staff and the CA. Any final adjustments to the O\&M manuals and as-builts due to the testing are made. Refer to specification sections 15997 and 16997 for seasonal testing details for this project. In addition the $\mathrm{CA}$ will return to the project approximately 10 months into the 12 month warranty period. During this visit(s) the CA will review with facility staff the current building operation and the condition of outstanding issues related to the original and seasonal commissioning. The $\mathrm{CA}$ will also interview facility staff and identify problems or concerns they have operating the building as originally intended. The CA will make suggestions for improvements and for recording these changes in the O\&M manuals. The $\mathrm{CA}$ will identify areas that may come under warranty or under the original construction contract. The CA will also assist facility staff in developing reports and documents and requests for services to remedy outstanding problems. 


\section{Written Work Products}

[Bid Docs]

The written work products from all parties are described in Form C-16, Formal Written Work Products. The table describes each product, who is responsible for producing it, the general due date, the parties who receive it and who approves it, etc.

\subsection{Summary Report}

A final summary report (about four to six pages, not including backup documentation) by the CA will be provided to the CM or PM. The report will focus on evaluating commissioning process issues, identifying areas where the process could be improved. All acquired documentation, logs, minutes, reports, deficiency lists, communications, findings, unresolved issues, etc., will be compiled in appendices and provided with the summary report. Prefunctional checklists, functional tests and monitoring reports will not be part of the final report, but will be stored in the Commissioning Record in the O\&M manuals.

\section{Schedule}

\subsection{General Issues}

[Bid Docs]

The following sequential priorities are followed:

1. Equipment is not "temporarily" started (for heating or cooling), until pre-start checklist items and all manufacturer's pre-start procedures are completed and moisture, dust and other environmental and building integrity issues have been addressed.

2. Functional testing is not begun until prefunctional and start-up and TAB is completed, for a given system (this does not preclude a phased approach).

3. The controls system and equipment it controls are not functionally tested until all points have been calibrated and pre-functional testing completed.

4. TAB is not performed until the controls system has been sufficiently functionally tested and approved by the CA for TAB work, except for

5. TAB is not performed until the envelope is completely enclosed and ceiling complete, unless the return are is ducted. 


\subsection{Project Schedule}

The initial commissioning schedule is summarized in Table 7-1. A more detailed schedule is contained in Form C-10, Detailed Commissioning Schedule, in Appendix 1.

Table 7-1. Initial Commissioning Schedule Summary

\begin{tabular}{|l|l|l|}
\hline \multicolumn{1}{|c|}{ Task / Activity } & $\begin{array}{c}\text { Estimated Start } \\
\text { Date }\end{array}$ & Estimated End Date \\
\hline \hline Initial scoping meeting and final plan & & \\
\hline Submittals obtained and reviewed & & \\
\hline Begin construction site visits/inspections & & \\
\hline Prefunctional forms developed and distributed & & \\
\hline Startup and initial checkout plans & & \\
\hline Startup and initial checkout executed & & \\
\hline TAB Aater & & \\
\hline Functional performance tests & & \\
\hline O\&M documentation review and verification & & \\
\hline Training and training verification & & \\
\hline Final commissioning report & & \\
\hline Seasonal testing & & \\
\hline
\end{tabular}


Part IV. Commissioning Plan-Construction Phase

\section{Part IV}

\section{APPENDIX 1}

\section{Construction Phase Application Forms}

\section{Form}

Number

C-1 Commissioning Issues Log

C-2 Request for Documentation and Record of Submissions

C-3a Commissioning Test or Review Approval

C-3b Commissioning Prefunctional Check Submittal / Approval

C-3c Commissioning Transmittal

C-3d Commissioning Request for Information

C-3e Commissioning Memorandum

C-3f Submittal for Sequences \& Test Forms

C-4 Commissioning Progress Report

Training Project Training and Orientation Procedures

C-5a Overall Staff Training and Orientation Plan

C-5b Training and Orientation Agenda

C-5c Staff Training and Orientation Record

C-6 Commissioning Corrective Action Report

$\mathrm{C}-7$ Commissioning Progress Record

C-8 Plan and Documentation Requirements for Startup and Initial Checkout

C-9 Detailed Commissioning Schedule (blank)

C-10 Detailed Commissioning Schedule (filled in)

C-11 Commissioning Functional Testing Plan Overview

C-12 Phasing of Commissioning Testing

C-13 Owner-Contracted Tests

C-14 Facility Staff Participation in Commissioning

C-15 Functional Testing Scope Outline (example)

C-16 Commissioning Formal Written Work Products

C-17

Commissioning Record Notebook Format
Name ${ }^{1}$
ISSULOG.CO1
DOCREQC2.XLS
APROVAL2.C3A
PCSUBMIT.C3B
TRANSMIT.CBC
INFOREQ.C3D
MEMORAND.C3E
SUBFTFRM.C3F
PROGREPT.CO4
TRAINPRO.CED
TRAINPLN.C5A
TRAINAGE.C5B
TRAINREC.C5C
CORECTON.CO6
RECORDC7.XLS
STARTPLN.COB
TIMEBLC9.XLS
TIMEFC10.XLS
FTOVRVU.C11
PHASES.C12
OWNRTEST.C13
STAFPART.C14
SCOPEFILC15
PRODUCTS.C16
BOOK_C17.XLS 


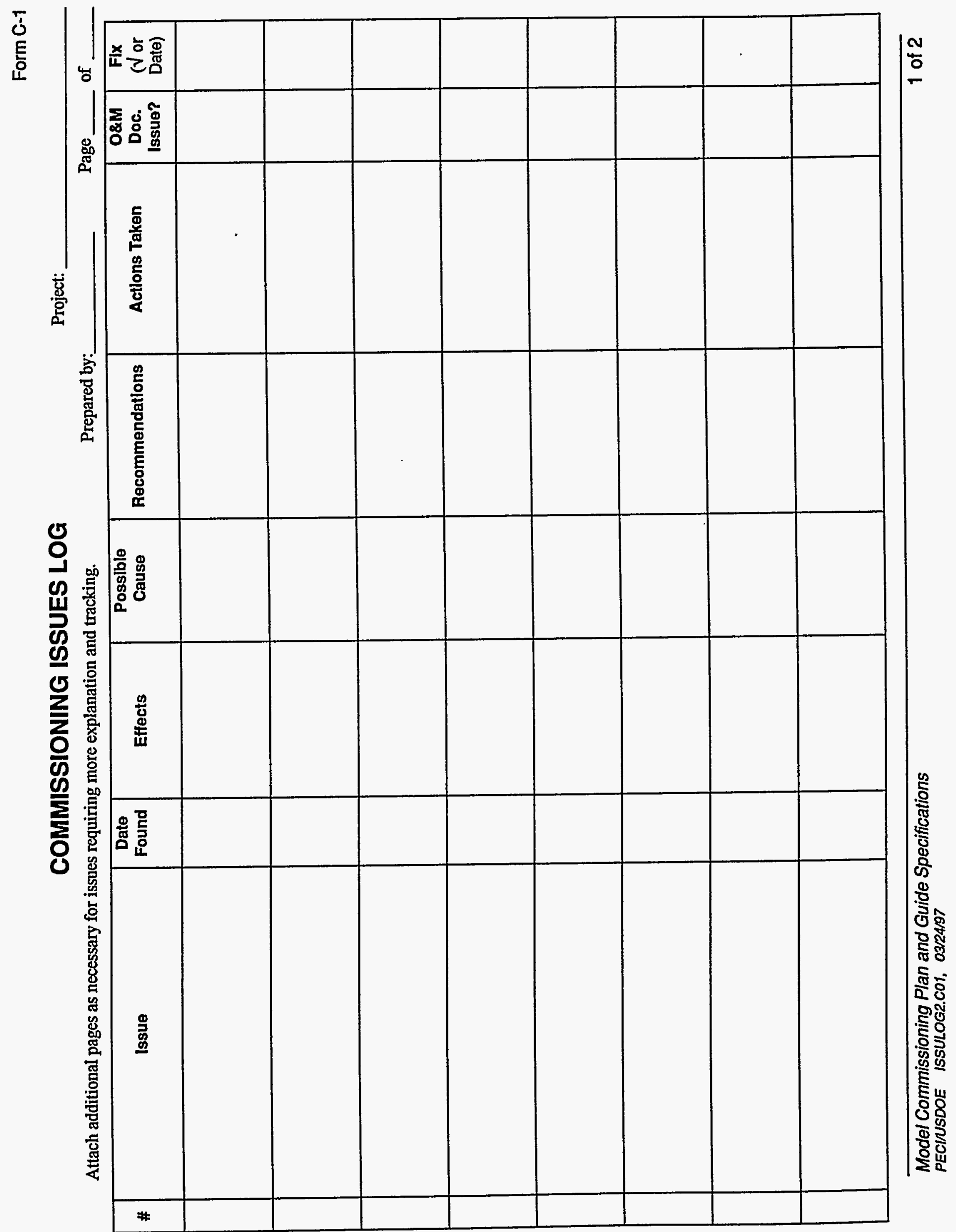




\section{REQUEST FOR DOCUMENTATION AND RECORD OF SUBMISSIONS}

Project:

Dates of Request:

Provide data for all BLANK or clrcied cells. Left $\checkmark$ or date $=$ recelved Right $x$ or date $=$ approved. [d]

Send to:

\begin{tabular}{|c|c|c|c|c|c|c|c|c|c|c|c|c|c|c|c|}
\hline & & & $1<-P a$ & d. Os & & & &  & & $3 M$ & 1 & $\rightarrow$ & & & \\
\hline $\begin{array}{c}\text { Equip. } \\
\text { Tag }\end{array}$ & $\begin{array}{l}\text { Equipment } \\
\text { Description }\end{array}$ & $\begin{array}{l}\text { Spec } \\
\text { Section }\end{array}$ & 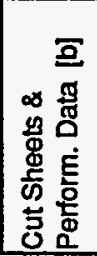 & 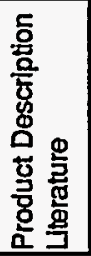 &  & 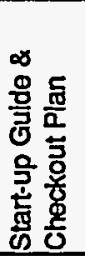 & 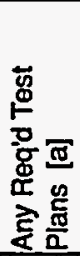 & 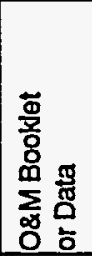 & 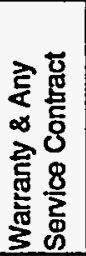 & 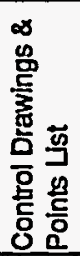 & 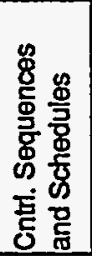 & 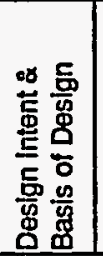 & $\begin{array}{l}\frac{9}{5} \\
\frac{8}{8} \\
\frac{1}{0} \\
\frac{0}{3} \\
\frac{1}{5} \\
\frac{5}{50}\end{array}$ & 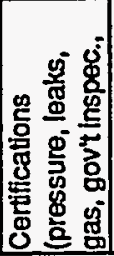 & 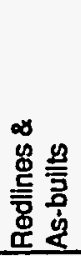 \\
\hline
\end{tabular}

PUMPS (HVAC)

Date needed by:

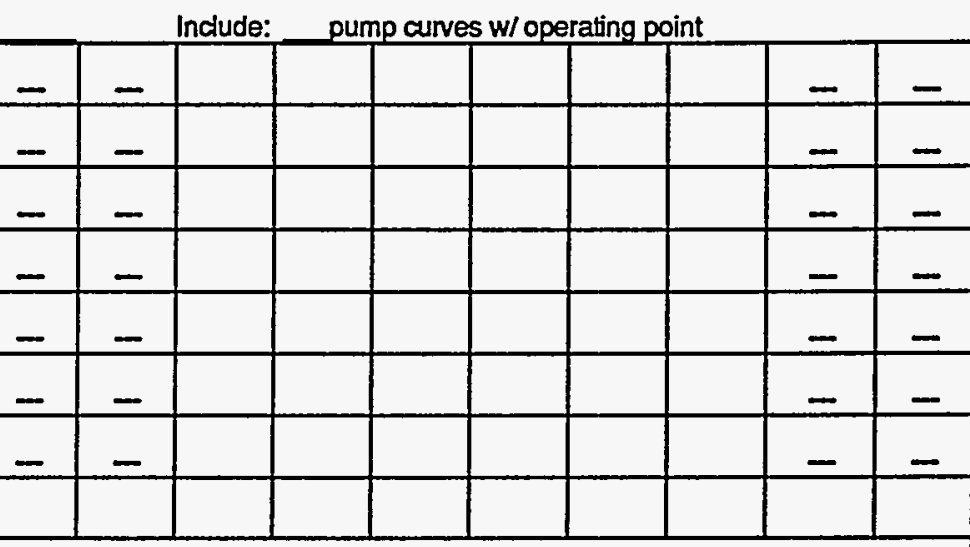

CHILLER SYSTEM

Date needed by:

Include: certified efficiencies

Chiller

Chiller

DHW circ. pump

DHW booster pump

Htg. primary

Htg secondary

HW primary

CHW secondary

CDW

\begin{tabular}{|l|l|}
\hline & \\
\hline &
\end{tabular}

\begin{tabular}{|l|l|l|}
\hline & & \\
\hline & & \\
\hline & & \\
\hline
\end{tabular}

COOUNG TOWER

Date needed by:

Include: certified efficiencies

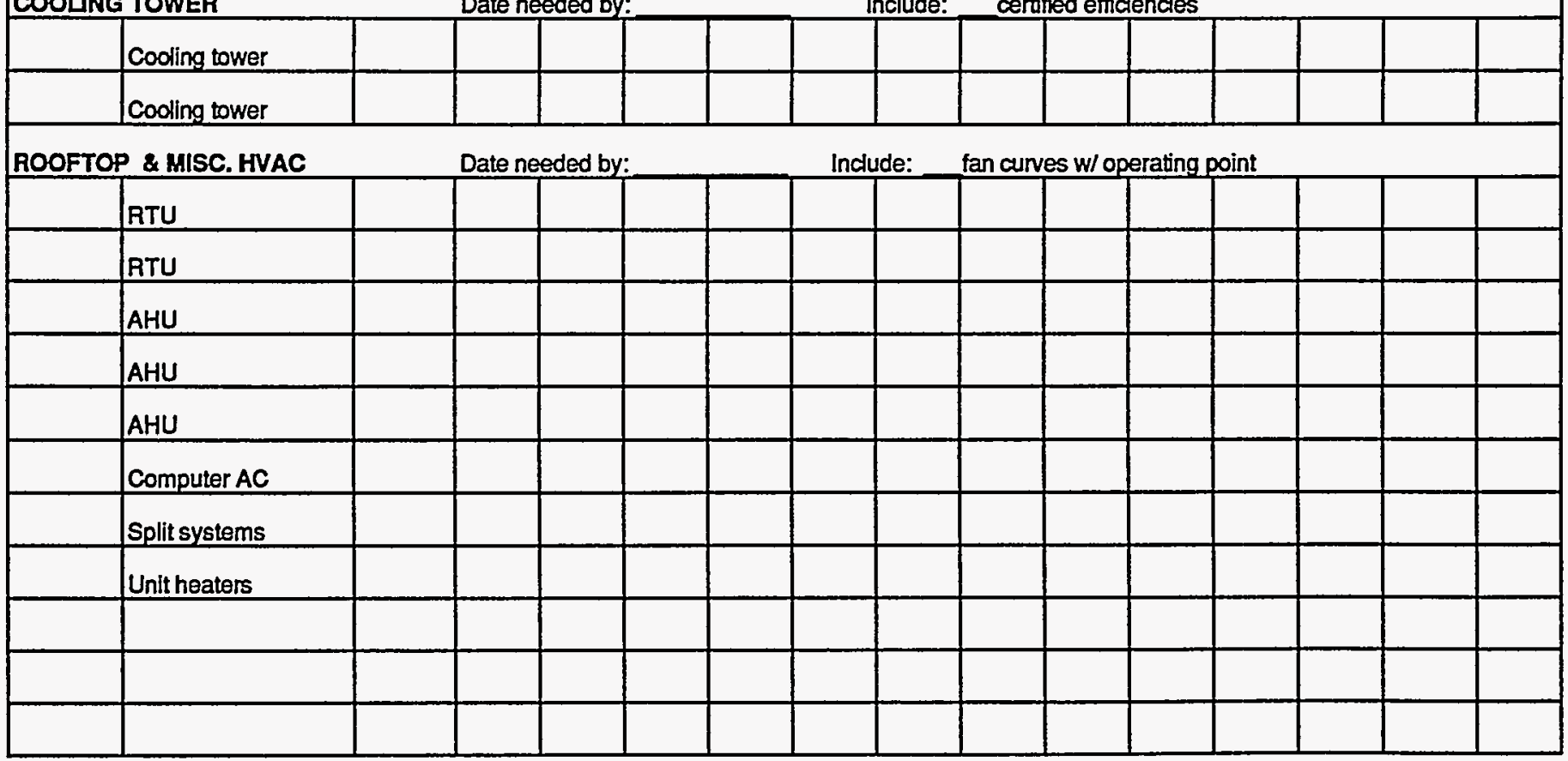




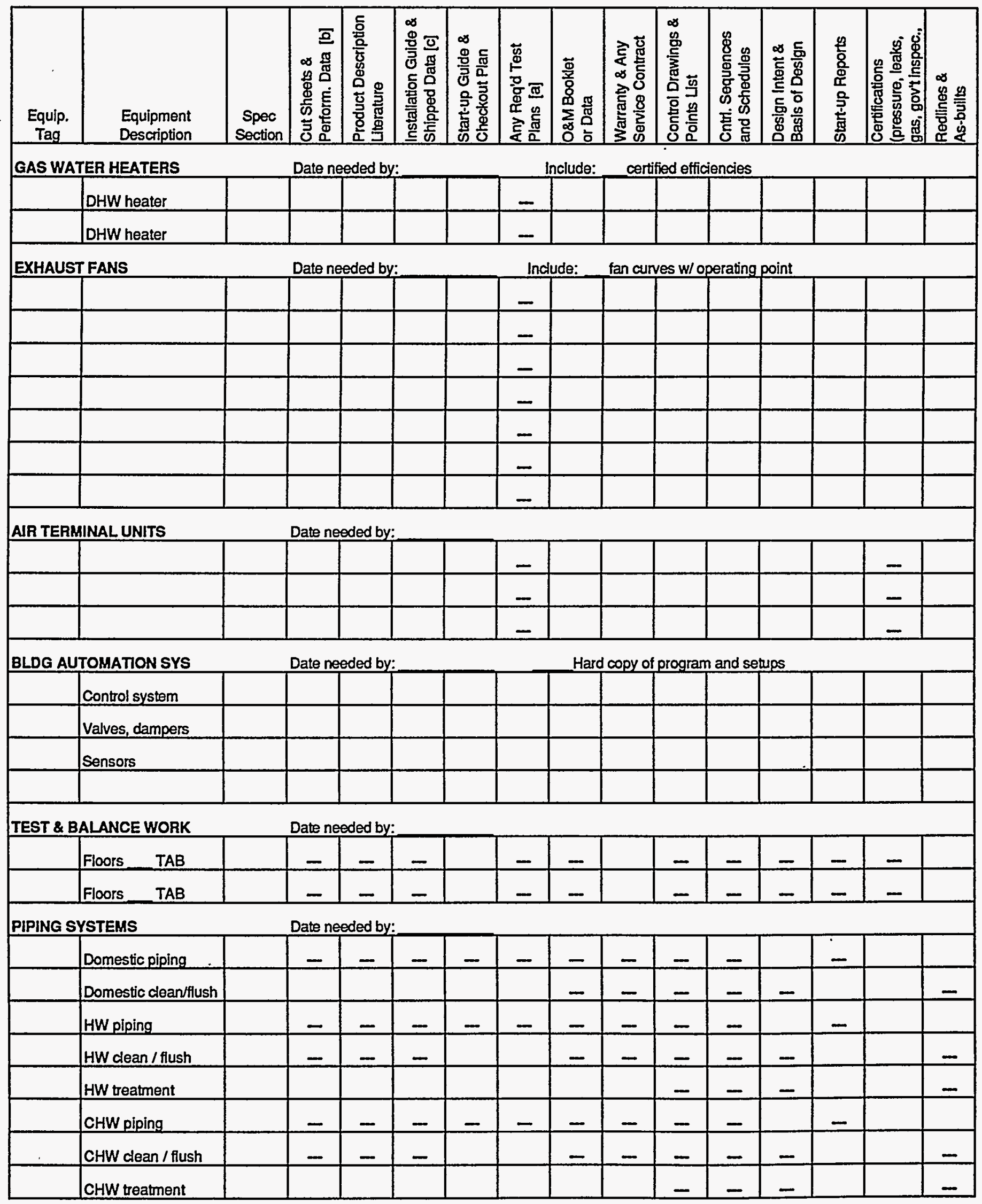




\begin{tabular}{|c|c|c|c|c|c|c|c|c|c|c|c|c|c|c|c|}
\hline $\begin{array}{l}\text { Equip. } \\
\text { Tag }\end{array}$ & $\begin{array}{l}\text { Equipment } \\
\text { Description }\end{array}$ & $\begin{array}{c}\text { Spec } \\
\text { Section }\end{array}$ & 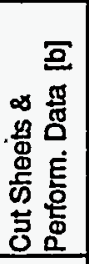 & 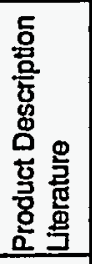 & 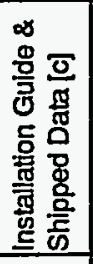 &  &  & 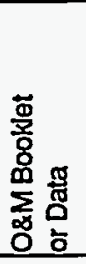 & 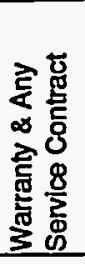 &  &  & 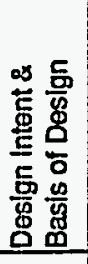 &  & 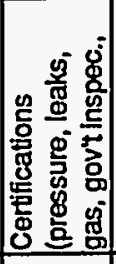 & 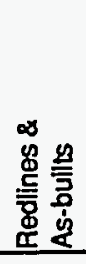 \\
\hline & CD piping & & $=$ & - & - & - & - & - & - & - & - & & - & & \\
\hline & CD dean / flush & & 二 & $=$ & $=$ & & & $=$ & - & - & - & $=$ & & & - \\
\hline & $C D$ treatment & & & & & & & & & $=$ & $=$ & $=$ & & & - \\
\hline & F. Sprinkler piping & & - & - & $=$ & - & - & - & - & - & - & & - & & \\
\hline & F. S. clean / flush & & - & - & $=$ & & & - & - & - & - & $=$ & & & $=$ \\
\hline & F.S. treatment & & & & & & & & & - & $=$ & - & & & $=$ \\
\hline LGGHTINC & CONTROLS & & Date ne & aded by: & & & & & & & & & & & \\
\hline & Daylighting controls & & & & & & - & & & & & & & - & \\
\hline & Occup. sensors & & & & & & - & & & & & & & $=$ & \\
\hline & Ltg. sweeps & & & & & & - & & & & & & & - & \\
\hline & Extlighting cotrls & & & & & & - & & & & & & & - & \\
\hline EMERG. & POWER SYSTEM & & Date ne & oded by: & & & & & & & & & & & \\
\hline & Generator & & & & & & - & & & & & & & & \\
\hline & ATS & & & & & & - & & & & & & & & \\
\hline & UPS & & & & & & $=$ & & & & & & & & \\
\hline & & & & & & & & & & & & & & & \\
\hline FIRE ANI & SMOKE ALARM & & Date ne & eded by & & & & & & & & & & & \\
\hline & FA System & & & & & & & & & & & & & & \\
\hline & Fire / smoke dampers & & & & & - & - & - & & & & & & $=$ & \\
\hline & Sys. response matrix & & - & - & $=$ & - & - & - & - & - & & & - & - & \\
\hline & Fire marshal test & & - & - & - & - & - & - & - & - & - & $=$ & - & - & \\
\hline & & & & & & & & & & & & & & & \\
\hline & & & & & & & & & & & & & & & \\
\hline MEDICA & GAS SYSTEMS & & Date ne & eded by & & & & & & & & & & & \\
\hline & Suction & & & & & & & & & & & & & & \\
\hline & 02 & & & & & & & & & & & & & & \\
\hline & NO2 & & & & & & & & & & & & & & \\
\hline & Piping & & & & & & & & & & & & & & \\
\hline
\end{tabular}

[a] Functional test plans or procedures required in the specifications to be submitted by the contractor.

[b] Plan Tag, Model and Features used on this project must be clearly marked.

[c] This includes the following: a) Installation guide found in the std. O\&M booklet or as a separate sheet. b) All installation and O\&M data shipped inside the pieces of equipment. c) The actual startup and checkout field record sheets used by the technician, not the generic one found with the installation guide. Additionally, any mfr. engineering bulletins applicable to this equipment shall be included.

[d] Enter a check or date in the left side of the cell when received and an $X$ or date in right side when approved. 


\section{COMMISSIONING TEST OR DOCUMENT APPROVAL}

Project:

_Completed Functional Test Approval

Equipment Name:

Equipment Tag:

Functional Test Description:

Document Review Document Name and ID:

Review Description:

The test(s) of the above equipment or the review of the referenced document(s) have been completed and performance of the component, system or documents complies with the acceptance criteria in the testing or document requirements of the Specifications and Contract Documents, subject to the changes being made as listed below or on an attached sheet.

Sheets attached

A copy of the completed test or document review is attached. (Y/N)

Commissioning Agent Approval:

Commissioning Agent

Date

Construction Manager Approval:

The test or review results relating to the above equipment has been reviewed and approved as complying with the contract documents.

Exclusions: 


\section{COMMISSIONING PREFUNCTIONAL CHECK LIST and START-UP SUBMITTAL / APPROVAL}

Project:

Cx Section No:

From (initially):
SUBMITTAL NO:

$\square$ New $\square$ Resubmittal

Equipment or System Tag and Name:

Included:

Prefunctional checklist form

Startup and Intitial Checkout: __ Documentation format, __ Execution Plan

\begin{tabular}{|c|c|c|c|c|c|}
\hline & & Submission & s/ Returns & & \\
\hline & $\begin{array}{c}\text { Transmittal } \\
\text { of blanks }\end{array}$ & $\begin{array}{c}\text { Transmital } \\
\text { of blanks }\end{array}$ & $\begin{array}{c}\text { Return of } \\
\text { completed forms }\end{array}$ & $\begin{array}{l}\text { Submission of } \\
\text { completed forms }\end{array}$ & $\begin{array}{l}\text { Submission of } \\
\text { completed forms }\end{array}$ \\
\hline Path & To $\left(\mathrm{CM}_{2} \_\mathrm{GC}\right):$ & To (sub): & $\begin{array}{l}\text { To }(C M, \\
\text { - GC, _CA): }\end{array}$ & $\begin{array}{l}\text { To _CA, } \\
\text { _ } / \mathrm{E}, \text { Owner) }\end{array}$ & $\begin{array}{l}\text { To ( } C A, \\
\text { A/E,_Owner, } \\
\text { _CM,_GC) }\end{array}$ \\
\hline & IIU⿴囗十⺝ & -GC, _CA): & from (sub): & $\begin{array}{l}\text { from }(C M \\
\text { GC, _CA): }\end{array}$ & $\begin{array}{l}\text { from }(C M, C M) \\
\text { GC, _CA : }\end{array}$ \\
\hline $\begin{array}{l}\text { Comments } \\
\text { by } \\
\text { Submitter }\end{array}$ & $\begin{array}{l}\text { Fill in the "Contr." } \\
\text { column with the } \\
\text { responsible party. } \\
\text { Copy and distribute } \\
\text { to all involved } \\
\text { contractors. } \\
\text { 口 Notes attached }\end{array}$ & $\begin{array}{l}\text { Execute checklists } \\
\text { per directions and } \\
\text { return to: } \\
\\
\square \text { Notes attached }\end{array}$ & $\begin{array}{l}\text { This checklist } \\
\text { and startup } \\
\text { report has been } \\
\text { executed } \\
\text { successfully per } \\
\text { the contract } \\
\text { documents. } \\
\square \text { Notes attached }\end{array}$ & $\begin{array}{l}\text { This completed } \\
\text { checklist_and } \\
\text { startup report has } \\
\text { been reviewed. } \\
\square \text { Notes attached }\end{array}$ & $\begin{array}{l}\text { This completed } \\
\text { checklist_and } \\
\text { startup report has } \\
\text { been reviewed. } \\
\square \text { Notes attached }\end{array}$ \\
\hline Copies & & & & & \\
\hline $\begin{array}{l}\text { Submitter } \\
\text { Signature }\end{array}$ & & & & & \\
\hline Title & & & & & \\
\hline Date & & & & & \\
\hline Code & $-\cdots$ & & & & \\
\hline
\end{tabular}

Submitting Codes: $\quad \mathrm{Sb}=$ Submitted as documentation of a completed checklist and/or startup report.

$\mathrm{A}=$ Approved as complying with the contract documents.

$\mathrm{NC}=$ Note Corrections. Approved, but need to resubmit for the record, after correcting.

$N A=$ Not Acceptable. Resubmittal required for review.

Abbreviations: $\quad C A=$ commissioning agent/authority, $\mathrm{CM}=$ construction manager, $\mathrm{GC}=$ general contractor's rep., $\mathrm{A} / \mathrm{E}=$ architect or engineer of record, $\mathrm{Sub}=$ responsible subcontractor or vendor. 


\section{COMMISSIONING TRANSMITTAL}

Project:

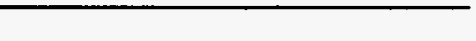

FROM:

\section{DESCRIPTION:}

\section{PURPOSE:}

$\square$ For your retention and use (no comments or approval necessary)

$\square$ For your approval:

$\square$ For your review and comments:

Respond by:

$\square$ Do not return this copy

Copied to: 


\section{COMMISSIONING REQUEST FOR INFORMATION}

Project:

From:

To:

RE:

\section{Description:}

\section{This Information Is Needed For The Following Reasons:}

$\square$ In order to clarify an area of control, so sequences of operation can be finished.

$\square$ In order to develop prefunctional and startup checklists.

$\square$ In order to develop functional performance test procedures.

$\square$ In order for functional testing to proceed as scheduled.

$\square$ In order to assist in trouble-shooting a functional problem.

$\square$ To fulfill other contracted commissioning responsibilities.

\section{Respond By:}

Copied To: 


\section{COMMISSIONING MEMORANDUM}

Project:

。

\section{RE:}

From:

\section{Discussion:}

e:

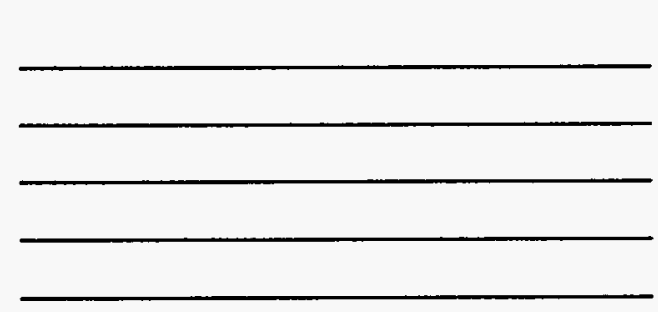

Date:
To:



\section{Discussion:}

\section{Purpose:}

$\square$ For your retention and use (no comments or approval necessary)

$\square$ For your review and comments:

$\square$ For your approval of the conclusions:

Respond by:

$\square$ Do not return this copy

Copied to: 


\section{SEQUENCES OF OPERATION AND FUNCTIONAL TEST PROCEDURES SUBMITTAL}

Project:

From (initially):
SUBMITTAL NO:

$\square$ New $\square$ Resubmittal

To (initially):

Equipment or System Tag and Name:

Included:

Sequences of Operation (enlarged from original control drawings and specification documents)

Functional test procedures and forms

\section{Submissions / Returns}

The following checked individuals will receive these documents for review and/or approval:
Party
For review \& comment only
For review \& approval
For record only

General Contractor

Mechanical Contractor

Electrical Contractor

Controls Contractor

Construction Manager

Owner's Representative

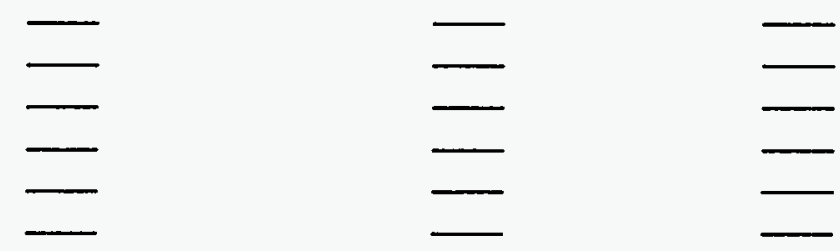

\begin{tabular}{|c|c|c|c|c|c|}
\hline \multirow{2}{*}{ Path } & To: & To: & To: & To: & To: \\
\hline & From: & From: & From: & From: & From: \\
\hline $\begin{array}{l}\text { Comments } \\
\text { by Submitter }\end{array}$ & $\begin{array}{l}\text { See Key (1) } \\
\square \text { Notes attached }\end{array}$ & $\begin{array}{l}\text { See Key (1) } \\
\square \text { Notes attached }\end{array}$ & $\begin{array}{l}\text { See Key (1) } \\
\square \text { Notes attached }\end{array}$ & $\begin{array}{l}\text { See Key (1) } \\
\square \text { Notes attached }\end{array}$ & $\begin{array}{l}\text { See Key (1) } \\
\square \text { Notes attached }\end{array}$ \\
\hline Copies & & & & & \\
\hline $\begin{array}{l}\text { Submitter } \\
\text { Signature }\end{array}$ & & & & & \\
\hline Title & & & & & \\
\hline Date & & & & & \\
\hline ReviewCode & & & & & \\
\hline
\end{tabular}

Key: (1) Review and comment on the sequences and/or test procedures as to their compliance with the specs. Check tests for personnel safety and to keep equip. warranty in force.

Review Codes: $\quad \mathrm{AM}=$ Approved by mechanical contractor (or electrical contractor) as complying with the contract documents. Tests will not void warranty or damage equipment and do not present unsafe conditions for personnel.

$\mathrm{AC}=$ Approved by controls contractor as complying with the contract documents.

$\mathrm{AE}=$ Approved by the design engineer as complying with the contract documents.

NC $=$ Note Corrections. Approved, but need to resubmit for the record, after correcting.

$\mathrm{NA}=$ Not Acceptable. Resubmittal required for review.

Abbreviations: $\quad \mathrm{CA}=$ commissioning agent/authority, $\mathrm{CM}=$ construction manager, $\mathrm{GC}=$ general contractor's rep., $\mathrm{A} / \mathrm{E}=$ architect or engineer of record, $\mathrm{Sub}=$ responsible subcontractor or vendor. 


\section{COMMISSIONING PROGRESS REPORT}

Project:

Date:

Prepared by:

Reporting Period:

Report \#:

Commissioning tasks worked on since last report and general progress:

Areas where schedule is not being met:

Recommended actions:

Requested schedule adjustments:

Next steps:

Other comments (include general comments and field notes):

Non-Compliance Report attached. (Y/N)

Issues Log Attached. (Y/N)

Misc. comment sheets attached. (Y/N)

Commissioning Agent 


\section{PROJECT TRAINING AND ORIENTATION PROCEDURE}

Owner training and orientation on equipment and systems provided by the Contractor is accomplished in three general steps using three forms.

1. Overall Plan. After reviewing the specifications, the Owner and Commissioning Agent (CA) fill out a table listing all the equipment that will have training or orientation provided for, on Form C-5a, Project Training Plan-General Scope and Responsible Parties. This form lists, among other things, the trainee type and number, rigor of desired training by the Owner, the primary responsible subcontractor, the trainer's company and columns for tracking training agendas. The Commissioning agent provides this form to the Contractor for reference.

2. Specific Training Agendas. For each piece of equipment or system being trained on, the Owner and CA fill out Section 1 of the Training and Orientation Agenda, Form C-5b. This section includes some of the information from Form C-5a regarding the scope of training and the intended audience, for reference by the trainer in developing their training agenda. The CA develops a plan for including in the training session contractors / trainers from different disciplines, when appropriate, by listing their company names in Section 2 of the form. In particular, the controls contractor will provide brief training on controls, in the same session with the mechanical training for equipment controlled by the building automation system.

This form is then submitted to the Contractor who has their trainer fill out the rest of Section 2 and 3 of the form (Form C-5b), describing the subjects covered, duration of each subject and the methods that will be used in the training, along with the name and qualifications of the trainer(s). The trainer returns this form to the Contractor, who submits it to the Owner and CA. The Owner and CA review the agenda; make comments; approve subject to the comments; and submit back to the Contractor. The Contractor provides the approved agenda to the trainer to use during the training. The trainer provides a copy of the agenda to each trainee.

3. Training Record. For each piece of equipment, prior to training, the Contractor provides to their trainer(s) Form C-5c, Training and Orientation Record. On this form, the trainer documents each training session (duration and general subjects covered). The trainer signs for the session and obtains the signature of each trainee. The trainer also checks off subjects covered on their Agenda (Form C$5 \mathrm{~b})$. When the training is complete, the Contractor provides a copy of the Training and Orientation Record, Form C-5c, and the trainer's Agenda, Form C-5b. The Owner and CA review C-5c and make final approval by signing it. The CA may witness any of the training sessions. 


\section{OVERALL STAFF TRAINING AND ORIENTATION PLAN}

Project:

Date:

Prepared by:

(To be filled out by the Commissioning Agent in consultation with the Owner)

\begin{tabular}{|c|c|c|c|c|c|c|c|c|}
\hline Equipment / System & $\begin{array}{l}\text { Spec } \\
\text { Section }\end{array}$ & $\begin{array}{c}\text { Total } \\
\text { Hours } \\
\text { (if } \\
\text { spec'd) } \\
\end{array}$ & $\begin{array}{l}\text { Scope } \\
\text { Code }\end{array}$ & $\begin{array}{c}\text { Trainee } \\
\text { Type } \\
\text { (ilst no. of } \\
\text { ea.) } \\
\end{array}$ & $\begin{array}{c}\text { Primary } \\
\text { Responsible } \\
\text { Contractor }\end{array}$ & $\begin{array}{l}\text { Trainers' } \\
\text { Company }\end{array}$ & $\begin{array}{l}\text { Agenda } \\
\text { Recr'd? }\end{array}$ & $\begin{array}{l}\text { Planned } \\
\text { Training } \\
\text { Date(s) }\end{array}$ \\
\hline \multicolumn{9}{|c|}{ Mechanical / HVAC } \\
\hline & & & & & & & & \\
\hline & & & & & & & & \\
\hline & & & & & & & & \\
\hline & & & & & & & & \\
\hline & & & & & & & & \\
\hline & & & & & & & & \\
\hline & & & & & & & & \\
\hline & & & & & & & & \\
\hline & & & & & & & & \\
\hline & & & & & & & & \\
\hline & & & & & & & & \\
\hline & & & & & & & & \\
\hline \multirow{2}{*}{\multicolumn{9}{|c|}{ Electrical }} \\
\hline & & & & & & & & \\
\hline & & & & & & & & \\
\hline & & & & & & & & \\
\hline & & & & & & & & \\
\hline & & & & & & & & \\
\hline & & & & & & & & \\
\hline
\end{tabular}




\begin{tabular}{|c|c|c|c|c|c|c|c|c|}
\hline Equipment / System & $\begin{array}{l}\text { Spec } \\
\text { Section }\end{array}$ & $\begin{array}{l}\text { Total } \\
\text { Hours } \\
\text { (if } \\
\text { spec'd) }\end{array}$ & $\begin{array}{l}\text { Scope } \\
\operatorname{Code}^{5}\end{array}$ & $\begin{array}{c}\text { Trainee } \\
\text { Type }^{6} \\
\text { (list no. of } \\
\text { ea.) }\end{array}$ & $\begin{array}{c}\text { Primary } \\
\text { Responsible } \\
\text { Contractor }\end{array}$ & $\begin{array}{l}\text { Trainers' } \\
\text { Company }\end{array}$ & $\begin{array}{l}\text { Agenda } \\
\text { Recr'd? }\end{array}$ & $\begin{array}{l}\text { Planned } \\
\text { Training } \\
\text { Date(s) }\end{array}$ \\
\hline & & & & & & & & \\
\hline & & & & & & & & \\
\hline \multicolumn{9}{|c|}{ Re-Commissioning $^{1}$} \\
\hline \multicolumn{9}{|l|}{ Architect $^{2}$} \\
\hline \multicolumn{9}{|c|}{ Mechanical Designer ${ }^{3}$} \\
\hline & & & & & & & & \\
\hline \multicolumn{9}{|c|}{ Electrical Designer ${ }^{4}$} \\
\hline & & & & & & & & \\
\hline
\end{tabular}

${ }^{1}$ Recommissioning. The commissioning agent will provide instruction on the use of blank functional test forms for periodic recommissioning of equipment and systems, per the specification.

${ }^{2}$ Architect. The architect will provide a general overview of the facility, its use, special features, tenant and public considerations, etc.

${ }^{3}$ Mechanical Design Engineer. The mechanical designer will provide an overview of the major systems and equipment in the facility, including for each system: the design intent, why the system was chosen, an overview of its operation, and interactions with other systems, any special areas to be aware of, issues regarding future expansion and remodeling, etc.

${ }^{4}$ Electrical Design Engineer. The electrical designer will provide an overview of the major electrical systems and equipment in the facility, particularly the lighting control systems, fire alarm, security and emergency power, focusing on the design intent, why the system was chosen, an overview of its operation, and interactions with other systems, any special areas to be aware of, issues regarding future expansion and remodeling, etc.

${ }^{5}$ General Scope Codes (refer to the specifications and to the specific equipment Training Agenda for additional details)

A Provide an overview of the purpose and operation of this equipment, including required interactions of trainees with the equipment.

B At an intermediate level, provide technical information regarding the purpose, operation and maintenance of this equipment, expecting that serious malfunctions will be addressed by factory reps.

C At a very technical level, provide information regarding the purpose, operation, troubleshooting and maintenance of this equipment, expecting that almost all operation, service and repair will be provided by the trainees.

\section{'Trainee Types}

FM = facility manager, $\mathrm{FE}=$ facility engineer and assistants, $\mathrm{FT}=$ facility technician $/$ maintenance,

$\mathrm{PM}=$ project manager, $\mathrm{T}=$ tenants, $\mathrm{O}=$ other

*OSCI = Owner supplied, contractor installed 


\section{TRAINING AND ORIENTATION AGENDA}

Project:

Date:

Equipment / System:

Spec Section:

Section 1. Audience and General Scope [Owner and Commissioning Agent fill out this section and transmit entire form to responsible contractors. Attach training specification section.

Intended audience type (enter number of staff): _ facility manager, _ facility engineer, _ facility technician, project manager, _tenant, _other:

General objectives and scope of training: (check all that apply)

A. Provide an overview of the purpose and operation of this equipment, including required interactions of trainees with the equipment.

B. Provide technical information regarding the purpose, operation and maintenance of this equipment at an intermediate level, expecting that serious malfunctions will be addressed by factory reps.

C. Provide technical information regarding the purpose, operation, troubleshooting and maintenance of this equipment at a very detailed level, expecting that almost all operation, service and repair will be provided by the trainees.

Section 2. Instructors [Commissioning agent fills in Company. Trainer fills out the balance, prior to training.]
ID Trainer
Company
Position / Qualifications

1)

2)

3)

Section 3. Agenda [The responsible contractors have their trainers fill out this section and submit to Owner and Commissioning Agent for review and approval prior to conducting training.]

Location:

site

Date classroom (location) , Date

Agenda of general subjects covered ( $\sqrt{ }$ all that will be covered)
Duration Instructor Completed (min.)

(ID)

( $)$

General purpose of this system or equipment (design intent)

Review of control drawings and schematics (have copies for attendees)

Startup, loading, normal operation, unloading, shutdown, unoccupied operation, seasonal changeover, etc., as applicable

Integral controls (packaged): programming, troubleshooting, alarms, manual operation

Building automation controls (BAS): programming, troubleshooting, alarms, manual operation, interface with integral controls

Interactions with other systems, operation during power outage and fire

Relevant health and safety issues and concerns and special safety features

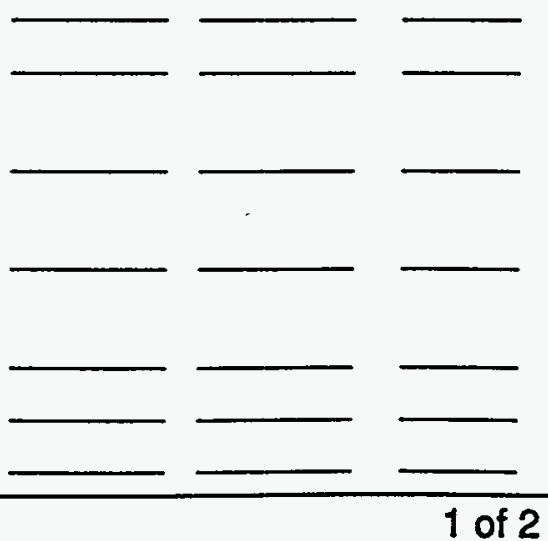


Energy conserving operation and strategies

Any special issues to maintain warranty

Common troubleshooting issues and methods, control system warnings

and error messages, including using the control system for diagnostics

Special requirements of tenants for this equipment's function

Service, maintenance, and preventative maintenance (sources,

spare parts inventory, special tools, etc.)

Question and answer period

Other subjects covered, specific to the equipment:

Duration Instructor Completed

Total duration of training (hrs)
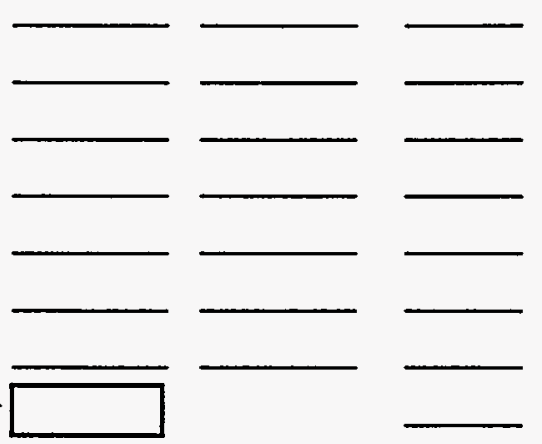

Training methods that will be included (clarify as needed): (Trainer checks all that apply)

$\checkmark$ use of the O\&M manuals, illustrating where the verbal training information is found in writing

$\checkmark$ each attendee will be provided: 1) the control drawing schematic and sequence of operations;

2) a copy of this agenda.

$\downarrow$ discussion/lecture at site

$\checkmark$ site demonstration of equipment operation

written handouts

manufacturer training manuals

classroom lecture

classroom hands-on equipment

video presentation

$\sqrt{ }$ question and answer period

Section 4. Approvals and Use [Once the Agenda has been filled out by the Trainer, the Owner and Commlssioning Agent review, make edits, sign and return to Contractor who provides to the Trainer for use during training. Coples of Agenda shall be provided to trainees.]

This plan has been approved by the following individuals, subject to the additions and clarifications noted in the left columns marked "add." (This is not an approval of training completion.) 


\section{STAFF TRAINING AND ORIENTATION RECORD}

Project:

System or Equipment:



Date:

Date:

Prepared by:

Prepared by:

$\cdot$

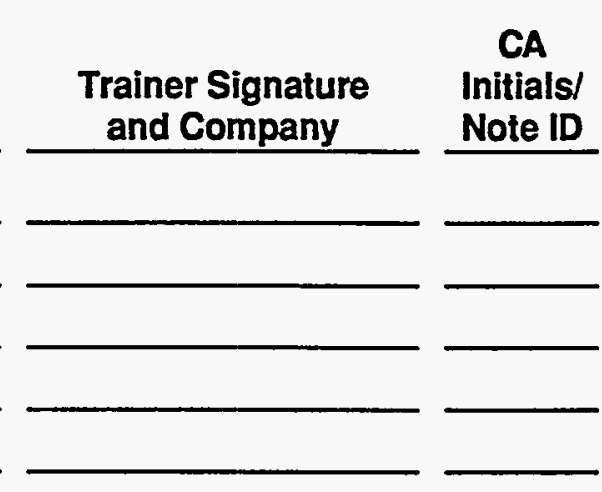

CA Initials/ Note ID



'The hours of required training have been filled out from the Specifications. Refer to the Specifications for additional details regarding the training requirements.

${ }^{2}$ Trainee signs after the training session is completed.

Notes attached. $(\mathrm{Y} / \mathrm{N})$

Final Approval of Training Completion

According to the Contract Documents:

Owner's Representative

Commissioning Agent
Date

Date 
Project:

ID:

Equipment:

Equipment ID:

Identified from: _ Test, __ Review, _ Discussion

$\square$ Site visit

The above equipment has been observed, tested or the performance report reviewed and was found to not comply with the contract documents.

Deficiencies or Issues and Effects:

Corrective Action: $\square$ Required $\square$ Recommended.

For testing to proceed in a timely manner, it is imperative that the required corrective action be completed by:

Date or Event

Commissioning Agent

Date

Owner's Representative

Date

Forwarded to the following parties on

Date for corrective action:

Attachments $(\mathrm{Y} / \mathrm{N})$

Fill in the following section and retum entire form to commissioning agent when corrected.

\section{Statement of Correction}

The above deficiencies have been corrected with the following actions: 


\section{COMMISSIONING PROGRESS RECORD}

PC_Del
SUSchd'ld
FTSchd'ld
FT_OK'd
PC
DocRev

$=P C$ delivered to Sub (date)

- Startup scheduled date

= Functional test scheduled date

$=F$. Test form OK'd by Installer

= Prefunctional checkllst

$=$ Documentation submiltal review
Project:
SUpPlan = Start-Up Plan

SUp Rep = Start-Up Report incl. PC

TAB $=$ TAB completed for this equip.

FT = Functional Test execution

Training = Training of facility staft

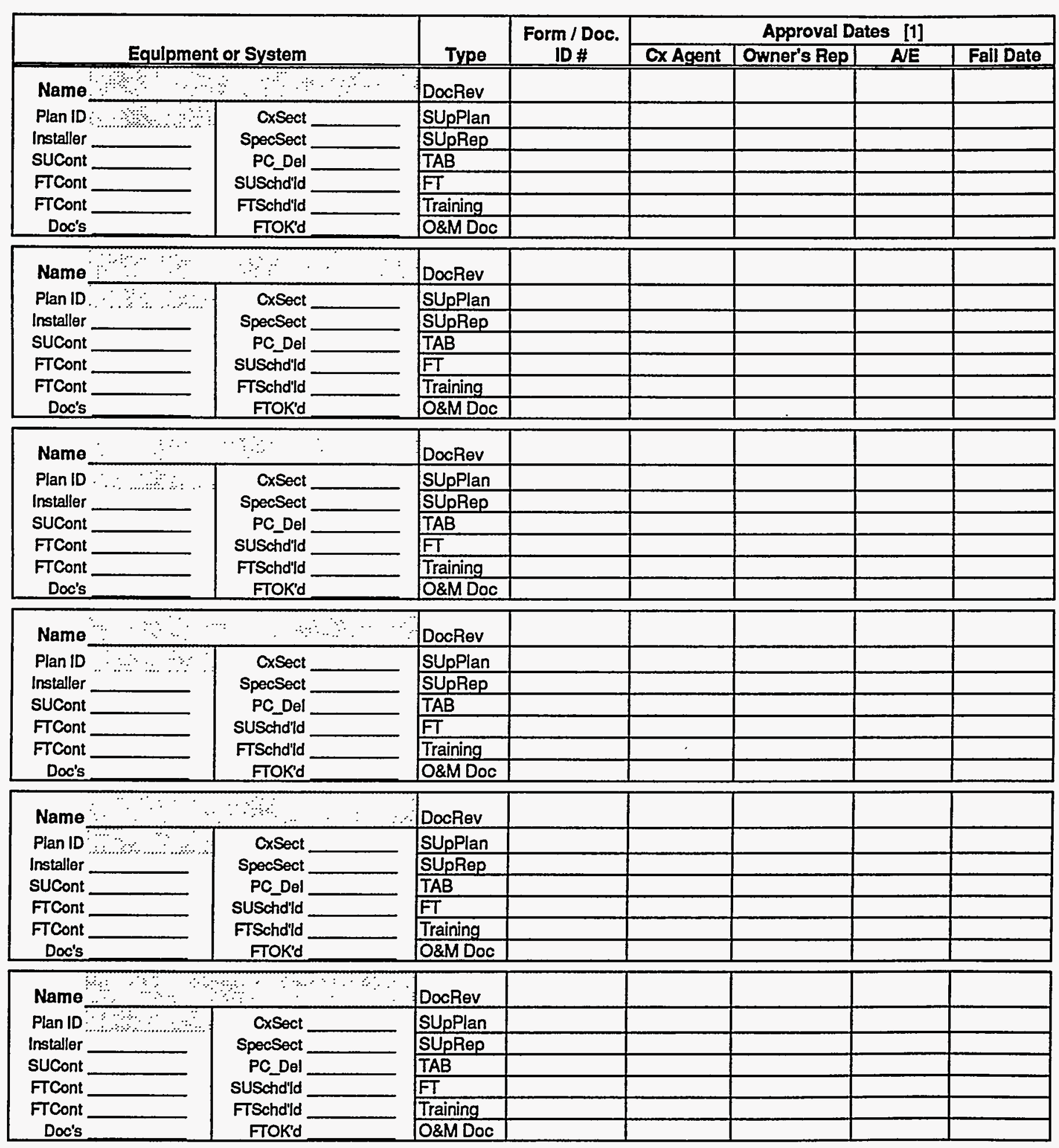

\section{Equlpment or System}

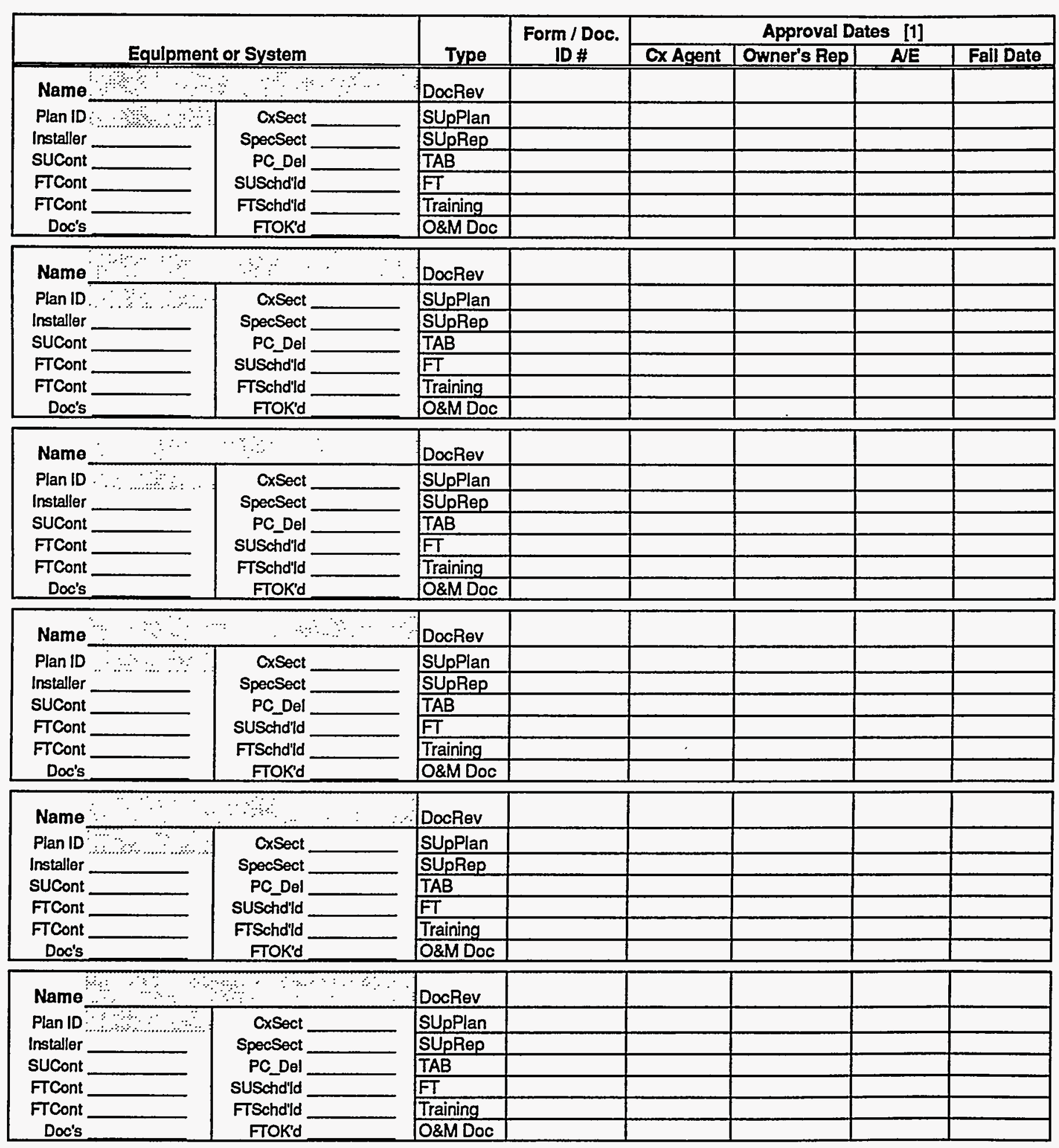


Form C-7

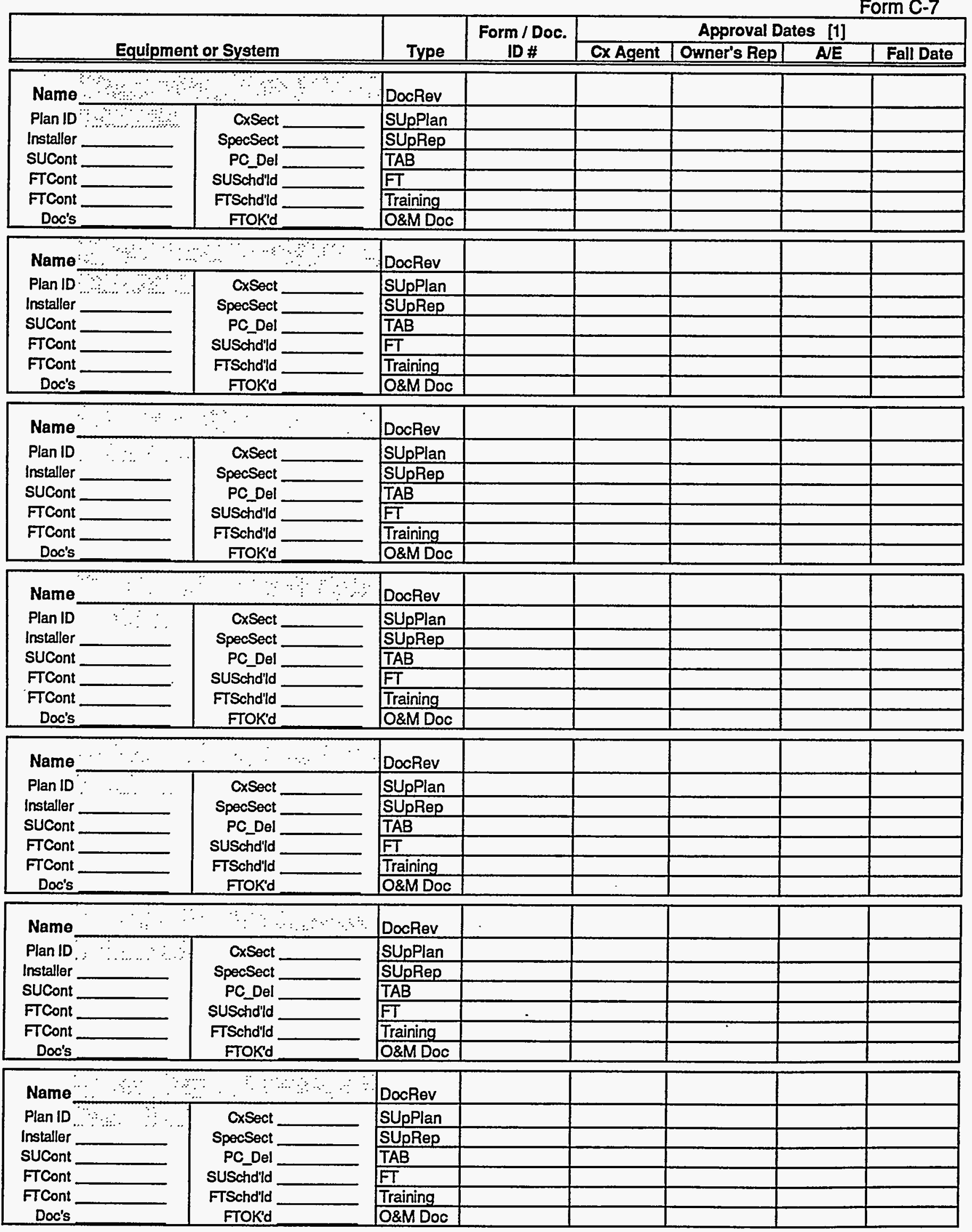




\section{PLAN AND DOCUMENTING REQUIREMENTS FOR STARTUP AND INITIAL CHECKOUT}

Project:

Date:

Prepared by:

Primary Equipment and Tag:

Component or Related Equipment Included:

The purpose of documenting the startup and checkout process is to ensure to the Owner that all recommended startup and initial checkout procedures are completed and that a written record of the work is generated.

\section{PLAN and PROCEDURES:}

1. The prefunctional checklists provided by should be filled out and signed for the above primary and related equipment.

2. The attached pages have been copied from the installation manuals submitted to . They have had paragraphs and sections identified and marked with a signature lines in the margins. Separately for each piece of equipment, during startup and checkout, the technician should check and date each check box and initial and date each line made for that purpose, signifying completion of the task. All readings and settings shall be recorded, not just checked. Provide clear, written notes at the bottom, margin or back-side of each page, as necessary. Written notes shall be provided for why an item was not done or does not apply. A signature and date of the startup technician shall be provided at the end of the startup and checkout documents.

3. This list of procedures does not constitute a recommendation of the full installation and startup procedures or release the installer from following all factory recommendations, the specifications, applicable codes and good practice. Other pages applicable to this piece of equipment in the installation manual or any other procedures completed should be added.

4. Other startup record forms normally used should also be filled out and submitted.

All documentation should be submitted to upon completion and is required prior to the execution of functional testing. 
Project

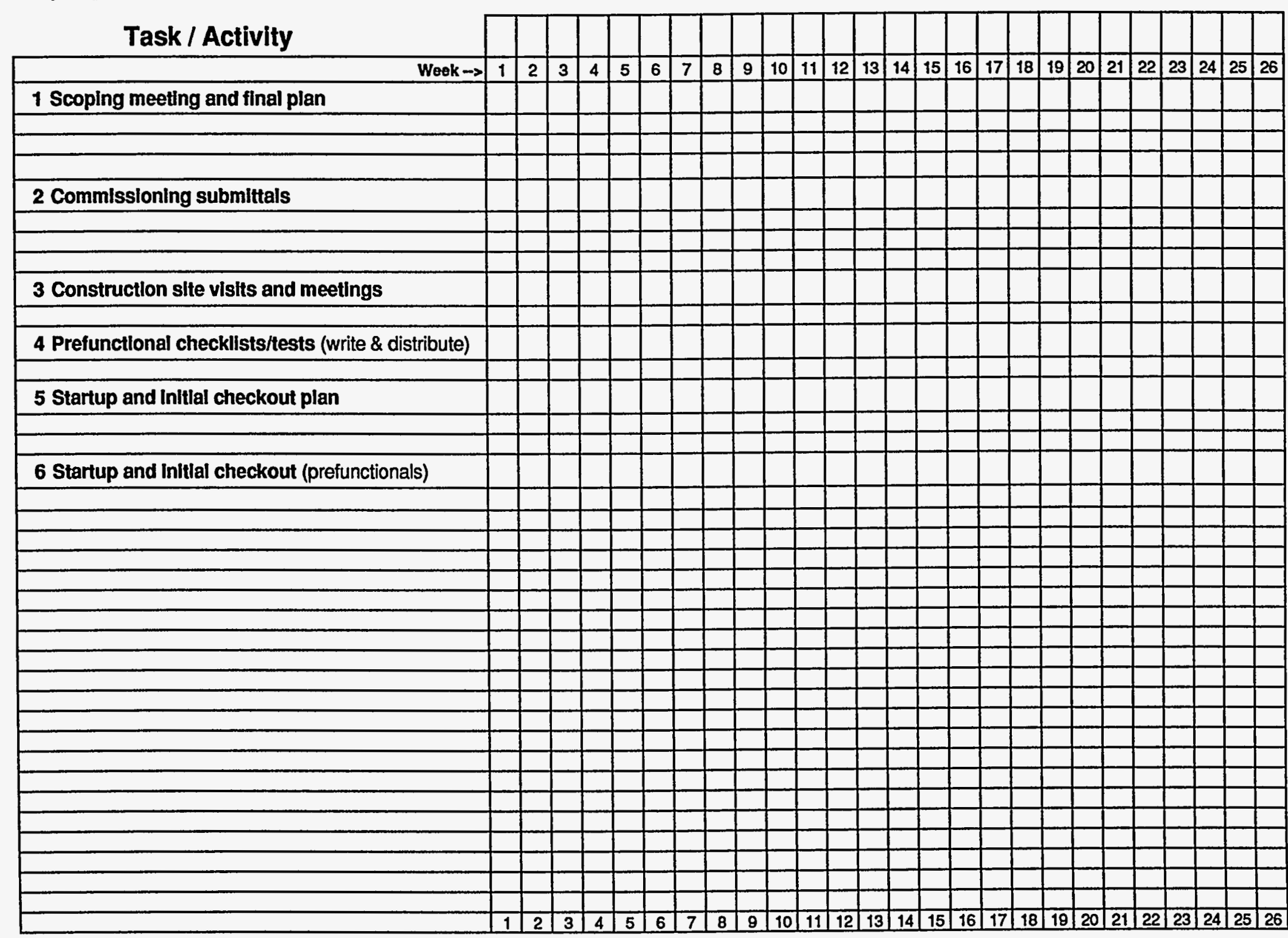


Task / Activity

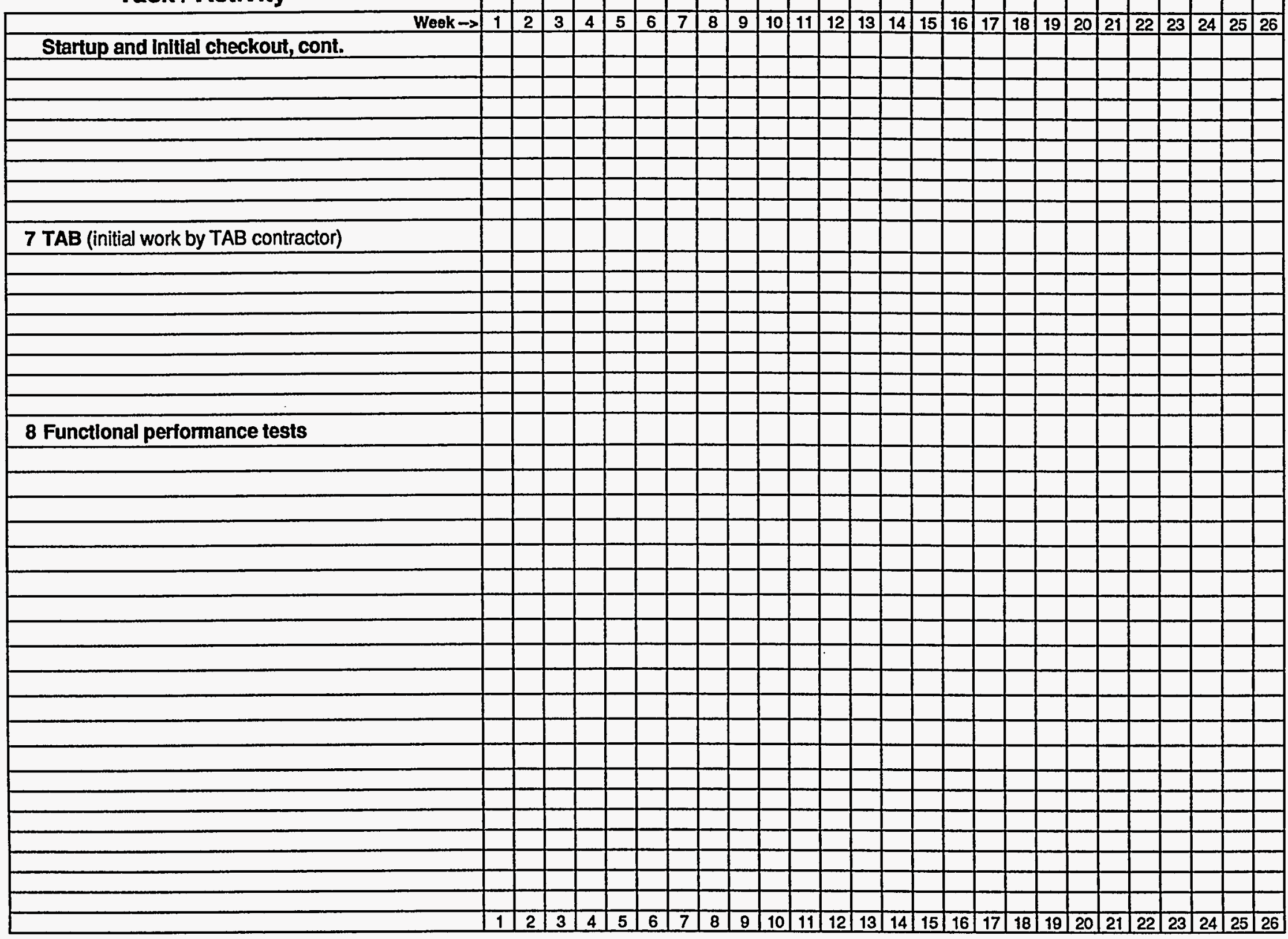




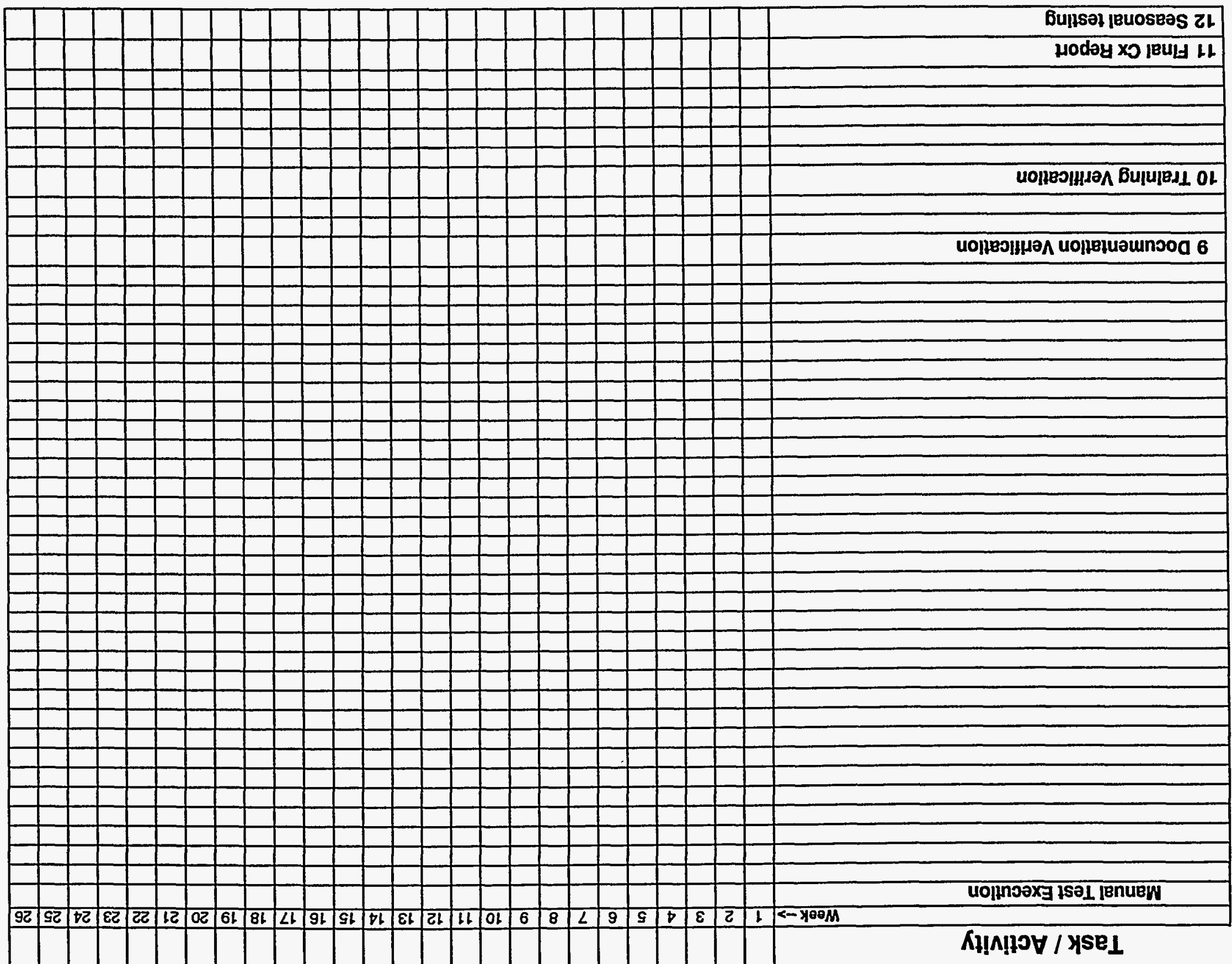


Project

DETAILED COMMISSIONING SCHEDULE Last Edit Date

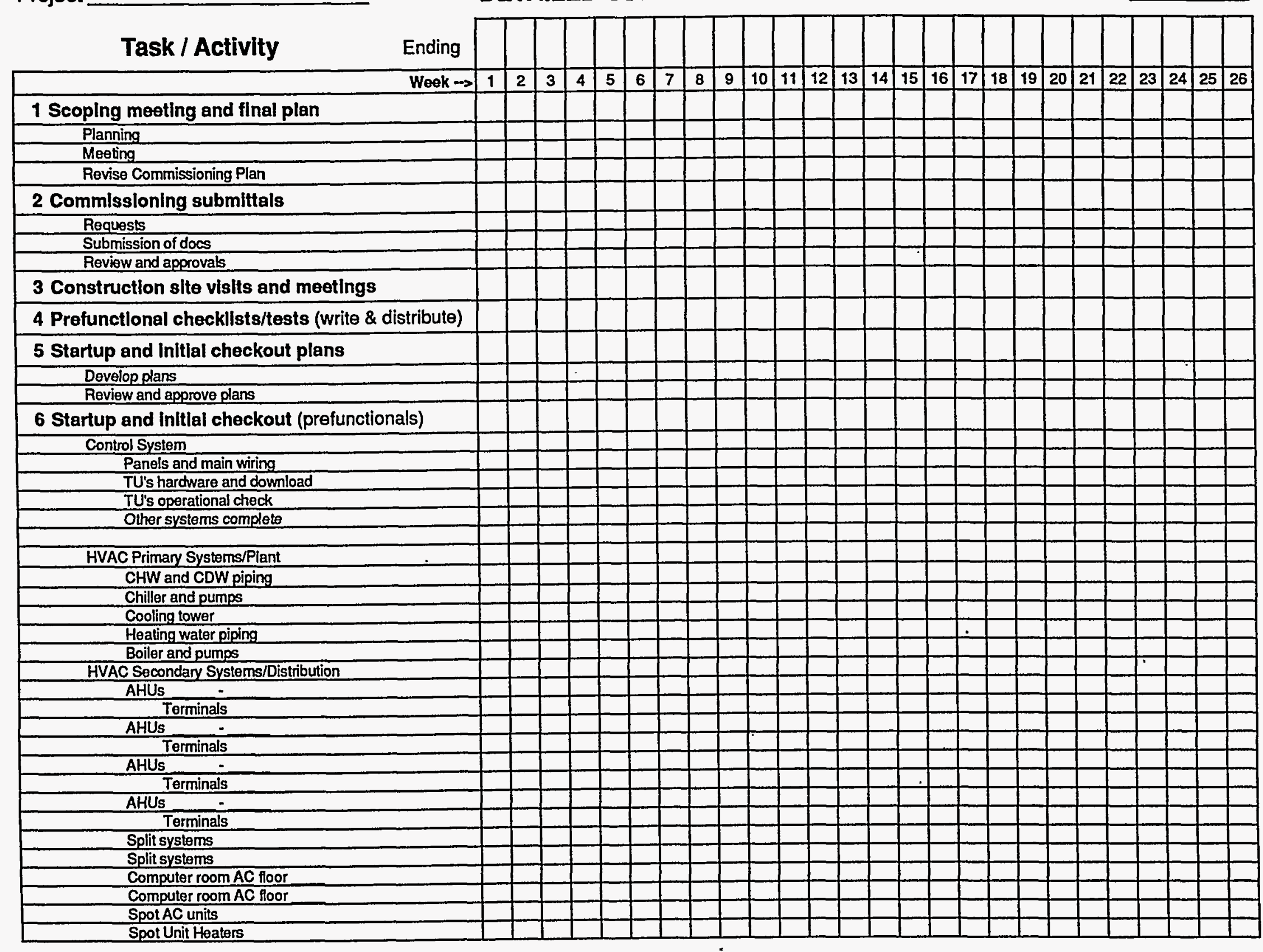







Task / Activity

Ending

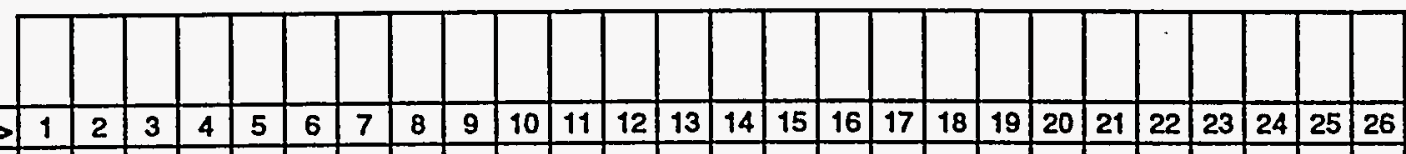

Manual Functlonal Test Executlon

\begin{tabular}{lllll|l|l|l|l|l|l|l|l|l|l|l|l|l|l|l|l|l|l|l|l|l|l|}
\hline Woek $\rightarrow$ & 1 & 2 & 3 & 4 & 5 & 6 & 7 & 8 & 9 & 10 & 11 & 12 & 13 & 14 & 15 & 16 & 17 & 18 & 19 & 20 & 21 & 22 & 23 & 24 & 25 & 26 \\
\hline
\end{tabular}

Control System

General functions

Controlled systems sequences

Primary Systems/Plan

Chiller and pumps

Cooling tower

Boiler and pumps
Secondary Systems/Distribution

\begin{tabular}{c}
\hline AHUs \\
\hline Terminal \\
\hline AHUs \\
\hline Terminal \\
\hline AHUs \\
\hline Terminal \\
\hline AHUs \\
\hline Terminal \\
\hline Serm
\end{tabular}

\begin{tabular}{c} 
Terminals \\
\hline Split systems \\
\hline Splisstems
\end{tabular}

Split systems

Computer room AC floor

Compuler room AC floor

Spot AC units

SpotUnit Heaters

Egress pressurization

Specially Fans

Packaged HVAC systems

Packaged HVAC systems

Service hot waler

Clean air rooms

ighting controls

Sweep control

Daylight dimming

\begin{tabular}{|c|}
\hline Daylight dimming \\
\hline Occupancy sensors \\
\hline
\end{tabular}

\begin{tabular}{|l|}
\hline Emergency power \\
\hline Fire protection \\
\hline
\end{tabular}

Fire protection

Fire alarm and reporting

Communications systems

Paging systems

Process gas systems

TAB (spot chreck)

Water side, Firs

Water side, Firs

Air side, Flrs

Air side, Firs - 


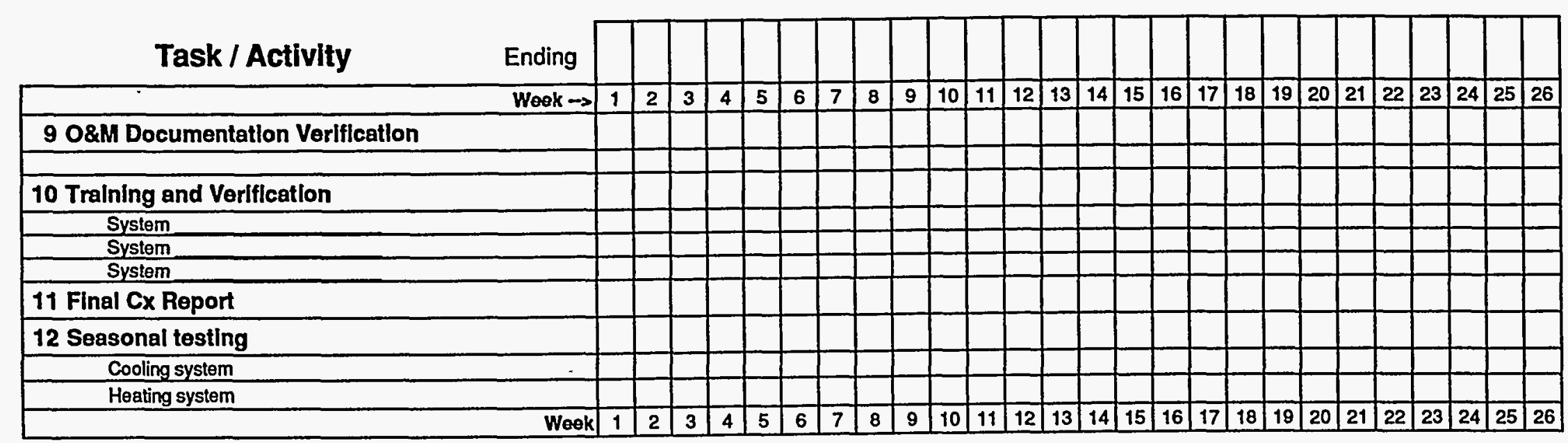




\section{COMMISSIONING FUNCTIONAL TESTING PLAN OVERVIEW}

\begin{tabular}{|c|c|c|c|c|c|c|}
\hline \multicolumn{2}{|l|}{ Project: } & \multirow{2}{*}{\multicolumn{2}{|c|}{$\begin{array}{c}\text { Date: } \\
\begin{array}{c}\text { Estimated Duration } \\
\text { of Test (hrs) }\end{array} \\
\end{array}$}} & \multicolumn{3}{|l|}{ Prepared by: } \\
\hline \multirow{2}{*}{$\begin{array}{c}\text { Equlpment / } \\
\text { System and } \\
\text { Rolated Controls }\end{array}$} & \multirow[b]{2}{*}{$\begin{array}{l}\text { When Testing Can Start } \\
\text { (date or event) }\end{array}$} & & & \multirow{2}{*}{$\begin{array}{l}\text { Neoded } \\
\text { Participants at } \\
\text { Testing } \\
\text { (besides CA) }\end{array}$} & \multirow[b]{2}{*}{$\begin{array}{c}\text { Test } \\
\text { Written? }\end{array}$} & \multirow{2}{*}{$\begin{array}{l}\text { Test } \\
\text { Proced } \\
\text { Neods } \\
\text { Revlew }\end{array}$} \\
\hline & & $\begin{array}{l}\text { During } \\
\text { Occupied } \\
\text { Period }\end{array}$ & $\begin{array}{l}\text { During } \\
\text { Unoccupjed } \\
\text { Perlod }^{1}\end{array}$ & & & \\
\hline & & & & & & \\
\hline & & & & & & \\
\hline & & & & & & \\
\hline & & & & & & \\
\hline & & & & & & \\
\hline & & & & & & \\
\hline & . & & & & & \\
\hline & & & - & & & \\
\hline & & & & & & \\
\hline & & & & & & \\
\hline & & & & & & \\
\hline & & & & & & \\
\hline & & & & & & \\
\hline & & & & & & \\
\hline & & & & & & \\
\hline & & & & & & \\
\hline & & . & & & & \\
\hline & & & & & & \\
\hline & & & & & & \\
\hline
\end{tabular}

${ }^{1}$ These columns are to designate whether tests must be done during hours when the building is not occupied. 


\section{PHASING OF COMMISSIONING TESTING}

Project:

Date:

Prepared by:

\begin{tabular}{|c|c|c|}
\hline \multirow[b]{2}{*}{$\begin{array}{c}\text { Main Equipment } \\
\text { or System }\end{array}$} & \multicolumn{2}{|c|}{ Group of Equipment to Test Together } \\
\hline & $\begin{array}{l}\text { Startup and Initial } \\
\text { Checkout } \\
\text { (Pre-functional } \\
\text { Checklisting) } \\
\end{array}$ & $\begin{array}{l}\text { Functional Performance } \\
\text { Testing }\end{array}$ \\
\hline & & \\
\hline & & \\
\hline & & \\
\hline & & \\
\hline & & \\
\hline & & \\
\hline & & \\
\hline & & \\
\hline & & \\
\hline & & \\
\hline & & \\
\hline & & \\
\hline & & \\
\hline & & \\
\hline & & \\
\hline
\end{tabular}

\section{Sample Phasing of Commissioning Testing}

\begin{tabular}{|c|c|c|}
\hline \multirow{2}{*}{$\begin{array}{c}\text { Main } \\
\begin{array}{c}\text { Equipment } \\
\text { or System }\end{array}\end{array}$} & $\begin{array}{c}|c| \\
\text { Group of Equipment to Test Together } \\
\text { (Pre-functional Work) } \\
\text { Checkout }\end{array}$ & $\begin{array}{c}\text { Functional } \\
\text { Performance } \\
\text { Testing-In-depth } \\
\text { Checkout }\end{array}$ \\
\hline \multirow{3}{*}{ AHU's } & AHU 1-4 & AHU 1-5 \\
\cline { 2 - 3 } & AHU 5 & - \\
\cline { 2 - 3 } Terminals & AHU 6-8 & AHU 6-8 \\
\cline { 2 - 3 }$\cdot$ & Floors 1-3 & All floors (sampling) \\
\hline TAB, air & Floors 4-9 & All floors (sampling) \\
\cline { 2 - 3 } & na & na \\
\hline
\end{tabular}




\section{OWNER-CONTRACTED OR OWNER-CONDUCTED TESTS OF COMMISSIONED EQUIPMENT}

Project:

Date:

Prepared by:

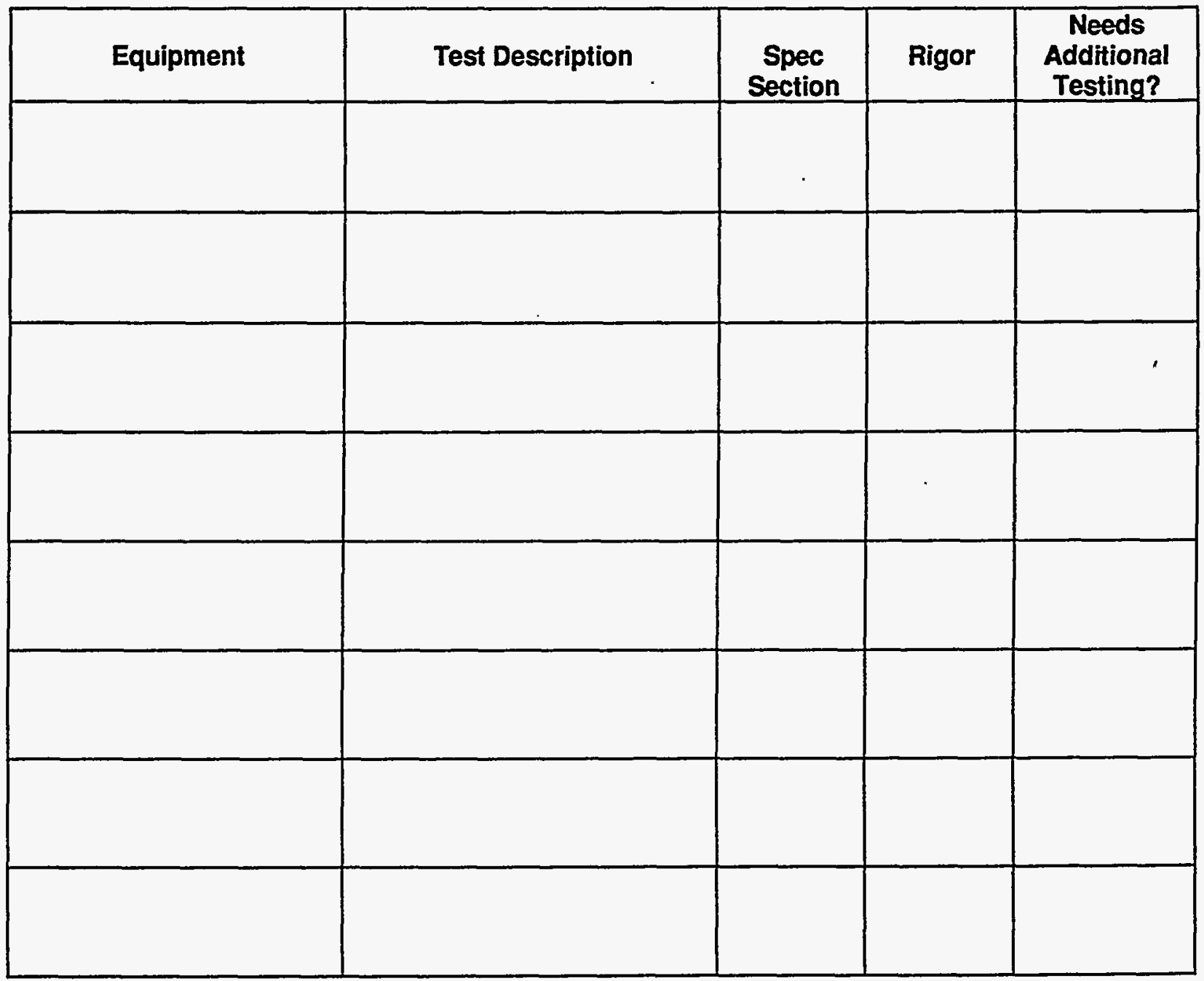




\section{FACILITY STAFF PARTICIPATION IN COMMISSIONING}

Project:

Date:

Prepared by:

\begin{tabular}{|c|c|}
\hline Activity & Staff ID \#'s \\
\hline \hline & \\
\hline & \\
\hline & \\
\hline & \\
\hline & \\
\hline & \\
\hline & \\
\hline & \\
\hline & \\
\hline & \\
\hline & \\
\hline & \\
\hline & \\
\hline & \\
\hline
\end{tabular}

See staff ID below.

Staff Data (Name, title, telepone, etc.)

Staff 1:

Staff 2:

Staff 3:

Staff 4:

Staff 5:

Staff 6:

Staff 7: 


\section{Example Functional Testing Scope Outline}

Project:

Date:

Prepared by:

Last Edit Date

\begin{tabular}{|c|c|c|c|c|c|c|}
\hline $\begin{array}{l}\text { System or } \\
\text { Equipment }\end{array}$ & $\begin{array}{l}\text { Equipment } \\
\text { or } \\
\text { Component } \\
\text { Tested }\end{array}$ & $\begin{array}{c}\text { General Description of } \\
\text { Modes and Functions } \\
\text { to Test }\end{array}$ & $\begin{array}{l}\text { Testing } \\
\text { Method } \\
\text { (Manual, } \\
\text { Irend-log, } \\
\text { Data- } \\
\text { logging) }\end{array}$ & $\begin{array}{l}\text { Sampling } \\
\text { Strategy } \\
\text { (list } \\
\text { applicable } \\
\text { equip.) }\end{array}$ & $\begin{array}{l}\text { Who } \\
\text { Executes } \\
\text { Test }\end{array}$ & $\begin{array}{l}\text { Seasonal } \\
\text { Test } \\
\text { Req'd } \\
\text { (list } \\
\text { applicable } \\
\text { equip. \& } \\
\text { modes) }\end{array}$ \\
\hline $\begin{array}{l}\text { Chilled } \\
\text { Water } \\
\text { System }\end{array}$ & $\begin{array}{l}\text { Chillers, } \\
\text { primary and } \\
\text { secondary } \\
\text { CHW } \\
\text { pumps, } \\
\text { CDW } \\
\text { pumps, } \\
\text { cooling } \\
\text { tower (CT), } \\
\text { VFD, } \\
\text { controls }\end{array}$ & $\begin{array}{l}\text { All sequences of chiller and } \\
\text { cooling tower and related } \\
\text { pumps (startup, shutdown, } \\
\text { load changes, resets, lead } \\
\text { lag action, alarms, } \\
\text { lockouts), VFD control, } \\
\text { temporary power, chiller } \\
\text { capacity and efficiency, CT } \\
\text { capacity and efficiency, part } \\
\text { load curves with manuf. }\end{array}$ & $\begin{array}{c}\text { Mostly } \mathrm{M} \text {, } \\
\text { with some } \\
\text { T and } \\
\text { some } \\
\text { D }\end{array}$ & $\begin{array}{l}\text { Test all } \\
\text { including } \\
\text { standby } \\
\text { equip., } \\
\text { except } \\
\text { capacity \& } \\
\text { efficiency } \\
\text { test of chiller } \\
\text { \& CT need } \\
\text { only be done } \\
\text { on } 1 \text { piece, } \\
\text { even if } \\
\text { identical }\end{array}$ & $\begin{array}{l}\text { Mech. } \\
\text { leads } \\
\text { with help } \\
\text { from: } \\
\text { Cntrl }\end{array}$ & $\begin{array}{l}\text { Chiller test } \\
\text { must be } \\
\text { done in } \\
\text { summer, } \\
\text { CT in } \\
\text { summer } \\
\text { and } \\
\text { ل winter }\end{array}$ \\
\hline $\begin{array}{l}\text { Hot Water } \\
\text { Heating } \\
\text { System }\end{array}$ & $\begin{array}{l}\text { Boiler, } \\
\text { steam } \\
\text { converter, } \\
\text { pumps, } \\
\text { controls }\end{array}$ & $\begin{array}{l}\text { All sequences of hot water } \\
\text { sytems and related pumps } \\
\text { (startup, shutdown, load } \\
\text { changes, resets, lead lag } \\
\text { action, alarms, lockouts), } \\
\text { VFD control, temporary } \\
\text { power, efficiency, venting }\end{array}$ & $\begin{array}{c}\text { Mostly M, } \\
\text { with some } \\
\text { T and } \\
\text { some } \\
\text { D }\end{array}$ & $\begin{array}{l}\text { Test all } \\
\text { including } \\
\text { standby } \\
\text { equip., } \\
\text { except effic. } \\
\text { test only one } \\
\text { boiler, even } \\
\text { if identical }\end{array}$ & $\begin{array}{l}\text { Mech. } \\
\text { leads } \\
\text { with help } \\
\text { from: } \\
\text { Cntrl }\end{array}$ & $\begin{array}{l}\text { Must test } \\
\text { in winter }\end{array}$ \\
\hline $\begin{array}{l}\text { Air } \\
\text { handling } \\
\text { system }\end{array}$ & $\begin{array}{l}\text { AHU, } \\
\text { supply, } \\
\text { return and } \\
\text { exhaust } \\
\text { fans, coils, } \\
\text { coil pumps, } \\
\text { valves, } \\
\text { dampers, } \\
\text { VFD, } \\
\text { controls }\end{array}$ & $\begin{array}{l}\text { All sequences of fans and } \\
\text { related components } \\
\text { (startup, shutdown, setup, } \\
\text { unoccupied conditions, } \\
\text { load changes, resets, } \\
\text { alarms, lockouts), VFD } \\
\text { control, operation of all } \\
\text { dampers in all modes, } \\
\text { temporary power, coil } \\
\text { capacity, coil effic., OSA } \\
\text { control, bldg. pressure, }\end{array}$ & $\begin{array}{c}\text { Mostly M, } \\
\text { with some } \\
\text { T and } \\
\text { some } \\
\text { D }\end{array}$ & Test all & $\begin{array}{l}\text { Cntrl } \\
\text { leads } \\
\text { with help } \\
\text { from } \\
\text { Mech. }\end{array}$ & $\begin{array}{l}\text { Must test } \\
\text { in } \\
\sqrt{\text { sum'r }} \\
\sqrt{ } \text { winter }\end{array}$ \\
\hline
\end{tabular}


Form C-15

\begin{tabular}{|c|c|c|c|c|c|c|}
\hline $\begin{array}{l}\text { System or } \\
\text { Equipment }\end{array}$ & $\begin{array}{l}\text { Equipment } \\
\text { or } \\
\text { Component } \\
\text { Tested }\end{array}$ & $\begin{array}{c}\text { General Description of } \\
\text { Modes and Functions } \\
\text { to Test }\end{array}$ & $\begin{array}{l}\text { Testing } \\
\text { Method } \\
\text { (Manual, } \\
\text { Irend-log, } \\
\text { Data- } \\
\text { logging) }\end{array}$ & $\begin{array}{l}\text { Sampling } \\
\text { Strategy } \\
\text { (list } \\
\text { applicable } \\
\text { equip.) }\end{array}$ & $\begin{array}{c}\text { Who } \\
\text { Executes } \\
\text { Test }\end{array}$ & $\begin{array}{l}\text { Seasonal } \\
\text { Test } \\
\text { Req'd } \\
\text { (list } \\
\text { applicable } \\
\text { equip. \& } \\
\text { modes) }\end{array}$ \\
\hline $\begin{array}{l}\text { Air } \\
\text { handling } \\
\text { system }\end{array}$ & $\begin{array}{l}\text { Terminal } \\
\text { units }\end{array}$ & $\begin{array}{l}\text { Verify damper and fan } \\
\text { sequences during heating, } \\
\text { cooling, debands, occupied, } \\
\text { unoccupied, verify flow }\end{array}$ & $\bar{M}$ & $\begin{array}{l}\text { Test } 10 \% \text { of } \\
\text { identical } \\
\text { units (see } \\
\text { Specs) }\end{array}$ & $\begin{array}{l}\text { Mech. } \\
\text { leads } \\
\text { with help } \\
\text { from } \\
\text { Cntrl }\end{array}$ & No \\
\hline $\begin{array}{l}\text { Computer } \\
\text { Room AC }\end{array}$ & $\begin{array}{l}\text { AC unit, } \\
\text { humidifier, } \\
\text { controls }\end{array}$ & $\begin{array}{l}\text { All sequences in all modes } \\
\text { (normal, deadband, } \\
\text { unoccupied, etc.), humidity } \\
\text { and reheat functions, } \\
\text { backup interlock with } \\
\text { primary cooling, temporary } \\
\text { power operation }\end{array}$ & $\bar{M}$ & Test all & Mech. & No \\
\hline $\begin{array}{l}\text { Spot } \\
\text { HVAC } \\
\text { Units }\end{array}$ & $\begin{array}{l}\text { Unit } \\
\text { heaters, } \\
\text { controls }\end{array}$ & $\begin{array}{l}\text { All sequences, occupied, } \\
\text { unoccupied, lockouts, } \\
\text { simultaneous heating } \\
\text { /cooling issues }\end{array}$ & $\mathbf{M}$ & $\begin{array}{l}\text { Test } 10 \% \text { of } \\
\text { identicals } \\
\text { and at least } 5\end{array}$ & Mech. & $\begin{array}{l}\text { No, if htg } \\
\text { \& cooling } \\
\text { condition } \\
\text { is } \\
\text { simulated }\end{array}$ \\
\hline $\begin{array}{l}\text { Spot } \\
\text { HVAC } \\
\text { Units }\end{array}$ & $\begin{array}{l}\text { Spot } \\
\text { coolers, } \\
\text { controls }\end{array}$ & $\begin{array}{l}\text { All sequences, occupied, } \\
\text { unoccupied, lockouts, } \\
\text { simultaneous heating } \\
\text { /cooling issues }\end{array}$ & $\mathbf{M}$ & $\begin{array}{l}\text { Test } 10 \% \text { of } \\
\text { identicals } \\
\text { and at least } 5\end{array}$ & Mech. & $\begin{array}{l}\text { No, if htg } \\
\text { \& cooling } \\
\text { condition } \\
\text { is } \\
\text { simulated }\end{array}$ \\
\hline $\begin{array}{l}\text { Specialty } \\
\text { Fans }\end{array}$ & $\begin{array}{l}\text { Stairwell } \\
\text { pressuriz- } \\
\text { ation fans, } \\
\text { controls }\end{array}$ & Tested by fire officials & & & & \\
\hline $\begin{array}{l}\text { Specialty } \\
\text { Fans }\end{array}$ & $\begin{array}{l}\text { Central } \\
\text { exhaust } \\
\text { fans, } \\
\text { controls }\end{array}$ & $\begin{array}{l}\text { Occupied, unoccupied, } \\
\text { local controls, overrides, } \\
\text { schedules, central controls }\end{array}$ & $\mathbf{M}$ & Test all & Mech. & No \\
\hline $\begin{array}{l}\text { Specialty } \\
\text { Fans }\end{array}$ & Fume hoods & $\begin{array}{l}\text { Capacity, varying } \\
\text { differential pressures, } \\
\text { interlocks, safeties }\end{array}$ & $\overline{\mathrm{M}}$ & Test all & $\begin{array}{l}\text { TAB } \\
\text { contr. }\end{array}$ & $\begin{array}{l}\text { No, if } \\
\text { tested } \\
\text { with full } \\
\text { and min. } \\
\text { OSA }\end{array}$ \\
\hline
\end{tabular}




\begin{tabular}{|c|c|c|c|c|c|c|}
\hline $\begin{array}{l}\text { System or } \\
\text { Equipment }\end{array}$ & $\begin{array}{c}\text { Equipment } \\
\text { or } \\
\text { Component } \\
\text { Tested }\end{array}$ & $\begin{array}{c}\text { General Description of } \\
\text { Modes and Functions } \\
\text { to Test }\end{array}$ & $\begin{array}{c}\text { Testing } \\
\text { Method } \\
\text { (Manual, } \\
\text { Irend-log, } \\
\text { Data- } \\
\text { logging) }\end{array}$ & $\begin{array}{l}\text { Sampling } \\
\text { Strategy } \\
\text { (list } \\
\text { applicable } \\
\text { equip.) }\end{array}$ & $\begin{array}{l}\text { Who } \\
\text { Executes } \\
\text { Test }\end{array}$ & $\begin{array}{l}\text { Seasonal } \\
\text { Test } \\
\text { Req'd } \\
\text { (list } \\
\text { applicable } \\
\text { equip. \& } \\
\text { modes) }\end{array}$ \\
\hline $\begin{array}{l}\text { Energy } \\
\text { Manage- } \\
\text { ment } \\
\text { Control } \\
\text { System }\end{array}$ & $\begin{array}{l}\text { Schedules, } \\
\text { sequences, } \\
\text { lockouts, } \\
\text { alarms, } \\
\text { interlocks, } \\
\text { control } \\
\text { strategies, } \\
\text { trending }\end{array}$ & $\begin{array}{l}\text { All sequences of control for } \\
\text { HVAC equipment and } \\
\text { lighting controls, }\end{array}$ & $\begin{array}{l}\text { M and } T \\
\text { with some } \\
\text { D }\end{array}$ & $\begin{array}{l}\text { Test all } \\
\text { controlled } \\
\text { equipment }\end{array}$ & Cntrl & $\begin{array}{l}\text { Yes, see } \\
\text { Specs }\end{array}$ \\
\hline $\begin{array}{l}\text { Packaged } \\
\text { HVAC }\end{array}$ & $\begin{array}{l}\text { AHU, } \\
\text { supply, } \\
\text { return and } \\
\text { exhaust } \\
\text { fans, } \\
\text { compressor, } \\
\text { condensers, } \\
\text { coils, } \\
\text { valves, } \\
\text { dampers, } \\
\text { heating } \\
\text { elements, } \\
\text { VFD, } \\
\text { controls }\end{array}$ & $\begin{array}{l}\text { All sequences of fans and } \\
\text { related components } \\
\text { (startup, shutdown, setup, } \\
\text { unoccupied conditions, } \\
\text { load changes, resets, } \\
\text { alarms, lockouts), VFD } \\
\text { control, operation of all } \\
\text { dampers in all modes, } \\
\text { temporary power, OSA } \\
\text { control, building pressure, } \\
\text { reversing valves (HIP), } \\
\text { compressor and cond. fan } \\
\text { staging, heating COP \& } \\
\text { capacity, cooling EER \& } \\
\text { capacity }\end{array}$ & $\begin{array}{l}\text { Mostly M } \\
\text { with some } \\
\mathrm{T} \text { and } \\
\text { some D }\end{array}$ & $\begin{array}{l}\text { Test } 20 \% \text { of } \\
\text { identical } \\
\text { units }<20 \\
\text { tons. } \\
\text { test } 40 \% \text { of } \\
\text { identical } \\
\text { units }>20 \\
\text { tons. } \\
\text { Test at least } \\
4 \text { of each. }\end{array}$ & $\begin{array}{l}\text { Mech. } \\
\text { Lead with } \\
\text { help } \\
\text { from: } \\
\text { Cntrl }\end{array}$ & $\begin{array}{l}\text { No, for } \\
\text { units } \\
<20 \text { tons, } \\
\text { if } \\
\text { simulated } \\
\text { condition } \\
\text { is used. } \\
\text { Yes, for } \\
\text { units }>20 \\
\text { tons }\end{array}$ \\
\hline $\begin{array}{l}\text { Heat } \\
\text { Exchanger }\end{array}$ & $\begin{array}{l}\text { Heat } \\
\text { exchanger, } \\
\text { controls }\end{array}$ & $\begin{array}{l}\text { Sequences, lockouts, } \\
\text { safeties }\end{array}$ & $M \& T$ & Test all & Mech. & No \\
\hline$\overline{T A B}$ & $\begin{array}{l}\text { Air and } \\
\text { water } \mathrm{TAB} \\
\text { work }\end{array}$ & $\begin{array}{l}\text { Primary air and water } \\
\text { flows and terminal flows }\end{array}$ & $\overline{\mathrm{M}}$ & $\begin{array}{l}\text { Verify a \% of } \\
\text { TAB } \\
\text { readings (see } \\
\text { Specs) }\end{array}$ & TAB & No \\
\hline $\begin{array}{l}\text { Clean } \\
\text { Room Air } \\
\text { Flows }\end{array}$ & $\begin{array}{l}\text { Air flows } \\
\text { and } \\
\text { pressures }\end{array}$ & $\begin{array}{l}\text { All sequences and all } \\
\text { possible affecting } \\
\text { conditions in bldg., varying } \\
\text { differential pressures, } \\
\text { interlocks, alarms }\end{array}$ & $\begin{array}{l}\text { M and } \\
\text { some T }\end{array}$ & Test all & TAB & $\begin{array}{l}\text { No, if } \\
\text { tested } \\
\text { with full } \\
\text { \& min. } \\
\text { OSA \& full } \\
\text { htg. \& } \\
\text { cooling }\end{array}$ \\
\hline
\end{tabular}


Form C-15

\begin{tabular}{|c|c|c|c|c|c|c|}
\hline $\begin{array}{l}\text { System or } \\
\text { Equipment }\end{array}$ & $\begin{array}{l}\text { Equipment } \\
\text { or } \\
\text { Component } \\
\text { Tested }\end{array}$ & $\begin{array}{l}\text { General Description of } \\
\text { Modes and Functions } \\
\text { to Test }\end{array}$ & $\begin{array}{c}\text { Testing } \\
\text { Method } \\
\text { (Manual, } \\
\text { Irend-log, } \\
\text { Data- } \\
\text { logging) }\end{array}$ & $\begin{array}{l}\text { Sampling } \\
\text { Strategy } \\
\text { (list } \\
\text { applicable } \\
\text { equip.) }\end{array}$ & $\begin{array}{l}\text { Who } \\
\text { Executes } \\
\text { Test }\end{array}$ & $\begin{array}{l}\text { Seasonal } \\
\text { Test } \\
\text { Req'd } \\
\text { (list } \\
\text { applicable } \\
\text { equip. \& } \\
\text { modes) }\end{array}$ \\
\hline $\begin{array}{l}\text { Service } \\
\text { Hot Water }\end{array}$ & $\begin{array}{l}\text { Boiler, } \\
\text { heaters, } \\
\text { pumps, } \\
\text { controls }\end{array}$ & $\begin{array}{l}\text { Boiler or heater sequences, } \\
\text { controls \& pump schedules }\end{array}$ & $\mathrm{M}$ & $\begin{array}{l}\text { Yes (see } \\
\text { Specs) }\end{array}$ & Mech. & No \\
\hline $\begin{array}{l}\text { Lighting } \\
\text { Controls }\end{array}$ & $\begin{array}{l}\text { Sweep, } \\
\text { occupancy } \\
\text { sensors, } \\
\text { daylighting }\end{array}$ & $\begin{array}{l}\text { Occupied, unoccupied, } \\
\text { overrides, sweep, varying } \\
\text { daylight, occupancy, as } \\
\text { applicable, occupant use }\end{array}$ & $\mathrm{M}$ & Test all & $\begin{array}{l}\text { Elec. } \\
\text { leads } \\
\text { Cntrls } \\
\text { helps }\end{array}$ & No \\
\hline
\end{tabular}


COMMISSIONING FORMAL WRITTEN WORK PRODUCTS

Project

Last Edit Date

\begin{tabular}{|c|c|c|c|c|c|c|}
\hline Product & $\begin{array}{c}\text { Created } \\
\text { By }\end{array}$ & $\begin{array}{l}\text { Product Description } \\
\text { and Form }\end{array}$ & Due Date & $\begin{array}{c}\text { Received } \\
\text { By }\end{array}$ & $\begin{array}{l}\text { Approved } \\
\text { By }\end{array}$ & $\begin{array}{l}\text { Product } \\
\text { Assigned In }\end{array}$ \\
\hline $\begin{array}{l}\text { Scoping Mtg } \\
\text { Minutes }\end{array}$ & $\mathrm{CA}$ & $\begin{array}{l}\text { Minutes and notes of the } \\
\text { scoping meeting }\end{array}$ & $\begin{array}{l}<1 \text { week after } \\
\text { meeting }\end{array}$ & $\begin{array}{l}\text { All Cx } \\
\text { team }\end{array}$ & na & $\begin{array}{l}\text { Cx Plan } 5.1 \\
\text { Specs } 17100,1.5\end{array}$ \\
\hline Final Cx Plan & $\mathrm{CA}$ & $\begin{array}{l}\text { Final Cx plan for const. phase } \\
\text { (edited version of Draft plan of } \\
\text { bid documents) }\end{array}$ & $\begin{array}{l}1-2 \text { weeks after } \\
\text { Cx scoping } \\
\text { mtg. }\end{array}$ & $\begin{array}{l}\text { All Cx } \\
\text { team }\end{array}$ & $\mathrm{CM}$ & $\begin{array}{l}\text { Cx Plan 5.2, Specs } \\
17100, \text { Pt } 1.5\end{array}$ \\
\hline Cx Schedule & $\mathrm{CA}$ & $\begin{array}{l}\text { Initial summary schedule } \\
\text { (Table 7-1) and detailed } \\
\text { version (Form C-10) }\end{array}$ & $\begin{array}{l}\text { Summary } \\
\text { schedule: 1wk } \\
\text { after scoping }\end{array}$ & $\begin{array}{l}\text { All Cx } \\
\text { team }\end{array}$ & $\mathrm{CM}$ & Cx Plan 7.1 \\
\hline $\begin{array}{l}\text { Equipment } \\
\text { submittals }\end{array}$ & All Subs & $\begin{array}{l}\text { Detailed data on all } \mathrm{Cx}^{\prime} \mathrm{d} \\
\text { equip. }\end{array}$ & $\begin{array}{l}\text { during normal } \\
\text { submittals }\end{array}$ & $\mathrm{CA}$ & $\begin{array}{l}\text { CA (for } \mathrm{Cx} \\
\text { req'r.) }\end{array}$ & $\begin{array}{l}\text { Cx Plan 5.7, Specs } \\
\text { 17100, Pt 3.3, } \\
15995 \text { Pt 3.1 } \\
\end{array}$ \\
\hline $\begin{array}{l}\text { Prefunctional } \\
\text { tests and } \\
\text { checklists }\end{array}$ & $\begin{array}{l}\text { Specs } \\
\text { and } \mathrm{CA}\end{array}$ & $\begin{array}{l}\text { List by equipment of } \\
\text { prefunctional checklists and } \\
\text { prefunctional tests } \\
\text { (Specs 15998) }\end{array}$ & $\begin{array}{l}\text { During normal } \\
\text { submittals }\end{array}$ & Subs & $\mathrm{CA}$ & $\begin{array}{l}\text { Cx Plan 5.8.1, } \\
\text { Specs 17100 Pt } \\
3.4 ; 15995 \text { Pt } 3.2\end{array}$ \\
\hline $\begin{array}{l}\text { Start-up and } \\
\text { initial checkout } \\
\text { plans }\end{array}$ & $\begin{array}{l}\text { All Subs } \\
\text { and } \mathrm{CA}\end{array}$ & $\begin{array}{l}\text { Specific listing of procedures } \\
\text { for combining CA } \\
\text { prefunctional checklists with } \\
\text { Sub's startup and checkout. } \\
\end{array}$ & $\begin{array}{l}\text { 2-weeks before } \\
\text { execution }\end{array}$ & $\mathrm{CA}$ & $C A$ & $\begin{array}{l}\text { Cx Plan 5.8.1, } \\
\text { Specs 17100 Pt } \\
3.4 ; 15995 \mathrm{Pt} 3.2\end{array}$ \\
\hline $\begin{array}{l}\text { Start-up and } \\
\text { initial checkout } \\
\text { reports }\end{array}$ & All Subs & $\begin{array}{l}\text { Filled out prefunctional } \\
\text { checklists, tests, startup and } \\
\text { initial checkout }\end{array}$ & $\begin{array}{l}\text { 1-week after } \\
\text { startup } \\
\text { completion }\end{array}$ & $\begin{array}{l}\text { CA+ } \\
\text { normal } \\
\text { others; } \\
\text { O\&M's } \\
\end{array}$ & $\begin{array}{l}\mathrm{CA} \\
\text { recommend } \\
\text { to } \mathrm{CM}\end{array}$ & $\begin{array}{l}\text { Cx Plan 5.8.2, } \\
\text { Specs 17100, Pt } \\
3.4\end{array}$ \\
\hline $\begin{array}{l}\text { Controls } \\
\text { Contractor } \\
\text { Initial Check- } \\
\text { out Plan } \\
\end{array}$ & $\begin{array}{l}\text { Controls } \\
\text { Contr. }\end{array}$ & $\begin{array}{l}\text { Complete step-by-step plan on } \\
\text { checkout and calibration } \\
\text { procedures, including forms } \\
\text { for documentating }\end{array}$ & $\begin{array}{l}3 \text { weeks before } \\
\text { beginning } \\
\text { checkout }\end{array}$ & $\mathrm{CA}$ & $\begin{array}{l}\mathrm{CA} \\
\text { recommend } \\
\text { to } \mathrm{CM}\end{array}$ & $\begin{array}{l}\text { Cx Plan 5.8.7, } \\
\text { Specs } 15995\end{array}$ \\
\hline $\begin{array}{l}\text { TAB plan and } \\
\text { approach }\end{array}$ & $\mathrm{TAB}$ & $\begin{array}{l}\text { Outline of TAB plan, approach } \\
\text { and schedule } \\
\text { (file: tabplan.c03) }\end{array}$ & $\begin{array}{l}<6 \text { weeks } \\
\text { before } \mathrm{TAB}\end{array}$ & $\begin{array}{l}\text { CA, CM; } \\
\text { Cntrls } \\
\text { contr. }\end{array}$ & $\mathrm{CA} ; \mathrm{CM}$ & $\begin{array}{l}\text { Cx Plan 5.8.6, } \\
\text { Specs } 159951.2\end{array}$ \\
\hline $\begin{array}{l}\text { TAB progress } \\
\text { reports }\end{array}$ & $\mathrm{TAB}$ & $\begin{array}{l}\text { List of discrepancies, } \\
\text { interpretations needed, tests } \\
\text { completed }\end{array}$ & Twice a week & $\begin{array}{l}\mathrm{CA} \text { and } \\
\mathrm{CM}\end{array}$ & none & $\begin{array}{l}\text { Cx Plan 5.8.6, } \\
\text { Specs 15995 Pt } \\
1.2\end{array}$ \\
\hline $\begin{array}{l}\text { Draft TAB } \\
\text { report }\end{array}$ & $\mathrm{TAB}$ & $\begin{array}{l}\text { Draft TAB report with method } \\
\text { and results }\end{array}$ & $\begin{array}{l}<2 \text { weeks after } \\
\text { TAB } \\
\text { completion }\end{array}$ & $\begin{array}{l}\mathrm{CA}+ \\
\text { normal } \\
\text { others }\end{array}$ & $\begin{array}{l}\mathrm{CA} \text { (for } \mathrm{Cx} \\
\text { req'r.) }\end{array}$ & $\begin{array}{l}\text { Cx Plan 5.7.2, } \\
\text { Specs 15995 Pt } \\
1.2\end{array}$ \\
\hline $\begin{array}{l}\text { Final TAB } \\
\text { report }\end{array}$ & $\mathrm{TAB}$ & $\begin{array}{l}\text { Draft TAB report with method } \\
\text { and results }\end{array}$ & $\begin{array}{l}<2 \text { weeks after } \\
\text { TAB } \\
\text { completion }\end{array}$ & $\begin{array}{l}\text { CA+ } \\
\text { normal } \\
\text { others; } \\
\text { O\&M's }\end{array}$ & $\begin{array}{l}\mathrm{CA} \text { (for } \mathrm{Cx} \\
\text { req'r.) }\end{array}$ & $\begin{array}{l}\text { Cx Plan 5.7.2, } \\
\text { Specs } 15995 \mathrm{Pt} \\
12 ; 3.6\end{array}$ \\
\hline Change orders & $\mathrm{GC} ; \mathrm{CM}$ & $\begin{array}{l}\text { Change orders that affect } \mathrm{Cx}^{\prime} \mathrm{d} \\
\text { equipment }\end{array}$ & $\begin{array}{l}<1 \text {-week after } \\
\text { approved }\end{array}$ & $\begin{array}{l}\mathrm{CA}+ \\
\text { others }\end{array}$ & na & $\begin{array}{l}\text { Cx Plan 5.7.2, } \\
\text { Specs } 171001.5\end{array}$ \\
\hline Issues Log & $\overline{C A}$ & $\begin{array}{l}\text { Record / track of all issues and } \\
\text { deficiencies (Form C-1) }\end{array}$ & ongoing & $\mathrm{CM}$ & na & Cx Plan 5.6 \\
\hline
\end{tabular}


Form C-16

\begin{tabular}{|c|c|c|c|c|c|c|}
\hline Product & $\begin{array}{l}\text { Created } \\
\text { By }\end{array}$ & $\begin{array}{l}\text { Product Description } \\
\text { and Form }\end{array}$ & Due Date & $\begin{array}{l}\text { Received } \\
\text { By }\end{array}$ & $\begin{array}{c}\text { Approved } \\
\text { By }\end{array}$ & $\begin{array}{c}\text { Product } \\
\text { Assigned in }\end{array}$ \\
\hline $\begin{array}{l}\text { Non- } \\
\text { Compliance } \\
\text { IDeficiency } \\
\text { reports }\end{array}$ & $\mathrm{CA}$ & $\begin{array}{l}\text { List of deficiencies and non- } \\
\text { compliance with Contract } \\
\text { Docs identified during } \mathrm{Cx} \\
\text { (Form C-6) }\end{array}$ & $\begin{array}{l}\text { Issued within } \\
3 \text { days of } \\
\text { identifying }\end{array}$ & $\begin{array}{l}C M \text { from } \\
C A \text { and by } \\
\text { Subs from } \\
C M \text { or } C A\end{array}$ & $\mathrm{CM}$ & $\begin{array}{l}\text { Cx Plan 5.8.4; } \\
\text { 5.10.2, Specs } \\
17100 \text { Pt 1.5, 3.4; } \\
3.7\end{array}$ \\
\hline $\begin{array}{l}\text { Cx'g } \\
\text { Progress } \\
\text { Record }\end{array}$ & $\mathrm{CA}$ & $\begin{array}{l}\text { Record / track of all } \\
\text { submittals, checklists, tests, } \\
\text { etc. (Form C-7) }\end{array}$ & ongoing. & $\mathrm{CM}$ & na & Cx Plan 5.6 \\
\hline $\begin{array}{l}\text { Cxprogress } \\
\text { reports }\end{array}$ & $\mathrm{CA}$ & $\begin{array}{l}\text { Gives scheduling needs and } \\
\text { update, deficiency report, } \mathrm{Cx} \\
\text { progress (Form C-4) }\end{array}$ & $\begin{array}{l}\text { Weekly to } \\
\text { Monthly (see } \\
5.5 \text { ) }\end{array}$ & $\mathrm{CM}$ or $\mathrm{PM}$ & na & $\begin{array}{l}\text { Cx Plan 5.6, Specs } \\
17100, \text { Pt } 1.5\end{array}$ \\
\hline $\begin{array}{l}\text { Owner- } \\
\text { contracted } \\
\text { functional test } \\
\text { forms }\end{array}$ & $\begin{array}{l}\text { Subs/ } \\
\text { vendor }\end{array}$ & $\begin{array}{l}\text { Full description of test } \\
\text { procedures in "form" format }\end{array}$ & $\begin{array}{l}>4 \text {-weeks } \\
\text { before test }\end{array}$ & $\mathrm{CA}$ & $\mathrm{CA}$ & $\begin{array}{l}\text { Cx Plan 5.9.2, } \\
\text { Specs } 17100 \mathrm{Pt} \\
1.5 ; 3.3\end{array}$ \\
\hline $\begin{array}{l}\text { Functional test } \\
\text { forms }\end{array}$ & $\mathrm{CA}$ & $\begin{array}{l}\text { Full description of test } \\
\text { procedures in "form" format } \\
\text { (Specs 15999; 16999) }\end{array}$ & $\begin{array}{l}>4 \text {-weeks } \\
\text { before test }\end{array}$ & $\begin{array}{l}\text { CM, Subs, } \\
\text { O\&Ms; } \\
\text { _ AVE }\end{array}$ & $\begin{array}{l}\text { CM and } \\
\text { Sub; } \\
\quad \mathrm{A} / \mathrm{E} \\
\end{array}$ & $\begin{array}{l}\text { Cx Plan 5.9.2, } \\
\text { Specs } 17100 \mathrm{Pt} \\
1.5 ; 3.6,15997\end{array}$ \\
\hline $\begin{array}{l}\text { Filled out } \\
\text { functional test } \\
\text { forms }\end{array}$ & $\mathrm{CA}$ & $\begin{array}{l}\text { Recorded documentation of the } \\
\text { test on the form }\end{array}$ & $\begin{array}{l}\text { With final } \\
\text { report }\end{array}$ & $\begin{array}{l}\mathrm{CM}, \\
\mathrm{O \& Ms} \\
\mathrm{A} / \mathrm{E} \\
\end{array}$ & $\mathrm{CM}$ & $\begin{array}{l}\text { Cx Plan 5.9, Specs } \\
17100 \text { Pt } 1.5 ; 3.6\end{array}$ \\
\hline $\begin{array}{l}\text { Functional test } \\
\text { final approvals }\end{array}$ & $\mathrm{CA}$ & $\begin{array}{l}\text { List of test number, and } \\
\text { descript., date of test, approval } \\
\text { signatures of CA and CM } \\
\text { Form C-3) }\end{array}$ & $\begin{array}{l}\text { Within } 4 \text { days } \\
\text { of successful } \\
\text { completion of } \\
\text { test }\end{array}$ & $\mathrm{CM}$ & $\mathrm{CM}$ & $\begin{array}{l}\text { Cx Plan 5.10, } \\
\text { Specs } 17100 \mathrm{Pt} \\
1.5 ; 3 . .7\end{array}$ \\
\hline $\begin{array}{l}\text { O\&M manuals } \\
\text { (normal) }\end{array}$ & $\begin{array}{l}\text { GC and } \\
\text { Subs }\end{array}$ & $\begin{array}{l}\text { Documentation of design, } \\
\text { equipment, operations and } \\
\text { maintenance, as-builts, etc. }\end{array}$ & $\begin{array}{l}\text { Before } \\
\text { substantial } \\
\text { completion }\end{array}$ & $\begin{array}{l}\text { CA } \\
\text { reviews } \\
\text { on-site }\end{array}$ & $\begin{array}{l}\text { CA (for } \mathrm{Cx} \\
\text { req'r) }\end{array}$ & $\begin{array}{l}\text { Cx Plan 5.11, } \\
\text { Specs } 17100 \mathrm{Pt} \\
3.8,15995 \mathrm{Pt} 3.6 \\
\end{array}$ \\
\hline Training plan & Subs & $\begin{array}{l}\text { Topics and methods } \\
\text { (Forms C-5a; } 5 \mathrm{~b} \text { ) }\end{array}$ & $\begin{array}{l}2 \text { weeks before } \\
\text { training }\end{array}$ & $\mathrm{CA} ; \mathrm{CM}$ & $\mathrm{CA} ; \mathrm{CM}$ & $\begin{array}{l}\text { Cx Plan 5.12, } \\
\text { Specs } 17100 \mathrm{Pt} \\
3.9,15995 \mathrm{Pt} 3.7 \\
\end{array}$ \\
\hline $\begin{array}{l}\text { Training } \\
\text { completion } \\
\text { form }\end{array}$ & $\mathrm{CA}$ & $\begin{array}{l}\text { List of trainees, completed hrs } \\
\text { and topics and approvals } \\
\text { (Form C-5c) }\end{array}$ & $\begin{array}{l}<2 \text { weeks after } \\
\text { training } \\
\text { completion } \\
\end{array}$ & $\mathrm{CA}$ & $\begin{array}{l}\mathrm{CA} \\
\text { recommend } \\
\text { to } \mathrm{CM} \\
\end{array}$ & $\begin{array}{l}\text { Cx Plan 5.12, } \\
\text { Specs } 17100 \mathrm{Pt} \\
1.5,3.9 \\
\end{array}$ \\
\hline Final Cx report & $\mathrm{CA}$ & $\begin{array}{l}\text { 4-6 page summary report with } \\
\text { important findings, etc. }\end{array}$ & $\begin{array}{l}\text { Draft within } 60 \\
\text { days of } \\
\text { substantial } \\
\text { completion }\end{array}$ & $\mathrm{CM}$ & $\mathrm{CM}$ & $\begin{array}{l}\text { Cx Plan } 6.1 \\
\text { Specs } 17100 \mathrm{Pt} \\
1.5\end{array}$ \\
\hline $\begin{array}{l}\text { Deferred } \\
\text { testing reports }\end{array}$ & $\mathrm{CA}$ & $\begin{array}{l}\text { Documentation of seasonal } \\
\text { and deferred tests }\end{array}$ & $\begin{array}{l}\text { Within } 2 \\
\text { weeks of test }\end{array}$ & CM \& PM & $\mathrm{CM} \& \mathrm{PM}$ & $\begin{array}{l}\text { Cx Plan 5.13, } \\
\text { Specs } 17100 \mathrm{Pt} \\
3.10\end{array}$ \\
\hline & & & & & & \\
\hline
\end{tabular}




\section{Form C-17. Sample Commissioning Record Notebook Format}

I-1 thru $1-6$ and $01-14$ are major tabs (colored). Sections A-C under major tabs are sub-tabs (clear). Major tabs may fill an entire binder as necessary.

Three Clear Tabs Under Each Major System [1]

(With contents listed on cover sheet)

\section{I-1 CORRESPONDENCE}

1-2 COMMISSIONING PLAN

1-3 COMMISSIONING SCHEDULE

1-4 MEETING MINUTES \&

1.4 PROGRESS REPORTS

I-5 PROGRESS RECORD

1-6 ISSUES LOG

01 CHILLER SYSTEM

02 HW SYSTEM

03 AIR HANDLERS

04 PACKAGED AC UNITS

05 TERMINAL UNITS

5a FLOOR 1

$5 b$ FLOOR 2

OR Zone 1, Zone 2....etc.

Major Tabs Continued:

06 Computer room $A C$ units

07 Unit heaters or AC spot coolers

08 Heat exchangers

09 Service water system

10 Test and balance (TAB)

11 Bullding automation system (controls)

12 Specialty fans

13 Fume hoods

14 Split AC / HP

15 Lighting controls

16 Emergency power

17 UPS

18 Fire alarm/ protection

19 Misc.
[1] For smaller projects, colored separator sheets may be used in place of sub-tabs.

O\&\&Manuals
The Record Notebook is edited before
becoming a part of the O\&M manuals.
Include:
* Final report
* Commissioning Plan
* Issues log
* Progress record
- All equipment-specific data from the
record book




\section{Part IV}

\section{APPENDIX 2}

\section{Document and Test Development} Flow Charts and Submittal Maps

Chart 1 Startup and Initial Checkout Form Development

Chart 2 Functional Test Form Development

Chart 3 Prefunctional Checklist and Startup Report Submittal Map

Chart 4 Functional Test Submittal Map

Chart 5 Checklist and Functional Testing Approval Process 


\section{Chart 1. Startup and Initial Checkout Form Development}

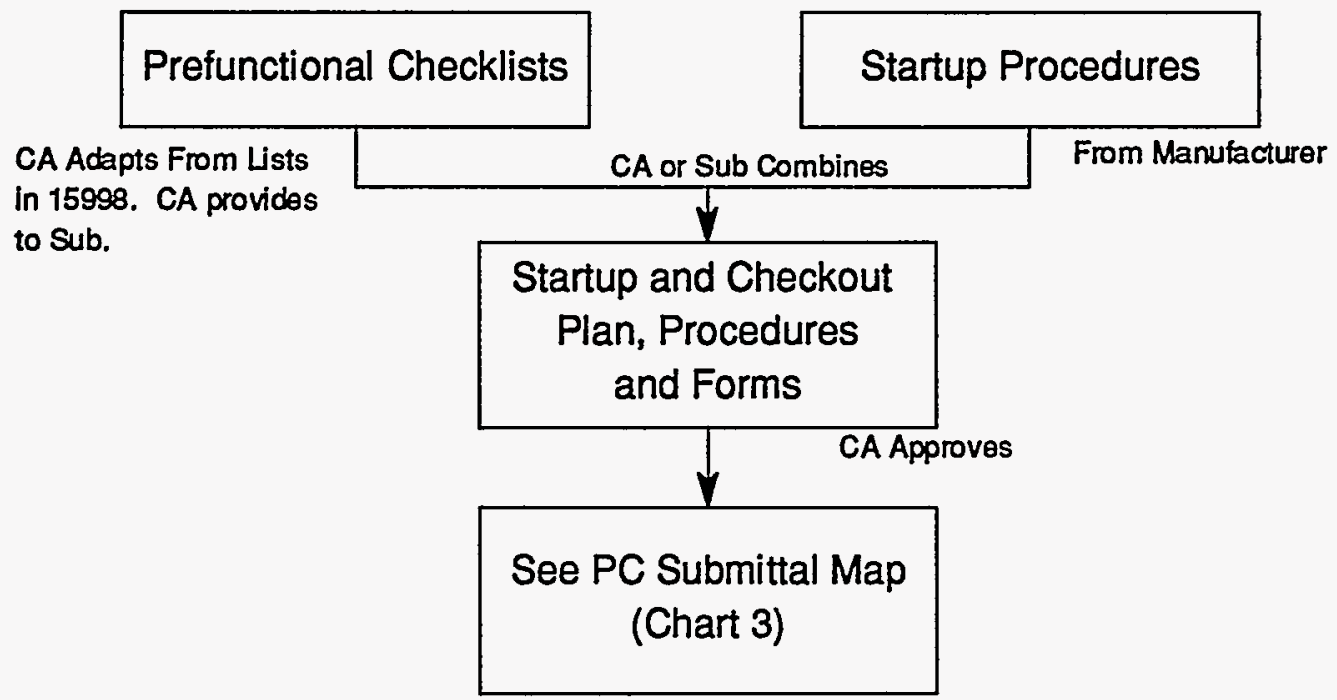

Chart 2. Functional Test Form Development




Chart 3. Prefunctional Checklist and Startup Report Submittal Map

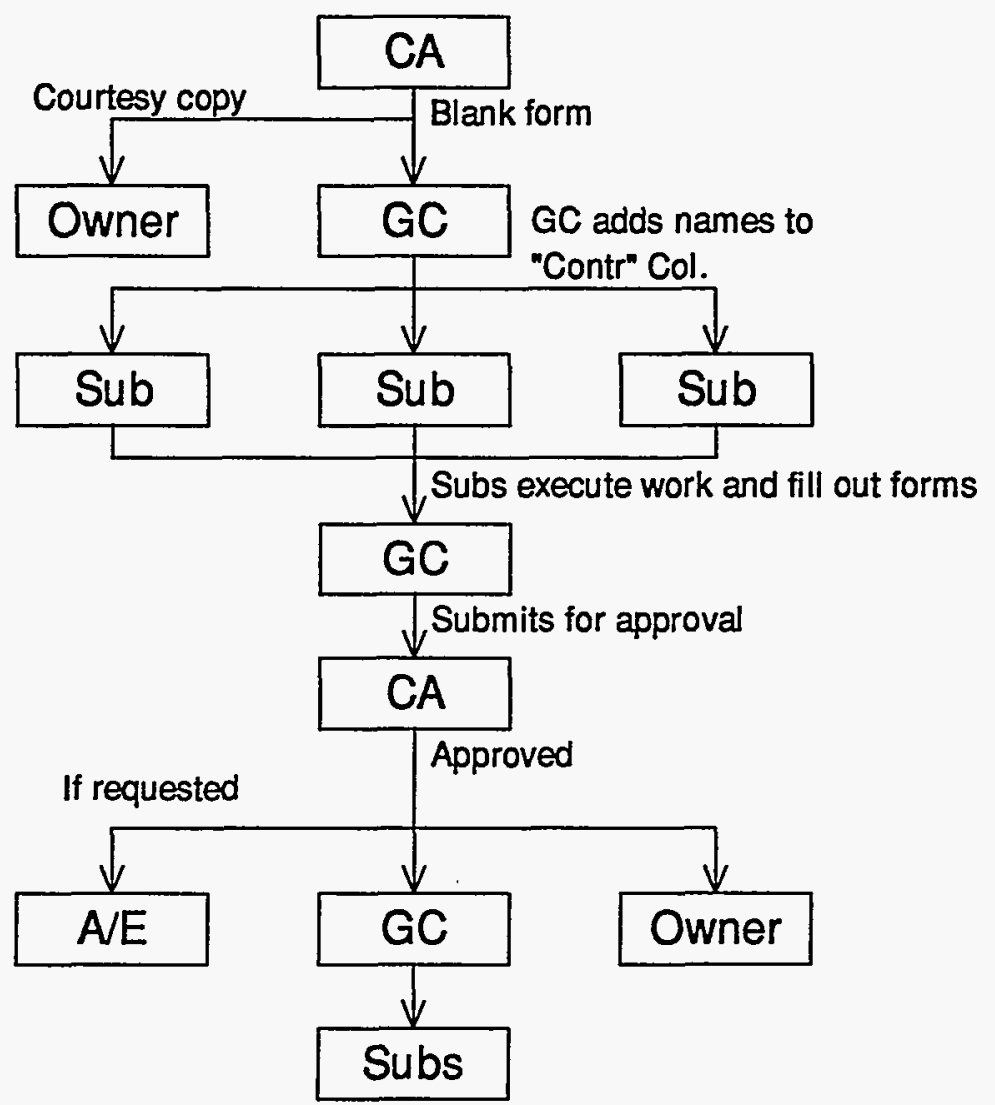

$C A=$ Commissioning Agent

$\mathrm{GC}=$ General Contractor

Sub $=$ Subcontractor

Owner = Owner's Rep (construction manager, etc.) 


\section{Chart 4. Functional Test Submittal Map}

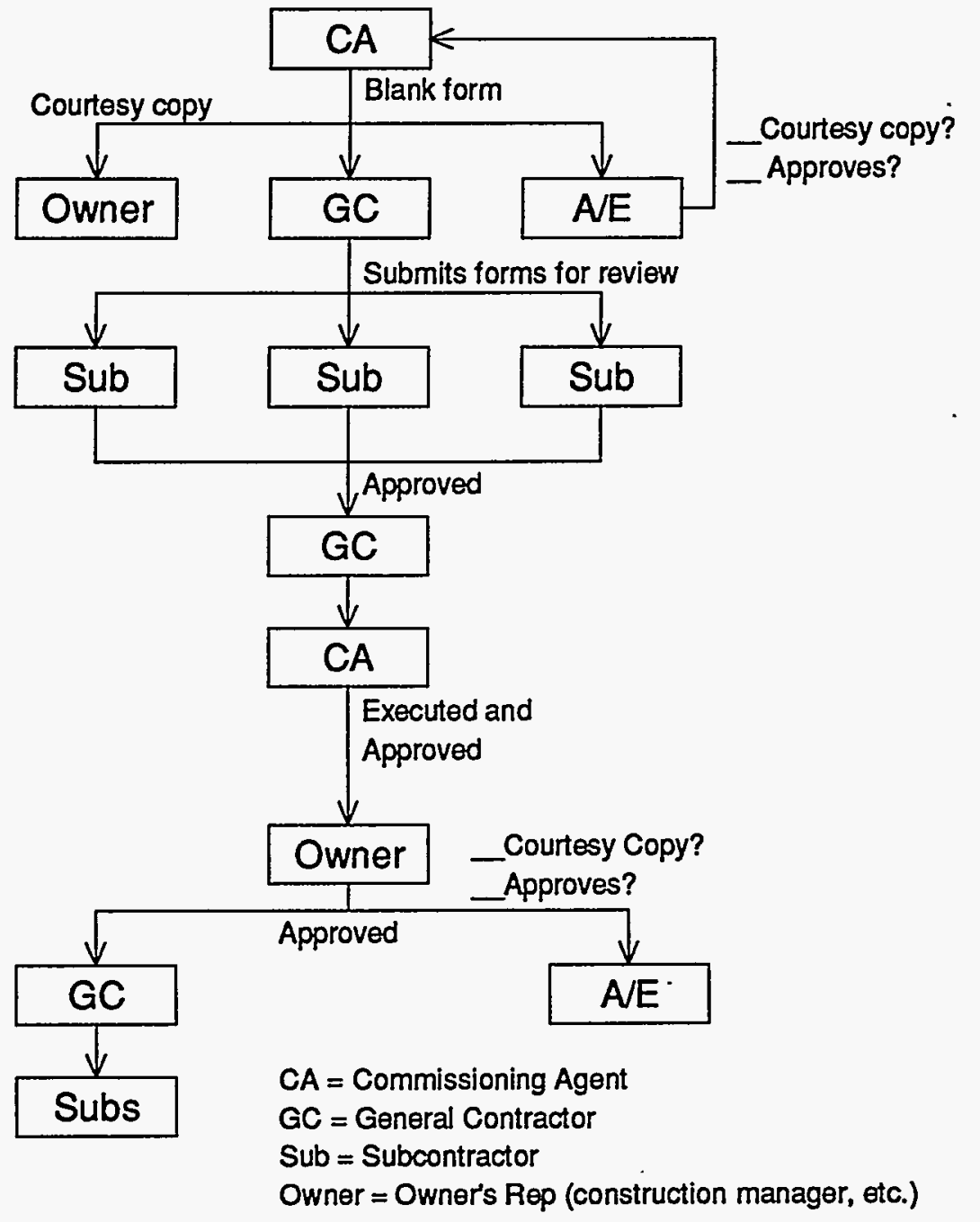




\section{Chart 5. Checkout and Functional Testing Approval Process}

(This chart begins with the Checklist or Test already completed.)

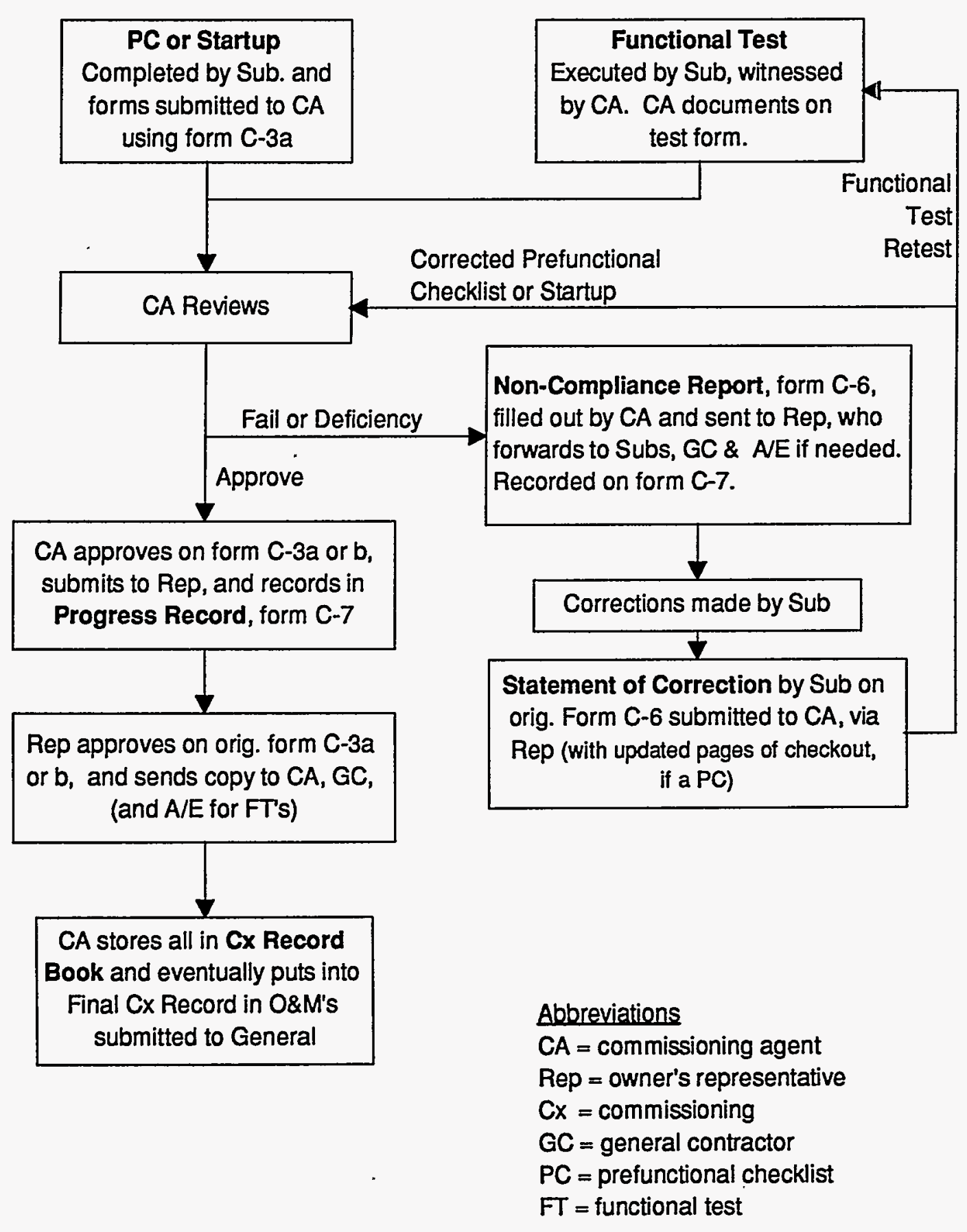

